US Army Corps

of Engineers ${ }_{\circledast}$

Engineer Research and

Development Center

Navigation Systems Research Program

\title{
Using Automatic Identification System (AIS) Data to Assess Collision and Grounding Risk in U.S. Coastal Ports
}

Martin T. Schultz and Scott G. Bourne

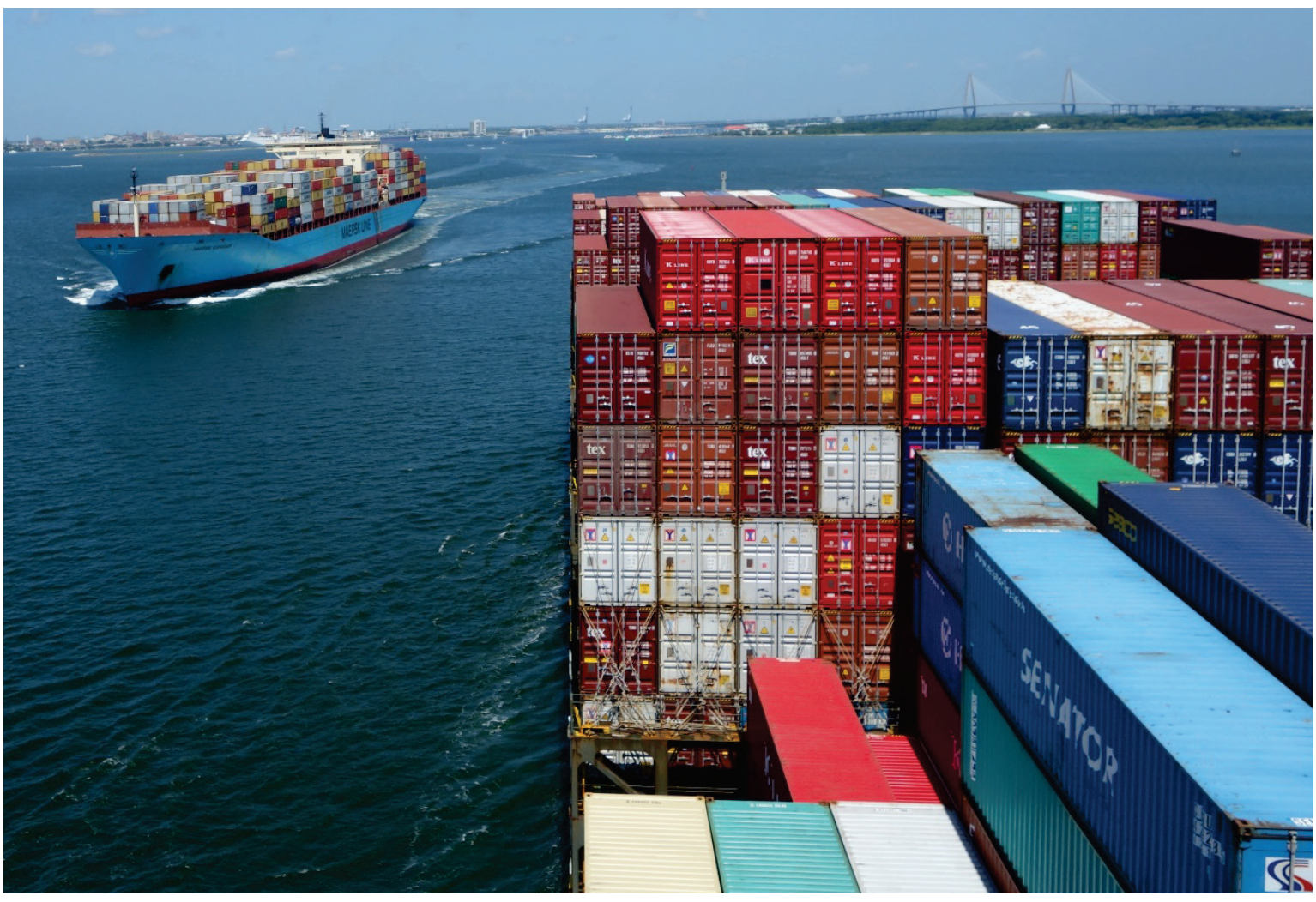


The U.S. Army Engineer Research and Development Center (ERDC) solves the nation's toughest engineering and environmental challenges. ERDC develops innovative solutions in civil and military engineering, geospatial sciences, water resources, and environmental sciences for the Army, the Department of Defense, civilian agencies, and our nation's public good. Find out more at www.erdc.usace.army.mil.

To search for other technical reports published by ERDC, visit the ERDC online library at http://acwc.sdp.sirsi.net/client/default. 


\section{Using Automatic Identification System (AIS) Data to Assess Collision and Grounding Risk in U.S. Coastal Ports}

Martin T. Schultz and Scott G. Bourne

Environmental Laboratory

U.S. Army Engineer Research and Development Center

3909 Halls Ferry Road

Vicksburg, Mississippi 39180-6199

Final report

Approved for public release; distribution is unlimited.

Prepared for Coastal and Hydraulics Laboratory

U.S. Army Engineer Research and Development Center

3909 Halls Ferry Road

Vicksburg, MS 39180-6199

Under Work Unit 468419, "Navigation Collision and Grounding Risk Assessment Using Automatic Identification System Data" 


\section{Abstract}

The conventional approach to navigation risk assessment is qualitative and relies on the subjective input of waterway users. Quantitative and objective approaches are needed to monitor and report on safety, identify navigation projects and channels where risks are high, and determine where improvements in design, construction, or maintenance might reduce the potential for accidents and associated losses. This study develops, demonstrates, and evaluates a method of using archival automatic identification system data to quantify collision and grounding risk to support the U.S. Army Corps of Engineers mission with respect to design, construction, and maintenance of navigation channels. The methods are demonstrated in five coastal ports, including Boston, Massachusetts; Charleston, South Carolina; Jacksonville, Florida; Calcasieu River, Louisiana; and Columbia River, Oregon.

DISCLAIMER: The contents of this report are not to be used for advertising, publication, or promotional purposes. Citation of trade names does not constitute an official endorsement or approval of the use of such commercial products. All product names and trademarks cited are the property of their respective owners. The findings of this report are not to be construed as an official Department of the Army position unless so designated by other authorized documents. 


\section{Contents}

Abstract............................................................................................................. ii

Figures and Tables....................................................................................................... vi

Preface ........................................................................................................................ xi

Unit Conversion Factors................................................................................................. xii

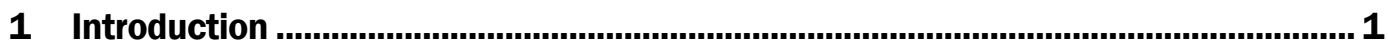

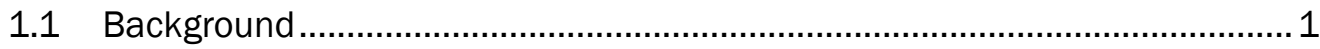

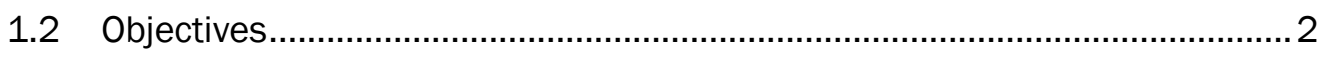

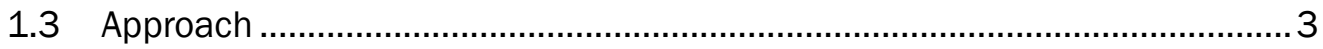

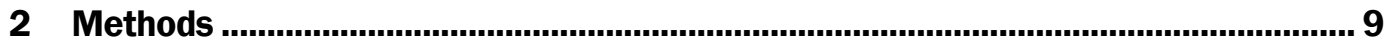

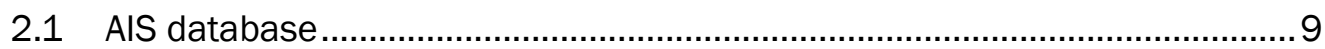

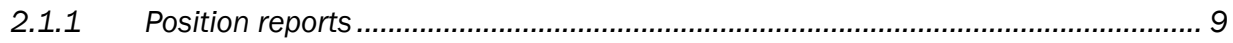

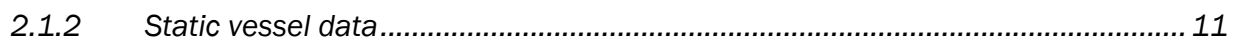

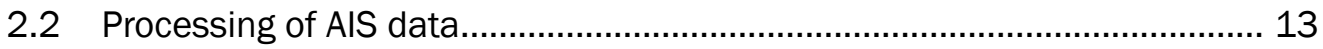

2.2.1 Screening of static vessel data .......................................................................... 13

2.2.2 Sampling of AIS position reports............................................................................ 14

2.2.3 Merging with supporting datasets ................................................................... 14

2.2.4 Determining geographic coordinates of vessel centroids .................................... 14

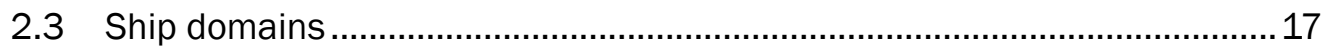

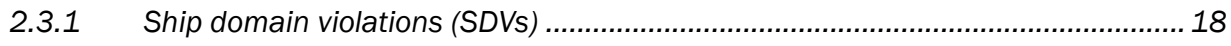

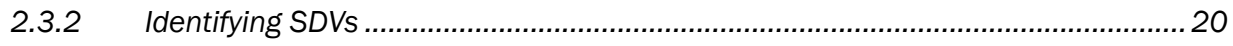

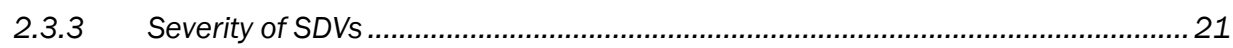

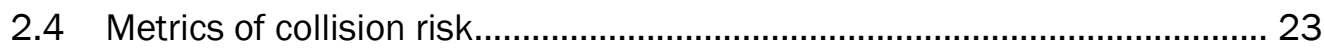

2.5 Metrics of grounding risk .................................................................... 25

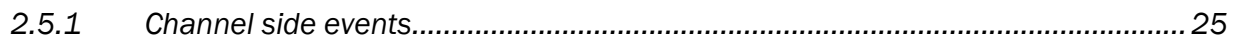

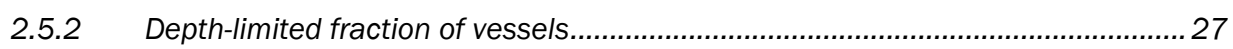

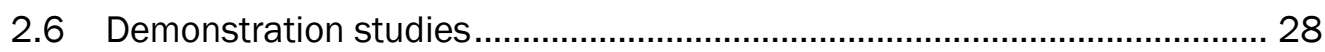

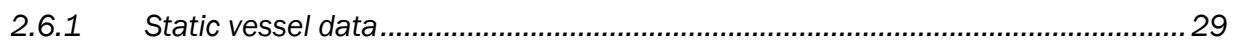

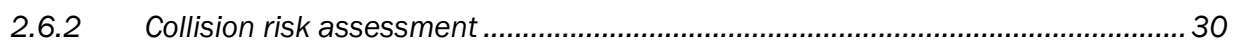

2.6.3 Grounding risk assessment............................................................................ 31

2.6.4 Marine Information for Safety and Law Enforcement (MISLE) database reports............ 32

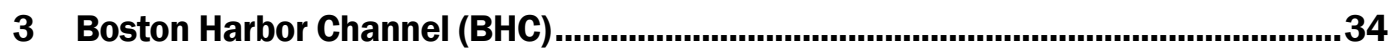

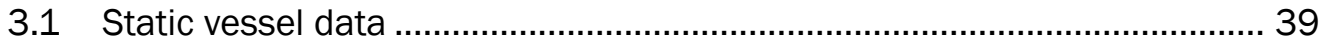

3.2 Collision risk assessment ..................................................................4 41

3.2.1 Location and severity of encounters................................................................. 41

3.2.2 Types of vessels involved in encounters............................................................... 45

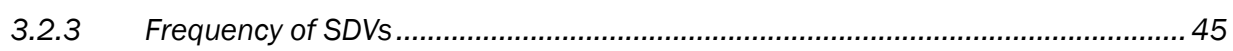

3.3 Grounding risk assessment ................................................................. 58

3.3.1 Powered grounding on the side of the channel ................................................59 
3.3.2 Powered grounding on a shoal in the channel...................................................62

3.4 Marine Information for Safety and Law Enforcement (MISLE)

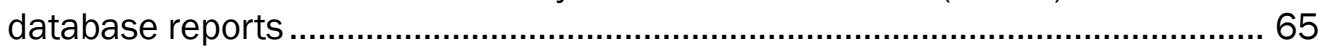

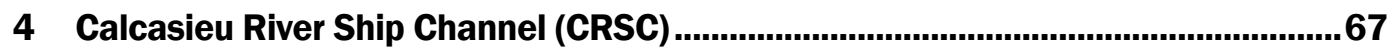

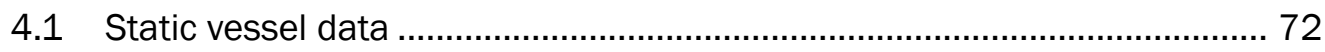

4.2 Collision risk assessment .................................................................... 74

4.2.1 Location and severity of encounters.................................................................... 75

4.2.2 Types of vessels involved in encounters........................................................... 79

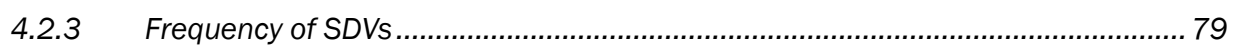

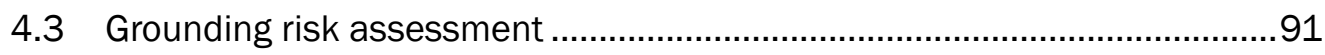

4.3.1 Powered grounding on the side of the channel ................................................. 91

4.3.2 Powered grounding on a shoal in the channel..................................................... 93

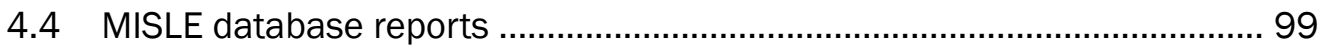

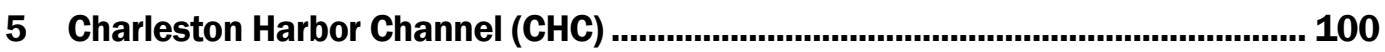

5.1 Static vessel data ................................................................................... 104

5.2 Collision risk assessment ................................................................ 105

5.2.1 Location and severity of encounters...............................................................106

5.2.2 Types of vessels involved in encounters.........................................................110

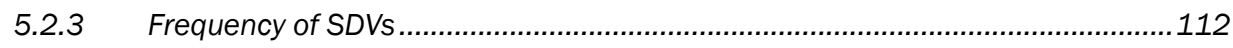

5.2.4 Correlations among collision risk metrics.......................................................122

5.3 Grounding risk assessment ........................................................... 123

5.3.1 Powered grounding on the side of the channel ..................................................123

5.3.2 Powered grounding on a shoal in the channel....................................................126

5.4 MISLE database reports ................................................................... 130

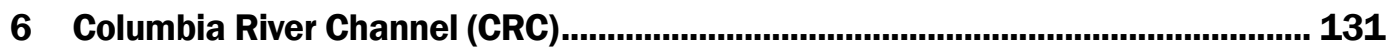

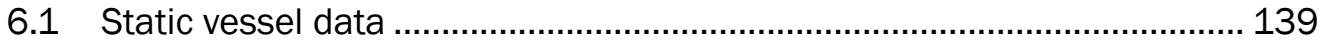

6.2 Collision risk assessment .....................................................................141

6.2.1 Location and severity of encounters.............................................................. 141

6.2.2 Types of vessels involved in encounters........................................................146

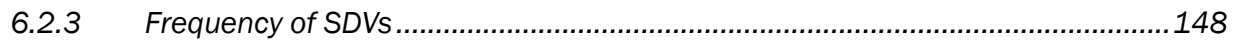

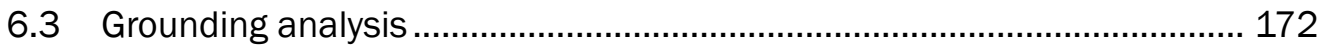

6.3.1 Powered grounding on the side of the channel .................................................172

6.3.2 Powered grounding on a shoal in the channel.................................................178

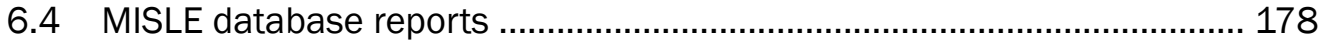

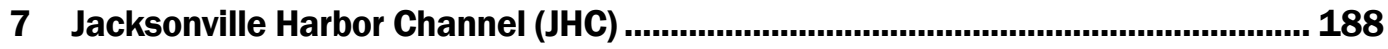

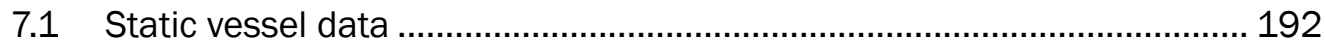

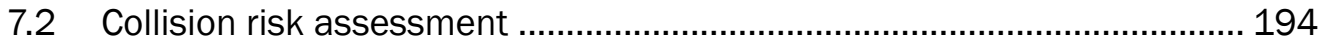

7.2.1 Location and severity of encounters................................................................. 194

7.2.2 Types of vessels involved in encounters...........................................................199

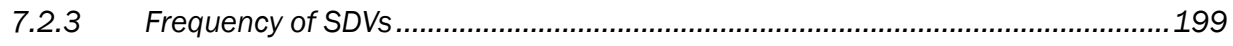

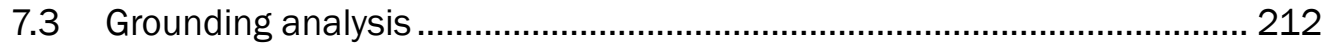

7.3.1 Powered groundings on the side of the channel.............................................212 
7.3.2 Powered groundings on a shoal in the channel..............................................217

7.4 MISLE database reports ............................................................... 222

8 Conclusion .......................................................................................................... 224

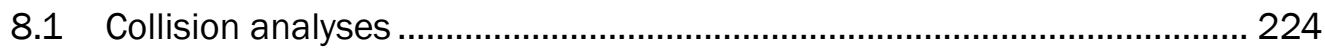

8.2 Grounding analyses.......................................................................... 228

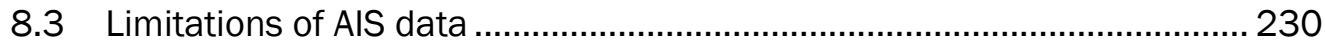

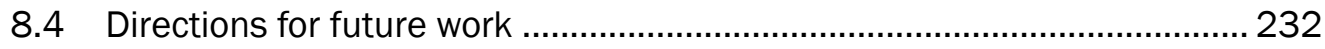

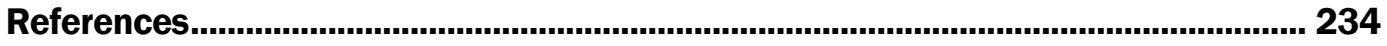

\section{Report Documentation Page}




\section{Figures and Tables}

\section{Figures}

Figure 1-1. Four ship domains proposed in the literature.

Figure 2-1. Translation of EPFS antenna coordinates ( $\left.X_{A I S T}, y_{A I S T}\right)$ to vessel center coordinates $\left(x_{c}, y_{c}\right)$.

Figure 2-2. Four possible locations for the EPFS antenna onboard a vessel. Shading indicates which of the four quadrants the EPFS antenna is located given the conditions for distance to vessel boundaries.

Figure 2-3. Dynamic ship domain. The domain is represented by a dashed ellipse centered on a $184 \mathrm{~m}$ vessel with a $26 \mathrm{~m}$ beam. The arrow indicates the vessel's course, which is $145^{\circ}$. The point at the tip of the vessel marks the vessel's bow to indicate the vessel's heading. The length of the major axis is four times the vessel length, and the length of the minor axis is three times its swept path, which depends on the difference between course and heading.

Figure 2-4. Three scenarios illustrating situations that may result in SDVs: (a) Vessel $i$ is passing behind vessel $j$. There is no violation of ship domains because neither vessel's perimeter is inside the other's ship domain. Overlapping ship domains are not a violation. (b) Vessel $j$ is crossing in front of Vessel $i$. Vessel $i$ 's ship domain is violated because the perimeter of vessel $j$ is inside Vessel i's ship domain. Vessel $j$ 's ship domain is not violated. (c) Vessel $j$ is passing vessel $i$. Vessel $i$ 's ship domain is violated because the perimeter of vessel $j$ is inside its ship domain.

Figure 2-5. SDV severity score. The SDV severity is calculated from the ratio of the minimum distance between vessel perimeters and the distance between vessel i's perimeter and its ship domain boundary along the line of minimum distance between vessel perimeters.

Figure 2-6. Criteria for channel side events. Channel side events occur when the distance between the keel line and the channel boundary, $d$, is less than $55 \%$ of the vessel's beam, $B$, leaving a distance between the hull and the channel

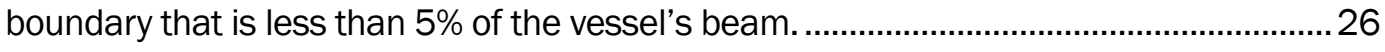

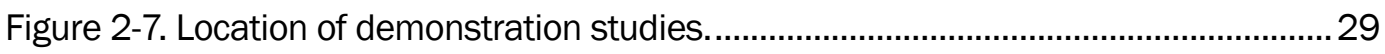

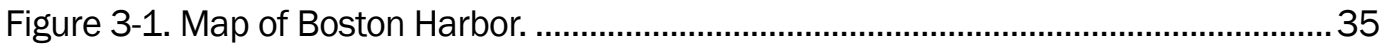

Figure 3-2. Federal navigation channel reaches in Boston Harbor...................................36

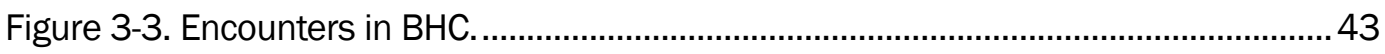

Figure 3-4. Characteristics of encounters in BHC. ....................................................... 44

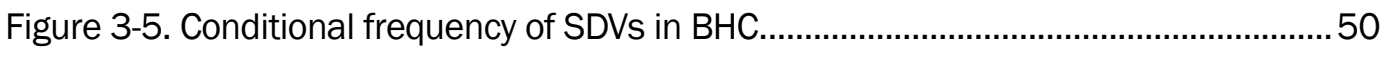

Figure 3-6. Unconditional frequency of SDVs in BHC. ..................................................... 57

Figure 3-7. Relative frequency of SDVs in BHC by navigation channel reach.....................58

Figure 3-8. Channel side events in BHC...................................................................... 61

Figure 3-9. Collision and grounding events in Boston Harbor, 2011-2015, as reported in the USCG MISLE database.

Figure 4-1. Map of the Calcasieu River. ....................................................................... 67

Figure 4-2. Federal navigation channel reaches in Calcasieu River...................................68 


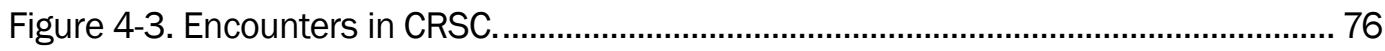

Figure 4-4. Characteristics of encounters in CRSC...................................................... 78

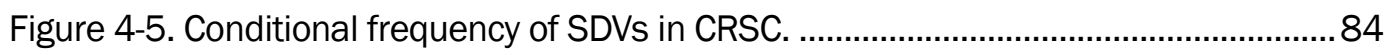

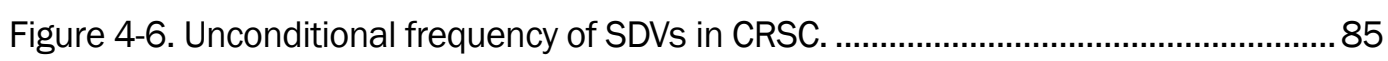

Figure 4-7. Relative frequency of SDVs in CRSC........................................................... 90

Figure 4-8. Channel side events in CRSC..................................................................... 92

Figure 4-9. Channel side events in vicinity of Moss Lake..................................................93

Figure 4-10. Collision and grounding events in Calcasieu River, 2011-2015, as

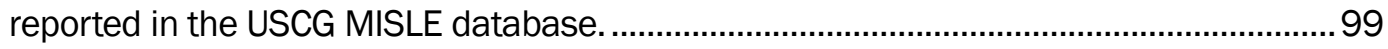

Figure 5-1. Map of Charleston Harbor.........................................................................100

Figure 5-2. Federal navigation channel reaches in Charleston Harbor...........................101

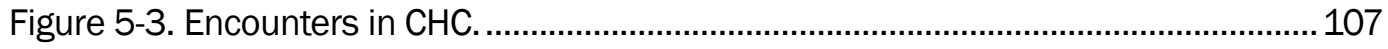

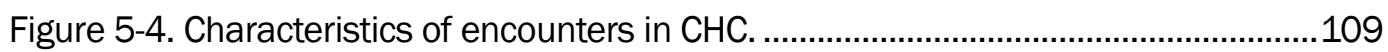

Figure 5-5. Conditional frequency of SDVs. ..............................................................115

Figure 5-6. Unconditional frequency of SDVs in CHC.................................................121

Figure 5-7. Relative frequency of SDVs in $\mathrm{CHC}$ by navigation channel reach...................122

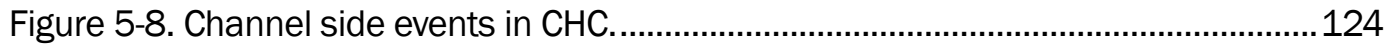

Figure 5-9. Channel side events in the inner harbor of $\mathrm{CHC}$..........................................125

Figure 5-10. Collision and grounding events in Charleston Harbor, 2011-2015, as reported in USCG MISLE database.

Figure 6-1. Map of Columbia River System - Entrance Range to Longview, Washington.

Figure 6-2. Map of Columbia River System - Longview, Washington to Interstate 5 bridge.

Figure 6-3. Federal navigation channel reaches in Columbia River, Entrance Range to Longview, Washington.

Figure 6-4. Federal navigation reaches in Columbia River, Longview, Washington to the Interstate 5 bridge.

Figure 6-5. Encounters in CRC, Entrance Range to Eureka Bar. Each point marks the geometric center of the encroached vessel at the time of maximum SDV severity during the encounter.

Figure 6-6. Encounters in CRC, Eureka Bar to the Interstate 5 bridge. Each point marks the geometric center of the encroached vessel at the time of maximum SDV severity during the encounter..

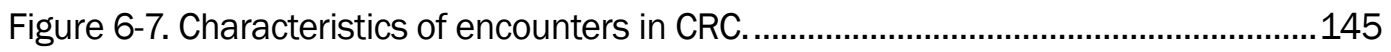

Figure 6-8. Conditional frequency of SDVs in CRC, Entrance Range to Longview, Washington.

Figure 6-9. Conditional frequency of SDVs in CRC, Eureka Bar to Interstate 5 bridge.

Figure 6-10. Unconditional frequency of SDVs in CRC, Entrance Range to Eureka Bar.

Figure 6-11. Unconditional frequency of SDVs in CRC, Eureka Bar to Interstate 5 bridge. 
Figure 6-12. Relative frequency of SDVs in CRC, Entrance Range to Eureka Bar. ..........170

Figure 6-13. Relative frequency of SDVs in CRC, Eureka Bar to Interstate 5 bridge....... 171

Figure 6-14. Channel side events in Columbia River, Entrance Range to Longview, Washington.

Figure 6-15. Channel side events in Columbia River, Longview, Washington to Interstate 5 bridge.

Figure 6-16. Detail map of channel side events showing (a) vessels avoiding the northern edge of Eureka Lower Channel (\#28) and (b) vessels avoiding the northern edge of Stella Range (\#33), between Crims Island and Hump Island.

Figure 6-17. Detail map of channel side events showing the lower prevalence of channel side events (a) on the northeast side of Cottonwood Island Turn (\#4142), and (b) on the east side of Bybee Ledge Channel (\#48) and Martin Island Channel (\#49).

Figure 6-18. Collision and grounding events in Columbia River, 2011-2015, as reported in the USCG MISLE database.

Figure 7-1. Map of Jacksonville Harbor............................................................................189

Figure 7-2. Jacksonville Harbor Navigation Channel. ......................................................190

Figure 7-3. Location and severity of SDVs in JHC.

Figure 7-4. Characteristics of SDVs in Jacksonville Harbor. The figure shows empirical distribution functions for (a) the maximum SDV severity score; (b) the minimum distance between vessels (meters); and (c) the duration of encounters between vessels.

Figure 7-5. Conditional frequency of SDVs in JHC.

Figure 7-6. Unconditional frequency of an SDV in JHC navigation reaches. ....................210

Figure 7-7. Relative frequency of SDVs in JHC by navigation channel reach....................211

Figure 7-8. Channel side events in Jacksonville Harbor.

Figure 7-9. Detail map of channel side events near (a) Mile Point and

(b) Bartram Island.

Figure 7-10. Detail map of channel side events near Talleyrand Terminal and downtown Jacksonville.

Figure 7-11. MISLE incidents in JHC. Each incident is identified by an activity identification number.

\section{Tables}

Table 2-1. Database fields provided in AIS position reports from NAIS................................ 9

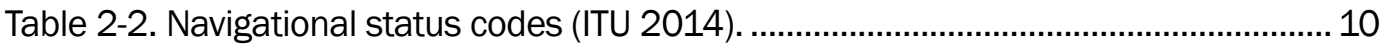

Table 2-3. Static vessel database fields (ITU 2014)....................................................... 11

Table 2-4. AIS ship and cargo type codes (ITU 2014)........................................................ 12

Table 3-1. Federal navigation channel reaches and reach characteristics in

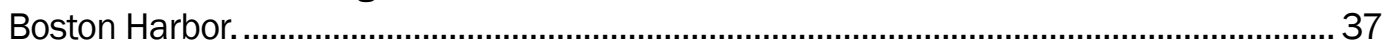

Table 3-2. Descriptive summary of vessels utilizing BHC.................................................. 40

Table 3-3. Number of encounters in BHC by encroached and encroaching vessel type. 
Table 3-4. Conditional frequency of SDVs in BHC by reach and vessel type.

Frequencies greater than $5 \times 10^{-3}$ are bold red typeface.

Table 3-5. Fraction of half-minute intervals during which at least one vessel is present in each $\mathrm{BHC}$ reach.

Table 3-6. Unconditional frequency of SDVs in BHC by reach and vessel type.

Frequencies greater than $5 \times 10^{-5}$ are in bold red typeface.

Table 3-7. Pearson correlation coefficients for collision risk metrics in BHC.

Table 3-8. Number and fraction of cargo vessels (70-79) that are depth limited in

BHC.

Table 3-9. Number and fraction of tankers (80-89) that are depth limited in BHC.

Table 4-1. Federal navigation channel reaches and reach characteristics in

Calcasieu River.

Table 4-2. Descriptive summary of vessels utilizing CRSC.

Table 4-3. Number of encounters in CRSC by encroached and encroaching vessel type.

Table 4-4. Conditional frequency of SDVs in CRSC by reach and vessel type.

Frequencies greater than $1 \times 10^{-2}$ are in bold red typeface.

Table 4-5. Fraction of half-minute intervals during which at least one vessel is present in each CRSC reach.

Table 4-6. Unconditional frequency of SDVs in CRSC by reach and vessel type.

Frequencies greater than $1 \times 10^{-4}$ are in bold red typeface.

Table 4-7. Pearson correlation coefficients for collision risk metrics in CRSC.

Table 4-8. Number and fraction of cargo vessels (70-79) that are depth limited in CRSC.

Table 4-9. Number and fraction of tankers (80-89) that are depth limited in CRSC.

Table 5-1. Federal navigation channel reaches and reach characteristics in

Charleston Harbor. 102

Table 5-2. Descriptive summary of vessels utilizing CHC in 2014.

Table 5-3. Number of encounters in CHC by AIS ship and cargo type.

Table 5-4. The conditional frequency of SDVs in CHC by reach and vessel type.

Frequencies greater than $1 \times 10^{-3}$ are in bold red typeface.

Table 5-5. Fraction of half-minute intervals during which at least one vessel is present in each $\mathrm{CHC}$ reach..

Table 5-6. The unconditional frequency of SDVs in $\mathrm{CHC}$ by reach and vessel type.

Frequencies greater than $1 \times 10^{-5}$ are in bold red typeface.

Table 5-7. Pearson correlation matrix for collision risk metrics. .......................................123

Table 5-8. Number and fraction of cargo vessels that are depth limited in $\mathrm{CHC}$..............128

Table 5-9. Number and fraction of cargo vessels that are depth limited in CHC.............129

Table 6-1. Federal navigation channel reaches and reach characteristics in

Columbia River, west of the Interstate 5 Bridge.

Table 6-2. Descriptive summary of vessels utilizing CRC in 2015.

Table 6-3. Number of encounters in CRC by AIS ship and cargo type code. 
Table 6-4. Conditional frequency of SDVs in CRC by reach and AIS ship and cargo type. Frequencies greater than $5 \times 10^{-4}$ are in bold red typeface.

Table 6-5. Fraction of half-minute intervals during which at least one vessel is present in each $\mathrm{CRC}$ reach.

Table 6-6. Unconditional frequency of SDVs in CRC by reach and AIS ship and cargo type code. Frequencies greater than $1 \times 10^{-5}$ are in bold red typeface.

Table 6-7. Pearson correlation coefficients for collision risk metrics in CRC. 169

Table 6-8. Number and fraction of cargo vessels (70-79) that are depth limited in CRC.

Table 6-9. Number and fraction of tankers (80-89) that are depth limited in CRC.

Table 7-1. Jacksonville Harbor Navigation Channel Reaches. 191

Table 7-2. Descriptive summary of vessels using JHC in 2014. Classification based on ITU-R M.1371-5 (February 2014). 193

Table 7-3. Number of encounters in JHC by encroached and encroaching vessel type.

Table 7-4. The conditional frequency of SDVs in JHC by reach and vessel type. Frequencies greater than $1 \times 10^{-3}$ are in bold red typeface. 201

Table 7-5. Fraction of half-minute intervals during which at least one vessel is present in each $\mathrm{JHC}$ reach 206

Table 7-6. Unconditional frequency of SDVs in JHC by reach and vessel type. Frequencies greater than $1 \times 10^{-5}$ are in bold red typeface. 208

Table 7-7 Pearson correlation matrix for collision risk metrics in JHC. .............................212

Table 7-8. Depth-limited fraction of cargo vessels in JHC. ............................................218

Table 7-9. Depth-limited fraction of tankers in JHC. .220

Table 8-1. Demonstration ports ranked by the overall conditional probability of an SDV. 


\section{Preface}

This study was conducted for the U.S. Army Engineer Research and Development Center, Coastal and Hydraulics Laboratory (ERDC-CHL), Navigation Systems Research and Development Program, under Work Unit 468419, "Navigation Risk Assessment Using Automatic Identification System Data." The technical monitor was Mr. Charles E. Wiggins.

The work was performed by the Environmental Risk Assessment Branch (EP-R) of the Environmental Processes and Engineering Division (EP), ERDC-Environmental Laboratory (ERDC-EL). At the time of publication of this report, Mr. William M. Nelson was Chief, CEERD-EP-R; Mr. Warren P. Lorentz was Chief, CEERD-EP; and Mr. Charles E. Wiggins, CEERD-CHL, was the Technical Director for Navigation System Research and Development. The Acting Deputy Director of ERDC-EL was Dr. William A. Martin, and the Acting Director was Dr. Jack E. Davis.

The U.S. Coast Guard provided data from the Nationwide Automatic Identification System and the Marine Information for Safety and Law Enforcement database.

Dr. Kenneth N. Mitchell, Dr. Brandan M. Scully, Mr. Brian J. Tetreault, and Dr. Patricia K. DiJoseph participated in discussions about the U.S. Army Corps of Engineers needs and objectives with respect to navigation risk assessment and the challenges and opportunities of using Automatic Identification System data. Dr. Scully, Mr. Tetreault, and Dr. Mitchell provided peer review comments on a draft of this report.

COL Ivan P. Beckman was the Commander of ERDC, and Dr. David W. Pittman was the Director. 


\section{Unit Conversion Factors}

\begin{tabular}{|l|c|l|}
\hline Multiply & By & To Obtain \\
\hline feet & 0.3048 & meters \\
\hline knots & 0.5144444 & meters per second \\
\hline miles (U.S. statute) & $1,609.347$ & meters \\
\hline
\end{tabular}




\section{Introduction}

\subsection{Background}

The U.S. Army Corps of Engineers (USACE) mission with respect to navigation is to provide safe, reliable, efficient, effective, and environmentally sustainable waterborne transportation systems for movement of commerce, national security needs, and recreation. USACE accomplishes this mission by designing, constructing, and maintaining navigation infrastructure. Guidance regarding navigation channel design is provided in USACE Engineer Manual 1110-2-1613 (USACE 2006). The applicable design goal is to provide a safe, efficient, environmentally sound, and cost-effective waterway for ships and other vessels while minimizing and balancing initial construction and future maintenance costs. Quantitative and objective approaches are needed to assist navigation managers to monitor and report on safety, identify navigation projects and channels where risks are high, and determine where improvements in design, construction, or maintenance might reduce the potential for accidents and associated losses.

Automatic identification systems (AIS) are very-high-frequency (VHF) radio communication systems that broadcast messages containing information on the identity of a vessel, its position, course, speed, and other safety related information and that automatically receive similar messages from other vessels. U.S. Coast Guard (USCG) regulations require that certain vessels operating within the jurisdiction of the United States be equipped with AIS. These include commercial vessels greater than 65 feet $(\mathrm{ft})$ in length, commercial towing vessels that are greater than $26 \mathrm{ft}$ in length and powered by engines greater than 600 horsepower, and passenger vessels certificated to carry more than 150 passengers. Many other vessels, including government, military, and recreational vessels, must also be equipped with AIS. The purpose of AIS is to enhance visibility and communication between vessels and reduce the probability of collisions.

The USCG operates a system of shore-based VHF receivers that harvest and compile AIS messages. That system, the Nationwide Automatic Identification System (NAIS), was authorized by the Maritime Transportation Security Act of 2002 (PL 107-295). The overall purpose of NAIS is to increase maritime domain awareness. NAIS coverage currently 
includes most coastal areas out to a distance of approximately 50 miles. Harvested AIS messages are available within 3 minutes after they are collected. The USCG stores AIS messages for at least 3 years after collection. The USACE may request archival NAIS data that are maintained by the USCG to support its mission.

One potential use of archival AIS data is collision and grounding risk assessment. Archival AIS data have the potential to improve the quality, efficiency, cost, consistency, and timeliness of navigation risk assessments. The quality of risk assessments may improve because AIS data provide the most up-to-date information about the identity and movement of vessels in coastal ports. The length of time required to complete a risk assessment and the costs associated with risk assessment may decrease because the data are collected through an existing process and no new data collection efforts are required. Risk assessments may become more consistent because data collection and formats have been standardized across ports, which reduces variability in the types and quality of information available for risk assessment.

\subsection{Objectives}

The objective of this study is to develop, demonstrate, and evaluate a method of using archival AIS data to quantify collision and grounding risk to support the USACE mission with respect to designing, building, and maintaining navigation channels. Risk assessments should provide coastal system managers with objective and quantitative information to compare risks in navigation channels and coastal ports and prioritize needs. These results will also enable coastal system managers to identify congested areas where vessels are likely to meet, identify locations where maneuverability may be limited, identify and prioritize potential improvements to reduce risk, understand surface and draft utilization, and understand the potential sensitivity of navigation to shoaling and deferred maintenance. Where navigation managers are already aware that such problems exist, the method described in this report will enable managers to quantify the extent and severity of those problems objectively.

These objectives, and the fact that USACE manages several hundred navigation projects, each consisting of many navigation channels, establish some requirements for the risk assessment approach. Coastal managers must be able to compare risks in a large number of projects, so the approach must be based on data that are broadly available 
geographically in a consistent format. Risk assessment methods must be applied consistently in each navigation project, and it should be possible for two people working independently to achieve comparable results. Results should be scalable to support characterizations of risk in navigation channels, in contiguous clusters of navigation channels, and in entire navigation projects. Risk metrics should be expressed in terms of ratio or interval scales to facilitate meaningful comparisons of risk across navigation channels. Because the goal is to support decisions about the design, construction, and management of navigation channels, risk metrics should also support the computation of expected losses from potential collision and grounding events. All decisions must be justified; therefore, it should be possible to audit the results of analyses supporting those decisions. Finally, because there are a large number of navigation projects and a finite amount of resources, it should be possible to apply the method efficiently and cost effectively.

\subsection{Approach}

AIS data were obtained for five coastal ports, including Boston Harbor Channel (BHC), Calcasieu River Ship Channel (CRSC), Charleston Harbor Channel (CHC), Jacksonville Harbor Channel (JHC), and Columbia River Channel (CRC). The scope of navigation risks considered in this report include (1) collisions between vessels inside the federal channel, (2) powered groundings on a shoal inside the federal channel, and (3) powered groundings on the sides of the federal channel. Other types of navigation risks exist but were not considered. These include allisions, drift grounding, and powered groundings outside the channel. Allisions occur when a vessel collides with an object other than another ship. Drift groundings occur when a vessel loses power or steerage or is blown by the wind. Powered groundings outside the channel are generally caused by navigational error (e.g., the operator misses a turn) or equipment failure. These are not considered because USACE makes few decisions with regard to designing and maintaining navigation channels that might influence the occurrence of these events.

Efforts to characterize navigation risks in the literature have been summarized by Goerlandt and Montewka (2015), Goerlandt and Kujala (2011, 2014), and Li et al. (2012). These sources indicate that most attempts to estimate the probability of collision and grounding events rely on a fundamental concept attributed to Macduff (1974), who proposed that the probability of collision or powered grounding, $P_{A}$, could be calculated 
as the product of a causation probability and a geometric probability: $P_{A}=$ $P_{C} \cdot P_{G}$. The causation probability, $P_{C}$, is the probability of failing to take evasive action to avoid a collision or grounding event given that evasive action is required. The geometric probability, $P_{G}$, is the probability of being in a situation where evasive action is required to avoid a collision or grounding event.

Causation probabilities have been estimated from historic accident data, fault trees, and Bayesian networks (Macduff 1974, Pedersen, 1995; FriisHansen and Pedersen 1998; Fowler and Sørgard 2000; Otto et al. 2002; Friis-Hansen and Simonsen 2002). Fault trees and Bayesian networks are useful because accident data are usually very sparse and they facilitate modeling the effects of human error, equipment failure, and environmental factors (Li et al. 2012). Other authors have used expert elicitation to estimate causation probabilities (Szwed et al., 2006; Merrick and van Dorp, 2006). Friis-Hansen (2008, p 30-32) provides a usable summary of causation probabilities from the literature. Causation probabilities typically vary with grounding or collision type, geographic location, vessel type, weather or sea-state, and pilotage. Estimated causation probabilities from the literature for grounding range from $0.8 \times 10^{-4}$ to $6.3 \times 10^{-4}$, depending on location. Estimated causation probabilities for ship-to-ship collisions range from $0.27 \times 10^{-4}$ to $5.2 \times 10^{-4}$.

Geometric probabilities are determined by calculating the frequency with which accident scenarios occur, where an accident scenario is an event that requires evasive action to avoid collision or grounding. Numerous methods have been developed to estimate geometric probabilities (Pedersen 1995; Friis-Hansen 2008; Montewka et al. 2010; Goerlandt and Kujala 2011; Goerlandt and Kujala 2014; Weng et al. 2012). There are basically two methods used to calculate the frequency of accident scenarios. These are traffic simulation and ship domain analysis. Traffic simulation was introduced by Pederson (1995) and is based on a statistical characterization of vessel movements along established routes assuming blind navigation. AIS data are used to develop probability distributions that describe vessel type, size, speed, course, movement, and arrival rates at cross sections of channels or over lengths of channel. These distributions are then used to simulate the frequency of collision or grounding events. The alternative approach is based on the concept of a ship domain, which is the area surrounding a vessel that should remain clear of other vessels and objects. Using this approach, geometric 
probabilities can be estimated from historical data by calculating the frequency of ship domain violations (SDVs), which occur when one vessel penetrates the domain of another vessel.

This study adopts a ship domain approach to risk assessment. The concept of the ship domain is analogous to that of personal space (Jingsong et al. 1993). Four ship domains are illustrated in Figure 1-1. Fuji and Tanaka (1971) described the ship domain from the perspective of a vessel operator who is approaching another ship. They defined it in the context of an overtaking situation as the area that "most of the navigators of the following ships avoid entering the surrounding domain of the foregoing ship." The boundary of the Fuji domain corresponds to the distance at which the density of passing ships reaches a local maximum value (Jingsong et al. 1993). Fuji and Tanaka (1971) proposed that ship domains can be represented as an ellipse centered on the vessel. In overtaking situations, Fuji and Tanaka (1971) estimated that the length of the major axis is eight times the length of the vessel and the length of the minor axis is 3.2 times the length of the vessel.

Figure 1-1. Four ship domains proposed in the literature.

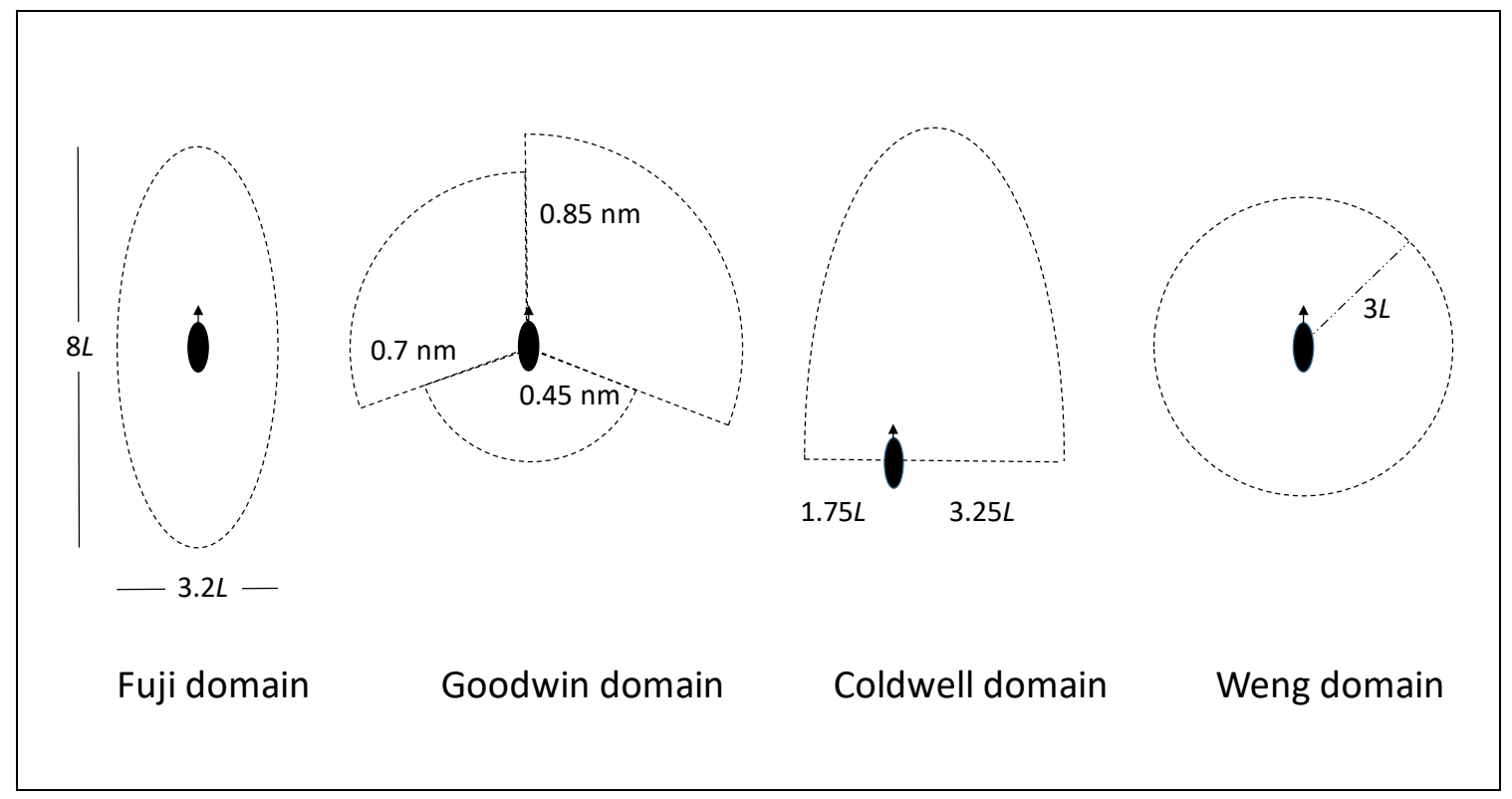

Other authors have confirmed the existence of ship domains and described them from different perspectives. Goodwin (1975) defined ship domains from the perspective of the vessel operator as "the surrounding effective waters which the navigator of a ship wants to keep clear of other ships or fixed objects." The domain is circular and is divided into three sectors that 
correspond to the arcs of a ships sidelights and stern light, each having a different diameter to reflect the varying obligations of the vessel operator under the International Regulations for Preventing Collisions at Sea (COLREGS) (International Maritime Organization [IMO] 1972). The diameter of the starboard arc is $0.85 \mathrm{~nm}$, the diameter of the port arc is $0.7 \mathrm{~nm}$, and the diameter of the stern arc is $0.45 \mathrm{~nm}$. Vessel operators prefer to maintain larger domains on the starboard side of their bow because their obligations are to give way to vessels approaching on that side.

Coldwell (1983) also described ship domains from the perspective of the vessel operator but defined the domain as "the surrounding effective waters which the typical navigator actually keeps clear of other vessels." Coldwell's model for head-on encounters consists of one-half of an ellipse that is aligned with the vessel's course. The positive major semi-axis is 6.1 ship lengths, and the minor axis is 5 ship lengths. The vessel is centered 0.75 vessel lengths to the left of center, providing a larger buffer on the starboard side. The asymmetry of the ship domain reflects the obligations of the vessel operator in a head-on nautical situation. For an overtaking situation, Coldwell (1983) proposed an ellipse that is centered on the vessel, similar to the one proposed by Fuji and Tanaka (1971). Weng et al. (2012) applied a circular ship domain with radius three times the length of the vessel to assess the risk of vessel collisions in the Singapore Strait. This circular ship domain was used for all three types of navigational situation: head-on, overtaking, and crossing.

Most authors agree that the size of a ship domain depends in part on the size of the vessel. Other factors may also affect the size of the ship domain (Fuji and Tanaka 1971; Goodwin 1975; Coldwell 1983; Weng 2012). For example, factors that limit visibility or maneuverability may lead vessel operators to increase the size of ship domains. Vessel operators tend to maintain larger domains at sea in open water than in narrow channels or congested waters, where they are forced to operate in close proximity to other vessels. Vessel operators may also vary their ship domain with the speed of the vessel. Vessels can be easier to maneuver at higher speeds, but the reaction time is reduced. Vessel operators will also adjust their domains to reflect individual preferences, culture, and experience (Jingsong et al. 1993).

Numerous other ship domains have been described in the literature. Wang et al. (2009) describe a variety of other ship domains from the literature, 
identifying three basic shapes: ellipses, circles, and polygons.

Pietrzykowski (2008) proposed fuzzy domains that change in size and shape to reflect the navigational risk given the context and nautical situation. Rawson et al. (2014) employed ship domains that were polygons that varied in size with the vessel's speed over ground and maneuverability. Hansen et al. (2013) used AIS data to study the movements of ships in southern Denmark to characterize the size and shape of ship domains that pilots maintain in practice. These authors showed "when operating in narrow channels and around bridges," pilots use ship domains that are similar in size and shape to those proposed by Fuji and Tanaka (1971).

Ship domains are a well-established concept and have been widely used in collision avoidance, trajectory planning, marine traffic simulation, and risk assessments (Wang et al. 2009; Weng et al. 2012; Rawson et al. 2014). There are several reasons for using a ship domain approach to calculating geometric probabilities. The primary reason is that the method can be applied consistently and cost effectively over a large area using existing AIS data without first setting up and running a detailed simulation of navigation traffic. Traffic simulation is more time consuming because all potential collision and grounding events must be identified, the waterway and its risk areas must be precisely defined, and statistical characterizations of vessels and their movements must be developed from AIS data to parameterize the model. Whereas the traffic simulation results are based on a statistical aggregation and summary of AIS data, the results of a ship domain analysis are based on the actual history of vessel movements documented in AIS data. Therefore, it may be easier to explain and defend the results to policy makers, to understand how specific events may have influenced the results, and to audit the analyses.

While the ship domain approach has been chosen over traffic simulation for this analysis of collision and grounding risk in USACE navigation projects, it is important to note that traffic simulation also has some advantages over ship domain analysis. In particular, the traffic simulation approach can be used to evaluate risk reduction alternatives. For example, port managers may wish to evaluate the risk reduction benefits of traffic separation schemes, traffic management measures, or alternative channel configurations. No models are developed in the course of a ship domain analysis, so there is no way to simulate the effect of measures to reduce risk on the probabilities of collision and grounding. 
It is also important to note that both the traffic simulation approach and the ship domain approach are based on critical assumptions. Traffic simulation assumes blind navigation, which implies that the AIS data used to characterize vessel movements are generated by vessels that do not see each other or react to each other's presence. The ship domain approach side-steps this assumption. However, when using ship domain analysis to compute a geometric probability and the probability of collision as described by MacDuff (1974), the implicit assumption is that a vessel whose domain is encroached by another vessel will collide with that vessel unless it takes evasive action. While all collisions are preceded by SDVs, whether or not a collision occurs also depends on the size, position, course, and speed of each vessel. Therefore, SDVs may resolve without a collision even if no evasive action is taken. 


\section{Methods}

This chapter describes how AIS data from NAIS are used in navigation risk assessment. NAIS is a system of shore-based VHF receivers that harvest AIS messages transmitted by vessels for the purpose of collision avoidance. These messages contain information about vessel identity, course, heading, speed, dimensions, and other important information. The data were obtained from the USCG, which operates and maintains NAIS.

\subsection{AIS database}

The USCG provided AIS data from NAIS in two comma-separated files: (1) position reports and (2) static vessel data. AIS data are also available from NAIS in other data formats and with additional data fields.

\subsubsection{Position reports}

The data fields contained in the AIS position reports are summarized in Table 2-1. The Maritime Mobile Service Identity (MMSI) is a unique identifier for the AIS transceiver that sent the message and is used to identify the vessel to which the AIS transceiver is registered. While the MMSI number is generally an accurate way to identify vessels, it is not perfect. Errors may be introduced when AIS systems are installed and configured or when AIS systems are transferred from one ship to another. Each position report also contains information on the geographic coordinates of the AIS transceiver in decimal degrees (LAT_AIST and LON_AIST) and a transmission date and time stamp (TX_DTTM). Location coordinates represent the geographic position of the AIS electronic position fixing system (EPFS) antenna on board the vessel. Time is reported in Coordinated Universal Time (UTC).

Table 2-1. Database fields provided in AIS position reports from NAIS.

\begin{tabular}{|l|l|l|l|}
\hline Field & Description & Format & Units \\
\hline MMSI & Maritime Mobile Service Identity & Numeric & \\
\hline LAT_AIST & Latitude & Numeric & Decimal degrees \\
\hline LON_AIST & Longitude & Numeric & Decimal degrees \\
\hline TX_DTTM & Transmission Date and Time (UTC) & DDMMMYY:HH:MM:SS & - \\
\hline NAV_STATUS & Navigational status & 1 digit code (0-9) & - \\
\hline SPEED & Speed over ground & Numeric & Tenths of knots \\
\hline COURSE & Course over ground & Numeric & Tenths of degrees \\
\hline HEADING & Heading & Numeric & Degrees \\
\hline RATE_OF_TURN & Rate of turn & Numeric & Degrees / minute \\
\hline
\end{tabular}


Each position record contains information about the location of the vessel and the date and time of transmission. The position of the vessel at the time the AIS signal is transmitted is documented using latitude and longitude coordinates. The date and time stamp, TX_DTTM, reports the time of transmission in hours, minutes, and seconds. Navigational status is an integer from $o$ to 15 . This code describes the vessel activity or situation at the time of transmission. The NAV_STATUS codes in use during 2014 are listed in Table 2-2. The navigation status field is not used in risk assessment. It is considered to be an unreliable source of information because it is updated manually as the status changes during the cruise (Robards et al. 2016).

Table 2-2. Navigational status codes (ITU 2014).

\begin{tabular}{|c|l|}
\hline Code & Description \\
\hline 0 & Under way using engine \\
\hline 1 & At anchor \\
\hline 2 & Not under command \\
\hline 3 & Restricted maneuverability \\
\hline 4 & Constrained by her draught \\
\hline 5 & Moored \\
\hline 6 & Aground \\
\hline 7 & Engaged in fishing \\
\hline 8 & Under way, sailing \\
\hline 9 & Reserved for future amendment \\
\hline 10 & Reserved for future amendment \\
\hline 11 & Power-driven vessel towing astern (regional use) \\
\hline 12 & Power-driven vessel pushing ahead or towing alongside (regional use) \\
\hline 13 & Reserved for future use \\
\hline 14 & AlS-SART (active), MOB-AIS, EPIRB-AlS \\
\hline 15 & Undefined \\
\hline
\end{tabular}

Each position report contains information about the vessel's speed and course at the time of transmission. Class A vessels are also required to report heading and rate of turn. Course over ground is the direction of travel. Heading is the direction the vessel's bow is pointing, which may differ from course because wind or currents may alter the orientation of a vessel or because a vessel is moving under the assistance of a tug. Rate of turn describes how fast the ship is turning. Speed, course, heading, and rate of turn are automatically reported by the AIS system and therefore 
more reliable than data fields that must be populated and updated by a vessel's operator. Missing value indicators are used to indicate that a field could not be populated. For example, a speed cannot be calculated when Global Positioning System (GPS) signals are obstructed.

NAIS data are processed to remove redundant records of vessel position that are generated when a single AIS transmission is received by more than one USCG receiver. Some numeric fields of databases acquired from the USCG contained an alpha-numeric missing value indicator. The text in these fields is converted to a numeric missing value indicator.

\subsubsection{Static vessel data}

The static vessel database provides information about the vessel that is associated with each MMSI number appearing in the position data. Static vessel data fields are outlined in Table 2-3. MMSI is the unique number registered to the AIS transceiver. The vessel name, IMO number, and radio call symbol are unique to the vessel. However, because these are manually entered fields, they are subject to duplication and other errors. DIM_BOW is the distance between the EPFS antenna and the bow of the vessel in meters. Similarly, DIM_STERN, DIM_PORT and DIM_STARBOARD indicate the distance between the EPFS antenna and the stern, port side, and starboard side of the vessel. These dimensions are needed to locate each vessel's center and perimeter. Vessel length is the sum of DIM_BOW and DIM_STERN and vessel beam is the sum of DIM_PORT and DIM_STARBOARD. DRAFT is the maximum draft of the vessel in meters. The DRAFT field contains a non-numeric missing value indicator that must be converted to numeric.

Table 2-3. Static vessel database fields (ITU 2014).

\begin{tabular}{|l|l|l|l|}
\hline Field & Description & Format & Units \\
\hline MMSI & Maritime Mobile Service Identity (MMSI) & Alpha-numeric & - \\
\hline NAME & Vessel name & Alpha-numeric & - \\
\hline IMO_NUMBER & IMO identifier & Alpha-numeric & - \\
\hline CALL_SIGN & Radio call symbol & Alpha-numeric & - \\
\hline DIM_BOW & Distance from EPFS antenna to bow & Numeric & Meters \\
\hline DIM_STERN & Distance from EPFS antenna to stern & Numeric & Meters \\
\hline DIM_PORT & Distance from EPFS antenna to port & Numeric & Meters \\
\hline DIM_STARBOARD & Distance from EPFS antenna to starboard & Numeric & Meters \\
\hline DRAFT & Maximum vessel draft & Numeric & Meters \\
\hline SHIP_AND_CARGO_TYPE & Two-digit AIS ship and cargo type code & Alpha-numeric & - \\
\hline
\end{tabular}


The SHIP_AND_CARGO_TYPE code is a system of two-digit codes developed by the International Telecommunications Union (ITU) to describe the ship and its cargo (ITU 2014). The interpretation of these ship and cargo type codes is summarized in Table 2-4. The ITU classification system is used here, but the USCG has also issued regulations that amplify the ITU encoding guidance, requiring a more elaborate system of codes for vessels operating in U.S. waters (USCG, n.d.). In principle, the USCG system should be consistent with the ITU system. However, there have been some discrepancies between the ITU and USCG systems in the past, and the USCG system has been periodically revised and updated.

Table 2-4. AIS ship and cargo type codes (ITU 2014).

\begin{tabular}{|c|l|}
\hline Code & Description \\
\hline 00 & Not available \\
\hline $20-29$ & Wing-in-ground craft (WIG) \\
\hline 30 & Fishing vessels \\
\hline 31 & Towing astern \\
\hline 32 & Towing astern and length of tow exceeds 200 meters (m) \\
\hline 33 & Engaged in dredging or underwater operations \\
\hline 34 & Engaged in diving operations \\
\hline 35 & Engaged in military operations \\
\hline 36 & Sailing \\
\hline 37 & Pleasure craft \\
\hline $38-39$ & Spare code for local assignment \\
\hline $40-49$ & High-speed craft and passenger ferries (HSC) \\
\hline 50 & Pilot vessel \\
\hline 51 & Search and rescue vessels \\
\hline 52 & Tugs or workboats \\
\hline 53 & Port tenders \\
\hline 54 & Vessels with anti-pollution facilities or equipment \\
\hline 55 & Law enforcement vessels \\
\hline $56-57$ & Spare code for local assignment \\
\hline 58 & Medical transports \\
\hline 59 & Ships according to RR Resolution No. 18 (Mob-83) \\
\hline $60-69$ & Passenger ships (other than HSC) \\
\hline $70-79$ & Cargo ships \\
\hline 89 & Tankers \\
\hline 59 & Other types \\
\hline 50 (H) \\
\hline 50
\end{tabular}




\subsection{Processing of AIS data}

The AIS data were processed prior to ship domain analysis. This processing includes screening the static vessel data, sampling the position reports, merging the AIS data with supporting datasets, and determining the geographic coordinates of vessel centroids.

\subsubsection{Screening of static vessel data}

Static vessel data were screened to assess their completeness and to identify and correct potential problems before analyzing collision and grounding risks because vessel names, dimensions, and ship and cargo type codes are often missing or erroneous. A second, more recent national inventory of vessels was generated using the Automatic Information System Analysis Package (AISAP) (Scully and Mitchell 2015). These data have the same source as static vessel data provided with NAIS position reports but is more recent, and because the quality of AIS data is gradually improving over time, it is potentially more complete. These data were used to impute missing dimensions and ship and cargo type codes when the MMSI number, vessel name, and dimensions could be matched with the MMSI number, vessel name, and any available dimensions in the original static vessel data. While this greatly reduced the number of records with missing dimensions, it did not eliminate the problem of missing dimensions.

For those records that still contained missing values, national mean values were imputed by two-digit ship and cargo-type code, and it was assumed that the EPFS antenna was positioned in the center of the vessel. National mean values of length, beam, and draft were calculated by two-digit ship and cargo-type code using the AISAP inventory. This ensured that all vessels have non-missing length, beam, and draft before analyzing collision and grounding risk. Prior to imputing national mean values, the NAIS static vessel data were screened to ensure proper classification of vessels under the ITU system of ship and cargo type codes. Vessels using specific ship and cargo-type codes were targeted for investigation. These included those vessels using codes reserved for WIG craft (20-29), spare codes for local assignment (38-39, 56-57), high-speed craft (40-49), ships according the RR Resolution No. 18 (Mob-83) (59), other types of vessels (90-99), and those using unknown ship and cargo-type codes (oo). Online databases such as MarineTraffic.com were searched for photographs of vessels using the MMSI numbers. If the identity of the vessel could be confirmed by a second piece of information, such as the vessel name 
displayed in the photograph, the ship and cargo type was updated to reflect the apparent characteristics of the vessel in the photograph.

\subsubsection{Sampling of AIS position reports}

The position data were sampled at half-minute intervals so that during any 30-second (sec) interval, each vessel was represented by exactly one record. This was accomplished by sorting the NAIS position records by MMSI and TX_DTTM, creating an index of half-minute intervals, and selecting the first position report during each half-minute interval. The static vessel data were then merged with the position data to create a single dataset. Ideally, every vessel within the navigation project will appear in the database exactly once during each half-minute interval. Vessels that are moored or anchored will transmit AIS messages at frequencies of once every 3 minutes and will not be represented with the same frequency as those that are underway. However, this analysis of AIS data is limited to those vessels inside the federal channel, and most vessels do not moor inside the federal channel unless that channel has been designated as a mooring area.

\subsubsection{Merging with supporting datasets}

Shapefiles of navigation channels were downloaded from the USACE eHydro website, http://navigation.usace.army.mil/Survey/Framework. These shapefiles were imported into $\mathrm{SAS}{ }^{\circledR}$, and the position reports were geo-referenced to navigation channels using PROC GINSIDE. The SDSFEATURE and CHANNELREA fields are read from navigation channel shapefiles and stored along with vessel position data to identify the navigation channel where the vessel was located at the time the AIS position report was transmitted. Tide data were downloaded from the National Oceanographic and Atmospheric Administration (NOAA), Center for Operational Oceanographic Products and Services, website (http://tidesandcurrents.noaa.gov). Six-minute water levels relative to mean lower low water were merged to position records using a six-minute time index and UTC time stamp for consistency with the NAIS data. In those ports containing more than one tide station, the most centrally located tide station was selected.

\subsubsection{Determining geographic coordinates of vessel centroids}

The location of each vessel's center must be determined to accurately project its perimeter and ship domain boundary. This requires 
information on the geographic location of the vessel, the course and heading at the time of AIS message transmission, and the location of the EPFS antenna on board the vessel. AIS messages report the location of the EPFS antenna using the geographic coordinate system (LAT_AIST, LON_AIST). Geographic coordinates are transformed to coordinates on the Universal Transverse Mercator (UTM) conformal projection ( $x_{A I S T}$, $y_{\text {AIST }}$ ), which have units of meters. Course, $C$, is the direction the vessel is moving relative to true north, and heading, $H$, is the orientation of the vessel relative to true north. Heading may not be aligned with course if wind or current is affecting the vessels movement or the vessel is under the control of a tug. Some vessels do not report heading. If heading was missing, it was assumed that heading was aligned with course.

The vessel's center is located using the four fields that describe the position of the EPFS antenna on board the vessel: DIM_BOW, DIM_STERN, DIM_PORT, and DIM_STARBOARD. Each field represents a distance, $d$, between the EPFS antenna and the indicated perimeter of the vessel, as shown in Figure 2-1. The distance between the EPFS antenna and an intermediate point $\left(x_{\mathrm{L}}, y_{\mathrm{L}}\right)$ on the longitudinal axis of the vessel (keel line), $r_{1}$, is calculated as follows:

$$
r_{1}=0.5 \cdot\left(d_{\text {port }}+d_{\text {starboard }}\right)-M I N\left(d_{\text {port }}, d_{\text {starboard }}\right)
$$

The distance between this intermediate point and the intersection of the keel line with the cross-sectional axis of the vessel $\left(x_{\mathrm{C}}, y_{\mathrm{C}}\right), r_{2}$, is calculated as follows:

$$
r_{2}=0.5 \cdot\left(d_{\text {bow }}+d_{\text {stern }}\right)-M I N\left(d_{\text {bow }}, d_{\text {stern }}\right)
$$

When the location of the EPFS antenna is not reported in static vessel data, then the EPFS antenna is assumed to be in the center of the vessel. 
Figure 2-1. Translation of EPFS antenna coordinates $\left(X_{A / S T}, y_{A I S T}\right)$ to vessel center coordinates $(x c, y c)$.

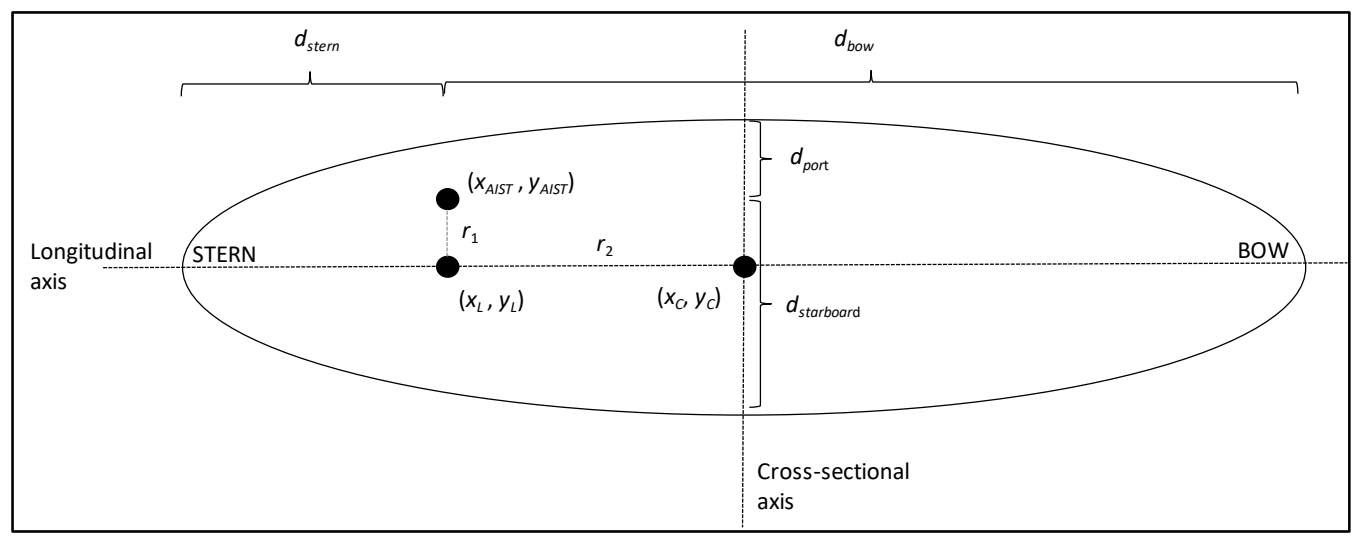

The signs of the distances $r_{1}$ and $r_{2}$ depend on in which quadrant of the vessel the EPFS antenna is located. The antenna may be located on board the vessel in one of four possible quadrants, as shown in Figure 2-2. Calculated values of $r_{1}$ and $r_{2}$ are given a sign that depends on which quadrant of the vessel the antenna is located.

- Case 1: $r_{1}$ is negative, $r_{2}$ is positive.

- Case 2: $r_{1}$ is positive, $r_{2}$ is positive.

- Case 3: $r_{1}$ is negative, $r_{2}$ is negative.

- Case 4: $r_{1}$ is positive, $r_{2}$ is negative.

The distances, $r_{1}$ and $r_{2}$, are used to transform the antenna coordinates $\left(x_{A I S T}, y_{A I S T}\right)$ to vessel center coordinates $\left(x_{\mathrm{C}}, y_{\mathrm{c}}\right)$ considering the vessels heading. UTM coordinates for the vessel center are calculated as follows:

$$
\begin{aligned}
& x_{c}=x_{A I S T}+r_{2} \cos H^{\prime}-r_{1} \sin H^{\prime} \\
& y_{c}=y_{A I S T}+r_{2} \sin H^{\prime}+r_{1} \cos H^{\prime}
\end{aligned}
$$

$H^{\prime}$ is the effective heading of the vessel, which is the orientation of the vessel in an un-rotated ellipse. In an un-rotated ellipse, the orientation of the positive major semi-axis is $H^{\prime}=\mathrm{O}^{\circ}$ and corresponds to a heading of due east, or $H=90^{\circ}$ relative to true north. The following relationship can be used to derive $H^{\prime}$ from $H$ :

$$
H^{\prime}= \begin{cases}90-H, & H \leq 90 \\ 360-(H-90), & H>90\end{cases}
$$


Figure 2-2. Four possible locations for the EPFS antenna onboard a vessel. Shading indicates which of the four quadrants the EPFS antenna is located given the conditions for distance to vessel boundaries.

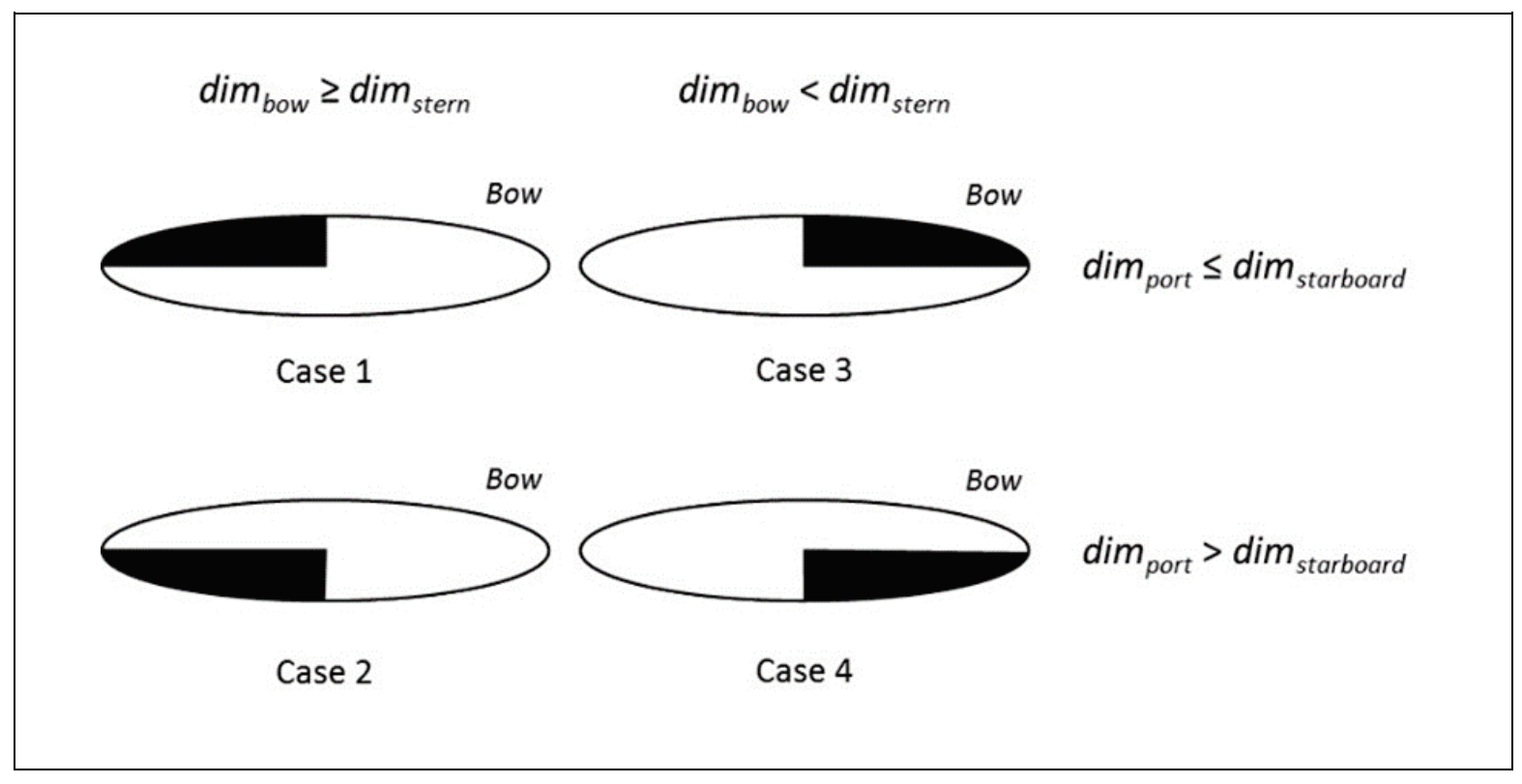

\subsection{Ship domains}

The ship domain is the area around a vessel that, if penetrated by another vessel, requires evasive action. Modified Fuji domains are used in this study. The domains are elliptical, centered on the vessel, and aligned with the vessel's course. The major axis length is four times the length of the vessel. The minor axis length is dynamic and varies with the vessel's swept path, which is the width of the vessel's track as it moves through the water. When a vessel's heading is aligned with its course, swept path is at a minimum and equal to the length of the vessel's beam. Heading may differ from course when the pilot points the bow of the vessel in a direction other than the course to compensate for the effects of wind and current that may be acting on the vessel or when initiating a turn. Beyond some critical angle that depends on the length and beam of the vessel, swept path increases with crab. Swept path is calculated as follows:

$$
\omega_{i}=\operatorname{MAX}\left(d_{\text {port }}+d_{\text {starboard }},\left(d_{\text {bow }}+d_{\text {stern }}\right) \cdot \sin \left(|C-H| \cdot \frac{\pi}{180}\right)\right)
$$

Ship domains are illustrated in Figure 2-3 for a $184 \mathrm{~m}$ vessel with a $26 \mathrm{~m}$ beam. The vessel is on a course of $145^{\circ}$. In Figure 2-3(a), the vessel heading is aligned with its course, and the swept path of the vessel is equal to the vessel's beam. Therefore, the minor axis of the elliptical ship domain 
is $78 \mathrm{~m}$, which is three times the vessel's beam. In Figure 2.3(b), the vessel's heading is $110^{\circ}$, which results in a crab angle of $35^{\circ}$. The swept path of the vessel is $105.5 \mathrm{~m}$, and the length of the minor axis of the ship domain is $316.6 \mathrm{~m}$, which is three times the swept path of the vessel. In Figure 2.3(c), the vessel has a heading of $55^{\circ}$, which results in a crab angle of $90^{\circ}$ and a swept path of $184 \mathrm{~m}$. The length of the minor axis of the ship domain reaches a maximum value of $552 \mathrm{~m}$.

Figure 2-3. Dynamic ship domain. The domain is represented by a dashed ellipse centered on a $184 \mathrm{~m}$ vessel with a $26 \mathrm{~m}$ beam. The arrow indicates the vessel's course, which is $145^{\circ}$. The point at the tip of the vessel marks the vessel's bow to indicate the vessel's heading. The length of the major axis is four times the vessel length, and the length of the minor axis is three times its swept path, which depends on the difference between course and heading.

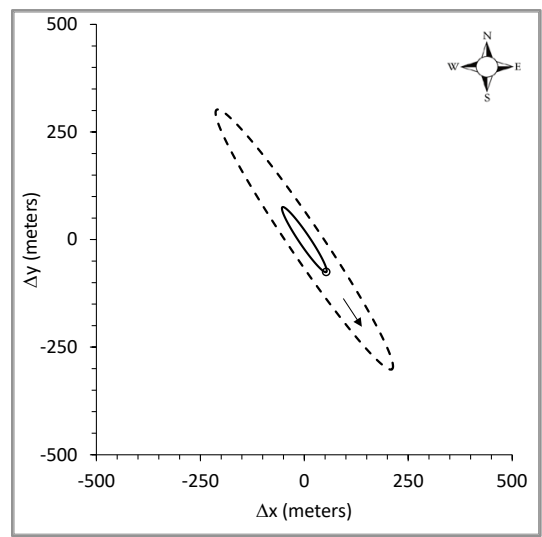

(a)

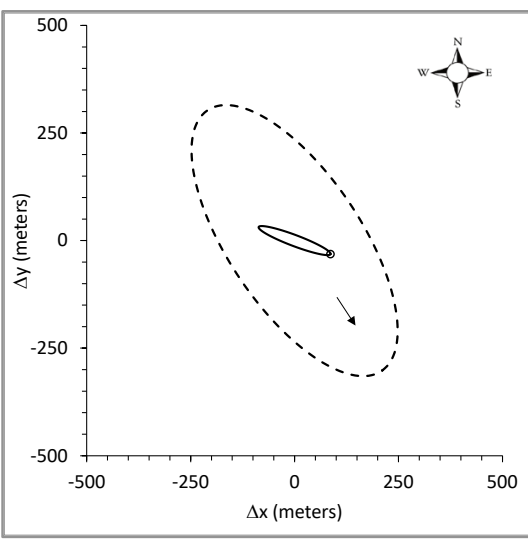

(b)

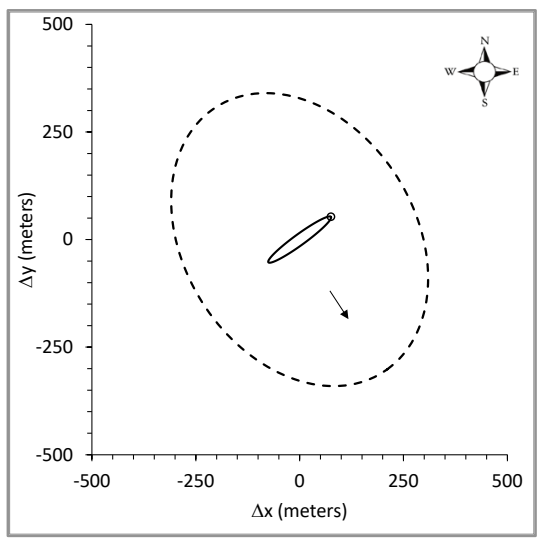

(c)

The ship domains used in this study are smaller than those suggested by other authors. The rationale for using a smaller ship domain is that vessels operating in coastal ports are moving around in navigation channels that range in width from 300 to $1000 \mathrm{ft}$. Given the context of narrow navigation channels, larger domains might result in SDVs being identified each time two vessels pass each other. An analysis dominated by such common events would not provide useful information about collision risks or help identify where improvements in channel design and maintenance might reduce risk. Smaller domains help ensure that only the most severe encounters are identified in AIS data.

\subsubsection{Ship domain violations (SDVs)}

An SDV occurs when the perimeter of one vessel is within the domain of another vessel. In this study, SDVs are used as a proxy for vessel collisions. The need for a proxy arises because vessel collisions are rare events. In general, rare events tend to be under-represented in historical data. 
Therefore, when an historical data set is used to estimate the probability of a rare event, the result tends to underestimate the probability of occurrence. SDVs occur more frequently than collisions, and although not all SDVs result in a collision, all collisions are preceded by SDVs.

The criteria for classifying position reports as SDVs is illustrated in Figure 2-4. In Figure 2-4(a), the situation is not classified as an SDV because, although the ship domains overlap, neither vessel's perimeter lies within the boundary of the other vessel's ship domain. This illustrates that overlapping ship domains do not constitute an SDV. In Figure 2-4(b), vessel $j$ is crossing in front of vessel $i$. Vessel $i$ 's ship domain is being violated because the perimeter of vessel $j$ lies within vessel $i$ 's ship domain. Vessel $i$ is labeled the encroached vessel and vessel $j$ is labeled the encroaching vessel. These labels do not imply fault. In this situation, vessel $j$ is the stand-on vessel according to the IMO COLREGS because vessel $j$ approached this situation from the starboard side of vessel $i$, and therefore, vessel $j$ has the right-of-way (IMO 1972, Rule 15). Figure 2-4(c) illustrates an overtaking situation. Vessel $j$ is overtaking vessel $i$ on the port side and has encroached on vessel $i$ 's ship domain. In this situation, the COLREGS specify that vessel $i$ is the stand-on vessel. Vessel $j$ is the give-way vessel and is directed to stay out of the way of the vessel being overtaken (IMO 1972, Rule 13). Despite vessel j's responsibility in this situation under the COLREGS, being classified as the encroaching vessel does not imply fault.

Figure 2-4. Three scenarios illustrating situations that may result in SDVs: (a) Vessel $i$ is passing behind vessel $j$. There is no violation of ship domains because neither vessel's perimeter is inside the other's ship domain. Overlapping ship domains are not a violation. (b) Vessel $j$ is crossing in front of Vessel $i$. Vessel is ship domain is violated because the perimeter of vessel $j$ is inside Vessel is ship domain. Vessel $j$ s ship domain is not violated. (c) Vessel $j$ is passing vessel $i$. Vessel is ship domain is violated because the perimeter of vessel $j$ is inside its ship domain.

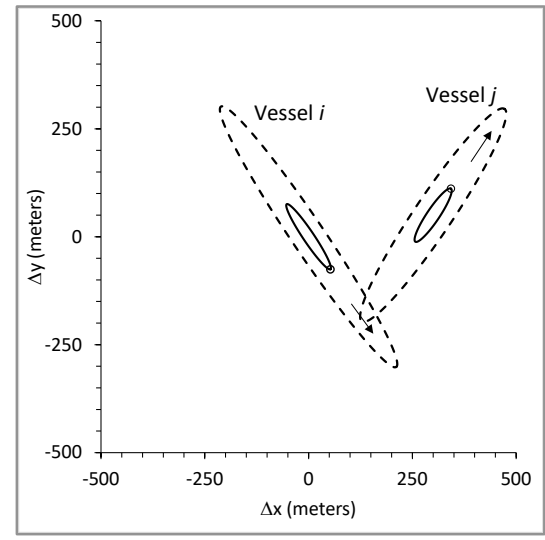

(a)

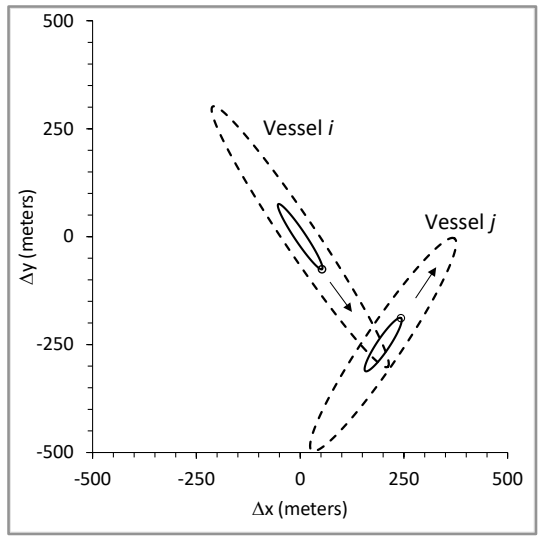

(b)

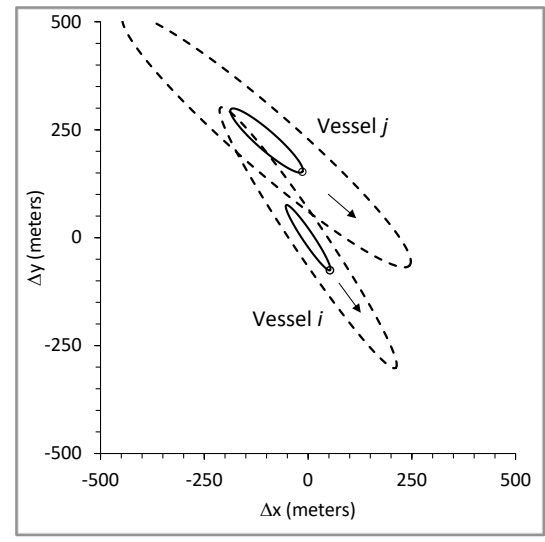

(c) 


\subsubsection{Identifying SDVs}

Candidates for SDVs are found by identifying every pair of vessels located within the federal channel during every 30 sec interval of the analysis period. A screening procedure is used to reduce the number of candidates for SDVs by calculating the distance between each pair of vessels and discarding those pairs that are more than some distance apart. The distance between each pair of vessels can be calculated from latitude and longitude coordinates using the Vincenty algorithm (Vincenty 1975) or by translating the latitude and longitude coordinates to UTM coordinates and applying the Pythagorean Theorem:

$$
d_{i j}=\sqrt{\left(x_{c_{j}}-x_{c_{i}}\right)^{2}+\left(y_{c_{j}}-y_{c_{i}}\right)^{2}}
$$

The distance $d_{i j}$ has units of meters. For the purpose of this study, the distance between candidates for SDVs must be less than or equal to $800 \mathrm{~m}$ apart. This distance is the maximum distance that two vessels, each $320 \mathrm{~m}$ in length, could be apart in a head-on situation and still satisfy the criteria for an SDV. Candidates for SDVs are retained in a separate database for further analysis with vessel $i$ designated as the potentially encroached vessel and vessel $j$ as the potentially encroaching vessel.

Given a set of candidate vessel pairs, SDVs are identified by determining whether or not any points on vessel $j$ 's perimeter lie within vessel $i$ 's ship domain. Vessel $j$ 's perimeter is represented by an ellipse that has a major axis equal to its length and a minor axis equal to its beam. Points on the ellipse representing $j$ 's perimeter $\left(x_{p_{j}}, y_{p_{j}}\right)$ are found using polar coordinates starting with a standard (un-rotated) ellipse centered on coordinates $(\mathrm{o}, \mathrm{o})$. The coordinates of each perimeter point on the unrotated ellipse $\left(x_{j}^{\prime}, y_{j}^{\prime}\right)$ are calculated as follows:

$$
\begin{aligned}
& x_{j}^{\prime}=0.5 L_{j} \cdot \cos \theta_{j} \\
& y_{j}^{\prime}=0.5 B_{j} \cdot \sin \theta_{j}
\end{aligned}
$$

The variable $\theta$ is the angle in radians between the forward major axis of the un-rotated ellipse and the line emanating from the center of the ellipse to the perimeter point. The angle is incremented at intervals of $5^{\circ}$ to identify 72 points on the perimeter. The points are then rotated using the vessel's effective heading: 


$$
\begin{aligned}
& x_{j}=x_{j}^{\prime} \cdot \cos H_{j}^{\prime}-y_{j}^{\prime} \cdot \sin H_{j}^{\prime} \\
& y_{j}=x_{j}^{\prime} \cdot \sin H_{j}^{\prime}+y_{j}^{\prime} \cdot \cos H_{j}^{\prime}
\end{aligned}
$$

The UTM coordinates associated with each perimeter point are calculated by adding the rotated distance to the UTM coordinates for the vessel centers:

$$
\begin{aligned}
& x_{p_{j}}=x_{c_{j}}+x_{j} \\
& y_{p_{j}}=y_{c_{j}}+y_{j}
\end{aligned}
$$

The following condition indicates whether a point on the perimeter of vessel $j\left(x_{p_{j}}, y_{p_{j}}\right)$ falls inside the domain of vessel $i$ is evaluated for all 72 points on the perimeter of vessel $j$ :

$$
\begin{aligned}
& \frac{\left(\cos C_{i}^{\prime}\left(x_{p_{j}}-x_{c_{i}}\right)+\sin C_{i}^{\prime}\left(y_{p_{j}}-y_{c_{i}}\right)\right)^{2}}{4 L_{i}{ }^{2}} \\
&+\frac{\left(\sin C_{i}^{\prime}\left(x_{p_{j}}-x_{c_{i}}\right)-\cos C_{i}^{\prime}\left(y_{p_{j}}-y_{c_{i}}\right)\right)^{2}}{3 \omega_{i}{ }^{2}} \leq 1
\end{aligned}
$$

$C_{i}^{\prime}$ is the effective course of vessel $i$. The size of vessel $i$ 's ship domain is determined by $L_{i}$ and $\omega_{i}$, which are the length and swept path of vessel $i$, respectively. If the condition is met for at least one point on the perimeter of vessel $j$, an SDV exists.

\subsubsection{Severity of SDVs}

A severity score is calculated for each position report that is classified as an SDV. The severity score, which is assessed from the perspective of vessel $i$, is calculated from the ratio of the minimum distance between 72 points on the perimeters of vessels $i$ and $j$ and the distance between vessel $i$ 's perimeter and its own ship domain boundary along the line between perimeter points:

$$
v_{i j}=1-\frac{d_{i j}}{d_{e}}=1-\frac{\sqrt{\left(x_{p_{j}}-x_{p_{i}}\right)^{2}+\left(y_{p_{j}}-y_{p_{i}}\right)^{2}}}{\sqrt{\left(x_{e_{i}}-x_{p_{i}}\right)^{2}+\left(y_{e_{i}}-y_{p_{i}}\right)^{2}}}
$$


The numerator $d_{i j}$ is the minimum distance between each pair of points on the perimeters of vessels $i$ and $j$. The distance between each 1,296 pairs of points is calculated to find the minimum. The denominator $d_{e}$ is the distance between the perimeter of vessel $i,\left(x_{p_{i}}, y_{p_{i}}\right)$, and a point, $\left(x_{e_{i}}, y_{e_{i}}\right)$, which lies at the intersection of the line between perimeter points and its own ship domain boundary (Figure 2-5).

An iterative procedure is used to locate the point on vessel $i$ 's ship domain boundary, $\left(x_{e_{i}}, y_{e_{i}}\right)$. The line between perimeter points is defined, and steps are made along this line in a cardinal direction away from vessel $i$. The cardinal direction of movement depends on the vessel's orientation, and each step is $1 \mathrm{~m}$ in that cardinal direction. Each point on the line between the vessels is evaluated using the condition above for determining whether or not a point lies within vessel $i$ 's elliptical ship domain. The first point that does not lie within vessel $i$ 's ship domain is used to represent the point on the boundary of vessel $i$ 's ship domain.

Higher values of the severity score are associated with greater severity. The severity scale is linear so that $v_{i j}=0$ indicates that vessel $j$ is on the boundary of vessel $i$ 's ship domain, a value of $v_{i j}=0.5$ indicates that vessel $j$ is half-way between vessel $i$ and the boundary of $i$ 's ship domain, and $v_{i j}=1$ indicates that there is no distance between vessel perimeters. This measure of severity is similar to one proposed by Szlapczynski (2006). The major difference in the method is that, in the present study, the distance between vessels reflects the distance between vessel perimeters. In Szlapczynski (2006), the distance between vessels reflected the distance between vessel centroids. 
Figure 2-5. SDV severity score. The SDV severity is calculated from the ratio of the minimum distance between vessel perimeters and the distance between vessel is perimeter and its ship domain boundary along the line of minimum distance between

vessel perimeters.

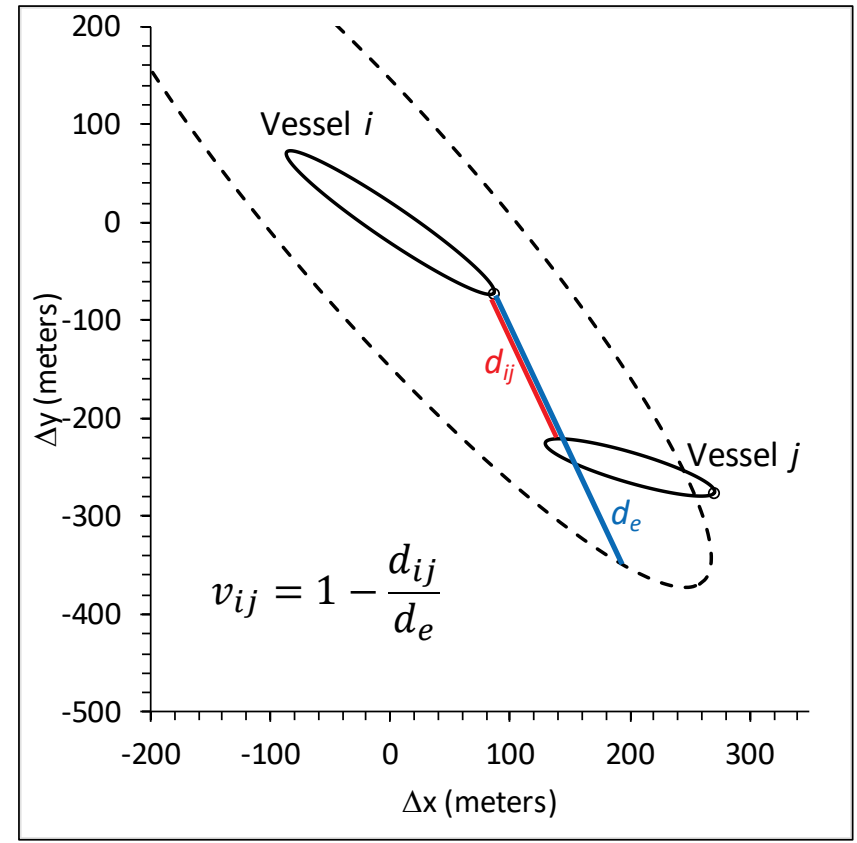

\subsection{Metrics of collision risk}

At least three distinct metrics of collision risk in navigation channels can be calculated from AIS data. These include (1) the probability of an SDV given that at least one vessel is present, (2) the overall probability of an SDV, and (3) the relative frequency of SDVs. AIS position reports are sampled from navigation reaches at 30 sec intervals. This process of sampling one position report from each vessel at $30 \mathrm{sec}$ intervals normalizes the data to control for the differences in AIS transmission frequency, reach surface area, the number and type of vessels utilizing each reach, and vessel dwell times and speeds. The database should contain exactly one position report from each vessel that is located within the federal channel during each thirty second interval of the watch or study period. Each pair of position reports in each $30 \mathrm{sec}$ interval is evaluated to determine if it meets the criteria for an SDV.

The first metric of collision risk is the probability that a vessel's ship domain is encroached given that at least one vessel is present in the reach. This can be estimated as the fraction of sampled position reports classified as SDVs in each reach: 


$$
p\left(S D V \mid n_{k t} \geq 1\right)=\frac{\sum_{t=1}^{T} n_{k t}^{+}}{\sum_{t=1}^{T} n_{k t}}=\frac{N_{k}^{+}}{N_{k}}
$$

Here, $n_{k t}$ is the number of position reports from reach $k$ at time $t$, which is equal to the number of vessels present in a reach during the time interval $t$. In the numerator, $n_{k t}^{+}$is the number of position reports classified as SDVs in reach $k$ during the $30 \mathrm{sec}$ interval $t$, and $\mathrm{N}^{+}$is the sum of sampled position reports classified as SDVs in that reach during the watch, which is 1 year. In the denominator, $n_{k t}$ is the total number of position reports in the reach during the $30 \mathrm{sec}$ time period $t$. Because the data are normalized, this metric can be used to compare and rank navigation channels in terms of collision risk. A vessel's ship domain is more likely to be encroached in navigation reaches where the conditional probability of an SDV is higher. Depending on the pattern of usage in a reach, this metric may indicate that SDVs are more common in reaches that are less frequently used.

A second possible metric of collision risk is the overall probability of an SDV. This metric is calculated by multiplying the conditional probability of an SDV by the probability that at least one vessel is present in the reach:

$$
p(S D V)=p\left(S D V \mid n_{k t} \geq 1\right) \times p\left(n_{k t} \geq 1\right)
$$

Here, $n_{k t}$ is the number of vessels in the reach. The probability that at least one vessel is present is calculated as the fraction of $30 \mathrm{sec}$ time periods during which at least one vessel was present in the watch area. In contrast to the conditional probability of an SDV, the probability of an SDV will tend to be higher in larger reaches and in reaches with more navigation traffic. Higher probabilities arise because vessels tend to spend more time transiting through larger reaches, resulting in a larger number of position reports and more opportunities for SDVs. This metric indicates in which navigation channel reach SDVs are most likely to occur. This metric could be used to anticipate the location where SDVs are most likely to occur in a navigation project and, for example, used to determine where first responders should be located within a navigation project to minimize response time.

A third possible metric of collision risk is the relative frequency of SDVs. This metric is simpler to calculate than the other two metrics because it can be calculated from just the inventory of SDVs in the watch area. The 
relative frequency of SDVs in a reach, $k, f_{k}$, is the fraction of all SDVs within a navigation project that occur in a particular reach:

$$
f_{k}=\frac{N_{k}^{+}}{\sum_{k=1}^{K} N_{k}^{+}}
$$

$\mathrm{N}^{+}{ }_{k}$ is the number of position reports classified as SDVs in navigation reach $k$, and the denominator is the total number of SDVs occurring within the navigation project. This metric can be interpreted as the probability that an SDV occurs in reach $k$ given that an SDV has occurred in the navigation project. As with the overall probability of an SDV, the second metric described above, the relative frequency of SDVs can be used to indicate where SDVs are most likely to occur in a navigation project. There should be a high correlation between these two metrics.

\subsection{Metrics of grounding risk}

Grounding risks are assessed with respect to powered groundings inside and on the edge of navigation channels. The depth-limited fraction of vessels is used as a metric of the risk of powered groundings on a shoal in the channel. Channel side events are used to indicate the risk of grounding on the side of a channel.

\subsubsection{Channel side events}

Federal navigation channels are flanked by embankments that rise to natural bathymetry. Vessels will ordinarily avoid the edge of a channel to prevent grounding but may approach the edge of the channel for several reasons. If the operator has information that the depth outside the channel is sufficient to accommodate the vessel's draft, he may intentionally cross the channel boundary to moor outside the channel or access a dock. Vessels may also approach the edge of the channel when passing one another, avoiding obstacles, or when wind or currents make maneuvering the vessel difficult.

This study uses AIS data to identify locations in the navigation project where the distance between the keel line of a vessel in transit and the side of a channel is less than $55 \%$ of the vessel's beam (Figure 2-6). These locations, termed channel side events, are found by sampling NAIS position reports at $30 \mathrm{sec}$ intervals and screening out all vessels with a maximum draft less than $5 \mathrm{~m}$ and all vessels transiting at less than 1 knot. 
The position of the bow, center, and stern on the keel are computed from information about the position of the EPFS antenna, vessel dimensions, and heading. The distance between each point and the nearest channel boundary is computed using ArcMap ${ }^{\circledR}$, a geographic information system software package. The distance to points on the keel line inside the channel is positive, and the distance to points on the keel line outside the channel are negative. The point on the keel line with the minimum distance is chosen to represent the distance between the vessel and the edge of the channel. Maps of channel side events are reviewed to identify clusters of channel side events. If there are a large number of events, additional transit speed and maximum draft filters can be used to thin the results.

Figure 2-6. Criteria for channel side events. Channel side events occur when the distance between the keel line and the channel boundary, $d$, is less than $55 \%$ of the vessel's beam, $B$, leaving a distance between the hull and the channel boundary that is less than $5 \%$ of the vessel's beam.

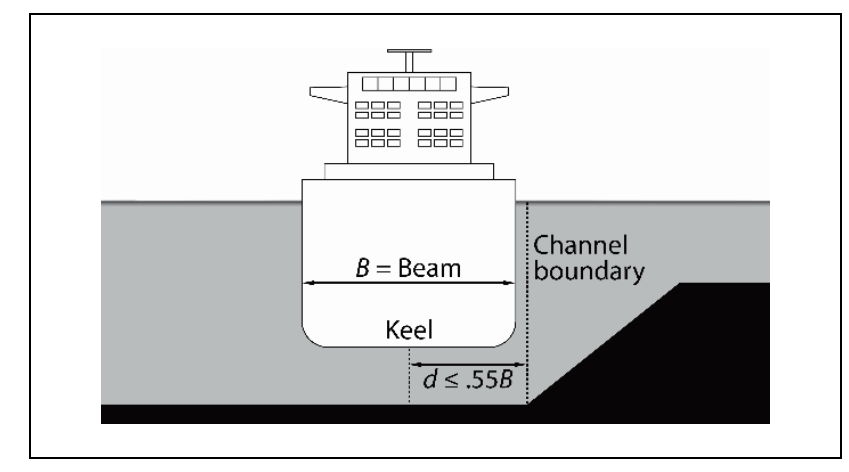

Clusters of channel side events at a location indicate that vessels are repeatedly approaching the edge of channel at that location. However, it is not possible to determine from AIS data alone what factors might have led the pilot to transit close to the edge of the channel, what the in-transit draft of the vessel was, and whether or not the natural bathymetry should have been expected to accommodate that draft at those locations. Additional study is needed. Some clusters of channel side events can be explained by the presence of docks or mooring areas, which may suggest that the vessels are leaving the navigation channel intentionally to access these features. In such cases, departures from the channel are explained and can be discounted. Where clusters of channel side events cannot be explained by the presence of docks or mooring areas, further investigation would still be needed to determine their cause and whether or not the risk of grounding on the side of the channel may be elevated at that location by 
conditions within the channel. Additional study might include conducting interviews with pilots or examining bathymetric maps and dredging histories to determine whether or not a hazard exists. Not all channel side events occur for reasons that would be of interest to USACE.

\subsubsection{Depth-limited fraction of vessels}

Grounding on the bottom of the channel is a serious threat to vessels operating in shallow water. To avoid grounding, vessel draft must be less than available water depth. It is preferred that vessel draft be less than maintenance depth, tide, squat, and minimum net underkeel clearance. Squat is the reduction in under-keel clearance caused by the resistance of water that is being pushed in front of the bow. The amount of vessel squat depends on the vessel's speed, block coefficient, cross-sectional area, the current, and the cross-sectional area of the waterway. Narrow waterways tend to produce more squat than un-restricted waterways. There are several empirical formulas for estimating squat, but the methods are approximate. After accounting for the tide and squat, a minimum net underkeel clearance of 2 to $3 \mathrm{ft}(0.61-0.92 \mathrm{~m})$ provides a margin of safety.

Vessels that require more than maintenance depth after accounting for tide, squat, and minimum net underkeel clearance are depth limited. These vessels could not transit the channel without operating at less than maximum draft. Therefore, the fraction of vessels utilizing a channel that are depth limited is an indication of the demand for depth. The depthlimited fraction of vessels could be calculated estimating tide, squat, and minimum net under-keel clearance, but this type of analysis might introduce more uncertainty than it resolves. Tide varies from one location in a navigation project to another but is usually measured only at a single location. Squat can be estimated but depends on vessel block coefficients and cross-sectional areas that are not reported in AIS. The actual draft of vessels during transit is also not reported in AIS. In addition, the actual depth of channels may exceed maintenance depth because of routine overdredging and advance maintenance.

In this study, the depth-limited fraction of cargo vessels and tankers is used to assess the risk of powered grounding on the bottom of the channel. Vessels that have maximum drafts greater than maintenance depth are depth limited. These vessels may be able to navigate in the channel by using the tide or by transiting at less than maximum draft. However, the 
fraction of vessels that are depth limited indicates the extent to which the maintenance depth of a channel may be a factor limiting access to the port.

The depth-limited fraction of vessels is calculated by first identifying all cargo vessels and tankers utilizing a reach during the period of interest. The fraction of those vessels that have maximum drafts greater than the maintenance depth of the channel is calculated. The risks associated with shoaling are assessed by recalculating the depth-limited fraction of cargo vessels and tankers for a series of $1 \mathrm{ft}$ reductions in maintenance depth. Maintenance depth is reduced in $1 \mathrm{ft}$ increments up to $6 \mathrm{ft}$ to simulate the presence of a depth-limiting shoal in the reach. The fraction of cargo vessels and tankers that have utilized the reach in the past year and have maximum drafts greater than limiting depth is calculated for each depth reduction.

The change in depth-limited fraction of vessels over incremental reductions in maintenance depth reveals where the depth-limited fraction of vessels would increase more rapidly in response to shoaling events. This may provide navigation managers with insights into the extent to which navigation in a reach might be impacted by shoaling or deferred maintenance. Although the approach is very simple, it is robust, meaning that it is based on concrete information that is generally available in all navigation projects.

This study makes no attempt to estimate the probability of grounding on a shoal in the channel. In general, that would require information on the actual draft of each vessel in transit and the water surface elevation and bathymetry of the navigation reach at the time of transit. Where sufficient data are available, probabilistic analyses are possible. Scully and Mitchell (2017) developed a model of net underkeel clearance and applied that model in Charleston Harbor to estimate channel reliability, which was defined as the probability that net underkeel clearance is greater than or equal to 0 . In addition to archival AIS data, that study incorporated bathymetric surveys, observed water level elevations, and data on the sailing draft of vessels at the time of transit. Such information is not uniformly available, making it difficult to apply this approach consistently in all ports.

\subsection{Demonstration studies}

The following chapters of this report describe implementation of the ship domain analysis in five coastal navigation projects, including Boston 
Harbor, Calcasieu River, Charleston Harbor, Jacksonville Harbor, and Columbia River (Figure 2-7). The methods are applied consistently in each port, and each chapter follows a consistent format. AIS data were provided by the USCG from NAIS. With exception of Columbia River, AIS data from calendar year 2014 were acquired for use in other studies. Not all of those studies required full coverage of every navigation channel in the project. Gaps in the coverage of each navigation project are described in the introductory paragraph of each chapter. These gaps in coverage do not interfere with demonstration of the methods. AIS data from Columbia River were acquired for calendar year 2015.

Figure 2-7. Location of demonstration studies.

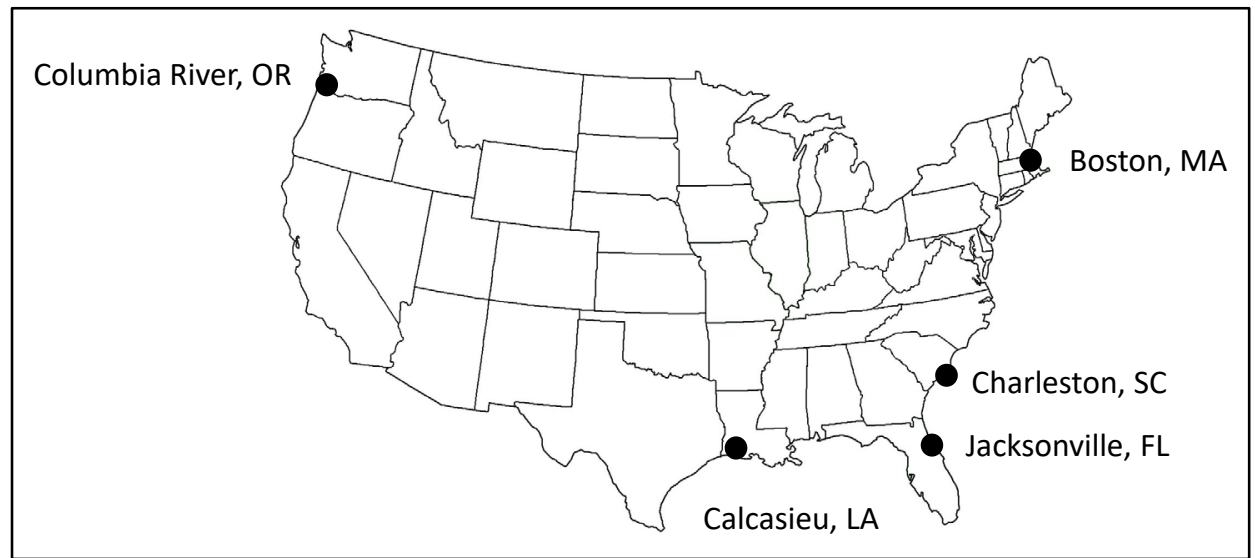

Each demonstration study includes maps and tables that describe the port. Maps of each coastal port illustrate the location of landmarks and features that are mentioned in the text. Shapefiles containing polygons outlining federal navigation channels were obtained from USACE e-Hydro Website. These have been mapped to show the location of navigation channel reaches. The names and dimensions of navigation channel reaches are summarized in tables. Reaches are indexed in each table and map for cross-referencing with the text.

\subsubsection{Static vessel data}

AIS data were screened prior to the analysis of collision and grounding risk. Missing and erroneous data on the identity, dimensions, and ship and cargo type were identified, corrected where possible, and imputed elsewhere. The identity, dimensions, and ship and cargo-type code of vessels were validated by referencing data and photographs in independent databases (e.g., MarineTraffic.com). In the future, an authoritative database such as Lloyds Register ${ }^{\circledR}$ could also be used. 
Length, beam, and draft are critical pieces of information for collision and grounding risk assessment. If length, beam, or draft was missing, national mean values of length, beam, and draft were imputed to missing data. These means were estimated for a master list of vessels detected in U.S. coastal waters, which was obtained from the USACE AISAP. The procedure ensures that each of the vessels in the static vessel database have a length, beam, and draft.

Missing vessel dimensions were imputed from national mean values by ship and cargo type. Each demonstration study includes a brief discussion of these efforts. The number of vessels by ship and cargo type code before and after the screening process is reported in a table. The column labeled "Before Review of Static Vessel Data" lists the number of vessels reporting each AIS ship and cargo type code. The column labeled "After Review of Static Vessel Data" lists the number of vessels assigned to each AIS ship and cargo type code after investigating and either confirming or reclassifying vessels suspected of being misclassified.

\subsubsection{Collision risk assessment}

AIS position reports were sampled from the federal channel at $30 \mathrm{sec}$ intervals. Each sampled position report was classified as an SDV if a point on the perimeter of another vessel was located within the domain of the vessel transmitting the AIS signal. Encounters are interactions between two vessels during which one vessel encroaches on the domain of another vessel. If both vessels encroach on each other's domain during an interaction, two encounters are recorded. Each encounter is documented by a series of position reports for the encroached vessel in which at least one position report is classified as an SDV. Two position reports that are classified as SDVs are regarded as belonging to the same encounter if separated by a period no more than 10 minutes.

Encounters between one or more vessels classified under selected AIS ship and cargo type codes were removed from the inventory. These include those involving tugboats, port tenders, police boats, anti-pollution vessels, and other vessels operating under AIS ship and cargo type codes 50-57. These encounters were removed because these vessels intentionally operate in close proximity to other vessels. Encounters involving towboats operating under AIS ship and cargo type code 31 or 32 have also been removed from the analysis. Towboats and tugboats are often poorly distinguished in the AIS classification system, and towboat dimensions 
reported in static vessel data do not ordinarily include information on the dimensions of the tow, which is critical information in the analysis of SDVs. Encounters involving AIS-equipped yacht tenders interacting with their own yachts have also been removed from the analysis, as have vessels classified as dredgers that are interacting with other dredgers.

The number, location, and characteristics of encounters is summarized. The spatial distribution of encounters in each navigation project is summarized in a map illustrating the location of encounters at the time of maximum SDV severity. The number of encounters by encroached and encroaching AIS ship and cargo type is tabulated to show which vessels are most frequently involved in encounters. Empirical distribution functions summarize selected characteristics of encounters, including maximum SDV severity during each encounter, the minimum distance between vessel perimeters during each encounter, and the duration of each encounter. These statistics help demonstrate that vessels are avoiding each other and that encounters are generally short in duration.

Collision risks are evaluated using three metrics. The first is the conditional frequency of an SDV, which is the probability that an SDV occurs in a navigation channel reach given that at least one vessel is present in that reach. This is estimated by calculating the ratio of sampled position reports classified as SDVs to the total number of sampled position reports and can be interpreted as an estimate of the probability that a vessel operating in a navigation channel is involved in an SDV. This metric of collision risk can be used to evaluate, compare, and rank navigation channels in terms of collision risk. The second metric is the overall probability of an SDV occurring in a reach, which is the probability an SDV occurs without regard to whether or not a vessel is present. This is calculated by multiplying the conditional probability of an SDV by the probability that at least one vessel is present in the reach. The third metric is the relative frequency of SDVs, which is similar to the overall probability of an SDV occurring in a reach. However, this statistic expresses the probability that an SDV occurred in a navigation channel reach given that an SDV has occurred in the navigation channel.

\subsubsection{Grounding risk assessment}

The assessment of grounding risk examines two types of potential grounding events. The risk of powered groundings on the side of the channel is assessed by identifying clusters of channel side events to reveal 
where vessels in transit have a tendency to operate near the edge of the channel. Minimum speed and draft filters may be used to identify deep draft vessels in transit. Results are summarized in maps of channel side events. The risk of powered grounding in the channel is assessed by calculating what fraction of vessels are depth limited at maintenance depth and as maintenance depth is reduced to simulate shoaling. These results are presented in two tables, one for cargo vessels and another for tankers. These tables can also be used to indicate the extent to which available draft is being utilized in a channel and the sensitivity of navigation to a potential shoaling event.

Channel side events are identified and mapped. Not all channel side events are of interest for risk assessment. For example, this includes intentional departures from the channel to approach a dock or to access a private channel. The channel side events of interest for a risk assessment are those that are caused by vessels approaching the edge of the channel to avoid one another or by vessels that have difficulty maneuvering a section of channel, perhaps because of wind, currents, or poor channel configuration. These are of interest because navigation managers may be able to mitigate grounding risk in these locations by modifying the channel. Causes of channel side events are difficult to infer from the map of channel side events. Therefore, clusters of channel side events that cannot be explained otherwise may require further study.

Grounding risk is indicated by the number and fraction of depth-limited cargo vessels and tankers. These are determined by comparing the maximum design draft of each cargo vessel and tanker using a reach to the maintenance depth of the navigation channel. Only cargo vessels and tankers are considered because they represent the majority of vessels that might be depth limited. No provisions were made for squat or under-keel clearance in this analysis because AIS contains no information on the actual draft of a vessel in transit. The analysis also does not account for overdredging and advance maintenance of navigation channels. Reaches where a large number or fraction of the vessels are depth limited at maintenance depth may be candidates for deepening.

\subsubsection{Marine Information for Safety and Law Enforcement (MISLE) database reports}

Each chapter concludes with a map of collision and grounding incidents occurring between 2011 and 2015. These data are as reported in the USCG 
MISLE database. Data from before 2011 were not included because they predated a major system upgrade, and there were concerns about the degree to which they could be compared to those in later years. These data were acquired in the hope that they might be used to help verify the analysis. One way of validating the results of the collision and grounding analyses presented in this report is to compare those results with MISLE data to see whether or not they occur in higher risk areas. Each of the following five chapters includes a map showing the location of collisions, allisions, and grounding events in the coastal port. Only the nature and location of each incident are shown in the map to prevent disclosing nonpublic information. 


\section{Boston Harbor Channel (BHC)}

The Boston Harbor area is shown in Figure 3-1. The network of navigation channels in Boston Harbor consists of 31 distinct reaches (Figure 3-2). These reaches are listed in Table 3-1 along with data on the length, width, and depth of each reach. Maintenance depths range from 6 to $40 \mathrm{ft}$ (Table $3-1$ ). In the first column of Table 3-1, a unique index has been assigned to each reach for ease of reference. NAIS data were requested for the inner harbor area west of Spectacle Island for calendar year 2014. The NAIS data covered the entire inner harbor except the upper-most reaches of the Mystic and Chelsea Rivers. In the Mystic River, this includes reaches west of the Massachusetts Port Authority (MASSPORT) Moran Terminal, including the three reaches comprising the 35-Foot Mystic River Channel (\#16-18), and the western third of the 40-Foot Mystic River Channel (\#15). In the Chelsea River, this includes the 38-Foot Chelsea River Turning Basin (\#21) and that portion of the 38-Foot Chelsea River Upper Reach (\#20) that is north of the Gulf Oil Terminal. 
Figure 3-1. Map of Boston Harbor.

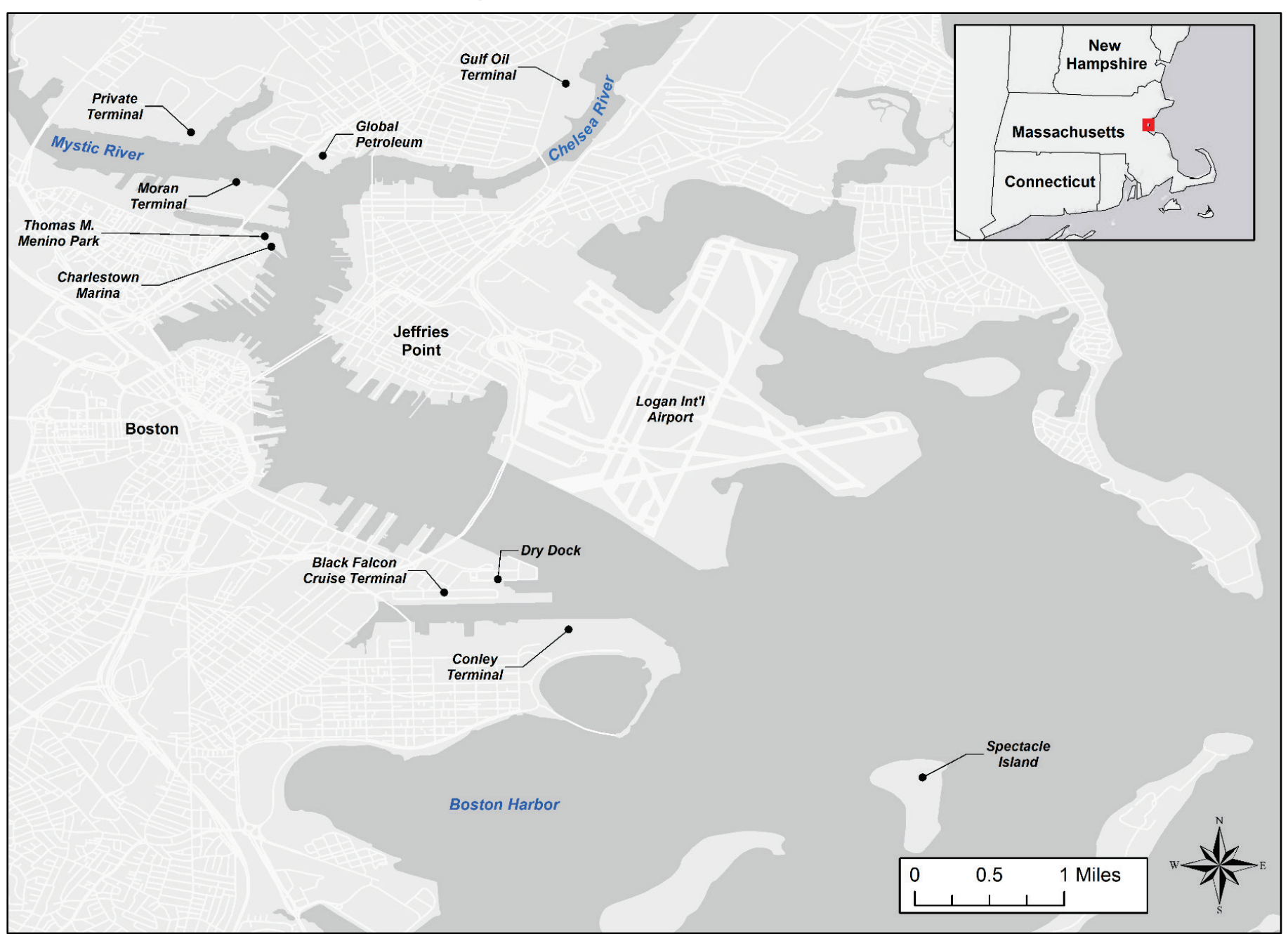

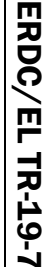


Figure 3-2. Federal navigation channel reaches in Boston Harbor.

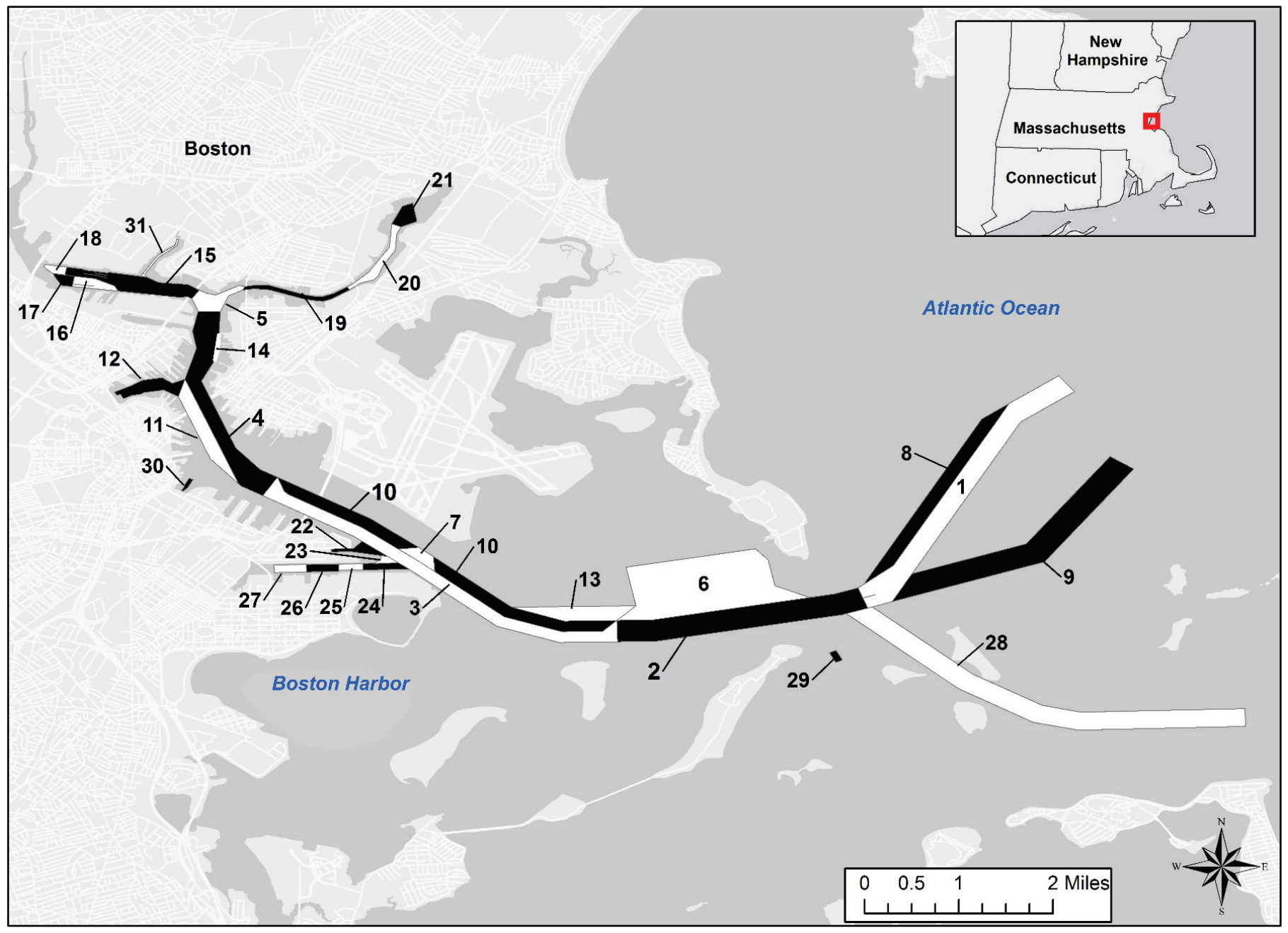


Table 3-1. Federal navigation channel reaches and reach characteristics in Boston Harbor.

\begin{tabular}{|c|c|c|c|c|c|c|}
\hline \# & Reach Code & Reach Descriptions & $\begin{array}{l}\text { Authorized Depth } \\
\text { (ft) }\end{array}$ & $\begin{array}{l}\text { Maintenance } \\
\text { Depth (ft) }\end{array}$ & $\begin{array}{l}\text { Length } \\
\text { (miles) }\end{array}$ & $\begin{array}{l}\text { Width } \\
\text { (ft) }\end{array}$ \\
\hline 1 & CENAE_MA_01_BOS_1 & 40-Foot North Broad Sound Reach & 40 & 40 & 2.47 & $900-1100$ \\
\hline 2 & CENAE_MA_01_BOS_2 & 40-Foot President Roads Reach & 40 & 40 & 1.71 & 1200 \\
\hline 3 & CENAE_MA_01_BOS_3 & 40-Foot Fort Independence Reach & 40 & 40 & 2.85 & 600 \\
\hline 4 & CENAE_MA_01_BOS_4 & 40-Foot Waterfront Reach & 40 & 40 & 1.78 & $600-1200$ \\
\hline 5 & CENAE_MA_01_BOS_5 & 40-Foot Inner Harbor Confluence & 40 & 40 & - & - \\
\hline 6 & CENAE_MA_01_BOS_6 & 40-Foot President Roads Anchorage & 35 & 35 & - & - \\
\hline 7 & CENAE_MA_01_BOS_7 & 40-Reserved Channel Turning Area & 40 & 40 & - & 600 \\
\hline 8 & CENAE_MA_01_BOS_8 & 35-Foot North Broad Sound Reach & 35 & 35 & 1.74 & 600 \\
\hline 9 & CENAE_MA_01_BOS_9 & 35-Foot South Broad Sound Reach & 35 & 35 & 1.98 & 1200 \\
\hline 10 & CENAE_MA_01_BOS_10 & 35-Foot Fort Independence Reach & 35 & 35 & - & - \\
\hline 11 & CENAE_MA_01_BOS_11 & 35-Foot Charlestown Waterfront Channel & 35 & 35 & 0.82 & 600 \\
\hline 12 & CENAE_MA_01_BOS_12 & 35-Foot Charles River & 35 & 35 & 0.45 & 600 \\
\hline 13 & CENAE_MA_01_BOS_13 & 35-Foot Anchorage & 40 & 40 & - & - \\
\hline 14 & CENAE_MA_01_BOS_14 & 35-Foot Area & 35 & 35 & 0 & 0 \\
\hline 15 & CENAE_MA_02_MYM_1 & 40-Foot Mystic River Channel & 40 & 40 & 0.92 & $444-575$ \\
\hline 16 & CENAE_MA_02_MYM_2 & 35-Foot Mystic River South Channel & 30 & 30 & 0.11 & - \\
\hline 17 & CENAE_MA_02_MYM_3 & 35-Foot Mystic River South Channel & 35 & 35 & 0.3 & - \\
\hline 18 & CENAE_MA_02_MYM_4 & 35-Foot Mystic River Channel & 35 & 35 & 0.14 & 444 \\
\hline 19 & CENAE_MA_03_BOS_1 & 38-Foot Chelsea River Lower Reach & 38 & 38 & 0.76 & $175-200$ \\
\hline 20 & CENAE_MA_03_BOS_2 & 38-Foot Chelsea River Upper Reach & 40 & 38 & 1.46 & $200-300$ \\
\hline 21 & CENAE_MA_03_BOS_3 & 38-Foot Chelsea River Turning Basin & 38 & 38 & - & - \\
\hline
\end{tabular}




\begin{tabular}{|c|c|c|c|c|c|c|}
\hline \# & Reach Code & Reach Descriptions & $\begin{array}{l}\text { Authorized Depth } \\
\text { (ft) }\end{array}$ & $\begin{array}{l}\text { Maintenance } \\
\text { Depth (ft) }\end{array}$ & $\begin{array}{l}\text { Length } \\
\text { (miles) }\end{array}$ & $\begin{array}{l}\text { Width } \\
\text { (ft) }\end{array}$ \\
\hline 22 & CENAE_MA_04_BOS_1 & 40-Foot Dry Dock Approach Channel & 40 & 40 & 0.29 & $170-1380$ \\
\hline 23 & CENAE_MA_04_BOS_2 & 40-Foot Reserved Channel Turning Area (West) & 40 & 40 & - & - \\
\hline 24 & CENAE_MA_04_BOS_3 & 40-Foot Reserved Channel & 40 & 40 & 0.28 & $346-361$ \\
\hline 25 & CENAE_MA_04_BOS_4 & 40-Foot Reserved Channel Middle Width & 40 & 40 & 0.17 & $346-400$ \\
\hline 26 & CENAE_MA_04_BOS_5 & 40-Foot Reserved Channel Inner Width & 40 & 40 & 0.22 & 400 \\
\hline 27 & CENAE_MA_04_BOS_6 & 35-Foot Reserved Channel Inner Width & 35 & 35 & 0.22 & 430 \\
\hline 28 & CENAE_MA_05_BOS_1 & 27-Foot Narrows Channel & 27 & 27 & 2.98 & 1000 \\
\hline 29 & CENAE_MA_06_BOS_1 & 15-Foot Nubble Channel & 15 & 15 & 0.96 & 300 \\
\hline 30 & CENAE_MA_07_BOS_1 & 23-Foot Fort Point Channel & 23 & 23 & 0.13 & $75-175$ \\
\hline 31 & CENAE_MA_13_ISL_1 & 6-Foot Channel & 6 & 6 & 0.49 & $75-90$ \\
\hline
\end{tabular}




\subsection{Static vessel data}

During the 2014 calendar year, NAIS receivers intercepted AIS messages from 844 unique AIS-equipped vessels in Boston Harbor. Static vessel data contained 1 record with a malformed MMSI code (0.12\%), 60 records with a missing vessel name (7.1\%), and 66 records with an unknown or missing ship and cargo type code (7.8\%). There were 105 records missing information about vessel length (12.4\%), 108 records missing information about vessel beam (12.8\%), and 329 records missing information about maximum design draught (38.9\%). Erroneous dimensions were detected in the record for a chemical tanker with a reported length equal to $693 \mathrm{~m}$ and a reported beam equal to $92 \mathrm{~m}$. Length and beam were corrected to $183 \mathrm{~m}$ and $27 \mathrm{~m}$ based on information from an independent database.

Characteristics of vessels utilizing federal channels in Boston Harbor during calendar year 2014 are summarized in Table 3-2. Ship and cargo type code classifications were validated, and if necessary, vessels were reclassified based on information from photographs of each vessel. Of the 844 AIS-equipped vessels utilizing the federal channel, the largest category was pleasure craft, with 210 vessels reporting an AIS ship and cargo type code 37 (24.9\%). Cargo vessels represented the second largest category, with 175 vessels reporting an AIS ship and cargo type code between 70 and 79 (20.7\%), and tankers represented the third largest category, with 95 vessels reporting an AIS ship and cargo type code between 80 and 89 (11.3\%).

Static vessel data were requested without information about the position of EPFS antenna on board each vessel. This information was obtained from the AISAP vessel inventory. Vessels in the AISAP database were matched to vessels in the Boston Harbor static vessel data by comparing MMSI numbers, length, and beam. There were 609 matches in static vessel data (72.1\%). If a matching MMSI was found, but the length and beam did not match, the vessel's name as reported in static vessel data was compared to the vessel's name as reported in the AISAP inventory, and if similar, the EPFS antenna was placed in relative proportion to the position reported in AISAP. This method was used for 25 vessels (3\%). If no matching MMSI was found in the AISAP inventory or if the length, beam, or transponder location was not reported, then the EPFS antenna was positioned at the center of the vessel. This procedure was used for 210 vessels (24.9\%). 
Table 3-2. Descriptive summary of vessels utilizing BHC.

\begin{tabular}{|c|c|c|c|}
\hline \multirow[b]{2}{*}{ AIS Ship and Cargo Type } & \multirow[b]{2}{*}{$\begin{array}{c}\text { AIS Ship and } \\
\text { Cargo } \\
\text { Type Code }\end{array}$} & \multicolumn{2}{|c|}{ Number of Unique Vessels } \\
\hline & & $\begin{array}{c}\text { Before Review } \\
\text { of Static Vessel } \\
\text { Data }\end{array}$ & $\begin{array}{c}\text { After Review of Static } \\
\text { Vessel Data }\end{array}$ \\
\hline Unknown & 0 & 66 & 66 \\
\hline Wing-in-ground craft (WIG) & $20-29$ & 12 & 0 \\
\hline Fishing vessels & 30 & 10 & 10 \\
\hline Towing astern & 31-32 & 43 & 43 \\
\hline Engaged in dredging or underwater operations & 33 & 1 & 1 \\
\hline Engaged in diving operations & 34 & 1 & 1 \\
\hline Engaged in military operations & 35 & 17 & 18 \\
\hline Sailing vessels & 36 & 83 & 83 \\
\hline Pleasure craft & 37 & 210 & 210 \\
\hline Reserved for future use & 38-39 & 0 & 0 \\
\hline High-speed craft or passenger ferries & $40-49$ & 5 & 5 \\
\hline Pilot vessels & 50 & 2 & 2 \\
\hline Search and rescue vessels & 51 & 12 & 12 \\
\hline Tugs & 52 & 33 & 44 \\
\hline Port tenders & 53 & 6 & 6 \\
\hline Vessels with anti-pollution facilities & 54 & 0 & 0 \\
\hline Law enforcement vessels & 55 & 6 & 6 \\
\hline Spare, for assignment to local vessels & $56-57$ & 0 & 0 \\
\hline Medical transports & 58 & 0 & 0 \\
\hline Ships according to RR Resolution no. 18 (Mob-83) & 59 & 0 & 0 \\
\hline Passenger ships & $60-69$ & 53 & 53 \\
\hline Cargo ships & $70-79$ & 175 & 175 \\
\hline Tankers & $80-89$ & 95 & 95 \\
\hline Other vessels & $90-99$ & 14 & 14 \\
\hline Total & - & 844 & 844 \\
\hline
\end{tabular}




\subsection{Collision risk assessment}

\subsubsection{Location and severity of encounters}

There were 356 encounters in BHC during the 2014 calendar year. The geometric center of the encroached vessel at the time of maximum SDV severity during each encounter is shown in Figure 3-3. Clusters of encounters can be seen at the entrance to the 40-Foot Reserved Channel (\#24), at the 40-Foot Inner Harbor Confluence (\#5), and in the Chelsea River Upper Reach (\#20). The color of each point in Figure 3-3 indicates the maximum SDV severity score during the encounter. Few encounters have maximum SDV severity scores greater than or equal to 0.8 , and encounters appear to be distributed throughout the navigation project.

Empirical cumulative distribution functions (CDFs) are used in Figure 3-4 to summarize selected characteristics of encounters in Boston Harbor. These include maximum SDV severity during each encounter, the minimum distance between vessel perimeters during each encounter, and the duration of each encounter. As shown in Figure 3-4(a), approximately $40 \%$ of encounters are associated with maximum SDV severity scores of 0.1 , and $90 \%$ of encounters are associated with severity scores less than 0.7. This indicates that vessels are staying away from each other, which is the anticipated behavior. Very few maximum SDV severity scores are greater than 0.9. Most of these involve at least one vessel operating under the AIS ship and cargo type code for high-speed craft or passenger ferries (40-49) or passenger vessels (60-69). These encounters occurred in the 23-Foot Fort Point Channel (\#30) and the 35-Foot Charlestown Waterfront Channel (\#11).

The minimum distance between vessel perimeters during each encounter is shown in Figure 3-4(b). Approximately 10\% of encounters in Boston Harbor are characterized by a minimum distance between vessel perimeters that is less than $10 \mathrm{~m}(32.4 \mathrm{ft})$, but almost $70 \%$ had minimum distances greater than $50 \mathrm{~m}(162 \mathrm{ft})$. If more than one pair of position reports document an encounter, the pair of position reports with the minimum distance will not necessarily be the same as the pair with the maximum SDV severity score. The reason is that ship domains are elliptical, and the SDV severity score depends on the size, orientation, and relative position of each vessel. 
It is expected that vessels will tend to stay away from each other, and therefore, the duration of any encounters will be brief. Results in Boston Harbor are consistent with this expected behavior. Figure 3-4(c) plots an empirical cumulative distribution on the duration of encounters in Boston Harbor. Most are brief, with 64\% lasting less than 2 minutes and 84\% lasting less than 2 minutes. This is consistent with the expected behavior of vessels that are avoiding SDVs. However, some encounters last longer than 5 minutes, and the longest encounter lasts 27 minutes. The longest encounter involves a liquefied natural gas carrier and a USCG cutter that was operating under AIS ship and cargo type code 35, for military operations. This may have been a security escort. Other lengthy encounters involved tankers and cargo vessels interacting with two vessels operating under AIS ship and cargo type for pleasure craft (37). The names of these two vessels include the word "responder," suggesting that they may actually be equipped with anti-pollution equipment and should be using AIS ship and cargo type code 54. These ship and cargo type codes were not corrected during the analysis because it was not possible to confirm the ship and cargo type of these vessels. However, these results suggest some additional screening of these AIS data may be needed. 
Figure 3-3. Encounters in BHC.

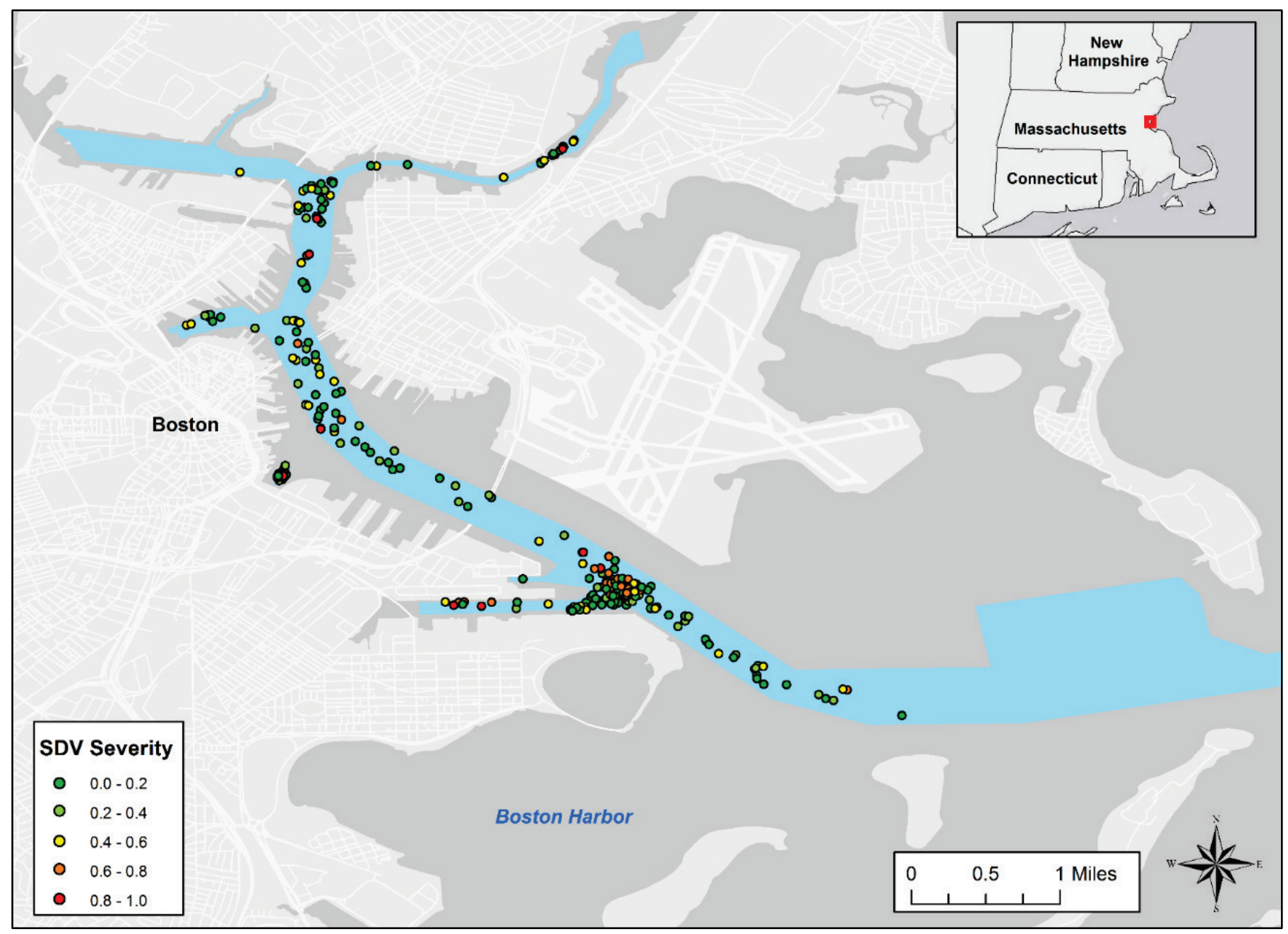

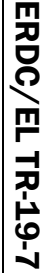


ERDC/EL TR-19-7

44

Figure 3-4. Characteristics of encounters in BHC.
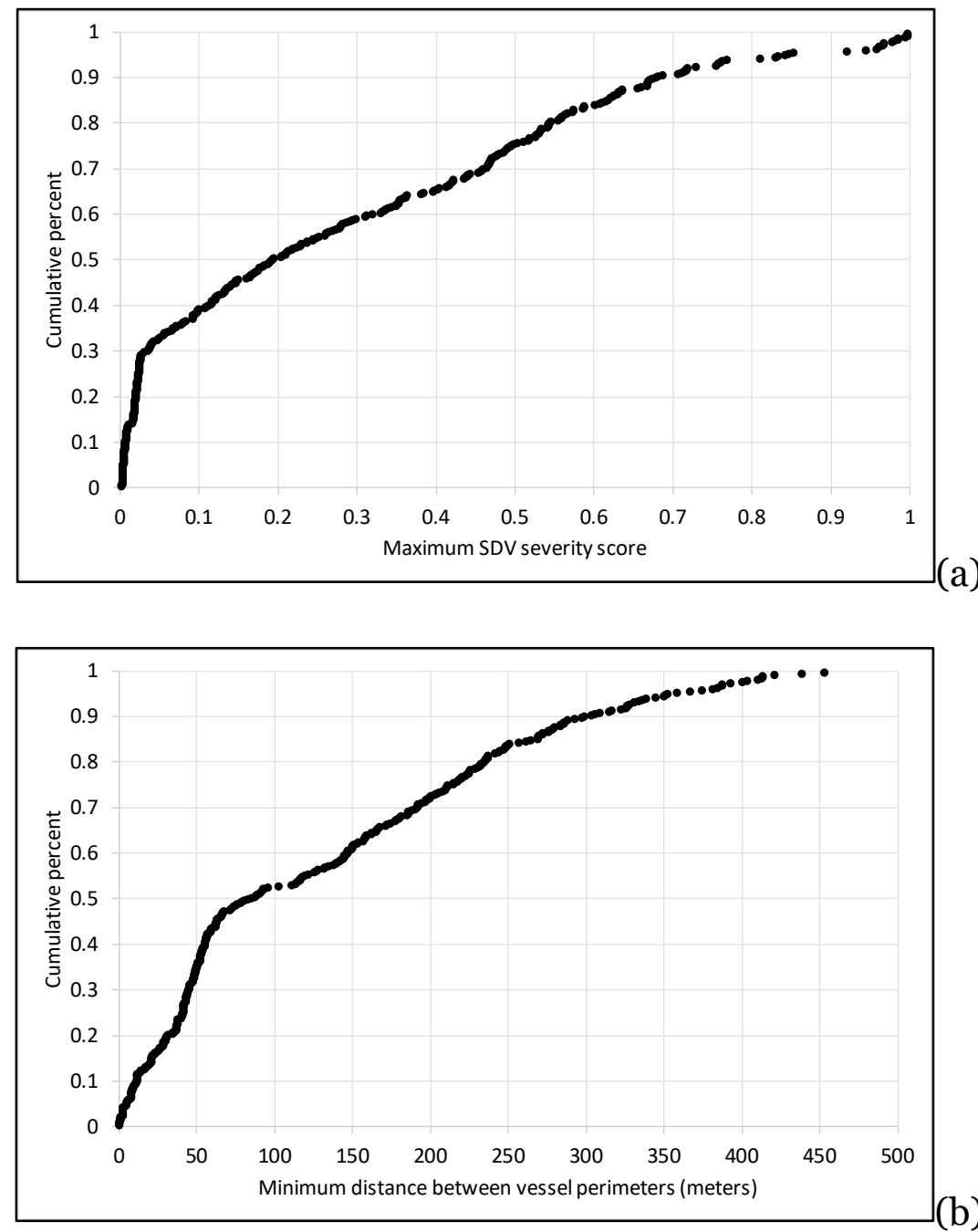

(b)

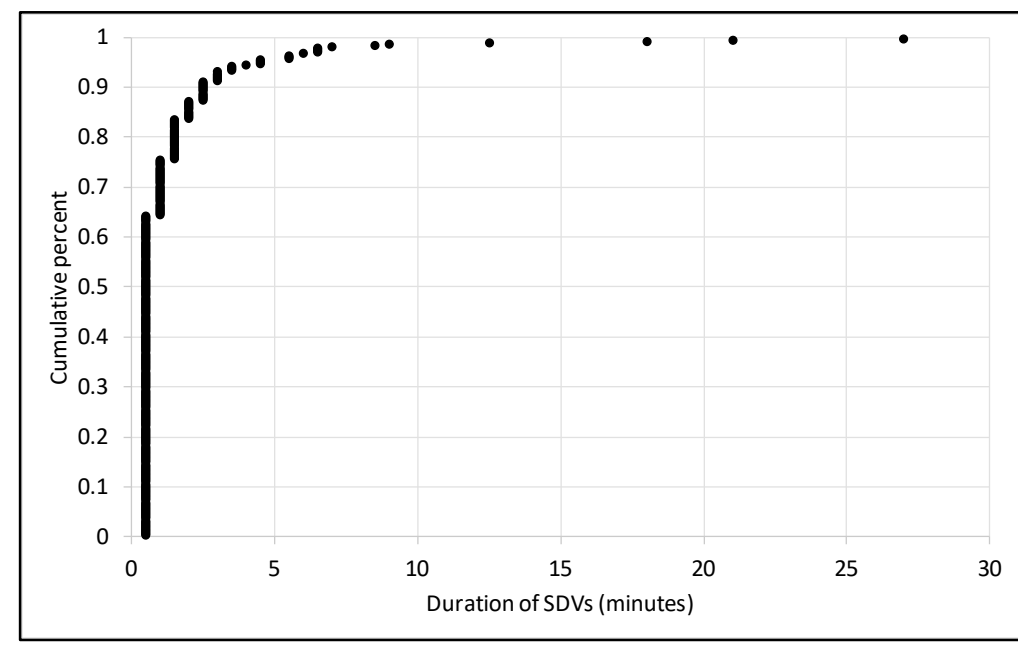

(c) 


\subsubsection{Types of vessels involved in encounters}

The types of vessels involved in encounters are summarized in Table 3-3. Encroached vessel categories are listed in the column on the left-hand side, and encroaching vessel categories are listed across the top. There were 356 encounters in BHC during 2014. The right-hand column of Table 3-3 lists the number of times each type of vessel was encroached; the bottom row lists the number of times each type of vessel encroached on another vessel. The interior cells of the table indicate the number of encounters between each pair of vessel types.

In Boston, most encounters involve passenger vessels (60-69) and highspeed craft or passenger ferries (70-79). The passenger vessel (60-69) ship and cargo type code should be used by cruise ships, passenger ferries, and tour boats. The high-speed craft or passenger ferries (40-49) ship and cargo type code includes catamarans and other types of vessels capable of traveling greater than 30 knots. As shown in Table 3-3, passenger vessels were classified as the encroached vessel 129 times during 2014 and as the encroaching vessel 207 times. There were 75 encounters involving two passenger vessels. Therefore, 261 encounters $(73 \%)$ involved at least one passenger vessel $(207+129-75=261)$. Vessels classified as high-speed craft or passenger ferries have 127 encounters, with this category classified as the encroached vessel 66 times and as the encroaching vessel 66 times. Most of these involved another passenger vessel (60-69). Only five encounters involved two vessels classified as high-speed craft or passenger ferries (40-49). Cargo vessels $(70-79)$ were involved in 101 encounters $(99+8-6=101)$ during 2014. Cargo vessels were classified as the encroached vessel 99 times and as the encroaching vessel 8 times. Six encounters involved two cargo vessels. Tankers were involved in 48 encounters during 2014.

\subsubsection{Frequency of SDVs}

During the 2014 calendar year, 733,074 position reports were sampled from vessels operating in the federal channels of Boston Harbor, and 682 of those position reports were classified as SDVs. The conditional frequencies of an SDV are summarized in Table 3-4 by reach and AIS ship and cargo type. The rows of the table correspond to each of the 31 reaches in Boston Harbor and the columns correspond to each of the nine major categories of AIS-equipped vessels as defined in the AIS encoding guide. The last column of Table 3-4 gives the conditional frequency of SDVs in 
each reach over all vessel categories, and the last row gives the conditional probability of SDVs for each vessel category over all reaches. Over all vessel types and reaches, the conditional frequency of SDVs in BHC is 9.3 $\times 10^{-4}$.

The conditional frequency of SDVs over all vessel types is illustrated in Figure 3-5, which shows the spatial distribution of collision risks. Over all vessel types, the highest conditional SDV frequencies are found in sections of the 40-Foot Reserved Channel (\#23, \#24, \#7). These reaches provide access to MASSPORT's Black Falcon Cruise Terminal and Conley Container Terminal. High frequencies in these reaches are attributed primarily to encounters between cargo vessels (70-79) and cruise ships, which operate under the AIS ship and cargo type code for passenger vessels (60-69). Cargo vessels also have high SDV frequencies in the 40-Foot Inner Harbor Confluence (\#5).

Cargo vessels and tankers may elicit more interest than other types of vessels because of their size and the magnitude of potential losses. Overall, the conditional probability of an SDV for cargo vessels was $4.52 \times 10^{-3}$. For cargo vessels, the highest conditional probabilities of an SDV are in the 40-Foot Inner Harbor Confluence (\#5), the 40-Foot Reserved Channel Turning Area (\#7), the 40-Foot Reserved Channel (\#23), and 40-Foot Reserved Channel Turning Area (West) (\#24). For tankers, the conditional probability of an SDV in Boston Harbor, $2.25 \times$ $10^{-3}$, is half that for cargo vessels. Tanker have the highest conditional probability of an SDV in the 35-Foot Reserved Channel Inner Width (\#27), the 35-Foot Charlestown Waterfront Channel (\#11), and the 38Foot Chelsea River Upper Reach (\#20).

For tankers operating in the 35-Foot Reserved Channel Inner Width (\#27), the conditional probability of an SDV is 0.237. This is much higher than other SDV frequencies. However, the encounters in this reach involve vessels with names containing the word "responder." These two vessels are using the AIS ship and cargo type code 37, which is reserved for pleasure craft. However, the names on these vessels suggest that they should be classified under AIS ship and cargo type code 54, which is designated for vessels carrying anti-pollution equipment. If so, these vessels should have been excluded from the analysis of SDVs. 
Table 3-3. Number of encounters in BHC by encroached and encroaching vessel type.

\begin{tabular}{|c|c|c|c|c|c|c|c|c|c|c|c|c|c|c|}
\hline & & & & & & Encroac & g Vessel A & Ship anc & argo Type & & & & & \\
\hline $\begin{array}{l}\text { Encroached } \\
\text { Ship and Ca }\end{array}$ & $\begin{array}{l}\text { AIS } \\
\text { pe }\end{array}$ & & WIG & Fishing & Military & Sailing & Pleasure & $\begin{array}{l}\text { High- } \\
\text { Speed }\end{array}$ & $\begin{array}{c}\text { Harbor } \\
\text { Boats }\end{array}$ & $\begin{array}{l}\text { Passen- } \\
\text { ger }\end{array}$ & & Tankers & & Total \\
\hline Unknown & (00) & - & - & - & - & - & 1 & - & - & 2 & - & - & - & 3 \\
\hline & (20-29) & - & - & - & - & - & - & - & - & - & - & - & - & - \\
\hline Sailing & (36) & - & - & - & - & - & - & - & - & 3 & - & - & - & 3 \\
\hline Pleasure & (37) & - & - & - & - & - & 4 & - & - & 3 & - & - & - & 7 \\
\hline High-Speed & $(40-49)$ & 1 & - & - & - & - & 3 & 5 & - & 57 & - & - & - & 66 \\
\hline Harbor Boats & $(50-57)$ & - & - & - & - & - & - & - & - & - & - & - & - & - \\
\hline Tankers & (80-89) & 1 & - & - & 3 & - & 21 & 5 & - & 16 & - & - & - & 46 \\
\hline Other & (90-99) & - & - & - & - & - & - & - & - & 2 & - & - & - & 2 \\
\hline Total & & 6 & - & 1 & 3 & 10 & 52 & 66 & - & 207 & 8 & 2 & 1 & 356 \\
\hline
\end{tabular}


Table 3-4. Conditional frequency of SDVs in BHC by reach and vessel type. Frequencies greater than $5 \times 10^{-3}$ are bold red typeface.

\begin{tabular}{|c|c|c|c|c|c|c|c|c|c|c|c|}
\hline \multirow[b]{2}{*}{$\#$} & \multirow[b]{2}{*}{ Reach Code } & \multicolumn{9}{|c|}{ AIS Ship and Cargo Type } & \multirow[b]{2}{*}{$\begin{array}{c}\text { All Vessel } \\
\text { Types }\end{array}$} \\
\hline & & $\begin{array}{c}\text { Unknown } \\
\text { (00) }\end{array}$ & $\begin{array}{c}\text { WIG } \\
(20-29)\end{array}$ & $\begin{array}{c}\text { Class } 3 \\
\text { Vessels } \\
(30,33-39)\end{array}$ & $\begin{array}{c}\text { High-Speed } \\
\text { (40-49) }\end{array}$ & $\begin{array}{l}\text { Harbor } \\
\text { Boats } \\
(50-57)\end{array}$ & $\begin{array}{c}\text { Passenger } \\
\text { (60-69) }\end{array}$ & $\begin{array}{l}\text { Cargo } \\
(70-79)\end{array}$ & $\begin{array}{l}\text { Tankers } \\
(80-89)\end{array}$ & $\begin{array}{l}\text { Other } \\
(90-99)\end{array}$ & \\
\hline 1 & CENAE_MA_01_BOS_1 & - & - & - & - & - & - & - & - & - & - \\
\hline 2 & CENAE_MA_01_BOS_2 & - & - & - & - & - & - & - & - & - & - \\
\hline 3 & CENAE_MA_01_BOS_3 & 4.31E-04 & - & 3.66E-04 & 3.01E-05 & - & $7.18 \mathrm{E}-04$ & 3.54E-03 & $1.02 \mathrm{E}-03$ & $0.00 E+00$ & 8.52E-04 \\
\hline 4 & CENAE_MA_01_BOS_4 & $0.00 E+00$ & - & $0.00 E+00$ & 2.91E-04 & - & 3.36E-04 & $1.33 \mathrm{E}-03$ & $2.37 \mathrm{E}-03$ & 7.08E-04 & $5.54 \mathrm{E}-04$ \\
\hline 5 & CENAE_MA_01_BOS_5 & $0.00 \mathrm{E}+00$ & - & $0.00 E+00$ & $0.00 E+00$ & - & $0.00 \mathrm{E}+00$ & 1.14E-02 & $2.48 \mathrm{E}-03$ & $0.00 E+00$ & $3.22 \mathrm{E}-03$ \\
\hline 6 & CENAE_MA_01_BOS_6 & - & - & - & - & - & - & - & - & - & - \\
\hline 7 & CENAE_MA_01_BOS_7 & $0.00 E+00$ & - & $0.00 \mathrm{E}+00$ & $0.00 E+00$ & - & 3.96E-04 & 4.47E-02 & $0.00 E+00$ & $0.00 E+00$ & 3.11E-03 \\
\hline 8 & CENAE_MA_01_BOS_8 & - & - & - & - & - & - & - & - & - & - \\
\hline 9 & CENAE_MA_01_BOS_9 & - & - & - & - & - & - & - & - & - & - \\
\hline 10 & CENAE_MA_01_BOS_10 & $0.00 \mathrm{E}+00$ & - & 2.06E-04 & 4.70E-05 & - & 2.69E-04 & 3.27E-03 & 1.89E-03 & $0.00 E+00$ & 3.45E-04 \\
\hline 11 & CENAE_MA_01_BOS_11 & $0.00 E+00$ & - & 2.59E-04 & 5.57E-04 & - & $1.89 \mathrm{E}-04$ & $1.82 \mathrm{E}-03$ & 7.74E-03 & $0.00 E+00$ & 3.42E-04 \\
\hline 12 & CENAE_MA_01_BOS_12 & $0.00 E+00$ & - & 1.79E-04 & $0.00 \mathrm{E}+00$ & - & $3.22 \mathrm{E}-04$ & - & - & $0.00 \mathrm{E}+00$ & $2.95 \mathrm{E}-04$ \\
\hline 13 & CENAE_MA_01_BOS_13 & $0.00 \mathrm{E}+00$ & - & $0.00 E+00$ & $0.00 E+00$ & - & $0.00 E+00$ & $0.00 \mathrm{E}+00$ & $0.00 \mathrm{E}+00$ & $0.00 E+00$ & $0.00 \mathrm{E}+00$ \\
\hline 14 & CENAE_MA_01_BOS_14 & - & - & $0.00 E+00$ & - & - & $0.00 E+00$ & - & - & - & $0.00 E+00$ \\
\hline 15 & CENAE_MA_02_MYM_1 & $0.00 E+00$ & - & $0.00 E+00$ & - & - & $0.00 E+00$ & $2.07 \mathrm{E}-03$ & $0.00 E+00$ & $0.00 E+00$ & $5.86 \mathrm{E}-04$ \\
\hline 16 & CENAE_MA_02_MYM_2 & - & - & - & - & - & - & - & - & - & - \\
\hline 17 & CENAE_MA_02_MYM_3 & - & - & - & - & - & - & - & - & - & - \\
\hline 18 & CENAE_MA_02_MYM_4 & - & - & - & - & - & - & - & - & - & - \\
\hline 19 & CENAE_MA_03_BOS_1 & $0.00 \mathrm{E}+00$ & - & $0.00 E+00$ & - & - & $0.00 \mathrm{E}+00$ & 3.06E-03 & $1.48 \mathrm{E}-03$ & $0.00 \mathrm{E}+00$ & 1.16E-03 \\
\hline 20 & CENAE_MA_03_BOS_2 & $0.00 \mathrm{E}+00$ & - & $0.00 \mathrm{E}+00$ & - & - & $0.00 E+00$ & - & $7.28 \mathrm{E}-03$ & - & 4.71E-03 \\
\hline 21 & CENAE_MA_03_BOS_3 & - & - & - & - & - & - & - & - & - & - \\
\hline 22 & CENAE_MA_04_BOS_1 & $0.00 E+00$ & - & $0.00 E+00$ & $0.00 E+00$ & - & $0.00 E+00$ & 2.60E-03 & - & $0.00 E+00$ & 4.95E-04 \\
\hline
\end{tabular}




\begin{tabular}{|c|c|c|c|c|c|c|c|c|c|c|c|}
\hline \multirow[b]{2}{*}{$\#$} & \multirow[b]{2}{*}{ Reach Code } & \multicolumn{9}{|c|}{ AIS Ship and Cargo Type } & \multirow[b]{2}{*}{$\begin{array}{c}\text { All Vessel } \\
\text { Types }\end{array}$} \\
\hline & & $\begin{array}{l}\text { Unknown } \\
(00)\end{array}$ & $\begin{array}{c}\text { WIG } \\
(20-29)\end{array}$ & $\begin{array}{c}\text { Class } 3 \\
\text { Vessels } \\
(30,33-39)\end{array}$ & $\begin{array}{l}\text { High-Speed } \\
\qquad(40-49)\end{array}$ & $\begin{array}{l}\text { Harbor } \\
\text { Boats } \\
(50-57)\end{array}$ & $\begin{array}{l}\text { Passenger } \\
(60-69)\end{array}$ & $\begin{array}{l}\text { Cargo } \\
\text { (70-79) }\end{array}$ & $\begin{array}{l}\text { Tankers } \\
(80-89)\end{array}$ & $\begin{array}{l}\text { Other } \\
(90-99)\end{array}$ & \\
\hline 23 & CENAE_MA_04_BOS_2 & $0.00 \mathrm{E}+00$ & - & $0.00 \mathrm{E}+00$ & $0.00 \mathrm{E}+00$ & - & 2.91E-02 & 1.69E-02 & $0.00 \mathrm{E}+00$ & $0.00 \mathrm{E}+00$ & 2.33E-02 \\
\hline 24 & CENAE_MA_04_BOS_3 & $0.00 \mathrm{E}+00$ & - & $0.00 \mathrm{E}+00$ & $0.00 \mathrm{E}+00$ & - & 5.19E-03 & 8.10E-03 & $0.00 \mathrm{E}+00$ & $0.00 \mathrm{E}+00$ & 6.36E-03 \\
\hline 25 & CENAE_MA_04_BOS_4 & $0.00 \mathrm{E}+00$ & - & $0.00 \mathrm{E}+00$ & - & - & $1.31 \mathrm{E}-03$ & $3.65 \mathrm{E}-03$ & $0.00 \mathrm{E}+00$ & $0.00 \mathrm{E}+00$ & $1.13 \mathrm{E}-03$ \\
\hline 26 & CENAE_MA_04_BOS_5 & $0.00 \mathrm{E}+00$ & - & $0.00 \mathrm{E}+00$ & - & - & 4.25E-03 & $0.00 \mathrm{E}+00$ & $0.00 \mathrm{E}+00$ & $0.00 E+00$ & $2.77 \mathrm{E}-03$ \\
\hline 27 & CENAE_MA_04_BOS_6 & - & - & $0.00 \mathrm{E}+00$ & - & - & 4.18E-03 & - & $2.37 \mathrm{E}-01$ & $0.00 \mathrm{E}+00$ & 4.87E-03 \\
\hline 28 & CENAE_MA_05_BOS_1 & - & - & - & - & - & - & - & - & - & - \\
\hline 29 & CENAE_MA_06_BOS_1 & - & - & - & - & - & - & - & - & - & - \\
\hline 30 & CENAE_MA_07_BOS_1 & $0.00 \mathrm{E}+00$ & - & $1.28 \mathrm{E}-02$ & $6.18 \mathrm{E}-03$ & - & $3.58 \mathrm{E}-03$ & - & - & $0.00 \mathrm{E}+00$ & $4.88 \mathrm{E}-03$ \\
\hline 31 & CENAE_MA_13_ISL_1 & - & - & $0.00 \mathrm{E}+00$ & - & - & - & - & - & - & $0.00 \mathrm{E}+00$ \\
\hline & Overall & $9.43 E-05$ & - & 2.03E-04 & $6.49 \mathrm{E}-04$ & - & 6.06E-04 & $4.52 \mathrm{E}-03$ & $2.25 \mathrm{E}-03$ & 1.17E-04 & $9.32 \mathrm{E}-04$ \\
\hline
\end{tabular}


Figure 3-5. Conditional frequency of SDVs in BHC.

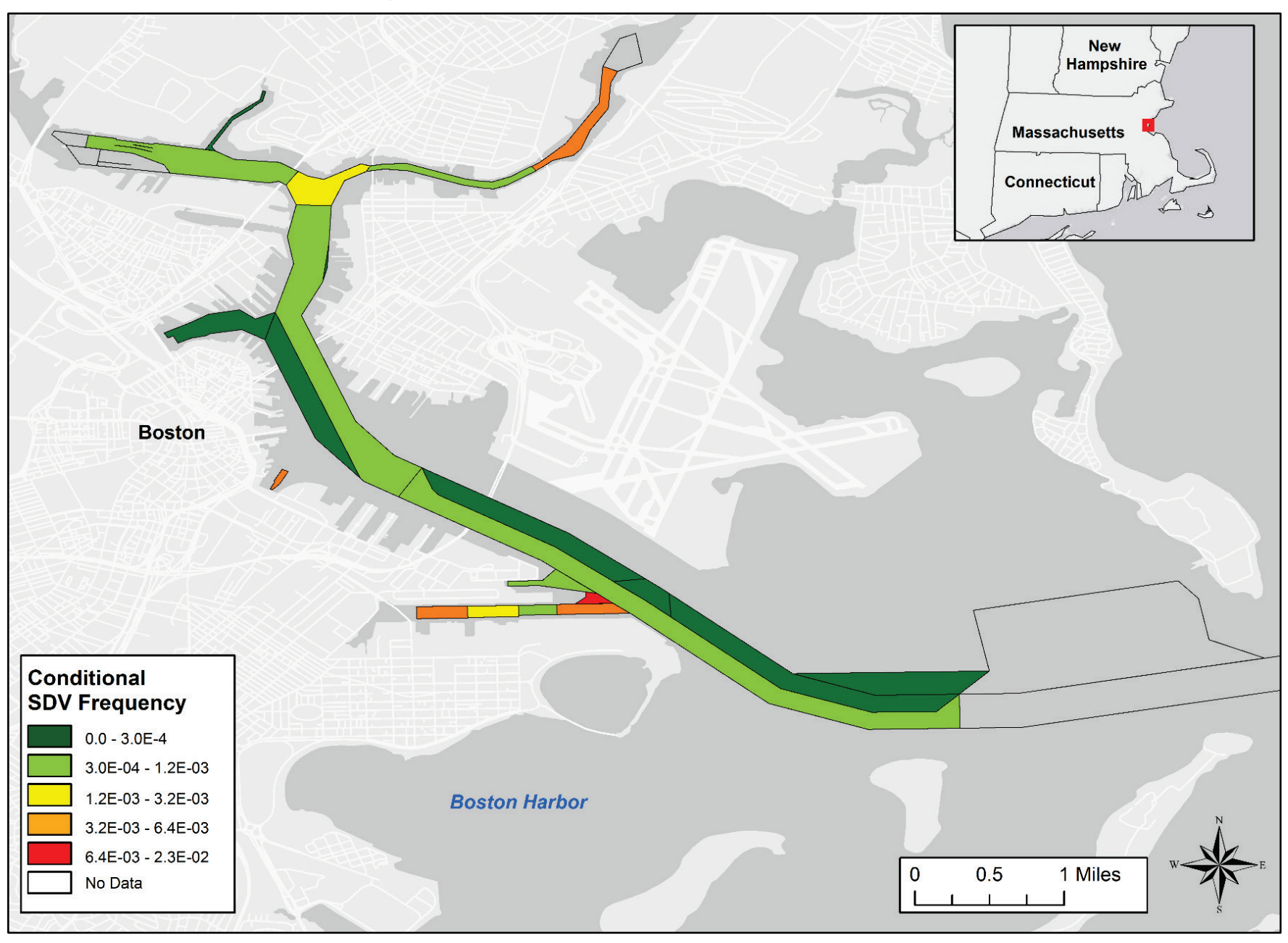


The unconditional probability of an SDV, which is the product of the conditional probability of an SDV in a reach and the probability that at least one vessel is present in that reach (Table 3-5), is calculated in Table 3-6. These results show that SDVs are most likely to occur in the 40-Foot Independence Reach (\#3), the 40-Foot Waterfront Reach (\#4), and the 40-Foot Inner Harbor Confluence (\#5). Vessels classified as passenger vessels (40-49) and cargo vessels (70-79) are most likely to have their ship domains violated. Tankers (80-89) are about half as likely as cargo vessels to have their ship domains violated. The probability of an SDV over all reaches and vessel types is $6.25 \times 10^{-4}$. A map showing where the reaches with the highest unconditional probability of an SDV are located is provided in Figure 3-6.

The third metric of collision risk is the relative frequency of SDVs by navigation channel reach, $f_{k}$. This metric is shown in Figure 3-7. During the 2014 calendar year, 26\% of SDVs occurred in the 23-Foot Fort Point Channel (\#30) and $23 \%$ of SDVs occurred in 40-Foot Fort Independence Reach (\#3). SDVs are approximately twice as likely to occur in these reaches as in the 40-Foot Waterfront Reach (\#4), where $12.6 \%$ of SDVs occurred. Qualitatively, this metric provides almost the same information as the unconditional probability of an SDV. 
Table 3-5. Fraction of half-minute intervals during which at least one vessel is present in each BHC reach.

\begin{tabular}{|c|c|c|c|c|c|c|c|c|c|c|c|}
\hline \multirow[b]{2}{*}{ \# } & \multirow[b]{2}{*}{ Reach Code } & \multicolumn{9}{|c|}{ AIS Ship and Cargo Type } & \multirow[b]{2}{*}{$\begin{array}{c}\text { All Vessel } \\
\text { Types }\end{array}$} \\
\hline & & $\begin{array}{c}\text { Unknown } \\
\text { (00) }\end{array}$ & $\begin{array}{c}\text { WIG } \\
(20-29)\end{array}$ & $\begin{array}{c}\text { Class } 3 \\
(30,33-39)\end{array}$ & $\begin{array}{l}\text { High-Speed } \\
\text { (40-49) }\end{array}$ & $\begin{array}{c}\text { Harbor Boats } \\
(50-57)\end{array}$ & $\begin{array}{c}\text { Passenger } \\
\text { (60-69) }\end{array}$ & $\begin{array}{l}\text { Cargo } \\
\text { (70-79) }\end{array}$ & $\begin{array}{l}\text { Tankers } \\
(80-89)\end{array}$ & $\begin{array}{l}\text { Other } \\
(90-99)\end{array}$ & \\
\hline 1 & CENAE_MA_01_BOS_1 & - & - & - & - & - & - & - & - & - & - \\
\hline 2 & CENAE_MA_01_BOS_2 & - & - & - & - & - & - & - & - & - & - \\
\hline 3 & CENAE_MA_01_BOS_3 & $2.16 \mathrm{E}-03$ & $2.80 \mathrm{E}-03$ & 1.50E-02 & 3.10E-02 & - & $9.04 \mathrm{E}-02$ & $1.90 \mathrm{E}-02$ & $1.40 \mathrm{E}-02$ & $4.22 \mathrm{E}-03$ & 1.67E-01 \\
\hline 4 & CENAE_MA_01_BOS_4 & $2.44 \mathrm{E}-03$ & $6.65 \mathrm{E}-03$ & 1.23E-02 & 3.50E-02 & - & 6.66E-02 & $1.14 \mathrm{E}-02$ & $1.52 \mathrm{E}-02$ & $2.68 \mathrm{E}-03$ & $1.41 \mathrm{E}-01$ \\
\hline 5 & CENAE_MA_01_BOS_5 & $2.50 \mathrm{E}-04$ & $2.96 \mathrm{E}-03$ & $6.69 \mathrm{E}-04$ & 4.09E-04 & - & $2.46 \mathrm{E}-03$ & 3.34E-03 & 4.98E-03 & $5.83 \mathrm{E}-04$ & 1.56E-02 \\
\hline 6 & CENAE_MA_01_BOS_6 & - & - & - & - & - & - & - & - & - & - \\
\hline 7 & CENAE_MA_01_BOS_7 & $2.61 \mathrm{E}-04$ & 4.41E-04 & $2.75 \mathrm{E}-03$ & $2.40 \mathrm{E}-03$ & - & $7.20 \mathrm{E}-03$ & $9.57 \mathrm{E}-04$ & 1.40E-04 & 4.65E-04 & $1.45 \mathrm{E}-02$ \\
\hline 8 & CENAE_MA_01_BOS_8 & - & - & - & - & - & - & - & - & - & - \\
\hline 9 & CENAE_MA_01_BOS_9 & - & - & - & - & - & - & - & - & - & - \\
\hline 10 & CENAE_MA_01_BOS_10 & $2.39 \mathrm{E}-03$ & 5.00E-03 & $2.18 \mathrm{E}-02$ & 2.01E-02 & - & 5.70E-02 & 4.08E-03 & $2.52 \mathrm{E}-03$ & 3.55E-03 & 1.10E-01 \\
\hline 11 & CENAE_MA_01_BOS_11 & 8.17E-04 & 5.81E-04 & 7.14E-03 & 1.19E-02 & - & $5.20 \mathrm{E}-02$ & $5.23 \mathrm{E}-04$ & 7.37E-04 & 5.75E-04 & 7.11E-02 \\
\hline 12 & CENAE_MA_01_BOS_12 & $5.04 \mathrm{E}-04$ & $6.09 \mathrm{E}-05$ & $5.22 \mathrm{E}-03$ & $1.12 \mathrm{E}-04$ & - & 3.97E-02 & $0.00 E+00$ & $0.00 E+00$ & 9.55E-04 & 4.58E-02 \\
\hline 13 & CENAE_MA_01_BOS_13 & $1.01 \mathrm{E}-04$ & $1.52 \mathrm{E}-05$ & $2.13 \mathrm{E}-03$ & $1.14 \mathrm{E}-04$ & - & 9.09E-04 & $2.47 \mathrm{E}-05$ & 1.90E-05 & 4.24E-04 & 3.71E-03 \\
\hline 14 & CENAE_MA_01_BOS_14 & $0.00 E+00$ & $0.00 E+00$ & $1.90 \mathrm{E}-06$ & $0.00 E+00$ & - & $9.51 \mathrm{E}-07$ & $0.00 E+00$ & $0.00 E+00$ & $0.00 E+00$ & 2.85E-06 \\
\hline 15 & CENAE_MA_02_MYM_1 & $1.68 \mathrm{E}-04$ & 1.67E-03 & 8.63E-04 & $0.00 E+00$ & - & 1.47E-03 & 3.68E-03 & $3.58 \mathrm{E}-03$ & $1.55 \mathrm{E}-03$ & $1.29 \mathrm{E}-02$ \\
\hline 16 & CENAE_MA_02_MYM_2 & - & - & - & - & - & - & - & - & - & - \\
\hline 17 & CENAE_MA_02_MYM_3 & - & - & - & - & - & - & - & - & - & - \\
\hline 18 & CENAE_MA_02_MYM_4 & - & - & - & - & - & - & - & - & - & - \\
\hline
\end{tabular}




\begin{tabular}{|c|c|c|c|c|c|c|c|c|c|c|c|}
\hline \multirow[b]{2}{*}{ \# } & \multirow[b]{2}{*}{ Reach Code } & \multicolumn{9}{|c|}{ AIS Ship and Cargo Type } & \multirow[b]{2}{*}{$\begin{array}{c}\text { All Vesse } \\
\text { Types }\end{array}$} \\
\hline & & $\begin{array}{c}\text { Unknown } \\
\text { (00) }\end{array}$ & $\begin{array}{c}\text { WIG } \\
(20-29)\end{array}$ & $\begin{array}{c}\text { Class } 3 \\
(30,33-39)\end{array}$ & $\begin{array}{c}\text { High-Speed } \\
\text { (40-49) }\end{array}$ & $\begin{array}{c}\text { Harbor Boats } \\
\qquad(50-57)\end{array}$ & $\begin{array}{c}\text { Passenger } \\
\text { (60-69) }\end{array}$ & $\begin{array}{l}\text { Cargo } \\
(70-79)\end{array}$ & $\begin{array}{l}\text { Tankers } \\
(80-89)\end{array}$ & $\begin{array}{c}\text { Other } \\
\text { (90-99) }\end{array}$ & \\
\hline 19 & CENAE_MA_03_BOS_1 & 4.66E-04 & $3.35 \mathrm{E}-03$ & 4.03E-04 & $0.00 \mathrm{E}+00$ & - & $4.28 \mathrm{E}-05$ & $1.24 \mathrm{E}-03$ & $9.61 \mathrm{E}-03$ & 4.35E-04 & $1.55 \mathrm{E}-02$ \\
\hline 20 & CENAE_MA_03_BOS_2 & $1.59 \mathrm{E}-04$ & $1.51 \mathrm{E}-03$ & $3.22 \mathrm{E}-04$ & $0.00 \mathrm{E}+00$ & - & $1.90 \mathrm{E}-06$ & $0.00 E+00$ & 3.66E-03 & $0.00 E+00$ & 5.63E-03 \\
\hline 21 & CENAE_MA_03_BOS_3 & - & - & - & - & - & - & - & - & - & - \\
\hline 22 & CENAE_MA_04_BOS_1 & 7.61E-06 & $0.00 \mathrm{E}+00$ & $5.00 \mathrm{E}-04$ & $6.56 \mathrm{E}-05$ & - & $9.41 \mathrm{E}-04$ & 3.66E-04 & $0.00 \mathrm{E}+00$ & $4.28 \mathrm{E}-05$ & $1.92 \mathrm{E}-03$ \\
\hline 23 & CENAE_MA_04_BOS_2 & $2.85 \mathrm{E}-06$ & $0.00 E+00$ & 5.23E-05 & 1.05E-05 & - & 4.90E-04 & $5.61 \mathrm{E}-05$ & $9.51 \mathrm{E}-07$ & 4.00E-05 & $6.53 \mathrm{E}-04$ \\
\hline 24 & CENAE_MA_04_BOS_3 & 4.76E-05 & $0.00 E+00$ & $2.40 \mathrm{E}-04$ & $2.85 \mathrm{E}-06$ & - & $2.02 \mathrm{E}-03$ & 3.17E-03 & $2.85 \mathrm{E}-05$ & 1.76E-04 & $5.68 \mathrm{E}-03$ \\
\hline 25 & CENAE_MA_04_BOS_4 & 1.33E-05 & $0.00 \mathrm{E}+00$ & $5.09 \mathrm{E}-04$ & $0.00 \mathrm{E}+00$ & - & $1.45 \mathrm{E}-03$ & $2.61 \mathrm{E}-04$ & $2.00 \mathrm{E}-05$ & $2.65 \mathrm{E}-04$ & $2.52 \mathrm{E}-03$ \\
\hline 26 & CENAE_MA_04_BOS_5 & 7.90E-05 & $0.00 E+00$ & 8.26E-04 & $0.00 E+00$ & - & $2.24 \mathrm{E}-03$ & $6.66 \mathrm{E}-06$ & $3.52 \mathrm{E}-05$ & $2.51 \mathrm{E}-04$ & 3.43E-03 \\
\hline 27 & CENAE_MA_04_BOS_6 & $0.00 E+00$ & $0.00 E+00$ & $1.34 \mathrm{E}-03$ & $0.00 E+00$ & - & $2.28 \mathrm{E}-03$ & $0.00 E+00$ & 3.61E-05 & 6.37E-05 & 3.71E-03 \\
\hline 28 & CENAE_MA_05_BOS_1 & - & - & - & - & - & - & - & - & - & - \\
\hline 29 & CENAE_MA_06_BOS_1 & - & - & - & - & - & - & - & - & - & - \\
\hline 30 & CENAE_MA_07_BOS_1 & $2.57 \mathrm{E}-05$ & $0.00 E+00$ & $1.48 \mathrm{E}-04$ & $8.62 \mathrm{E}-03$ & - & $9.29 \mathrm{E}-03$ & $0.00 \mathrm{E}+00$ & $0.00 \mathrm{E}+00$ & $6.66 \mathrm{E}-06$ & $1.80 \mathrm{E}-02$ \\
\hline 31 & CENAE_MA_13_ISL_1 & $0.00 E+00$ & $0.00 E+00$ & 1.14E-05 & $0.00 \mathrm{E}+00$ & - & $0.00 E+00$ & $0.00 E+00$ & $0.00 E+00$ & $0.00 E+00$ & $1.14 \mathrm{E}-05$ \\
\hline & Overall & $9.71 \mathrm{E}-03$ & $2.46 \mathrm{E}-02$ & $6.62 \mathrm{E}-02$ & 1.03E-01 & - & $2.68 \mathrm{E}-01$ & 4.73E-02 & $5.29 \mathrm{E}-02$ & $1.62 \mathrm{E}-02$ & 4.39E-01 \\
\hline
\end{tabular}


Table 3-6. Unconditional frequency of SDVs in BHC by reach and vessel type. Frequencies greater than $5 \times 10^{-5}$ are in bold red typeface.

\begin{tabular}{|c|c|c|c|c|c|c|c|c|c|c|c|}
\hline \multirow[b]{2}{*}{$\#$} & \multirow[b]{2}{*}{ Reach Code } & \multicolumn{9}{|c|}{ AIS Ship and Cargo Type } & \multirow[b]{2}{*}{$\begin{array}{c}\text { All Vessel } \\
\text { Types }\end{array}$} \\
\hline & & $\begin{array}{c}\text { Unknown } \\
\text { (00) }\end{array}$ & $\begin{array}{c}\text { WIG } \\
(20-29)\end{array}$ & $\begin{array}{c}\text { Class } 3 \\
(30,33-39)\end{array}$ & $\begin{array}{l}\text { High-Speed } \\
\text { (40-49) }\end{array}$ & $\begin{array}{c}\text { Harbor Boats } \\
(50-57)\end{array}$ & $\begin{array}{c}\text { Passenger } \\
\text { (60-69) }\end{array}$ & $\begin{array}{l}\text { Cargo } \\
\text { (70-79) }\end{array}$ & $\begin{array}{l}\text { Tankers } \\
(80-89)\end{array}$ & $\begin{array}{l}\text { Other } \\
(90-99)\end{array}$ & \\
\hline 1 & CENAE_MA_01_BOS_1 & - & - & - & - & - & - & - & - & - & - \\
\hline 2 & CENAE_MA_01_BOS_2 & - & - & - & - & - & - & - & - & - & - \\
\hline 3 & CENAE_MA_01_BOS_3 & $9.29 \mathrm{E}-07$ & $0.00 E+00$ & 5.50E-06 & $9.32 \mathrm{E}-07$ & - & $6.49 \mathrm{E}-05$ & $6.74 \mathrm{E}-05$ & 1.43E-05 & $0.00 E+00$ & $1.42 \mathrm{E}-04$ \\
\hline 4 & CENAE_MA_01_BOS_4 & $0.00 E+00$ & $0.00 E+00$ & $0.00 \mathrm{E}+00$ & 1.02E-05 & - & $2.24 \mathrm{E}-05$ & $1.51 \mathrm{E}-05$ & 3.60E-05 & 1.90E-06 & 7.79E-05 \\
\hline 5 & CENAE_MA_01_BOS_5 & $0.00 E+00$ & $0.00 E+00$ & $0.00 E+00$ & $0.00 \mathrm{E}+00$ & - & $0.00 E+00$ & 3.81E-05 & $1.24 \mathrm{E}-05$ & $0.00 E+00$ & $5.01 \mathrm{E}-05$ \\
\hline 6 & CENAE_MA_01_BOS_6 & - & - & - & - & - & - & - & - & - & - \\
\hline 7 & CENAE_MA_01_BOS_7 & $0.00 E+00$ & $0.00 E+00$ & $0.00 E+00$ & $0.00 E+00$ & - & $2.85 \mathrm{E}-06$ & 4.28E-05 & $0.00 E+00$ & $0.00 E+00$ & $4.52 \mathrm{E}-05$ \\
\hline 8 & CENAE_MA_01_BOS_8 & - & - & - & - & - & - & - & - & - & - \\
\hline 9 & CENAE_MA_01_BOS_9 & - & - & - & - & - & - & - & - & - & - \\
\hline 10 & CENAE_MA_01_BOS_10 & $0.00 E+00$ & $0.00 E+00$ & 4.48E-06 & $9.44 \mathrm{E}-07$ & - & 1.53E-05 & 1.33E-05 & 4.75E-06 & $0.00 E+00$ & 3.70E-05 \\
\hline 11 & CENAE_MA_01_BOS_11 & $0.00 E+00$ & $0.00 E+00$ & $1.85 \mathrm{E}-06$ & 6.60E-06 & - & $9.85 E-06$ & 9.51E-07 & $5.71 \mathrm{E}-06$ & $0.00 \mathrm{E}+00$ & 2.43E-05 \\
\hline 12 & CENAE_MA_01_BOS_12 & $0.00 E+00$ & $0.00 E+00$ & 9.33E-07 & $0.00 E+00$ & - & $1.28 \mathrm{E}-05$ & - & - & $0.00 E+00$ & 1.35E-05 \\
\hline 13 & CENAE_MA_01_BOS_13 & $0.00 E+00$ & $0.00 E+00$ & $0.00 \mathrm{E}+00$ & $0.00 E+00$ & - & $0.00 E+00$ & $0.00 E+00$ & $0.00 E+00$ & $0.00 E+00$ & $0.00 \mathrm{E}+00$ \\
\hline 14 & CENAE_MA_01_BOS_14 & - & - & $0.00 \mathrm{E}+00$ & - & - & $0.00 E+00$ & - & - & - & $0.00 E+00$ \\
\hline 15 & CENAE_MA_02_MYM_1 & $0.00 E+00$ & $0.00 E+00$ & $0.00 E+00$ & - & - & $0.00 E+00$ & 7.61E-06 & $0.00 E+00$ & $0.00 E+00$ & 7.59E-06 \\
\hline 16 & CENAE_MA_02_MYM_2 & - & - & - & - & - & - & - & - & - & - \\
\hline 17 & CENAE_MA_02_MYM_3 & - & - & - & - & - & - & - & - & - & - \\
\hline 18 & CENAE_MA_02_MYM_4 & - & - & - & - & - & - & - & - & - & - \\
\hline
\end{tabular}




\begin{tabular}{|c|c|c|c|c|c|c|c|c|c|c|c|}
\hline \multirow[b]{2}{*}{$\#$} & \multirow[b]{2}{*}{ Reach Code } & \multicolumn{9}{|c|}{ AIS Ship and Cargo Type } & \multirow[b]{2}{*}{$\begin{array}{c}\text { All Vessel } \\
\text { Types }\end{array}$} \\
\hline & & $\begin{array}{c}\text { Unknown } \\
(00)\end{array}$ & $\begin{array}{c}\text { WIG } \\
(20-29)\end{array}$ & $\begin{array}{c}\text { Class } 3 \\
(30,33-39)\end{array}$ & $\begin{array}{c}\text { High-Speed } \\
(40-49)\end{array}$ & $\begin{array}{c}\text { Harbor Boats } \\
\qquad(50-57)\end{array}$ & $\begin{array}{c}\text { Passenger } \\
(60-69)\end{array}$ & $\begin{array}{l}\text { Cargo } \\
(70-79)\end{array}$ & $\begin{array}{l}\text { Tankers } \\
(80-89)\end{array}$ & $\begin{array}{c}\text { Other } \\
\text { (90-99) }\end{array}$ & \\
\hline 19 & CENAE_MA_03_BOS_1 & $0.00 \mathrm{E}+00$ & $0.00 \mathrm{E}+00$ & $0.00 \mathrm{E}+00$ & - & - & $0.00 \mathrm{E}+00$ & $3.81 \mathrm{E}-06$ & $1.43 \mathrm{E}-05$ & $0.00 \mathrm{E}+00$ & $1.80 \mathrm{E}-05$ \\
\hline 20 & CENAE_MA_03_BOS_2 & $0.00 \mathrm{E}+00$ & $0.00 \mathrm{E}+00$ & $0.00 E+00$ & - & - & $0.00 \mathrm{E}+00$ & - & $2.66 \mathrm{E}-05$ & - & 2.65E-05 \\
\hline 21 & CENAE_MA_03_BOS_3 & - & - & - & - & - & - & - & - & - & - \\
\hline 22 & CENAE_MA_04_BOS_1 & $0.00 \mathrm{E}+00$ & - & $0.00 \mathrm{E}+00$ & $0.00 \mathrm{E}+00$ & - & $0.00 \mathrm{E}+00$ & $9.51 \mathrm{E}-07$ & - & $0.00 \mathrm{E}+00$ & $9.51 \mathrm{E}-07$ \\
\hline 23 & CENAE_MA_04_BOS_2 & $0.00 \mathrm{E}+00$ & - & $0.00 \mathrm{E}+00$ & $0.00 \mathrm{E}+00$ & - & 1.43E-05 & $9.51 \mathrm{E}-07$ & $0.00 E+00$ & $0.00 E+00$ & $1.52 \mathrm{E}-05$ \\
\hline 24 & CENAE_MA_04_BOS_3 & $0.00 E+00$ & - & $0.00 E+00$ & $0.00 E+00$ & - & $1.05 E-05$ & $2.57 \mathrm{E}-05$ & $0.00 E+00$ & $0.00 E+00$ & 3.61E-05 \\
\hline 25 & CENAE_MA_04_BOS_4 & $0.00 \mathrm{E}+00$ & - & $0.00 \mathrm{E}+00$ & - & - & $1.90 \mathrm{E}-06$ & $9.51 \mathrm{E}-07$ & $0.00 \mathrm{E}+00$ & $0.00 E+00$ & $2.85 \mathrm{E}-06$ \\
\hline 26 & CENAE_MA_04_BOS_5 & $0.00 \mathrm{E}+00$ & - & $0.00 \mathrm{E}+00$ & - & - & $9.51 \mathrm{E}-06$ & $0.00 E+00$ & $0.00 E+00$ & $0.00 E+00$ & $9.50 \mathrm{E}-06$ \\
\hline 27 & CENAE_MA_04_BOS_6 & - & - & $0.00 E+00$ & - & - & $9.51 \mathrm{E}-06$ & - & 8.56E-06 & $0.00 E+00$ & $1.81 \mathrm{E}-05$ \\
\hline 28 & CENAE_MA_05_BOS_1 & - & - & - & - & - & - & - & - & - & - \\
\hline 29 & CENAE_MA_06_BOS_1 & - & - & - & - & - & - & - & - & - & - \\
\hline 30 & CENAE_MA_07_BOS_1 & $0.00 \mathrm{E}+00$ & - & $1.90 \mathrm{E}-06$ & $5.32 \mathrm{E}-05$ & - & $3.32 \mathrm{E}-05$ & - & - & $0.00 E+00$ & $8.81 E-05$ \\
\hline 31 & CENAE_MA_13_ISL_1 & - & - & $0.00 E+00$ & - & - & - & - & - & - & $0.00 E+00$ \\
\hline & Overall & $9.16 \mathrm{E}-07$ & $0.00 E+00$ & 1.34E-05 & $6.68 \mathrm{E}-05$ & - & $1.62 \mathrm{E}-04$ & 2.14E-04 & $1.19 E-04$ & $1.89 \mathrm{E}-06$ & 4.09E-04 \\
\hline
\end{tabular}


Table 3-7. Pearson correlation coefficients for collision risk metrics in BHC.

\begin{tabular}{|c|c|c|c|c|}
\hline Metric of Collision Risk & $p\left(\right.$ SDV $\left.\mid n_{k t} \geq 1\right)$ & $p\left(n_{k t} \geq 1\right)$ & $p(\mathrm{SDV})$ & $f_{k}$ \\
\hline$p\left(\mathrm{SDV} \mid n_{k t} \geq 1\right)$ & 1.0000 & -0.2565 & -0.0096 & 0.0097 \\
\hline$p\left(n_{k t} \geq 1\right)$ & - & 1.0000 & 0.7350 & 0.5999 \\
\hline$p(\mathrm{SDV})$ & - & - & 1.0000 & 0.9282 \\
\hline$f_{k}$ & - & - & - & 1.0000 \\
\hline
\end{tabular}

The extent to which the three metrics of collision risk may be providing redundant information is evaluated by calculating the correlation among metrics of collision risk. Correlations are summarized in Table 3-7. The correlation between the conditional probability of an SDV, $p\left(\mathrm{SDV} \mid \mathrm{n}_{\mathrm{jkt}} \geq 1\right)$, and other two risk metrics, the unconditional probability of an SDV, $p(\mathrm{SDV})$, and the relative frequency of SDVs, $f k$, is very low. This indicates that the conditional probability of an SDV is providing unique information. The correlation between the conditional probability of an SDV and the relative frequency of an SDV is greater than 0.9. This high correlation suggests that these two metrics provide similar information.

Correlations can also be used to assess the extent to which any one risk metric may be higher in those reaches that have a higher probability of vessels being present. A high correlation indicates that metric is higher in reaches that are busier. A moderate correlation was found between the probability that at least one vessel is present in a reach, $p\left(n_{j k t} \geq 1\right)$ and two of the risk metrics, the unconditional probability of an SDV and the relative frequency of SDVs. These results are consistent with the idea that the unconditional probability of an SDV and the relative frequency of SDVs will tend to be greater in those reaches that have more traffic. In contrast, there is a negative correlation between the conditional probability of an SDV and the probability that at least one vessel is present in a reach. 
Figure 3-6. Unconditional frequency of SDVs in BHC.

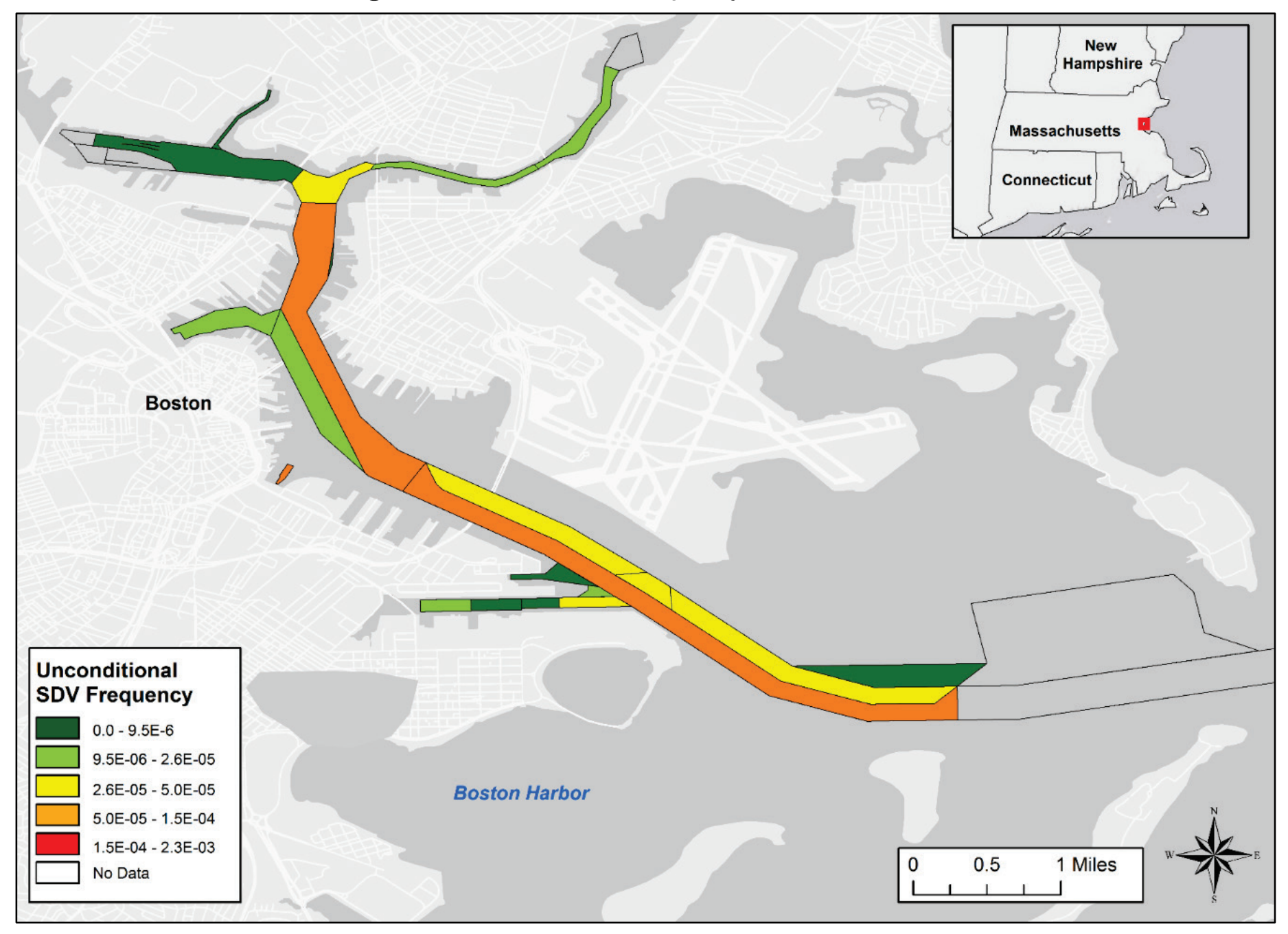


Figure 3-7. Relative frequency of SDVs in BHC by navigation channel reach.

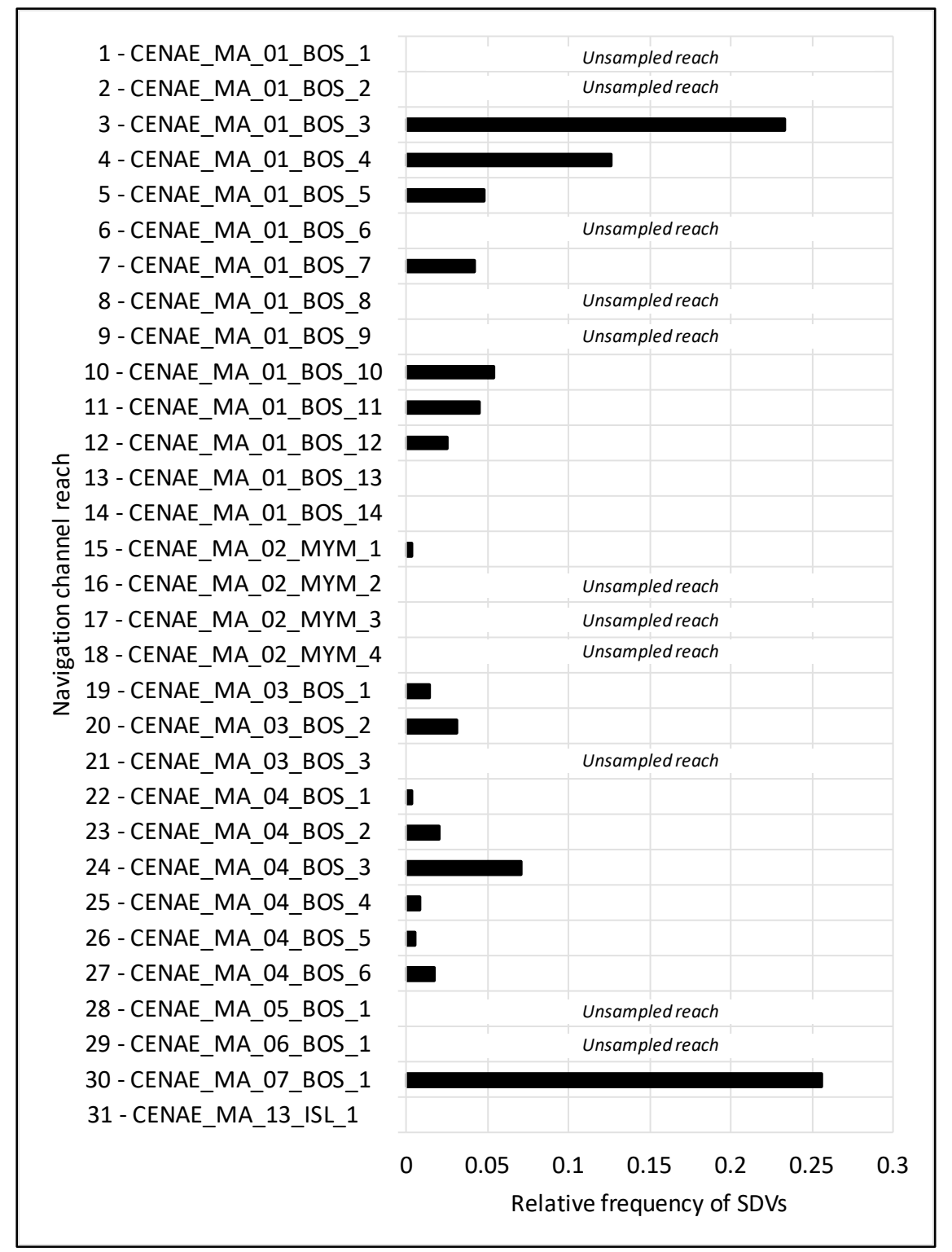

\subsection{Grounding risk assessment}

This assessment of grounding risk examines two types of potential grounding events. The risk of powered groundings on the side of the channel is assessed by identifying clusters of channel side events to reveal where vessels have a tendency to operate near the edge of the channel. The risk of powered grounding in the channel is assessed by calculating what fraction of vessels are depth-limited at maintenance depth and as maintenance depth is reduced to simulate shoaling. These results also 
provide an indication of draft utilization in the channel and the sensitivity of navigation to a potential shoaling event.

\subsubsection{Powered grounding on the side of the channel}

Channel side events in Boston Harbor were identified using transit speed and maximum draft filters of 1 knot and $5 \mathrm{~m}$, respectively. Results are plotted in Figure 3-8. The figure distinguishes between channel side events involving tankers, cargo vessels, and passenger ships. Other types of vessels have been lumped into a single category. Clusters of points show those locations where vessels have a tendency to transit close to or cross the channel boundary, and a trail of channel side events shows where vessels are probably leaving the channel intentionally to access docks. For example, the cluster of points in the 40-Foot Reserved Channel (\#23-27) are easily explained by cruise ships and cargo vessels accessing the MASSPORT terminals, and the cluster of points on the northeast side of the 40-Foot Reserved Channel Turning Area (\#7) can be explained by vessels turning. Similarly, there is a trail of position reports leading to Jefferies Point that can be explained by vessels accessing those piers. While this analysis is not concerned with intentional departures from the channel, it is important to understand what these events look like so that they can be distinguished from those channel side events that are of interest.

There is a cluster of 45 position reports representing 10 different cargo vessels and tankers that appear to be cutting the inside corner of the 35Foot Area (\#14) between Charlestown Marina and Thomas M. Menino Park. This cluster of points suggests a pattern of vessel behavior, but there is no apparent reason that would explain this behavior. Therefore, these channel side events should be investigated to explain this behavior. Figure 3-8 also shows that tanker traffic in the Chelsea River often operates near the boundaries of the channel. The Chelsea River channels are relatively narrow, with widths ranging from 53 to $91 \mathrm{~m}(175-300 \mathrm{ft})$, which explains the behavior. In this case, the width of the channel is constrained by the size of the river, so there may be little that can be done to alleviate this problem by widening the channel. Other clusters of channel side events that might warrant further investigation include cargo and tanker traffic at the confluence of the Mystic and Chelsea Rivers. Cargo vessel traffic appears to be cutting the corner along the eastern embankment of the 40-Foot Inner Harbor Confluence at the entrance to the Chelsea River. Tanker traffic appears to be cutting the corner along the southwest 
embankment of the 40-Foot Inner Harbor Confluence at the entrance to the Mystic River.

Maps of channel side events can also be used to identify locations where such hazards exist but may not have been reported. For example, seven points in the Fort Independence Reach (\#3), just northwest of Spectacle Island, show the track of a $261 \mathrm{~m}$ Hong Kong-flagged container ship that appears to have crossed over the channel boundary while heading out to sea on the morning of 6 November 2014. This event lasted approximately 4 minutes, and at its most extreme point, the stern of the vessel strayed $15 \mathrm{~m}$ outside the channel boundaries. Because this is an isolated event that occurred in water that is probably deep enough to accommodate the maximum draft of the vessel, it probably raises no cause for concern. 
Figure 3-8. Channel side events in BHC.

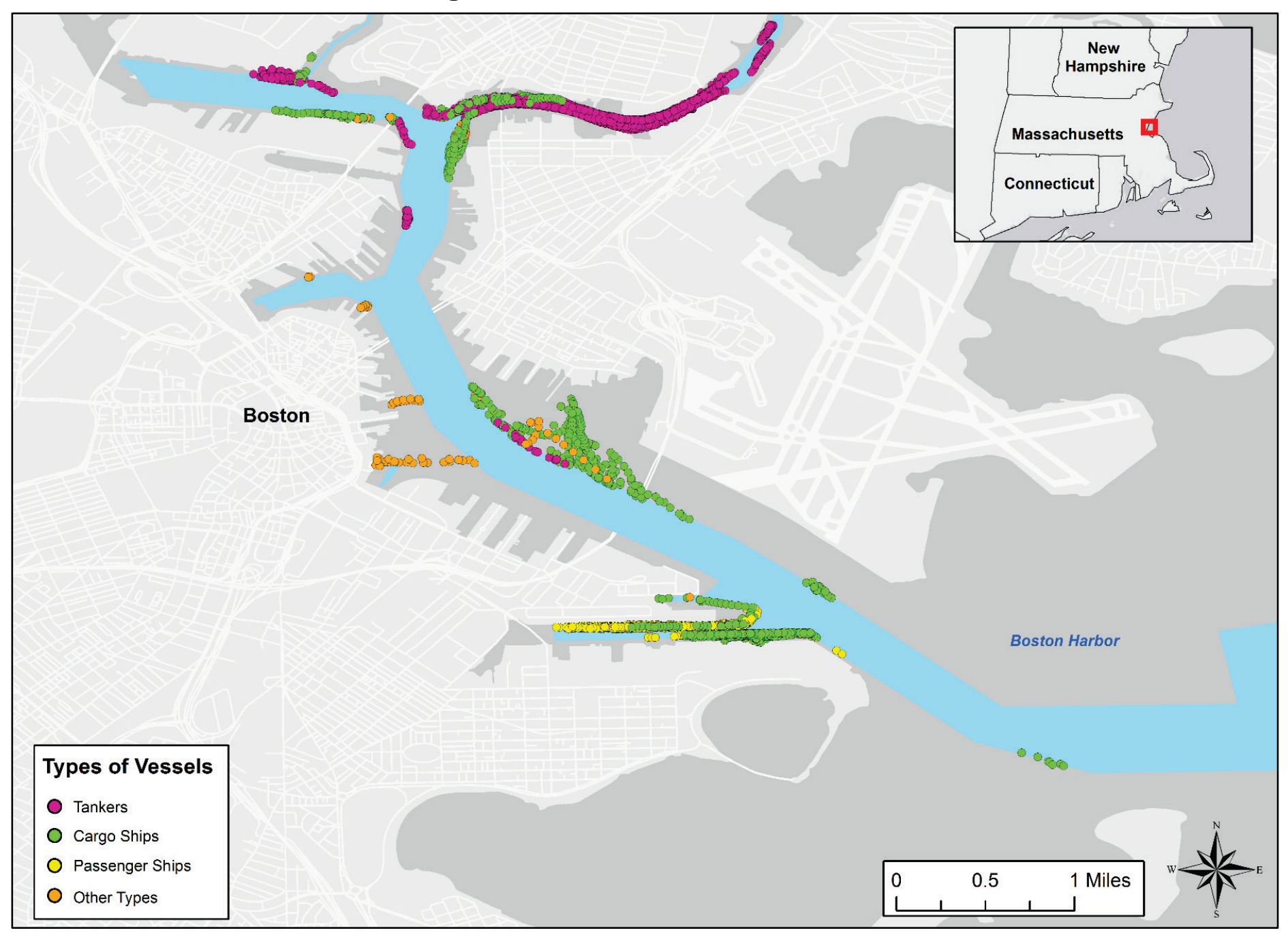




\subsubsection{Powered grounding on a shoal in the channel}

The number and fraction of depth-limited cargo vessels is summarized in Table 3-8. Only those reaches that have cargo traffic are listed in the table. The table shows that, at maintenance depth, the depth-limited fraction of vessels is greater than 0.3 in 3 of the 15 reaches used by cargo vessels. Reaches where a large fraction of the vessels are depth limited at maintenance depth may be candidates for deepening. The 35-Foot Fort Independence Reach (\#10) has a large number and fraction of vessels with maximum drafts greater than maintenance depth. However, the case for deepening is mitigated by the presence of the 40-Foot Fort Independence Channel (\#3), which runs parallel to it. The number and fraction of depth limited vessels in this reach is low. Other reaches with a large fraction of depth-limited vessels at maintenance depth include the 40-Foot Reserved Channel Turning Area (West) (\#23), the 40-Foot Reserved Channel (\#24), and 40-Foot Reserved Channel Middle Width (\#25). However, the absolute numbers are relatively low, which also mitigates the case for deepening.

As shoaling occurs between dredging events, the available depth in a channel is reduced, and the depth-limited fraction of vessels will increase. For example, in the 35-Foot Fort Independence Reach (\#10), $6 \mathrm{ft}$ of shoaling increases the depth-limited fraction of cargo vessels from 0.33 to o.62. Reaches where the depth-limited fraction increases rapidly in response to shoaling may be candidates for more frequent dredging to maintain depth.

The depth-limited fraction of tankers is summarized in Table 3-9. These results are similar to those in Table 3-8, but tankers use a somewhat different set of navigation reaches and, in general, require less draft than cargo vessels. These results suggest that tankers are also depth limited in the 35-Foot Fort Independence Channel (\#10) and in the 35-Foot Charlestown Waterfront Channel (\#11), and that shoaling of $2 \mathrm{ft}$ would cause more than $50 \%$ of the tankers using the reach to become depth limited.

A well-maintained channel should not contain shoals, but shoals can develop gradually over time between dredging events and following heavy rainfall or storm events. Shoaling reduces the available depth in a channel and disrupts navigation if vessels are forced to lighter their loads or operate in other ways to accommodate the change in available depth. The results in Tables 3-8 and 3-9 can also be interpreted as an indication of to what extent deferred maintenance might disrupt navigation in a reach. 
Table 3-8. Number and fraction of cargo vessels (70-79) that are depth limited in BHC.

\begin{tabular}{|c|c|c|c|c|c|c|c|c|c|c|}
\hline \multirow[b]{2}{*}{ \# } & \multirow[b]{2}{*}{ Reach Code } & \multirow{2}{*}{$\begin{array}{l}\text { Main- } \\
\text { tenance } \\
\text { Depth } \\
\text { (ft) }\end{array}$} & \multirow{2}{*}{$\begin{array}{c}\text { Number of } \\
\text { Unique } \\
\text { Vessels }\end{array}$} & \multicolumn{7}{|c|}{ Reduction in Maintenance Depth (ft) } \\
\hline & & & & 0 & 1 & 2 & 3 & 4 & 5 & 6 \\
\hline 2 & CENAE_MA_01_BOS_2 & 40 & 174 & $25 / 0.144$ & $33 / 0.19$ & $38 / 0.218$ & $46 / 0.264$ & $56 / 0.322$ & $58 / 0.333$ & $65 / 0.374$ \\
\hline 3 & CENAE_MA_01_BOS_3 & 40 & 175 & 26/0.149 & $34 / 0.194$ & $39 / 0.223$ & $47 / 0.269$ & $57 / 0.326$ & $59 / 0.337$ & $66 / 0.377$ \\
\hline 4 & CENAE_MA_01_BOS_4 & 40 & 114 & $9 / 0.079$ & $15 / 0.132$ & $17 / 0.149$ & $19 / 0.167$ & $23 / 0.202$ & $23 / 0.202$ & $24 / 0.211$ \\
\hline 5 & CENAE_MA_01_BOS_5 & 40 & 114 & $9 / 0.079$ & $15 / 0.132$ & $17 / 0.149$ & $19 / 0.167$ & $23 / 0.202$ & $23 / 0.202$ & $24 / 0.211$ \\
\hline 7 & CENAE_MA_01_BOS_7 & 40 & 83 & $13 / 0.157$ & $15 / 0.181$ & $17 / 0.205$ & $20 / 0.241$ & $27 / 0.325$ & $29 / 0.349$ & $36 / 0.434$ \\
\hline 10 & CENAE_MA_01_BOS_10 & 35 & 155 & $51 / 0.329$ & $58 / 0.374$ & $65 / 0.419$ & $70 / 0.452$ & $74 / 0.477$ & $82 / 0.529$ & $96 / 0.619$ \\
\hline 11 & CENAE_MA_01_BOS_11 & 35 & 67 & $14 / 0.209$ & $15 / 0.224$ & $16 / 0.239$ & $18 / 0.269$ & $19 / 0.284$ & $25 / 0.373$ & $36 / 0.537$ \\
\hline 13 & CENAE_MA_01_BOS_13 & 40 & 2 & $0 / 0$ & $0 / 0$ & $0 / 0$ & $0 / 0$ & $0 / 0$ & $0 / 0$ & $0 / 0$ \\
\hline 15 & CENAE_MA_02_MYM_1 & 40 & 83 & $4 / 0.048$ & $7 / 0.084$ & 9/0.108 & $9 / 0.108$ & $11 / 0.133$ & $11 / 0.133$ & $11 / 0.133$ \\
\hline 19 & CENAE_MA_03_BOS_1 & 38 & 32 & $8 / 0.25$ & $10 / 0.313$ & $12 / 0.375$ & $12 / 0.375$ & $13 / 0.406$ & $14 / 0.438$ & $16 / 0.5$ \\
\hline 22 & CENAE_MA_04_BOS_1 & 40 & 4 & $0 / 0$ & $0 / 0$ & $0 / 0$ & $0 / 0$ & $0 / 0$ & $0 / 0$ & $0 / 0$ \\
\hline 23 & CENAE_MA_04_BOS_2 & 40 & 29 & $9 / 0.31$ & $10 / 0.345$ & $11 / 0.379$ & $13 / 0.448$ & $16 / 0.552$ & $17 / 0.586$ & $20 / 0.69$ \\
\hline 24 & CENAE_MA_04_BOS_3 & 40 & 57 & $17 / 0.298$ & $19 / 0.333$ & $22 / 0.386$ & $28 / 0.491$ & $34 / 0.596$ & $36 / 0.632$ & $42 / 0.737$ \\
\hline 25 & CENAE_MA_04_BOS_4 & 40 & 27 & $10 / 0.37$ & $10 / 0.37$ & $11 / 0.407$ & $13 / 0.481$ & $15 / 0.556$ & $16 / 0.593$ & $18 / 0.667$ \\
\hline 26 & CENAE_MA_04_BOS_5 & 40 & 1 & $0 / 0$ & $0 / 0$ & $0 / 0$ & $0 / 0$ & $0 / 0$ & $0 / 0$ & $0 / 0$ \\
\hline
\end{tabular}


Table 3-9. Number and fraction of tankers (80-89) that are depth limited in BHC.

\begin{tabular}{|c|c|c|c|c|c|c|c|c|c|c|}
\hline \multirow[b]{2}{*}{$\#$} & \multirow[b]{2}{*}{ Reach Code } & \multirow{2}{*}{$\begin{array}{l}\text { Main- } \\
\text { tenance } \\
\text { Depth } \\
\text { (ft) }\end{array}$} & \multirow{2}{*}{$\begin{array}{c}\text { Number of } \\
\text { Unique } \\
\text { Vessels }\end{array}$} & \multicolumn{7}{|c|}{ Reduction in Maintenance Depth (ft) } \\
\hline & & & & 0 & 1 & 2 & 3 & 4 & 5 & 6 \\
\hline 2 & CENAE_MA_01_BOS_2 & 40 & 95 & $3 / 0.032$ & $11 / 0.116$ & $16 / 0.168$ & $21 / 0.221$ & $30 / 0.316$ & $34 / 0.358$ & $46 / 0.484$ \\
\hline 3 & CENAE_MA_01_BOS_3 & 40 & 95 & $3 / 0.032$ & $11 / 0.116$ & $16 / 0.168$ & $21 / 0.221$ & $30 / 0.316$ & $34 / 0.358$ & $46 / 0.484$ \\
\hline 4 & CENAE_MA_01_BOS_4 & 40 & 94 & $3 / 0.032$ & $11 / 0.117$ & $16 / 0.17$ & $21 / 0.223$ & $30 / 0.319$ & $34 / 0.362$ & $46 / 0.489$ \\
\hline 5 & CENAE_MA_01_BOS_5 & 40 & 94 & $3 / 0.032$ & $11 / 0.117$ & $16 / 0.17$ & $21 / 0.223$ & $30 / 0.319$ & $34 / 0.362$ & $46 / 0.489$ \\
\hline 6 & CENAE_MA_01_BOS_6 & 35 & 1 & $1 / 1$ & $1 / 1$ & $1 / 1$ & $1 / 1$ & $1 / 1$ & $1 / 1$ & $1 / 1$ \\
\hline 7 & CENAE_MA_01_BOS_7 & 40 & 25 & $0 / 0$ & $1 / 0.04$ & $2 / 0.08$ & $2 / 0.08$ & $4 / 0.16$ & $5 / 0.2$ & $11 / 0.44$ \\
\hline 10 & CENAE_MA_01_BOS_10 & 35 & 77 & $27 / 0.351$ & $37 / 0.481$ & $44 / 0.571$ & $46 / 0.597$ & $48 / 0.623$ & $50 / 0.649$ & $53 / 0.688$ \\
\hline 11 & CENAE_MA_01_BOS_11 & 35 & 63 & 23/0.365 & $32 / 0.508$ & $37 / 0.587$ & 39/0.619 & $39 / 0.619$ & $41 / 0.651$ & $43 / 0.683$ \\
\hline 13 & CENAE_MA_01_BOS_13 & 40 & 1 & $0 / 0$ & $0 / 0$ & $0 / 0$ & $1 / 1$ & $1 / 1$ & $1 / 1$ & $1 / 1$ \\
\hline 15 & CENAE_MA_02_MYM_1 & 40 & 55 & $3 / 0.055$ & $11 / 0.2$ & $13 / 0.236$ & $15 / 0.273$ & 21/0.382 & $21 / 0.382$ & $25 / 0.455$ \\
\hline 19 & CENAE_MA_03_BOS_1 & 38 & 56 & $7 / 0.125$ & 11/0.196 & $15 / 0.268$ & $18 / 0.321$ & $26 / 0.464$ & 33/0.589 & $35 / 0.625$ \\
\hline 20 & CENAE_MA_03_BOS_2 & 38 & 27 & $1 / 0.037$ & $1 / 0.037$ & $3 / 0.111$ & $5 / 0.185$ & $9 / 0.333$ & $13 / 0.481$ & $14 / 0.519$ \\
\hline 23 & CENAE_MA_04_BOS_2 & 40 & 1 & $0 / 0$ & $0 / 0$ & 0/0 & 0/0 & $0 / 0$ & $0 / 0$ & $0 / 0$ \\
\hline 24 & CENAE_MA_04_BOS_3 & 40 & 1 & $0 / 0$ & $0 / 0$ & $0 / 0$ & 0/0 & $0 / 0$ & $0 / 0$ & $0 / 0$ \\
\hline 25 & CENAE_MA_04_BOS_4 & 40 & 1 & 0/0 & $0 / 0$ & $0 / 0$ & 0/0 & 0/0 & $0 / 0$ & $0 / 0$ \\
\hline 26 & CENAE_MA_04_BOS_5 & 40 & 1 & $0 / 0$ & $0 / 0$ & 0/0 & 0/0 & $0 / 0$ & $0 / 0$ & $0 / 0$ \\
\hline 27 & CENAE_MA_04_BOS_6 & 35 & 1 & 0/0 & $0 / 0$ & 0/0 & 0/0 & $0 / 0$ & $0 / 0$ & $0 / 0$ \\
\hline
\end{tabular}




\subsection{Marine Information for Safety and Law Enforcement (MISLE) database reports}

The USCG maintains the MISLE database, which contains information about reported accidents and pollution events in U.S. territorial waters. The location of collision and grounding events that occurred during the period 2011 to 2015 are shown in Figure 3-9, which shows the location of each incident and the seven-digit Activity Number associated with it. While MISLE was established in 2001, significant improvements were made to the system beginning in 2011. Therefore, only 4 years of data are shown in Figure 3-9 because location data were not consistently reported in prior years. Each incident is classified as a collision, an allision, or a grounding event. The term allision is used to describe collisions with moored vessels as well as objects. Events classified as groundings include powered groundings and groundings preceded by other events, such as loss of propulsion or steering. Near misses are not reported in the database. Privacy concerns preclude providing more information about these events. However, public information about these events can be obtained by entering the Activity Number at the USCG MISLE website: http://cgmix.uscg.mil/IIR/IIRSearch.aspx. If information about an incident is not public, the system will not return a result. 
Figure 3-9. Collision and grounding events in Boston Harbor, 2011-2015, as reported in the USCG MISLE database.

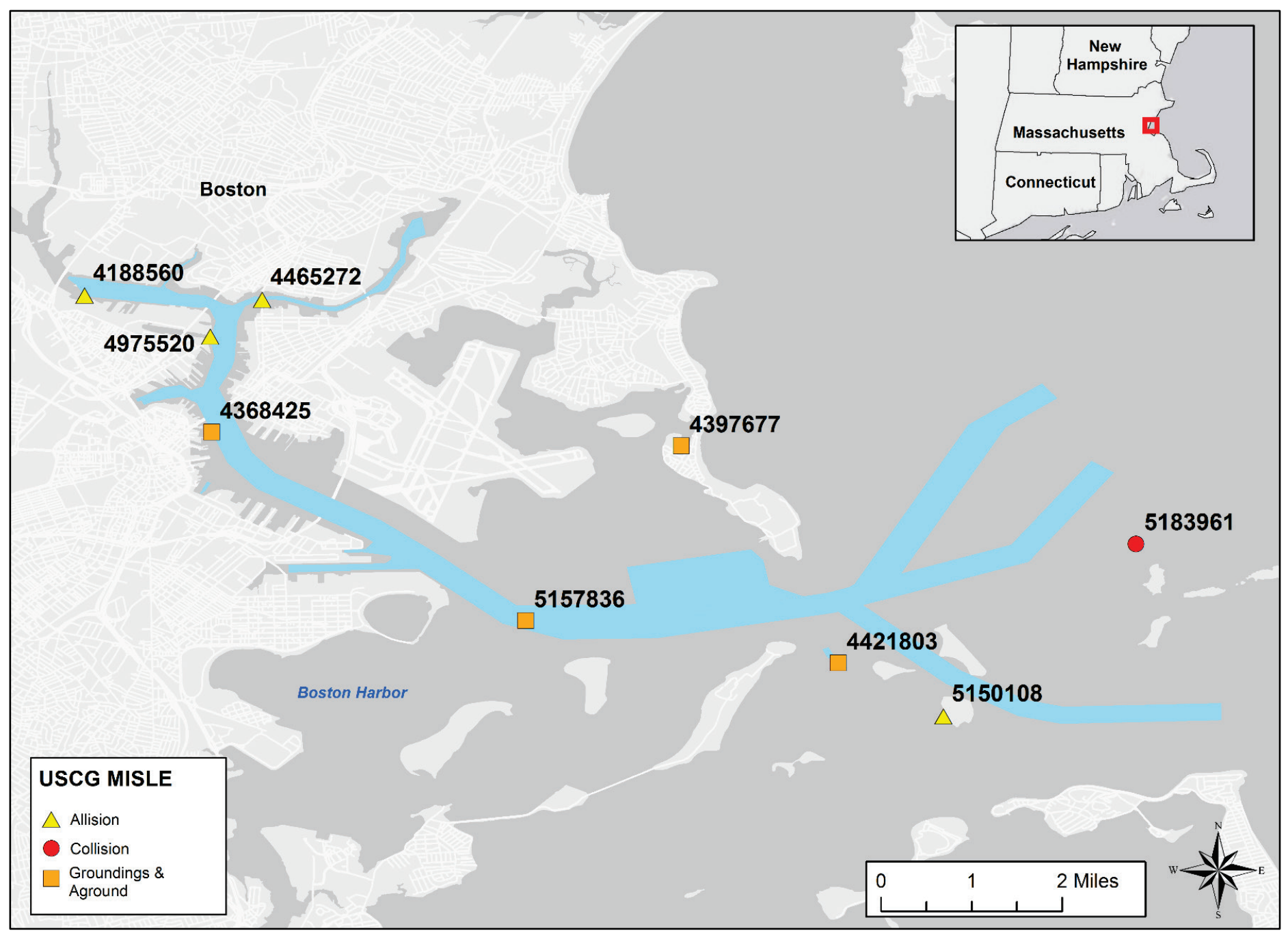




\section{Calcasieu River Ship Channel (CRSC)}

The CRSC links the Port of Lake Charles, Louisiana, with the Gulf of Mexico. The Port of Lake Charles is an industrial center for oil and gas production located approximately 40 miles inland from the Gulf of Mexico (Figure 4-1). When ranked in terms of cargo tonnage, it is presently the tenth largest port in the United States. The waterway consists of 53 channels with a combined length of 75 miles and a maintenance depth between 35 and $42 \mathrm{ft}$ (Table 4-1). The location of each reach within the navigation project is shown in Figure 4-2. NAIS data were requested for all reaches north of reach CEMVN_CR_38_BAR_11, which is located in the Gulf of Mexico approximately 16 miles south of the Calcasieu River mouth.

Figure 4-1. Map of the Calcasieu River.

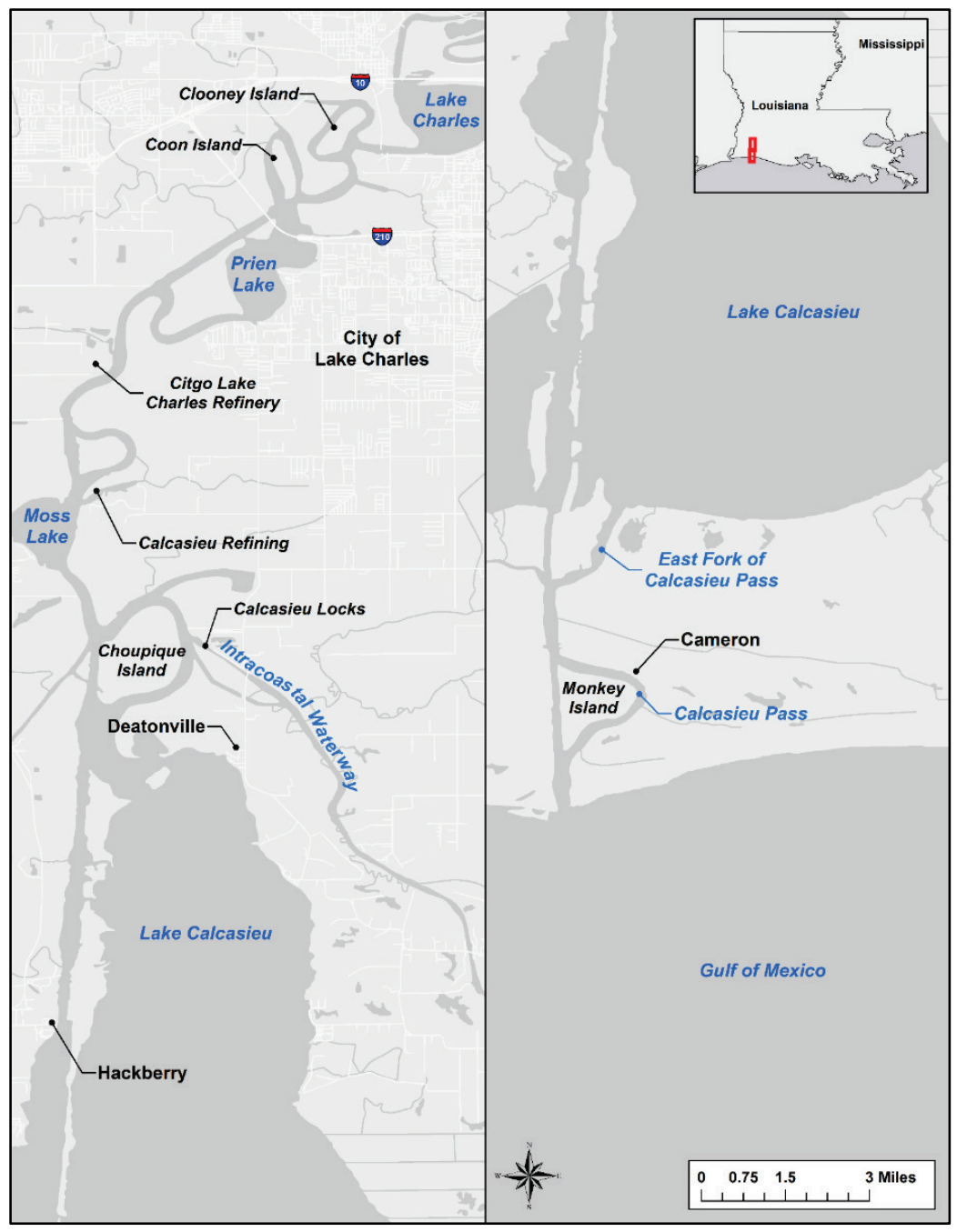


Figure 4-2. Federal navigation channel reaches in Calcasieu River.

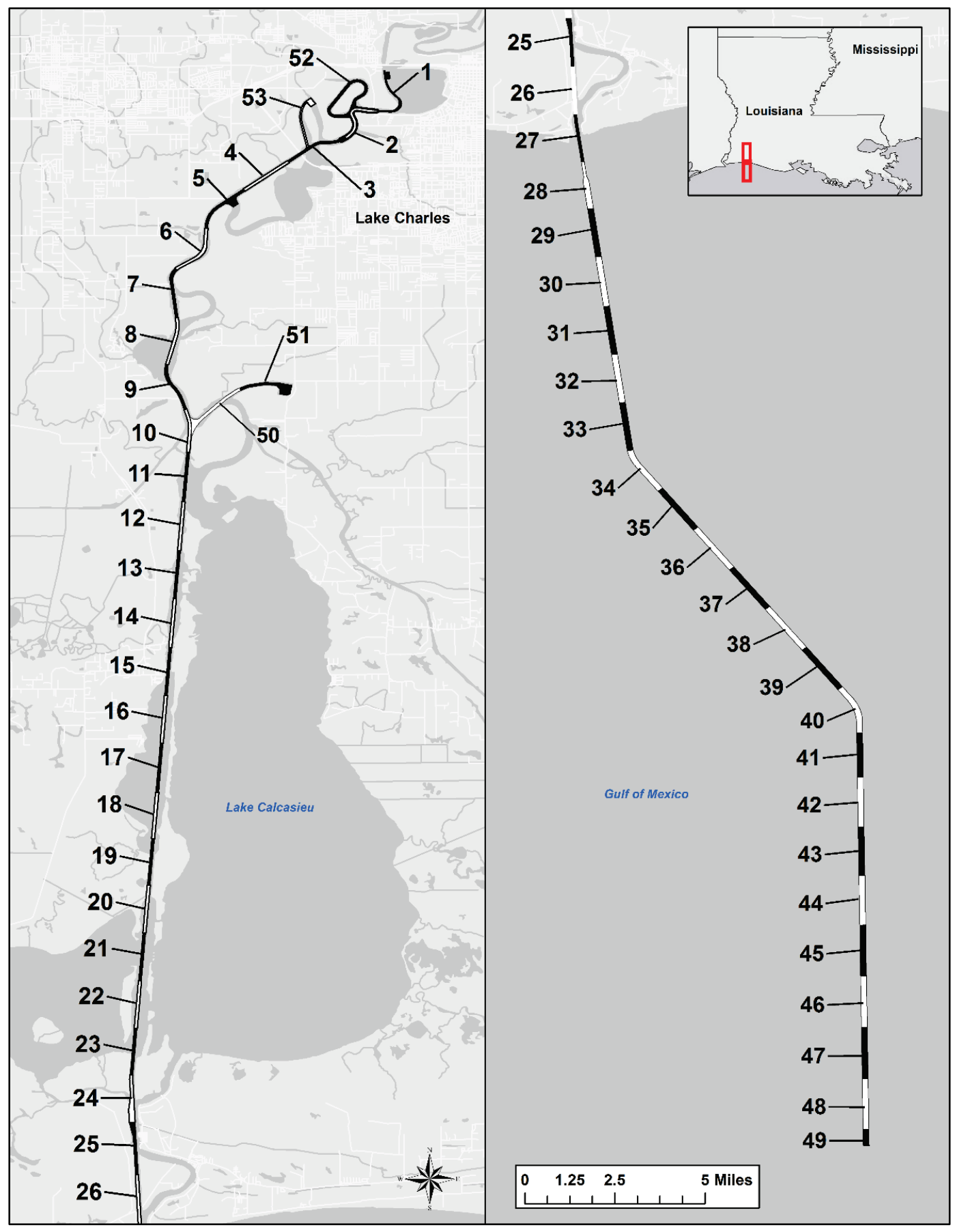


Table 4-1. Federal navigation channel reaches and reach characteristics in Calcasieu River.

\begin{tabular}{|c|c|c|c|c|c|c|}
\hline$\#$ & Reach Code & Reach Description & $\begin{array}{c}\text { Authorized Depth } \\
\text { (ft) }\end{array}$ & $\begin{array}{l}\text { Maintenance } \\
\text { Depth (ft) }\end{array}$ & $\begin{array}{l}\text { Length } \\
\text { (miles) }\end{array}$ & $\begin{array}{l}\text { Width } \\
\text { (ft) }\end{array}$ \\
\hline 1 & CEMVN_CR_01_UPR_01 & UPPR01 & 35 & 35 & 1.72 & $250-800$ \\
\hline 2 & CEMVN_CR_02_UPR_02 & UPPR02 & 40 & 40 & 1.60 & $400-400$ \\
\hline 3 & CEMVN_CR_03_UPR_03 & UPPR03 & 40 & 40 & 1.45 & $400-400$ \\
\hline 4 & CEMVN_CR_04_UPR_04 & UPPR04 & 40 & 40 & 1.33 & $400-400$ \\
\hline 5 & CEMVN_CR_05_UPR_05 & UPPR05 & 40 & 40 & 1.46 & $400-400$ \\
\hline 6 & CEMVN_CR_06_UPR_06 & UPPR06 & 40 & 40 & 1.48 & $400-400$ \\
\hline 7 & CEMVN_CR_07_UPR_07 & UPPR07 & 40 & 40 & 1.38 & $400-400$ \\
\hline 8 & CEMVN_CR_08_UPR_08 & UPPR08 & 40 & 40 & 1.33 & $400-400$ \\
\hline 9 & CEMVN_CR_09_UPR_09 & UPPR09 & 40 & 40 & 1.36 & $400-400$ \\
\hline 10 & CEMVN_CR_10_UPR_10 & UPPR10 & 40 & 40 & 1.21 & $400-400$ \\
\hline 11 & CEMVN_CR_11_LWR_01 & LOWR01 & 40 & 40 & 1.36 & $400-400$ \\
\hline 12 & CEMVN_CR_12_LWR_02 & LOWRO2 & 40 & 40 & 1.36 & $400-400$ \\
\hline 13 & CEMVN_CR_13_LWR_03 & LOWRO3 & 40 & 40 & 1.33 & $400-400$ \\
\hline 14 & CEMVN_CR_14_LWR_04 & LOWRO4 & 40 & 40 & 1.36 & $400-400$ \\
\hline 15 & CEMVN_CR_15_LWR_05 & LOWR05 & 40 & 40 & 1.33 & $400-400$ \\
\hline 16 & CEMVN_CR_16_LWR_06 & LOWR06 & 40 & 40 & 1.33 & $400-400$ \\
\hline 17 & CEMVN_CR_17_LWR_07 & LOWRO7 & 40 & 40 & 1.36 & $400-400$ \\
\hline 18 & CEMVN_CR_18_LWR_08 & LOWR08 & 40 & 40 & 1.29 & $400-400$ \\
\hline 19 & CEMVN_CR_19_LWR_09 & LOWR09 & 40 & 40 & 1.29 & $400-400$ \\
\hline 20 & CEMVN_CR_20_LWR_10 & LOWR10 & 40 & 40 & 1.33 & $400-400$ \\
\hline 21 & CEMVN_CR_21_LWR_11 & LOWR11 & 40 & 40 & 1.33 & $400-400$ \\
\hline 22 & CEMVN_CR_22_LWR_12 & LOWR12 & 40 & 40 & 1.33 & $400-400$ \\
\hline
\end{tabular}




\begin{tabular}{|c|c|c|c|c|c|c|}
\hline \# & Reach Code & Reach Description & $\begin{array}{c}\text { Authorized Depth } \\
(\mathrm{ft})\end{array}$ & $\begin{array}{l}\text { Maintenance } \\
\text { Depth (ft) }\end{array}$ & $\begin{array}{l}\text { Length } \\
\text { (miles) }\end{array}$ & $\begin{array}{l}\text { Width } \\
\text { (ft) }\end{array}$ \\
\hline 23 & CEMVN_CR_23_LWR_13 & LOWR13 & 40 & 40 & 1.29 & $400-400$ \\
\hline 24 & CEMVN_CR_24_LWR_14 & LOWR14 & 40 & 40 & 1.32 & $400-400$ \\
\hline 25 & CEMVN_CR_25_GAP_01 & GAP01 & 40 & 40 & 1.44 & $400-400$ \\
\hline 26 & CEMVN_CR_26_GAP_02 & GAP02 & 40 & 40 & 1.38 & $400-400$ \\
\hline 27 & CEMVN_CR_27_GAP_03 & GAP03 & 40 & 40 & 1.42 & $400-400$ \\
\hline 28 & CEMVN_CR_28_BAR_01 & BAR01 & 42 & 42 & 1.38 & $400-800$ \\
\hline 29 & CEMVN_CR_29_BAR_02 & BAR02 & 42 & 42 & 1.42 & $800-800$ \\
\hline 30 & CEMVN_CR_30_BAR_03 & BAR03 & 42 & 42 & 1.46 & $800-800$ \\
\hline 31 & CEMVN_CR_31_BAR_04 & BAR04 & 42 & 42 & 1.42 & $800-800$ \\
\hline 32 & CEMVN_CR_32_BAR_05 & BAR05 & 42 & 42 & 1.42 & $800-800$ \\
\hline 33 & CEMVN_CR_33_BAR_06 & BAR06 & 42 & 42 & 1.42 & $800-800$ \\
\hline 34 & CEMVN_CR_34_BAR_07 & BAR07 & 42 & 42 & 1.38 & $800-800$ \\
\hline 35 & CEMVN_CR_35_BAR_08 & BAR08 & 42 & 42 & 1.46 & $800-800$ \\
\hline 36 & CEMVN_CR_36_BAR_09 & BAR09 & 42 & 42 & 1.48 & $800-800$ \\
\hline 37 & CEMVN_CR_37_BAR_10 & BAR10 & 42 & 42 & 1.48 & $800-800$ \\
\hline 38 & CEMVN_CR_38_BAR_11 & BAR11 & 42 & 42 & 1.51 & $800-800$ \\
\hline 39 & CEMVN_CR_39_BAR_12 & BAR12 & 42 & 42 & 1.48 & $800-800$ \\
\hline 40 & CEMVN_CR_40_BAR_13 & BAR13 & 42 & 42 & 1.44 & $800-800$ \\
\hline 41 & CEMVN_CR_41_BAR_14 & BAR14 & 42 & 42 & 1.31 & $800-800$ \\
\hline 42 & CEMVN_CR_42_BAR_15 & BAR15 & 42 & 42 & 1.46 & $800-800$ \\
\hline 43 & CEMVN_CR_43_BAR_16 & BAR16 & 42 & 42 & 1.42 & $800-800$ \\
\hline 44 & CEMVN_CR_44_BAR_17 & BAR17 & 42 & 42 & 1.44 & $800-800$ \\
\hline
\end{tabular}




\begin{tabular}{|c|l|c|c|c|c|c|}
\hline$\#$ & Reach Code & Reach Description & $\begin{array}{c}\text { Authorized Depth } \\
(\mathrm{ft})\end{array}$ & $\begin{array}{c}\text { Maintenance } \\
\text { Depth (ft) }\end{array}$ & $\begin{array}{c}\text { Length } \\
\text { (miles) }\end{array}$ & $\begin{array}{c}\text { Width } \\
\text { (ft) }\end{array}$ \\
\hline 45 & CEMVN_CR_45_BAR_18 & BAR18 & 42 & 42 & 1.50 & $800-800$ \\
\hline 46 & CEMVN_CR_46_BAR_19 & BAR19 & 42 & 42 & 1.50 & $800-800$ \\
\hline 47 & CEMVN_CR_47_BAR_20 & BAR20 & 42 & 42 & 1.48 & $800-800$ \\
\hline 48 & CEMVN_CR_48_BAR_21 & BAR21 & 42 & 42 & 0.49 & $800-800$ \\
\hline 49 & CEMVN_CR_49_BAR_22 & BAR22 & 42 & 42 & 1.56 & $400-800$ \\
\hline 50 & CEMVN_CR_50_DE1_01 & DE1 & 40 & 40 & 1.27 & $400-800$ \\
\hline 51 & CEMVN_CR_51_DE2_02 & DE2 & 40 & 40 & 2.82 & $800-800$ \\
\hline 52 & CEMVN_CR_52_CLI_01 & CLOONEY & 40 & 40 & 400 \\
\hline 53 & CEMVN_CR_53_CNI_01 & COON & 40 & 40 & $800-800$ \\
\hline
\end{tabular}




\subsection{Static vessel data}

During the 2014 calendar year, NAIS receivers intercepted AIS messages from 2,357 unique vessels in the CRSC. Static vessel data were screened to assess their completeness and to identify and correct potential problems before analyzing collision and grounding risks. At least six records contained malformed MMSI codes, 84 records (3.5\%) contained no information about vessel name, and 248 records (10.5\%) contained unknown or missing ship and cargo type codes. Many records were also missing data on vessel dimensions. There were 315 records (13.4\%) missing data on length, 321 records (13.6\%) missing data on beam, and 560 records (23.7\%) missing data on maximum design draft.

A summary of the vessels operating in CRSC during calendar year 2014 is provided in Table 4-2. Ship and cargo type code classifications were validated, and if necessary, vessels were re-classified based on information from photographs of each vessel. The number of vessels with unknown ship and cargo type codes was reduced from 248 to 75 , and the number of vessels using codes 20-29 from 32 to zero. In addition, 55 vessels using ship and cargo type codes 90-99 were re-classified as tugboats, dredgers, military operations, and towboats or pushboats.

Other issues with ship and cargo type codes were noted but not corrected because they reflect inherent ambiguity in the classification system. For example, many of the vessels utilizing ship and cargo type code 40-49 were identified as crewboats. This ship and cargo type code is reserved for "high-speed craft and passenger ferries," which includes catamarans and other vessels capable of traveling at speeds greater than 30 knots. However, these crewboats exhibited no particular features that would enable them to operate at high speed. Therefore, they might have been more accurately classified as passenger vessels (code 60-69). In this case, no changes were made to the ship and cargo type classification because the title of the category itself is ambiguous.

Similarly, no effort was made to standardize ship and cargo type code of offshore supply vessels, which transport supplies, equipment, and crew to oil rigs in the Gulf of Mexico. The 5 January 2012 version of the USCG AIS encoding guide directed offshore supply vessels to use AIS ship and cargo type code 25. In 2014, no vessels were using ship and cargo type code 25, and most offshore supply vessels in the CRSC appeared to be using the code for cargo vessels (70-79) or other types of vessels (90-99). Offshore 
supply vessels are smaller than container vessels and bulk carriers and have shallower drafts. Therefore, it would be better to distinguish them from larger cargo vessels for the purpose of risk assessment. When offshore supply vessels were encountered in the static vessel data, the ship and cargo type codes were changed to 90. However, not all ship and cargo type codes were corrected because it was too difficult to identify which vessels in the static vessel data were miscoded offshore supply vessels. A more recent version of the USCG AIS encoding guide, published 5 July 2015, directs offshore supply vessels to use AIS ship and cargo type code 53 , for port tenders.

As shown in Table 4-2, the largest categories of vessels utilizing CRSC were tugboats and towboats $(1,174$ vessels were classified under AIS ship and cargo type codes 31,32 , or 52$)$. Tankers represented the secondlargest category, with 351 vessels reporting an AIS ship and cargo type code of 8o-89, and cargo vessels represented the third largest category, with 320 vessels reporting an AIS ship and cargo type code 70-79.

Table 4-2. Descriptive summary of vessels utilizing CRSC.

\begin{tabular}{|c|c|c|c|}
\hline \multirow[b]{2}{*}{ AIS Ship and Cargo Type } & \multirow{2}{*}{$\begin{array}{c}\text { AIS Ship and } \\
\text { Cargo } \\
\text { Type Code }\end{array}$} & \multicolumn{2}{|c|}{ Number of Unique Vessels } \\
\hline & & $\begin{array}{c}\text { Before Review } \\
\text { of Static } \\
\text { Vessel Data }\end{array}$ & $\begin{array}{c}\text { After Review } \\
\text { of Static } \\
\text { Vessel Data }\end{array}$ \\
\hline Unknown & 0 & 248 & 75 \\
\hline WIG & $20-29$ & 32 & 0 \\
\hline Fishing vessels & 30 & 25 & 13 \\
\hline Towing & $31-32$ & 722 & 821 \\
\hline Engaged in dredging or underwater operations & 33 & 16 & 21 \\
\hline Engaged in diving operations & 34 & 20 & 20 \\
\hline Engaged in military operations & 35 & 1 & 2 \\
\hline Sailing vessels & 36 & 18 & 18 \\
\hline Pleasure craft & 37 & 43 & 43 \\
\hline Reserved for future use & $38-39$ & 41 & 0 \\
\hline High-speed craft (HSC) or passenger ferries & $40-49$ & 7 & 7 \\
\hline Pilot vessels & 50 & 9 & 11 \\
\hline Search and rescue vessels & 51 & 3 & 3 \\
\hline Tugs & 52 & 292 & 412 \\
\hline Port tenders & 53 & 1 & 1 \\
\hline
\end{tabular}




\begin{tabular}{|c|c|c|c|}
\hline \multirow[b]{2}{*}{ AIS Ship and Cargo Type } & \multirow{2}{*}{$\begin{array}{c}\text { AIS Ship and } \\
\text { Cargo } \\
\text { Type Code }\end{array}$} & \multicolumn{2}{|c|}{ Number of Unique Vessels } \\
\hline & & $\begin{array}{c}\text { Before Review } \\
\text { of Static } \\
\text { Vessel Data }\end{array}$ & $\begin{array}{c}\text { After Review } \\
\text { of Static } \\
\text { Vessel Data }\end{array}$ \\
\hline Vessels with anti-pollution facilities & 54 & 1 & 2 \\
\hline Law enforcement vessels & 55 & 2 & 2 \\
\hline Spare, for assignment to local vessels & $56-57$ & 2 & 0 \\
\hline Medical transports & 58 & 0 & 0 \\
\hline Ships according to RR Resolution no. 18 (Mob-83) & 59 & 1 & 0 \\
\hline Passenger ships & $60-69$ & 63 & 72 \\
\hline Cargo ships & $70-79$ & 285 & 289 \\
\hline Tankers & $80-89$ & 339 & 351 \\
\hline Other vessels & $90-99$ & 186 & 194 \\
\hline Total & - & 2357 & 2357 \\
\hline
\end{tabular}

Static vessel data were requested without information about the position of the EPFS antenna on board each vessel. This information was obtained from the AISAP vessel inventory. Vessels in the AISAP database were matched to vessels in the CRSC static vessel data by comparing MMSI numbers, length, and beam. There were 1,801 matches in static vessel data (76.4\%). If a matching MMSI was found, but the length and beam did not match, the vessels name as reported in static vessel data was compared to that reported in AISAP, and if similar, the EPFS antenna was placed in relative proportion to the position reported in AISAP. This method was used for 77 vessels (3.2 \%). If no matching MMSI was found in the AISAP inventory, or if the length, beam, or EPFS antenna position on board the vessel was not reported, then the EPFS antenna was positioned at the center of the vessel. This method was used for 479 vessels (20.3\%).

\subsection{Collision risk assessment}

Position reports were sampled at $30 \mathrm{sec}$ intervals. The position report from each vessel in each $30 \mathrm{sec}$ interval was compared to the position report from every other vessel in that $30 \mathrm{sec}$ interval. The position report was classified as an SDV if the perimeter of another vessel was located within the domain of the vessel transmitting the AIS signal. Encounters are interactions between two vessels during which one vessel encroaches on the domain of another vessel. If both vessels encroach on each other's domain during an interaction, two encounters are recorded. Each 
encounter is documented by a series of position reports for the encroached vessel in which at least one position report is classified as an SDV. Two position reports that are classified as SDVs are regarded as belonging to the same encounter if separated by a period no more than 10 minutes. Encounters between one or more vessels classified under AIS ship and cargo type codes 31, 32, and 50-57 were removed from the inventory. Encounters between dredgers or dredgers and crew boats, and encounters between tenders and their mother ships were also removed from the inventory. Only position reports from within the federal channel are considered in the analysis of SDVs.

\subsubsection{Location and severity of encounters}

During calendar year 2014, there were 956 encounters in the federal channels of CRSC. The geometric center of the encroached vessel at the time of maximum severity during each encounter is shown in Figure 4-3. Clusters of points indicate locations where encounters are common. There is a cluster of encounters at the northern end of the CRSC, near the Citgo Lake Charles Refinery, in UPPRo5 (\#5) and UPPRo6 (\#6). Clusters of encounters are apparent between Moss Lake and the intersection of the CRSC with the Intracoastal Waterway, in UPPRo9 (\#9) and between Long Point Lake and Lake Calcasieu in LOWRo9 (\#19) and LOWR10 (\#20). The largest cluster of encounters is located between the East Fork of Calcasieu Pass and the entrance to the Gulf of Mexico at the mouth of the jetty (\#25-28). 
Figure 4-3. Encounters in CRSC.

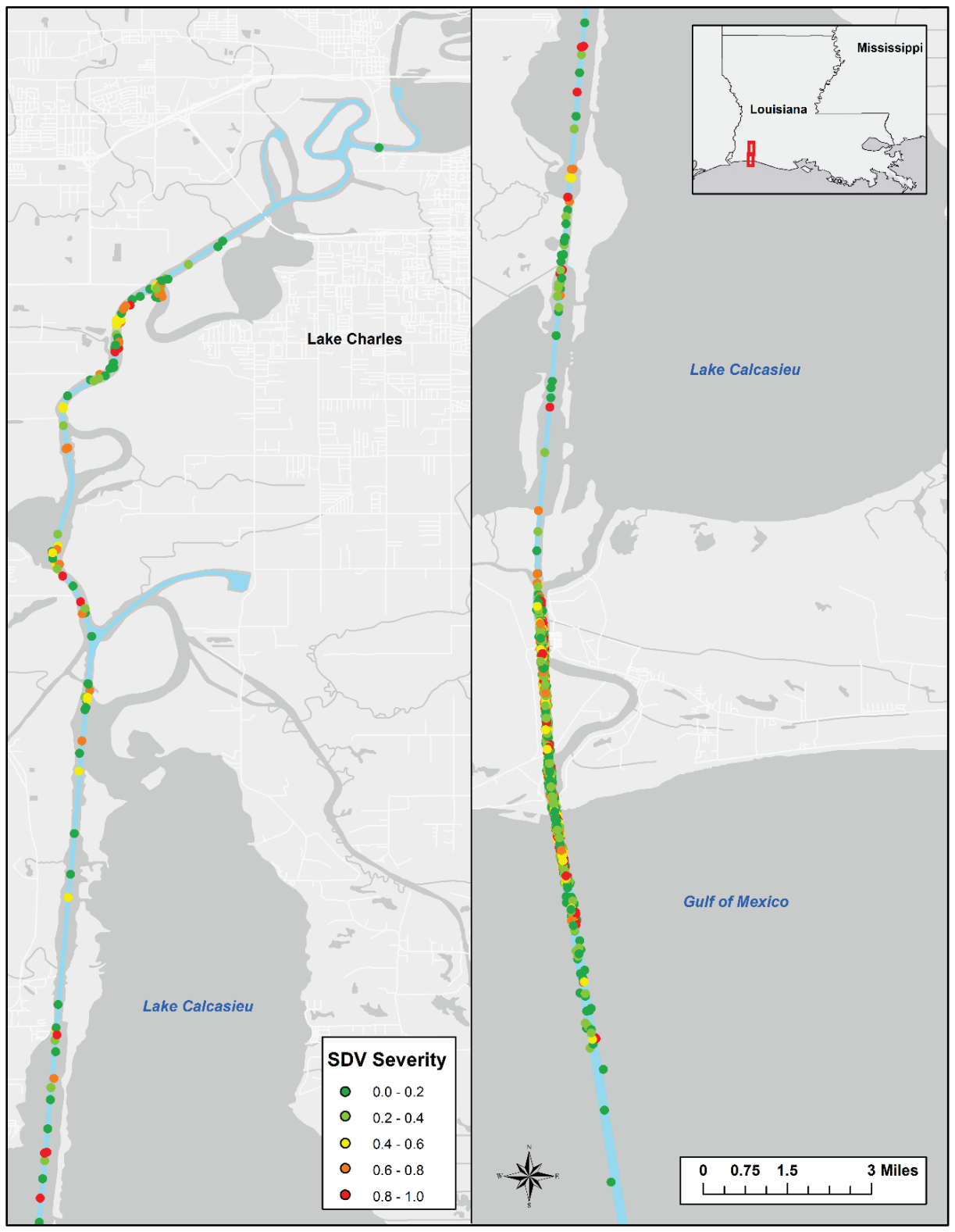

Empirical CDFs are used in Figure 4-4 to summarize selected characteristics of encounters in CRSC. These include maximum SDV severity during an encounter, minimum distance between vessel perimeters during an encounter, and duration of encounters. As shown in Figure 4-4(a), approximately 70\% of encounters have maximum severity scores less than 0.5 . Only $10 \%$ of encounters have maximum severity scores greater than approximately 0.8. The minimum distance between vessel perimeters is shown in Figure 4-4(b). Approximately 10\% of vessels are involved in encounters during which the minimum distance between the two vessels is $10 \mathrm{~m}$ or less, but $70 \%$ of encounters were characterized 
by minimum distances greater than $30 \mathrm{~m}$. No particular ship and cargo type code appeared to be associated with those encounters with the highest severity scores or the least distance between vessel perimeters.

The duration of encounters in CRSC is shown in Figure 4-4(c). Approximately $82 \%$ of the encounters lasted 2 minutes or less, and $90 \%$ of encounters lasted 5 minutes or less. This is consistent with the anticipated behavior of vessels that are attempting to avoid one another. There were 93 encounters lasting more than 5 minutes. With three exceptions, these occurred between the mouth of the jetty in the Gulf of Mexico and the East Fork of Calcasieu Pass. Most of these encounters involved vessels classified under ship and cargo type codes for passenger vessels (60-69), cargo vessels (70-79), tankers (80-89), and other (90-99). 
ERDC/EL TR-19-7

78

Figure 4-4. Characteristics of encounters in CRSC.
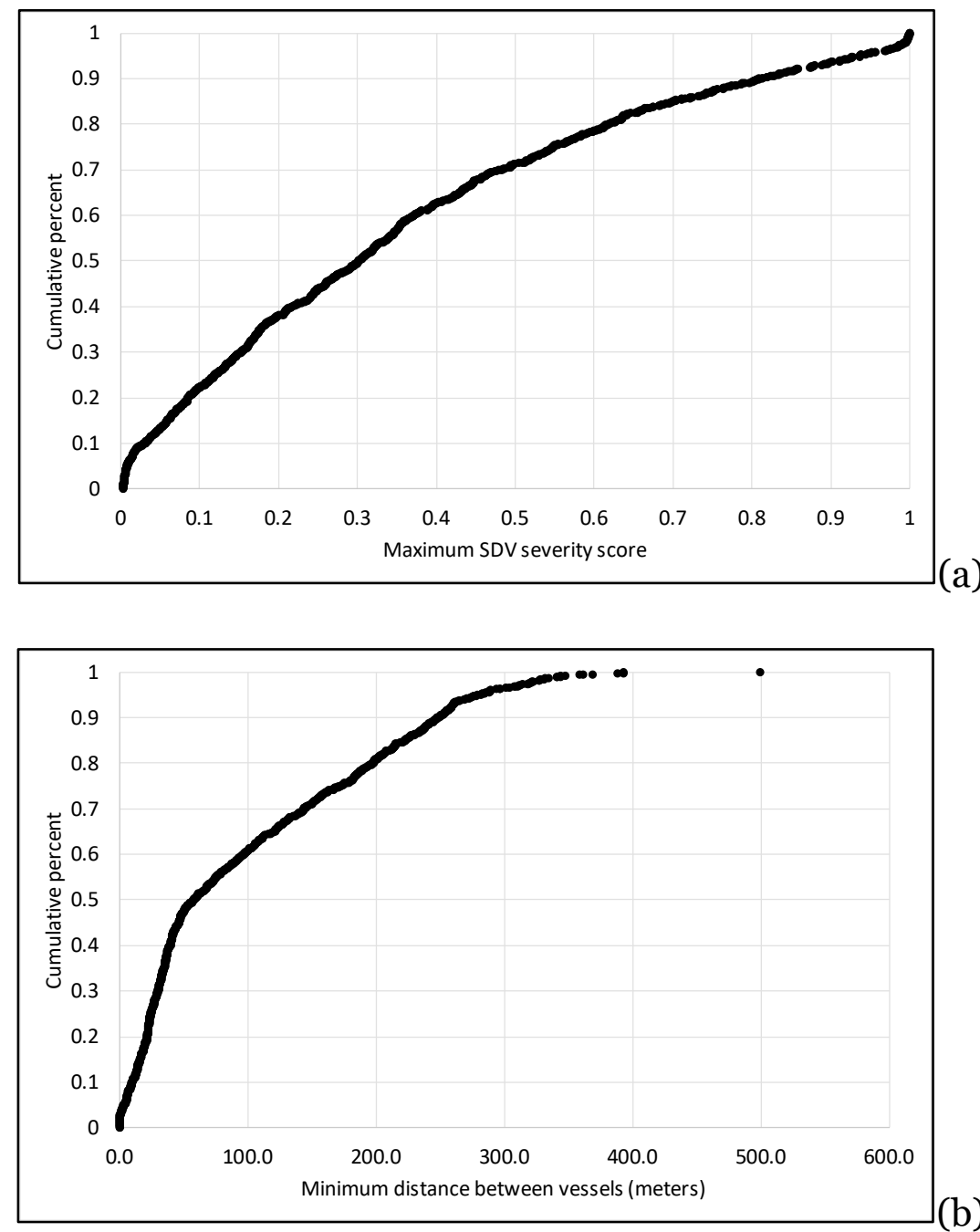

(b)

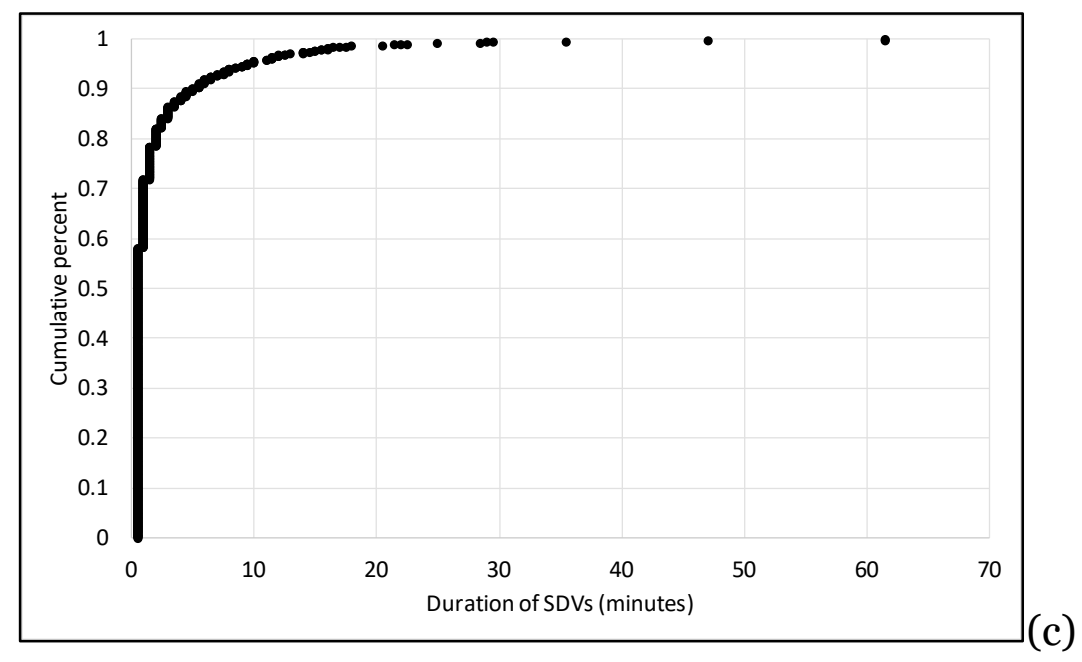




\subsubsection{Types of vessels involved in encounters}

The types of vessels involved in encounters are summarized in Table 4-3. Vessels classified under ship and cargo type codes for cargo vessels (70-79) and tankers (80-89) were classified as the encroached vessel in 292 and 358 instances, respectively. This accounts for $68 \%$ of all encroachments in CRSC. This is not unexpected because these vessels tend to have larger ship domains. Vessels classified under the ship and cargo type codes for passenger vessels (60-69) and cargo vessels (70-79) were classified as the encroaching vessel in 393 and 203 instances, respectively. Passenger vessel encroachments accounted for $45 \%$ of encroachments on cargo vessels (132/292) and 42\% of encroachments on tankers (150/358). Vessels classified under the cargo vessel ship and cargo type code, which includes a large fraction of the offshore supply vessels operating in CRSC, were found encroaching on other cargo vessels in 62 instances, accounting for 21\% of cargo vessel encroachments (62/292), and on tankers in 72 instances, accounting for $20 \%$ of tanker encroachments (72/358). Vessels classified under the ship and cargo type code for dredgers were classified as the encroached vessel in 68 encounters and as the encroaching vessel in 70 encounters. This excludes encounters involving two vessels that are both classified under the ship and cargo type code for dredgers.

\subsubsection{Frequency of SDVs}

During calendar year 2014, a total of 2,883,877 position reports were sampled from federal navigation channels in the CRSC. This number excludes vessels classified under ship and cargo type code 31-32 and 50-57. Of these, 3,186 position reports were classified as SDVs. Over all reaches and ship and cargo type codes, the conditional frequency of an SDV in CRSC is $1.1 \times 10^{-3}(3,186 / 2,883,877)$. This frequency is synonymous with the probability of an SDV given that at least one vessel is present in the reach. The conditional probability of an SDV by reach and vessel type is summarized in Table 4-4. Vessels with unknown ship and cargo type codes have the highest conditional probability of an SDV equal to $3.9 \times 10^{-3}$.

Vessels classified under the omnibus ship and cargo type code (90-99) have the second highest conditional probability of an SDV equal to $2.8 \times 10^{-3}$. Vessels classified as tankers (80-89) and cargo vessels (70-79) have the third and fourth highest conditional probability of an SDV equal to $1.8 \times$ $10^{-3}$ and $1.4 \times 10^{-3}$, respectively. 
Table 4-3. Number of encounters in CRSC by encroached and encroaching vessel type.

\begin{tabular}{|c|c|c|c|c|c|c|c|c|c|c|c|c|c|c|c|}
\hline \multirow{2}{*}{\multicolumn{2}{|c|}{$\begin{array}{l}\text { Encroached Vessel AIS } \\
\text { Ship and Cargo Type }\end{array}$}} & \multicolumn{13}{|c|}{ Encroaching Vessel AIS Ship and Cargo Type } & \multirow{2}{*}{$\begin{array}{c}\text { All } \\
\text { Vessel } \\
\text { Types }\end{array}$} \\
\hline & & \multirow{2}{*}{$\begin{array}{l}\text { Unknown } \\
\qquad \begin{array}{c}(00) \\
-\end{array}\end{array}$} & \multirow{2}{*}{$\begin{array}{c}\text { WIG } \\
\frac{(20-29)}{-}\end{array}$} & \multirow{2}{*}{$\begin{array}{c}\text { Fishing } \\
(30) \\
-\end{array}$} & \multirow{2}{*}{$\begin{array}{c}\text { Dredging } \\
\begin{array}{c}(33) \\
1\end{array}\end{array}$} & \multirow{2}{*}{$\begin{array}{l}\text { Diving } \\
\qquad \begin{array}{c}(34) \\
1\end{array}\end{array}$} & \multirow{2}{*}{$\begin{array}{l}\text { Sailing } \\
\qquad \begin{array}{c}(36) \\
-\end{array}\end{array}$} & \multirow{2}{*}{$\begin{array}{l}\text { Pleasure } \\
\qquad \begin{array}{c}(37) \\
3\end{array}\end{array}$} & \multirow{2}{*}{$\begin{array}{c}\text { High- } \\
\text { Speed } \\
(40-49) \\
-\end{array}$} & \multirow{2}{*}{$\begin{array}{c}\text { Harbor } \\
\text { Boats } \\
(50-57) \\
-\end{array}$} & \multirow{2}{*}{$\begin{array}{c}\begin{array}{c}\text { Passen- } \\
\text { ger } \\
(60-69)\end{array} \\
8\end{array}$} & \multirow{2}{*}{$\begin{array}{c}\text { Cargo } \\
\frac{(70-79)}{2}\end{array}$} & \multirow{2}{*}{$\begin{array}{c}\text { Tanker } \\
(80-89) \\
2\end{array}$} & \multirow{2}{*}{$\begin{array}{c}\text { Other } \\
(90-99) \\
4\end{array}$} & \\
\hline Unknown & $(00)$ & & & & & & & & & & & & & & 21 \\
\hline WIG & $(20-29)$ & - & - & - & - & - & - & - & - & - & - & - & - & - & - \\
\hline Fishing & (30) & - & - & - & - & - & - & - & - & - & - & - & - & - & - \\
\hline Dredging & (33) & - & - & 1 & $-\dagger$ & - & - & 5 & 2 & - & 19 & 13 & 17 & 11 & 68 \\
\hline Diving & (34) & - & - & - & - & - & 1 & - & - & - & 5 & 3 & - & 2 & 11 \\
\hline Sailing & (36) & - & - & - & - & - & - & - & - & - & - & 1 & - & - & 1 \\
\hline Pleasure & (37) & 1 & - & - & 1 & - & - & 4 & - & - & 3 & - & - & - & 9 \\
\hline High-Speed & $(40-49)$ & - & - & - & - & - & - & - & - & - & - & - & - & - & - \\
\hline Harbor Boats & $(50-57)$ & - & - & - & - & - & - & - & - & - & - & - & - & - & - \\
\hline Passenger & $(60-69)$ & 1 & - & - & 4 & 2 & - & 5 & 1 & - & 16 & 29 & 4 & 15 & 77 \\
\hline Cargo & (70-79) & 3 & - & 2 & 15 & 2 & 1 & 3 & 7 & - & 132 & 62 & 15 & 50 & 292 \\
\hline Tanker & $(80-89)$ & 4 & - & 2 & 44 & 3 & - & 8 & 6 & - & 150 & 72 & 23 & 46 & 358 \\
\hline Other & $(90-99)$ & 2 & - & - & 5 & 1 & - & - & 1 & - & 60 & 21 & 11 & 18 & 119 \\
\hline To & & 11 & - & 5 & 70 & 9 & 2 & 28 & 17 & - & 393 & 203 & 72 & 146 & 956 \\
\hline
\end{tabular}


Table 4-4. Conditional frequency of SDVs in CRSC by reach and vessel type. Frequencies greater than $1 \times 10^{-2}$ are in bold red typeface.

\begin{tabular}{|c|c|c|c|c|c|c|c|c|c|c|c|}
\hline \multirow[b]{2}{*}{$\#$} & \multirow[b]{2}{*}{ Reach Code } & \multicolumn{9}{|c|}{ AIS Ship and Cargo Type } & \multirow[b]{2}{*}{$\begin{array}{c}\text { All Vesse } \\
\text { Types }\end{array}$} \\
\hline & & $\begin{array}{l}\text { Unknown } \\
(00)\end{array}$ & $\begin{array}{c}\text { WIG } \\
(20-29)\end{array}$ & $\begin{array}{c}\text { Class } 3 \\
(30,33-39)\end{array}$ & $\begin{array}{c}\text { High-Speed } \\
\text { (40-49) }\end{array}$ & $\begin{array}{c}\text { Harbor } \\
\text { Boats } \\
(50-57)\end{array}$ & $\begin{array}{c}\text { Passenger } \\
(60-69)\end{array}$ & $\begin{array}{c}\text { Cargo } \\
\text { (70-79) }\end{array}$ & $\begin{array}{l}\text { Tanker } \\
(80-89)\end{array}$ & $\begin{array}{l}\text { Other } \\
(90-99)\end{array}$ & \\
\hline 1 & CEMVN_CR_01_UPR_01 & $0.00 \mathrm{E}+00$ & - & - & $0.00 \mathrm{E}+00$ & $0.00 E+00$ & - & - & $0.00 E+00$ & - & $0.00 \mathrm{E}+00$ \\
\hline 2 & CEMVN_CR_02_UPR_02 & $0.00 E+00$ & - & - & $0.00 \mathrm{E}+00$ & 2.03E-04 & $0.00 E+00$ & $0.00 E+00$ & $0.00 \mathrm{E}+00$ & - & 8.66E-05 \\
\hline 3 & CEMVN_CR_03_UPR_03 & $0.00 E+00$ & - & - & $0.00 \mathrm{E}+00$ & $0.00 E+00$ & $0.00 E+00$ & $0.00 \mathrm{E}+00$ & $0.00 E+00$ & - & $0.00 \mathrm{E}+00$ \\
\hline 4 & CEMVN_CR_04_UPR_04 & 4.03E-05 & - & - & $0.00 E+00$ & $0.00 E+00$ & 3.62E-04 & $0.00 E+00$ & 4.03E-05 & - & 9.83E-05 \\
\hline 5 & CEMVN_CR_05_UPR_05 & $2.12 \mathrm{E}-04$ & - & - & $0.00 \mathrm{E}+00$ & 1.50E-03 & 2.00E-03 & $0.00 \mathrm{E}+00$ & $2.12 \mathrm{E}-04$ & - & 1.07E-03 \\
\hline 6 & CEMVN_CR_06_UPR_06 & $1.51 \mathrm{E}-04$ & - & - & - & $6.68 \mathrm{E}-04$ & $5.74 \mathrm{E}-04$ & $0.00 E+00$ & $1.51 \mathrm{E}-04$ & - & 3.55E-04 \\
\hline 7 & CEMVN_CR_07_UPR_07 & $2.44 \mathrm{E}-03$ & - & - & - & $5.25 \mathrm{E}-04$ & 1.10E-04 & $1.18 \mathrm{E}-03$ & $2.44 \mathrm{E}-03$ & - & $2.66 \mathrm{E}-04$ \\
\hline 8 & CEMVN_CR_08_UPR_08 & 5.92E-04 & - & - & - & $0.00 E+00$ & 1.30E-04 & $0.00 E+00$ & 5.92E-04 & - & 1.96E-04 \\
\hline 9 & CEMVN_CR_09_UPR_09 & 3.09E-04 & - & - & $0.00 \mathrm{E}+00$ & $5.44 \mathrm{E}-04$ & 2.86E-04 & $0.00 E+00$ & 3.09E-04 & - & 3.14E-04 \\
\hline 10 & CEMVN_CR_10_UPR_10 & 3.18E-04 & - & - & $0.00 E+00$ & 3.88E-04 & $0.00 \mathrm{E}+00$ & $0.00 E+00$ & 3.18E-04 & - & 1.74E-04 \\
\hline 11 & CEMVN_CR_11_LWR_01 & $1.08 \mathrm{E}-04$ & - & - & $0.00 \mathrm{E}+00$ & 1.29E-04 & 3.53E-04 & 4.02E-03 & $1.08 \mathrm{E}-04$ & - & 3.33E-04 \\
\hline 12 & CEMVN_CR_12_LWR_02 & $0.00 \mathrm{E}+00$ & - & - & $0.00 \mathrm{E}+00$ & 1.43E-04 & $0.00 \mathrm{E}+00$ & $0.00 \mathrm{E}+00$ & $0.00 \mathrm{E}+00$ & - & 3.35E-05 \\
\hline 13 & CEMVN_CR_13_LWR_03 & $0.00 E+00$ & - & - & $0.00 \mathrm{E}+00$ & $0.00 \mathrm{E}+00$ & $2.24 \mathrm{E}-04$ & $0.00 \mathrm{E}+00$ & $0.00 \mathrm{E}+00$ & - & $1.53 \mathrm{E}-04$ \\
\hline 14 & CEMVN_CR_14_LWR_04 & $0.00 \mathrm{E}+00$ & - & - & $0.00 E+00$ & $0.00 \mathrm{E}+00$ & $0.00 \mathrm{E}+00$ & $0.00 \mathrm{E}+00$ & $0.00 \mathrm{E}+00$ & - & $0.00 E+00$ \\
\hline 15 & CEMVN_CR_15_LWR_05 & $0.00 \mathrm{E}+00$ & - & - & $0.00 \mathrm{E}+00$ & 1.17E-04 & 2.33E-04 & $0.00 E+00$ & $0.00 E+00$ & - & $1.89 \mathrm{E}-04$ \\
\hline 16 & CEMVN_CR_16_LWR_06 & $1.96 \mathrm{E}-05$ & - & - & $0.00 \mathrm{E}+00$ & $2.88 \mathrm{E}-04$ & 1.95E-04 & $0.00 \mathrm{E}+00$ & 1.96E-05 & - & 8.74E-05 \\
\hline 17 & CEMVN_CR_17_LWR_07 & 5.67E-05 & - & - & $0.00 \mathrm{E}+00$ & $0.00 E+00$ & $3.51 \mathrm{E}-04$ & $0.00 E+00$ & 5.67E-05 & - & 1.74E-04 \\
\hline 18 & CEMVN_CR_18_LWR_08 & $0.00 \mathrm{E}+00$ & - & - & $1.32 \mathrm{E}-02$ & 7.86E-04 & $1.06 \mathrm{E}-04$ & $0.00 E+00$ & $0.00 \mathrm{E}+00$ & - & 3.26E-04 \\
\hline 19 & CEMVN_CR_19_LWR_09 & $2.81 \mathrm{E}-05$ & - & - & $0.00 \mathrm{E}+00$ & 3.03E-04 & 5.10E-04 & 8.34E-04 & 2.81E-05 & - & 2.99E-04 \\
\hline 20 & CEMVN_CR_20_LWR_10 & 1.05E-04 & - & - & $0.00 \mathrm{E}+00$ & $0.00 E+00$ & 7.97E-04 & $0.00 E+00$ & 1.05E-04 & - & 2.29E-04 \\
\hline 21 & CEMVN_CR_21_LWR_11 & $0.00 \mathrm{E}+00$ & - & - & $0.00 E+00$ & $0.00 E+00$ & $2.14 \mathrm{E}-04$ & $0.00 E+00$ & $0.00 \mathrm{E}+00$ & - & 2.18E-04 \\
\hline 22 & CEMVN_CR_22_LWR_12 & $0.00 E+00$ & - & - & $0.00 E+00$ & $0.00 \mathrm{E}+00$ & $1.12 \mathrm{E}-04$ & $0.00 \mathrm{E}+00$ & $0.00 \mathrm{E}+00$ & - & $1.87 \mathrm{E}-04$ \\
\hline 23 & CEMVN_CR_23_LWR_13 & $0.00 E+00$ & - & - & $0.00 E+00$ & 1.65E-04 & $1.80 \mathrm{E}-04$ & $0.00 E+00$ & $0.00 E+00$ & - & $1.57 \mathrm{E}-04$ \\
\hline 24 & CEMVN_CR_24_LWR_14 & 2.73E-04 & $0.00 E+00$ & - & $0.00 E+00$ & 1.25E-03 & 3.94E-03 & 1.16E-03 & 2.73E-04 & $0.00 \mathrm{E}+00$ & $1.54 \mathrm{E}-03$ \\
\hline 25 & CEMVN_CR_25_GAP_01 & 1.33E-04 & $0.00 \mathrm{E}+00$ & - & 3.92E-04 & $3.24 \mathrm{E}-03$ & $1.41 \mathrm{E}-02$ & $5.53 \mathrm{E}-03$ & 1.33E-04 & $0.00 \mathrm{E}+00$ & $2.85 \mathrm{E}-03$ \\
\hline 26 & CEMVN_CR_26_GAP_02 & 3.84E-04 & $0.00 \mathrm{E}+00$ & - & 2.07E-04 & $2.58 \mathrm{E}-03$ & 1.27E-02 & 3.38E-03 & $3.84 \mathrm{E}-04$ & $0.00 \mathrm{E}+00$ & $2.72 \mathrm{E}-03$ \\
\hline 27 & CEMVN_CR_27_GAP_03 & 1.67E-03 & $0.00 E+00$ & - & $6.38 \mathrm{E}-04$ & 2.31E-03 & 1.47E-02 & 3.15E-03 & 1.67E-03 & $0.00 E+00$ & 2.67E-03 \\
\hline
\end{tabular}




\begin{tabular}{|c|c|c|c|c|c|c|c|c|c|c|c|}
\hline \multirow[b]{2}{*}{ \# } & \multirow[b]{2}{*}{ Reach Code } & \multicolumn{9}{|c|}{ AlS Ship and Cargo Type } & \multirow[b]{2}{*}{$\begin{array}{c}\text { All Vesse } \\
\text { Types }\end{array}$} \\
\hline & & $\begin{array}{c}\text { Unknown } \\
\text { (00) }\end{array}$ & $\begin{array}{c}\text { WIG } \\
(20-29)\end{array}$ & $\begin{array}{c}\text { Class } 3 \\
(30,33-39)\end{array}$ & $\begin{array}{c}\text { High-Speed } \\
(40-49)\end{array}$ & $\begin{array}{c}\text { Harbor } \\
\text { Boats } \\
(50-57)\end{array}$ & $\begin{array}{c}\text { Passenger } \\
(60-69)\end{array}$ & $\begin{array}{l}\text { Cargo } \\
\text { (70-79) }\end{array}$ & $\begin{array}{l}\text { Tanker } \\
(80-89)\end{array}$ & $\begin{array}{l}\text { Other } \\
(90-99)\end{array}$ & \\
\hline 28 & CEMVN_CR_28_BAR_01 & $3.99 \mathrm{E}-04$ & $0.00 E+00$ & - & $8.55 \mathrm{E}-04$ & $1.55 \mathrm{E}-03$ & $4.88 \mathrm{E}-03$ & $3.32 \mathrm{E}-03$ & $3.99 \mathrm{E}-04$ & $0.00 E+00$ & $1.58 \mathrm{E}-03$ \\
\hline 29 & CEMVN_CR_29_BAR_02 & $6.41 E-05$ & $0.00 \mathrm{E}+00$ & - & 3.04E-04 & $4.59 \mathrm{E}-04$ & $1.45 \mathrm{E}-03$ & $1.71 \mathrm{E}-03$ & $6.41 E-05$ & $0.00 E+00$ & $4.49 \mathrm{E}-04$ \\
\hline 30 & CEMVN_CR_30_BAR_03 & $4.55 \mathrm{E}-05$ & $0.00 E+00$ & - & $0.00 E+00$ & $1.81 \mathrm{E}-04$ & $1.02 \mathrm{E}-03$ & $3.26 \mathrm{E}-03$ & 4.55E-05 & $0.00 E+00$ & 3.43E-04 \\
\hline 31 & CEMVN_CR_31_BAR_04 & $0.00 E+00$ & $0.00 \mathrm{E}+00$ & - & $0.00 E+00$ & $0.00 E+00$ & $6.48 \mathrm{E}-05$ & $0.00 E+00$ & $0.00 E+00$ & $0.00 E+00$ & $1.03 E-05$ \\
\hline 32 & CEMVN_CR_32_BAR_05 & $2.65 \mathrm{E}-05$ & $0.00 E+00$ & - & $0.00 E+00$ & $0.00 E+00$ & $0.00 E+00$ & $0.00 E+00$ & $2.65 \mathrm{E}-05$ & $0.00 E+00$ & $1.34 \mathrm{E}-05$ \\
\hline 33 & CEMVN_CR_33_BAR_06 & $0.00 E+00$ & $0.00 \mathrm{E}+00$ & - & $0.00 E+00$ & $0.00 E+00$ & $0.00 E+00$ & $0.00 E+00$ & $0.00 E+00$ & $0.00 E+00$ & $0.00 E+00$ \\
\hline 34 & CEMVN_CR_34_BAR_07 & $0.00 E+00$ & $0.00 E+00$ & - & $0.00 E+00$ & $0.00 E+00$ & $0.00 E+00$ & $0.00 E+00$ & $0.00 E+00$ & $0.00 E+00$ & $0.00 E+00$ \\
\hline 35 & CEMVN_CR_35_BAR_08 & $0.00 E+00$ & $0.00 \mathrm{E}+00$ & - & $0.00 E+00$ & $0.00 E+00$ & $8.91 \mathrm{E}-05$ & $0.00 E+00$ & $0.00 \mathrm{E}+00$ & $0.00 \mathrm{E}+00$ & $1.24 \mathrm{E}-04$ \\
\hline 36 & CEMVN_CR_36_BAR_09 & $0.00 E+00$ & $0.00 E+00$ & - & $0.00 E+00$ & $0.00 E+00$ & $0.00 E+00$ & $0.00 E+00$ & $0.00 E+00$ & $0.00 E+00$ & $0.00 E+00$ \\
\hline 37 & CEMVN_CR_37_BAR_10 & $0.00 E+00$ & $0.00 E+00$ & - & $0.00 E+00$ & $0.00 E+00$ & $0.00 E+00$ & $0.00 \mathrm{E}+00$ & $0.00 \mathrm{E}+00$ & $0.00 E+00$ & $0.00 E+00$ \\
\hline 50 & CEMVN_CR_50_DE1_01 & $0.00 E+00$ & - & - & $0.00 E+00$ & $0.00 E+00$ & $0.00 E+00$ & $0.00 E+00$ & $0.00 E+00$ & - & $0.00 E+00$ \\
\hline 51 & CEMVN_CR_51_DE2_02 & $0.00 E+00$ & - & - & $0.00 E+00$ & $0.00 E+00$ & - & $0.00 \mathrm{E}+00$ & $0.00 E+00$ & - & $0.00 E+00$ \\
\hline 52 & CEMVN_CR_52_CLI_01 & - & - & - & - & - & - & - & - & - & $0.00 E+00$ \\
\hline 53 & CEMVN_CR_53_CNI_01 & - & - & - & - & - & - & - & - & - & $0.00 E+00$ \\
\hline & All Federal Channels & $3.89 \mathrm{E}-03$ & - & $1.74 \mathrm{E}-04$ & $0.00 \mathrm{E}+00$ & - & 4.15E-04 & $1.41 \mathrm{E}-03$ & $1.80 \mathrm{E}-03$ & $2.80 \mathrm{E}-03$ & $1.10 \mathrm{E}-03$ \\
\hline
\end{tabular}


Conditional probabilities of SDVs are unusually high at several locations in CRSC. Just north of the jetty, near Calcasieu Pass, the conditional probability of an SDV for tankers (80-89) ranges from 0.013 to 0.015 (GAPo1-GAPo3, \#25-27). The conditional probability of an SDV is also greater than 0.01 for vessels classified under the ship and cargo type code for passenger vessels (60-69) in reach LOWRo8 (\#18), where two of 151 position reports transmitted by passenger vessels were classified as SDVs. There are an additional 13 reaches in this section of the CRSC, but no position reports from passenger vessel were classified as SDVs in those reaches (LOWRo1 - LOWR07, \#11-17, and LOWRo9-LOWR14, \#18-24). In terms of absolute number, most encroachments of passenger vessel ship domains occur in Calcasieu Pass (GAPo1-GAPo3, \#25-27), but there are many more AIS position reports from passenger vessels in these reaches.

The conditional probability of an SDV can be used to evaluate, compare, and rank navigation channels in terms of collision risk. For example, as shown in Figure 4-5, displays the location of reaches with the highest frequency of SDVs over all vessel types. The highest conditional probabilities are near Calcasieu Pass, in GAPo1-GAPo3 (\#25-27). The two reaches flanking these three reaches, LOWR14 (\#24), which is upstream at the East Fork of Calcasieu Pass, and BARo1 (\#28), which is downstream at the entrance to the jetty in the Gulf of Mexico, also have elevated SDV frequencies.

Whereas the conditional probability of an SDV indicates where a vessel's ship domain is most likely to be encroached, the unconditional probability of an SDV indicates in which reach SDVs are most likely to occur. The unconditional probability is obtained by multiplying the conditional probability of an SDV by the probability that at least one vessel is present in a reach. The latter is calculated as the fraction of half-minute time intervals during which at least one position report was sampled from the reach, which is reported in Table 4-5. The unconditional probability of an SDV is reported in Table 4-6 and mapped in Figure 4-6. Results are similar to those obtained for the conditional probability of an SDV. They show that SDVs are most likely to occur near Calcasieu Pass, GAPo1GAPo3 (\#25-27), in the upstream reach at the East Fork of Calcasieu Pass, LWR14 (\#24), and in the downstream reach at the entrance to the jetty in the Gulf of Mexico, BARo1 (\#28). 
Figure 4-5. Conditional frequency of SDVs in CRSC.

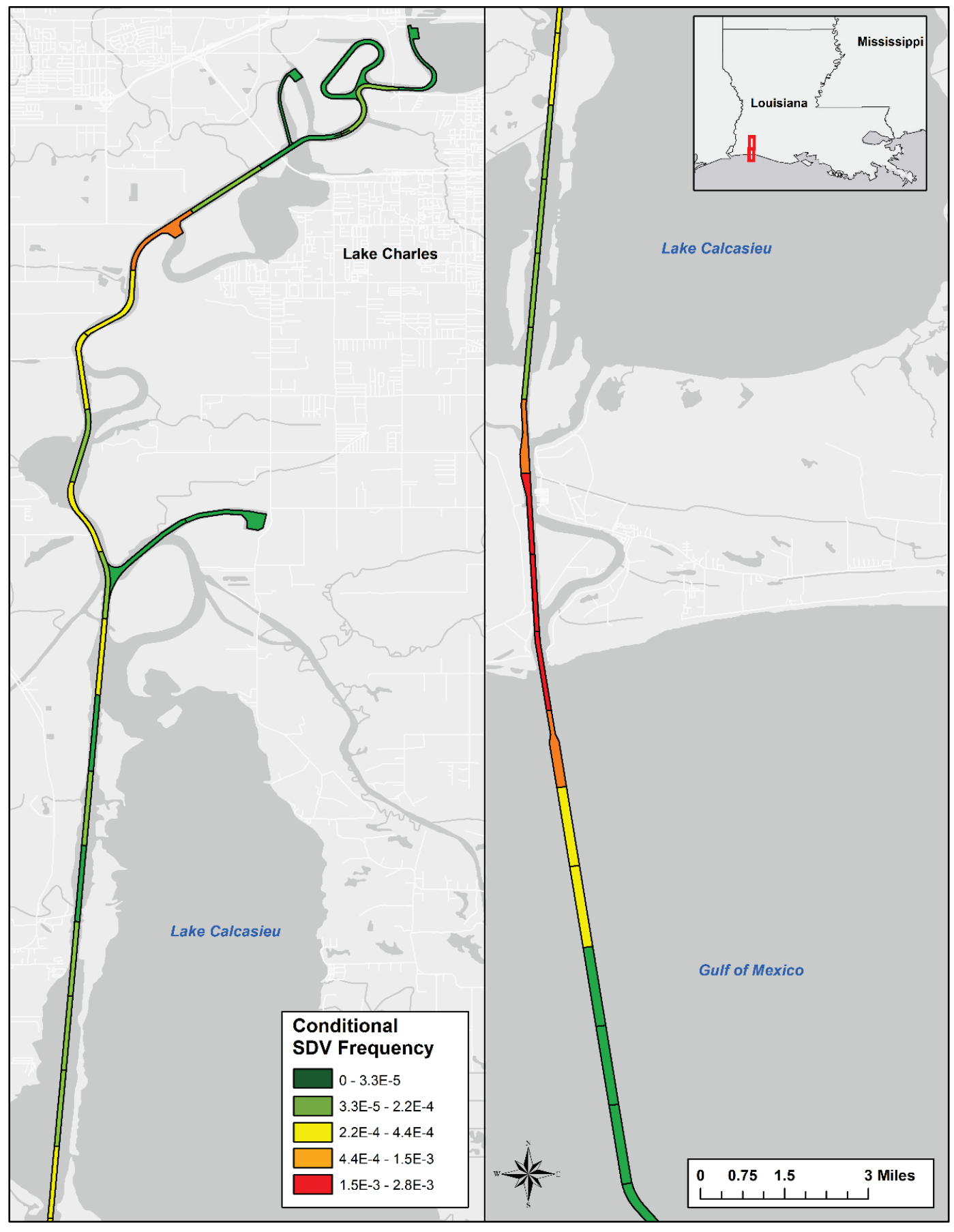


Figure 4-6. Unconditional frequency of SDVs in CRSC.

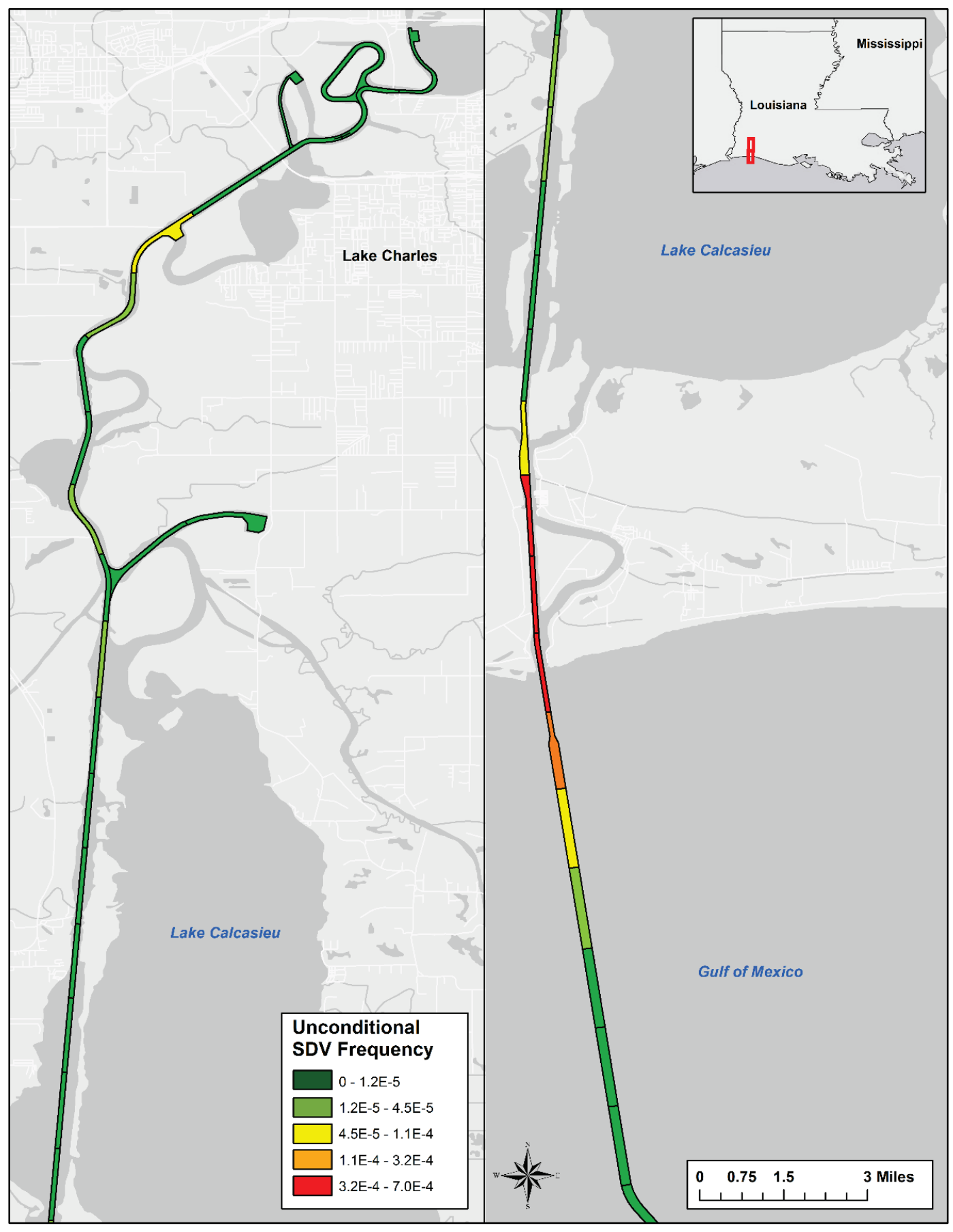


Table 4-5. Fraction of half-minute intervals during which at least one vessel is present in each CRSC reach.

\begin{tabular}{|c|c|c|c|c|c|c|c|c|c|c|c|}
\hline \multirow[b]{2}{*}{ \# } & \multirow[b]{2}{*}{ Reach Code } & \multicolumn{9}{|c|}{ AIS Ship and Cargo Type } & \multirow[b]{2}{*}{$\begin{array}{c}\text { All Vesse } \\
\text { Types }\end{array}$} \\
\hline & & $\begin{array}{c}\text { Unknown } \\
(00)\end{array}$ & $\begin{array}{c}\text { WIG } \\
(20-29)\end{array}$ & $\begin{array}{c}\text { Class } 3 \\
(30,33-39)\end{array}$ & $\begin{array}{c}\text { High-Speed } \\
(40-49)\end{array}$ & $\begin{array}{c}\text { Harbor Boats } \\
(50-57)\end{array}$ & $\begin{array}{c}\text { Passenger } \\
(60-69)\end{array}$ & $\begin{array}{l}\text { Cargo } \\
(70-79)\end{array}$ & $\begin{array}{l}\text { Tanker } \\
(80-89)\end{array}$ & $\begin{array}{l}\text { Other } \\
(90-99)\end{array}$ & \\
\hline 1 & CEMVN_CR_01_UPR_01 & $8.28 \mathrm{E}-04$ & $0.00 E+00$ & 1.75E-04 & $0.00 E+00$ & - & $1.62 \mathrm{E}-05$ & $3.28 \mathrm{E}-03$ & $0.00 E+00$ & $0.00 E+00$ & 4.30E-03 \\
\hline 2 & CEMVN_CR_02_UPR_02 & 8.14E-04 & $0.00 E+00$ & 9.67E-04 & $0.00 E+00$ & - & $1.62 \mathrm{E}-05$ & 4.70E-03 & 4.43E-03 & 5.42E-05 & 1.10E-02 \\
\hline 3 & CEMVN_CR_03_UPR_03 & 5.80E-04 & $0.00 E+00$ & 1.01E-03 & $0.00 E+00$ & - & $1.81 \mathrm{E}-05$ & 3.18E-03 & $6.37 \mathrm{E}-03$ & $1.25 \mathrm{E}-04$ & 1.13E-02 \\
\hline 4 & CEMVN_CR_04_UPR_04 & 6.16E-04 & $0.00 E+00$ & 2.36E-02 & $0.00 E+00$ & - & $8.56 \mathrm{E}-06$ & $6.41 \mathrm{E}-03$ & 7.85E-03 & 1.36E-04 & 3.85E-02 \\
\hline 5 & CEMVN_CR_05_UPR_05 & 1.26E-03 & $0.00 E+00$ & 4.04E-02 & $0.00 E+00$ & - & 3.81E-06 & 1.14E-02 & $3.48 \mathrm{E}-02$ & 1.71E-03 & $8.82 \mathrm{E}-02$ \\
\hline 6 & CEMVN_CR_06_UPR_06 & 1.00E-03 & $0.00 E+00$ & 4.40E-02 & $0.00 E+00$ & - & $0.00 E+00$ & $9.92 \mathrm{E}-03$ & 2.96E-02 & 7.15E-04 & 8.45E-02 \\
\hline 7 & CEMVN_CR_07_UPR_07 & $9.81 \mathrm{E}-04$ & $0.00 E+00$ & $1.11 \mathrm{E}-03$ & $0.00 E+00$ & - & $0.00 E+00$ & $9.05 E-03$ & $3.42 \mathrm{E}-02$ & 8.03E-04 & 4.59E-02 \\
\hline 8 & CEMVN_CR_08_UPR_08 & 9.11E-04 & $0.00 E+00$ & 7.99E-03 & $0.00 E+00$ & - & $0.00 E+00$ & $6.61 \mathrm{E}-03$ & 2.18E-02 & 1.37E-03 & 3.85E-02 \\
\hline 9 & CEMVN_CR_09_UPR_09 & $1.02 \mathrm{E}-03$ & $0.00 E+00$ & 4.30E-02 & $0.00 E+00$ & - & 2.95E-05 & 6.99E-03 & 2.32E-02 & 1.45E-03 & 7.53E-02 \\
\hline 10 & CEMVN_CR_10_UPR_10 & $6.48 \mathrm{E}-04$ & $0.00 E+00$ & 1.19E-02 & $0.00 E+00$ & - & 1.16E-04 & 7.32E-03 & $2.21 \mathrm{E}-02$ & $1.57 \mathrm{E}-03$ & 4.35E-02 \\
\hline 11 & CEMVN_CR_11_LWR_01 & 4.60E-04 & $0.00 E+00$ & 1.76E-02 & $0.00 E+00$ & - & $1.78 \mathrm{E}-04$ & 7.37E-03 & $2.15 \mathrm{E}-02$ & $1.42 \mathrm{E}-03$ & $4.82 \mathrm{E}-02$ \\
\hline 12 & CEMVN_CR_12_LWR_02 & 4.20E-04 & $0.00 E+00$ & $6.19 \mathrm{E}-04$ & $0.00 \mathrm{E}+00$ & - & $1.73 \mathrm{E}-04$ & $6.65 \mathrm{E}-03$ & $1.91 \mathrm{E}-02$ & $1.32 \mathrm{E}-03$ & 2.83E-02 \\
\hline 13 & CEMVN_CR_13_LWR_03 & 4.59E-04 & $0.00 E+00$ & 6.37E-04 & $0.00 E+00$ & - & 2.14E-04 & 7.16E-03 & $2.12 \mathrm{E}-02$ & 1.33E-03 & 3.08E-02 \\
\hline 14 & CEMVN_CR_14_LWR_04 & 4.59E-04 & $0.00 E+00$ & 6.50E-04 & $0.00 E+00$ & - & 2.08E-04 & 8.07E-03 & 2.42E-02 & 1.39E-03 & 3.49E-02 \\
\hline 15 & CEMVN_CR_15_LWR_05 & $4.51 \mathrm{E}-04$ & $0.00 E+00$ & $6.79 \mathrm{E}-04$ & $0.00 \mathrm{E}+00$ & - & 2.01E-04 & 8.14E-03 & $2.44 \mathrm{E}-02$ & $1.26 \mathrm{E}-03$ & $3.50 \mathrm{E}-02$ \\
\hline 16 & CEMVN_CR_16_LWR_06 & $3.48 \mathrm{E}-04$ & $0.00 \mathrm{E}+00$ & 4.84E-02 & $0.00 E+00$ & - & 1.49E-04 & 6.57E-03 & 1.95E-02 & 1.13E-03 & 7.57E-02 \\
\hline 17 & CEMVN_CR_17_LWR_07 & 3.30E-04 & $0.00 E+00$ & $1.68 \mathrm{E}-02$ & $0.00 \mathrm{E}+00$ & - & $1.46 \mathrm{E}-04$ & $6.42 \mathrm{E}-03$ & $1.89 \mathrm{E}-02$ & $1.16 \mathrm{E}-03$ & 4.36E-02 \\
\hline 18 & CEMVN_CR_18_LWR_08 & 3.19E-04 & $0.00 \mathrm{E}+00$ & $7.85 \mathrm{E}-04$ & $0.00 E+00$ & - & $1.44 \mathrm{E}-04$ & $6.04 \mathrm{E}-03$ & $1.78 \mathrm{E}-02$ & $1.10 \mathrm{E}-03$ & $2.62 \mathrm{E}-02$ \\
\hline 19 & CEMVN_CR_19_LWR_09 & 3.39E-04 & $0.00 E+00$ & 3.38E-02 & $0.00 E+00$ & - & $1.62 \mathrm{E}-04$ & $6.27 \mathrm{E}-03$ & 1.86E-02 & 1.14E-03 & 6.00E-02 \\
\hline 20 & CEMVN_CR_20_LWR_10 & 3.46E-04 & $0.00 E+00$ & $7.22 \mathrm{E}-02$ & $0.00 E+00$ & - & $2.12 \mathrm{E}-04$ & $6.48 \mathrm{E}-03$ & 1.91E-02 & $1.22 \mathrm{E}-03$ & $9.89 \mathrm{E}-02$ \\
\hline 21 & CEMVN_CR_21_LWR_11 & $3.24 \mathrm{E}-04$ & $0.00 E+00$ & $7.02 \mathrm{E}-04$ & $0.00 \mathrm{E}+00$ & - & $2.55 \mathrm{E}-04$ & $6.13 \mathrm{E}-03$ & 1.77E-02 & $1.02 \mathrm{E}-03$ & $2.61 \mathrm{E}-02$ \\
\hline 22 & CEMVN_CR_22_LWR_12 & 3.03E-04 & $0.00 \mathrm{E}+00$ & 7.15E-04 & $0.00 \mathrm{E}+00$ & - & $3.42 \mathrm{E}-04$ & $5.94 \mathrm{E}-03$ & 1.70E-02 & $1.02 \mathrm{E}-03$ & 2.53E-02 \\
\hline 23 & CEMVN_CR_23_LWR_13 & 2.86E-04 & $0.00 E+00$ & 7.61E-04 & $0.00 E+00$ & - & $5.18 \mathrm{E}-04$ & 5.76E-03 & $1.58 \mathrm{E}-02$ & 1.02E-03 & 2.40E-02 \\
\hline
\end{tabular}




\begin{tabular}{|c|c|c|c|c|c|c|c|c|c|c|c|}
\hline \multirow[b]{2}{*}{$\#$} & \multirow[b]{2}{*}{ Reach Code } & \multicolumn{9}{|c|}{ AIS Ship and Cargo Type } & \multirow{2}{*}{$\begin{array}{c}\text { All Vessel } \\
\text { Types }\end{array}$} \\
\hline & & $\begin{array}{c}\text { Unknown } \\
(00)\end{array}$ & $\begin{array}{c}\text { WIG } \\
(20-29)\end{array}$ & $\begin{array}{c}\text { Class } 3 \\
(30,33-39)\end{array}$ & $\begin{array}{l}\text { High-Speed } \\
\text { (40-49) }\end{array}$ & $\begin{array}{c}\text { Harbor Boats } \\
\qquad(50-57)\end{array}$ & $\begin{array}{c}\text { Passenger } \\
(60-69)\end{array}$ & $\begin{array}{l}\text { Cargo } \\
(70-79)\end{array}$ & $\begin{array}{l}\text { Tanker } \\
(80-89)\end{array}$ & $\begin{array}{c}\text { Other } \\
\text { (90-99) }\end{array}$ & \\
\hline 24 & CEMVN_CR_24_LWR_14 & 4.69E-04 & $0.00 \mathrm{E}+00$ & 3.45E-03 & $5.88 \mathrm{E}-04$ & - & $2.19 \mathrm{E}-02$ & $2.77 \mathrm{E}-02$ & $1.73 \mathrm{E}-02$ & $5.73 \mathrm{E}-03$ & $7.53 \mathrm{E}-02$ \\
\hline 25 & CEMVN_CR_25_GAP_01 & 1.11E-03 & $0.00 \mathrm{E}+00$ & 6.37E-02 & 4.67E-03 & - & 7.05E-02 & 8.41E-02 & 2.16E-02 & $2.76 \mathrm{E}-02$ & 2.48E-01 \\
\hline 26 & CEMVN_CR_26_GAP_02 & 9.54E-04 & $0.00 \mathrm{E}+00$ & $1.23 \mathrm{E}-02$ & 4.69E-03 & - & 6.69E-02 & 8.00E-02 & $2.02 \mathrm{E}-02$ & 2.68E-02 & $1.98 \mathrm{E}-01$ \\
\hline 27 & CEMVN_CR_27_GAP_03 & $1.35 \mathrm{E}-03$ & $0.00 \mathrm{E}+00$ & $2.52 \mathrm{E}-02$ & $5.25 \mathrm{E}-03$ & - & $8.82 \mathrm{E}-02$ & 9.37E-02 & $1.84 \mathrm{E}-02$ & 3.36E-02 & 2.43E-01 \\
\hline 28 & CEMVN_CR_28_BAR_01 & 1.03E-03 & $0.00 \mathrm{E}+00$ & 4.67E-02 & 3.33E-03 & - & $5.42 \mathrm{E}-02$ & $7.45 \mathrm{E}-02$ & $1.52 \mathrm{E}-02$ & $2.61 \mathrm{E}-02$ & 2.05E-01 \\
\hline 29 & CEMVN_CR_29_BAR_02 & $5.98 \mathrm{E}-04$ & $0.00 \mathrm{E}+00$ & 7.29E-02 & $1.14 \mathrm{E}-03$ & - & 3.09E-02 & $5.65 \mathrm{E}-02$ & $1.56 \mathrm{E}-02$ & 1.39E-02 & 1.80E-01 \\
\hline 30 & CEMVN_CR_30_BAR_03 & $3.22 \mathrm{E}-04$ & $0.00 \mathrm{E}+00$ & $6.21 \mathrm{E}-02$ & $1.37 \mathrm{E}-04$ & - & $1.60 \mathrm{E}-02$ & 3.64E-02 & $1.57 \mathrm{E}-02$ & 6.69E-03 & $1.32 \mathrm{E}-01$ \\
\hline 31 & CEMVN_CR_31_BAR_04 & $2.48 \mathrm{E}-04$ & $0.00 \mathrm{E}+00$ & 4.49E-02 & $6.28 \mathrm{E}-05$ & - & 9.31E-03 & $1.97 \mathrm{E}-02$ & $1.46 \mathrm{E}-02$ & 2.86E-03 & 8.99E-02 \\
\hline 32 & CEMVN_CR_32_BAR_05 & $2.21 \mathrm{E}-04$ & $0.00 \mathrm{E}+00$ & $3.56 \mathrm{E}-02$ & $2.28 \mathrm{E}-05$ & - & $6.90 \mathrm{E}-03$ & $1.21 \mathrm{E}-02$ & $1.40 \mathrm{E}-02$ & $1.59 \mathrm{E}-03$ & 6.89E-02 \\
\hline 33 & CEMVN_CR_33_BAR_06 & $1.54 \mathrm{E}-04$ & $0.00 \mathrm{E}+00$ & $2.42 \mathrm{E}-02$ & 3.81E-06 & - & $5.02 \mathrm{E}-03$ & 7.84E-03 & $1.26 \mathrm{E}-02$ & 9.63E-04 & 5.05E-02 \\
\hline 34 & CEMVN_CR_34_BAR_07 & $1.20 \mathrm{E}-04$ & $0.00 E+00$ & $3.30 \mathrm{E}-03$ & $2.85 \mathrm{E}-06$ & - & $1.61 \mathrm{E}-03$ & $4.20 \mathrm{E}-03$ & $1.13 \mathrm{E}-02$ & 4.41E-04 & 2.09E-02 \\
\hline 35 & CEMVN_CR_35_BAR_08 & $1.34 \mathrm{E}-04$ & $0.00 \mathrm{E}+00$ & 4.30E-04 & $9.51 \mathrm{E}-07$ & - & $6.64 \mathrm{E}-04$ & $3.16 \mathrm{E}-03$ & $1.07 \mathrm{E}-02$ & $2.87 \mathrm{E}-04$ & $1.53 \mathrm{E}-02$ \\
\hline 36 & CEMVN_CR_36_BAR_09 & $1.13 \mathrm{E}-04$ & $0.00 \mathrm{E}+00$ & 9.15E-03 & 2.09E-05 & - & $4.41 \mathrm{E}-04$ & 2.93E-03 & 9.91E-03 & 2.34E-04 & 2.27E-02 \\
\hline 37 & CEMVN_CR_37_BAR_10 & $1.04 \mathrm{E}-04$ & $0.00 \mathrm{E}+00$ & $1.04 \mathrm{E}-02$ & $1.05 E-05$ & - & $2.34 \mathrm{E}-04$ & $2.25 \mathrm{E}-03$ & $7.52 \mathrm{E}-03$ & $1.81 \mathrm{E}-04$ & 2.06E-02 \\
\hline 50 & CEMVN_CR_50_DE1_01 & $6.90 \mathrm{E}-04$ & $0.00 \mathrm{E}+00$ & 1.17E-03 & $0.00 \mathrm{E}+00$ & - & $2.85 \mathrm{E}-04$ & $2.79 \mathrm{E}-03$ & $1.90 \mathrm{E}-05$ & $5.67 \mathrm{E}-03$ & 1.06E-02 \\
\hline 51 & CEMVN_CR_51_DE2_02 & $1.37 \mathrm{E}-04$ & $0.00 \mathrm{E}+00$ & $8.54 \mathrm{E}-04$ & $0.00 E+00$ & - & $6.34 \mathrm{E}-04$ & 3.06E-03 & $0.00 E+00$ & $1.18 \mathrm{E}-03$ & $5.85 \mathrm{E}-03$ \\
\hline 52 & CEMVN_CR_52_CLI_01 & $8.56 \mathrm{E}-06$ & $0.00 \mathrm{E}+00$ & $8.41 \mathrm{E}-04$ & $0.00 \mathrm{E}+00$ & - & $0.00 \mathrm{E}+00$ & $2.09 \mathrm{E}-04$ & $7.86 \mathrm{E}-03$ & $2.66 \mathrm{E}-05$ & 8.94E-03 \\
\hline 53 & CEMVN_CR_53_CNI_01 & $2.26 \mathrm{E}-04$ & $0.00 \mathrm{E}+00$ & $0.00 \mathrm{E}+00$ & $0.00 \mathrm{E}+00$ & - & $0.00 E+00$ & 4.53E-04 & $5.75 \mathrm{E}-03$ & $0.00 E+00$ & 6.43E-03 \\
\hline & All Federal Channels & 2.09E-02 & $0.00 \mathrm{E}+00$ & 6.31E-01 & 1.99E-02 & - & $3.22 \mathrm{E}-01$ & 4.90E-01 & 5.09E-01 & $1.64 \mathrm{E}-01$ & 9.53E-01 \\
\hline
\end{tabular}


Table 4-6. Unconditional frequency of SDVs in CRSC by reach and vessel type. Frequencies greater than $1 \times 10^{-4}$ are in bold red typeface.

\begin{tabular}{|c|c|c|c|c|c|c|c|c|c|c|c|}
\hline \multirow[b]{2}{*}{ \# } & \multirow[b]{2}{*}{ Reach Code } & \multicolumn{9}{|c|}{ AIS Ship and Cargo Type } & \multirow[b]{2}{*}{$\begin{array}{c}\text { All Vesse } \\
\text { Types }\end{array}$} \\
\hline & & $\begin{array}{c}\text { Unknown } \\
\text { (00) }\end{array}$ & $\begin{array}{c}\text { WIG } \\
(20-29)\end{array}$ & $\begin{array}{c}\text { Class } 3 \\
(30,33-39)\end{array}$ & $\begin{array}{c}\text { High-Speed } \\
\text { (40-49) }\end{array}$ & $\begin{array}{c}\text { Harbor Boats } \\
(50-57)\end{array}$ & $\begin{array}{c}\text { Passenger } \\
(60-69)\end{array}$ & $\begin{array}{l}\text { Cargo } \\
(70-79)\end{array}$ & $\begin{array}{l}\text { Tanker } \\
\text { (80-89) }\end{array}$ & $\begin{array}{l}\text { Other } \\
(90-99)\end{array}$ & \\
\hline 1 & CEMVN_CR_01_UPR_01 & $0.00 E+00$ & - & $0.00 E+00$ & - & - & $0.00 E+00$ & $0.00 \mathrm{E}+00$ & - & - & $0.00 E+00$ \\
\hline 2 & CEMVN_CR_02_UPR_02 & $0.00 E+00$ & - & $0.00 \mathrm{E}+00$ & - & - & $0.00 E+00$ & $9.51 \mathrm{E}-07$ & $0.00 \mathrm{E}+00$ & $0.00 E+00$ & $9.48 \mathrm{E}-07$ \\
\hline 3 & CEMVN_CR_03_UPR_03 & $0.00 E+00$ & - & $0.00 E+00$ & - & - & $0.00 E+00$ & $0.00 E+00$ & $0.00 E+00$ & $0.00 E+00$ & $0.00 E+00$ \\
\hline 4 & CEMVN_CR_04_UPR_04 & $0.00 E+00$ & - & $9.49 \mathrm{E}-07$ & - & - & $0.00 E+00$ & $0.00 E+00$ & 2.85E-06 & $0.00 E+00$ & $3.78 \mathrm{E}-06$ \\
\hline 5 & CEMVN_CR_05_UPR_05 & $0.00 E+00$ & - & 8.55E-06 & - & - & $0.00 E+00$ & 1.71E-05 & 6.98E-05 & $0.00 \mathrm{E}+00$ & $9.42 \mathrm{E}-05$ \\
\hline 6 & CEMVN_CR_06_UPR_06 & $0.00 E+00$ & - & 6.65E-06 & - & - & - & $6.62 \mathrm{E}-06$ & $1.70 \mathrm{E}-05$ & $0.00 E+00$ & 3.01E-05 \\
\hline 7 & CEMVN_CR_07_UPR_07 & $0.00 E+00$ & - & 2.71E-06 & - & - & - & 4.75E-06 & 3.77E-06 & $9.51 \mathrm{E}-07$ & $1.22 \mathrm{E}-05$ \\
\hline 8 & CEMVN_CR_08_UPR_08 & $0.00 E+00$ & - & 4.73E-06 & - & - & - & $0.00 E+00$ & $2.84 \mathrm{E}-06$ & $0.00 E+00$ & $7.52 \mathrm{E}-06$ \\
\hline 9 & CEMVN_CR_09_UPR_09 & $0.00 E+00$ & - & 1.33E-05 & - & - & $0.00 E+00$ & 3.81E-06 & 6.64E-06 & $0.00 E+00$ & 2.36E-05 \\
\hline 10 & CEMVN_CR_10_UPR_10 & 9.51E-07 & - & 3.80E-06 & - & - & $0.00 E+00$ & 2.84E-06 & $0.00 E+00$ & $0.00 E+00$ & 7.56E-06 \\
\hline 11 & CEMVN_CR_11_LWR_01 & $0.00 E+00$ & - & 1.90E-06 & - & - & $0.00 E+00$ & $9.47 \mathrm{E}-07$ & $7.58 \mathrm{E}-06$ & $5.71 \mathrm{E}-06$ & 1.60E-05 \\
\hline 12 & CEMVN_CR_12_LWR_02 & $0.00 E+00$ & - & $0.00 E+00$ & - & - & $0.00 E+00$ & $9.49 \mathrm{E}-07$ & $0.00 E+00$ & $0.00 E+00$ & 9.46E-07 \\
\hline 13 & CEMVN_CR_13_LWR_03 & $0.00 E+00$ & - & $0.00 E+00$ & - & - & $0.00 E+00$ & $0.00 E+00$ & 4.74E-06 & $0.00 E+00$ & 4.72E-06 \\
\hline 14 & CEMVN_CR_14_LWR_04 & $0.00 E+00$ & - & $0.00 E+00$ & - & - & $0.00 E+00$ & $0.00 E+00$ & $0.00 \mathrm{E}+00$ & $0.00 \mathrm{E}+00$ & $0.00 E+00$ \\
\hline 15 & CEMVN_CR_15_LWR_05 & $0.00 E+00$ & - & $0.00 E+00$ & - & - & $0.00 E+00$ & $9.48 \mathrm{E}-07$ & 5.69E-06 & $0.00 E+00$ & 6.61E-06 \\
\hline 16 & CEMVN_CR_16_LWR_06 & $0.00 E+00$ & - & 9.50E-07 & - & - & $0.00 E+00$ & 1.89E-06 & 3.80E-06 & $0.00 E+00$ & 6.61E-06 \\
\hline 17 & CEMVN_CR_17_LWR_07 & $0.00 E+00$ & - & $9.50 \mathrm{E}-07$ & - & - & $0.00 \mathrm{E}+00$ & $0.00 \mathrm{E}+00$ & 6.63E-06 & $0.00 E+00$ & 7.57E-06 \\
\hline 18 & CEMVN_CR_18_LWR_08 & $0.00 E+00$ & - & $0.00 E+00$ & - & - & 1.90E-06 & 4.75E-06 & 1.90E-06 & $0.00 E+00$ & 8.53E-06 \\
\hline 19 & CEMVN_CR_19_LWR_09 & 4.76E-06 & - & $9.49 \mathrm{E}-07$ & - & - & $0.00 E+00$ & $1.90 \mathrm{E}-06$ & 9.50E-06 & $9.51 \mathrm{E}-07$ & $1.79 \mathrm{E}-05$ \\
\hline 20 & CEMVN_CR_20_LWR_10 & $0.00 E+00$ & - & 7.60E-06 & - & - & $0.00 E+00$ & $0.00 E+00$ & $1.52 \mathrm{E}-05$ & $0.00 E+00$ & 2.27E-05 \\
\hline 21 & CEMVN_CR_21_LWR_11 & 1.90E-06 & - & $0.00 E+00$ & - & - & $0.00 E+00$ & $0.00 E+00$ & 3.80E-06 & $0.00 E+00$ & $5.68 \mathrm{E}-06$ \\
\hline 22 & CEMVN_CR_22_LWR_12 & 2.85E-06 & - & $0.00 E+00$ & - & - & $0.00 E+00$ & $0.00 E+00$ & 1.90E-06 & $0.00 E+00$ & 4.74E-06 \\
\hline 23 & CEMVN_CR_23_LWR_13 & $0.00 E+00$ & - & $0.00 E+00$ & - & - & $0.00 E+00$ & 9.50E-07 & 2.85E-06 & $0.00 E+00$ & 3.78E-06 \\
\hline
\end{tabular}




\begin{tabular}{|c|c|c|c|c|c|c|c|c|c|c|c|}
\hline \multirow[b]{2}{*}{$\#$} & \multirow[b]{2}{*}{ Reach Code } & \multicolumn{9}{|c|}{ AIS Ship and Cargo Type } & \multirow{2}{*}{$\begin{array}{c}\text { All Vessel } \\
\text { Types }\end{array}$} \\
\hline & & $\begin{array}{c}\text { Unknown } \\
(00)\end{array}$ & $\begin{array}{c}\text { WIG } \\
(20-29)\end{array}$ & $\begin{array}{c}\text { Class } 3 \\
(30,33-39)\end{array}$ & $\begin{array}{l}\text { High-Speed } \\
\text { (40-49) }\end{array}$ & $\begin{array}{c}\text { Harbor Boats } \\
\qquad(50-57)\end{array}$ & $\begin{array}{c}\text { Passenger } \\
\text { (60-69) }\end{array}$ & $\begin{array}{l}\text { Cargo } \\
\text { (70-79) }\end{array}$ & $\begin{array}{l}\text { Tanker } \\
\text { (80-89) }\end{array}$ & $\begin{array}{l}\text { Other } \\
(90-99)\end{array}$ & \\
\hline 24 & CEMVN_CR_24_LWR_14 & $8.56 \mathrm{E}-06$ & - & $9.42 \mathrm{E}-07$ & $0.00 E+00$ & - & $0.00 E+00$ & $3.47 \mathrm{E}-05$ & 6.83E-05 & $6.64 \mathrm{E}-06$ & 1.16E-04 \\
\hline 25 & CEMVN_CR_25_GAP_01 & $1.62 \mathrm{E}-05$ & - & $8.47 \mathrm{E}-06$ & $0.00 \mathrm{E}+00$ & - & 2.76E-05 & $2.72 \mathrm{E}-04$ & 3.05E-04 & $1.53 \mathrm{E}-04$ & 7.06E-04 \\
\hline 26 & CEMVN_CR_26_GAP_02 & $9.51 \mathrm{E}-06$ & - & 4.73E-06 & $0.00 \mathrm{E}+00$ & - & 1.39E-05 & $2.06 \mathrm{E}-04$ & $2.56 \mathrm{E}-04$ & 9.03E-05 & 5.39E-04 \\
\hline 27 & CEMVN_CR_27_GAP_03 & $2.75 \mathrm{E}-05$ & - & $4.20 \mathrm{E}-05$ & $0.00 \mathrm{E}+00$ & - & 5.63E-05 & 2.17E-04 & 2.71E-04 & $1.06 \mathrm{E}-04$ & $6.49 \mathrm{E}-04$ \\
\hline 28 & CEMVN_CR_28_BAR_01 & $1.04 \mathrm{E}-05$ & - & $1.86 \mathrm{E}-05$ & $0.00 \mathrm{E}+00$ & - & 4.63E-05 & $1.16 \mathrm{E}-04$ & 7.40E-05 & 8.64E-05 & 3.25E-04 \\
\hline 29 & CEMVN_CR_29_BAR_02 & $0.00 \mathrm{E}+00$ & - & 4.67E-06 & $0.00 \mathrm{E}+00$ & - & 9.39E-06 & $2.59 \mathrm{E}-05$ & 2.27E-05 & 2.37E-05 & 8.08E-05 \\
\hline 30 & CEMVN_CR_30_BAR_03 & $0.00 \mathrm{E}+00$ & - & $2.83 \mathrm{E}-06$ & $0.00 \mathrm{E}+00$ & - & $0.00 \mathrm{E}+00$ & $6.59 \mathrm{E}-06$ & $1.61 \mathrm{E}-05$ & $2.18 \mathrm{E}-05$ & 4.53E-05 \\
\hline 31 & CEMVN_CR_31_BAR_04 & $0.00 \mathrm{E}+00$ & - & $0.00 \mathrm{E}+00$ & $0.00 \mathrm{E}+00$ & - & $0.00 E+00$ & $0.00 E+00$ & $9.48 \mathrm{E}-07$ & $0.00 E+00$ & $9.27 \mathrm{E}-07$ \\
\hline 32 & CEMVN_CR_32_BAR_05 & $0.00 \mathrm{E}+00$ & - & $9.43 \mathrm{E}-07$ & $0.00 \mathrm{E}+00$ & - & $0.00 E+00$ & $0.00 E+00$ & $0.00 \mathrm{E}+00$ & $0.00 E+00$ & $9.26 \mathrm{E}-07$ \\
\hline 33 & CEMVN_CR_33_BAR_06 & $0.00 E+00$ & - & $0.00 \mathrm{E}+00$ & $0.00 E+00$ & - & $0.00 E+00$ & $0.00 \mathrm{E}+00$ & $0.00 E+00$ & $0.00 E+00$ & $0.00 E+00$ \\
\hline 34 & CEMVN_CR_34_BAR_07 & $0.00 \mathrm{E}+00$ & - & $0.00 \mathrm{E}+00$ & $0.00 \mathrm{E}+00$ & - & $0.00 E+00$ & $0.00 \mathrm{E}+00$ & $0.00 \mathrm{E}+00$ & $0.00 E+00$ & $0.00 E+00$ \\
\hline 35 & CEMVN_CR_35_BAR_08 & $9.51 \mathrm{E}-07$ & - & $0.00 \mathrm{E}+00$ & $0.00 \mathrm{E}+00$ & - & $0.00 \mathrm{E}+00$ & $0.00 E+00$ & $9.49 \mathrm{E}-07$ & $0.00 \mathrm{E}+00$ & 1.90E-06 \\
\hline 36 & CEMVN_CR_36_BAR_09 & $0.00 E+00$ & - & $0.00 E+00$ & $0.00 E+00$ & - & $0.00 \mathrm{E}+00$ & $0.00 \mathrm{E}+00$ & $0.00 \mathrm{E}+00$ & $0.00 E+00$ & $0.00 E+00$ \\
\hline 37 & CEMVN_CR_37_BAR_10 & $0.00 \mathrm{E}+00$ & - & $0.00 \mathrm{E}+00$ & $0.00 \mathrm{E}+00$ & - & $0.00 E+00$ & $0.00 \mathrm{E}+00$ & $0.00 \mathrm{E}+00$ & $0.00 \mathrm{E}+00$ & $0.00 E+00$ \\
\hline 50 & CEMVN_CR_50_DE1_01 & $0.00 E+00$ & - & $0.00 \mathrm{E}+00$ & - & - & $0.00 E+00$ & $0.00 \mathrm{E}+00$ & $0.00 \mathrm{E}+00$ & $0.00 E+00$ & $0.00 E+00$ \\
\hline 51 & CEMVN_CR_51_DE2_02 & $0.00 \mathrm{E}+00$ & - & $0.00 E+00$ & - & - & $0.00 E+00$ & $0.00 \mathrm{E}+00$ & - & $0.00 E+00$ & $0.00 E+00$ \\
\hline 52 & CEMVN_CR_52_CLI_01 & $0.00 \mathrm{E}+00$ & - & $0.00 \mathrm{E}+00$ & - & - & - & $0.00 \mathrm{E}+00$ & - & $0.00 E+00$ & $0.00 E+00$ \\
\hline 53 & CEMVN_CR_53_CNI_01 & $0.00 \mathrm{E}+00$ & - & - & - & - & - & $0.00 \mathrm{E}+00$ & - & - & $0.00 E+00$ \\
\hline & All Federal Channels & $8.14 \mathrm{E}-05$ & - & 1.10E-04 & $0.00 E+00$ & - & $1.34 \mathrm{E}-04$ & $6.90 \mathrm{E}-04$ & $9.15 \mathrm{E}-04$ & $4.58 \mathrm{E}-04$ & $1.05 \mathrm{E}-03$ \\
\hline
\end{tabular}


The relative frequency of SDVs is similar to the unconditional probability of an SDV because it indicates in which navigation reach SDVs are most likely to occur. The relative frequency of SDVs in each reach over all vessel types is shown in Figure 4-7. The navigation channels with the highest relative frequencies are between Lake Calcasieu and the mouth of the jetty in reaches GAPo1-GAPO3 (\#25-27) and BARo1 (\#28). These results are similar to those obtained using the other two metrics.

Figure 4-7. Relative frequency of SDVs in CRSC.

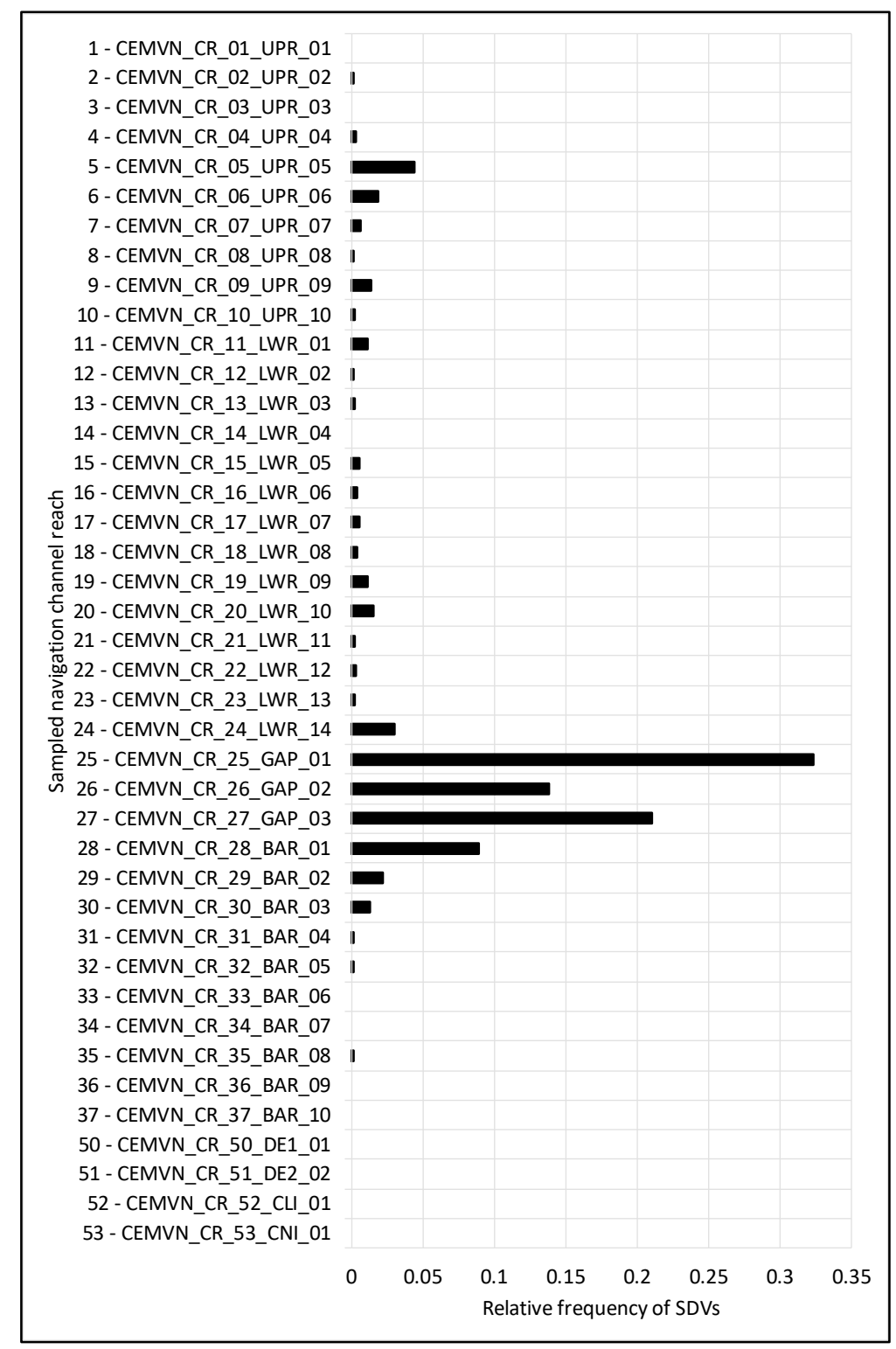

Pearson product moment correlations indicate that the three metrics of collision risk are highly correlated (Table 4-7). The correlation between the conditional probability of an SDV, $p\left(\mathrm{SDV} \mid n_{j k t} \geq 1\right)$ and the unconditional 
probability of an SDV, $p(\mathrm{SDV})$, is 0.9625 . The correlation between the conditional probability of an SDV and the relative frequency of an SDV, $f_{k}$, is 0.9153. The correlation between the unconditional probability of an SDV and the relative frequency of SDVs is 0.9698. These high levels of agreement indicate that the three metrics are communicating similar information. Those reaches where a vessel is most likely to be involved in an SDV are the same as those reaches where SDVs are most likely to occur.

Table 4-7. Pearson correlation coefficients for collision risk metrics in CRSC.

\begin{tabular}{|c|c|c|c|c|}
\hline Metric of Collision Risk & $p\left(\right.$ SDV $\left.\mid n_{k t} \geq 1\right)$ & $p\left(n_{k t} \geq 1\right)$ & $p($ SDV $)$ & $f_{k}$ \\
\hline$p\left(\right.$ SDV $\left.\mid n_{k t} \geq 1\right)$ & 1.0000 & 0.8496 & 0.9625 & 0.9153 \\
\hline$p\left(n_{k t} \geq 1\right)$ & - & 1.0000 & 0.8622 & 0.8227 \\
\hline$p($ SDV $)$ & - & - & 1.0000 & 0.9698 \\
\hline$f_{k}$ & - & - & - & 1.0000 \\
\hline
\end{tabular}

\subsection{Grounding risk assessment}

This assessment of grounding risk examines two types of potential grounding events. The potential for powered groundings on the side of the channel is assessed by identifying clusters of channel side events to reveal where vessels have a tendency to operate near the edge of the channel. The potential for powered grounding in the channel is assessed by calculating what fraction of vessels are depth limited at maintenance depth and as the maintenance depth is reduced to simulate shoaling. This information also provides a useful indication of draft utilization within the channel and the sensitivity of navigation to a potential shoaling scenario.

\subsubsection{Powered grounding on the side of the channel}

Channel side events occur when the distance between a point on the keel and the channel boundary is less than $55 \%$ of the vessels beam. The location of channel side events during the 2014 calendar year in the CRSC is shown in Figure 4-8. Several data filters were used to reduce the volume of data: (1) position reports were limited to those from vessels with AIS transponders inside a USACE navigation channel reach; (2) position reports were limited to vessels classified under ship and cargo type codes other than towing, (31-32), dredging (33), and harbor work boats (50-59); and (3) position reports were limited to those from vessels drafting at least $7.5 \mathrm{~m}$ and transiting at speeds greater than or equal to $7.5 \mathrm{knots}$. Towboats and harbor work boats were excluded because they rarely require more 
than approximately $10 \mathrm{ft}$ of draft, thus are not generally at risk of grounding on the side of the channel. Dredgers were excluded because they appeared to be working at the edge of the channel intentionally.

Figure 4-8. Channel side events in CRSC.

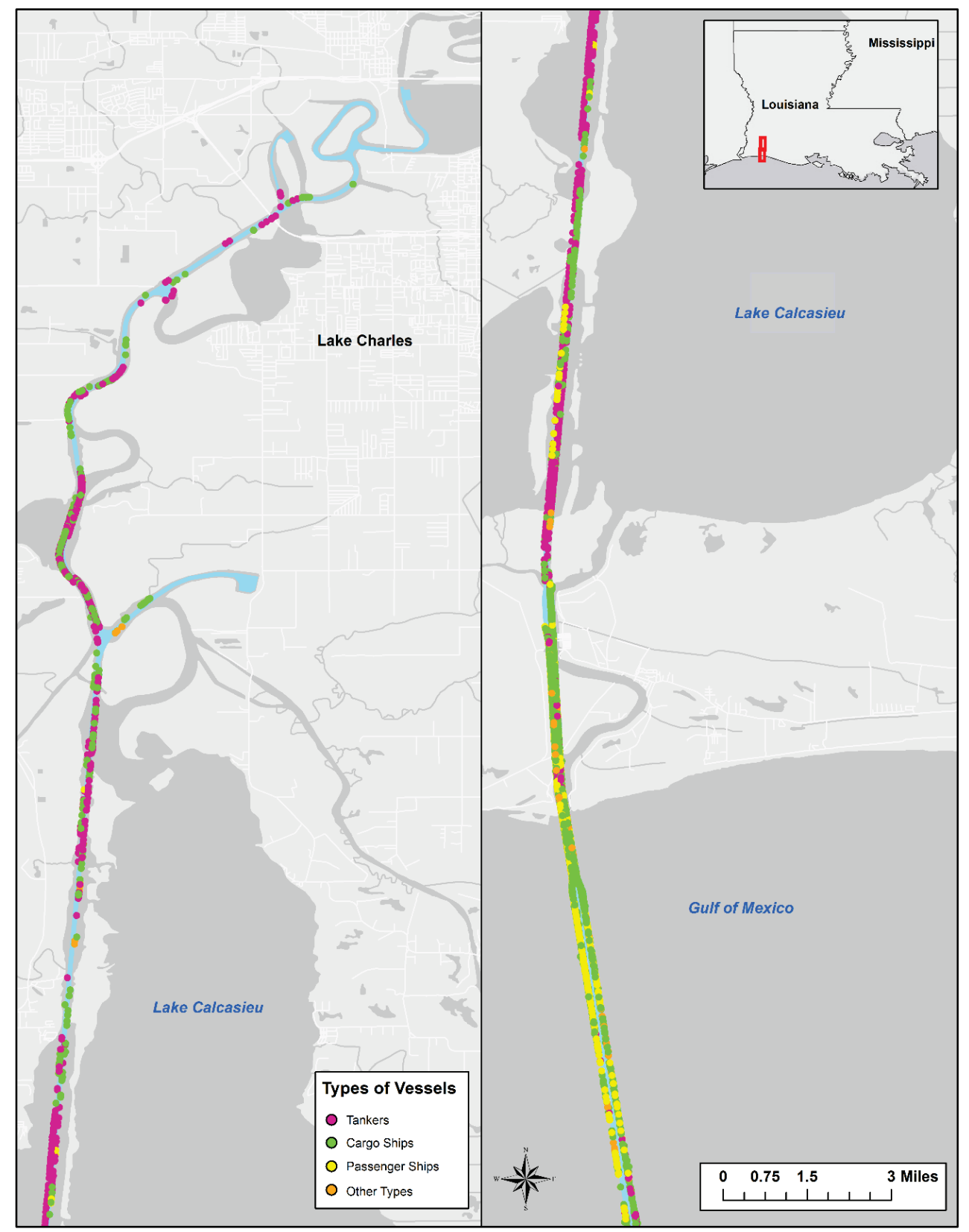

The scale used in Figure 4-8 shows the entire waterway; it is difficult to see what the potential causes of these events might be. Patterns in channel side events become more apparent at larger map scales, making it easier to infer potential causes. This is illustrated in Figure 4-9, which shows a detail of the intersection of the CRSC with the Intracoastal Waterway. 
Tankers and cargo vessels are approaching the edge of the channel as they attempt to make the bend going into Moss Lake and again along the bend passing Calcasieu Refining. There are a few channel side events located along the bends at Citgo Lake Charles Refinery. Vessels in transit at speeds of 7.5 knots or greater appear to be staying away from the edge of the channel at this bend. However, when the speed filter is relaxed, many more vessels can be seen departing from the channel at this location. These vessels appear to be docking at the Citgo Lake Charles Refinery.

Figure 4-9. Channel side events in vicinity of Moss Lake.

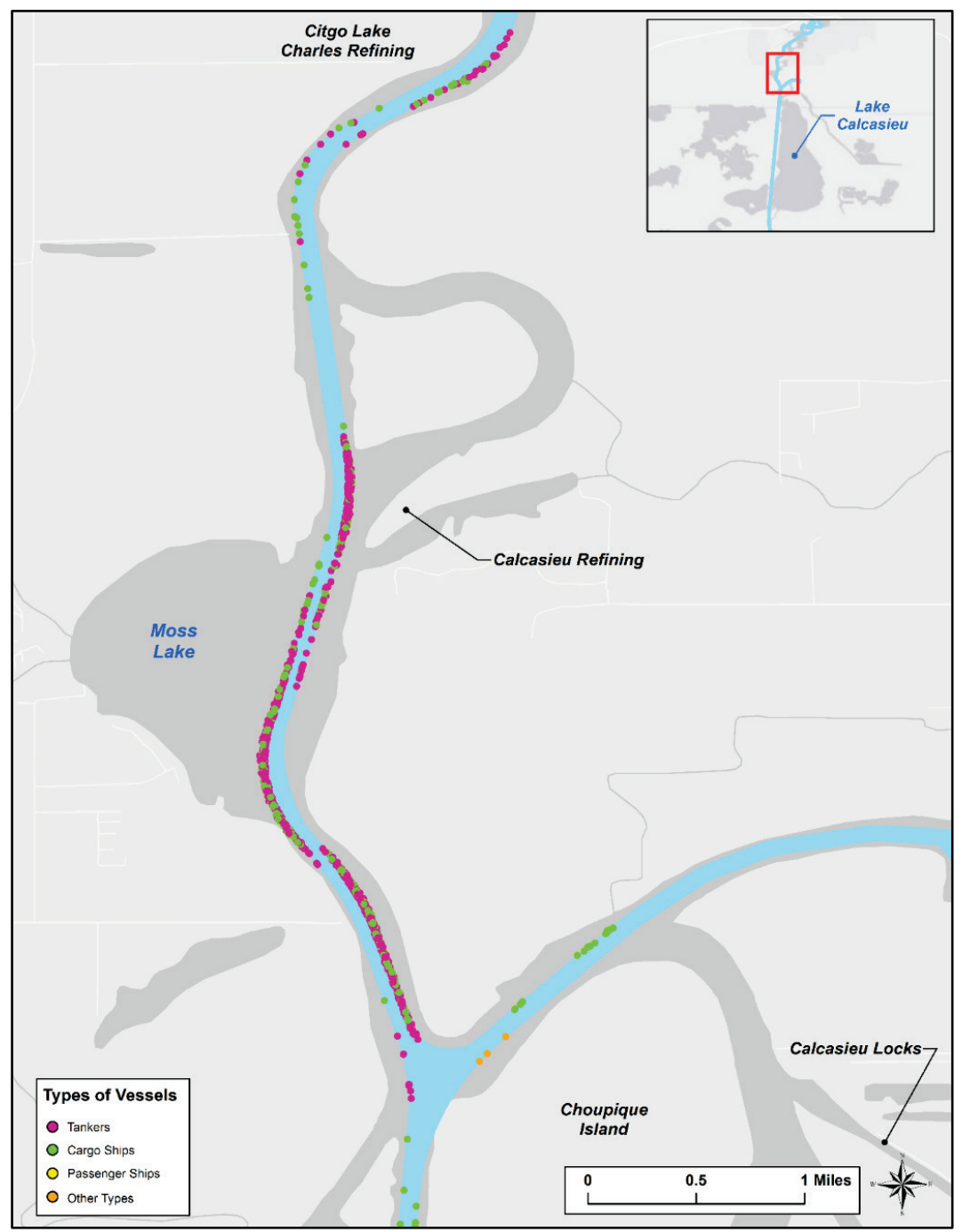

\subsubsection{Powered grounding on a shoal in the channel}

The number and fraction of depth-limited vessels classified under the ship and cargo type code for cargo vessels (70-79) is summarized in Table 4-8. Maintenance depth appears to be adequate because, at most, $10 \%$ of the 
cargo vessels utilizing the $40 \mathrm{ft}$ channels are depth limited. The fraction of cargo vessels that become depth limited increases as the limiting depth of the channel is reduced to simulate shoaling or deferred maintenance. If the limiting depth is reduced by $3 \mathrm{ft}$, approximately $20 \%$ of cargo vessels utilizing the reach become depth limited. If the limiting depth is reduced by $6 \mathrm{ft}$, as much as 30\% of cargo vessels become depth limited. Cargo vessel navigation in the $42 \mathrm{ft}$ reaches that extend from the jetty entrance out into the Gulf of Mexico appear to be robust against shoaling.

The existing maintenance depth appears adequate for cargo vessels. However, there are an undetermined number of offshore supply vessels operating under the ship and cargo type code for cargo vessels (70-79) in the CRSC. In general, these vessels have a shallower maximum static draft than the larger bulk carriers and container vessels that are usually indicated by the ship and cargo type codes for cargo vessels. Were these offshore supply vessels classified more appropriately, this analysis might reveal a higher depth-limited fraction of cargo vessels.

A similar pattern is observed for vessels classified under the ship and cargo type code for tankers (80-89), as summarized in Table 4-9. At maintenance depth, the fraction of depth limited tankers operating in the $40 \mathrm{ft}$ channels is less than $10 \%$. As available depth is reduced to simulate shoaling between dredging events, limiting depth is reduced. The depthlimited fraction of tankers tends to increase more rapidly than the depthlimited fraction of cargo vessels. Given $6 \mathrm{ft}$ of shoaling, as much as $45 \%$ of tankers become depth limited. 
Table 4-8. Number and fraction of cargo vessels (70-79) that are depth limited in CRSC.

\begin{tabular}{|c|c|c|c|c|c|c|c|c|c|c|}
\hline \multirow[b]{2}{*}{$\#$} & \multirow[b]{2}{*}{ Reach Code } & \multirow{2}{*}{$\begin{array}{l}\text { Main- } \\
\text { tenance } \\
\text { Depth } \\
\text { (ft) }\end{array}$} & \multirow{2}{*}{$\begin{array}{c}\text { Number of } \\
\text { Unique } \\
\text { Vessels }\end{array}$} & \multicolumn{7}{|c|}{ Reduction in Maintenance Depth (ft) } \\
\hline & & & & 0 & 1 & 2 & 3 & 4 & 5 & 6 \\
\hline 1 & CEMVN_CR_01_UPR_01 & 35 & 6 & $1 / 0.167$ & $1 / 0.167$ & $1 / 0.167$ & $1 / 0.167$ & $1 / 0.167$ & $1 / 0.167$ & $1 / 0.167$ \\
\hline 2 & CEMVN_CR_02_UPR_02 & 40 & 42 & $1 / 0.023$ & $2 / 0.047$ & $3 / 0.07$ & 4/0.093 & 4/0.093 & $7 / 0.163$ & 9/0.209 \\
\hline 3 & CEMVN_CR_03_UPR_03 & 40 & 44 & $1 / 0.022$ & $2 / 0.044$ & $3 / 0.067$ & 4/0.089 & 4/0.089 & $7 / 0.156$ & $9 / 0.2$ \\
\hline 4 & CEMVN_CR_04_UPR_04 & 40 & 131 & $16 / 0.118$ & 26/0.191 & $29 / 0.213$ & $37 / 0.272$ & $39 / 0.287$ & $43 / 0.316$ & $51 / 0.375$ \\
\hline 5 & CEMVN_CR_05_UPR_05 & 40 & 131 & $16 / 0.118$ & 26/0.191 & $29 / 0.213$ & $37 / 0.272$ & $39 / 0.287$ & $43 / 0.316$ & $51 / 0.375$ \\
\hline 6 & CEMVN_CR_06_UPR_06 & 40 & 131 & $16 / 0.118$ & 26/0.191 & $29 / 0.213$ & $37 / 0.272$ & $39 / 0.287$ & $43 / 0.316$ & $51 / 0.375$ \\
\hline 7 & CEMVN_CR_07_UPR_07 & 40 & 145 & $16 / 0.107$ & $26 / 0.173$ & $29 / 0.193$ & $37 / 0.247$ & $40 / 0.267$ & $44 / 0.293$ & $52 / 0.347$ \\
\hline 8 & CEMVN_CR_08_UPR_08 & 40 & 145 & $16 / 0.107$ & $26 / 0.173$ & 29/0.193 & $37 / 0.247$ & $40 / 0.267$ & $44 / 0.293$ & $52 / 0.347$ \\
\hline 9 & CEMVN_CR_09_UPR_09 & 40 & 146 & $16 / 0.105$ & $26 / 0.171$ & $29 / 0.191$ & $37 / 0.243$ & $40 / 0.263$ & $44 / 0.289$ & $52 / 0.342$ \\
\hline 10 & CEMVN_CR_10_UPR_10 & 40 & 166 & $16 / 0.089$ & $26 / 0.145$ & $29 / 0.162$ & $37 / 0.207$ & $40 / 0.223$ & $46 / 0.257$ & $54 / 0.302$ \\
\hline 11 & CEMVN_CR_11_LWR_01 & 40 & 165 & $16 / 0.091$ & $26 / 0.148$ & $29 / 0.165$ & $37 / 0.21$ & $40 / 0.227$ & $46 / 0.261$ & $54 / 0.307$ \\
\hline 12 & CEMVN_CR_12_LWR_02 & 40 & 165 & $16 / 0.091$ & $26 / 0.148$ & 29/0.165 & $37 / 0.21$ & $40 / 0.227$ & $46 / 0.261$ & $54 / 0.307$ \\
\hline 13 & CEMVN_CR_13_LWR_03 & 40 & 165 & 16/0.091 & $26 / 0.148$ & $29 / 0.165$ & $37 / 0.21$ & $40 / 0.227$ & $46 / 0.261$ & $54 / 0.307$ \\
\hline 14 & CEMVN_CR_14_LWR_04 & 40 & 165 & $16 / 0.091$ & $26 / 0.148$ & $29 / 0.165$ & $37 / 0.21$ & $40 / 0.227$ & $46 / 0.261$ & $54 / 0.307$ \\
\hline 15 & CEMVN_CR_15_LWR_05 & 40 & 165 & $16 / 0.091$ & $26 / 0.148$ & 29/0.165 & $37 / 0.21$ & $40 / 0.227$ & $46 / 0.261$ & $54 / 0.307$ \\
\hline 16 & CEMVN_CR_16_LWR_06 & 40 & 165 & $16 / 0.091$ & $26 / 0.148$ & $29 / 0.165$ & $37 / 0.21$ & $40 / 0.227$ & $46 / 0.261$ & $54 / 0.307$ \\
\hline 17 & CEMVN_CR_17_LWR_07 & 40 & 165 & 16/0.091 & $26 / 0.148$ & 29/0.165 & $37 / 0.21$ & $40 / 0.227$ & $46 / 0.261$ & $54 / 0.307$ \\
\hline 18 & CEMVN_CR_18_LWR_08 & 40 & 165 & $16 / 0.091$ & $26 / 0.148$ & $29 / 0.165$ & $37 / 0.21$ & $40 / 0.227$ & $46 / 0.261$ & $54 / 0.307$ \\
\hline 19 & CEMVN_CR_19_LWR_09 & 40 & 165 & $16 / 0.091$ & $26 / 0.148$ & 29/0.165 & $37 / 0.21$ & $40 / 0.227$ & $46 / 0.261$ & $54 / 0.307$ \\
\hline 20 & CEMVN_CR_20_LWR_10 & 40 & 165 & 16/0.09 & $26 / 0.147$ & $29 / 0.164$ & $37 / 0.209$ & $40 / 0.226$ & $46 / 0.26$ & $54 / 0.305$ \\
\hline 21 & CEMVN_CR_21_LWR_11 & 40 & 165 & $16 / 0.09$ & $26 / 0.147$ & 29/0.164 & $37 / 0.209$ & $40 / 0.226$ & $46 / 0.26$ & $54 / 0.305$ \\
\hline 22 & CEMVN_CR_22_LWR_12 & 40 & 165 & $16 / 0.09$ & $26 / 0.147$ & $29 / 0.164$ & $37 / 0.209$ & $40 / 0.226$ & $46 / 0.26$ & $54 / 0.305$ \\
\hline
\end{tabular}




\begin{tabular}{|c|c|c|c|c|c|c|c|c|c|c|}
\hline \multirow[b]{2}{*}{$\#$} & \multirow[b]{2}{*}{ Reach Code } & \multirow{2}{*}{$\begin{array}{l}\text { Main- } \\
\text { tenance } \\
\text { Depth } \\
\text { (ft) }\end{array}$} & \multirow{2}{*}{$\begin{array}{c}\text { Number of } \\
\text { Unique } \\
\text { Vessels }\end{array}$} & \multicolumn{7}{|c|}{ Reduction in Maintenance Depth (ft) } \\
\hline & & & & 0 & 1 & 2 & 3 & 4 & 5 & 6 \\
\hline 23 & CEMVN_CR_23_LWR_13 & 40 & 165 & 16/0.09 & $26 / 0.147$ & $29 / 0.164$ & $37 / 0.209$ & $40 / 0.226$ & $46 / 0.26$ & $54 / 0.305$ \\
\hline 24 & CEMVN_CR_24_LWR_14 & 40 & 234 & $16 / 0.062$ & 26/0.101 & $29 / 0.113$ & $37 / 0.144$ & $40 / 0.156$ & $46 / 0.179$ & $54 / 0.21$ \\
\hline 25 & CEMVN_CR_25_GAP_01 & 40 & 265 & $17 / 0.057$ & $27 / 0.091$ & 30/0.101 & $38 / 0.128$ & $41 / 0.138$ & $47 / 0.158$ & $55 / 0.185$ \\
\hline 26 & CEMVN_CR_26_GAP_02 & 40 & 276 & $17 / 0.055$ & $27 / 0.087$ & $30 / 0.097$ & $38 / 0.123$ & $41 / 0.133$ & $47 / 0.152$ & $55 / 0.178$ \\
\hline 27 & CEMVN_CR_27_GAP_03 & 40 & 276 & $17 / 0.055$ & $27 / 0.087$ & $30 / 0.097$ & $38 / 0.123$ & $41 / 0.133$ & $47 / 0.152$ & $55 / 0.178$ \\
\hline 28 & CEMVN_CR_28_BAR_01 & 42 & 276 & $9 / 0.029$ & $15 / 0.049$ & $17 / 0.055$ & $27 / 0.087$ & $30 / 0.097$ & $38 / 0.123$ & $41 / 0.133$ \\
\hline 29 & CEMVN_CR_29_BAR_02 & 42 & 275 & $9 / 0.029$ & $15 / 0.049$ & $17 / 0.055$ & $27 / 0.088$ & $30 / 0.097$ & $38 / 0.123$ & $41 / 0.133$ \\
\hline 30 & CEMVN_CR_30_BAR_03 & 42 & 271 & $9 / 0.03$ & $15 / 0.049$ & $17 / 0.056$ & $27 / 0.089$ & $30 / 0.099$ & $38 / 0.125$ & $41 / 0.135$ \\
\hline 31 & CEMVN_CR_31_BAR_04 & 42 & 255 & $9 / 0.032$ & $15 / 0.053$ & $17 / 0.06$ & $27 / 0.095$ & $30 / 0.105$ & $38 / 0.133$ & $41 / 0.144$ \\
\hline 32 & CEMVN_CR_32_BAR_05 & 42 & 236 & $8 / 0.031$ & $14 / 0.055$ & $16 / 0.063$ & 26/0.102 & $29 / 0.114$ & $37 / 0.145$ & $40 / 0.157$ \\
\hline 33 & CEMVN_CR_33_BAR_06 & 42 & 209 & 8/0.035 & $14 / 0.062$ & $16 / 0.07$ & 26/0.115 & $29 / 0.128$ & $36 / 0.159$ & $39 / 0.172$ \\
\hline 34 & CEMVN_CR_34_BAR_07 & 42 & 177 & $9 / 0.046$ & $15 / 0.077$ & $16 / 0.082$ & $26 / 0.133$ & $29 / 0.149$ & $35 / 0.179$ & $38 / 0.195$ \\
\hline 35 & CEMVN_CR_35_BAR_08 & 42 & 153 & $8 / 0.048$ & $14 / 0.083$ & $15 / 0.089$ & $24 / 0.143$ & $27 / 0.161$ & 33/0.196 & $35 / 0.208$ \\
\hline 36 & CEMVN_CR_36_BAR_09 & 42 & 146 & $8 / 0.05$ & $14 / 0.088$ & $16 / 0.101$ & $25 / 0.157$ & $27 / 0.17$ & $33 / 0.208$ & $34 / 0.214$ \\
\hline 37 & CEMVN_CR_37_BAR_10 & 42 & 131 & $7 / 0.05$ & $13 / 0.092$ & $15 / 0.106$ & $23 / 0.163$ & $25 / 0.177$ & $30 / 0.213$ & $31 / 0.22$ \\
\hline 50 & CEMVN_CR_50_DE1_01 & 40 & 32 & $0 / 0$ & $0 / 0$ & $0 / 0$ & $1 / 0.026$ & $1 / 0.026$ & $3 / 0.079$ & 4/0.105 \\
\hline 51 & CEMVN_CR_51_DE2_02 & 40 & 28 & $0 / 0$ & $0 / 0$ & $0 / 0$ & $1 / 0.032$ & $1 / 0.032$ & 3/0.097 & 4/0.129 \\
\hline 52 & CEMVN_CR_OO_CSC_04 & 40 & 17 & $17 / 1.000$ & $17 / 1.000$ & $17 / 1.000$ & $17 / 1.000$ & $17 / 1.000$ & $17 / 1.000$ & $17 / 1$ \\
\hline 53 & CEMVN_CR_00_CSC_05 & 40 & 3 & $3 / 1.000$ & $3 / 1.000$ & $3 / 1.000$ & $3 / 1.000$ & $3 / 1.000$ & $3 / 1.000$ & $3 / 1$ \\
\hline
\end{tabular}


Table 4-9. Number and fraction of tankers (80-89) that are depth limited in CRSC.

\begin{tabular}{|c|c|c|c|c|c|c|c|c|c|c|}
\hline \multirow[b]{2}{*}{ \# } & \multirow[b]{2}{*}{ Reach Code } & \multirow{2}{*}{$\begin{array}{c}\text { Maint- } \\
\text { enance } \\
\text { Depth } \\
\text { (ft) }\end{array}$} & \multirow{2}{*}{$\begin{array}{c}\text { Number of } \\
\text { Unique } \\
\text { Vessels }\end{array}$} & \multicolumn{7}{|c|}{ Reduction in Maintenance Depth (ft) } \\
\hline & & & & 0 & 1 & 2 & 3 & 4 & 5 & 6 \\
\hline 2 & CEMVN_CR_02_UPR_02 & 40 & 83 & $3 / 0.035$ & $7 / 0.082$ & $11 / 0.129$ & $19 / 0.224$ & $29 / 0.341$ & $33 / 0.388$ & $39 / 0.459$ \\
\hline 3 & CEMVN_CR_03_UPR_03 & 40 & 121 & $3 / 0.024$ & $9 / 0.073$ & $16 / 0.129$ & $25 / 0.202$ & $35 / 0.282$ & $40 / 0.323$ & $46 / 0.371$ \\
\hline 4 & CEMVN_CR_04_UPR_04 & 40 & 127 & $3 / 0.023$ & $11 / 0.085$ & $18 / 0.138$ & $27 / 0.208$ & $37 / 0.285$ & $43 / 0.331$ & $50 / 0.385$ \\
\hline 5 & CEMVN_CR_05_UPR_05 & 40 & 275 & $21 / 0.074$ & $52 / 0.183$ & $72 / 0.254$ & $94 / 0.331$ & $108 / 0.38$ & $120 / 0.423$ & $131 / 0.461$ \\
\hline 6 & CEMVN_CR_06_UPR_06 & 40 & 320 & $26 / 0.079$ & $59 / 0.179$ & $80 / 0.242$ & $104 / 0.315$ & $123 / 0.373$ & $138 / 0.418$ & $149 / 0.452$ \\
\hline 7 & CEMVN_CR_07_UPR_07 & 40 & 335 & $27 / 0.078$ & $62 / 0.179$ & $84 / 0.243$ & $108 / 0.312$ & $127 / 0.367$ & $143 / 0.413$ & $155 / 0.448$ \\
\hline 8 & CEMVN_CR_08_UPR_08 & 40 & 335 & $27 / 0.078$ & $62 / 0.179$ & $84 / 0.243$ & $108 / 0.312$ & $127 / 0.367$ & $143 / 0.413$ & $155 / 0.448$ \\
\hline 9 & CEMVN_CR_09_UPR_09 & 40 & 335 & $27 / 0.078$ & $62 / 0.179$ & $84 / 0.243$ & $108 / 0.312$ & $127 / 0.367$ & $143 / 0.413$ & $155 / 0.448$ \\
\hline 10 & CEMVN_CR_10_UPR_10 & 40 & 335 & $27 / 0.078$ & $62 / 0.179$ & $84 / 0.242$ & $108 / 0.311$ & $128 / 0.369$ & $144 / 0.415$ & $156 / 0.45$ \\
\hline 11 & CEMVN_CR_11_LWR_01 & 40 & 335 & $27 / 0.078$ & $62 / 0.179$ & $84 / 0.242$ & $108 / 0.311$ & $128 / 0.369$ & $144 / 0.415$ & $156 / 0.45$ \\
\hline 12 & CEMVN_CR_12_LWR_02 & 40 & 335 & $27 / 0.078$ & $62 / 0.179$ & $84 / 0.242$ & $108 / 0.311$ & $128 / 0.369$ & $144 / 0.415$ & $156 / 0.45$ \\
\hline 13 & CEMVN_CR_13_LWR_03 & 40 & 335 & $27 / 0.078$ & $62 / 0.179$ & $84 / 0.242$ & $108 / 0.311$ & $128 / 0.369$ & $144 / 0.415$ & $156 / 0.45$ \\
\hline 14 & CEMVN_CR_14_LWR_04 & 40 & 335 & $27 / 0.078$ & $62 / 0.179$ & $84 / 0.242$ & $108 / 0.311$ & $128 / 0.369$ & $144 / 0.415$ & $156 / 0.45$ \\
\hline 15 & CEMVN_CR_15_LWR_05 & 40 & 335 & $27 / 0.078$ & $62 / 0.179$ & $84 / 0.242$ & $108 / 0.311$ & $128 / 0.369$ & $144 / 0.415$ & $156 / 0.45$ \\
\hline 16 & CEMVN_CR_16_LWR_06 & 40 & 335 & $27 / 0.078$ & $62 / 0.179$ & $84 / 0.242$ & $108 / 0.311$ & $128 / 0.369$ & $144 / 0.415$ & $156 / 0.45$ \\
\hline 17 & CEMVN_CR_17_LWR_07 & 40 & 335 & $27 / 0.078$ & $62 / 0.179$ & $84 / 0.242$ & $108 / 0.311$ & $128 / 0.369$ & $144 / 0.415$ & $156 / 0.45$ \\
\hline 18 & CEMVN_CR_18_LWR_08 & 40 & 335 & $27 / 0.078$ & $62 / 0.179$ & $84 / 0.242$ & $108 / 0.311$ & $128 / 0.369$ & $144 / 0.415$ & $156 / 0.45$ \\
\hline 19 & CEMVN_CR_19_LWR_09 & 40 & 335 & $27 / 0.078$ & $62 / 0.179$ & $84 / 0.242$ & $108 / 0.311$ & $128 / 0.369$ & $144 / 0.415$ & $156 / 0.45$ \\
\hline 20 & CEMVN_CR_20_LWR_10 & 40 & 335 & $27 / 0.078$ & $62 / 0.179$ & $84 / 0.242$ & $108 / 0.311$ & $128 / 0.369$ & $144 / 0.415$ & $156 / 0.45$ \\
\hline 21 & CEMVN_CR_21_LWR_11 & 40 & 335 & $27 / 0.078$ & $62 / 0.179$ & $84 / 0.242$ & $108 / 0.311$ & $128 / 0.369$ & $144 / 0.415$ & $156 / 0.45$ \\
\hline 22 & CEMVN_CR_22_LWR_12 & 40 & 335 & $27 / 0.078$ & $62 / 0.179$ & $84 / 0.242$ & $108 / 0.311$ & $128 / 0.369$ & $144 / 0.415$ & $156 / 0.45$ \\
\hline 23 & CEMVN_CR_23_LWR_13 & 40 & 335 & $27 / 0.078$ & $62 / 0.179$ & $84 / 0.242$ & $108 / 0.311$ & $128 / 0.369$ & $144 / 0.415$ & $156 / 0.45$ \\
\hline
\end{tabular}




\begin{tabular}{|c|c|c|c|c|c|c|c|c|c|c|}
\hline \multirow[b]{2}{*}{ \# } & \multirow[b]{2}{*}{ Reach Code } & \multirow{2}{*}{$\begin{array}{c}\text { Maint- } \\
\text { enance } \\
\text { Depth } \\
\text { (ft) }\end{array}$} & \multirow{2}{*}{$\begin{array}{c}\text { Number of } \\
\text { Unique } \\
\text { Vessels }\end{array}$} & \multicolumn{7}{|c|}{ Reduction in Maintenance Depth (ft) } \\
\hline & & & & 0 & 1 & 2 & 3 & 4 & 5 & 6 \\
\hline 24 & CEMVN_CR_24_LWR_14 & 40 & 335 & $27 / 0.078$ & $62 / 0.179$ & $84 / 0.242$ & $108 / 0.311$ & $128 / 0.369$ & $144 / 0.415$ & $156 / 0.45$ \\
\hline 25 & CEMVN_CR_25_GAP_01 & 40 & 335 & $27 / 0.078$ & $62 / 0.179$ & $84 / 0.242$ & $108 / 0.311$ & $128 / 0.369$ & $144 / 0.415$ & $156 / 0.45$ \\
\hline 26 & CEMVN_CR_26_GAP_02 & 40 & 335 & $27 / 0.078$ & $62 / 0.179$ & $84 / 0.242$ & $108 / 0.311$ & $128 / 0.369$ & $144 / 0.415$ & $156 / 0.45$ \\
\hline 27 & CEMVN_CR_27_GAP_03 & 40 & 335 & $27 / 0.078$ & $62 / 0.179$ & $84 / 0.242$ & $108 / 0.311$ & $128 / 0.369$ & $144 / 0.415$ & $156 / 0.45$ \\
\hline 28 & CEMVN_CR_28_BAR_01 & 42 & 335 & $15 / 0.043$ & $18 / 0.052$ & $27 / 0.078$ & $62 / 0.179$ & $84 / 0.242$ & $108 / 0.311$ & $128 / 0.369$ \\
\hline 29 & CEMVN_CR_29_BAR_02 & 42 & 335 & $15 / 0.043$ & $18 / 0.052$ & $27 / 0.078$ & $62 / 0.179$ & $84 / 0.242$ & $108 / 0.311$ & $128 / 0.369$ \\
\hline 30 & CEMVN_CR_30_BAR_03 & 42 & 335 & $15 / 0.043$ & $18 / 0.052$ & $27 / 0.078$ & $62 / 0.179$ & $84 / 0.242$ & $108 / 0.311$ & $128 / 0.369$ \\
\hline 31 & CEMVN_CR_31_BAR_04 & 42 & 335 & $15 / 0.043$ & $18 / 0.052$ & $27 / 0.078$ & $62 / 0.179$ & $84 / 0.242$ & $108 / 0.311$ & $128 / 0.369$ \\
\hline 32 & CEMVN_CR_32_BAR_05 & 42 & 335 & $15 / 0.043$ & $18 / 0.052$ & $27 / 0.078$ & $62 / 0.179$ & $84 / 0.242$ & $108 / 0.311$ & $128 / 0.369$ \\
\hline 33 & CEMVN_CR_33_BAR_06 & 42 & 333 & $15 / 0.043$ & $18 / 0.052$ & $27 / 0.078$ & $62 / 0.18$ & $84 / 0.243$ & $108 / 0.313$ & $128 / 0.371$ \\
\hline 34 & CEMVN_CR_34_BAR_07 & 42 & 326 & $15 / 0.044$ & $18 / 0.053$ & $27 / 0.08$ & $61 / 0.18$ & $83 / 0.246$ & $107 / 0.317$ & $127 / 0.376$ \\
\hline 35 & CEMVN_CR_35_BAR_08 & 42 & 319 & $15 / 0.045$ & $18 / 0.055$ & $27 / 0.082$ & $62 / 0.188$ & $83 / 0.252$ & $108 / 0.327$ & $128 / 0.388$ \\
\hline 36 & CEMVN_CR_36_BAR_09 & 42 & 302 & $15 / 0.048$ & $18 / 0.058$ & $27 / 0.086$ & $57 / 0.182$ & $77 / 0.246$ & $99 / 0.316$ & $119 / 0.38$ \\
\hline 37 & CEMVN_CR_37_BAR_10 & 42 & 290 & $15 / 0.05$ & $18 / 0.06$ & 27/0.09 & $54 / 0.18$ & $73 / 0.243$ & $95 / 0.317$ & $115 / 0.383$ \\
\hline 50 & CEMVN_CR_50_DE1_01 & 40 & 5 & $0 / 0$ & $0 / 0$ & $0 / 0$ & $2 / 0.333$ & $2 / 0.333$ & $2 / 0.333$ & $2 / 0.333$ \\
\hline 52 & CEMVN_CR_O0_CSC_04 & 40 & 78 & $80 / 1.000$ & $80 / 1.000$ & $80 / 1.000$ & $80 / 1.000$ & $80 / 1.000$ & $80 / 1.000$ & $80 / 1.000$ \\
\hline 53 & CEMVN_CR_00_CSC_05 & 40 & 48 & $50 / 1.000$ & $50 / 1.000$ & $50 / 1.000$ & $50 / 1.000$ & $50 / 1.000$ & $50 / 1.000$ & $50 / 1.000$ \\
\hline
\end{tabular}




\subsection{MISLE database reports}

The nature and location of allisions, collisions, and groundings in Calcasieu River that were reported in the MISLE database between 2011 and 2015 are shown in Figure 4-10. Incidents appear to be clustered in the upper reaches near Lake Charles and at the intersection with the Intracoastal Waterway. It is difficult to quantify the extent to which these data match the results of the risk assessment. During the period 2011 2014, there were three collision events at the intersection of the Intracoastal Waterway and the CRSC (\#3996410, \#4347669, and \#5017018), one collision at the mouth of Lake Calcasieu (\#4400710), one collision between the Gulf of Mexico and Lake Calcasieu (\#4218491). The analysis of NAIS data showed that collision risks are highest between the Gulf of Mexico and Lake Calcasieu. Only one of the five collisions occurred in these reaches. The remaining four events occurred in reaches where the analysis suggested collision risks were relatively low.

Figure 4-10. Collision and grounding events in Calcasieu

River, 2011-2015, as reported in the USCG MISLE database.

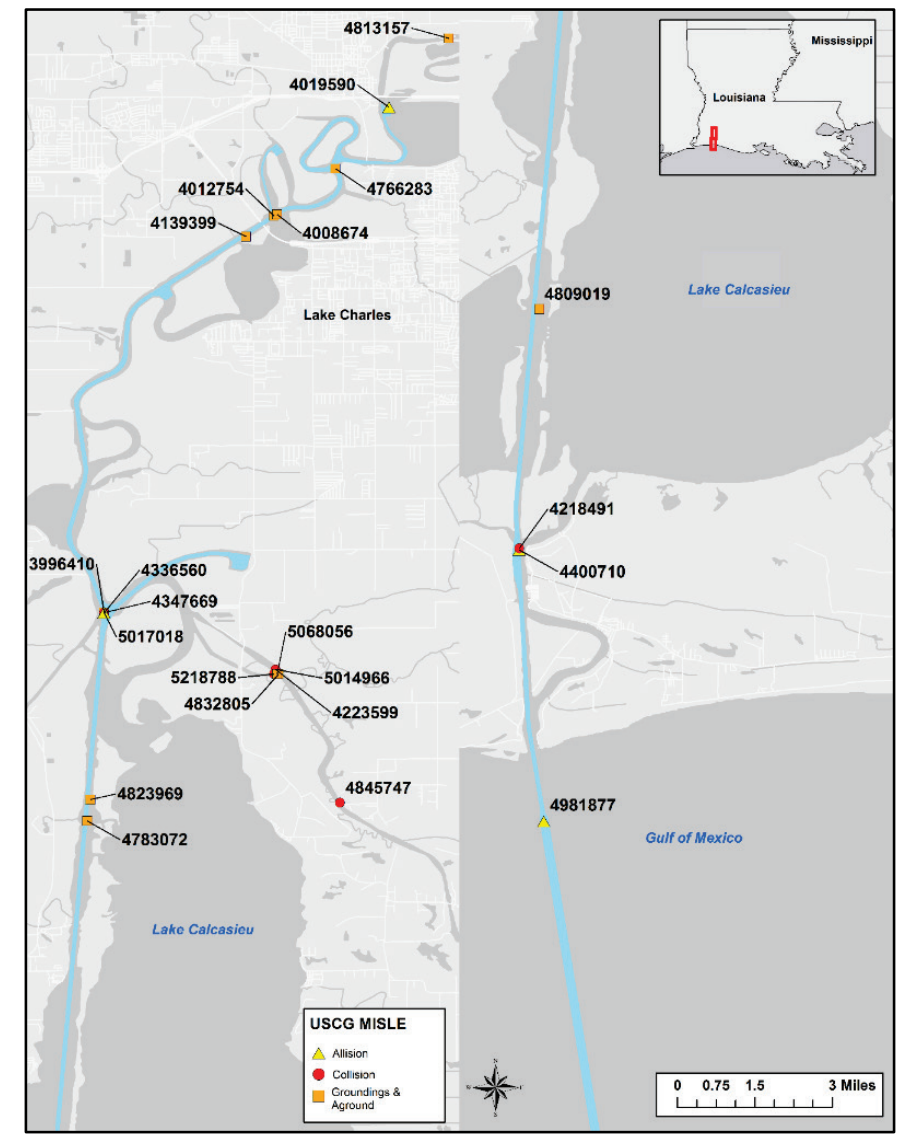




\section{Charleston Harbor Channel (CHC)}

Charleston Harbor is among the largest ports on the eastern seaboard. The port authority operates several facilities that specialize in handling containerized cargo and automobiles; there are several private bulk container terminals, and there is a Naval Weapons Station located in the Cooper River. The harbor area and its landmarks are shown in Figure 5-1. The CHC consists of 37 navigation reaches that are maintained at depths of up to $47 \mathrm{ft}$ and four Intracoastal Waterway reaches. These are shown in Figure 5-2 and listed in Table 5-1. A harbor improvement project is currently underway to increase the depth of the Harbor Entrance Channel (\#1) from $52 \mathrm{ft}$ to $54 \mathrm{ft}$ and the depth of the main harbor channels from $45 \mathrm{ft}$ to $52 \mathrm{ft}$. NAIS data were obtained for all navigation project reaches west of the midpoint of the Harbor Entrance Channel, which extends approximately 15 miles from the land side of the jetty into the Atlantic Ocean.

Figure 5-1. Map of Charleston Harbor.

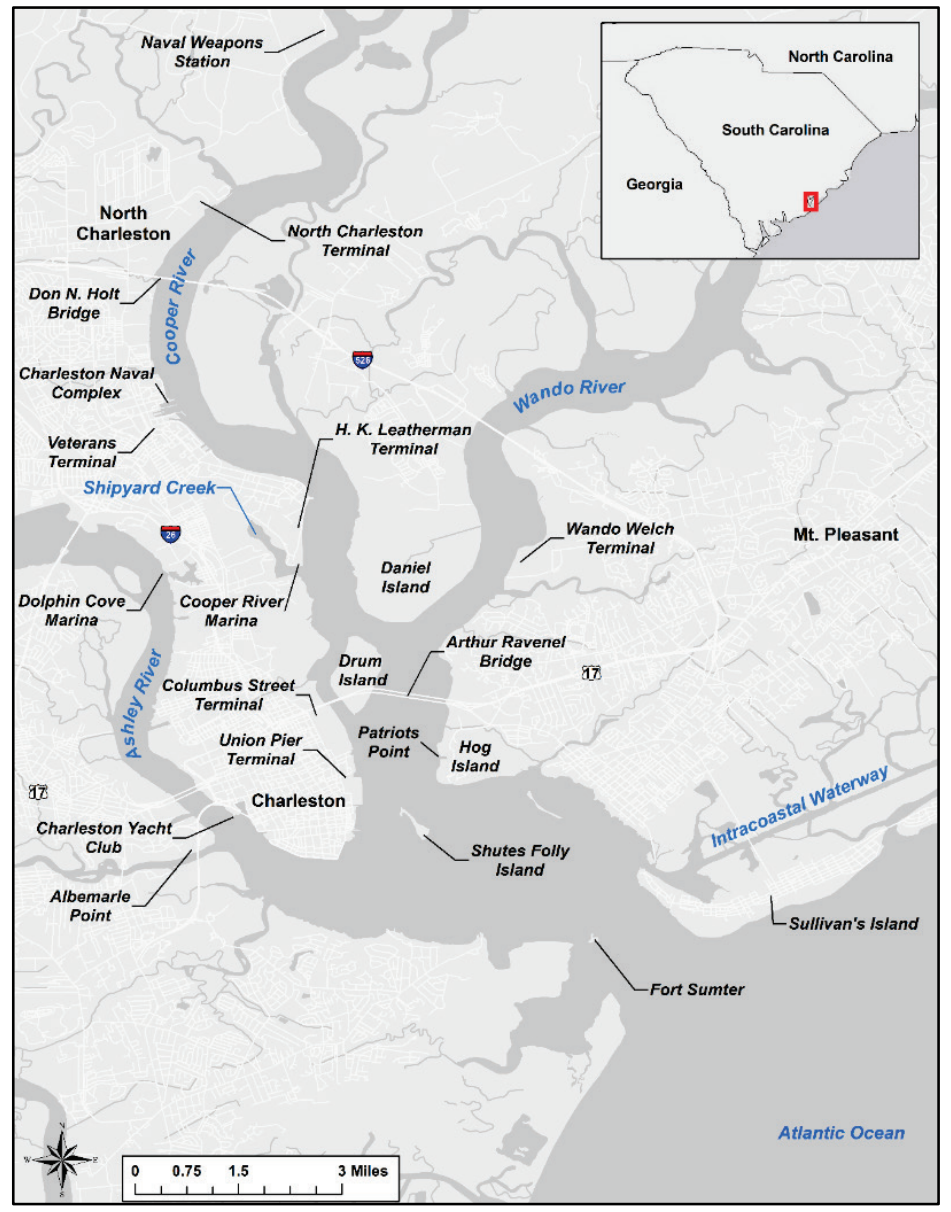


Figure 5-2. Federal navigation channel reaches in Charleston Harbor.

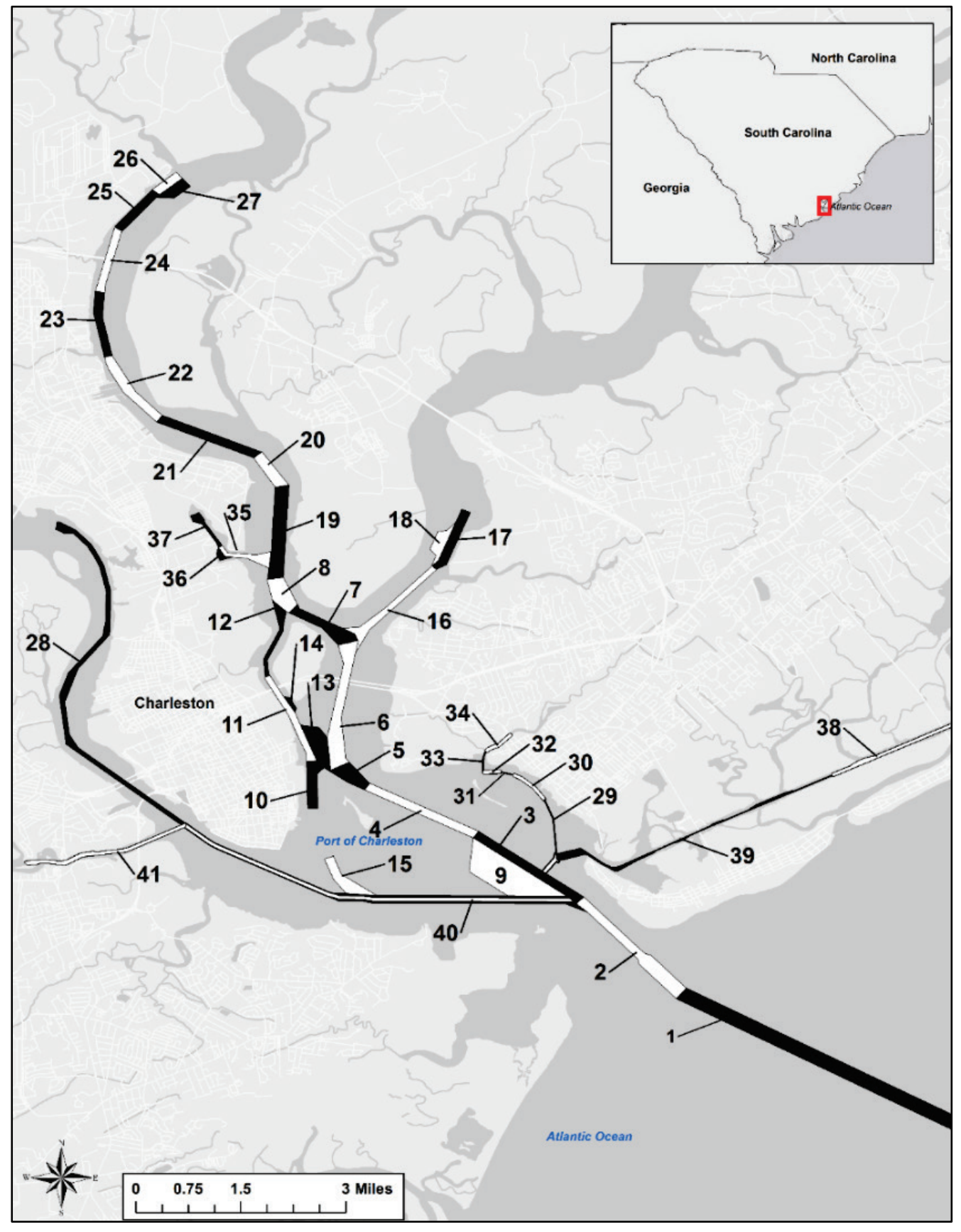


Table 5-1. Federal navigation channel reaches and reach characteristics in Charleston Harbor.

\begin{tabular}{|c|c|c|c|c|c|c|}
\hline \# & Reach Code & Description & $\begin{array}{l}\text { Authorized } \\
\text { Depth (ft) }\end{array}$ & $\begin{array}{c}\text { Maintenance } \\
\text { Depth }(\mathrm{ft})\end{array}$ & $\begin{array}{l}\text { Length } \\
\text { (miles) }\end{array}$ & $\begin{array}{l}\text { Width } \\
\text { (ft) }\end{array}$ \\
\hline 1 & CESAC_CH_01_CHE_1 & HARBOR ENTRANCE CHANNEL & 47 & 47 & 17.0 & 1000 \\
\hline 2 & CESAC_CH_02_CHL_1 & MT. PLEASANT REACH & 45 & 45 & 1.8 & $600-1000$ \\
\hline 3 & CESAC_CH_02_CHL_2 & REBELLION REACH & 45 & 45 & 1.6 & 600 \\
\hline 4 & CESAC_CH_02_CHL_3 & BENNIS REACH & 45 & 45 & 1.5 & 600 \\
\hline 5 & CESAC_CH_02_CHL_4 & HORSE REACH & 45 & 45 & 0.4 & 600 \\
\hline 6 & CESAC_CH_02_CHL_5 & HOG ISLAND REACH & 45 & 45 & 1.8 & $600-800$ \\
\hline 7 & CESAC_CH_02_CHL_6 & DRUM ISLAND REACH & 45 & 45 & 0.8 & 880 \\
\hline 8 & CESAC_CH_02_CHL_7 & MYERS BEND & 45 & 45 & 0.5 & - \\
\hline 9 & CESAC_CH_02_CHL_8 & ANCHORAGE BASIN A & 45 & 45 & 1.4 & - \\
\hline 10 & CESAC_CH_02_CHL_9 & TIDEWATER REACH & 40 & 40 & 0.7 & 650 \\
\hline 11 & CESAC_CH_02_CHL_10 & LOWER TOWN CREEK REACH & 45 & 45 & 1.3 & $400-450$ \\
\hline 12 & CESAC_CH_02_CHL_11 & UPPER TOWN CREEK REACH & 16 & 16 & 1.1 & - \\
\hline 13 & CESAC_CH_02_CHL_12 & CUSTOMHOUSE REACH & 45 & 45 & 0.7 & - \\
\hline 14 & CESAC_CH_02_CHL_13 & TOWN CREEK T.B. & 35 & 35 & 0.3 & 300 \\
\hline 15 & CESAC_CH_02_CHL_14 & AUXILLARY CHANNEL & 27 & 27 & 0.6 & - \\
\hline 16 & CESAC_CH_02_CHL_15 & WANDO RIVER LOWER & 45 & 45 & 1.4 & $400-1500$ \\
\hline 17 & CESAC_CH_02_CHL_16 & WANDO RIVER UPPER & 45 & 45 & 0.9 & $600-850$ \\
\hline 18 & CESAC_CH_02_CHL_17 & WANDO RIVER TURNING & 45 & 45 & 0.7 & 550 \\
\hline 19 & CESAC_CH_03_CHU_1 & DANIEL ISLAND REACH & 45 & 45 & 1.3 & 880 \\
\hline 20 & CESAC_CH_03_CHU_2 & DANIEL ISLAND BEND & 45 & 45 & 0.5 & $700-800$ \\
\hline 21 & CESAC_CH_03_CHU_3 & CLOUTER CREEK REACH & 45 & 45 & 1.3 & 600 \\
\hline 22 & CESAC_CH_03_CHU_4 & NAVY YARD REACH & 45 & 45 & 1.1 & $700-600$ \\
\hline
\end{tabular}




\begin{tabular}{|c|c|c|c|c|c|c|}
\hline \# & Reach Code & Description & $\begin{array}{c}\text { Authorized } \\
\text { Depth (ft) }\end{array}$ & $\begin{array}{c}\text { Maintenance } \\
\text { Depth }(\mathrm{ft})\end{array}$ & $\begin{array}{l}\text { Length } \\
\text { (miles) }\end{array}$ & $\begin{array}{l}\text { Width } \\
\text { (ft) }\end{array}$ \\
\hline 23 & CESAC_CH_03_CHU_5 & NORTH CHARLESON REACH & 45 & 45 & 0.9 & $600-500$ \\
\hline 24 & CESAC_CH_03_CHU_6 & FILBIN CREEK REACH & 45 & 45 & 0.9 & 500 \\
\hline 25 & CESAC_CH_03_CHU_7 & PORT TERMINAL REACH & 45 & 45 & 0.7 & 600 \\
\hline 26 & CESAC_CH_03_CHU_8 & ORDNANCE REACH & 45 & 45 & 0.4 & 600 \\
\hline 27 & CESAC_CH_03_CHU_9 & ORDNANCE REACH T.B. & 45 & 45 & 0.4 & 800 \\
\hline 28 & CESAC_CH_04_ASR_1 & ASHLEY RIVER REACH 1 & 30 & 30 & 10.3 & $300-600$ \\
\hline 29 & CESAC_CH_05_SHM_1 & SHEM CREEK REACH 1 & 10 & 10 & 0.9 & 90 \\
\hline 30 & CESAC_CH_05_SHM_2 & SHEM CREEK REACH 2 & 10 & 10 & 0.6 & 90 \\
\hline 31 & CESAC_CH_05_SHM_3 & SHEM CREEK REACH 3 & 10 & 10 & 1.4 & 90 \\
\hline 32 & CESAC_CH_05_SHM_4 & SHEM CREEK REACH 4 & 10 & 10 & 1.5 & 110 \\
\hline 33 & CESAC_CH_05_SHM_5 & SHEM CREEK REACH 5 & 10 & 10 & 1.7 & 110 \\
\hline 34 & CESAC_CH_05_SHM_6 & SHEM CREEK REACH 6 & 10 & 10 & 2.1 & $90-130$ \\
\hline 35 & CESAC_CH_06_SYR_1 & LOWER SHIPYARD RIVER & 45 & 45 & 0.7 & $300-1300$ \\
\hline 36 & CESAC_CH_06_SYR_2 & UPPER SHIPYARD RIVER & 30 & 30 & 0.6 & 200 \\
\hline 37 & CESAC_CH_06_SYR_3 & LOWER SHIPYARD RIVER T.B. & 45 & 45 & 0.2 & - \\
\hline 38 & CESAC_AW_04_WBC_11 & REACH 20 (Intracoastal Waterway) & 12 & 12 & 5.5 & 90 \\
\hline 39 & CESAC_AW_04_WBC_12 & REACH 21 (Intracoastal Waterway) & 12 & 12 & 3.7 & 90 \\
\hline 40 & CESAC_AW_05_CHH_1 & REACH 22 (Intracoastal Waterway) & 12 & 12 & 5.8 & 90 \\
\hline 41 & CESAC_AW_06_CHP_1 & REACH 23 (Intracoastal Waterway) & 12 & 12 & 3.3 & 90 \\
\hline
\end{tabular}




\subsection{Static vessel data}

During the 2014 Calendar year, NAIS receivers intercepted AIS messages from 2,230 unique vessels. Four records contained a malformed MMSI code, 249 records (11.2\%) contained unknown or missing ship and cargo type codes, and 170 records (7.6\%) did not report vessel name. A large number of records were missing data on length, beam, and maximum static draft. Length was missing from 302 records (13.2\%), beam was missing from 305 records (13.6\%), and 1,177 records (52.7\%) were missing maximum static draft. This includes vessels equipped with Class B AIS transponders, which are not required to broadcast maximum static draft. Independent databases were used to determine the ship and cargo type codes of vessels with missing or unknown ship and cargo type codes, and the ship and cargo type codes of vessels using the code for WIG craft (2029) or the omnibus category of vessels (90-99).

A summary of vessels operating in CHC during calendar year 2014 is provided in Table 5-2. Of the 2,230 AIS-equipped vessels utilizing the federal channel, the largest category was pleasure craft and sailboats, with 1,189 vessels reporting ship and cargo type codes 36 or 37. Cargo vessels were the third largest category, with 624 vessels reporting code 70-79. Tankers were the fourth largest category, with 97 tankers reporting codes $80-89$. Together, these four categories accounted for $85 \%$ of all vessels utilizing the harbor.

Static vessel data were requested without information about the location of the EPFS antenna on the vessel. The location of the EPFS antenna on board each vessel was taken from the AISAP vessel inventory where the MMSI number, length, and beam reported in the NAIS data matched those reported in AISAP. This method worked for 1,524 vessels (68.3\%). If a matching MMSI was found, but the length and beam did not match, the vessel's name as reported in static vessel data was compared to that reported in AISAP, and if similar, the EPFS antenna was placed in relative proportion to the position reported in AISAP. This method worked for 78 vessels (3.5\%). If no matching MMSI was found in the AISAP inventory or if the length, beam, or transponder location was not reported, the AIS transponder was positioned at the center of the vessel. This method was used for 628 vessels (28.2\%), including 173 vessels classified under unknown ship and cargo type codes, 255 vessels operating as pleasure craft or sailing vessels, 124 vessels operating as cargo vessels, and 17 vessels operating as tankers. 
Table 5-2. Descriptive summary of vessels utilizing CHC in 2014.

\begin{tabular}{|c|c|c|c|}
\hline \multirow[b]{2}{*}{ AIS Ship and Cargo Type } & \multirow{2}{*}{$\begin{array}{l}\text { AIS Ship and } \\
\text { Cargo } \\
\text { Type Code }\end{array}$} & \multicolumn{2}{|c|}{ Number of Unique Vessels } \\
\hline & & $\begin{array}{c}\text { Before Review } \\
\text { of Static Vessel } \\
\text { Data }\end{array}$ & $\begin{array}{c}\text { After Review of } \\
\text { Static Vessel } \\
\text { Data }\end{array}$ \\
\hline Unknown & 00 & 192 & 57 \\
\hline WIG & $20-29$ & 1 & 0 \\
\hline Fishing vessels & 30 & 22 & 24 \\
\hline Towing & $31-32$ & 45 & 48 \\
\hline Engaged in dredging or underwater operations & 33 & 13 & 17 \\
\hline Engaged in diving operations & 34 & 0 & 0 \\
\hline Engaged in military operations & 35 & 31 & 39 \\
\hline Sailing vessels & 36 & 404 & 441 \\
\hline Pleasure craft & 37 & 699 & 748 \\
\hline Reserved for future use & $38-39$ & 0 & 0 \\
\hline High-speed craft (HSC) or passenger ferries & $40-49$ & 3 & 3 \\
\hline Pilot vessels & 50 & 3 & 3 \\
\hline Search and rescue vessels & 51 & 6 & 6 \\
\hline Tugs & 52 & 55 & 68 \\
\hline Port tenders & 53 & 1 & 1 \\
\hline Vessels with anti-pollution facilities & 54 & 2 & 2 \\
\hline Law enforcement vessels & 55 & 3 & 5 \\
\hline Spare for assignment to local vessels & $56-57$ & 0 & 0 \\
\hline Medical transports & 58 & 1 & 1 \\
\hline Ships according to RR Resolution (Mob-83) & 59 & 0 & 0 \\
\hline Passenger ships & $60-69$ & 30 & 30 \\
\hline Cargo ships & $70-79$ & 595 & 624 \\
\hline Tankers & $80-89$ & 95 & 97 \\
\hline Other vessels & $90-99$ & 29 & 16 \\
\hline Total & & 2230 & 2230 \\
\hline
\end{tabular}

\subsection{Collision risk assessment}

Position reports were sampled at $30 \mathrm{sec}$ intervals. The position report from each vessel in each 30 sec interval was compared to the position report from every other vessel in that $30 \mathrm{sec}$ interval. The position report was classified as an SDV if the perimeter of another vessel was located within the domain of the vessel transmitting the AIS signal. Encounters are interactions between two vessels during which one vessel encroaches 
on the domain of another vessel. If both vessels encroach on each other's domain during an interaction, two encounters are recorded. Each encounter is documented by a series of position reports for the encroached vessel in which at least one position report is classified as an SDV. Two position reports that are classified as SDVs are regarded as belonging to the same encounter if separated by a period no more than 10 minutes. Encounters between one or more vessels classified under AIS ship and cargo type codes 31, 32, and 50-57 were removed from the inventory. Encounters between dredgers or dredgers and crew boats, and encounters between tenders and their mother ships were also removed from the inventory. Only position reports from within the federal channel are considered in the analysis of SDVs.

\subsubsection{Location and severity of encounters}

During 2014, this analysis of AIS data identified 253 encounters in the federal channels of Charleston Harbor. The location and severity of encounters in $\mathrm{CHC}$ are shown in Figure 5-3. Each point represents the geometric center of the encroached vessel at the time of maximum SDV severity during its encounter with the other vessel. The color of each point indicates the maximum SDV severity score. Clusters of points indicate locations where encounters are most common. There is a cluster of encounters in Horse Reach (\#5) and at the base of Hog Island Reach (\#6). Myer's Bend (\#8) and Daniel Island Reach (\#19) also have clusters of encounters.

Clusters of encounters with high maximum SDV severity scores can be seen in the Wando River Upper Reach (\#17), near Wando Welch Terminal, and in the Port Terminal Reach (\#25), near the North Charleston Terminal. Cargo vessels are generally under tug assist while docking, and these events may not raise the same level of concern as those that occur while two vessels are in transit. Aside from the concentrations of orange and red dots near the Wando Welch and North Charleston terminals, the highest maximum SDV severity scores appear to be scattered throughout CHC. 
Figure 5-3. Encounters in $\mathrm{CHC}$.

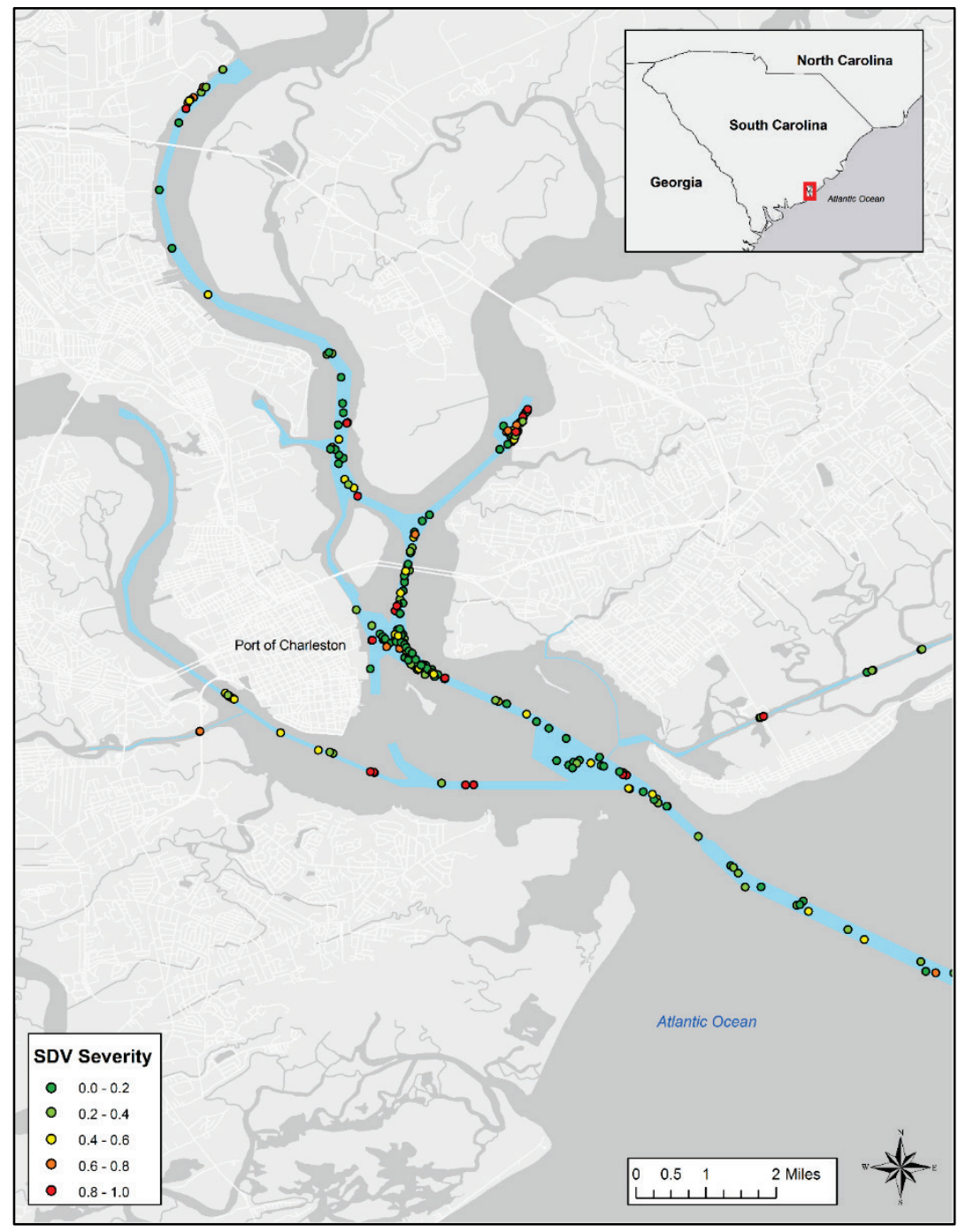

Empirical CDFs summarize selected characteristics of encounters in Figure 5-4. These include the maximum SDV severity score during each encounter, the minimum distance between vessels during each encounter, and the duration of each encounter. Approximately 30\% of encounters have maximum SDV severity scores less than approximately 0.05, and $82 \%$ of encounters have maximum SDV severity scores less than 0.7. Only $10 \%$ of encounters have maximum SDV severity scores greater than 0.9. Most of the encounters with the highest SDV severity scores occurred near Wando Welch Terminal. However, one of these encounters involved two cargo vessels in the Harbor Entrance Channel (\#1), and another encounter involved a cargo vessel and a tanker in Rebellion Reach (\#3). Each of these encounters is discussed here in greater detail. 
The encounter between cargo vessels in the Harbor Entrance Channel (\#1) involved two container ships operated by the same company, Vessel A and Vessel B. Vessel A was traveling at 17.5 knots on a course of $118^{\circ}$, and Vessel B was traveling at 16.1 knots on a course of $119^{\circ}$. During the encounter, the minimum estimated distance between vessel perimeters was $0.97 \mathrm{~m}$. This is estimated based on each vessel's reported position during the $30 \mathrm{sec}$ time interval. While it is possible that these two vessels came within such a small distance of one another, it is recommended that results such as these be investigated more fully to identify potential sources of error.

Sources of error in estimating the minimum distance between vessel perimeters during an encounter include errors in vessel dimensions and differences in position report transmission times. In this case, each vessel's dimensions and AIS transponder location were fully reported in static vessel data and verified. Therefore, error projecting vessel perimeters seems unlikely. However, there was a $15 \mathrm{sec}$ difference in position report transmission times. Vessel A transmitted its position at 00:00:46 UTC and Vessel B transmitted its position fifteen seconds later, at 00:01:01 UTC. During the 15 seconds between transmission times, each vessel moved approximately $129.5 \mathrm{~m}\left(\operatorname{sqrt}\left(17.5^{*} 16.1\right)=16.75 \mathrm{knots}=8.63 \mathrm{~m} / \mathrm{sec}\right.$; $8.63 \mathrm{~m} / \mathrm{sec} * 16 \mathrm{sec}=129.5 \mathrm{~m}$ ). This results in an underestimate of the minimum distance between vessel perimeters. In the absence of this error, this analysis would still have indicated that an SDV had occurred and the SDV severity score would still have been relatively high.

The encounter between a cargo vessel and a tanker in Rebellion Reach occurred on 28 June 2014. The $294 \mathrm{~m}$ container ship was traveling at 13.1 knots on a course of $130^{\circ}$ when it encountered a $144 \mathrm{~m}$ tanker traveling at 11.5 knots on a course of $133^{\circ}$. The encounter lasted between 1 and 1.5 minutes, and the minimum distance between vessels was $5.2 \mathrm{~m}$. The maximum SDV severity scores were 0.965 for the tanker and 0.975 for the cargo vessel. The distance between vessels seems very small, but there are no apparent sources of error in the record. Vessel dimensions and the location of the AIS transponder on board each vessel are known from the NAIS static vessel data. Differences in the time of AIS message transmission from each vessel were 2 sec or less, so this does not seem like a major source of potential error. In this case, more study would be needed to gain a better understanding of this encounter and assess the accuracy of the estimated minimum distance between vessels. 
Empirical CDFs for the minimum distance between vessel perimeters during an encounter and the duration of CDFs are shown in Figure 5-4. The analysis shows that the minimum distance between encroached and encroaching vessel perimeters is less than $5 \mathrm{~m}$ in approximately $10 \%$ of encounters. Approximately $75 \%$ of encounters are characterized by a minimum distance of more than $50 \mathrm{~m}$. Approximately $70 \%$ of encounters last less than 1 minute, and $90 \%$ of encounters last less than 5 minutes. The longest encounters involved two vessels in the vicinity of piers or terminals, and two vessels in transit at a similar speed and course.

Figure 5-4. Characteristics of encounters in $\mathrm{CHC}$.
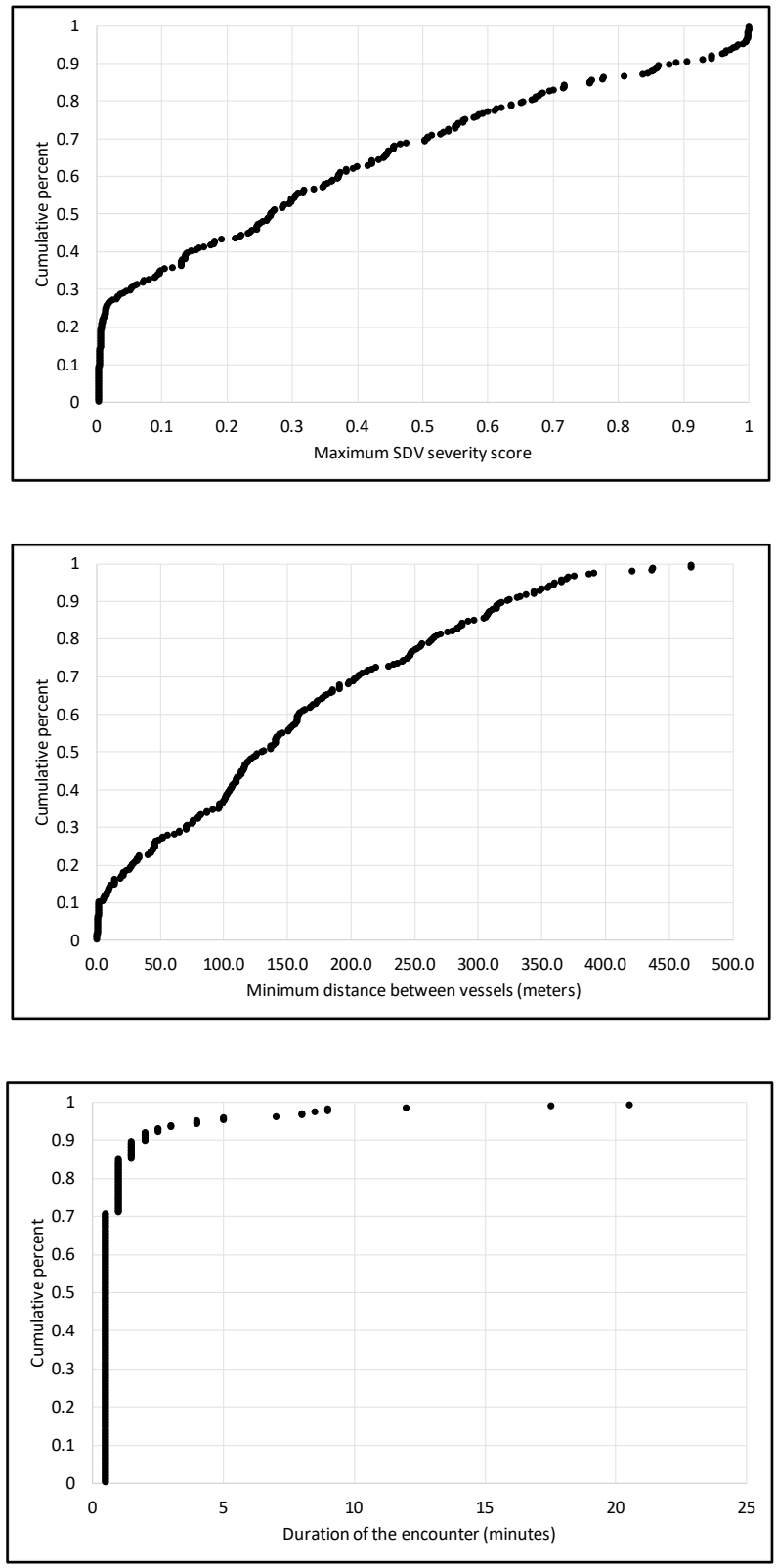


\subsubsection{Types of vessels involved in encounters}

The types of vessels involved in encounters in $\mathrm{CHC}$ are summarized in Table 5-3. This table shows the encroaching vessel category across the top and the encroached vessel category down the left-hand side of the table. Most encounters involve at least one cargo vessel (70-79). Cargo vessel ship domains were encroached 181 times during 2014, and cargo vessels encroached on another vessel's ship domain 104 times. There were 83 ship domain violations involving two cargo vessels. There were 202 encounters involving at least one cargo vessel $(181+104-83=202)$. Vessels classified under the ship and cargo type code for tankers (80-89), which are rarely involved in encounters, were identified as the encroaching vessel in four encounters and as the encroached vessel in nine encounters.

Passenger vessels (60-69) encroached on the ship domains of cargo vessels (70-79) and tankers (80-89) a total of 49 times during calendar year 2014. Three passenger vessels accounted for all but two of these encroachments. The passenger vessel with the largest number of encounters was a vessel that provides sightseeing tours of Charleston Harbor. This vessel was classified as the encroaching vessel in 21 of the 49 encounters. Two crew boats account for 26 of the remaining SDVs. During each encounter, the crew boats were in transit and operating at speeds of 10 to 25 knots. Two cruise boats were also identified as the encroaching vessel in encounters involving cargo vessels and tankers. These cruise boats were each in transit at the time the encounters occurred. The encounters occurred in Horse Reach (\#5) and in Anchorage Basin A (\#9).

Vessels identified as sailing vessels (36) were involved in 34 encounters in CHC during calendar year 2014. In 94\% of these encounters, the sailing vessel was classified as the encroaching vessel. The statistics are similar for vessels classified under the ship and cargo type code for pleasure craft (37). These vessels were involved in 43 encounters during 2014. Pleasure craft were identified as the encroaching vessel during $84 \%$ of those SDVs (36 times). A total of 71 encounters involved at least one pleasure craft or sailing vessel. However, only 6 of these 71 encounters (8.5\%) involved one sailing vessel and one pleasure craft. Sailing vessels were far more likely to be involved in encounters with other sailing vessels than with other pleasure craft. Similarly, pleasure craft were far more likely to be involved in encounters with other pleasure craft than with sailing vessels. 
Table 5-3. Number of encounters in CHC by AIS ship and cargo type.

\begin{tabular}{|c|c|c|c|c|c|c|c|c|c|c|c|c|c|c|}
\hline \multirow{2}{*}{\multicolumn{2}{|c|}{$\begin{array}{l}\text { Encroached Vessel AIS } \\
\text { Ship and Cargo Type }\end{array}$}} & \multicolumn{12}{|c|}{ Encroaching Vessel AIS Ship and Cargo Type } & \multirow[b]{2}{*}{ Total } \\
\hline & & $\begin{array}{l}\text { Unknown } \\
\text { (00) }\end{array}$ & $\begin{array}{c}\text { WIG } \\
(20-29)\end{array}$ & $\begin{array}{c}\text { Dredging } \\
\text { (33) }\end{array}$ & $\begin{array}{c}\text { Military } \\
\text { (35) }\end{array}$ & $\begin{array}{l}\text { Sailing } \\
\text { (36) }\end{array}$ & $\begin{array}{c}\text { Pleasure } \\
\text { (37) }\end{array}$ & $\begin{array}{l}\text { High- } \\
\text { Speed } \\
(40-49)\end{array}$ & $\begin{array}{l}\text { Harbor } \\
\text { Boats } \\
(50-57)\end{array}$ & $\begin{array}{c}\text { Passenger } \\
(60-69)\end{array}$ & $\begin{array}{l}\text { Cargo } \\
(70-79)\end{array}$ & $\begin{array}{l}\text { Tanker } \\
(80-89)\end{array}$ & $\begin{array}{l}\text { Other } \\
(90-99)\end{array}$ & \\
\hline Unknown & $(00)$ & - & - & - & - & - & - & - & - & - & - & - & - & 0 \\
\hline WIG & $(20-29)$ & - & - & - & - & - & - & - & - & - & - & - & - & 0 \\
\hline Dredging & (33) & - & - & - & 1 & - & - & - & - & - & 14 & - & 1 & 16 \\
\hline Military & (35) & - & - & 1 & - & 1 & - & - & - & - & 1 & - & - & 3 \\
\hline Sailing & (36) & - & - & - & - & 12 & 2 & - & - & - & - & - & - & 14 \\
\hline Pleasure & (37) & 1 & - & - & - & 4 & 14 & - & - & 2 & - & - & - & 21 \\
\hline High-Speed & $(40-49)$ & - & - & - & - & - & - & - & - & - & - & - & - & 0 \\
\hline Harbor Boats & $(50-57)$ & - & - & - & - & - & - & - & - & - & - & - & - & - \\
\hline Passenger & $(60-69)$ & - & - & - & - & 1 & 2 & - & - & 2 & 4 & - & - & 9 \\
\hline Cargo & (70-79) & 5 & - & 10 & 4 & 12 & 16 & - & - & 46 & 83 & 4 & 1 & 181 \\
\hline Tanker & $(80-89)$ & - & - & - & - & 2 & 2 & - & - & 3 & 2 & - & - & 9 \\
\hline Other & (90-99) & - & - & - & - & - & - & - & - & - & - & - & - & 0 \\
\hline To & & 6 & 0 & 11 & 5 & 32 & 36 & 0 & - & 53 & 104 & 4 & 2 & 253 \\
\hline
\end{tabular}




\subsubsection{Frequency of SDVs}

The NAIS database for calendar year 2014 was sampled at $30 \mathrm{sec}$ intervals. Vessels identified as towboats and tugboats were excluded from the analysis (ship and cargo type codes 31-32 and 50-57). Position reports from outside the federal channel were also excluded from the analysis. This yielded a database of $1,571,942$ position reports. Vessels identified as being in Intracoastal Waterway Reach 22 (\#40) were assigned to Ashley River Reach 1 (\#28) because these two reaches overlap each other.

The conditional frequency of an SDV is calculated as the ratio of the number of position reports in a reach that are classified as SDVs to the total number of position reports in that reach. The conditional frequency of an SDV is an estimate of the probability that an SDV occurs in a reach given that at least one vessel is present in that reach. The conditional frequency of an SDV is summarized in Table 5-4 by navigation channel reach and by ship and cargo type code. Over all ship and cargo types, there were 447 position reports classified as SDVs. Therefore, the overall conditional frequency of SDVs in federal navigation channels in Charleston Harbor is $2.84 \times 10^{-4}$. Three reaches have overall conditional probabilities of an SDV greater than $1.0 \times 10^{-3}$. These are Horse Reach (\#5), Wando River Upper (\#17), and Port Terminal Reach (\#25). Hog Island Reach (\#6) and Customhouse Reach (\#11) have conditional probabilities of an SDV that are higher than those in other reaches, but still less than $1.0 \times 10^{-3}$.

Vessels classified under ship and cargo type codes for cargo vessels (70-79) and tankers (80-89) are the largest vessels in the harbor, and because they have the largest ship domains, may tend to have the highest conditional probabilities of an SDV. For cargo vessels, the highest conditional probabilities of an SDV are in Lower Shipyard River (\#35), Anchorage Basin A (\#9), and Horse Reach. Cargo vessels also have high conditional probabilities of SDVs in the Wando River Upper Reach, Hog Island Reach, and Port Terminal Reach. For tankers, the highest conditional probabilities of an SDV are in the Lower Shipyard River, Anchorage Basin A, and in the Harbor Entrance Channel (\#1). 
Table 5-4. The conditional frequency of SDVs in $\mathrm{CHC}$ by reach and vessel type. Frequencies greater than $1 \times 10^{-3}$ are in bold red typeface.

\begin{tabular}{|c|c|c|c|c|c|c|c|c|c|c|c|}
\hline \multirow[b]{2}{*}{ \# } & \multirow[b]{2}{*}{ Reach Code } & \multicolumn{9}{|c|}{ AIS Ship and Cargo Type } & \multirow[b]{2}{*}{$\begin{array}{c}\text { All Vesse } \\
\text { Types }\end{array}$} \\
\hline & & $\begin{array}{c}\text { Unknown } \\
(00)\end{array}$ & $\begin{array}{c}\text { WIG } \\
(20-29)\end{array}$ & $\begin{array}{c}\text { Class } 3 \\
(30,33-39)\end{array}$ & $\begin{array}{c}\text { High-Speed } \\
\text { (40-49) }\end{array}$ & $\begin{array}{c}\text { Harbor Boats } \\
\qquad(50-57)\end{array}$ & $\begin{array}{c}\text { Passenger } \\
\text { (60-69) }\end{array}$ & $\begin{array}{l}\text { Cargo } \\
\text { (70-79) }\end{array}$ & $\begin{array}{l}\text { Tanker } \\
\text { (80-89) }\end{array}$ & $\begin{array}{c}\text { Other } \\
\text { (90-99) }\end{array}$ & \\
\hline 1 & CESAC_CH_01_CHE_1 & $0.00 \mathrm{E}+00$ & - & 7.64E-05 & $0.00 \mathrm{E}+00$ & - & $0.00 \mathrm{E}+00$ & 1.70E-04 & $1.00 \mathrm{E}-03$ & $0.00 \mathrm{E}+00$ & $1.62 \mathrm{E}-04$ \\
\hline 2 & CESAC_CH_02_CHL_1 & $0.00 \mathrm{E}+00$ & - & $0.00 E+00$ & $0.00 \mathrm{E}+00$ & - & $0.00 \mathrm{E}+00$ & $2.70 \mathrm{E}-04$ & $2.40 \mathrm{E}-04$ & $0.00 \mathrm{E}+00$ & $1.61 \mathrm{E}-04$ \\
\hline 3 & CESAC_CH_02_CHL_2 & $0.00 E+00$ & - & $0.00 E+00$ & $0.00 E+00$ & - & $0.00 E+00$ & $1.62 \mathrm{E}-04$ & $5.42 \mathrm{E}-04$ & $0.00 E+00$ & 1.43E-04 \\
\hline 4 & CESAC_CH_02_CHL_3 & $0.00 \mathrm{E}+00$ & - & 1.46E-04 & $0.00 \mathrm{E}+00$ & - & $0.00 \mathrm{E}+00$ & 3.64E-04 & 2.60E-04 & $0.00 \mathrm{E}+00$ & 2.83E-04 \\
\hline 5 & CESAC_CH_02_CHL_4 & $0.00 E+00$ & - & $2.41 \mathrm{E}-04$ & $0.00 E+00$ & - & $0.00 E+00$ & $1.84 \mathrm{E}-03$ & $0.00 E+00$ & $0.00 E+00$ & $1.33 E-03$ \\
\hline 6 & CESAC_CH_02_CHL_5 & $0.00 E+00$ & - & $0.00 E+00$ & - & - & $1.72 \mathrm{E}-04$ & $1.12 \mathrm{E}-03$ & $3.81 \mathrm{E}-04$ & $0.00 \mathrm{E}+00$ & $8.41 \mathrm{E}-04$ \\
\hline 7 & CESAC_CH_02_CHL_6 & $0.00 E+00$ & - & $0.00 E+00$ & - & - & $0.00 \mathrm{E}+00$ & 4.48E-04 & $0.00 E+00$ & $0.00 \mathrm{E}+00$ & $2.53 \mathrm{E}-04$ \\
\hline 8 & CESAC_CH_02_CHL_7 & $0.00 E+00$ & - & $0.00 E+00$ & - & - & $0.00 E+00$ & $9.21 \mathrm{E}-04$ & $0.00 \mathrm{E}+00$ & $0.00 \mathrm{E}+00$ & 4.66E-04 \\
\hline 9 & CESAC_CH_02_CHL_8 & $0.00 \mathrm{E}+00$ & - & $1.53 \mathrm{E}-05$ & $0.00 E+00$ & - & $0.00 E+00$ & $1.73 \mathrm{E}-03$ & 4.26E-03 & $0.00 \mathrm{E}+00$ & $1.26 \mathrm{E}-04$ \\
\hline 10 & CESAC_CH_02_CHL_9 & - & - & $0.00 \mathrm{E}+00$ & - & - & 2.66E-04 & $0.00 E+00$ & - & $0.00 \mathrm{E}+00$ & 2.03E-04 \\
\hline 11 & CESAC_CH_02_CHL_10 & $0.00 E+00$ & - & $8.94 \mathrm{E}-04$ & - & - & $0.00 E+00$ & $1.34 \mathrm{E}-04$ & $0.00 E+00$ & $0.00 \mathrm{E}+00$ & $2.12 \mathrm{E}-04$ \\
\hline 12 & CESAC_CH_02_CHL_11 & - & - & $0.00 E+00$ & - & - & $0.00 \mathrm{E}+00$ & - & - & - & $0.00 E+00$ \\
\hline 13 & CESAC_CH_02_CHL_12 & $0.00 E+00$ & - & $0.00 E+00$ & - & - & 9.09E-04 & $8.47 \mathrm{E}-04$ & $0.00 E+00$ & $0.00 \mathrm{E}+00$ & $7.24 \mathrm{E}-04$ \\
\hline 14 & CESAC_CH_02_CHL_13 & - & - & $0.00 E+00$ & - & - & $0.00 \mathrm{E}+00$ & $0.00 E+00$ & - & - & $0.00 \mathrm{E}+00$ \\
\hline 15 & CESAC_CH_02_CHL_14 & $0.00 E+00$ & - & $0.00 E+00$ & $0.00 E+00$ & - & $0.00 E+00$ & $0.00 E+00$ & - & $0.00 \mathrm{E}+00$ & $0.00 E+00$ \\
\hline 16 & CESAC_CH_02_CHL_15 & $0.00 \mathrm{E}+00$ & - & $0.00 E+00$ & - & - & $0.00 \mathrm{E}+00$ & 7.46E-05 & - & - & 7.10E-05 \\
\hline 17 & CESAC_CH_02_CHL_16 & - & - & $0.00 E+00$ & - & - & $0.00 E+00$ & $1.10 \mathrm{E}-03$ & - & - & $1.09 \mathrm{E}-03$ \\
\hline 18 & CESAC_CH_02_CHL_17 & - & - & $0.00 E+00$ & - & - & $0.00 \mathrm{E}+00$ & $5.01 \mathrm{E}-04$ & - & - & 4.62E-04 \\
\hline 19 & CESAC_CH_03_CHU_1 & $0.00 E+00$ & - & $7.04 \mathrm{E}-05$ & - & - & $0.00 E+00$ & $2.98 \mathrm{E}-04$ & $0.00 E+00$ & $0.00 E+00$ & $1.08 \mathrm{E}-04$ \\
\hline 20 & CESAC_CH_03_CHU_2 & $0.00 \mathrm{E}+00$ & - & 9.66E-05 & - & - & $0.00 E+00$ & 4.31E-04 & $0.00 \mathrm{E}+00$ & $0.00 \mathrm{E}+00$ & $2.14 \mathrm{E}-04$ \\
\hline 21 & CESAC_CH_03_CHU_3 & $0.00 E+00$ & - & $0.00 E+00$ & - & - & $0.00 \mathrm{E}+00$ & $0.00 E+00$ & $0.00 E+00$ & $0.00 E+00$ & $0.00 E+00$ \\
\hline 22 & CESAC_CH_03_CHU_4 & $0.00 E+00$ & - & $0.00 E+00$ & - & - & $0.00 E+00$ & $1.34 \mathrm{E}-04$ & $0.00 \mathrm{E}+00$ & $0.00 E+00$ & $1.01 \mathrm{E}-04$ \\
\hline
\end{tabular}




\begin{tabular}{|c|c|c|c|c|c|c|c|c|c|c|c|}
\hline \multirow[b]{2}{*}{ \# } & \multirow[b]{2}{*}{ Reach Code } & \multicolumn{9}{|c|}{ AIS Ship and Cargo Type } & \multirow{2}{*}{$\begin{array}{c}\text { All Vessel } \\
\text { Types }\end{array}$} \\
\hline & & $\begin{array}{c}\text { Unknown } \\
(00)\end{array}$ & $\begin{array}{c}\text { WIG } \\
(20-29)\end{array}$ & $\begin{array}{c}\text { Class } 3 \\
(30,33-39)\end{array}$ & $\begin{array}{l}\text { High-Speed } \\
\qquad(40-49)\end{array}$ & $\begin{array}{c}\text { Harbor Boats } \\
\qquad(50-57)\end{array}$ & $\begin{array}{c}\text { Passenger } \\
\text { (60-69) }\end{array}$ & $\begin{array}{l}\text { Cargo } \\
\text { (70-79) }\end{array}$ & $\begin{array}{l}\text { Tanker } \\
(80-89)\end{array}$ & $\begin{array}{c}\text { Other } \\
\text { (90-99) }\end{array}$ & \\
\hline 23 & CESAC_CH_03_CHU_5 & $0.00 \mathrm{E}+00$ & - & $0.00 \mathrm{E}+00$ & - & - & $0.00 E+00$ & 7.65E-05 & $0.00 \mathrm{E}+00$ & $0.00 \mathrm{E}+00$ & $6.27 \mathrm{E}-05$ \\
\hline 24 & CESAC_CH_03_CHU_6 & $0.00 E+00$ & - & $0.00 \mathrm{E}+00$ & - & - & $0.00 E+00$ & 7.18E-05 & $0.00 \mathrm{E}+00$ & $0.00 \mathrm{E}+00$ & 6.15E-05 \\
\hline 25 & CESAC_CH_03_CHU_7 & $0.00 \mathrm{E}+00$ & - & $0.00 E+00$ & - & - & $0.00 \mathrm{E}+00$ & $1.40 \mathrm{E}-03$ & $0.00 \mathrm{E}+00$ & $0.00 \mathrm{E}+00$ & 1.27E-03 \\
\hline 26 & CESAC_CH_03_CHU_8 & - & - & $0.00 \mathrm{E}+00$ & - & - & $0.00 E+00$ & $1.00 \mathrm{E}-04$ & $0.00 \mathrm{E}+00$ & $0.00 \mathrm{E}+00$ & 9.27E-05 \\
\hline 27 & CESAC_CH_03_CHU_9 & $0.00 E+00$ & - & $0.00 \mathrm{E}+00$ & - & - & $0.00 E+00$ & $0.00 E+00$ & $0.00 E+00$ & - & $0.00 E+00$ \\
\hline 28 & CESAC_CH_04_ASR_1 & $0.00 \mathrm{E}+00$ & - & $2.73 E-04$ & $0.00 \mathrm{E}+00$ & - & $9.40 \mathrm{E}-05$ & $0.00 E+00$ & $0.00 E+00$ & $0.00 \mathrm{E}+00$ & $2.45 \mathrm{E}-04$ \\
\hline 29 & CESAC_CH_05_SHM_1 & $0.00 E+00$ & - & $0.00 E+00$ & - & - & $0.00 E+00$ & - & - & - & $0.00 E+00$ \\
\hline 30 & CESAC_CH_05_SHM_2 & $0.00 E+00$ & - & $0.00 \mathrm{E}+00$ & - & - & - & - & - & - & $0.00 E+00$ \\
\hline 31 & CESAC_CH_05_SHM_3 & - & - & $0.00 \mathrm{E}+00$ & - & - & - & - & - & - & $0.00 \mathrm{E}+00$ \\
\hline 32 & CESAC_CH_05_SHM_4 & $0.00 E+00$ & - & $0.00 E+00$ & - & - & - & - & - & - & $0.00 E+00$ \\
\hline 33 & CESAC_CH_05_SHM_5 & $0.00 E+00$ & - & $0.00 \mathrm{E}+00$ & - & - & - & - & - & - & $0.00 E+00$ \\
\hline 34 & CESAC_CH_05_SHM_6 & $0.00 \mathrm{E}+00$ & - & $0.00 \mathrm{E}+00$ & - & - & - & - & - & - & $0.00 E+00$ \\
\hline 35 & CESAC_CH_06_SYR_1 & $0.00 E+00$ & - & $0.00 E+00$ & - & - & $0.00 E+00$ & $3.46 \mathrm{E}-03$ & $6.35 \mathrm{E}-03$ & $0.00 \mathrm{E}+00$ & 9.16E-05 \\
\hline 36 & CESAC_CH_06_SYR_2 & - & - & $0.00 E+00$ & - & - & $0.00 E+00$ & $0.00 \mathrm{E}+00$ & - & - & $0.00 E+00$ \\
\hline 37 & CESAC_CH_06_SYR_3 & - & - & $0.00 E+00$ & - & - & $0.00 \mathrm{E}+00$ & - & - & - & $0.00 \mathrm{E}+00$ \\
\hline 38 & CESAC_AW_04_WBC_11 & $0.00 \mathrm{E}+00$ & - & $2.16 \mathrm{E}-04$ & $0.00 \mathrm{E}+00$ & - & $0.00 \mathrm{E}+00$ & - & - & - & $2.12 \mathrm{E}-04$ \\
\hline 39 & CESAC_AW_04_WBC_12 & $0.00 E+00$ & - & 5.89E-04 & $0.00 E+00$ & - & $0.00 E+00$ & - & - & - & $5.75 \mathrm{E}-04$ \\
\hline 40 & CESAC_AW_05_CHH_1 & - & - & - & - & - & - & - & - & - & - \\
\hline 41 & CESAC_AW_06_CHP_1 & $0.00 E+00$ & - & $2.88 \mathrm{E}-04$ & $0.00 E+00$ & - & $0.00 E+00$ & - & - & - & 2.60E-04 \\
\hline & All navigation channels & $0.00 E+00$ & - & $1.24 \mathrm{E}-04$ & $0.00 \mathrm{E}+00$ & - & $1.02 \mathrm{E}-04$ & $4.38 \mathrm{E}-04$ & $5.22 \mathrm{E}-04$ & $0.00 \mathrm{E}+00$ & 2.84E-04 \\
\hline
\end{tabular}


The reaches are compared in terms of their overall conditional probability of an SDV in Figure 5-5. Reaches with the highest conditional probability of an SDV are shown in red, orange, and yellow. Reaches with lower conditional probabilities are shown in green. Congestion in the Port Terminal Reach and the Upper Wando River seem hard to avoid because vessels are approaching other vessels at the pier. While these are risky maneuvers, the vessels are operating with the assistance of a tug, and the proximity to other vessels is intentional. Therefore, from a risk management perspective, these can be discounted. The figure shows that the highest risks are in the central part of the port, where most of the routes converge.

Figure 5-5. Conditional frequency of SDVs.

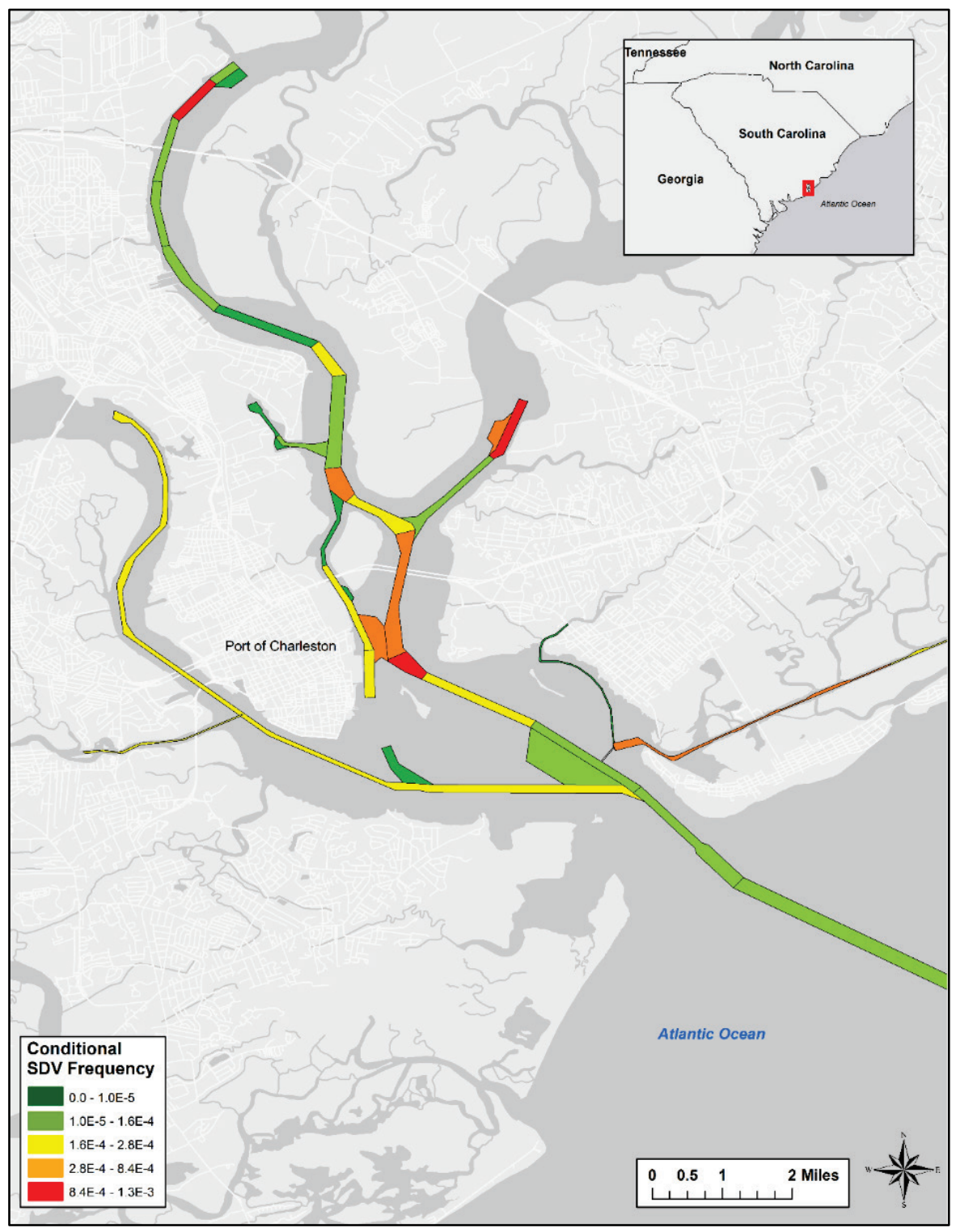


The probability that at least one vessel is present in a reach is estimated as the fraction of half-minute intervals during which there is at least one position report from the reach. Table 5-5 reports the fraction of halfminute intervals during which at least one vessel is present in federal navigation reaches located in Charleston Harbor. For example, during calendar year 2014, there was at least one vessel located within the Charleston Harbor Entrance Channel (\#1) approximately 35.6\% of the time and in the Mt. Pleasant Reach (\#2) approximately $8.5 \%$ of the time. As before, this analysis excludes those vessels classified under ship and cargo type codes 31-32 and 50-57. Over all vessels considered in this analysis and all federal navigation reaches of Charleston Harbor, at least one vessel was present in the system approximately $74.8 \%$ of the time. By itself, this statistic provides some measure of channel utilization, but there are better ways to characterize utilization. The primary purpose of calculating this statistic is to convert the conditional probability of an SDV to an unconditional probability of an SDV.

The unconditional probability that an SDV occurs in a reach is calculated by multiplying the conditional probability of an SDV by the probability that at least one vessel is present in the reach. The probability that an SDV occurs in a reach is summarized in Table 5-6 and in Figure 5-6. SDVs are most likely to occur in the Harbor Entrance Channel (\#1), Bennis Reach (\#4), Horse Reach (\#5), and Hog Island Reach (\#6). While the unconditional probability of an SDV indicates in which reaches SDVs are most likely to occur, it cannot be used to rank navigation channels or projects in terms of collision risk because it will tend to be higher in larger reaches and in reaches with more navigation traffic.

The relative frequency of SDVs is the proportion of SDVs in a port that occur in a reach. This metric is an estimate of the probability that an SDV occurs in a particular reach given that an SDV has occurred in the navigation project. The metric can be used to help planners anticipate where a collision would most likely occur. The relative frequency of SDVs in Charleston Harbor is shown in the bar chart on Figure 5-7. The highest relative frequencies are in Horse Reach (\#5), Wando River Upper (\#17), Harbor Entrance Channel (\#1), and Bennis Reach (\#4). 
Table 5-5. Fraction of half-minute intervals during which at least one vessel is present in each $\mathrm{CHC}$ reach..

\begin{tabular}{|c|c|c|c|c|c|c|c|c|c|c|c|}
\hline \multirow[b]{2}{*}{$\#$} & \multirow[b]{2}{*}{ Reach Code } & \multicolumn{9}{|c|}{ AIS Ship and Cargo Type } & \multirow[b]{2}{*}{$\begin{array}{c}\text { All Vessel } \\
\text { Types }\end{array}$} \\
\hline & & $\begin{array}{c}\text { Unknown } \\
\text { (00) }\end{array}$ & $\begin{array}{c}\text { WIG } \\
(20-29)\end{array}$ & $\begin{array}{c}\text { Class } 3 \\
(30,33-39)\end{array}$ & $\begin{array}{c}\text { High-Speed } \\
\text { (40-49) }\end{array}$ & $\begin{array}{c}\text { Harbor Boats } \\
\text { (50-57) }\end{array}$ & $\begin{array}{c}\text { Passenger } \\
\text { (60-69) }\end{array}$ & $\begin{array}{l}\text { Cargo } \\
(70-79)\end{array}$ & $\begin{array}{l}\text { Tanker } \\
\text { (80-89) }\end{array}$ & $\begin{array}{l}\text { Other } \\
(90-99)\end{array}$ & \\
\hline 1 & CESAC_CH_01_CHE_1 & 3.36E-03 & - & $1.44 \mathrm{E}-01$ & $1.83 \mathrm{E}-04$ & - & 1.56E-02 & 2.10E-01 & 1.97E-02 & 4.59E-03 & 3.56E-01 \\
\hline 2 & CESAC_CH_02_CHL_1 & 7.93E-04 & - & 2.66E-02 & $6.66 \mathrm{E}-05$ & - & 5.73E-03 & 4.84E-02 & 3.95E-03 & $9.98 \mathrm{E}-04$ & $8.52 \mathrm{E}-02$ \\
\hline 3 & CESAC_CH_02_CHL_2 & 4.07E-04 & - & $1.02 \mathrm{E}-02$ & $2.66 \mathrm{E}-05$ & - & 4.32E-03 & $4.58 \mathrm{E}-02$ & $3.48 \mathrm{E}-03$ & 7.74E-04 & $6.45 \mathrm{E}-02$ \\
\hline 4 & CESAC_CH_02_CHL_3 & 4.99E-04 & - & $1.26 \mathrm{E}-02$ & $5.61 \mathrm{E}-05$ & - & 7.07E-03 & $5.16 \mathrm{E}-02$ & $3.65 \mathrm{E}-03$ & $6.92 \mathrm{E}-04$ & $7.52 \mathrm{E}-02$ \\
\hline 5 & CESAC_CH_02_CHL_4 & $1.10 \mathrm{E}-04$ & - & $3.88 \mathrm{E}-03$ & 1.33E-05 & - & $2.22 \mathrm{E}-03$ & $1.80 \mathrm{E}-02$ & $1.21 \mathrm{E}-03$ & $2.20 \mathrm{E}-04$ & $2.55 \mathrm{E}-02$ \\
\hline 6 & CESAC_CH_02_CHL_5 & 4.95E-04 & - & $7.59 \mathrm{E}-03$ & $0.00 E+00$ & - & $1.10 \mathrm{E}-02$ & $6.12 \mathrm{E}-02$ & 4.99E-03 & $8.28 \mathrm{E}-04$ & 8.49E-02 \\
\hline 7 & CESAC_CH_02_CHL_6 & 2.07E-04 & - & 2.00E-03 & $0.00 E+00$ & - & 2.87E-03 & 1.06E-02 & 2.70E-03 & 3.61E-04 & 1.87E-02 \\
\hline 8 & CESAC_CH_02_CHL_7 & 1.26E-04 & - & $1.21 \mathrm{E}-03$ & $0.00 E+00$ & - & 2.10E-03 & 6.19E-03 & 2.37E-03 & 2.14E-04 & $1.22 \mathrm{E}-02$ \\
\hline 9 & CESAC_CH_02_CHL_8 & 8.85E-05 & - & $6.16 \mathrm{E}-02$ & 7.99E-05 & - & $1.20 \mathrm{E}-03$ & $3.29 \mathrm{E}-03$ & 4.47E-04 & 5.67E-04 & $6.69 \mathrm{E}-02$ \\
\hline 10 & CESAC_CH_02_CHL_9 & $0.00 E+00$ & - & $1.68 \mathrm{E}-03$ & $0.00 E+00$ & - & 7.14E-03 & 5.21E-04 & $0.00 E+00$ & $3.23 \mathrm{E}-05$ & 9.36E-03 \\
\hline 11 & CESAC_CH_02_CHL_10 & $1.71 \mathrm{E}-05$ & - & $2.11 \mathrm{E}-03$ & $0.00 E+00$ & - & 4.07E-03 & $7.08 \mathrm{E}-03$ & 4.28E-05 & $8.75 \mathrm{E}-05$ & 1.34E-02 \\
\hline 12 & CESAC_CH_02_CHL_11 & $0.00 E+00$ & - & $2.31 \mathrm{E}-04$ & $0.00 E+00$ & - & 4.96E-04 & $0.00 \mathrm{E}+00$ & $0.00 E+00$ & $0.00 E+00$ & 7.27E-04 \\
\hline 13 & CESAC_CH_02_CHL_12 & 2.09E-05 & - & $1.68 \mathrm{E}-03$ & $0.00 E+00$ & - & 4.18E-03 & $6.73 \mathrm{E}-03$ & $1.05 \mathrm{E}-05$ & 4.86E-04 & 1.31E-02 \\
\hline 14 & CESAC_CH_02_CHL_13 & $0.00 E+00$ & - & 2.19E-05 & $0.00 E+00$ & - & $2.38 \mathrm{E}-05$ & 3.81E-06 & $0.00 E+00$ & $0.00 E+00$ & 4.95E-05 \\
\hline 15 & CESAC_CH_02_CHL_14 & 3.04E-05 & - & $3.60 \mathrm{E}-03$ & $1.90 \mathrm{E}-06$ & - & $1.31 \mathrm{E}-03$ & $1.05 \mathrm{E}-05$ & $0.00 E+00$ & 5.90E-05 & 5.00E-03 \\
\hline 16 & CESAC_CH_02_CHL_15 & $2.38 \mathrm{E}-05$ & - & 1.80E-03 & $0.00 E+00$ & - & $1.20 \mathrm{E}-04$ & 3.83E-02 & $0.00 E+00$ & $0.00 E+00$ & 4.02E-02 \\
\hline 17 & CESAC_CH_02_CHL_16 & $0.00 E+00$ & - & $3.26 \mathrm{E}-04$ & $0.00 E+00$ & - & $2.19 \mathrm{E}-05$ & $5.02 \mathrm{E}-02$ & $0.00 E+00$ & $0.00 \mathrm{E}+00$ & $5.05 \mathrm{E}-02$ \\
\hline 18 & CESAC_CH_02_CHL_17 & $0.00 E+00$ & - & 4.66E-04 & $0.00 E+00$ & - & $9.51 \mathrm{E}-06$ & 5.70E-03 & $0.00 E+00$ & $0.00 E+00$ & $6.17 \mathrm{E}-03$ \\
\hline 19 & CESAC_CH_03_CHU_1 & 3.87E-04 & - & 6.74E-02 & $0.00 E+00$ & - & 1.02E-03 & $1.57 \mathrm{E}-02$ & 2.73E-03 & $6.05 \mathrm{E}-04$ & 8.64E-02 \\
\hline 20 & CESAC_CH_03_CHU_2 & 1.81E-04 & - & 9.85E-03 & $0.00 E+00$ & - & 1.71E-05 & 6.62E-03 & 8.35E-04 & 2.62E-04 & 1.77E-02 \\
\hline 21 & CESAC_CH_03_CHU_3 & 4.09E-04 & - & $2.91 \mathrm{E}-03$ & $0.00 E+00$ & - & 4.66E-05 & $1.65 \mathrm{E}-02$ & $2.16 \mathrm{E}-03$ & $5.77 \mathrm{E}-04$ & $2.26 \mathrm{E}-02$ \\
\hline 22 & CESAC_CH_03_CHU_4 & 9.04E-05 & - & $1.76 \mathrm{E}-03$ & $0.00 E+00$ & - & 3.71E-05 & $1.42 \mathrm{E}-02$ & $2.28 \mathrm{E}-03$ & 5.09E-04 & 1.89E-02 \\
\hline
\end{tabular}




\begin{tabular}{|c|c|c|c|c|c|c|c|c|c|c|c|}
\hline \multirow[b]{2}{*}{$\#$} & \multirow[b]{2}{*}{ Reach Code } & \multicolumn{9}{|c|}{ AIS Ship and Cargo Type } & \multirow{2}{*}{$\begin{array}{c}\text { All Vesse } \\
\text { Types }\end{array}$} \\
\hline & & $\begin{array}{c}\text { Unknown } \\
(00)\end{array}$ & $\begin{array}{c}\text { WIG } \\
(20-29)\end{array}$ & $\begin{array}{c}\text { Class } 3 \\
(30,33-39)\end{array}$ & $\begin{array}{c}\text { High-Speed } \\
\text { (40-49) }\end{array}$ & $\begin{array}{c}\text { Harbor Boats } \\
\qquad(50-57)\end{array}$ & $\begin{array}{c}\text { Passenger } \\
\text { (60-69) }\end{array}$ & $\begin{array}{l}\text { Cargo } \\
\text { (70-79) }\end{array}$ & $\begin{array}{l}\text { Tanker } \\
(80-89)\end{array}$ & $\begin{array}{c}\text { Other } \\
\text { (90-99) }\end{array}$ & \\
\hline 23 & CESAC_CH_03_CHU_5 & $8.56 \mathrm{E}-06$ & - & $6.11 \mathrm{E}-04$ & $0.00 \mathrm{E}+00$ & - & $1.14 \mathrm{E}-05$ & $1.24 \mathrm{E}-02$ & $2.09 \mathrm{E}-03$ & $2.76 \mathrm{E}-05$ & $1.52 \mathrm{E}-02$ \\
\hline 24 & CESAC_CH_03_CHU_6 & $9.51 \mathrm{E}-06$ & - & $6.80 \mathrm{E}-04$ & $0.00 \mathrm{E}+00$ & - & $4.76 \mathrm{E}-06$ & 1.33E-02 & $1.50 \mathrm{E}-03$ & 2.09E-05 & $1.54 \mathrm{E}-02$ \\
\hline 25 & CESAC_CH_03_CHU_7 & $9.51 \mathrm{E}-07$ & - & $9.86 \mathrm{E}-04$ & $0.00 \mathrm{E}+00$ & - & $3.81 \mathrm{E}-06$ & $1.96 \mathrm{E}-02$ & 1.13E-03 & $2.28 \mathrm{E}-05$ & 2.17E-02 \\
\hline 26 & CESAC_CH_03_CHU_8 & $0.00 E+00$ & - & 2.03E-04 & $0.00 \mathrm{E}+00$ & - & $1.90 \mathrm{E}-06$ & 9.49E-03 & 5.35E-04 & 3.04E-05 & 1.03E-02 \\
\hline 27 & CESAC_CH_03_CHU_9 & 5.71E-06 & - & $1.53 \mathrm{E}-04$ & $0.00 E+00$ & - & $1.90 \mathrm{E}-06$ & $1.35 \mathrm{E}-03$ & 9.04E-05 & $0.00 \mathrm{E}+00$ & $1.61 \mathrm{E}-03$ \\
\hline 28 & CESAC_CH_04_ASR_1 & $6.90 \mathrm{E}-04$ & - & $6.37 \mathrm{E}-02$ & $1.20 \mathrm{E}-04$ & - & $1.01 \mathrm{E}-02$ & $2.62 \mathrm{E}-04$ & $2.66 \mathrm{E}-05$ & $5.26 \mathrm{E}-04$ & 7.39E-02 \\
\hline 29 & CESAC_CH_05_SHM_1 & 9.51E-07 & - & $1.56 \mathrm{E}-02$ & $0.00 \mathrm{E}+00$ & - & $9.51 \mathrm{E}-07$ & $0.00 E+00$ & $0.00 E+00$ & $0.00 E+00$ & 1.56E-02 \\
\hline 30 & CESAC_CH_05_SHM_2 & $2.85 \mathrm{E}-06$ & - & 4.94E-03 & $0.00 E+00$ & - & $0.00 E+00$ & $0.00 E+00$ & $0.00 E+00$ & $0.00 E+00$ & 4.94E-03 \\
\hline 31 & CESAC_CH_05_SHM_3 & $0.00 E+00$ & - & $6.20 \mathrm{E}-03$ & $0.00 \mathrm{E}+00$ & - & $0.00 \mathrm{E}+00$ & $0.00 E+00$ & $0.00 \mathrm{E}+00$ & $0.00 \mathrm{E}+00$ & $6.20 \mathrm{E}-03$ \\
\hline 32 & CESAC_CH_05_SHM_4 & $1.90 \mathrm{E}-06$ & - & $5.31 \mathrm{E}-03$ & $0.00 \mathrm{E}+00$ & - & $0.00 E+00$ & $0.00 E+00$ & $0.00 \mathrm{E}+00$ & $0.00 \mathrm{E}+00$ & 5.31E-03 \\
\hline 33 & CESAC_CH_05_SHM_5 & $1.90 \mathrm{E}-06$ & - & 8.04E-03 & $0.00 E+00$ & - & $0.00 E+00$ & $0.00 E+00$ & $0.00 \mathrm{E}+00$ & $0.00 E+00$ & 8.05E-03 \\
\hline 34 & CESAC_CH_05_SHM_6 & $4.76 \mathrm{E}-06$ & - & $1.01 \mathrm{E}-02$ & $0.00 \mathrm{E}+00$ & - & $0.00 E+00$ & $0.00 E+00$ & $0.00 E+00$ & $0.00 \mathrm{E}+00$ & $1.01 \mathrm{E}-02$ \\
\hline 35 & CESAC_CH_06_SYR_1 & $3.81 \mathrm{E}-06$ & - & $4.44 \mathrm{E}-02$ & $0.00 \mathrm{E}+00$ & - & $6.36 \mathrm{E}-03$ & $8.24 \mathrm{E}-04$ & 3.00E-04 & $9.51 \mathrm{E}-07$ & 5.19E-02 \\
\hline 36 & CESAC_CH_06_SYR_2 & $0.00 E+00$ & - & $1.50 \mathrm{E}-02$ & $0.00 E+00$ & - & $7.61 \mathrm{E}-06$ & $1.31 \mathrm{E}-04$ & $0.00 E+00$ & $0.00 \mathrm{E}+00$ & $1.52 \mathrm{E}-02$ \\
\hline 37 & CESAC_CH_06_SYR_3 & $0.00 E+00$ & - & 7.23E-05 & $0.00 \mathrm{E}+00$ & - & $5.12 \mathrm{E}-03$ & $0.00 E+00$ & $0.00 \mathrm{E}+00$ & $0.00 \mathrm{E}+00$ & 5.19E-03 \\
\hline 38 & CESAC_AW_04_WBC_11 & $7.52 \mathrm{E}-05$ & - & $8.46 \mathrm{E}-03$ & $6.66 \mathrm{E}-06$ & - & $1.09 \mathrm{E}-04$ & $0.00 E+00$ & $0.00 \mathrm{E}+00$ & $0.00 \mathrm{E}+00$ & 8.65E-03 \\
\hline 39 & CESAC_AW_04_WBC_12 & $2.13 \mathrm{E}-04$ & - & $1.96 \mathrm{E}-02$ & $2.28 \mathrm{E}-05$ & - & $2.78 \mathrm{E}-04$ & $0.00 \mathrm{E}+00$ & $0.00 E+00$ & $0.00 E+00$ & 2.01E-02 \\
\hline 40 & CESAC_AW_05_CHH_1 & - & - & - & - & - & - & - & - & - & - \\
\hline 41 & CESAC_AW_06_CHP_1 & 7.99E-05 & - & $6.38 \mathrm{E}-03$ & $9.51 \mathrm{E}-07$ & - & $6.36 \mathrm{E}-04$ & $0.00 E+00$ & $0.00 E+00$ & $0.00 E+00$ & 7.05E-03 \\
\hline & All navigation channels & $8.29 \mathrm{E}-03$ & - & 4.46E-01 & $5.77 \mathrm{E}-04$ & - & 8.96E-02 & $4.68 \mathrm{E}-01$ & $5.35 \mathrm{E}-02$ & $1.25 \mathrm{E}-02$ & $7.48 \mathrm{E}-01$ \\
\hline
\end{tabular}


Table 5-6. The unconditional frequency of SDVs in $\mathrm{CHC}$ by reach and vessel type. Frequencies greater than $1 \times 10^{-5}$ are in bold red typeface.

\begin{tabular}{|c|c|c|c|c|c|c|c|c|c|c|c|}
\hline \multirow[b]{2}{*}{ \# } & \multirow[b]{2}{*}{ Reach Code } & \multicolumn{9}{|c|}{ AIS Ship and Cargo Type } & \multirow[b]{2}{*}{$\begin{array}{c}\text { All Vesse } \\
\text { Types }\end{array}$} \\
\hline & & $\begin{array}{l}\text { Unknown } \\
\text { (00) }\end{array}$ & $\begin{array}{c}\text { WIG } \\
(20-29)\end{array}$ & $\begin{array}{c}\text { Class } 3 \\
(30,33-39)\end{array}$ & $\begin{array}{c}\text { High-speed } \\
\text { (40-49) }\end{array}$ & $\begin{array}{c}\text { Harbor Boats } \\
\text { (50-57) }\end{array}$ & $\begin{array}{c}\text { Passenger } \\
\text { (60-69) }\end{array}$ & $\begin{array}{l}\text { Cargo } \\
(70-79)\end{array}$ & $\begin{array}{l}\text { Tanker } \\
\text { (80-89) }\end{array}$ & $\begin{array}{c}\text { Other } \\
(90-99)\end{array}$ & \\
\hline 1 & CESAC_CH_01_CHE_1 & $0.00 \mathrm{E}+00$ & - & 1.10E-05 & $0.00 E+00$ & - & $0.00 \mathrm{E}+00$ & $3.58 \mathrm{E}-05$ & $1.98 \mathrm{E}-05$ & $0.00 E+00$ & 5.77E-05 \\
\hline 2 & CESAC_CH_02_CHL_1 & $0.00 E+00$ & - & $0.00 E+00$ & $0.00 E+00$ & - & $0.00 E+00$ & $1.31 \mathrm{E}-05$ & $9.47 \mathrm{E}-07$ & $0.00 \mathrm{E}+00$ & 1.37E-05 \\
\hline 3 & CESAC_CH_02_CHL_2 & $0.00 E+00$ & - & $0.00 E+00$ & $0.00 E+00$ & - & $0.00 E+00$ & 7.40E-06 & $1.88 \mathrm{E}-06$ & $0.00 E+00$ & $9.21 \mathrm{E}-06$ \\
\hline 4 & CESAC_CH_02_CHL_3 & $0.00 \mathrm{E}+00$ & - & 1.83E-06 & $0.00 \mathrm{E}+00$ & - & $0.00 \mathrm{E}+00$ & $1.88 \mathrm{E}-05$ & 9.51E-07 & $0.00 \mathrm{E}+00$ & 2.13E-05 \\
\hline 5 & CESAC_CH_02_CHL_4 & $0.00 E+00$ & - & $9.38 \mathrm{E}-07$ & $0.00 \mathrm{E}+00$ & - & $0.00 \mathrm{E}+00$ & 3.31E-05 & $0.00 \mathrm{E}+00$ & $0.00 \mathrm{E}+00$ & 3.39E-05 \\
\hline 6 & CESAC_CH_02_CHL_5 & $0.00 E+00$ & - & $0.00 E+00$ & - & - & $1.90 \mathrm{E}-06$ & $6.85 \mathrm{E}-05$ & $1.90 \mathrm{E}-06$ & $0.00 \mathrm{E}+00$ & 7.13E-05 \\
\hline 7 & CESAC_CH_02_CHL_6 & $0.00 E+00$ & - & $0.00 E+00$ & - & - & $0.00 E+00$ & 4.75E-06 & $0.00 E+00$ & $0.00 \mathrm{E}+00$ & 4.74E-06 \\
\hline 8 & CESAC_CH_02_CHL_7 & $0.00 E+00$ & - & $0.00 E+00$ & - & - & $0.00 \mathrm{E}+00$ & 5.70E-06 & $0.00 \mathrm{E}+00$ & $0.00 \mathrm{E}+00$ & $5.68 \mathrm{E}-06$ \\
\hline 9 & CESAC_CH_02_CHL_8 & $0.00 E+00$ & - & $9.42 \mathrm{E}-07$ & $0.00 E+00$ & - & $0.00 E+00$ & 5.70E-06 & 1.90E-06 & $0.00 \mathrm{E}+00$ & 8.43E-06 \\
\hline 10 & CESAC_CH_02_CHL_9 & - & - & $0.00 E+00$ & - & - & 1.90E-06 & $0.00 E+00$ & - & $0.00 E+00$ & 1.90E-06 \\
\hline 11 & CESAC_CH_02_CHL_10 & $0.00 E+00$ & - & $1.88 \mathrm{E}-06$ & - & - & $0.00 \mathrm{E}+00$ & $9.51 \mathrm{E}-07$ & $0.00 E+00$ & $0.00 \mathrm{E}+00$ & $2.84 \mathrm{E}-06$ \\
\hline 12 & CESAC_CH_02_CHL_11 & - & - & $0.00 E+00$ & - & - & $0.00 E+00$ & - & - & - & $0.00 \mathrm{E}+00$ \\
\hline 13 & CESAC_CH_02_CHL_12 & $0.00 E+00$ & - & $0.00 E+00$ & - & - & 3.80E-06 & 5.70E-06 & $0.00 E+00$ & $0.00 \mathrm{E}+00$ & $9.47 \mathrm{E}-06$ \\
\hline 14 & CESAC_CH_02_CHL_13 & - & - & $0.00 E+00$ & - & - & $0.00 \mathrm{E}+00$ & $0.00 E+00$ & - & - & $0.00 E+00$ \\
\hline 15 & CESAC_CH_02_CHL_14 & $0.00 E+00$ & - & $0.00 E+00$ & $0.00 E+00$ & - & $0.00 \mathrm{E}+00$ & $0.00 E+00$ & - & $0.00 \mathrm{E}+00$ & $0.00 E+00$ \\
\hline 16 & CESAC_CH_02_CHL_15 & $0.00 \mathrm{E}+00$ & - & $0.00 E+00$ & - & - & $0.00 \mathrm{E}+00$ & $2.85 \mathrm{E}-06$ & - & - & 2.85E-06 \\
\hline 17 & CESAC_CH_02_CHL_16 & - & - & $0.00 E+00$ & - & - & $0.00 E+00$ & $5.50 \mathrm{E}-05$ & - & - & 5.50E-05 \\
\hline 18 & CESAC_CH_02_CHL_17 & - & - & $0.00 E+00$ & - & - & $0.00 E+00$ & $2.85 \mathrm{E}-06$ & - & - & $2.85 \mathrm{E}-06$ \\
\hline 19 & CESAC_CH_03_CHU_1 & $0.00 E+00$ & - & 4.74E-06 & - & - & $0.00 E+00$ & 4.67E-06 & $0.00 E+00$ & $0.00 E+00$ & $9.31 \mathrm{E}-06$ \\
\hline 20 & CESAC_CH_03_CHU_2 & $0.00 E+00$ & - & 9.51E-07 & - & - & $0.00 \mathrm{E}+00$ & $2.85 \mathrm{E}-06$ & $0.00 E+00$ & $0.00 \mathrm{E}+00$ & 3.79E-06 \\
\hline 21 & CESAC_CH_03_CHU_3 & $0.00 E+00$ & - & $0.00 E+00$ & - & - & $0.00 \mathrm{E}+00$ & $0.00 E+00$ & $0.00 E+00$ & $0.00 E+00$ & $0.00 E+00$ \\
\hline 22 & CESAC_CH_03_CHU_4 & $0.00 E+00$ & - & $0.00 \mathrm{E}+00$ & - & - & $0.00 E+00$ & 1.90E-06 & $0.00 \mathrm{E}+00$ & $0.00 E+00$ & 1.90E-06 \\
\hline
\end{tabular}




\begin{tabular}{|c|c|c|c|c|c|c|c|c|c|c|c|}
\hline \multirow[b]{2}{*}{$\#$} & \multirow[b]{2}{*}{ Reach Code } & \multicolumn{9}{|c|}{ AIS Ship and Cargo Type } & \multirow[b]{2}{*}{$\begin{array}{c}\text { All Vessel } \\
\text { Types }\end{array}$} \\
\hline & & $\begin{array}{c}\text { Unknown } \\
\text { (00) }\end{array}$ & $\begin{array}{c}\text { WIG } \\
(20-29)\end{array}$ & $\begin{array}{c}\text { Class } 3 \\
(30,33-39)\end{array}$ & $\begin{array}{l}\text { High-speed } \\
\text { (40-49) }\end{array}$ & $\begin{array}{c}\text { Harbor Boats } \\
\qquad(50-57)\end{array}$ & $\begin{array}{c}\text { Passenger } \\
\text { (60-69) }\end{array}$ & $\begin{array}{l}\text { Cargo } \\
\text { (70-79) }\end{array}$ & $\begin{array}{l}\text { Tanker } \\
\text { (80-89) }\end{array}$ & $\begin{array}{c}\text { Other } \\
\text { (90-99) }\end{array}$ & \\
\hline 23 & CESAC_CH_03_CHU_5 & $0.00 E+00$ & - & $0.00 E+00$ & - & - & $0.00 E+00$ & $9.51 \mathrm{E}-07$ & $0.00 E+00$ & $0.00 E+00$ & $9.50 \mathrm{E}-07$ \\
\hline 24 & CESAC_CH_03_CHU_6 & $0.00 E+00$ & - & $0.00 \mathrm{E}+00$ & - & - & $0.00 E+00$ & 9.51E-07 & $0.00 \mathrm{E}+00$ & $0.00 \mathrm{E}+00$ & 9.50E-07 \\
\hline 25 & CESAC_CH_03_CHU_7 & $0.00 \mathrm{E}+00$ & - & $0.00 E+00$ & - & - & $0.00 E+00$ & $2.75 \mathrm{E}-05$ & $0.00 E+00$ & $0.00 E+00$ & $2.75 \mathrm{E}-05$ \\
\hline 26 & CESAC_CH_03_CHU_8 & - & - & $0.00 E+00$ & - & - & $0.00 E+00$ & $9.51 \mathrm{E}-07$ & $0.00 E+00$ & $0.00 \mathrm{E}+00$ & $9.51 \mathrm{E}-07$ \\
\hline 27 & CESAC_CH_03_CHU_9 & $0.00 \mathrm{E}+00$ & - & $0.00 E+00$ & - & - & $0.00 \mathrm{E}+00$ & $0.00 E+00$ & $0.00 \mathrm{E}+00$ & - & $0.00 E+00$ \\
\hline 28 & CESAC_CH_04_ASR_1 & $0.00 E+00$ & - & $1.74 \mathrm{E}-05$ & $0.00 E+00$ & - & $9.46 \mathrm{E}-07$ & $0.00 E+00$ & $0.00 E+00$ & $0.00 E+00$ & $1.81 \mathrm{E}-05$ \\
\hline 29 & CESAC_CH_05_SHM_1 & $0.00 E+00$ & - & $0.00 E+00$ & - & - & $0.00 E+00$ & - & - & - & $0.00 E+00$ \\
\hline 30 & CESAC_CH_05_SHM_2 & $0.00 E+00$ & - & $0.00 E+00$ & - & - & - & - & - & - & $0.00 E+00$ \\
\hline 31 & CESAC_CH_05_SHM_3 & - & - & $0.00 E+00$ & - & - & - & - & - & - & $0.00 \mathrm{E}+00$ \\
\hline 32 & CESAC_CH_05_SHM_4 & $0.00 \mathrm{E}+00$ & - & $0.00 E+00$ & - & - & - & - & - & - & $0.00 E+00$ \\
\hline 33 & CESAC_CH_05_SHM_5 & $0.00 E+00$ & - & $0.00 \mathrm{E}+00$ & - & - & - & - & - & - & $0.00 E+00$ \\
\hline 34 & CESAC_CH_05_SHM_6 & $0.00 E+00$ & - & $0.00 E+00$ & - & - & - & - & - & - & $0.00 E+00$ \\
\hline 35 & CESAC_CH_06_SYR_1 & $0.00 E+00$ & - & $0.00 E+00$ & - & - & $0.00 E+00$ & $2.85 \mathrm{E}-06$ & 1.90E-06 & $0.00 \mathrm{E}+00$ & 4.75E-06 \\
\hline 36 & CESAC_CH_06_SYR_2 & - & - & $0.00 E+00$ & - & - & $0.00 E+00$ & $0.00 E+00$ & - & - & $0.00 E+00$ \\
\hline 37 & CESAC_CH_06_SYR_3 & - & - & $0.00 E+00$ & - & - & $0.00 E+00$ & - & - & - & $0.00 E+00$ \\
\hline 38 & CESAC_AW_04_WBC_11 & $0.00 \mathrm{E}+00$ & - & $1.83 \mathrm{E}-06$ & $0.00 E+00$ & - & $0.00 E+00$ & - & - & - & $1.83 \mathrm{E}-06$ \\
\hline 39 & CESAC_AW_04_WBC_12 & $0.00 \mathrm{E}+00$ & - & $1.16 \mathrm{E}-05$ & $0.00 \mathrm{E}+00$ & - & $0.00 E+00$ & - & - & - & $1.16 \mathrm{E}-05$ \\
\hline 40 & CESAC_AW_05_CHH_1 & - & - & - & - & - & - & - & - & - & - \\
\hline 41 & CESAC_AW_06_CHP_1 & $0.00 E+00$ & - & $1.83 \mathrm{E}-06$ & $0.00 E+00$ & - & $0.00 E+00$ & - & - & - & $1.83 \mathrm{E}-06$ \\
\hline & All navigation channels & $0.00 E+00$ & - & $5.52 \mathrm{E}-05$ & $0.00 E+00$ & - & 9.13E-06 & 2.05E-04 & $2.79 E-05$ & $0.00 E+00$ & 2.13E-04 \\
\hline
\end{tabular}


Figure 5-6. Unconditional frequency of SDVs in CHC.

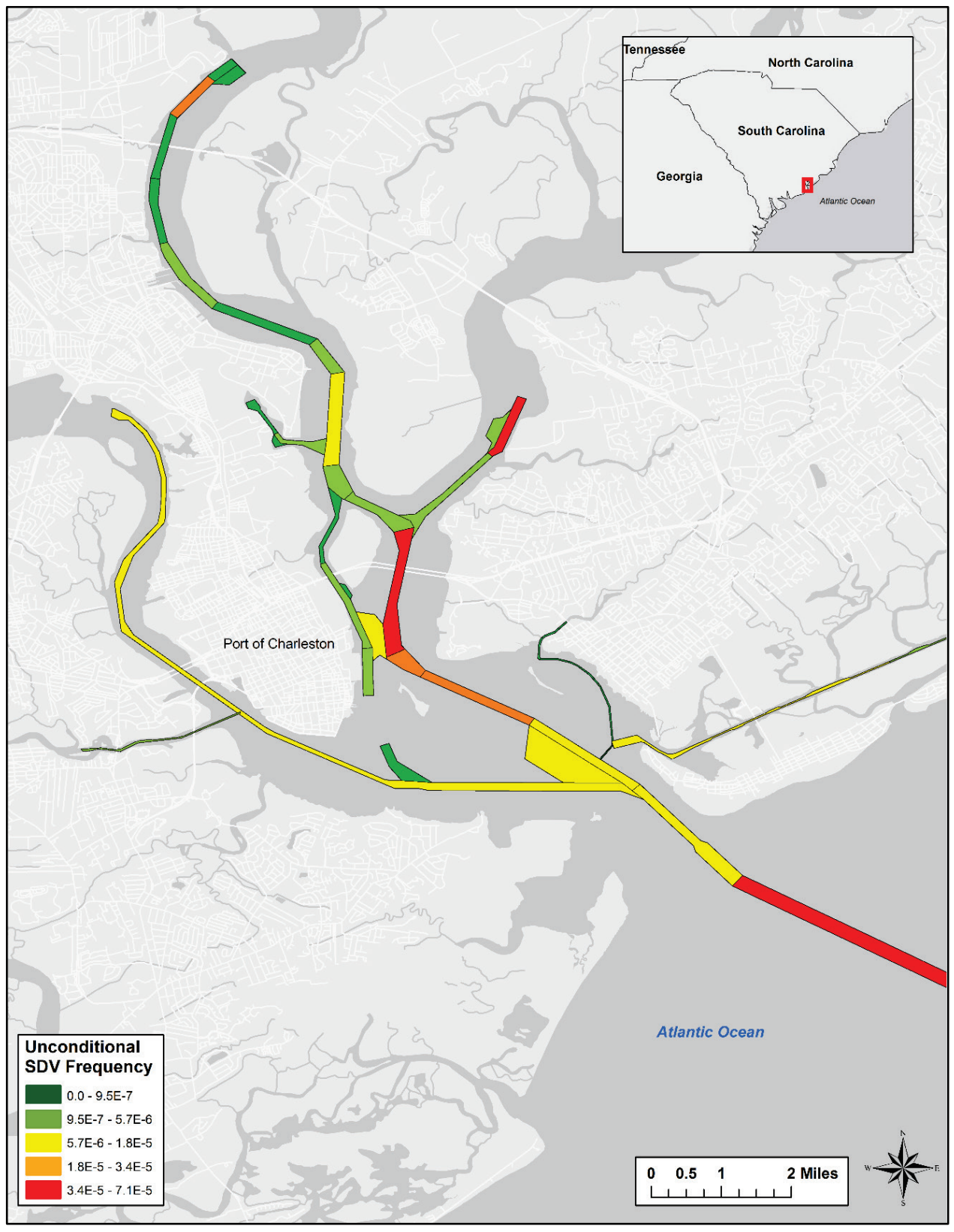


Figure 5-7. Relative frequency of SDVs in $\mathrm{CHC}$ by navigation channel reach.

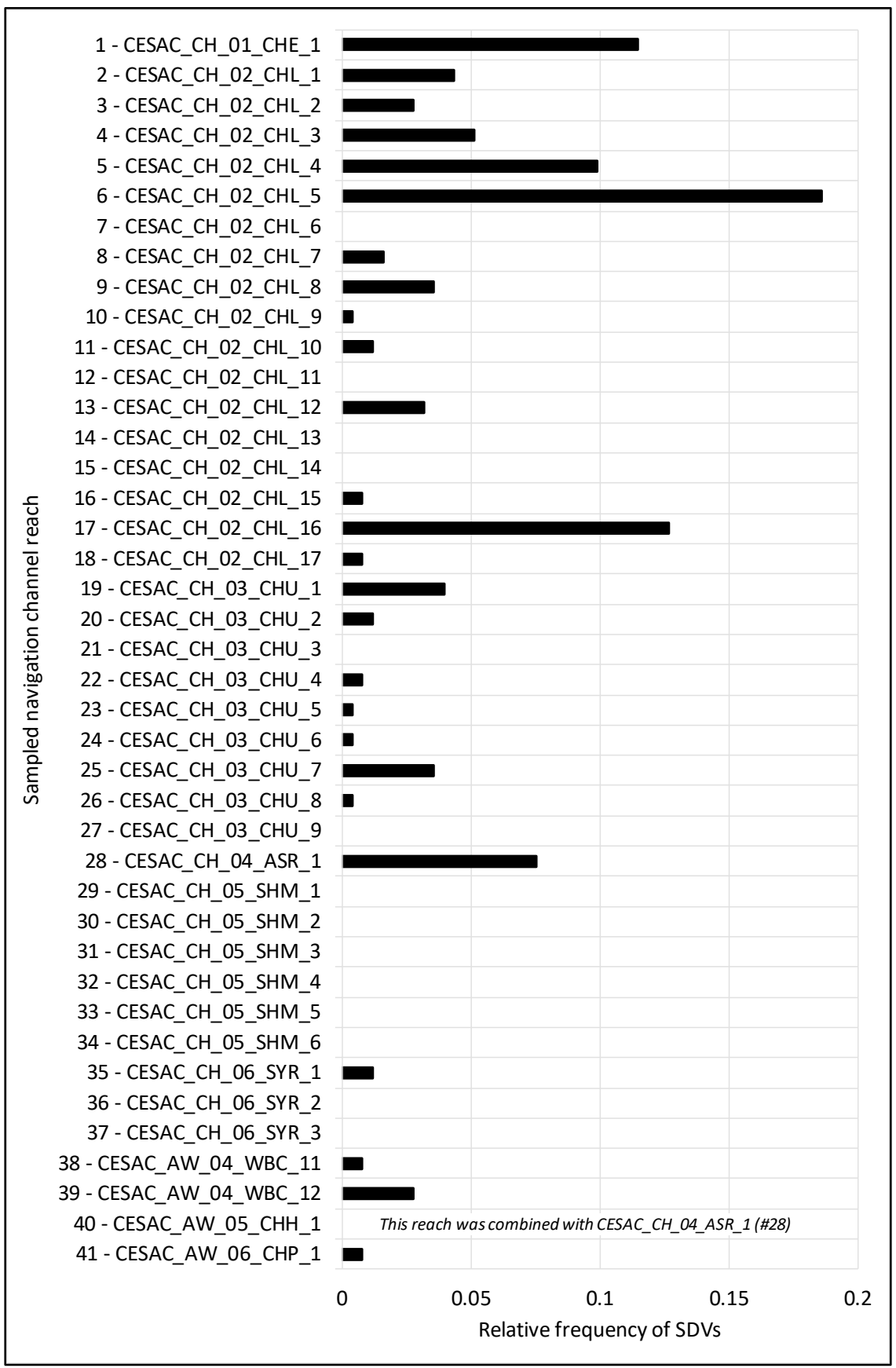

\subsubsection{Correlations among collision risk metrics}

Three metrics of collision risk have been described. These metrics have subtle differences. The correlation among metrics is evaluated here to assess the extent to which each metric provides unique information and the extent to which one might be used as a substitute for the other. Correlations among the four metrics of collision risk are summarized in 
Table 5-7. The correlation between the relative frequency of SDVs, $f_{k}$, and the probability of an SDV occurs in a reach, $p(\mathrm{SDV})$, is 0.9767 . This high correlation suggests the two metrics are providing the same information and one can be used as a substitute for the other. Correlations among the remaining pairs of metrics are relatively low. In particular, the correlation between the probabilities of an SDV given that at least one vessel is present in the reach, $p$ (SDV $\mid n_{j k t} \geq 1$ ), and the relative frequency of an SDV is 0.6502 . This low correlation suggests that attempting to rank navigation channels in terms of collision risk using the relative frequency as an alternative metric because it is easier to calculate would yield a different result than a ranking based on the probability of an SDV given that at least one vessel is present in the reach.

Table 5-7. Pearson correlation matrix for collision risk metrics.

\begin{tabular}{|c|c|c|c|c|}
\hline Metric of Collision Risk & $p\left(\right.$ SDV $\left.\mid n_{k t} \geq 1\right)$ & $p\left(n_{k t} \geq 1\right)$ & $p($ SDV $)$ & $f_{k}$ \\
\hline$p\left(\right.$ SDV $\left.\mid n_{k t} \geq 1\right)$ & 1.0000 & 0.0609 & 0.6652 & 0.6502 \\
\hline$p\left(n_{k t} \geq 1\right)$ & - & 1.0000 & 0.6420 & 0.5881 \\
\hline$p($ SDV & - & - & 1.0000 & 0.9767 \\
\hline$f_{k}$ & - & - & - & 1.0000 \\
\hline
\end{tabular}

\subsection{Grounding risk assessment}

Two types of grounding events may be influenced by channel design and maintenance decisions. These include powered grounding on the side of a channel and powered grounding on a shoal in the channel. This analysis of grounding potential in Charleston Harbor considers each event in turn.

\subsubsection{Powered grounding on the side of the channel}

The distribution of channel side events in Charleston Harbor is illustrated in Figure 5-8 for vessels with maximum drafts that are greater than $7.5 \mathrm{~m}$ and in transit at speeds greater than 7.5 knots. There are a large number of channel side events throughout the navigation project, and in particular on the north side of Mount Pleasant Reach (\#2), Rebellion Reach (\#3), and Bennis Reach (\#3), Hog Island Reach (\#6), Wando River Lower (\#16), and Wando River Upper (\#17). A larger scale map of channel side events is shown in Figure 5-9. Events on the western boundary of Wando River Turning Basin (\#18) are associated with vessels that are turning under tug assist. Events along the waterfront in downtown Charleston, at Union Pier and Columbus Street Terminal, are associated with cruise and cargo 
vessels docking. Lower Shipyard River (\#35) events are associated with vessels accessing terminals in Shipyard Creek. However, the clusters of points on the north side of Mount Pleasant Reach, Rebellion Reach, and Bennis Reach remain, as do those in Hog Island Reach, Lower Wando River. While these cannot be explained away by vessels accessing a pier or terminal, the natural bathymetry at these sites should be considered before drawing any conclusions about whether or not these channel side events indicate a problem that needs to be corrected by widening or reshaping navigation channels.

Figure 5-8. Channel side events in CHC.

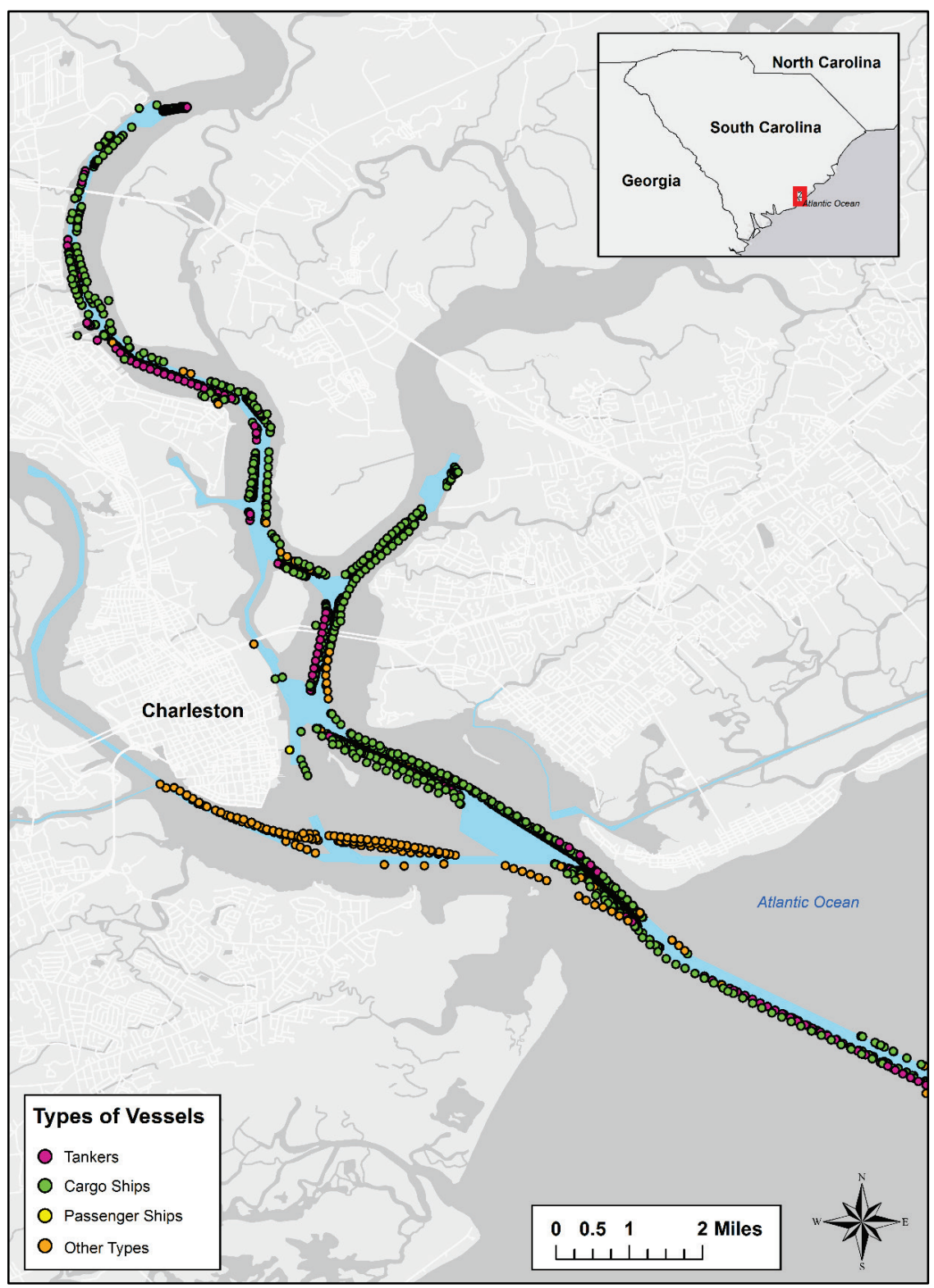


Figure 5-9. Channel side events in the inner harbor of CHC.

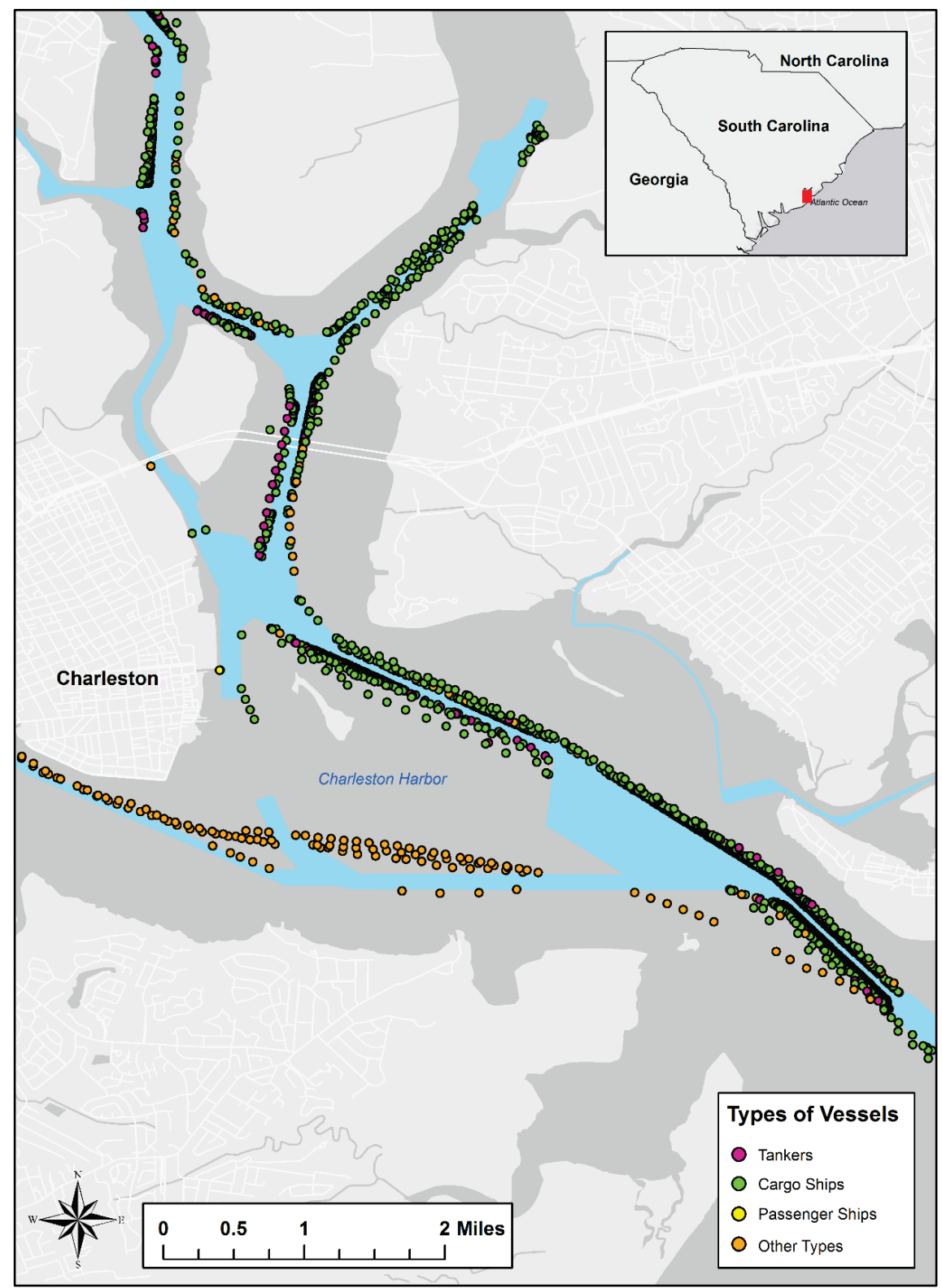

Several points in Figure 5-9 illustrate the potential for GPS errors to be mistaken for channel side events. There is a point in Hog Island Reach (\#6) just east of Drum Island and north of the Arthur Ravenel Bridge that represents the position of a $231 \mathrm{~m}$ cargo vessel on 11 April 2014. This point is clearly a GPS error because it is located approximately $250 \mathrm{~m}$ west of the vessel's actual line of transit as indicated by the other position reports from that vessel. A second example involves multiple position reports showing an unusual line of transit located approximately $200 \mathrm{~m}$ southwest of the Bennis Reach boundary that extends from Customhouse Reach (\#12) to Anchorage Basin A (\#9). This line, marked by green points, is the transit of 
a $245 \mathrm{~m}$ cargo vessel. The cargo vessel departed the North Charleston Terminal approximately 0430 UTC on 26 November 2014 and was headed out to sea. It departed Customhouse Reach at 0538 UTC and entered Anchorage Basin A 8 minutes later, at 0546 UTC. At 0551 UTC, the cargo vessel can be seen exiting Anchorage Basin A west of Rebellion Reach and merging into Mount Pleasant Reach at 0554 UTC. Because this line of transit deviates so much from expected behavior, it seems reasonable to ask whether or not this line of transit reflects GPS errors. However, there do not appear to be obvious discontinuities in the transit of this vessel as it leaves and re-enters the channel.

\subsubsection{Powered grounding on a shoal in the channel}

Vessels that are depth limited have maximum drafts greater than the maintenance depth of a channel. The number and fraction of depthlimited cargo vessels (70-79) operating in each navigation reach is summarized in Table 5-8. At maintenance depth, the fraction of depthlimited cargo vessels is very low throughout the navigation project. There are two notable exceptions. These include Upper Shipyard River (\#36) and the Ashley River (\#28). The Upper Shipyard River has a $30 \mathrm{ft}$ maintenance draft, and five of the six cargo vessels utilizing that reach had maximum static drafts exceeding that depth. These vessels may be been riding high in the water to access the dry dock. The Ashley River has a $30 \mathrm{ft}$ maintenance draft and 48 of the 72 cargo vessels utilizing that navigation channel (65.8\%) have maximum drafts that exceed that depth. However, few if any cargo vessels utilize the Ashley River Reach. These vessels appear to be cutting across the eastern portion of the Ashley River reach to access Anchorage Basin A.

Shoaling over time can reduce available depth. Table 5-8 shows how the fraction of cargo vessels that are depth limited would increase in response to shoaling at $1 \mathrm{ft}$ intervals. As available depth is reduced up to $6 \mathrm{ft}$, the fraction of depth-limited cargo vessels increases to approximately $30 \%$ through much of the project. In the Wando River, the depth-limited fraction of cargo vessels increases to $45 \%$.

The number and fraction of depth-limited tankers (80-89) is shown in Table 5-9. Throughout much of the navigation project, only $2 \%-5 \%$ of tankers are depth limited at maintenance depth. The high fraction of tankers that are depth limited in the Ashley River can be explained as above. Tankers are utilizing the Ashley River to access Anchorage Basin A 
but are not operating in much of the channel. Shoaling that reduces available depth up to $6 \mathrm{ft}$ has relatively little impact on navigation by tankers, with $6 \mathrm{ft}$ of shoaling increasing the depth-limited fraction of tankers to between $10 \%$ and $20 \%$ in the upper reaches of the Cooper River. However, the absolute number of tanker vessels affected by shoaling of up to $6 \mathrm{ft}$ seems very small. 
Table 5-8. Number and fraction of cargo vessels that are depth limited in $\mathrm{CHC}$.

\begin{tabular}{|c|c|c|c|c|c|c|c|c|c|c|}
\hline \multirow[b]{2}{*}{ \# } & \multirow{2}{*}{ Reach Code } & \multirow{2}{*}{$\begin{array}{c}\text { Main- } \\
\text { tenance } \\
\text { Depth (ft) }\end{array}$} & \multirow{2}{*}{$\begin{array}{c}\text { Number of } \\
\text { Unique } \\
\text { Vessels }\end{array}$} & \multicolumn{7}{|c|}{ Reduction in Maintenance Depth (ft) } \\
\hline & & & & 0 & 1 & 2 & 3 & 4 & 5 & 6 \\
\hline 1 & CESAC_CH_01_CHE_1 & 47 & 623 & $5 / 0.008$ & $12 / 0.019$ & $21 / 0.034$ & $29 / 0.047$ & $42 / 0.067$ & $61 / 0.098$ & $97 / 0.156$ \\
\hline 2 & CESAC_CH_02_CHL_1 & 45 & 622 & $21 / 0.034$ & $29 / 0.047$ & $42 / 0.068$ & $61 / 0.098$ & $97 / 0.156$ & $127 / 0.204$ & $173 / 0.278$ \\
\hline 3 & CESAC_CH_02_CHL_2 & 45 & 622 & $21 / 0.034$ & $29 / 0.047$ & $42 / 0.068$ & $61 / 0.098$ & $97 / 0.156$ & $127 / 0.204$ & $173 / 0.278$ \\
\hline 4 & CESAC_CH_02_CHL_3 & 45 & 621 & $21 / 0.034$ & $29 / 0.047$ & $42 / 0.068$ & $61 / 0.098$ & $97 / 0.156$ & $127 / 0.205$ & $173 / 0.279$ \\
\hline 5 & CESAC_CH_02_CHL_4 & 45 & 621 & $21 / 0.034$ & $29 / 0.047$ & $42 / 0.068$ & $61 / 0.098$ & $97 / 0.156$ & $127 / 0.205$ & $173 / 0.279$ \\
\hline 6 & CESAC_CH_02_CHL_5 & 45 & 620 & $21 / 0.034$ & $29 / 0.047$ & $42 / 0.068$ & $61 / 0.098$ & $97 / 0.156$ & $127 / 0.205$ & $173 / 0.279$ \\
\hline 7 & CESAC_CH_02_CHL_6 & 45 & 427 & $20 / 0.047$ & $26 / 0.061$ & $38 / 0.089$ & $54 / 0.126$ & $83 / 0.194$ & $109 / 0.255$ & $147 / 0.344$ \\
\hline 8 & CESAC_CH_02_CHL_7 & 45 & 207 & $2 / 0.01$ & $2 / 0.01$ & $3 / 0.014$ & $6 / 0.029$ & $20 / 0.097$ & $30 / 0.145$ & $47 / 0.227$ \\
\hline 9 & CESAC_CH_02_CHL_8 & 45 & 101 & $3 / 0.03$ & $5 / 0.05$ & $5 / 0.05$ & $6 / 0.059$ & $11 / 0.109$ & $15 / 0.149$ & $22 / 0.218$ \\
\hline 10 & CESAC_CH_02_CHL_9 & 40 & 20 & $0 / 0$ & $2 / 0.1$ & $4 / 0.2$ & $5 / 0.25$ & $6 / 0.3$ & $7 / 0.35$ & $9 / 0.45$ \\
\hline 11 & CESAC_CH_02_CHL_10 & 45 & 149 & $0 / 0$ & $0 / 0$ & $0 / 0$ & $0 / 0$ & $0 / 0$ & $0 / 0$ & $2 / 0.013$ \\
\hline 13 & CESAC_CH_02_CHL_12 & 45 & 156 & $0 / 0$ & $0 / 0$ & $0 / 0$ & $1 / 0.006$ & $1 / 0.006$ & $1 / 0.006$ & $4 / 0.026$ \\
\hline 14 & CESAC_CH_02_CHL_13 & 35 & 2 & $0 / 0$ & $0 / 0$ & $1 / 0.5$ & $1 / 0.5$ & $1 / 0.5$ & $1 / 0.5$ & $2 / 1$ \\
\hline 15 & CESAC_CH_02_CHL_14 & 27 & 1 & $0 / 0$ & $0 / 0$ & $0 / 0$ & $0 / 0$ & $0 / 0$ & $0 / 0$ & $0 / 0$ \\
\hline 16 & CESAC_CH_02_CHL_15 & 45 & 282 & $20 / 0.071$ & $28 / 0.099$ & $40 / 0.142$ & $56 / 0.199$ & $80 / 0.284$ & $100 / 0.355$ & $127 / 0.45$ \\
\hline 17 & CESAC_CH_02_CHL_16 & 45 & 282 & $20 / 0.071$ & $28 / 0.099$ & $40 / 0.142$ & $56 / 0.199$ & $80 / 0.284$ & $100 / 0.355$ & $127 / 0.45$ \\
\hline 18 & CESAC_CH_02_CHL_17 & 45 & 236 & $20 / 0.085$ & $26 / 0.11$ & $34 / 0.144$ & $50 / 0.212$ & $74 / 0.314$ & $90 / 0.381$ & $111 / 0.47$ \\
\hline 19 & CESAC_CH_03_CHU_1 & 45 & 207 & $2 / 0.01$ & $2 / 0.01$ & $3 / 0.014$ & $6 / 0.029$ & $20 / 0.097$ & $30 / 0.145$ & $47 / 0.227$ \\
\hline 20 & CESAC_CH_03_CHU_2 & 45 & 192 & $2 / 0.01$ & $2 / 0.01$ & $3 / 0.016$ & $5 / 0.026$ & $17 / 0.089$ & $26 / 0.135$ & $43 / 0.224$ \\
\hline 21 & CESAC_CH_03_CHU_3 & 45 & 192 & $2 / 0.01$ & $2 / 0.01$ & $3 / 0.016$ & $5 / 0.026$ & $17 / 0.089$ & $26 / 0.135$ & $43 / 0.224$ \\
\hline 22 & CESAC_CH_03_CHU_4 & 45 & 185 & $2 / 0.011$ & $2 / 0.011$ & $3 / 0.016$ & $5 / 0.027$ & $17 / 0.092$ & $26 / 0.141$ & $42 / 0.227$ \\
\hline 23 & CESAC_CH_03_CHU_5 & 45 & 174 & $2 / 0.011$ & $2 / 0.011$ & $3 / 0.017$ & $5 / 0.029$ & $17 / 0.098$ & $26 / 0.149$ & $42 / 0.241$ \\
\hline 24 & CESAC_CH_03_CHU_6 & 45 & 164 & $2 / 0.012$ & $2 / 0.012$ & $3 / 0.018$ & $5 / 0.03$ & $17 / 0.104$ & $24 / 0.146$ & $40 / 0.244$ \\
\hline 25 & CESAC_CH_03_CHU_7 & 45 & 164 & $2 / 0.012$ & $2 / 0.012$ & $3 / 0.018$ & $5 / 0.03$ & $17 / 0.104$ & $24 / 0.146$ & $40 / 0.244$ \\
\hline 26 & CESAC_CH_03_CHU_8 & 45 & 163 & $2 / 0.012$ & $2 / 0.012$ & $3 / 0.018$ & $5 / 0.031$ & $17 / 0.104$ & $24 / 0.147$ & $40 / 0.245$ \\
\hline 27 & CESAC_CH_03_CHU_9 & 45 & 83 & $2 / 0.024$ & $2 / 0.024$ & $3 / 0.036$ & $5 / 0.06$ & $11 / 0.133$ & $14 / 0.169$ & $19 / 0.229$ \\
\hline 28 & CESAC_CH_04_ASR_1 & 30 & 78 & $50 / 0.641$ & $53 / 0.679$ & $57 / 0.731$ & $60 / 0.769$ & $64 / 0.821$ & $66 / 0.846$ & $68 / 0.872$ \\
\hline 35 & CESAC_CH_06_SYR_1 & 45 & 21 & $0 / 0$ & $0 / 0$ & $0 / 0$ & $1 / 0.048$ & $3 / 0.143$ & $4 / 0.19$ & $4 / 0.19$ \\
\hline 36 & CESAC_CH_06_SYR_2 & 30 & 7 & $5 / 0.714$ & $5 / 0.714$ & $5 / 0.714$ & $5 / 0.714$ & $5 / 0.714$ & $5 / 0.714$ & $5 / 0.714$ \\
\hline
\end{tabular}


Table 5-9. Number and fraction of cargo vessels that are depth limited in $\mathrm{CHC}$.

\begin{tabular}{|c|c|c|c|c|c|c|c|c|c|c|}
\hline \multirow[b]{2}{*}{ \# } & \multirow{2}{*}{ Reach Code } & \multirow{2}{*}{$\begin{array}{c}\text { Main- } \\
\text { tenance } \\
\text { Depth (ft) }\end{array}$} & \multirow{2}{*}{$\begin{array}{c}\text { Number of } \\
\text { Unique } \\
\text { Vessels }\end{array}$} & \multicolumn{7}{|c|}{ Reduction In Maintenance Depth (ft) } \\
\hline & & & & 0 & 1 & 2 & 3 & 4 & 5 & 6 \\
\hline 1 & CESAC_CH_01_CHE_1 & 47 & 97 & $0 / 0$ & $0 / 0$ & $0 / 0$ & $0 / 0$ & $2 / 0.021$ & $2 / 0.021$ & $3 / 0.031$ \\
\hline 2 & CESAC_CH_02_CHL_1 & 45 & 97 & $0 / 0$ & $0 / 0$ & $2 / 0.021$ & $2 / 0.021$ & $3 / 0.031$ & $5 / 0.052$ & $10 / 0.103$ \\
\hline 3 & CESAC_CH_02_CHL_2 & 45 & 97 & $0 / 0$ & $0 / 0$ & $2 / 0.021$ & $2 / 0.021$ & $3 / 0.031$ & $5 / 0.052$ & $10 / 0.103$ \\
\hline 4 & CESAC_CH_02_CHL_3 & 45 & 96 & $0 / 0$ & $0 / 0$ & $2 / 0.021$ & $2 / 0.021$ & $3 / 0.031$ & $5 / 0.052$ & $10 / 0.104$ \\
\hline 5 & CESAC_CH_02_CHL_4 & 45 & 96 & $0 / 0$ & $0 / 0$ & $2 / 0.021$ & $2 / 0.021$ & $3 / 0.031$ & $5 / 0.052$ & $10 / 0.104$ \\
\hline 6 & CESAC_CH_02_CHL_5 & 45 & 96 & $0 / 0$ & $0 / 0$ & $2 / 0.021$ & $2 / 0.021$ & $3 / 0.031$ & $5 / 0.052$ & $10 / 0.104$ \\
\hline 7 & CESAC_CH_02_CHL_6 & 45 & 96 & $0 / 0$ & $0 / 0$ & $2 / 0.021$ & $2 / 0.021$ & $3 / 0.031$ & $5 / 0.052$ & $10 / 0.104$ \\
\hline 8 & CESAC_CH_02_CHL_7 & 45 & 96 & $0 / 0$ & $0 / 0$ & $2 / 0.021$ & $2 / 0.021$ & $3 / 0.031$ & $5 / 0.052$ & $10 / 0.104$ \\
\hline 9 & CESAC_CH_02_CHL_8 & 45 & 16 & $0 / 0$ & $0 / 0$ & $0 / 0$ & $0 / 0$ & $1 / 0.063$ & $1 / 0.063$ & $1 / 0.063$ \\
\hline 11 & CESAC_CH_02_CHL_10 & 45 & 1 & $0 / 0$ & $0 / 0$ & $0 / 0$ & $0 / 0$ & $0 / 0$ & $0 / 0$ & $0 / 0$ \\
\hline 13 & CESAC_CH_02_CHL_12 & 45 & 1 & $0 / 0$ & $0 / 0$ & $0 / 0$ & $0 / 0$ & $0 / 0$ & $0 / 0$ & $0 / 0$ \\
\hline 19 & CESAC_CH_03_CHU_1 & 45 & 96 & $0 / 0$ & $0 / 0$ & $2 / 0.021$ & $2 / 0.021$ & $3 / 0.031$ & $5 / 0.052$ & $10 / 0.104$ \\
\hline 20 & CESAC_CH_03_CHU_2 & 45 & 52 & $0 / 0$ & $0 / 0$ & $2 / 0.038$ & $2 / 0.038$ & $2 / 0.038$ & 4/0.077 & $7 / 0.135$ \\
\hline 21 & CESAC_CH_03_CHU_3 & 45 & 52 & $0 / 0$ & $0 / 0$ & $2 / 0.038$ & $2 / 0.038$ & $2 / 0.038$ & $4 / 0.077$ & $7 / 0.135$ \\
\hline 22 & CESAC_CH_03_CHU_4 & 45 & 52 & $0 / 0$ & $0 / 0$ & $2 / 0.038$ & $2 / 0.038$ & $2 / 0.038$ & $4 / 0.077$ & $7 / 0.135$ \\
\hline 23 & CESAC_CH_03_CHU_5 & 45 & 47 & $0 / 0$ & $0 / 0$ & $2 / 0.043$ & $2 / 0.043$ & $2 / 0.043$ & $4 / 0.085$ & $7 / 0.149$ \\
\hline 24 & CESAC_CH_03_CHU_6 & 45 & 37 & $0 / 0$ & $0 / 0$ & $2 / 0.054$ & $2 / 0.054$ & $2 / 0.054$ & $4 / 0.108$ & $6 / 0.162$ \\
\hline 25 & CESAC_CH_03_CHU_7 & 45 & 36 & $0 / 0$ & $0 / 0$ & $2 / 0.056$ & $2 / 0.056$ & $2 / 0.056$ & $4 / 0.111$ & $6 / 0.167$ \\
\hline 26 & CESAC_CH_03_CHU_8 & 45 & 36 & $0 / 0$ & $0 / 0$ & $2 / 0.056$ & $2 / 0.056$ & $2 / 0.056$ & $4 / 0.111$ & $6 / 0.167$ \\
\hline 27 & CESAC_CH_03_CHU_9 & 45 & 13 & $0 / 0$ & $0 / 0$ & $1 / 0.077$ & $1 / 0.077$ & $1 / 0.077$ & $2 / 0.154$ & $3 / 0.231$ \\
\hline 28 & CESAC_CH_04_ASR_1 & 30 & 11 & $5 / 0.455$ & $5 / 0.455$ & $6 / 0.545$ & $6 / 0.545$ & $6 / 0.545$ & $9 / 0.818$ & $9 / 0.818$ \\
\hline 35 & CESAC_CH_06_SYR_1 & 45 & 41 & $0 / 0$ & $0 / 0$ & $0 / 0$ & $0 / 0$ & $1 / 0.024$ & $2 / 0.049$ & $5 / 0.122$ \\
\hline
\end{tabular}




\subsection{MISLE database reports}

The USCG MISLE database reports the location of safety and law enforcement incidents in Charleston Harbor. Two collisions and four grounding events were reported between 2011 and 2015. The location of these events is reported in Figure 5-10. It is difficult to compare the MISLE data with the results of the collision and grounding analysis because so few events have been reported.

Figure 5-10. Collision and grounding events in Charleston Harbor, 2011-2015, as reported in USCG MISLE database.

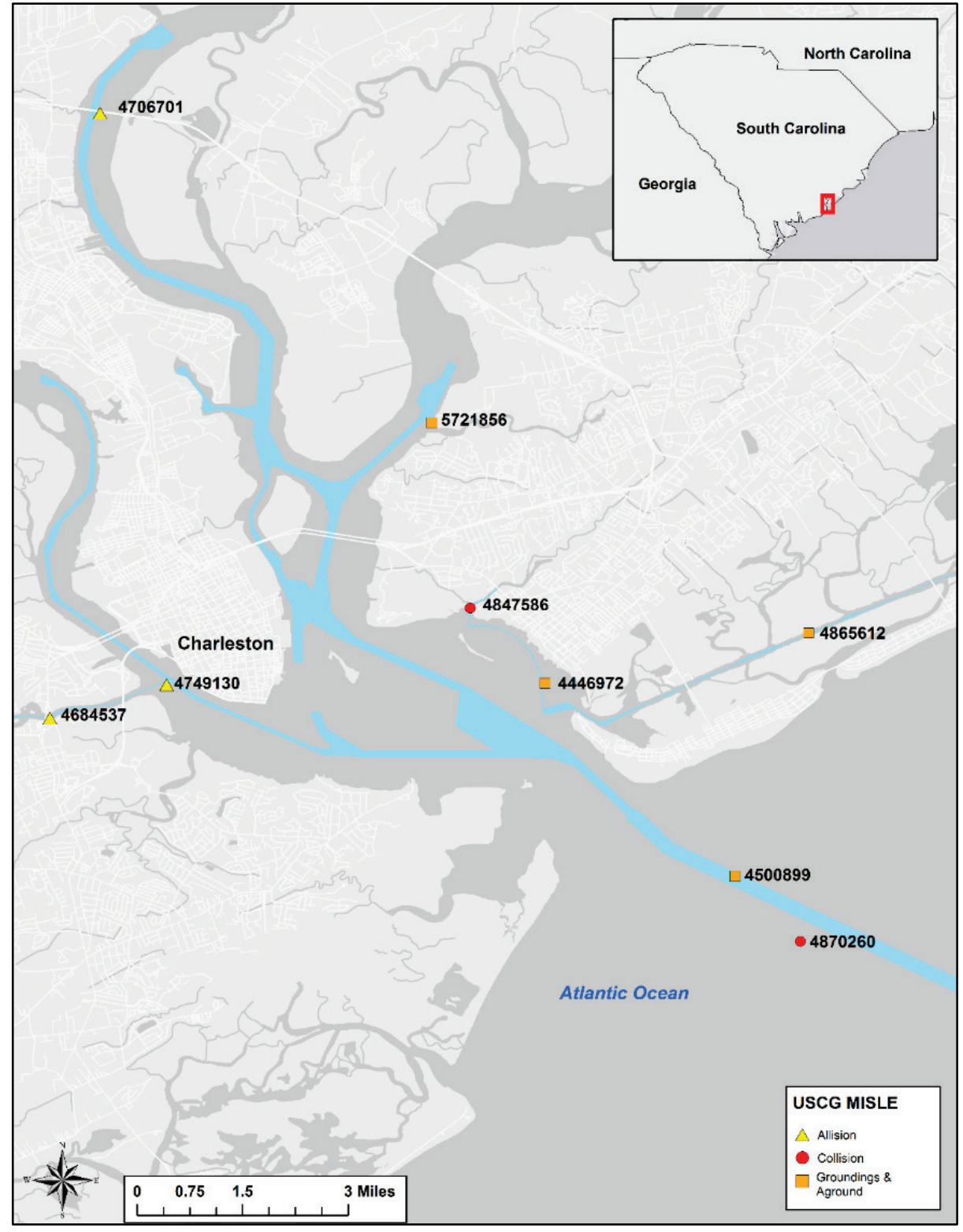




\section{Columbia River Channel (CRC)}

The CRC supports navigation between the Pacific Ocean and McNary Lock and Dam at Umatilla, OR, where it ties into the Snake River system. NAIS data from calendar year 2015 were requested for sections of the Columbia River between the entrance channel and the Interstate 5 bridge, which is the limit of deep-draft navigation. The Columbia River region is illustrated in Figures 6-1 and 6-2. Figure 6-1 shows the lower reaches of the navigation system from the Entrance Range to Eureka Bar and Figure 6-2 shows the upper reaches of the system from Eureka Bar to the Interstate 5 bridge. West of the Interstate 5 bridge, CRC consists of 157.35 miles of navigation channel divided into 102 reaches with maintenance depths ranging from 6.5 to $55 \mathrm{ft}$. The navigation reaches are summarized in Table 6-1, and their locations are shown in Figures 6-3 and 6-4. 
Figure 6-1. Map of Columbia River System - Entrance Range to Longview, Washington.

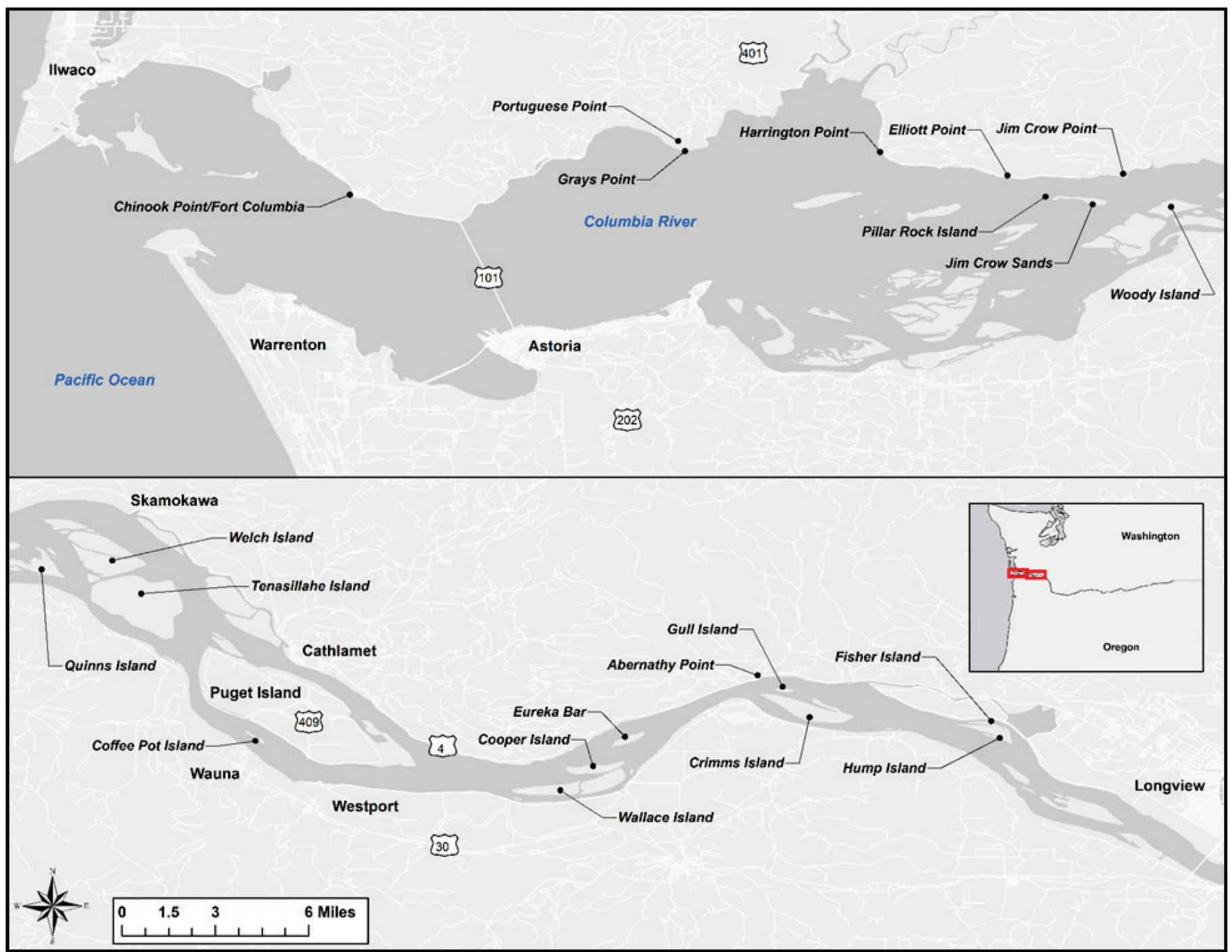


Figure 6-2. Map of Columbia River System - Longview, Washington to Interstate 5 bridge.

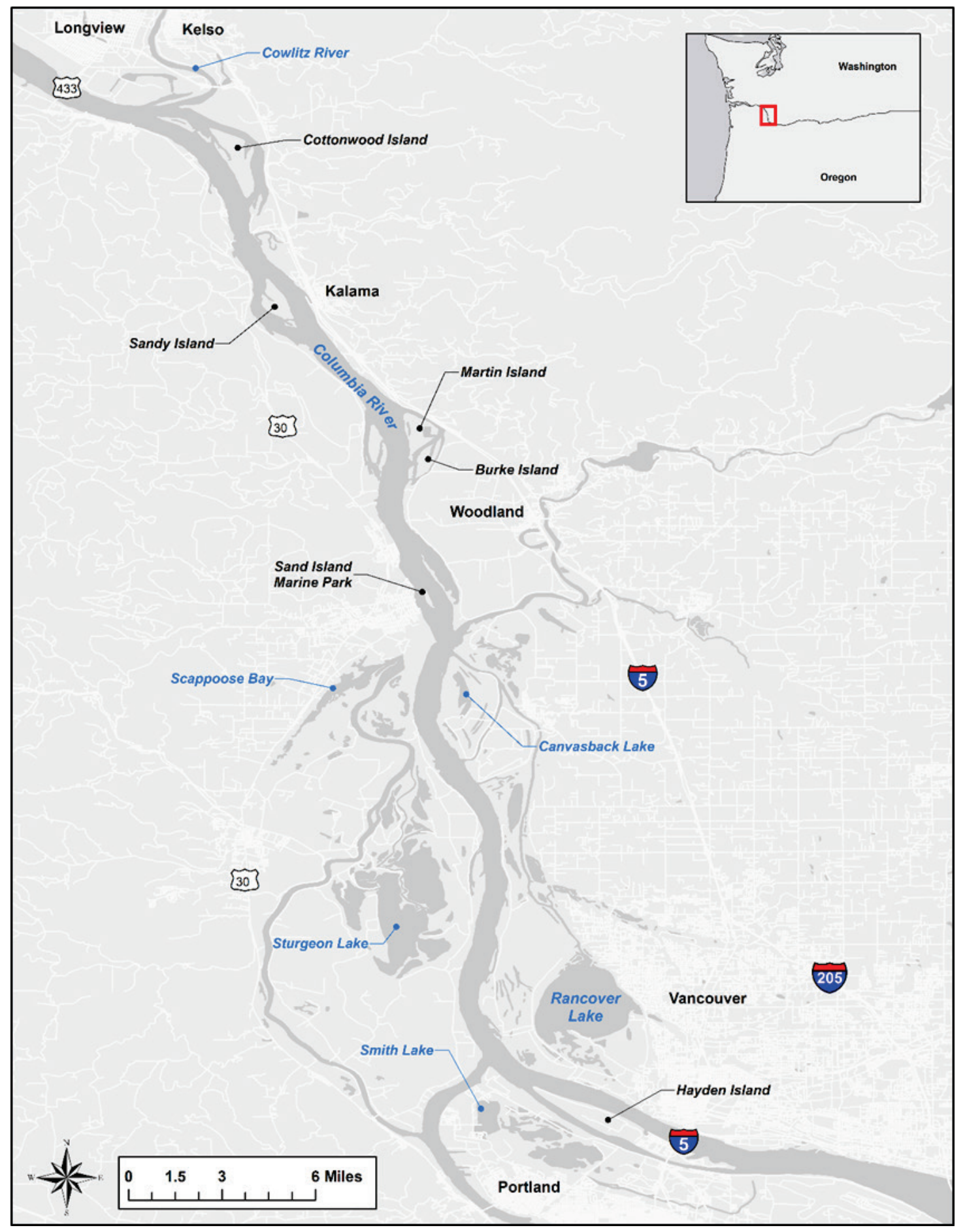


Figure 6-3. Federal navigation channel reaches in Columbia River, Entrance Range to Longview, Washington.

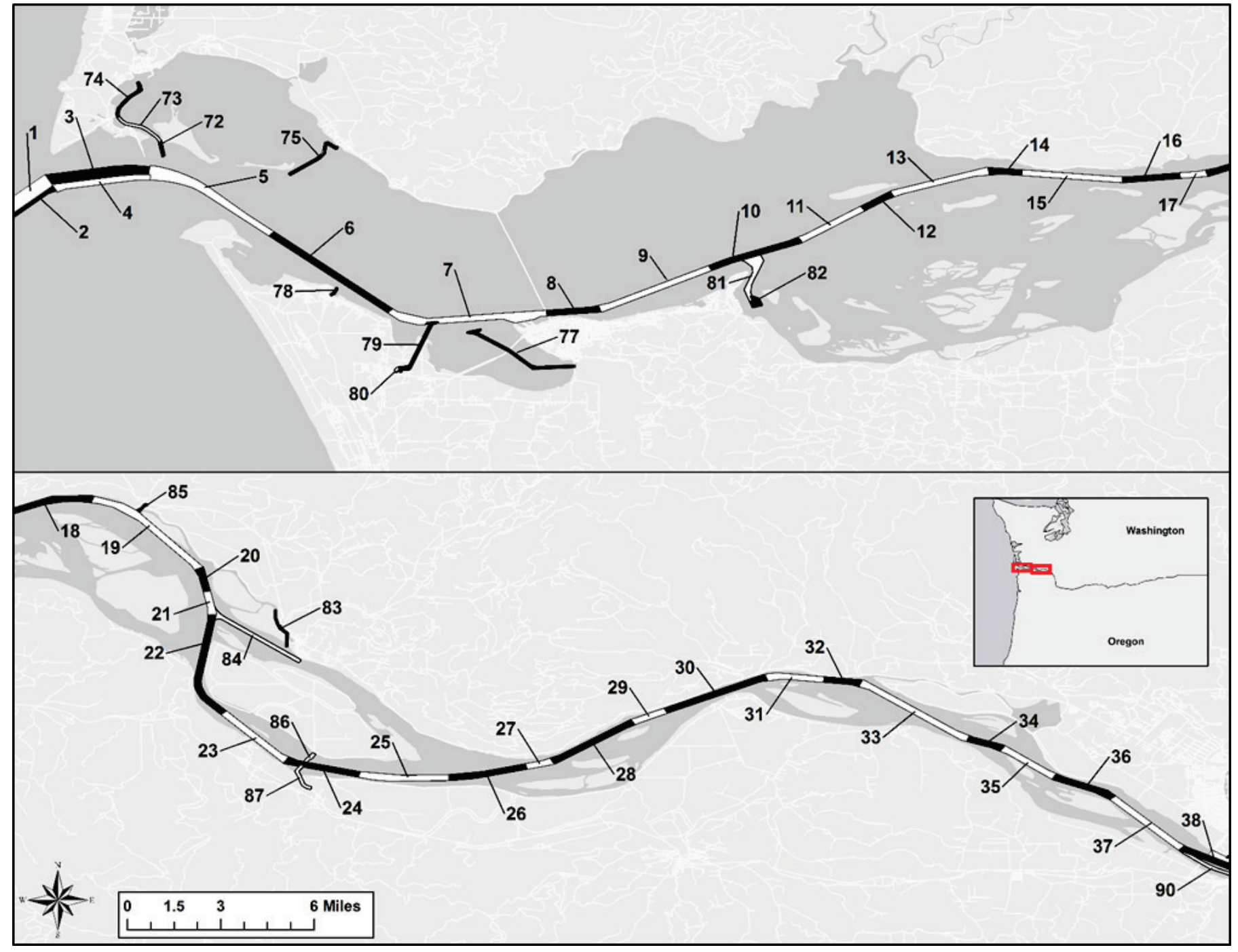


Figure 6-4. Federal navigation reaches in Columbia River, Longview, Washington to the Interstate 5 bridge.

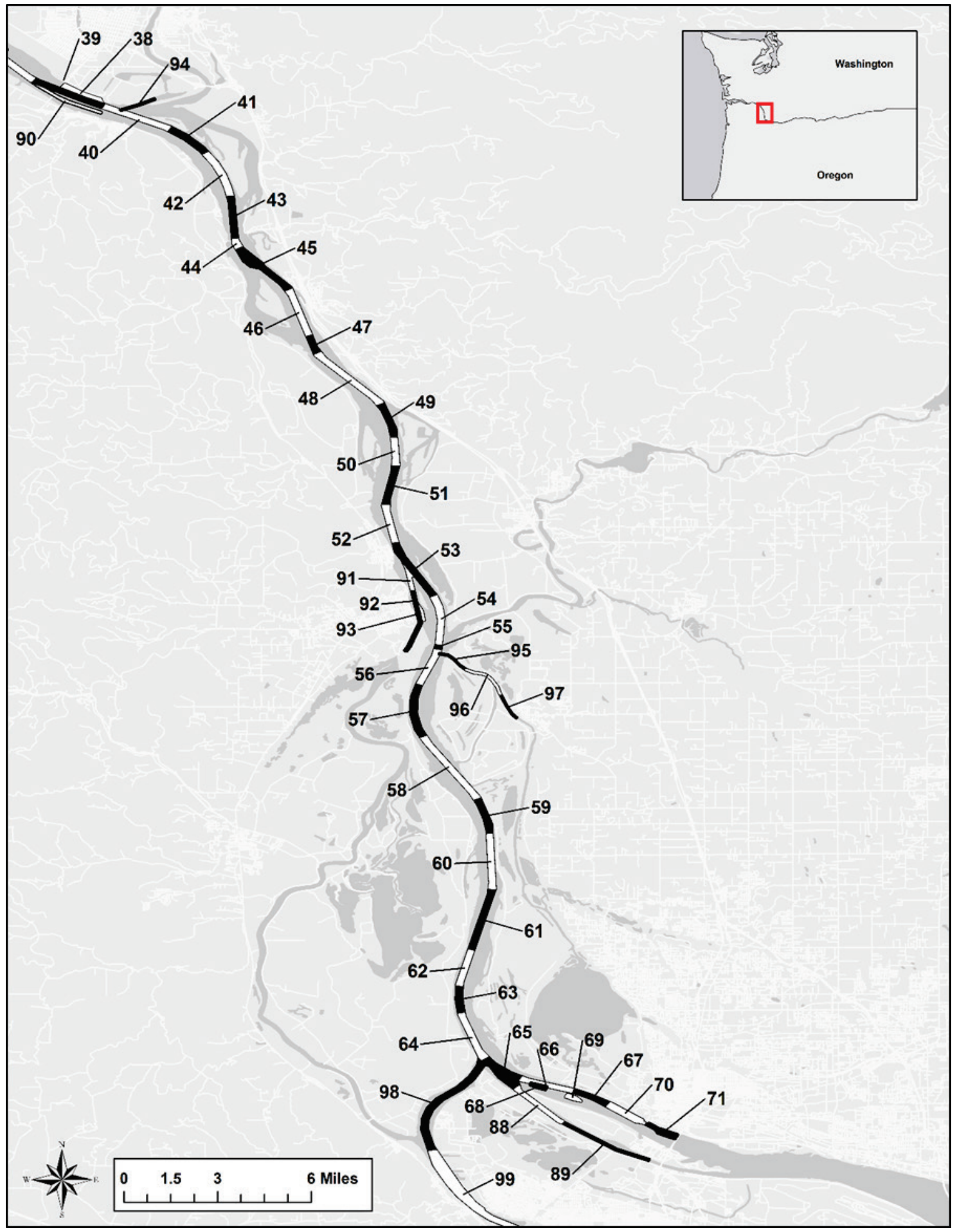


Table 6-1. Federal navigation channel reaches and reach characteristics in Columbia River, west of the Interstate 5 Bridge.

\begin{tabular}{|c|c|c|c|c|c|c|}
\hline$\#$ & Reach Code & Reach Description & $\begin{array}{c}\text { Authorized } \\
\text { Depth (ft) }\end{array}$ & $\begin{array}{l}\text { Maintenance } \\
\text { Depth } \\
\text { (ft) }\end{array}$ & $\begin{array}{l}\text { Length } \\
\text { (miles) }\end{array}$ & $\begin{array}{c}\text { Width } \\
\text { (ft) }\end{array}$ \\
\hline 1 & CENWP_CL_00_MCR_1 & Entrance Range & 55 & 55 & 3.3 & 2000 \\
\hline 2 & CENWP_CL_OO_MCR_2 & Entrance Range & 48 & 48 & 3.3 & 640 \\
\hline 3 & CENWP_CL_00_MCR_3 & Sand Island Range & 55 & 55 & 2.2 & 2000 \\
\hline 4 & CENWP_CL_OO_MCR_4 & Sand Island Range & 48 & 48 & 2.2 & 640 \\
\hline 5 & CENWP_CL_01_LDS_1 & Lower Desdemona Shoal & 43 & 43 & 3.4 & 600 \\
\hline 6 & CENWP_CL_02_UDS_1 & Upper Desdemona Shoal & 43 & 43 & 3.6 & 600 \\
\hline 7 & CENWP_CL_03_FLV_1 & Tansy Point Turn \& Range & 43 & 43 & 3.6 & 600 \\
\hline 8 & CENWP_CL_04_USN_1 & Tansy Point Turn \& Range & 43 & 43 & 1.2 & 600 \\
\hline 9 & CENWP_CL_04_USN_2 & Astoria Range & 43 & 43 & 2.7 & 600 \\
\hline 10 & CENWP_CL_05_TNG_1 & Tongue Point Channel & 43 & 43 & 2.2 & 600 \\
\hline 11 & CENWP_CL_05_TNG_2 & Harrington Point Range & 43 & 43 & 1.7 & 600 \\
\hline 12 & CENWP_CL_06_MLN_1 & Harrington Point Range & 43 & 43 & 0.9 & 600 \\
\hline 13 & CENWP_CL_06_MLN_2 & Miller Sands Range & 43 & 43 & 2.2 & 600 \\
\hline 14 & CENWP_CL_06_MLN_3 & Pillar Rock Lower Range & 43 & 43 & 0.7 & 600 \\
\hline 15 & CENWP_CL_07_PIL_1 & Pillar Rock Lower Range & 43 & 43 & 2.3 & 600 \\
\hline 16 & CENWP_CL_07_PIL_2 & Pillar Rock Upper Range & 43 & 43 & 1.3 & 600 \\
\hline 17 & CENWP_CL_08_BKW_1 & Pillar Rock Upper Range & 43 & 43 & 0.6 & 600 \\
\hline 18 & CENWP_CL_08_BKW_2 & Welch Island Reach & 43 & 43 & 3.2 & 600 \\
\hline 19 & CENWP_CL_09_SKM_1 & Skamokawa Channel & 43 & 43 & 3.3 & 600 \\
\hline 20 & CENWP_CL_09_SKM_2 & Steamboat Reach & 43 & 43 & 0.7 & 600 \\
\hline 21 & CENWP_CL_10_PGT_1 & Steamboat Reach & 43 & 43 & 0.7 & 600 \\
\hline 22 & CENWP_CL_10_PGT_2 & Puget Island Range \& Turn & 43 & 43 & 3.5 & 600 \\
\hline 23 & CENWP_CL_11_WAN_1 & Wauna Range & 43 & 43 & 2 & 600 \\
\hline 24 & CENWP_CL_11_WAN_2 & Driscoll Range & 43 & 43 & 1.7 & 600 \\
\hline 25 & CENWP_CL_12_WST_1 & Westport Turn \& Range & 43 & 43 & 2 & 600 \\
\hline 26 & CENWP_CL_12_WST_2 & Westport Channel & 43 & 43 & 1.7 & 600 \\
\hline 27 & CENWP_CL_13_EUR_1 & Westport Channel & 43 & 43 & 0.7 & 600 \\
\hline 28 & CENWP_CL_13_EUR_2 & Eureka Lower Channel & 43 & 43 & 2.1 & 600 \\
\hline 29 & CENWP_CL_13_EUR_3 & Eureka Upper Channel & 43 & 43 & 0.8 & 600 \\
\hline 30 & CENWP_CL_14_GUL_1 & Oak Point Channel & 43 & 43 & 3 & 600 \\
\hline 31 & CENWP_CL_14_GUL_2 & Gull Island Turn \& Channel & 43 & 43 & 1.4 & 600 \\
\hline 32 & CENWP_CL_15_STL_1 & Gull Island Channel & 43 & 43 & 0.8 & 600 \\
\hline 33 & CENWP_CL_15_STL_2 & Stella Range & 43 & 43 & 3 & 600 \\
\hline
\end{tabular}




\begin{tabular}{|c|c|c|c|c|c|c|}
\hline \# & Reach Code & Reach Description & $\begin{array}{c}\text { Authorized } \\
\text { Depth (ft) }\end{array}$ & $\begin{array}{l}\text { Maintenance } \\
\text { Depth } \\
\text { (ft) }\end{array}$ & $\begin{array}{l}\text { Length } \\
\text { (miles) }\end{array}$ & $\begin{array}{c}\text { Width } \\
\text { (ft) }\end{array}$ \\
\hline 34 & CENWP_CL_16_WLK_1 & Fisher Island Channel & 43 & 43 & 0.8 & 600 \\
\hline 35 & CENWP_CL_16_WLK_2 & Walker Island Channel & 43 & 43 & 1.4 & 600 \\
\hline 36 & CENWP_CL_16_WLK_3 & Barlow Point Channel & 43 & 43 & 1.6 & 600 \\
\hline 37 & CENWP_CL_17_SLG_1 & Slaughters Channel & 43 & 43 & 2.2 & 600 \\
\hline 38 & CENWP_CL_17_SLG_2 & Slaughters Turn \& Turn Basin & 43 & 43 & 1.7 & 600 \\
\hline 39 & CENWP_CL_17_SLG_3 & Slaughters Bar & 40 & 40 & 0 & 600 \\
\hline 40 & CENWP_CL_18_LDB_1 & Cottonwood Island Lower Range & 43 & 43 & 1.7 & 600 \\
\hline 41 & CENWP_CL_18_LDB_2 & Cottonwood Island Turn & 43 & 43 & 1.1 & 600 \\
\hline 42 & CENWP_CL_19_UDB_1 & Cottonwood Island Turn & 43 & 43 & 1.6 & 600 \\
\hline 43 & CENWP_CL_19_UDB_2 & Cottonwood Island Upper Range & 43 & 43 & 1.3 & 600 \\
\hline 44 & CENWP_CL_20_KLM_1 & Cottonwood Island Upper Range & 43 & 43 & 0.3 & 600 \\
\hline 45 & CENWP_CL_20_KLM_2 & Kalama Lower Range & 43 & 43 & 1.8 & 600 \\
\hline 46 & CENWP_CL_20_KLM_3 & Kalama Upper Range & 43 & 43 & 1.6 & 600 \\
\hline 47 & CENWP_CL_21_LMT_1 & Kalama Upper Range & 43 & 43 & 0.6 & 600 \\
\hline 48 & CENWP_CL_21_LMT_2 & Bybee Ledge Channel & 43 & 43 & 2.1 & 600 \\
\hline 49 & CENWP_CL_21_LMT_3 & Martin Island Channel & 43 & 43 & 1.1 & 600 \\
\hline 50 & CENWP_CL_22_UMT_1 & Martin Island Channel & 43 & 43 & 0.9 & 600 \\
\hline 51 & CENWP_CL_22_UMT_2 & Martin Island Range & 43 & 43 & 1.4 & 600 \\
\hline 52 & CENWP_CL_22_UMT_3 & Columbia City Channel & 43 & 43 & 1.2 & 600 \\
\hline 53 & CENWP_CL_23_STH_1 & St. Helens Range & 43 & 43 & 2 & 600 \\
\hline 54 & CENWP_CL_23_STH_2 & St. Helens Turn & 43 & 43 & 1.4 & 600 \\
\hline 55 & CENWP_CL_24_WAR_1 & St. Helens Turn & 43 & 43 & 0.3 & 600 \\
\hline 56 & CENWP_CL_24_WAR_2 & Warrior Rock Range & 43 & 43 & 1.3 & 600 \\
\hline 57 & CENWP_CL_24_WAR_3 & Duck Club Turn & 43 & 43 & 1.4 & 600 \\
\hline 58 & CENWP_CL_25_HEN_1 & Henrici Range & 43 & 43 & 2.6 & 600 \\
\hline 59 & CENWP_CL_25_HEN_2 & Fales Channel & 43 & 43 & 1.1 & 600 \\
\hline 60 & CENWP_CL_26_WLW_1 & Knapp Point Channel & 43 & 43 & 1.8 & 600 \\
\hline 61 & CENWP_CL_26_WLW_2 & Willow Lower Range & 43 & 43 & 2.1 & 600 \\
\hline 62 & CENWP_CL_27_MGN_1 & Willow Upper Range & 43 & 43 & 1.1 & 600 \\
\hline 63 & CENWP_CL_27_MGN_2 & Morgan Bar & 43 & 43 & 1 & 600 \\
\hline 64 & CENWP_CL_27_MGN_3 & Morgan Channel & 43 & 43 & 1.5 & 600 \\
\hline 65 & CENWP_CL_28_VBR_1 & Vancouver Lower Channel & 43 & 43 & 1 & 500 \\
\hline 66 & CENWP_CL_28_VBR_2 & Vancouver Range & 43 & 43 & 1.3 & 500 \\
\hline 67 & CENWP_CL_28_VBR_3 & Vancouver Upper Channel & 43 & 43 & 0.9 & 500 \\
\hline
\end{tabular}




\begin{tabular}{|c|c|c|c|c|c|c|}
\hline \# & Reach Code & Reach Description & $\begin{array}{c}\text { Authorized } \\
\text { Depth (ft) }\end{array}$ & $\begin{array}{l}\text { Maintenance } \\
\text { Depth } \\
\text { (ft) }\end{array}$ & $\begin{array}{l}\text { Length } \\
\text { (miles) }\end{array}$ & $\begin{array}{l}\text { Width } \\
\text { (ft) }\end{array}$ \\
\hline 68 & CENWP_CL_28_VBR_4 & Lower Vancouver Bar & 43 & 43 & 0 & $300-600$ \\
\hline 69 & CENWP_CL_28_VBR_5 & Lower Vancouver Bar & 25 & 25 & 0 & $500-600$ \\
\hline 70 & CENWP_CL_29_VTB_1 & Vancouver Lower Turn Basin & 43 & 43 & 1 & 800 \\
\hline 71 & CENWP_CL_29_VTB_2 & Vancouver Upper Turn Basin & 35 & 35 & 0.9 & 800 \\
\hline 72 & CENWP_CM_01_BB1_1 & Entrance & 16 & 16 & 0.7 & 200 \\
\hline 73 & CENWP_CM_01_BB1_2 & Entrance to Ft. Canby & 16 & 16 & 1.2 & 150 \\
\hline 74 & CENWP_CM_02_BB2_1 & Ft. Canby to Ilwaco & 16 & 16 & 1.3 & 150 \\
\hline 75 & CENWP_CM_05_CHK_1 & Chinook Channel & 10 & 10 & 1.2 & 150 \\
\hline 76 & CENWP_CM_05_CHK_2 & Chinook Channel & 10 & 10 & 1.2 & 150 \\
\hline 77 & CENWP_CM_07_YGB_1 & Youngs Bay & 10 & 10 & 2.5 & 150 \\
\hline 78 & CENWP_CM_08_HMB_1 & Hammond Boat Basin & 10 & 10 & 0.3 & 100 \\
\hline 79 & CENWP_CM_09_SKP_1 & Skipanon Channel & 30 & 16 & 1.8 & 200 \\
\hline 80 & CENWP_CM_09_SKP_2 & Skipanon Channel & 30 & 16 & 0.2 & $150-200$ \\
\hline 81 & CENWP_CM_11_CBY_1 & Cathlamet Bay & 34 & 34 & 0.4 & 350 \\
\hline 82 & CENWP_CM_11_CBY_2 & Anchorage & 25 & 25 & 0.15 & 350 \\
\hline 83 & CENWP_CM_13_ELO_1 & Elochoman Slough & 10 & 10 & 1.5 & 100 \\
\hline 84 & CENWP_CM_14_CC1_1 & Cathlamet Channel & 10 & 10 & 1.2 & 300 \\
\hline 85 & CENWP_CM_15_SKC_1 & Skamokawa Creek & 6.5 & 6.5 & 0.4 & 75 \\
\hline 86 & CENWP_CM_16_WFC_1 & Wahkiakum Ferry & 9 & 9 & 0.5 & 200 \\
\hline 87 & CENWP_CM_17_WSL_1 & Westport Slough & 32 & 28 & 0.7 & 150 \\
\hline 88 & CENWP_CM_19_OSL_1 & Oregon Slough Lower & 43 & 43 & 1.5 & 400 \\
\hline 89 & CENWP_CM_19_OSL_2 & Oregon Slough Lower & 20 & 20 & 2.3 & 200 \\
\hline 90 & CENWP_CM_21_RAI_1 & Ranier Channel & 24 & 24 & 1.3 & 200 \\
\hline 91 & CENWP_CM_24_MUC_1 & North End & 25 & 25 & 1 & 300 \\
\hline 92 & CENWP_CM_24_MUC_2 & South End & 25 & 25 & 1.8 & 250 \\
\hline 93 & CENWP_CM_24_MUC_A & Anchorage & 25 & 25 & 0 & 400 \\
\hline 94 & CENWP_CZ_00_CWM_1 & Cowlitz River & 8 & 8 & 0.4 & 150 \\
\hline 95 & CENWP_LK_01_LK1_1 & Lake River 1 & 6 & 6 & 0 & 100 \\
\hline 96 & CENWP_LK_02_LK2_1 & Lake River 2 & 6 & 6 & 0 & 100 \\
\hline 97 & CENWP_LK_03_LK3_1 & Lake River 3 & 6 & 6 & 0 & 100 \\
\hline 98 & CENWP_WR_01_WR1_1 & Willamette River \#1 & 40 & 40 & 3.5 & $600-1400$ \\
\hline 99 & CENWP_WR_02_WR2_1 & Willamette River \#2 & 40 & 40 & 4 & $600-1400$ \\
\hline 100 & CENWP_WR_03_WR3_1 & Willamette River \#3 & 40 & 40 & 4 & $600-1400$ \\
\hline
\end{tabular}




\subsection{Static vessel data}

During calendar year 2015, NAIS receivers intercepted AIS messages from 1,749 unique vessels. Static vessel data were screened to assess their completeness and to identify and correct potential problems before analyzing collision and grounding risks. The static vessel data supplied by the USCG contained information on only 315 vessels. Records for seven vessels (0.4\%) contained malformed MMSI numbers. Since the static vessel data were incomplete, they were supplemented by transferring vessel name, ship and cargo type, and dimensions from the AISAP national vessel inventory. The AISAP-supplemented static vessel database contained 145 records (8.3\%) with no name, 209 records (11.9\%) with unknown ship and cargo type code, and 278 records (15.9\%) without information about length, beam, or AIS transponder location. There were 650 records $(37.2 \%)$ that contained no information about maximum vessel draft.

The summary of vessels operating in CRC during calendar year 2015 is provided in Table 6-2. The classification of each vessel using selected ship and cargo type codes was validated by reviewing photographs on the website MarineTraffic.com. Specifically, vessels with missing ship and cargo type codes and those classified under ship and cargo type codes for unknown vessel types, WIG craft (20-29), and the omnibus category of vessels (90-99) were targeted for review. Ship and cargo type codes were corrected when a revised classification was indicated and could be verified. These ship and cargo type codes were targeted for review because they appear to be miscoded more often than others. National mean values for length, beam, and draft were calculated for two-digit ship and cargo type codes using the AISAP national inventory. These were imputed to records with missing data on vessel dimensions. AIS transponders were located on each vessel based on data contained in the AISAP national inventory of vessels. When the AIS transponder location was missing, it was assumed to be located at the center of the vessel. 
Table 6-2. Descriptive summary of vessels utilizing CRC in 2015.

\begin{tabular}{|c|c|c|c|}
\hline \multirow[b]{2}{*}{ AIS Ship and Cargo Type } & \multirow{2}{*}{$\begin{array}{l}\text { AIS Ship and } \\
\text { Cargo } \\
\text { Type Code }\end{array}$} & \multicolumn{2}{|c|}{ Number of Unique Vessels } \\
\hline & & $\begin{array}{c}\text { Before Review of } \\
\text { Static Vessel } \\
\text { Data }\end{array}$ & $\begin{array}{c}\text { After Review of } \\
\text { Static Vessel } \\
\text { Data }\end{array}$ \\
\hline Unknown & 00 & 241 & 148 \\
\hline Wing-in-ground craft (WIG) & $20-29$ & 5 & 0 \\
\hline Fishing vessels & 30 & 143 & 166 \\
\hline Towing & $31-32$ & 93 & 93 \\
\hline Engaged in dredging or underwater operations & 33 & 10 & 12 \\
\hline Engaged in diving operations & 34 & 1 & 1 \\
\hline Engaged in military operations & 35 & 24 & 30 \\
\hline Sailing vessels & 36 & 79 & 79 \\
\hline Pleasure craft & 37 & 165 & 172 \\
\hline Reserved for future use & 38-39 & 0 & 0 \\
\hline High-speed craft (HSC) or passenger ferries & $40-49$ & 0 & 0 \\
\hline Pilot vessels & 50 & 7 & 9 \\
\hline Search and rescue vessels & 51 & 20 & 21 \\
\hline Tugs & 52 & 43 & 54 \\
\hline Port tenders & 53 & 1 & 2 \\
\hline Vessels with anti-pollution facilities & 54 & 12 & 12 \\
\hline Law enforcement vessels & 55 & 2 & 3 \\
\hline Spare for assignment to local vessels & $56-57$ & 3 & 0 \\
\hline Medical transports & 58 & 3 & 3 \\
\hline Ships according to RR Resolution (Mob-83) & 59 & 0 & 0 \\
\hline Passenger ships & $60-69$ & 29 & 30 \\
\hline Cargo ships & $70-79$ & 775 & 832 \\
\hline Tankers & $80-89$ & 54 & 54 \\
\hline Other vessels & $90-99$ & 35 & 28 \\
\hline Total & & 1749 & 1749 \\
\hline
\end{tabular}




\subsection{Collision risk assessment}

AIS position reports were sampled at 30 sec intervals. Each sampled position report was classified as an SDV if a point on the perimeter of another vessel was located within the domain of the vessel transmitting the AIS signal. These data are used to calculate three metrics of collision risk in CRC. The first is the conditional frequency of an SDV, which is an estimate of the probability that an SDV occurs in a navigation channel reach given that at least one vessel is present in that reach. The second is the overall probability of an SDV occurring in a reach, which is the probability an SDV occurs without regard to whether or not a vessel is present. This is calculated by multiplying the conditional probability of an SDV by the probability that at least one vessel is present in the reach. The third metric is the relative frequency of SDVs, which is similar to the overall probability of an SDV occurring in a reach. The conditional frequency of an SDV is estimated by calculating the ratio of sampled position reports classified as SDVs to the total number of sampled position reports. This is an estimate of the probability that a vessel that is operating in a particular navigation reach will be involved in an SDV in that reach. This metric of collision risk can be used to evaluate, compare, and rank navigation channels in terms of collision risk.

The assessment of collision risk in CRC excludes SDVs involving vessels classified as tow boats (31-32) and harbor work boats (50-57), SDVs involving two vessels classified as dredgers, and between dredgers and crew boats, and dredgers and USACE survey boats. Additional exclusions included two vessels identified as crew boats operating under the ship and cargo type code for passenger vessels (60-69). A large number of SDVs involved National Oceanic and Atmospheric Administration (NOAA) research vessels that appeared to be working together in the Columbia River. These vessels were also excluded from the risk assessment.

\subsubsection{Location and severity of encounters}

During calendar year 2015, there were 496 encounters in the CRC west of Interstate 5. The location and severity of encounters is shown in Figure 6-5 and 6-6. The data points in Figures 6-5 and 6-6 indicate the geometric center of the encroached vessel at the time of maximum SDV severity. The color of each point indicates the severity of each encounter. Encounters are distributed throughout the system, and clusters of encounters can be seen at the Port of Astoria, Oregon, and at the Ports of Longview, Kalama, 
and Vancouver, in Washington. Several clusters of encounters involved dredgers operating in the channel and bulk carriers passing those dredgers. These clusters can be seen in the Harrington Point Range (\#12), Pillar Rock Upper Range (\#17), Welch Island Reach (\#18), Skamokawa Channel (\#19), Westport Channel (\#26-27), Kalama Upper Range (\#46), and in St. Helen's Range and Turn (\#53-54). The color of each point in Figures 6-5 and 6-6 reflects the maximum SDV severity score during the encounter. The highest maximum SDV severity scores do not appear to be clustered at any one location. The deep-draft portions of the CRC are 600 $\mathrm{ft}$ (183 m) wide, which is sufficient to permit two cargo vessels to pass each other without causing an SDV.

Empirical distribution functions are used in Figure 6-7 to summarize selected characteristics of encounters in CRC. These include maximum SDV severity score during an encounter, minimum distance between vessel perimeters during an encounter, and duration of encounters. As shown in Figure 6-7(a), approximately $75 \%$ of encounters have maximum SDV severity scores less than 0.5. A score less than 0.5 indicates that the perimeter of the encroaching vessel was closer to the encroached vessel's ship domain boundary than to the perimeter of the encroached vessel. Only $10 \%$ of SDVs have maximum severity scores that are greater than o.8. The types of vessels involved in those encounters with the highest maximum SDV severity scores are fishing boats, dredgers, cargo vessels, and passenger vessels.

The other two characteristics that can help put the results of the risk assessment in context are the minimum distance between the perimeters of vessels involved in an SDV and the duration of the SDV. The empirical distribution function in Figure 6-7(b) shows that the minimum distance between vessel perimeters is greater than $50 \mathrm{~m}$ in $85 \%$ of cases. The empirical distribution function in Figure 6-7(c) shows that $70 \%$ of encounters last less than 1 minute and $90 \%$ of encounters last less than 2 minutes. No particular ship and cargo types are involved in those encounters with the smallest distance between perimeters or the longest duration. 
Figure 6-5. Encounters in CRC, Entrance Range to Eureka Bar. Each point marks the geometric center of the encroached vessel at the time of maximum SDV severity during the encounter.

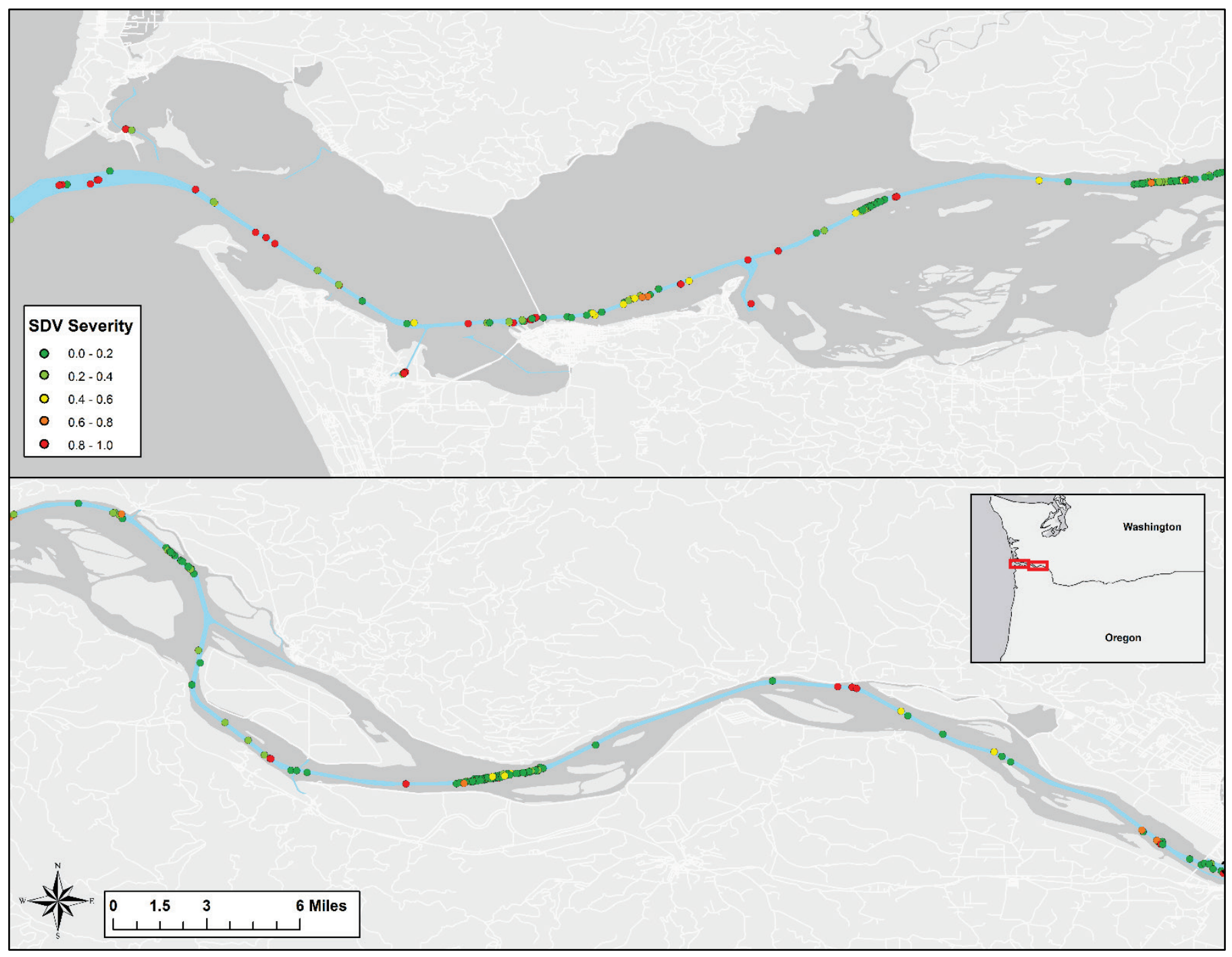


Figure 6-6. Encounters in CRC, Eureka Bar to the Interstate 5 bridge. Each point marks the geometric center of the encroached vessel at the time of maximum SDV severity during the encounter.

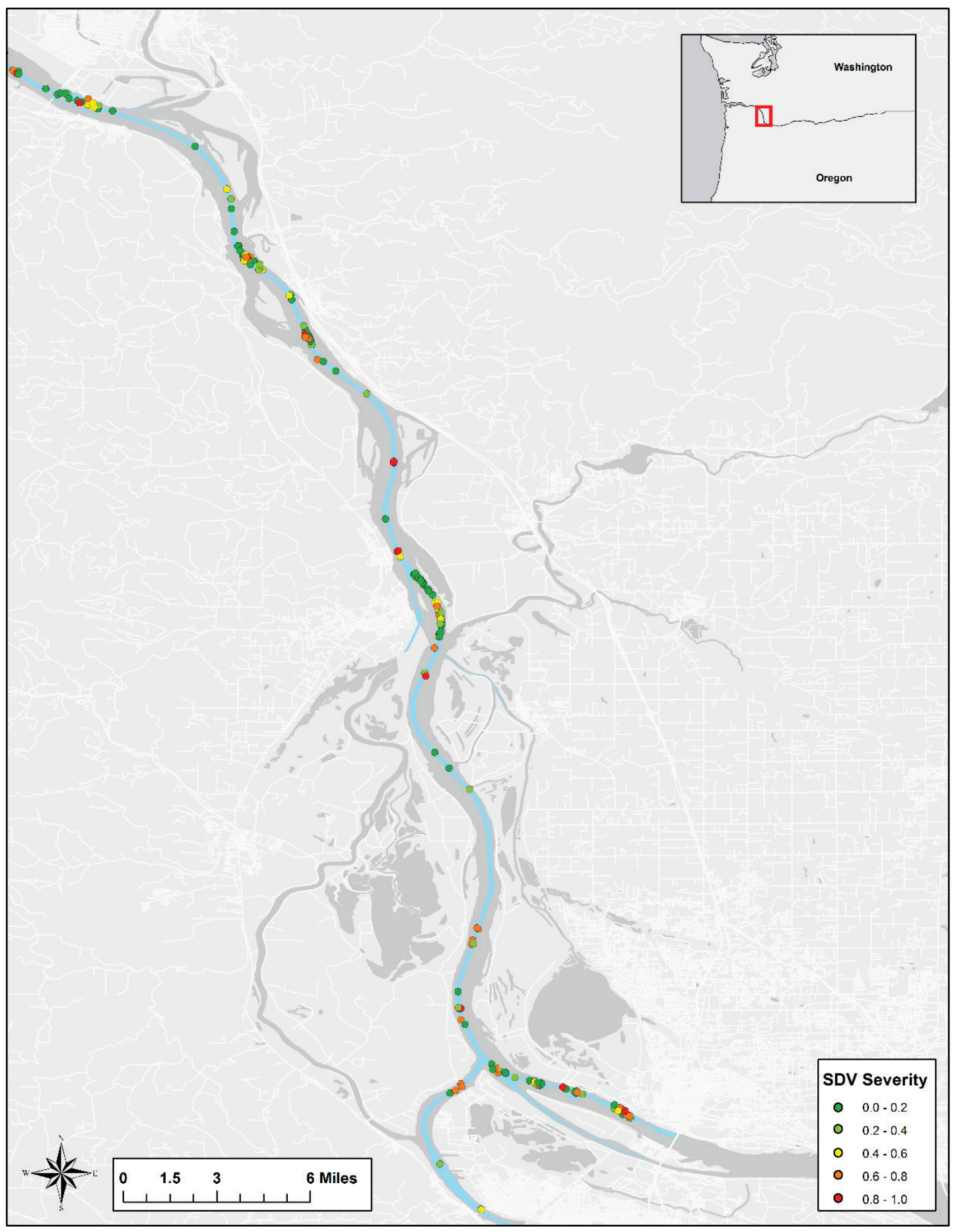


ERDC/EL TR-19-7

145

Figure 6-7. Characteristics of encounters in CRC.
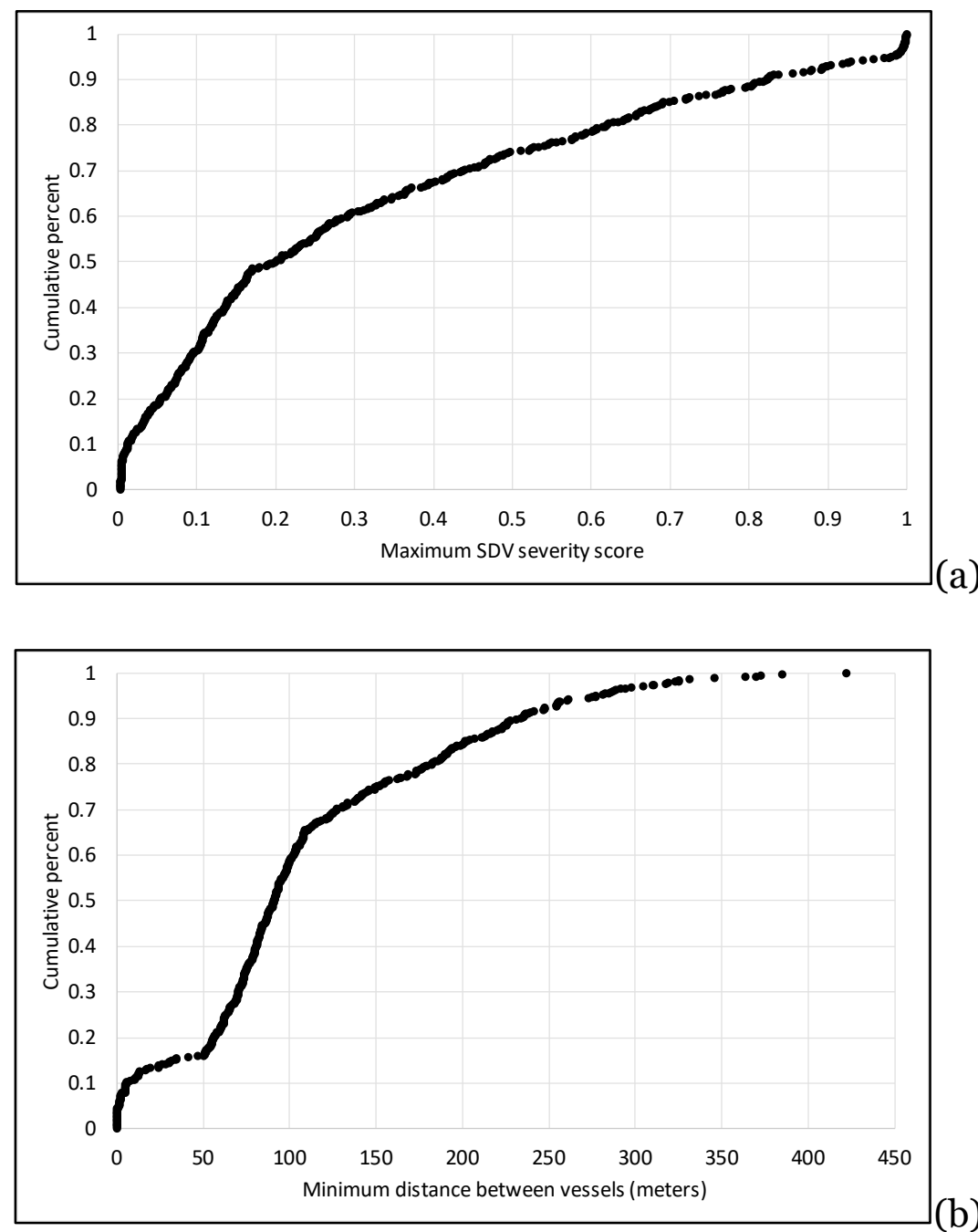

(b)

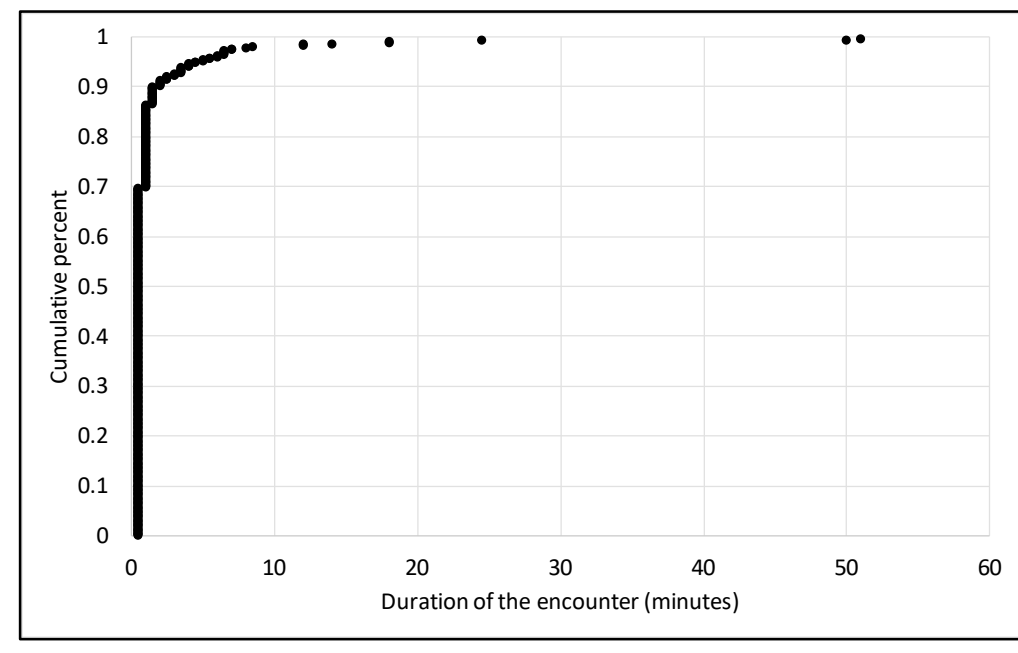

(c) 


\subsubsection{Types of vessels involved in encounters}

What types of vessels are involved in encounters are summarized in Table 6-3. The encroached vessel category is listed in the right-hand column, and the encroaching vessel category is listed across the top. Each element of the table is the number of encounters that involved two vessels with ship and cargo types in each respective category. There were 496 encounters identified in the analysis of AIS data from calendar year 2015.

Cargo vessels were classified as the encroached vessel in 231 encounters and as the encroaching vessel in 251 encounters. Of these, 99 encounters involved two cargo vessels. Therefore, 383 of the 496 encounters in CRC (77\%) involved at least one cargo vessel. Dredgers were classified as the encroached vessel in 191 encounters and as the encroaching vessel in 28 encounters. Since encounters involving two dredgers have been excluded from this inventory, a total of 219 encounters (44\%) involved at least one dredger. There were 164 encounters involving one dredger and one cargo vessel. Cargo vessels were classified as the encroaching vessel in $85 \%$ of these encounters.

Passenger vessels were classified as the encroaching vessel in 61 SDVs and as the encroached vessel in 11 SDVs. Of these, one SDV involved two passenger vessels. Therefore, $70 \mathrm{SDV}$ involved at least one passenger vessel. The inventory of SDVs includes $38 \mathrm{SDVs}$ involving a passenger vessel encroaching on a cargo vessel, and 35 of these SDVs (92\%) involved a $10 \mathrm{~m}$ crew boat. These SDVs do not appear to be instances of the crew boat servicing the cargo vessels because they were less than 2 minutes in duration, both vessels were in transit at the time of the SDV, and the SDVs are distributed throughout the CRC.

There are 18 SDVs involving encroaching vessels classified under the ship and cargo type code for military operations (35). Thirteen of these SDVs involve a USACE survey vessel and five of these SDVs involve USCG and U.S. Navy vessels. 
Table 6-3. Number of encounters in CRC by AIS ship and cargo type code.

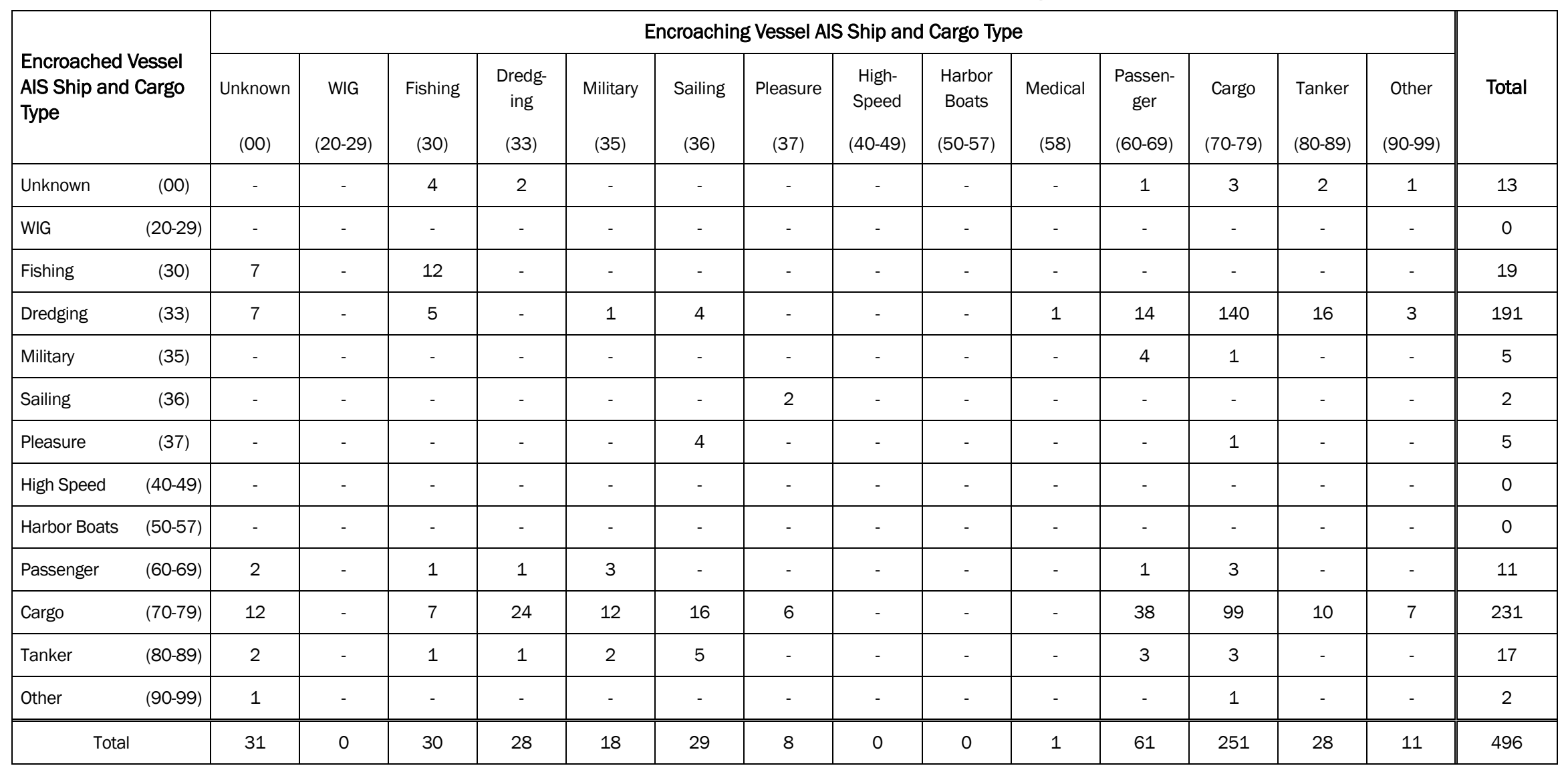




\subsubsection{Frequency of SDVs}

During the 2015 calendar year, 4,061,314 position reports were sampled from vessels operating in $\mathrm{CRC}$, and 1,048 of these position reports were classified as SDVs. The conditional frequencies of SDVs are summarized in Table 6-4 by reach and AIS ship and cargo type. The rows of the table correspond to each of the 100 reaches west of the Interstate 5 bridge, and the columns correspond to each of the nine major categories of AIS-equipped vessels as defined in the AIS encoding guide. In Table 6-4, the last column gives the conditional probability of an SDV in each reach over all vessel categories, and the last row gives the conditional probability of an SDV for each vessel category over all reaches of the navigation project. Frequencies greater than $5.0 \times 10^{-4}$ are printed in boldface type. Over all vessel types and reaches, the conditional probability of an SDV in $\mathrm{CRC}$ is $2.58 \times 10^{-4}$. 
Table 6-4. Conditional frequency of SDVs in CRC by reach and AIS ship and cargo type. Frequencies greater than $5 \times 10^{-4}$ are in bold red typeface.

\begin{tabular}{|c|c|c|c|c|c|c|c|c|c|c|c|c|}
\hline \multirow[b]{2}{*}{ \# } & \multirow[b]{2}{*}{ Reach Code } & \multicolumn{10}{|c|}{ AIS Ship and Cargo Type } & \multirow[b]{2}{*}{$\begin{array}{c}\text { All Vessel } \\
\text { Types }\end{array}$} \\
\hline & & $\begin{array}{l}\text { Unknown } \\
\text { (00) }\end{array}$ & $\begin{array}{c}\text { WIG } \\
(20-29)\end{array}$ & $\begin{array}{c}\text { Class } 3 \\
(30,33-39)\end{array}$ & $\begin{array}{c}\text { High-Speed } \\
\text { (40-49) }\end{array}$ & $\begin{array}{l}\text { Harbor } \\
\text { Boats } \\
(50-57)\end{array}$ & $\begin{array}{c}\text { Medical } \\
\text { (58) }\end{array}$ & $\begin{array}{l}\text { Passenger } \\
\text { (60-69) }\end{array}$ & $\begin{array}{l}\text { Cargo } \\
(70-79)\end{array}$ & $\begin{array}{l}\text { Tanker } \\
(80-89)\end{array}$ & $\begin{array}{l}\text { Other } \\
(90-99)\end{array}$ & \\
\hline 1 & CENWP_CL_O0_MCR_1 & $0.00 E+00$ & - & $0.00 \mathrm{E}+00$ & - & - & $0.00 E+00$ & $0.00 E+00$ & $0.00 E+00$ & $0.00 E+00$ & $0.00 \mathrm{E}+00$ & $0.00 E+00$ \\
\hline 2 & CENWP_CL_O0_MCR_2 & $0.00 E+00$ & - & $6.90 \mathrm{E}-05$ & - & - & $0.00 \mathrm{E}+00$ & $0.00 E+00$ & $0.00 E+00$ & $0.00 E+00$ & $0.00 E+00$ & $5.84 \mathrm{E}-05$ \\
\hline 3 & CENWP_CL_O0_MCR_3 & $1.05 \mathrm{E}-03$ & - & $1.84 \mathrm{E}-05$ & - & - & $0.00 \mathrm{E}+00$ & $0.00 E+00$ & $8.24 \mathrm{E}-05$ & $0.00 E+00$ & $0.00 E+00$ & 4.54E-05 \\
\hline 4 & CENWP_CL_OO_MCR_4 & $0.00 \mathrm{E}+00$ & - & $0.00 E+00$ & - & - & $0.00 E+00$ & $0.00 \mathrm{E}+00$ & $0.00 \mathrm{E}+00$ & $0.00 E+00$ & $0.00 \mathrm{E}+00$ & $0.00 \mathrm{E}+00$ \\
\hline 5 & CENWP_CL_01_LDS_1 & $6.47 \mathrm{E}-03$ & - & 2.39E-03 & - & - & $0.00 \mathrm{E}+00$ & $0.00 \mathrm{E}+00$ & $1.61 \mathrm{E}-05$ & $0.00 \mathrm{E}+00$ & $0.00 \mathrm{E}+00$ & $1.04 \mathrm{E}-03$ \\
\hline 6 & CENWP_CL_02_UDS_1 & 4.07E-03 & - & $1.71 \mathrm{E}-03$ & - & - & $0.00 \mathrm{E}+00$ & $0.00 E+00$ & $1.48 \mathrm{E}-05$ & $3.22 \mathrm{E}-04$ & $2.36 \mathrm{E}-04$ & 7.27E-04 \\
\hline 7 & CENWP_CL_03_FLV_1 & $2.53 \mathrm{E}-03$ & - & $2.38 \mathrm{E}-04$ & - & - & $0.00 E+00$ & 3.71E-03 & $1.27 \mathrm{E}-04$ & $1.41 \mathrm{E}-04$ & $0.00 E+00$ & $3.00 E-04$ \\
\hline 8 & CENWP_CL_04_USN_1 & 1.17E-03 & - & $8.41 \mathrm{E}-05$ & - & - & $0.00 E+00$ & $0.00 E+00$ & $2.20 \mathrm{E}-04$ & $0.00 E+00$ & $0.00 E+00$ & $1.71 \mathrm{E}-04$ \\
\hline 9 & CENWP_CL_04_USN_2 & 3.17E-03 & - & $6.20 \mathrm{E}-04$ & - & - & $0.00 \mathrm{E}+00$ & $0.00 E+00$ & $2.15 \mathrm{E}-04$ & $0.00 E+00$ & $0.00 E+00$ & 2.64E-04 \\
\hline 10 & CENWP_CL_05_TNG_1 & $0.00 E+00$ & - & $0.00 \mathrm{E}+00$ & - & - & $0.00 \mathrm{E}+00$ & $0.00 \mathrm{E}+00$ & 4.85E-05 & $0.00 E+00$ & $0.00 \mathrm{E}+00$ & 3.23E-05 \\
\hline 11 & CENWP_CL_05_TNG_2 & $0.00 \mathrm{E}+00$ & - & $2.18 \mathrm{E}-04$ & - & - & $0.00 \mathrm{E}+00$ & $0.00 \mathrm{E}+00$ & 9.27E-05 & $0.00 \mathrm{E}+00$ & $0.00 \mathrm{E}+00$ & 9.30E-05 \\
\hline 12 & CENWP_CL_06_MLN_1 & $0.00 E+00$ & - & $9.52 \mathrm{E}-04$ & - & - & $0.00 E+00$ & $0.00 \mathrm{E}+00$ & $6.18 \mathrm{E}-05$ & $0.00 E+00$ & $0.00 E+00$ & 4.64E-04 \\
\hline 13 & CENWP_CL_06_MLN_2 & 8.99E-04 & - & $0.00 \mathrm{E}+00$ & - & - & $0.00 E+00$ & $0.00 E+00$ & $0.00 \mathrm{E}+00$ & $2.45 \mathrm{E}-04$ & $0.00 \mathrm{E}+00$ & 2.92E-05 \\
\hline 14 & CENWP_CL_06_MLN_3 & $0.00 E+00$ & - & $0.00 \mathrm{E}+00$ & - & - & $0.00 \mathrm{E}+00$ & $0.00 E+00$ & $0.00 E+00$ & $0.00 E+00$ & $0.00 E+00$ & $0.00 E+00$ \\
\hline 15 & CENWP_CL_07_PIL_1 & $0.00 E+00$ & - & $0.00 \mathrm{E}+00$ & - & - & $0.00 \mathrm{E}+00$ & $0.00 \mathrm{E}+00$ & 7.11E-05 & $0.00 E+00$ & $0.00 E+00$ & $4.32 \mathrm{E}-05$ \\
\hline 16 & CENWP_CL_07_PIL_2 & $0.00 E+00$ & - & $1.52 \mathrm{E}-03$ & - & - & $0.00 \mathrm{E}+00$ & $1.27 \mathrm{E}-04$ & $1.65 \mathrm{E}-04$ & $0.00 E+00$ & $0.00 E+00$ & $7.20 \mathrm{E}-04$ \\
\hline 17 & CENWP_CL_08_BKW_1 & $0.00 E+00$ & - & $6.75 \mathrm{E}-04$ & - & - & $0.00 \mathrm{E}+00$ & 2.43E-04 & 2.68E-04 & $0.00 \mathrm{E}+00$ & $0.00 \mathrm{E}+00$ & 4.06E-04 \\
\hline 18 & CENWP_CL_08_BKW_2 & $0.00 E+00$ & - & $2.34 \mathrm{E}-04$ & - & - & $0.00 E+00$ & $1.18 \mathrm{E}-04$ & $1.15 \mathrm{E}-04$ & 3.35E-04 & $2.54 \mathrm{E}-04$ & $1.54 \mathrm{E}-04$ \\
\hline 19 & CENWP_CL_09_SKM_1 & $0.00 E+00$ & - & $6.05 \mathrm{E}-04$ & - & - & $0.00 \mathrm{E}+00$ & $0.00 E+00$ & 8.00E-05 & $0.00 E+00$ & $0.00 \mathrm{E}+00$ & $2.38 \mathrm{E}-04$ \\
\hline 20 & CENWP_CL_09_SKM_2 & $0.00 \mathrm{E}+00$ & - & $0.00 \mathrm{E}+00$ & - & - & $0.00 \mathrm{E}+00$ & $0.00 \mathrm{E}+00$ & $0.00 \mathrm{E}+00$ & $0.00 \mathrm{E}+00$ & $0.00 \mathrm{E}+00$ & $0.00 E+00$ \\
\hline 21 & CENWP_CL_10_PGT_1 & $0.00 E+00$ & - & $0.00 E+00$ & - & - & $0.00 E+00$ & $0.00 \mathrm{E}+00$ & $0.00 E+00$ & $0.00 E+00$ & $0.00 E+00$ & $0.00 E+00$ \\
\hline
\end{tabular}




\begin{tabular}{|c|c|c|c|c|c|c|c|c|c|c|c|c|}
\hline \multirow[b]{2}{*}{$\#$} & \multirow[b]{2}{*}{ Reach Code } & \multicolumn{10}{|c|}{ AIS Ship and Cargo Type } & \multirow[b]{2}{*}{$\begin{array}{c}\text { All Vesse } \\
\text { Types }\end{array}$} \\
\hline & & $\begin{array}{l}\text { Unknown } \\
(00)\end{array}$ & $\begin{array}{c}\text { WIG } \\
(20-29)\end{array}$ & $\begin{array}{c}\text { Class } 3 \\
(30,33-39)\end{array}$ & $\begin{array}{c}\text { High-Speed } \\
\text { (40-49) }\end{array}$ & $\begin{array}{l}\text { Harbor } \\
\text { Boats } \\
(50-57)\end{array}$ & $\begin{array}{l}\text { Medical } \\
\text { (58) }\end{array}$ & $\begin{array}{l}\text { Passenger } \\
(60-69)\end{array}$ & $\begin{array}{l}\text { Cargo } \\
\text { (70-79) }\end{array}$ & $\begin{array}{l}\text { Tanker } \\
\text { (80-89) }\end{array}$ & $\begin{array}{l}\text { Other } \\
(90-99)\end{array}$ & \\
\hline 22 & CENWP_CL_10_PGT_2 & $0.00 E+00$ & - & 3.94E-05 & - & - & $0.00 E+00$ & $1.34 \mathrm{E}-04$ & 1.49E-05 & $0.00 E+00$ & $0.00 E+00$ & 2.65E-05 \\
\hline 23 & CENWP_CL_11_WAN_1 & $9.22 \mathrm{E}-04$ & - & $6.22 \mathrm{E}-05$ & - & - & $0.00 \mathrm{E}+00$ & $0.00 \mathrm{E}+00$ & $2.18 \mathrm{E}-05$ & $4.50 \mathrm{E}-04$ & $0.00 E+00$ & $6.35 E-05$ \\
\hline 24 & CENWP_CL_11_WAN_2 & $0.00 \mathrm{E}+00$ & - & $1.32 \mathrm{E}-04$ & - & - & $0.00 E+00$ & $0.00 E+00$ & 5.77E-05 & $0.00 \mathrm{E}+00$ & $0.00 \mathrm{E}+00$ & 5.19E-05 \\
\hline 25 & CENWP_CL_12_WST_1 & $0.00 \mathrm{E}+00$ & - & $0.00 \mathrm{E}+00$ & - & - & $0.00 \mathrm{E}+00$ & $0.00 \mathrm{E}+00$ & $2.59 \mathrm{E}-05$ & $0.00 \mathrm{E}+00$ & $0.00 \mathrm{E}+00$ & $1.51 \mathrm{E}-05$ \\
\hline 26 & CENWP_CL_12_WST_2 & $1.26 \mathrm{E}-03$ & - & $9.25 \mathrm{E}-04$ & - & - & $0.00 \mathrm{E}+00$ & $0.00 E+00$ & $4.02 \mathrm{E}-04$ & $6.26 \mathrm{E}-04$ & $0.00 \mathrm{E}+00$ & $5.83 \mathrm{E}-04$ \\
\hline 27 & CENWP_CL_13_EUR_1 & $0.00 \mathrm{E}+00$ & - & $7.09 \mathrm{E}-04$ & - & - & $0.00 \mathrm{E}+00$ & $0.00 \mathrm{E}+00$ & $2.49 \mathrm{E}-04$ & $0.00 \mathrm{E}+00$ & $0.00 E+00$ & 4.19E-04 \\
\hline 28 & CENWP_CL_13_EUR_2 & $0.00 \mathrm{E}+00$ & - & $0.00 \mathrm{E}+00$ & - & - & $0.00 E+00$ & $0.00 E+00$ & $0.00 \mathrm{E}+00$ & $2.54 \mathrm{E}-04$ & $0.00 E+00$ & $1.59 \mathrm{E}-05$ \\
\hline 29 & CENWP_CL_13_EUR_3 & $0.00 \mathrm{E}+00$ & - & $0.00 \mathrm{E}+00$ & - & - & $0.00 \mathrm{E}+00$ & $0.00 \mathrm{E}+00$ & 3.17E-04 & $0.00 \mathrm{E}+00$ & $0.00 E+00$ & $1.91 \mathrm{E}-04$ \\
\hline 30 & CENWP_CL_14_GUL_1 & $0.00 \mathrm{E}+00$ & - & $0.00 \mathrm{E}+00$ & - & - & $0.00 \mathrm{E}+00$ & $0.00 \mathrm{E}+00$ & $1.81 \mathrm{E}-04$ & $0.00 \mathrm{E}+00$ & $0.00 \mathrm{E}+00$ & $1.23 \mathrm{E}-04$ \\
\hline 31 & CENWP_CL_14_GUL_2 & $0.00 \mathrm{E}+00$ & - & 9.57E-05 & - & - & $0.00 \mathrm{E}+00$ & $0.00 \mathrm{E}+00$ & $2.50 \mathrm{E}-04$ & $0.00 \mathrm{E}+00$ & $0.00 \mathrm{E}+00$ & $1.72 \mathrm{E}-04$ \\
\hline 32 & CENWP_CL_15_STL_1 & $0.00 \mathrm{E}+00$ & - & $1.61 \mathrm{E}-03$ & - & - & $0.00 E+00$ & $4.90 \mathrm{E}-04$ & 4.16E-04 & $0.00 \mathrm{E}+00$ & $0.00 \mathrm{E}+00$ & $5.88 \mathrm{E}-04$ \\
\hline 33 & CENWP_CL_15_STL_2 & $0.00 \mathrm{E}+00$ & - & 5.36E-05 & - & - & $0.00 \mathrm{E}+00$ & $0.00 \mathrm{E}+00$ & 1.09E-04 & $0.00 \mathrm{E}+00$ & $0.00 \mathrm{E}+00$ & 7.50E-05 \\
\hline 34 & CENWP_CL_16_WLK_1 & $0.00 \mathrm{E}+00$ & - & $0.00 \mathrm{E}+00$ & - & - & $0.00 \mathrm{E}+00$ & $0.00 E+00$ & $6.79 \mathrm{E}-05$ & $0.00 E+00$ & $0.00 E+00$ & $4.28 \mathrm{E}-05$ \\
\hline 35 & CENWP_CL_16_WLK_2 & $0.00 E+00$ & - & $9.14 \mathrm{E}-05$ & - & - & $0.00 E+00$ & $0.00 \mathrm{E}+00$ & 3.44E-05 & $0.00 E+00$ & $0.00 E+00$ & 4.21E-05 \\
\hline 36 & CENWP_CL_16_WLK_3 & $0.00 \mathrm{E}+00$ & - & $0.00 E+00$ & - & - & $0.00 E+00$ & $0.00 E+00$ & $0.00 \mathrm{E}+00$ & $0.00 E+00$ & $0.00 E+00$ & $0.00 \mathrm{E}+00$ \\
\hline 37 & CENWP_CL_17_SLG_1 & $0.00 \mathrm{E}+00$ & - & $0.00 \mathrm{E}+00$ & - & - & $0.00 \mathrm{E}+00$ & $0.00 \mathrm{E}+00$ & $1.51 \mathrm{E}-04$ & $0.00 \mathrm{E}+00$ & $0.00 \mathrm{E}+00$ & $9.08 \mathrm{E}-05$ \\
\hline 38 & CENWP_CL_17_SLG_2 & $0.00 \mathrm{E}+00$ & - & $5.64 \mathrm{E}-05$ & - & - & $0.00 \mathrm{E}+00$ & $0.00 E+00$ & $1.92 \mathrm{E}-04$ & $0.00 \mathrm{E}+00$ & $0.00 \mathrm{E}+00$ & $1.32 \mathrm{E}-04$ \\
\hline 39 & CENWP_CL_17_SLG_3 & $0.00 \mathrm{E}+00$ & - & $0.00 \mathrm{E}+00$ & - & - & - & $0.00 \mathrm{E}+00$ & 4.31E-03 & - & - & $3.25 \mathrm{E}-03$ \\
\hline 40 & CENWP_CL_18_LDB_1 & $0.00 E+00$ & - & $0.00 E+00$ & - & - & $0.00 E+00$ & $0.00 E+00$ & $1.26 \mathrm{E}-04$ & $0.00 E+00$ & $0.00 E+00$ & 6.96E-05 \\
\hline 41 & CENWP_CL_18_LDB_2 & $0.00 \mathrm{E}+00$ & - & $0.00 \mathrm{E}+00$ & - & - & $0.00 \mathrm{E}+00$ & $0.00 \mathrm{E}+00$ & 9.96E-05 & $0.00 \mathrm{E}+00$ & $0.00 \mathrm{E}+00$ & 6.49E-05 \\
\hline 42 & CENWP_CL_19_UDB_1 & $0.00 \mathrm{E}+00$ & - & $0.00 \mathrm{E}+00$ & - & - & $0.00 \mathrm{E}+00$ & $0.00 \mathrm{E}+00$ & $2.78 \mathrm{E}-04$ & $0.00 \mathrm{E}+00$ & $0.00 \mathrm{E}+00$ & 1.71E-04 \\
\hline 43 & CENWP_CL_19_UDB_2 & $0.00 E+00$ & - & $1.52 \mathrm{E}-04$ & - & - & $0.00 E+00$ & $0.00 E+00$ & $8.65 \mathrm{E}-05$ & $0.00 E+00$ & $0.00 E+00$ & 8.31E-05 \\
\hline
\end{tabular}




\begin{tabular}{|c|c|c|c|c|c|c|c|c|c|c|c|c|}
\hline \multirow[b]{2}{*}{$\#$} & \multirow[b]{2}{*}{ Reach Code } & \multicolumn{10}{|c|}{ AIS Ship and Cargo Type } & \multirow[b]{2}{*}{$\begin{array}{c}\text { All Vesse } \\
\text { Types }\end{array}$} \\
\hline & & $\begin{array}{l}\text { Unknown } \\
(00)\end{array}$ & $\begin{array}{c}\text { WIG } \\
(20-29)\end{array}$ & $\begin{array}{c}\text { Class } 3 \\
(30,33-39)\end{array}$ & $\begin{array}{c}\text { High-Speed } \\
\text { (40-49) }\end{array}$ & $\begin{array}{l}\text { Harbor } \\
\text { Boats } \\
(50-57)\end{array}$ & $\begin{array}{l}\text { Medical } \\
\text { (58) }\end{array}$ & $\begin{array}{l}\text { Passenger } \\
(60-69)\end{array}$ & $\begin{array}{l}\text { Cargo } \\
(70-79)\end{array}$ & $\begin{array}{l}\text { Tanker } \\
\text { (80-89) }\end{array}$ & $\begin{array}{l}\text { Other } \\
(90-99)\end{array}$ & \\
\hline 44 & CENWP_CL_20_KLM_1 & $0.00 E+00$ & - & $0.00 E+00$ & - & - & $0.00 E+00$ & $0.00 E+00$ & $2.46 \mathrm{E}-04$ & $0.00 E+00$ & $0.00 E+00$ & 1.63E-04 \\
\hline 45 & CENWP_CL_20_KLM_2 & $0.00 E+00$ & - & $0.00 \mathrm{E}+00$ & - & - & $0.00 \mathrm{E}+00$ & $0.00 \mathrm{E}+00$ & $2.90 \mathrm{E}-03$ & $0.00 E+00$ & $0.00 E+00$ & $1.92 \mathrm{E}-03$ \\
\hline 46 & CENWP_CL_20_KLM_3 & $1.68 \mathrm{E}-03$ & - & $7.61 \mathrm{E}-04$ & - & - & $0.00 E+00$ & $1.21 \mathrm{E}-03$ & 1.19E-04 & $0.00 E+00$ & $0.00 \mathrm{E}+00$ & $5.26 \mathrm{E}-04$ \\
\hline 47 & CENWP_CL_21_LMT_1 & $0.00 \mathrm{E}+00$ & - & $2.96 \mathrm{E}-04$ & - & - & $0.00 \mathrm{E}+00$ & $0.00 E+00$ & $0.00 \mathrm{E}+00$ & $0.00 \mathrm{E}+00$ & $0.00 \mathrm{E}+00$ & 1.66E-04 \\
\hline 48 & CENWP_CL_21_LMT_2 & $0.00 E+00$ & - & $0.00 \mathrm{E}+00$ & - & - & $0.00 E+00$ & $0.00 \mathrm{E}+00$ & $2.82 \mathrm{E}-04$ & $0.00 E+00$ & $0.00 E+00$ & 1.64E-04 \\
\hline 49 & CENWP_CL_21_LMT_3 & $0.00 \mathrm{E}+00$ & - & $0.00 \mathrm{E}+00$ & - & - & $0.00 \mathrm{E}+00$ & $0.00 \mathrm{E}+00$ & $0.00 \mathrm{E}+00$ & $0.00 \mathrm{E}+00$ & $0.00 E+00$ & $0.00 \mathrm{E}+00$ \\
\hline 50 & CENWP_CL_22_UMT_1 & $3.85 \mathrm{E}-03$ & - & $0.00 \mathrm{E}+00$ & - & - & $0.00 E+00$ & $0.00 E+00$ & $8.62 \mathrm{E}-05$ & $0.00 E+00$ & $0.00 E+00$ & $9.34 \mathrm{E}-05$ \\
\hline 51 & CENWP_CL_22_UMT_2 & $0.00 \mathrm{E}+00$ & - & $0.00 \mathrm{E}+00$ & - & - & $0.00 \mathrm{E}+00$ & $0.00 \mathrm{E}+00$ & $0.00 \mathrm{E}+00$ & $0.00 \mathrm{E}+00$ & $0.00 E+00$ & $0.00 \mathrm{E}+00$ \\
\hline 52 & CENWP_CL_22_UMT_3 & $0.00 \mathrm{E}+00$ & - & $0.00 \mathrm{E}+00$ & - & - & $0.00 \mathrm{E}+00$ & $0.00 \mathrm{E}+00$ & $0.00 \mathrm{E}+00$ & 4.43E-04 & $0.00 \mathrm{E}+00$ & 3.27E-05 \\
\hline 53 & CENWP_CL_23_STH_1 & $0.00 \mathrm{E}+00$ & - & 3.17E-04 & - & - & $0.00 \mathrm{E}+00$ & $1.10 \mathrm{E}-04$ & $3.16 \mathrm{E}-04$ & $2.83 \mathrm{E}-04$ & $0.00 \mathrm{E}+00$ & 2.89E-04 \\
\hline 54 & CENWP_CL_23_STH_2 & $0.00 \mathrm{E}+00$ & - & $6.80 \mathrm{E}-04$ & - & - & $0.00 E+00$ & $0.00 \mathrm{E}+00$ & $6.42 \mathrm{E}-04$ & 3.59E-04 & $0.00 E+00$ & 5.57E-04 \\
\hline 55 & CENWP_CL_24_WAR_1 & $0.00 E+00$ & - & $0.00 \mathrm{E}+00$ & - & - & $0.00 \mathrm{E}+00$ & $1.92 \mathrm{E}-03$ & $0.00 \mathrm{E}+00$ & $0.00 \mathrm{E}+00$ & $0.00 \mathrm{E}+00$ & 2.01E-04 \\
\hline 56 & CENWP_CL_24_WAR_2 & $0.00 \mathrm{E}+00$ & - & $0.00 \mathrm{E}+00$ & - & - & $0.00 \mathrm{E}+00$ & $0.00 E+00$ & $1.94 \mathrm{E}-04$ & $0.00 E+00$ & $0.00 E+00$ & 1.12E-04 \\
\hline 57 & CENWP_CL_24_WAR_3 & $0.00 E+00$ & - & $0.00 E+00$ & - & - & $0.00 E+00$ & $0.00 \mathrm{E}+00$ & $0.00 \mathrm{E}+00$ & $0.00 E+00$ & $0.00 E+00$ & $0.00 \mathrm{E}+00$ \\
\hline 58 & CENWP_CL_25_HEN_1 & $0.00 \mathrm{E}+00$ & - & $0.00 \mathrm{E}+00$ & - & - & $0.00 E+00$ & $0.00 E+00$ & $1.74 \mathrm{E}-04$ & $2.50 \mathrm{E}-04$ & $0.00 E+00$ & $1.20 \mathrm{E}-04$ \\
\hline 59 & CENWP_CL_25_HEN_2 & $0.00 E+00$ & - & $0.00 E+00$ & - & - & $0.00 E+00$ & $0.00 \mathrm{E}+00$ & $0.00 \mathrm{E}+00$ & $0.00 E+00$ & $0.00 E+00$ & $0.00 \mathrm{E}+00$ \\
\hline 60 & CENWP_CL_26_WLW_1 & $0.00 \mathrm{E}+00$ & - & $0.00 \mathrm{E}+00$ & - & - & $0.00 \mathrm{E}+00$ & $0.00 E+00$ & $0.00 E+00$ & $0.00 \mathrm{E}+00$ & $0.00 \mathrm{E}+00$ & $0.00 \mathrm{E}+00$ \\
\hline 61 & CENWP_CL_26_WLW_2 & $0.00 \mathrm{E}+00$ & - & $0.00 \mathrm{E}+00$ & - & - & $0.00 \mathrm{E}+00$ & $0.00 \mathrm{E}+00$ & $2.27 \mathrm{E}-04$ & $0.00 \mathrm{E}+00$ & $0.00 \mathrm{E}+00$ & $1.24 \mathrm{E}-04$ \\
\hline 62 & CENWP_CL_27_MGN_1 & $0.00 E+00$ & - & $0.00 E+00$ & - & - & $0.00 \mathrm{E}+00$ & $0.00 E+00$ & $0.00 E+00$ & $0.00 E+00$ & $0.00 E+00$ & $0.00 E+00$ \\
\hline 63 & CENWP_CL_27_MGN_2 & $0.00 \mathrm{E}+00$ & - & $0.00 \mathrm{E}+00$ & - & - & $0.00 \mathrm{E}+00$ & $0.00 \mathrm{E}+00$ & 2.23E-04 & $5.64 \mathrm{E}-04$ & $0.00 \mathrm{E}+00$ & 2.01E-04 \\
\hline 64 & CENWP_CL_27_MGN_3 & $0.00 \mathrm{E}+00$ & - & $0.00 \mathrm{E}+00$ & - & - & $0.00 \mathrm{E}+00$ & $0.00 \mathrm{E}+00$ & $8.46 \mathrm{E}-05$ & $0.00 \mathrm{E}+00$ & $0.00 \mathrm{E}+00$ & 5.79E-05 \\
\hline 65 & CENWP_CL_28_VBR_1 & $0.00 E+00$ & - & $1.28 \mathrm{E}-04$ & - & - & - & $0.00 E+00$ & $1.09 \mathrm{E}-03$ & $0.00 E+00$ & $0.00 E+00$ & 7.17E-04 \\
\hline
\end{tabular}




\begin{tabular}{|c|c|c|c|c|c|c|c|c|c|c|c|c|}
\hline \multirow[b]{2}{*}{$\#$} & \multirow[b]{2}{*}{ Reach Code } & \multicolumn{10}{|c|}{ AIS Ship and Cargo Type } & \multirow[b]{2}{*}{$\begin{array}{c}\text { All Vesse } \\
\text { Types }\end{array}$} \\
\hline & & $\begin{array}{l}\text { Unknown } \\
(00)\end{array}$ & $\begin{array}{c}\text { WIG } \\
(20-29)\end{array}$ & $\begin{array}{c}\text { Class } 3 \\
(30,33-39)\end{array}$ & $\begin{array}{c}\text { High-Speed } \\
\text { (40-49) }\end{array}$ & $\begin{array}{l}\text { Harbor } \\
\text { Boats } \\
(50-57)\end{array}$ & $\begin{array}{c}\text { Medical } \\
(58)\end{array}$ & $\begin{array}{l}\text { Passenger } \\
(60-69)\end{array}$ & $\begin{array}{l}\text { Cargo } \\
(70-79)\end{array}$ & $\begin{array}{l}\text { Tanker } \\
\text { (80-89) }\end{array}$ & $\begin{array}{l}\text { Other } \\
(90-99)\end{array}$ & \\
\hline 66 & CENWP_CL_28_VBR_2 & $0.00 E+00$ & - & $0.00 E+00$ & - & - & - & $0.00 E+00$ & 7.73E-05 & $0.00 E+00$ & - & 3.88E-05 \\
\hline 67 & CENWP_CL_28_VBR_3 & $0.00 E+00$ & - & $0.00 \mathrm{E}+00$ & - & - & - & $0.00 E+00$ & $0.00 E+00$ & $8.16 \mathrm{E}-04$ & - & 5.27E-05 \\
\hline 68 & CENWP_CL_28_VBR_4 & $0.00 E+00$ & - & $0.00 E+00$ & - & - & - & $0.00 E+00$ & 4.09E-03 & $0.00 E+00$ & - & $3.24 \mathrm{E}-03$ \\
\hline 69 & CENWP_CL_28_VBR_5 & - & - & $0.00 \mathrm{E}+00$ & - & - & - & $0.00 \mathrm{E}+00$ & $5.07 \mathrm{E}-03$ & $0.00 \mathrm{E}+00$ & - & 4.09E-03 \\
\hline 70 & CENWP_CL_29_VTB_1 & $0.00 E+00$ & - & $1.37 \mathrm{E}-04$ & - & - & - & $0.00 \mathrm{E}+00$ & $1.58 \mathrm{E}-03$ & $0.00 E+00$ & - & 8.38E-04 \\
\hline 71 & CENWP_CL_29_VTB_2 & $0.00 \mathrm{E}+00$ & - & $0.00 \mathrm{E}+00$ & - & - & - & $0.00 \mathrm{E}+00$ & - & - & - & $0.00 \mathrm{E}+00$ \\
\hline 72 & CENWP_CM_01_BB1_1 & $0.00 E+00$ & - & $0.00 \mathrm{E}+00$ & - & - & - & - & - & - & $0.00 E+00$ & $0.00 \mathrm{E}+00$ \\
\hline 73 & CENWP_CM_01_BB1_2 & $0.00 \mathrm{E}+00$ & - & $2.29 \mathrm{E}-04$ & - & - & - & - & - & - & $0.00 \mathrm{E}+00$ & 2.16E-04 \\
\hline 74 & CENWP_CM_02_BB2_1 & $0.00 \mathrm{E}+00$ & - & $0.00 \mathrm{E}+00$ & - & - & - & - & - & - & - & $0.00 \mathrm{E}+00$ \\
\hline 75 & CENWP_CM_05_CHK_1 & $0.00 \mathrm{E}+00$ & - & $0.00 \mathrm{E}+00$ & - & - & - & - & - & - & - & $0.00 \mathrm{E}+00$ \\
\hline 76 & CENWP_CM_05_CHK_2 & $0.00 \mathrm{E}+00$ & - & $0.00 \mathrm{E}+00$ & - & - & - & - & - & - & - & $0.00 \mathrm{E}+00$ \\
\hline 77 & CENWP_CM_07_YGB_1 & - & - & $0.00 \mathrm{E}+00$ & - & - & - & - & - & - & - & $0.00 \mathrm{E}+00$ \\
\hline 78 & CENWP_CM_08_HMB_1 & - & - & $0.00 \mathrm{E}+00$ & - & - & - & $0.00 \mathrm{E}+00$ & - & - & $0.00 \mathrm{E}+00$ & $0.00 \mathrm{E}+00$ \\
\hline 79 & CENWP_CM_09_SKP_1 & $0.00 \mathrm{E}+00$ & - & $3.75 \mathrm{E}-04$ & - & - & - & $0.00 \mathrm{E}+00$ & $0.00 \mathrm{E}+00$ & $0.00 E+00$ & $0.00 \mathrm{E}+00$ & 3.65E-04 \\
\hline 80 & CENWP_CM_09_SKP_2 & $0.00 \mathrm{E}+00$ & - & $0.00 \mathrm{E}+00$ & - & - & - & $0.00 E+00$ & - & - & - & $0.00 \mathrm{E}+00$ \\
\hline 81 & CENWP_CM_11_CBY_1 & $6.25 \mathrm{E}-02$ & - & 4.12E-04 & - & - & - & $0.00 \mathrm{E}+00$ & $0.00 \mathrm{E}+00$ & $0.00 \mathrm{E}+00$ & $0.00 \mathrm{E}+00$ & 4.39E-04 \\
\hline 82 & CENWP_CM_11_CBY_2 & $6.00 \mathrm{E}-01$ & - & $2.37 \mathrm{E}-03$ & - & - & - & $0.00 \mathrm{E}+00$ & - & - & $0.00 \mathrm{E}+00$ & 4.40E-03 \\
\hline 83 & CENWP_CM_13_ELO_1 & $0.00 \mathrm{E}+00$ & - & $0.00 \mathrm{E}+00$ & - & - & - & $0.00 \mathrm{E}+00$ & - & - & - & $0.00 \mathrm{E}+00$ \\
\hline 84 & CENWP_CM_14_CC1_1 & $0.00 E+00$ & - & $0.00 E+00$ & - & - & - & $0.00 E+00$ & $0.00 E+00$ & - & $0.00 E+00$ & $0.00 E+00$ \\
\hline 85 & CENWP_CM_15_SKC_1 & - & - & - & - & - & - & $0.00 \mathrm{E}+00$ & - & - & $0.00 \mathrm{E}+00$ & $0.00 \mathrm{E}+00$ \\
\hline 86 & CENWP_CM_16_WFC_1 & - & - & $0.00 \mathrm{E}+00$ & - & - & - & $0.00 \mathrm{E}+00$ & $0.00 \mathrm{E}+00$ & - & $0.00 \mathrm{E}+00$ & $0.00 \mathrm{E}+00$ \\
\hline 87 & CENWP_CM_17_WSL_1 & - & - & $0.00 \mathrm{E}+00$ & - & - & - & $0.00 E+00$ & $0.00 E+00$ & - & $0.00 E+00$ & $0.00 E+00$ \\
\hline
\end{tabular}




\begin{tabular}{|c|c|c|c|c|c|c|c|c|c|c|c|c|}
\hline \multirow[b]{2}{*}{$\#$} & \multirow[b]{2}{*}{ Reach Code } & \multicolumn{10}{|c|}{ AIS Ship and Cargo Type } & \multirow[b]{2}{*}{$\begin{array}{c}\text { All Vessel } \\
\text { Types }\end{array}$} \\
\hline & & $\begin{array}{l}\text { Unknown } \\
(00)\end{array}$ & $\begin{array}{c}\text { WIG } \\
(20-29)\end{array}$ & $\begin{array}{c}\text { Class } 3 \\
(30,33-39)\end{array}$ & $\begin{array}{c}\text { High-Speed } \\
\text { (40-49) }\end{array}$ & $\begin{array}{l}\text { Harbor } \\
\text { Boats } \\
(50-57)\end{array}$ & $\begin{array}{l}\text { Medical } \\
\text { (58) }\end{array}$ & $\begin{array}{l}\text { Passenger } \\
(60-69)\end{array}$ & $\begin{array}{l}\text { Cargo } \\
(70-79)\end{array}$ & $\begin{array}{l}\text { Tanker } \\
\text { (80-89) }\end{array}$ & $\begin{array}{l}\text { Other } \\
\text { (90-99) }\end{array}$ & \\
\hline 88 & CENWP_CM_19_OSL_1 & - & - & $0.00 E+00$ & - & - & - & $0.00 E+00$ & $0.00 \mathrm{E}+00$ & - & $0.00 E+00$ & $0.00 E+00$ \\
\hline 89 & CENWP_CM_19_OSL_2 & - & - & $0.00 \mathrm{E}+00$ & - & - & - & $0.00 \mathrm{E}+00$ & - & - & $0.00 \mathrm{E}+00$ & $0.00 \mathrm{E}+00$ \\
\hline 90 & CENWP_CM_21_RAI_1 & - & - & $0.00 E+00$ & - & - & - & $0.00 E+00$ & $0.00 \mathrm{E}+00$ & $0.00 E+00$ & $0.00 E+00$ & $0.00 \mathrm{E}+00$ \\
\hline 91 & CENWP_CM_24_MUC_1 & $0.00 \mathrm{E}+00$ & - & $5.56 \mathrm{E}-04$ & - & - & - & $0.00 E+00$ & $0.00 \mathrm{E}+00$ & $0.00 E+00$ & $0.00 \mathrm{E}+00$ & $5.12 \mathrm{E}-04$ \\
\hline 92 & CENWP_CM_24_MUC_2 & $0.00 E+00$ & - & $0.00 E+00$ & - & - & - & $0.00 E+00$ & - & - & $0.00 E+00$ & $0.00 E+00$ \\
\hline 93 & CENWP_CM_24_MUC_A & $0.00 \mathrm{E}+00$ & - & $0.00 \mathrm{E}+00$ & - & - & - & $0.00 E+00$ & - & - & - & $0.00 \mathrm{E}+00$ \\
\hline 94 & CENWP_CZ_00_CWM_1 & - & - & $0.00 E+00$ & - & - & - & $0.00 E+00$ & $0.00 E+00$ & - & - & $0.00 E+00$ \\
\hline 95 & CENWP_LK_01_LK1_1 & - & - & $0.00 \mathrm{E}+00$ & - & - & - & - & - & - & - & $0.00 \mathrm{E}+00$ \\
\hline 96 & CENWP_LK_02_LK2_1 & - & - & $0.00 E+00$ & - & - & - & - & - & - & - & $0.00 E+00$ \\
\hline 97 & CENWP_LK_03_LK3_1 & - & - & $0.00 \mathrm{E}+00$ & - & - & - & - & - & - & - & $0.00 \mathrm{E}+00$ \\
\hline 98 & CENWP_WR_01_WR1_1 & $0.00 E+00$ & - & $0.00 \mathrm{E}+00$ & - & - & $0.00 E+00$ & $0.00 \mathrm{E}+00$ & $6.07 \mathrm{E}-04$ & $0.00 E+00$ & $0.00 \mathrm{E}+00$ & 3.17E-04 \\
\hline 99 & CENWP_WR_02_WR2_1 & $0.00 \mathrm{E}+00$ & - & $1.74 \mathrm{E}-04$ & - & - & $0.00 \mathrm{E}+00$ & $0.00 \mathrm{E}+00$ & $1.08 \mathrm{E}-04$ & $0.00 E+00$ & $0.00 \mathrm{E}+00$ & $9.80 \mathrm{E}-05$ \\
\hline 100 & CENWP_WR_03_WR3_1 & $0.00 \mathrm{E}+00$ & - & $0.00 \mathrm{E}+00$ & - & - & $0.00 E+00$ & $0.00 E+00$ & 3.16E-04 & 7.89E-04 & $0.00 E+00$ & 2.18E-04 \\
\hline & All Federal Channels & 7.91E-04 & - & 3.82E-04 & - & - & $0.00 E+00$ & $1.07 \mathrm{E}-04$ & $2.17 \mathrm{E}-04$ & $9.11 \mathrm{E}-05$ & $1.48 \mathrm{E}-05$ & $2.58 \mathrm{E}-04$ \\
\hline
\end{tabular}


The conditional probability of an SDV over all vessel categories is displayed in Figures 6-8 and 6-9. Those reaches with the highest frequencies are in the vicinity of ports, specifically Longview, Woodland, and Vancouver, WA. Desdemona Shoal (\#5-6) and several other locations also show higher conditional probabilities of an SDV. Cargo vessels and tankers may elicit more interest than other types of vessels because of their size and the magnitude of potential losses arising from cargo vessel collisions. Overall, the conditional probability of an SDV for cargo vessels was $2.17 \times 10^{-4}$. In general, cargo vessels appear more likely to be involved in SDVs upstream of Cottonwood Island than downstream. The conditional probability of an SDV for tankers is $9.11 \times 10^{-5}$. This is less than half that for cargo vessels.

The probability that at least one vessel is present in a reach is summarized by reach and AIS ship and cargo type code in Table 6-5. This metric provides some indication of channel utilization. However, its primary purpose is to calculate the unconditional probability of an SDV. The unconditional frequency of an SDV is calculated in Table 6-6. Figures 6-10 and 6-11 show where the probabilities are highest within the navigation project. Substantively, these results are similar to those for the conditional frequency of an SDV. They indicate that SDVs are more likely to occur in reaches adjacent to Washington ports (e.g., Longview, Woodland, and Vancouver), the section of channel from Lower Desdemona Shoal (\#5) to Tongue Point Channel (\#10), and the section of channel from Pillar Rock Upper Range (\#16) to Steam Boat Reach (\#20). 
Figure 6-8. Conditional frequency of SDVs in CRC, Entrance Range to Longview, Washington.

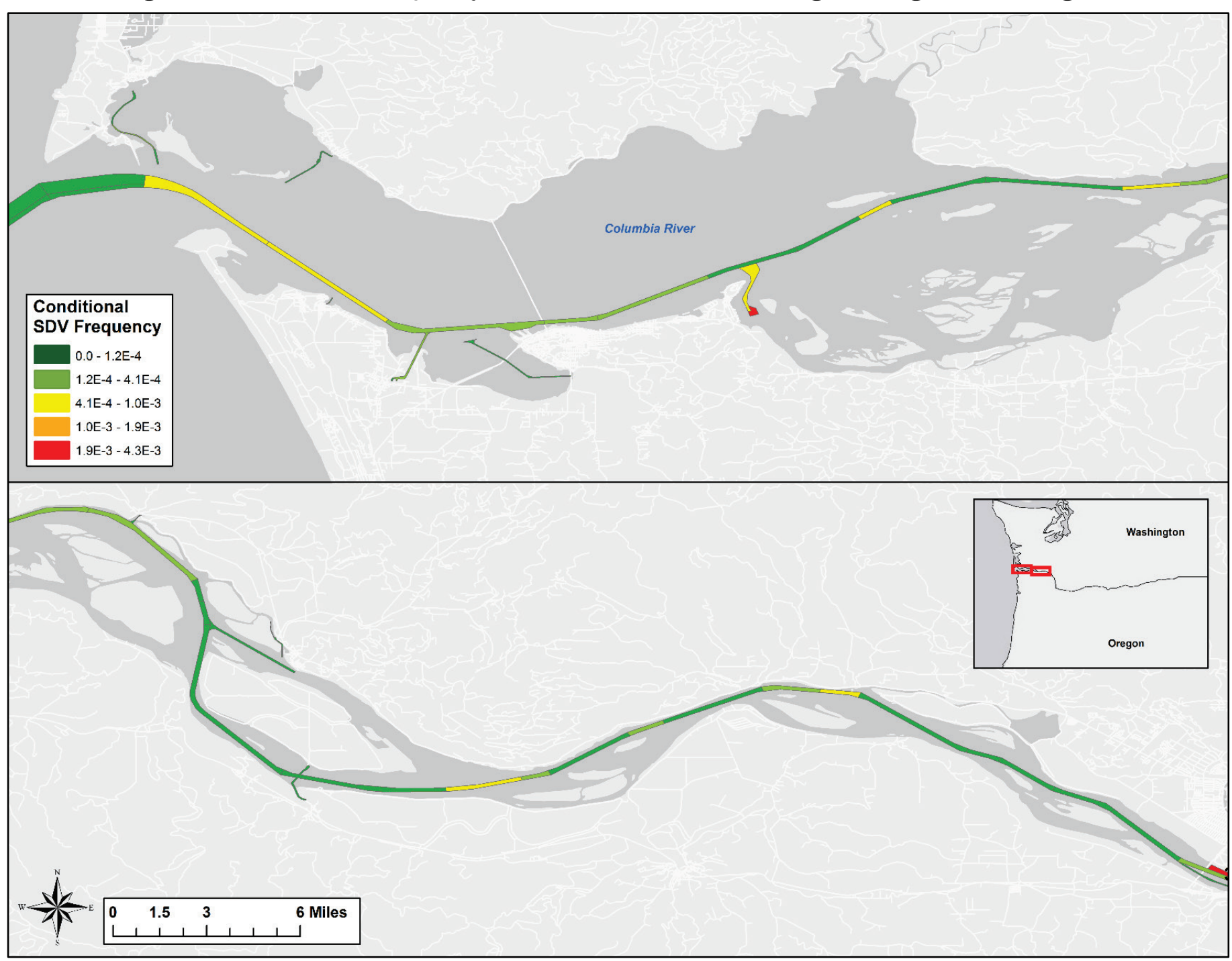


Figure 6-9. Conditional frequency of SDVs in CRC, Eureka Bar to Interstate 5 bridge.

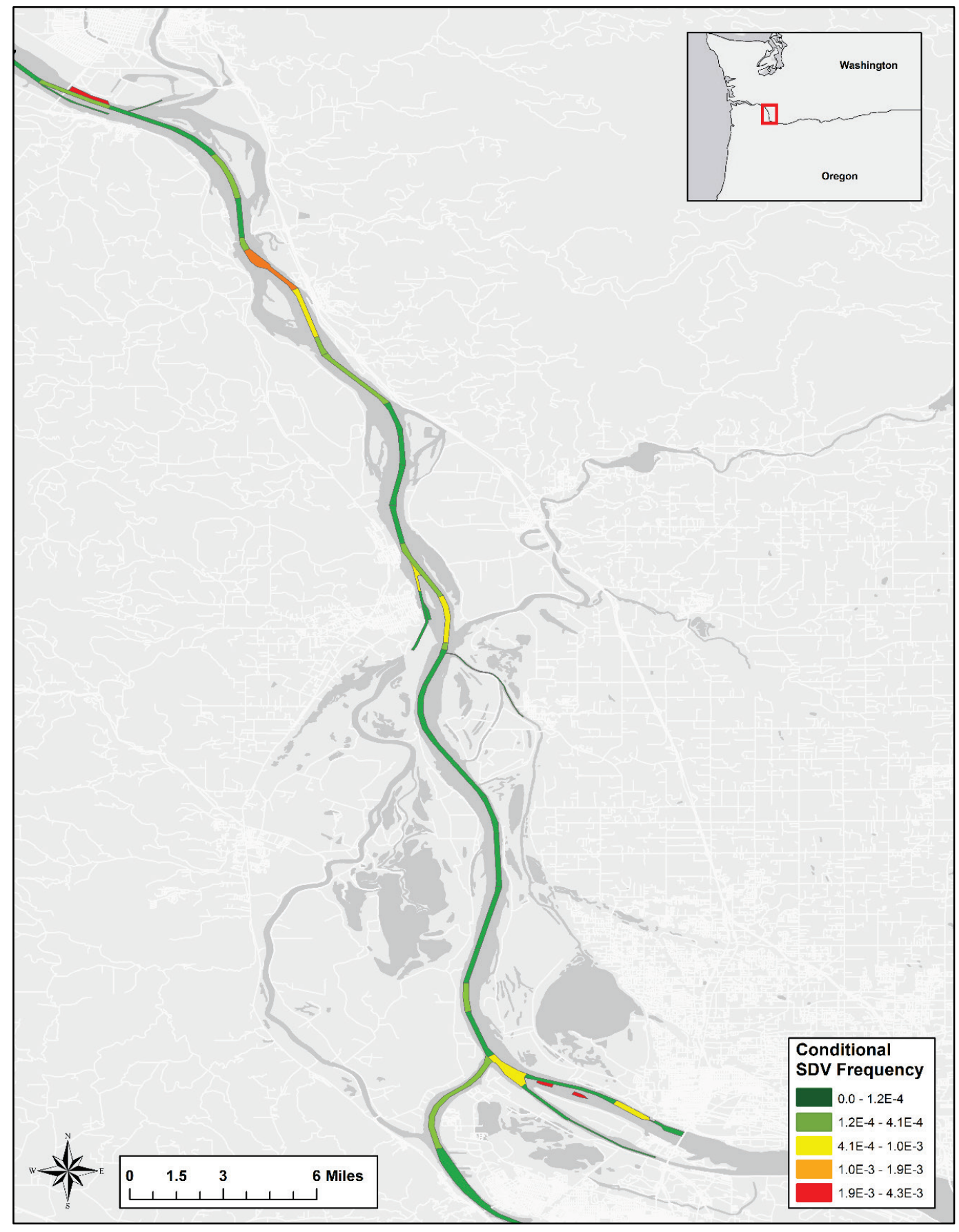


Table 6-5. Fraction of half-minute intervals during which at least one vessel is present in each CRC reach.

\begin{tabular}{|c|c|c|c|c|c|c|c|c|c|c|c|c|}
\hline \multirow[b]{2}{*}{$\#$} & \multirow[b]{2}{*}{ Reach Code } & \multicolumn{10}{|c|}{ AIS Ship and Cargo Type } & \multirow[b]{2}{*}{$\begin{array}{c}\text { All Vesse } \\
\text { Types }\end{array}$} \\
\hline & & $\begin{array}{l}\text { Unknown } \\
\text { (00) }\end{array}$ & $\begin{array}{c}\text { WIG } \\
(20-29)\end{array}$ & $\begin{array}{c}\text { Class } 3 \\
(30,33-39)\end{array}$ & $\begin{array}{l}\text { High-Speed } \\
\text { (40-49) }\end{array}$ & $\begin{array}{l}\text { Harbor } \\
\text { Boats } \\
(50-57)\end{array}$ & $\begin{array}{c}\text { Medical } \\
\text { Transports } \\
\text { (58) }\end{array}$ & $\begin{array}{c}\text { Passenger } \\
(60-69)\end{array}$ & $\begin{array}{l}\text { Cargo } \\
\text { (70-79) }\end{array}$ & $\begin{array}{l}\text { Tanker } \\
\text { (80-89) }\end{array}$ & $\begin{array}{l}\text { Other } \\
(90-99)\end{array}$ & \\
\hline 1 & CENWP_CL_00_MCR_1 & $1.73 \mathrm{E}-03$ & - & $6.15 \mathrm{E}-02$ & - & - & $4.28 \mathrm{E}-05$ & $1.09 \mathrm{E}-03$ & 5.33E-02 & 5.23E-03 & 4.33E-03 & $1.23 \mathrm{E}-01$ \\
\hline 2 & CENWP_CL_OO_MCR_2 & $3.58 \mathrm{E}-04$ & - & $2.72 \mathrm{E}-02$ & - & - & $1.90 \mathrm{E}-06$ & 6.66E-05 & 2.97E-03 & $1.87 \mathrm{E}-04$ & 1.41E-03 & $3.21 \mathrm{E}-02$ \\
\hline 3 & CENWP_CL_OO_MCR_3 & 1.81E-03 & - & $9.53 \mathrm{E}-02$ & - & - & 1.90E-05 & $6.58 \mathrm{E}-04$ & 3.44E-02 & 3.11E-03 & 3.04E-03 & $1.34 \mathrm{E}-01$ \\
\hline 4 & CENWP_CL_OO_MCR_4 & 3.84E-04 & - & 4.83E-02 & - & - & $7.61 \mathrm{E}-06$ & $9.23 \mathrm{E}-05$ & 7.97E-03 & $8.56 \mathrm{E}-04$ & $1.12 \mathrm{E}-03$ & $5.85 \mathrm{E}-02$ \\
\hline 5 & CENWP_CL_01_LDS_1 & 1.76E-03 & - & 4.39E-02 & - & - & 3.33E-05 & $1.24 \mathrm{E}-03$ & 5.80E-02 & $5.58 \mathrm{E}-03$ & 3.97E-03 & $1.12 \mathrm{E}-01$ \\
\hline 6 & CENWP_CL_02_UDS_1 & $1.87 \mathrm{E}-03$ & - & 4.38E-02 & - & - & $3.04 \mathrm{E}-05$ & $1.40 \mathrm{E}-03$ & $6.28 \mathrm{E}-02$ & $5.90 \mathrm{E}-03$ & 4.04E-03 & 1.17E-01 \\
\hline 7 & CENWP_CL_03_FLV_1 & $2.26 \mathrm{E}-03$ & - & 4.99E-02 & - & - & $6.85 \mathrm{E}-05$ & $3.84 \mathrm{E}-03$ & $7.27 \mathrm{E}-02$ & $6.75 \mathrm{E}-03$ & 5.80E-03 & $1.37 \mathrm{E}-01$ \\
\hline 8 & CENWP_CL_04_USN_1 & $8.12 \mathrm{E}-04$ & - & $1.12 \mathrm{E}-02$ & - & - & 2.57E-05 & $2.53 \mathrm{E}-03$ & 3.02E-02 & 2.85E-03 & 2.20E-03 & 4.93E-02 \\
\hline 9 & CENWP_CL_04_USN_2 & 1.50E-03 & - & 9.06E-03 & - & - & $6.28 \mathrm{E}-05$ & 7.60E-03 & $6.07 \mathrm{E}-02$ & $6.15 \mathrm{E}-03$ & 3.74E-03 & $8.74 \mathrm{E}-02$ \\
\hline 10 & CENWP_CL_05_TNG_1 & $9.76 \mathrm{E}-04$ & - & $6.80 \mathrm{E}-03$ & - & - & 4.38E-05 & $4.40 \mathrm{E}-03$ & $3.88 \mathrm{E}-02$ & $3.82 \mathrm{E}-03$ & 3.43E-03 & $5.77 \mathrm{E}-02$ \\
\hline 11 & CENWP_CL_05_TNG_2 & $7.56 \mathrm{E}-04$ & - & 8.70E-03 & - & - & $2.95 \mathrm{E}-05$ & 4.60E-03 & $3.05 \mathrm{E}-02$ & 3.00E-03 & $3.24 \mathrm{E}-03$ & $5.04 \mathrm{E}-02$ \\
\hline 12 & CENWP_CL_06_MLN_1 & 4.03E-04 & - & $1.56 \mathrm{E}-02$ & - & - & $1.24 \mathrm{E}-05$ & 4.37E-03 & $1.54 \mathrm{E}-02$ & $1.50 \mathrm{E}-03$ & $1.35 \mathrm{E}-03$ & $3.66 \mathrm{E}-02$ \\
\hline 13 & CENWP_CL_06_MLN_2 & 1.06E-03 & - & $1.17 \mathrm{E}-02$ & - & - & 3.04E-05 & $5.13 \mathrm{E}-03$ & 3.90E-02 & $3.88 \mathrm{E}-03$ & 3.65E-03 & $6.36 \mathrm{E}-02$ \\
\hline 14 & CENWP_CL_06_MLN_3 & $3.68 \mathrm{E}-04$ & - & 4.96E-03 & - & - & $1.14 \mathrm{E}-05$ & $1.57 \mathrm{E}-03$ & 1.33E-02 & $1.30 \mathrm{E}-03$ & $1.68 \mathrm{E}-03$ & 2.31E-02 \\
\hline 15 & CENWP_CL_07_PIL_1 & $1.12 \mathrm{E}-03$ & - & 1.13E-02 & - & - & $3.23 \mathrm{E}-05$ & $5.23 \mathrm{E}-03$ & $3.96 \mathrm{E}-02$ & $3.98 \mathrm{E}-03$ & 4.06E-03 & $6.44 \mathrm{E}-02$ \\
\hline 16 & CENWP_CL_07_PIL_2 & $6.29 \mathrm{E}-04$ & - & $2.06 \mathrm{E}-02$ & - & - & $1.71 \mathrm{E}-05$ & $7.50 \mathrm{E}-03$ & $2.29 \mathrm{E}-02$ & $2.27 \mathrm{E}-03$ & $2.38 \mathrm{E}-03$ & 5.31E-02 \\
\hline 17 & CENWP_CL_08_BKW_1 & $2.92 \mathrm{E}-04$ & - & 9.33E-03 & - & - & $8.56 \mathrm{E}-06$ & $3.91 \mathrm{E}-03$ & 1.06E-02 & 1.04E-03 & 9.33E-04 & $2.50 \mathrm{E}-02$ \\
\hline 18 & CENWP_CL_08_BKW_2 & $1.58 \mathrm{E}-03$ & - & $1.94 \mathrm{E}-02$ & - & - & 4.76E-05 & $1.60 \mathrm{E}-02$ & $5.67 \mathrm{E}-02$ & $5.68 \mathrm{E}-03$ & 3.73E-03 & $9.99 \mathrm{E}-02$ \\
\hline 19 & CENWP_CL_09_SKM_1 & $1.52 \mathrm{E}-03$ & - & $4.11 \mathrm{E}-02$ & - & - & $4.85 \mathrm{E}-05$ & $1.72 \mathrm{E}-02$ & $5.81 \mathrm{E}-02$ & 5.90E-03 & 3.66E-03 & 1.19E-01 \\
\hline 20 & CENWP_CL_09_SKM_2 & $3.22 \mathrm{E}-04$ & - & $2.62 \mathrm{E}-03$ & - & - & $9.51 \mathrm{E}-06$ & $1.65 \mathrm{E}-03$ & $1.23 \mathrm{E}-02$ & $1.22 \mathrm{E}-03$ & $9.99 \mathrm{E}-04$ & $1.91 \mathrm{E}-02$ \\
\hline 21 & CENWP_CL_10_PGT_1 & 3.39E-04 & - & 3.23E-03 & - & - & $1.14 \mathrm{E}-05$ & $1.51 \mathrm{E}-03$ & $1.32 \mathrm{E}-02$ & $1.31 \mathrm{E}-03$ & $9.13 \mathrm{E}-04$ & $2.04 \mathrm{E}-02$ \\
\hline 22 & CENWP_CL_10_PGT_2 & 1.53E-03 & - & $2.38 \mathrm{E}-02$ & - & - & 5.52E-05 & $7.06 \mathrm{E}-03$ & $6.26 \mathrm{E}-02$ & $6.16 \mathrm{E}-03$ & 4.73E-03 & 1.03E-01 \\
\hline
\end{tabular}




\begin{tabular}{|c|c|c|c|c|c|c|c|c|c|c|c|c|}
\hline \multirow[b]{2}{*}{$\#$} & \multirow[b]{2}{*}{ Reach Code } & \multicolumn{10}{|c|}{ AIS Ship and Cargo Type } & \multirow[b]{2}{*}{$\begin{array}{c}\text { All Vesse } \\
\text { Types }\end{array}$} \\
\hline & & $\begin{array}{l}\text { Unknown } \\
\text { (00) }\end{array}$ & $\begin{array}{c}\text { WIG } \\
(20-29)\end{array}$ & $\begin{array}{c}\text { Class } 3 \\
(30,33-39)\end{array}$ & $\begin{array}{l}\text { High-Speed } \\
\text { (40-49) }\end{array}$ & $\begin{array}{l}\text { Harbor } \\
\text { Boats } \\
(50-57)\end{array}$ & $\begin{array}{c}\text { Medical } \\
\text { Transports } \\
\text { (58) }\end{array}$ & $\begin{array}{c}\text { Passenger } \\
(60-69)\end{array}$ & $\begin{array}{l}\text { Cargo } \\
\text { (70-79) }\end{array}$ & $\begin{array}{l}\text { Tanker } \\
\text { (80-89) }\end{array}$ & $\begin{array}{l}\text { Other } \\
(90-99)\end{array}$ & \\
\hline 23 & CENWP_CL_11_WAN_1 & 1.03E-03 & - & $1.52 \mathrm{E}-02$ & - & - & 4.47E-05 & 4.15E-03 & 4.31E-02 & 4.23E-03 & 5.56E-03 & 7.24E-02 \\
\hline 24 & CENWP_CL_11_WAN_2 & 7.91E-04 & - & 7.14E-03 & - & - & 2.95E-05 & $3.40 \mathrm{E}-03$ & $3.27 \mathrm{E}-02$ & $3.18 \mathrm{E}-03$ & $6.31 \mathrm{E}-03$ & 5.30E-02 \\
\hline 25 & CENWP_CL_12_WST_1 & 8.79E-04 & - & 8.69E-03 & - & - & $2.95 \mathrm{E}-05$ & 3.81E-03 & 3.63E-02 & 3.58E-03 & 7.66E-03 & 6.03E-02 \\
\hline 26 & CENWP_CL_12_WST_2 & $7.53 \mathrm{E}-04$ & - & $5.40 \mathrm{E}-02$ & - & - & $2.38 \mathrm{E}-05$ & $1.34 \mathrm{E}-02$ & 3.05E-02 & 3.03E-03 & 9.96E-03 & 1.03E-01 \\
\hline 27 & CENWP_CL_13_EUR_1 & $2.87 \mathrm{E}-04$ & - & $1.64 \mathrm{E}-02$ & - & - & $5.71 \mathrm{E}-06$ & $2.70 \mathrm{E}-03$ & 1.15E-02 & $1.16 \mathrm{E}-03$ & 2.66E-03 & 3.37E-02 \\
\hline 28 & CENWP_CL_13_EUR_2 & $1.02 \mathrm{E}-03$ & - & $8.72 \mathrm{E}-03$ & - & - & 3.14E-05 & 4.70E-03 & 3.69E-02 & $3.75 \mathrm{E}-03$ & 3.05E-03 & 5.76E-02 \\
\hline 29 & CENWP_CL_13_EUR_3 & $3.94 \mathrm{E}-04$ & - & $5.91 \mathrm{E}-03$ & - & - & 1.33E-05 & $1.85 \mathrm{E}-03$ & $1.50 \mathrm{E}-02$ & $1.47 \mathrm{E}-03$ & 2.60E-04 & $2.48 \mathrm{E}-02$ \\
\hline 30 & CENWP_CL_14_GUL_1 & $1.20 \mathrm{E}-03$ & - & 8.69E-03 & - & - & 3.81E-05 & $5.25 \mathrm{E}-03$ & 4.16E-02 & 4.09E-03 & $5.12 \mathrm{E}-04$ & 6.06E-02 \\
\hline 31 & CENWP_CL_14_GUL_2 & $6.64 \mathrm{E}-04$ & - & $9.89 \mathrm{E}-03$ & - & - & 2.09E-05 & $2.84 \mathrm{E}-03$ & $2.27 \mathrm{E}-02$ & $2.27 \mathrm{E}-03$ & $2.53 \mathrm{E}-04$ & 3.84E-02 \\
\hline 32 & CENWP_CL_15_STL_1 & 4.05E-04 & - & 4.11E-03 & - & - & 1.33E-05 & $1.94 \mathrm{E}-03$ & 1.60E-02 & $1.59 \mathrm{E}-03$ & 1.66E-04 & $2.41 \mathrm{E}-02$ \\
\hline 33 & CENWP_CL_15_STL_2 & $1.31 \mathrm{E}-03$ & - & $3.45 \mathrm{E}-02$ & - & - & $4.38 \mathrm{E}-05$ & $6.22 \mathrm{E}-03$ & $5.16 \mathrm{E}-02$ & $5.28 \mathrm{E}-03$ & $5.90 \mathrm{E}-04$ & $9.72 \mathrm{E}-02$ \\
\hline 34 & CENWP_CL_16_WLK_1 & 3.71E-04 & - & 4.53E-03 & - & - & $1.24 \mathrm{E}-05$ & 1.71E-03 & $1.40 \mathrm{E}-02$ & $1.44 \mathrm{E}-03$ & $1.49 \mathrm{E}-04$ & $2.21 \mathrm{E}-02$ \\
\hline 35 & CENWP_CL_16_WLK_2 & $7.23 \mathrm{E}-04$ & - & 1.03E-02 & - & - & $2.28 \mathrm{E}-05$ & 3.31E-03 & $2.74 \mathrm{E}-02$ & $2.76 \mathrm{E}-03$ & 2.96E-04 & 4.44E-02 \\
\hline 36 & CENWP_CL_16_WLK_3 & 7.30E-04 & - & $7.40 \mathrm{E}-03$ & - & - & $2.85 \mathrm{E}-05$ & $3.11 \mathrm{E}-03$ & $2.82 \mathrm{E}-02$ & $2.77 \mathrm{E}-03$ & 2.67E-04 & $4.22 \mathrm{E}-02$ \\
\hline 37 & CENWP_CL_17_SLG_1 & 1.04E-03 & - & 1.90E-02 & - & - & 4.19E-05 & 4.36E-03 & 4.34E-02 & 4.06E-03 & 5.81E-04 & 7.13E-02 \\
\hline 38 & CENWP_CL_17_SLG_2 & $9.05 \mathrm{E}-04$ & - & $1.66 \mathrm{E}-02$ & - & - & $3.71 \mathrm{E}-05$ & $3.50 \mathrm{E}-03$ & $3.92 \mathrm{E}-02$ & $3.82 \mathrm{E}-03$ & $3.85 \mathrm{E}-04$ & 6.37E-02 \\
\hline 39 & CENWP_CL_17_SLG_3 & $2.10 \mathrm{E}-04$ & - & $1.94 \mathrm{E}-03$ & - & - & $0.00 \mathrm{E}+00$ & $6.94 \mathrm{E}-05$ & $6.83 \mathrm{E}-03$ & $0.00 E+00$ & $0.00 E+00$ & $9.04 \mathrm{E}-03$ \\
\hline 40 & CENWP_CL_18_LDB_1 & $8.50 \mathrm{E}-04$ & - & $1.61 \mathrm{E}-02$ & - & - & 3.04E-05 & $3.55 \mathrm{E}-03$ & $3.00 \mathrm{E}-02$ & $3.38 \mathrm{E}-03$ & 3.27E-04 & $5.38 \mathrm{E}-02$ \\
\hline 41 & CENWP_CL_18_LDB_2 & $4.71 \mathrm{E}-04$ & - & $4.62 \mathrm{E}-03$ & - & - & $1.81 \mathrm{E}-05$ & $2.72 \mathrm{E}-03$ & $1.90 \mathrm{E}-02$ & $2.16 \mathrm{E}-03$ & $2.11 \mathrm{E}-04$ & 2.90E-02 \\
\hline 42 & CENWP_CL_19_UDB_1 & $5.30 \mathrm{E}-04$ & - & $6.46 \mathrm{E}-03$ & - & - & $2.57 \mathrm{E}-05$ & $4.89 \mathrm{E}-03$ & $2.39 \mathrm{E}-02$ & $2.70 \mathrm{E}-03$ & $2.76 \mathrm{E}-04$ & $3.82 \mathrm{E}-02$ \\
\hline 43 & CENWP_CL_19_UDB_2 & $6.12 \mathrm{E}-04$ & - & $6.23 \mathrm{E}-03$ & - & - & 2.09E-05 & $2.74 \mathrm{E}-03$ & 2.19E-02 & $2.46 \mathrm{E}-03$ & 2.53E-04 & 3.39E-02 \\
\hline 44 & CENWP_CL_20_KLM_1 & $2.14 \mathrm{E}-04$ & - & $1.98 \mathrm{E}-03$ & - & - & $7.61 \mathrm{E}-06$ & 8.54E-04 & 7.71E-03 & $8.27 \mathrm{E}-04$ & 8.09E-05 & 1.17E-02 \\
\hline
\end{tabular}




\begin{tabular}{|c|c|c|c|c|c|c|c|c|c|c|c|c|}
\hline \multirow[b]{2}{*}{ \# } & \multirow[b]{2}{*}{ Reach Code } & \multicolumn{10}{|c|}{ AIS Ship and Cargo Type } & \multirow[b]{2}{*}{$\begin{array}{c}\text { All Vesse } \\
\text { Types }\end{array}$} \\
\hline & & $\begin{array}{l}\text { Unknown } \\
\text { (00) }\end{array}$ & $\begin{array}{c}\text { WIG } \\
(20-29)\end{array}$ & $\begin{array}{c}\text { Class } 3 \\
(30,33-39)\end{array}$ & $\begin{array}{l}\text { High-Speed } \\
\text { (40-49) }\end{array}$ & $\begin{array}{l}\text { Harbor } \\
\text { Boats } \\
(50-57)\end{array}$ & $\begin{array}{c}\text { Medical } \\
\text { Transports } \\
\text { (58) }\end{array}$ & $\begin{array}{c}\text { Passenger } \\
(60-69)\end{array}$ & $\begin{array}{l}\text { Cargo } \\
\text { (70-79) }\end{array}$ & $\begin{array}{l}\text { Tanker } \\
\text { (80-89) }\end{array}$ & $\begin{array}{l}\text { Other } \\
(90-99)\end{array}$ & \\
\hline 45 & CENWP_CL_2O_KLM_2 & $1.13 \mathrm{E}-03$ & - & $9.82 \mathrm{E}-03$ & - & - & $3.52 \mathrm{E}-05$ & 3.50E-03 & 3.56E-02 & 3.68E-03 & 3.35E-04 & 5.35E-02 \\
\hline 46 & CENWP_CL_20_KLM_3 & $5.66 \mathrm{E}-04$ & - & $2.32 \mathrm{E}-02$ & - & - & $2.47 \mathrm{E}-05$ & $6.28 \mathrm{E}-03$ & $2.38 \mathrm{E}-02$ & $2.88 \mathrm{E}-03$ & $3.01 \mathrm{E}-04$ & $5.50 \mathrm{E}-02$ \\
\hline 47 & CENWP_CL_21_LMT_1 & 1.93E-04 & - & 1.33E-02 & - & - & 9.51E-06 & 2.29E-03 & 8.84E-03 & 1.07E-03 & $1.21 \mathrm{E}-04$ & $2.51 \mathrm{E}-02$ \\
\hline 48 & CENWP_CL_21_LMT_2 & $6.71 \mathrm{E}-04$ & - & $9.71 \mathrm{E}-03$ & - & - & 3.61E-05 & $4.92 \mathrm{E}-03$ & 2.67E-02 & 3.64E-03 & $3.85 \mathrm{E}-04$ & 4.56E-02 \\
\hline 49 & CENWP_CL_21_LMT_3 & $3.00 \mathrm{E}-04$ & - & 7.53E-03 & - & - & $1.62 \mathrm{E}-05$ & $2.27 \mathrm{E}-03$ & $1.35 \mathrm{E}-02$ & 1.83E-03 & $1.88 \mathrm{E}-04$ & $2.55 \mathrm{E}-02$ \\
\hline 50 & CENWP_CL_22_UMT_1 & $2.47 \mathrm{E}-04$ & - & $5.42 \mathrm{E}-03$ & - & - & $1.43 \mathrm{E}-05$ & $1.91 \mathrm{E}-03$ & $1.10 \mathrm{E}-02$ & $1.54 \mathrm{E}-03$ & $1.64 \mathrm{E}-04$ & $2.02 \mathrm{E}-02$ \\
\hline 51 & CENWP_CL_22_UMT_2 & $3.86 \mathrm{E}-04$ & - & $7.52 \mathrm{E}-03$ & - & - & 2.00E-05 & $2.85 \mathrm{E}-03$ & $1.58 \mathrm{E}-02$ & $2.18 \mathrm{E}-03$ & $2.46 \mathrm{E}-04$ & $2.88 \mathrm{E}-02$ \\
\hline 52 & CENWP_CL_22_UMT_3 & $3.55 \mathrm{E}-04$ & - & $7.92 \mathrm{E}-03$ & - & - & 1.90E-05 & $2.95 \mathrm{E}-03$ & $1.54 \mathrm{E}-02$ & 2.15E-03 & $2.42 \mathrm{E}-04$ & 2.87E-02 \\
\hline 53 & CENWP_CL_23_STH_1 & $5.76 \mathrm{E}-04$ & - & $3.27 \mathrm{E}-02$ & - & - & 3.04E-05 & 8.63E-03 & $2.40 \mathrm{E}-02$ & 3.36E-03 & 3.67E-04 & $6.55 \mathrm{E}-02$ \\
\hline 54 & CENWP_CL_23_STH_2 & $4.36 \mathrm{E}-04$ & - & 3.04E-02 & - & - & $2.47 \mathrm{E}-05$ & $1.02 \mathrm{E}-02$ & $1.92 \mathrm{E}-02$ & 2.65E-03 & $2.89 \mathrm{E}-04$ & $5.84 \mathrm{E}-02$ \\
\hline 55 & CENWP_CL_24_WAR_1 & $6.85 \mathrm{E}-05$ & - & $1.05 \mathrm{E}-03$ & - & - & $2.85 \mathrm{E}-06$ & 4.93E-04 & $2.69 \mathrm{E}-03$ & $3.75 \mathrm{E}-04$ & 4.19E-05 & 4.71E-03 \\
\hline 56 & CENWP_CL_24_WAR_2 & 3.66E-04 & - & 5.35E-03 & - & - & 2.00E-05 & 2.70E-03 & $1.46 \mathrm{E}-02$ & 2.02E-03 & 2.33E-04 & $2.52 \mathrm{E}-02$ \\
\hline 57 & CENWP_CL_24_WAR_3 & $4.62 \mathrm{E}-04$ & - & $7.02 \mathrm{E}-03$ & - & - & $2.47 \mathrm{E}-05$ & $3.56 \mathrm{E}-03$ & $1.97 \mathrm{E}-02$ & $2.75 \mathrm{E}-03$ & 3.13E-04 & 3.36E-02 \\
\hline 58 & CENWP_CL_25_HEN_1 & $6.82 \mathrm{E}-04$ & - & 1.03E-02 & - & - & 3.14E-05 & $4.81 \mathrm{E}-03$ & $2.71 \mathrm{E}-02$ & 3.81E-03 & 4.19E-04 & 4.66E-02 \\
\hline 59 & CENWP_CL_25_HEN_2 & 3.35E-04 & - & 4.66E-03 & - & - & 1.71E-05 & 2.30E-03 & $1.42 \mathrm{E}-02$ & 1.96E-03 & 2.15E-04 & 2.36E-02 \\
\hline 60 & CENWP_CL_26_WLW_1 & $4.82 \mathrm{E}-04$ & - & $6.65 \mathrm{E}-03$ & - & - & 2.47E-05 & 3.53E-03 & 2.04E-02 & 2.83E-03 & 3.07E-04 & 3.40E-02 \\
\hline 61 & CENWP_CL_26_WLW_2 & $6.43 \mathrm{E}-04$ & - & 1.15E-02 & - & - & 3.04E-05 & $4.52 \mathrm{E}-03$ & $2.50 \mathrm{E}-02$ & $3.41 \mathrm{E}-03$ & 3.81E-04 & $4.51 \mathrm{E}-02$ \\
\hline 62 & CENWP_CL_27_MGN_1 & $3.58 \mathrm{E}-04$ & - & $2.83 \mathrm{E}-03$ & - & - & $1.81 \mathrm{E}-05$ & 2.30E-03 & $1.43 \mathrm{E}-02$ & $1.98 \mathrm{E}-03$ & 2.14E-04 & 2.19E-02 \\
\hline 63 & CENWP_CL_27_MGN_2 & $3.13 \mathrm{E}-04$ & - & $1.96 \mathrm{E}-03$ & - & - & $1.81 \mathrm{E}-05$ & $2.00 \mathrm{E}-03$ & $1.27 \mathrm{E}-02$ & 1.69E-03 & $1.95 \mathrm{E}-04$ & $1.88 \mathrm{E}-02$ \\
\hline 64 & CENWP_CL_27_MGN_3 & $5.07 \mathrm{E}-04$ & - & $3.27 \mathrm{E}-03$ & - & - & 4.19E-05 & $3.26 \mathrm{E}-03$ & $2.23 \mathrm{E}-02$ & $2.88 \mathrm{E}-03$ & 3.39E-04 & 3.24E-02 \\
\hline 65 & CENWP_CL_28_VBR_1 & $2.81 \mathrm{E}-04$ & - & 7.38E-03 & - & - & $0.00 \mathrm{E}+00$ & $2.11 \mathrm{E}-03$ & $1.82 \mathrm{E}-02$ & $9.24 \mathrm{E}-04$ & 5.04E-05 & $2.88 \mathrm{E}-02$ \\
\hline 66 & CENWP_CL_28_VBR_2 & $3.14 \mathrm{E}-04$ & - & 7.97E-03 & - & - & $0.00 E+00$ & $2.68 \mathrm{E}-03$ & 1.23E-02 & 1.19E-03 & $0.00 E+00$ & $2.43 \mathrm{E}-02$ \\
\hline
\end{tabular}




\begin{tabular}{|c|c|c|c|c|c|c|c|c|c|c|c|c|}
\hline \multirow[b]{2}{*}{$\#$} & \multirow[b]{2}{*}{ Reach Code } & \multicolumn{10}{|c|}{ AIS Ship and Cargo Type } & \multirow[b]{2}{*}{$\begin{array}{c}\text { All Vesse } \\
\text { Types }\end{array}$} \\
\hline & & $\begin{array}{l}\text { Unknown } \\
\text { (00) }\end{array}$ & $\begin{array}{c}\text { WIG } \\
(20-29)\end{array}$ & $\begin{array}{c}\text { Class } 3 \\
(30,33-39)\end{array}$ & $\begin{array}{l}\text { High-Speed } \\
\text { (40-49) }\end{array}$ & $\begin{array}{l}\text { Harbor } \\
\text { Boats } \\
(50-57)\end{array}$ & $\begin{array}{c}\text { Medical } \\
\text { Transports } \\
(58)\end{array}$ & $\begin{array}{c}\text { Passenger } \\
(60-69)\end{array}$ & $\begin{array}{l}\text { Cargo } \\
(70-79)\end{array}$ & $\begin{array}{l}\text { Tanker } \\
\text { (80-89) }\end{array}$ & $\begin{array}{l}\text { Other } \\
(90-99)\end{array}$ & \\
\hline 67 & CENWP_CL_28_VBR_3 & $2.08 \mathrm{E}-04$ & - & 4.93E-03 & - & - & $0.00 E+00$ & $1.57 \mathrm{E}-03$ & 1.01E-02 & $1.15 \mathrm{E}-03$ & $0.00 \mathrm{E}+00$ & 1.79E-02 \\
\hline 68 & CENWP_CL_28_VBR_4 & $1.42 \mathrm{E}-04$ & - & $5.20 \mathrm{E}-04$ & - & - & $0.00 \mathrm{E}+00$ & $2.38 \mathrm{E}-05$ & $3.25 \mathrm{E}-03$ & $1.76 \mathrm{E}-04$ & $0.00 E+00$ & $4.11 \mathrm{E}-03$ \\
\hline 69 & CENWP_CL_28_VBR_5 & $0.00 E+00$ & - & $4.42 \mathrm{E}-04$ & - & - & $0.00 E+00$ & 4.19E-05 & $2.06 \mathrm{E}-03$ & $7.61 \mathrm{E}-06$ & $0.00 E+00$ & $2.56 \mathrm{E}-03$ \\
\hline 70 & CENWP_CL_29_VTB_1 & $4.82 \mathrm{E}-04$ & - & $6.88 \mathrm{E}-03$ & - & - & $0.00 E+00$ & $2.88 \mathrm{E}-03$ & $1.14 \mathrm{E}-02$ & $9.77 \mathrm{E}-04$ & $0.00 \mathrm{E}+00$ & $2.25 \mathrm{E}-02$ \\
\hline 71 & CENWP_CL_29_VTB_2 & $9.51 \mathrm{E}-07$ & - & 2.87E-03 & - & - & $0.00 \mathrm{E}+00$ & 2.00E-03 & $0.00 \mathrm{E}+00$ & $0.00 E+00$ & $0.00 E+00$ & 4.86E-03 \\
\hline 72 & CENWP_CM_01_BB1_1 & $2.49 \mathrm{E}-04$ & - & 4.34E-03 & - & - & $0.00 \mathrm{E}+00$ & $0.00 E+00$ & $0.00 \mathrm{E}+00$ & $0.00 E+00$ & $1.71 \mathrm{E}-05$ & 4.61E-03 \\
\hline 73 & CENWP_CM_01_BB1_2 & $6.93 \mathrm{E}-04$ & - & $1.23 \mathrm{E}-02$ & - & - & $0.00 E+00$ & $0.00 E+00$ & $0.00 E+00$ & $0.00 E+00$ & $5.14 \mathrm{E}-05$ & 1.30E-02 \\
\hline 74 & CENWP_CM_02_BB2_1 & $6.41 \mathrm{E}-04$ & - & 1.07E-02 & - & - & $0.00 \mathrm{E}+00$ & $0.00 \mathrm{E}+00$ & $0.00 \mathrm{E}+00$ & $0.00 E+00$ & $0.00 \mathrm{E}+00$ & 1.13E-02 \\
\hline 75 & CENWP_CM_05_CHK_1 & $3.23 \mathrm{E}-05$ & - & 7.65E-04 & - & - & $0.00 \mathrm{E}+00$ & $0.00 \mathrm{E}+00$ & $0.00 \mathrm{E}+00$ & $0.00 E+00$ & $0.00 \mathrm{E}+00$ & 7.97E-04 \\
\hline 76 & CENWP_CM_05_CHK_2 & $2.85 \mathrm{E}-06$ & - & $1.62 \mathrm{E}-05$ & - & - & $0.00 \mathrm{E}+00$ & $0.00 \mathrm{E}+00$ & $0.00 \mathrm{E}+00$ & $0.00 \mathrm{E}+00$ & $0.00 \mathrm{E}+00$ & 1.90E-05 \\
\hline 77 & CENWP_CM_07_YGB_1 & $0.00 \mathrm{E}+00$ & - & $1.38 \mathrm{E}-03$ & - & - & $0.00 \mathrm{E}+00$ & $0.00 \mathrm{E}+00$ & $0.00 \mathrm{E}+00$ & $0.00 E+00$ & $0.00 E+00$ & $1.38 \mathrm{E}-03$ \\
\hline 78 & CENWP_CM_08_HMB_1 & $0.00 \mathrm{E}+00$ & - & $1.28 \mathrm{E}-04$ & - & - & $0.00 \mathrm{E}+00$ & 9.51E-06 & $0.00 \mathrm{E}+00$ & $0.00 \mathrm{E}+00$ & $1.42 \mathrm{E}-04$ & 2.80E-04 \\
\hline 79 & CENWP_CM_09_SKP_1 & $2.08 \mathrm{E}-04$ & - & $4.41 \mathrm{E}-02$ & - & - & $0.00 \mathrm{E}+00$ & $2.16 \mathrm{E}-04$ & $8.08 \mathrm{E}-04$ & $6.66 \mathrm{E}-06$ & 3.04E-05 & 4.53E-02 \\
\hline 80 & CENWP_CM_09_SKP_2 & $6.66 \mathrm{E}-06$ & - & $4.28 \mathrm{E}-05$ & - & - & $0.00 \mathrm{E}+00$ & 4.76E-06 & $0.00 \mathrm{E}+00$ & $0.00 \mathrm{E}+00$ & $0.00 \mathrm{E}+00$ & $5.42 \mathrm{E}-05$ \\
\hline 81 & CENWP_CM_11_CBY_1 & 3.04E-05 & - & $6.88 \mathrm{E}-03$ & - & - & $0.00 E+00$ & $1.85 \mathrm{E}-03$ & $3.42 \mathrm{E}-04$ & 3.14E-05 & $1.63 \mathrm{E}-03$ & $1.07 \mathrm{E}-02$ \\
\hline 82 & CENWP_CM_11_CBY_2 & $4.76 \mathrm{E}-06$ & - & $1.20 \mathrm{E}-03$ & - & - & $0.00 \mathrm{E}+00$ & $2.38 \mathrm{E}-05$ & $0.00 \mathrm{E}+00$ & $0.00 \mathrm{E}+00$ & $6.56 \mathrm{E}-05$ & $1.29 \mathrm{E}-03$ \\
\hline 83 & CENWP_CM_13_ELO_1 & $7.61 \mathrm{E}-06$ & - & 4.03E-04 & - & - & $0.00 E+00$ & $6.66 \mathrm{E}-05$ & $0.00 \mathrm{E}+00$ & $0.00 \mathrm{E}+00$ & $0.00 \mathrm{E}+00$ & $4.78 \mathrm{E}-04$ \\
\hline 84 & CENWP_CM_14_CC1_1 & 4.66E-05 & - & $6.29 \mathrm{E}-04$ & - & - & $0.00 E+00$ & $5.71 \mathrm{E}-05$ & $1.90 \mathrm{E}-06$ & $0.00 \mathrm{E}+00$ & 4.47E-05 & 7.79E-04 \\
\hline 85 & CENWP_CM_15_SKC_1 & $0.00 E+00$ & - & $0.00 E+00$ & - & - & $0.00 \mathrm{E}+00$ & 6.66E-06 & $0.00 E+00$ & $0.00 E+00$ & 1.33E-05 & 2.00E-05 \\
\hline 86 & CENWP_CM_16_WFC_1 & $0.00 \mathrm{E}+00$ & - & 6.47E-05 & - & - & $0.00 \mathrm{E}+00$ & 4.57E-05 & 1.90E-06 & $0.00 E+00$ & 8.34E-04 & $9.47 \mathrm{E}-04$ \\
\hline 87 & CENWP_CM_17_WSL_1 & $0.00 \mathrm{E}+00$ & - & $1.47 \mathrm{E}-04$ & - & - & $0.00 E+00$ & $1.71 \mathrm{E}-05$ & 9.51E-07 & $0.00 \mathrm{E}+00$ & 3.54E-03 & 3.70E-03 \\
\hline 88 & CENWP_CM_19_OSL_1 & $0.00 E+00$ & - & 2.71E-03 & - & - & $0.00 E+00$ & $1.52 \mathrm{E}-04$ & 2.76E-03 & $0.00 E+00$ & $1.62 \mathrm{E}-05$ & 5.63E-03 \\
\hline
\end{tabular}




\begin{tabular}{|c|c|c|c|c|c|c|c|c|c|c|c|c|}
\hline \multirow[b]{2}{*}{ \# } & \multirow[b]{2}{*}{ Reach Code } & \multicolumn{10}{|c|}{ AIS Ship and Cargo Type } & \multirow[b]{2}{*}{$\begin{array}{c}\text { All Vesse } \\
\text { Types }\end{array}$} \\
\hline & & $\begin{array}{l}\text { Unknown } \\
\text { (00) }\end{array}$ & $\begin{array}{c}\text { WIG } \\
(20-29)\end{array}$ & $\begin{array}{c}\text { Class } 3 \\
(30,33-39)\end{array}$ & $\begin{array}{l}\text { High-Speed } \\
\text { (40-49) }\end{array}$ & $\begin{array}{l}\text { Harbor } \\
\text { Boats } \\
(50-57)\end{array}$ & $\begin{array}{c}\text { Medical } \\
\text { Transports } \\
\text { (58) }\end{array}$ & $\begin{array}{c}\text { Passenger } \\
(60-69)\end{array}$ & $\begin{array}{l}\text { Cargo } \\
\text { (70-79) }\end{array}$ & $\begin{array}{l}\text { Tanker } \\
\text { (80-89) }\end{array}$ & $\begin{array}{l}\text { Other } \\
(90-99)\end{array}$ & \\
\hline 89 & CENWP_CM_19_OSL_2 & $0.00 E+00$ & - & 3.73E-03 & - & - & $0.00 \mathrm{E}+00$ & $1.25 \mathrm{E}-04$ & $0.00 \mathrm{E}+00$ & $0.00 E+00$ & $1.16 \mathrm{E}-04$ & 3.95E-03 \\
\hline 90 & CENWP_CM_21_RAI_1 & $0.00 \mathrm{E}+00$ & - & 2.33E-04 & - & - & $0.00 E+00$ & $1.24 \mathrm{E}-05$ & $5.04 \mathrm{E}-05$ & $9.51 \mathrm{E}-07$ & $7.61 \mathrm{E}-06$ & 3.04E-04 \\
\hline 91 & CENWP_CM_24_MUC_1 & $2.28 \mathrm{E}-05$ & - & 3.38E-03 & - & - & $0.00 E+00$ & $2.60 \mathrm{E}-04$ & $9.51 \mathrm{E}-07$ & $2.85 \mathrm{E}-06$ & $9.51 \mathrm{E}-06$ & $3.65 \mathrm{E}-03$ \\
\hline 92 & CENWP_CM_24_MUC_2 & $6.56 \mathrm{E}-05$ & - & $6.44 \mathrm{E}-03$ & - & - & $0.00 \mathrm{E}+00$ & $1.36 \mathrm{E}-03$ & $0.00 \mathrm{E}+00$ & $0.00 \mathrm{E}+00$ & $1.62 \mathrm{E}-05$ & 7.87E-03 \\
\hline 93 & CENWP_CM_24_MUC_A & $4.76 \mathrm{E}-06$ & - & $1.42 \mathrm{E}-03$ & - & - & $0.00 \mathrm{E}+00$ & $1.01 \mathrm{E}-03$ & $0.00 \mathrm{E}+00$ & $0.00 \mathrm{E}+00$ & $0.00 E+00$ & $2.43 \mathrm{E}-03$ \\
\hline 94 & CENWP_CZ_OO_CWM_1 & $0.00 \mathrm{E}+00$ & - & $3.52 \mathrm{E}-05$ & - & - & $0.00 E+00$ & $1.90 \mathrm{E}-06$ & 9.51E-07 & $0.00 \mathrm{E}+00$ & $0.00 E+00$ & 3.81E-05 \\
\hline 95 & CENWP_LK_01_LK1_1 & $0.00 \mathrm{E}+00$ & - & $3.90 \mathrm{E}-05$ & - & - & $0.00 E+00$ & $0.00 E+00$ & $0.00 E+00$ & $0.00 E+00$ & $0.00 E+00$ & $3.90 \mathrm{E}-05$ \\
\hline 96 & CENWP_LK_02_LK2_1 & $0.00 \mathrm{E}+00$ & - & 9.70E-05 & - & - & $0.00 E+00$ & $0.00 \mathrm{E}+00$ & $0.00 \mathrm{E}+00$ & $0.00 E+00$ & $0.00 \mathrm{E}+00$ & $9.70 \mathrm{E}-05$ \\
\hline 97 & CENWP_LK_03_LK3_1 & $0.00 E+00$ & - & $5.80 \mathrm{E}-05$ & - & - & $0.00 \mathrm{E}+00$ & $0.00 \mathrm{E}+00$ & $0.00 \mathrm{E}+00$ & $0.00 E+00$ & $0.00 \mathrm{E}+00$ & $5.80 \mathrm{E}-05$ \\
\hline 98 & CENWP_WR_01_WR1_1 & $7.82 \mathrm{E}-04$ & - & $1.20 \mathrm{E}-02$ & - & - & $9.13 \mathrm{E}-05$ & 3.14E-03 & $2.42 \mathrm{E}-02$ & $5.90 \mathrm{E}-03$ & $7.98 \mathrm{E}-04$ & 4.60E-02 \\
\hline 99 & CENWP_WR_02_WR2_1 & $5.50 \mathrm{E}-04$ & - & $1.59 \mathrm{E}-02$ & - & - & $1.23 \mathrm{E}-04$ & 4.37E-03 & $1.74 \mathrm{E}-02$ & $8.16 \mathrm{E}-03$ & $1.15 \mathrm{E}-03$ & 4.66E-02 \\
\hline 100 & CENWP_WR_03_WR3_1 & $2.65 \mathrm{E}-04$ & - & 1.04E-02 & - & - & 2.83E-04 & 4.10E-03 & $1.47 \mathrm{E}-02$ & $3.62 \mathrm{E}-03$ & 5.53E-04 & 3.32E-02 \\
\hline & All Federal Channels & $5.02 \mathrm{E}-02$ & - & 6.05E-01 & - & - & 2.15E-03 & 2.38E-01 & 8.26E-01 & $1.87 \mathrm{E}-01$ & 1.07E-01 & 9.51E-01 \\
\hline
\end{tabular}


Table 6-6. Unconditional frequency of SDVs in CRC by reach and AIS ship and cargo type code. Frequencies greater than $1 \times 10^{-5}$ are in bold red typeface.

\begin{tabular}{|c|c|c|c|c|c|c|c|c|c|c|c|c|}
\hline \multirow[b]{2}{*}{$\#$} & \multirow[b]{2}{*}{ Reach Code } & \multicolumn{10}{|c|}{ AIS Ship and Cargo Type } & \multirow[b]{2}{*}{$\begin{array}{c}\text { All Vessel } \\
\text { Types }\end{array}$} \\
\hline & & $\begin{array}{l}\text { Unknown } \\
\text { (00) }\end{array}$ & $\begin{array}{c}\text { WIG } \\
(20-29)\end{array}$ & $\begin{array}{c}\text { Class } 3 \\
(30,33-39)\end{array}$ & $\begin{array}{l}\text { High-Speed } \\
\qquad(40-49)\end{array}$ & $\begin{array}{l}\text { Harbor } \\
\text { Boats } \\
(50-57)\end{array}$ & $\begin{array}{c}\text { Medical } \\
\text { Transports } \\
\text { (58) }\end{array}$ & $\begin{array}{l}\text { Passenger } \\
(60-69)\end{array}$ & $\begin{array}{l}\text { Cargo } \\
\text { (70-79) }\end{array}$ & $\begin{array}{l}\text { Tanker } \\
\text { (80-89) }\end{array}$ & $\begin{array}{l}\text { Other } \\
\text { (90-99) }\end{array}$ & \\
\hline 1 & CENWP_CL_00_MCR_1 & $0.00 E+00$ & - & $0.00 E+00$ & - & - & $0.00 E+00$ & $0.00 E+00$ & $0.00 E+00$ & $0.00 E+00$ & $0.00 \mathrm{E}+00$ & $0.00 \mathrm{E}+00$ \\
\hline 2 & CENWP_CL_00_MCR_2 & $0.00 \mathrm{E}+00$ & - & $1.88 \mathrm{E}-06$ & - & - & $0.00 E+00$ & $0.00 E+00$ & $0.00 E+00$ & $0.00 E+00$ & $0.00 E+00$ & $1.88 \mathrm{E}-06$ \\
\hline 3 & CENWP_CL_00_MCR_3 & 1.90E-06 & - & 1.75E-06 & - & - & $0.00 E+00$ & $0.00 E+00$ & 2.83E-06 & $0.00 E+00$ & $0.00 E+00$ & $6.10 \mathrm{E}-06$ \\
\hline 4 & CENWP_CL_OO_MCR_4 & $0.00 \mathrm{E}+00$ & - & $0.00 \mathrm{E}+00$ & - & - & $0.00 E+00$ & $0.00 E+00$ & $0.00 E+00$ & $0.00 \mathrm{E}+00$ & $0.00 \mathrm{E}+00$ & $0.00 \mathrm{E}+00$ \\
\hline 5 & CENWP_CL_01_LDS_1 & $1.14 \mathrm{E}-05$ & - & $1.05 \mathrm{E}-04$ & - & - & $0.00 E+00$ & $0.00 \mathrm{E}+00$ & 9.34E-07 & $0.00 \mathrm{E}+00$ & $0.00 E+00$ & $1.16 \mathrm{E}-04$ \\
\hline 6 & CENWP_CL_02_UDS_1 & 7.61E-06 & - & $7.49 \mathrm{E}-05$ & - & - & $0.00 E+00$ & $0.00 \mathrm{E}+00$ & $9.32 \mathrm{E}-07$ & 1.90E-06 & $9.51 \mathrm{E}-07$ & 8.54E-05 \\
\hline 7 & CENWP_CL_03_FLV_1 & $5.71 \mathrm{E}-06$ & - & 1.19E-05 & - & - & $0.00 E+00$ & $1.42 E-05$ & $9.21 \mathrm{E}-06$ & $9.51 \mathrm{E}-07$ & $0.00 E+00$ & 4.09E-05 \\
\hline 8 & CENWP_CL_04_USN_1 & $9.51 \mathrm{E}-07$ & - & $9.40 \mathrm{E}-07$ & - & - & $0.00 E+00$ & $0.00 E+00$ & 6.63E-06 & $0.00 E+00$ & $0.00 E+00$ & 8.44E-06 \\
\hline 9 & CENWP_CL_04_USN_2 & 4.76E-06 & - & $5.62 \mathrm{E}-06$ & - & - & $0.00 E+00$ & $0.00 E+00$ & 1.31E-05 & $0.00 E+00$ & $0.00 \mathrm{E}+00$ & 2.31E-05 \\
\hline 10 & CENWP_CL_05_TNG_1 & $0.00 E+00$ & - & $0.00 E+00$ & - & - & $0.00 E+00$ & $0.00 E+00$ & $1.88 \mathrm{E}-06$ & $0.00 E+00$ & $0.00 E+00$ & 1.86E-06 \\
\hline 11 & CENWP_CL_05_TNG_2 & $0.00 E+00$ & - & $1.89 \mathrm{E}-06$ & - & - & $0.00 E+00$ & $0.00 E+00$ & 2.83E-06 & $0.00 E+00$ & $0.00 E+00$ & 4.69E-06 \\
\hline 12 & CENWP_CL_06_MLN_1 & $0.00 E+00$ & - & $1.49 \mathrm{E}-05$ & - & - & $0.00 E+00$ & $0.00 E+00$ & 9.50E-07 & $0.00 \mathrm{E}+00$ & $0.00 \mathrm{E}+00$ & $1.70 \mathrm{E}-05$ \\
\hline 13 & CENWP_CL_06_MLN_2 & $9.51 \mathrm{E}-07$ & - & $0.00 E+00$ & - & - & $0.00 E+00$ & $0.00 E+00$ & $0.00 E+00$ & 9.51E-07 & $0.00 E+00$ & $1.86 \mathrm{E}-06$ \\
\hline 14 & CENWP_CL_06_MLN_3 & $0.00 E+00$ & - & $0.00 E+00$ & - & - & $0.00 E+00$ & $0.00 E+00$ & $0.00 E+00$ & $0.00 E+00$ & $0.00 E+00$ & $0.00 \mathrm{E}+00$ \\
\hline 15 & CENWP_CL_07_PIL_1 & $0.00 E+00$ & - & $0.00 E+00$ & - & - & $0.00 E+00$ & $0.00 E+00$ & 2.81E-06 & $0.00 E+00$ & $0.00 E+00$ & $2.78 \mathrm{E}-06$ \\
\hline 16 & CENWP_CL_07_PIL_2 & $0.00 E+00$ & - & 3.14E-05 & - & - & $0.00 E+00$ & $9.49 \mathrm{E}-07$ & 3.79E-06 & $0.00 E+00$ & $0.00 E+00$ & 3.83E-05 \\
\hline 17 & CENWP_CL_08_BKW_1 & $0.00 E+00$ & - & $6.30 \mathrm{E}-06$ & - & - & $0.00 E+00$ & $9.51 \mathrm{E}-07$ & $2.85 \mathrm{E}-06$ & $0.00 E+00$ & $0.00 E+00$ & $1.01 \mathrm{E}-05$ \\
\hline 18 & CENWP_CL_08_BKW_2 & $0.00 E+00$ & - & 4.54E-06 & - & - & $0.00 E+00$ & $1.89 \mathrm{E}-06$ & $6.54 \mathrm{E}-06$ & 1.90E-06 & $9.48 \mathrm{E}-07$ & $1.53 E-05$ \\
\hline 19 & CENWP_CL_09_SKM_1 & $0.00 E+00$ & - & $2.49 \mathrm{E}-05$ & - & - & $0.00 E+00$ & $0.00 E+00$ & 4.65E-06 & $0.00 E+00$ & $0.00 E+00$ & 2.84E-05 \\
\hline 20 & CENWP_CL_09_SKM_2 & $0.00 \mathrm{E}+00$ & - & $0.00 E+00$ & - & - & $0.00 E+00$ & $0.00 E+00$ & $0.00 E+00$ & $0.00 E+00$ & $0.00 E+00$ & $0.00 E+00$ \\
\hline 21 & CENWP_CL_10_PGT_1 & $0.00 E+00$ & - & $0.00 E+00$ & - & - & $0.00 E+00$ & $0.00 \mathrm{E}+00$ & $0.00 \mathrm{E}+00$ & $0.00 E+00$ & $0.00 \mathrm{E}+00$ & $0.00 \mathrm{E}+00$ \\
\hline
\end{tabular}




\begin{tabular}{|c|c|c|c|c|c|c|c|c|c|c|c|c|}
\hline \multirow[b]{2}{*}{$\#$} & \multirow[b]{2}{*}{ Reach Code } & \multicolumn{10}{|c|}{ AIS Ship and Cargo Type } & \multirow[b]{2}{*}{$\begin{array}{c}\text { All Vessel } \\
\text { Types }\end{array}$} \\
\hline & & $\begin{array}{l}\text { Unknown } \\
(00)\end{array}$ & $\begin{array}{c}\text { WIG } \\
(20-29)\end{array}$ & $\begin{array}{c}\text { Class } 3 \\
(30,33-39)\end{array}$ & $\begin{array}{l}\text { High-Speed } \\
\text { (40-49) }\end{array}$ & $\begin{array}{l}\text { Harbor } \\
\text { Boats } \\
(50-57)\end{array}$ & $\begin{array}{c}\text { Medical } \\
\text { Transports } \\
\text { (58) }\end{array}$ & $\begin{array}{l}\text { Passenger } \\
(60-69)\end{array}$ & $\begin{array}{l}\text { Cargo } \\
\text { (70-79) }\end{array}$ & $\begin{array}{l}\text { Tanker } \\
\text { (80-89) }\end{array}$ & $\begin{array}{l}\text { Other } \\
\text { (90-99) }\end{array}$ & \\
\hline 22 & CENWP_CL_10_PGT_2 & $0.00 \mathrm{E}+00$ & - & $9.37 \mathrm{E}-07$ & - & - & $0.00 E+00$ & $9.49 \mathrm{E}-07$ & 9.34E-07 & $0.00 \mathrm{E}+00$ & $0.00 \mathrm{E}+00$ & $2.74 \mathrm{E}-06$ \\
\hline 23 & CENWP_CL_11_WAN_1 & $9.51 \mathrm{E}-07$ & - & $9.43 \mathrm{E}-07$ & - & - & $0.00 E+00$ & $0.00 E+00$ & $9.40 \mathrm{E}-07$ & 1.90E-06 & $0.00 E+00$ & 4.59E-06 \\
\hline 24 & CENWP_CL_11_WAN_2 & $0.00 \mathrm{E}+00$ & - & $9.41 \mathrm{E}-07$ & - & - & $0.00 E+00$ & $0.00 E+00$ & $1.89 \mathrm{E}-06$ & $0.00 E+00$ & $0.00 E+00$ & $2.75 \mathrm{E}-06$ \\
\hline 25 & CENWP_CL_12_WST_1 & $0.00 \mathrm{E}+00$ & - & $0.00 \mathrm{E}+00$ & - & - & $0.00 E+00$ & $0.00 \mathrm{E}+00$ & $9.42 \mathrm{E}-07$ & $0.00 \mathrm{E}+00$ & $0.00 \mathrm{E}+00$ & $9.10 \mathrm{E}-07$ \\
\hline 26 & CENWP_CL_12_WST_2 & $9.51 \mathrm{E}-07$ & - & $5.00 \mathrm{E}-05$ & - & - & $0.00 E+00$ & $0.00 \mathrm{E}+00$ & $1.23 E-05$ & 1.90E-06 & $0.00 E+00$ & $6.03 E-05$ \\
\hline 27 & CENWP_CL_13_EUR_1 & $0.00 \mathrm{E}+00$ & - & $1.16 \mathrm{E}-05$ & - & - & $0.00 E+00$ & $0.00 \mathrm{E}+00$ & 2.85E-06 & $0.00 \mathrm{E}+00$ & $0.00 E+00$ & $1.41 \mathrm{E}-05$ \\
\hline 28 & CENWP_CL_13_EUR_2 & $0.00 \mathrm{E}+00$ & - & $0.00 \mathrm{E}+00$ & - & - & $0.00 E+00$ & $0.00 E+00$ & $0.00 E+00$ & $9.51 \mathrm{E}-07$ & $0.00 \mathrm{E}+00$ & 9.15E-07 \\
\hline 29 & CENWP_CL_13_EUR_3 & $0.00 \mathrm{E}+00$ & - & $0.00 E+00$ & - & - & $0.00 E+00$ & $0.00 \mathrm{E}+00$ & 4.75E-06 & $0.00 \mathrm{E}+00$ & $0.00 \mathrm{E}+00$ & $4.73 E-06$ \\
\hline 30 & CENWP_CL_14_GUL_1 & $0.00 E+00$ & - & $0.00 E+00$ & - & - & $0.00 E+00$ & $0.00 E+00$ & 7.54E-06 & $0.00 E+00$ & $0.00 \mathrm{E}+00$ & 7.44E-06 \\
\hline 31 & CENWP_CL_14_GUL_2 & $0.00 \mathrm{E}+00$ & - & $9.46 \mathrm{E}-07$ & - & - & $0.00 E+00$ & $0.00 E+00$ & $5.68 \mathrm{E}-06$ & $0.00 E+00$ & $0.00 E+00$ & $6.58 \mathrm{E}-06$ \\
\hline 32 & CENWP_CL_15_STL_1 & $0.00 \mathrm{E}+00$ & - & 6.63E-06 & - & - & $0.00 E+00$ & $9.51 \mathrm{E}-07$ & 6.63E-06 & $0.00 E+00$ & $0.00 E+00$ & $1.42 \mathrm{E}-05$ \\
\hline 33 & CENWP_CL_15_STL_2 & $0.00 \mathrm{E}+00$ & - & 1.85E-06 & - & - & $0.00 E+00$ & $0.00 E+00$ & 5.62E-06 & $0.00 \mathrm{E}+00$ & $0.00 E+00$ & 7.29E-06 \\
\hline 34 & CENWP_CL_16_WLK_1 & $0.00 \mathrm{E}+00$ & - & $0.00 \mathrm{E}+00$ & - & - & $0.00 E+00$ & $0.00 \mathrm{E}+00$ & 9.50E-07 & $0.00 \mathrm{E}+00$ & $0.00 \mathrm{E}+00$ & $9.46 \mathrm{E}-07$ \\
\hline 35 & CENWP_CL_16_WLK_2 & $0.00 E+00$ & - & $9.45 \mathrm{E}-07$ & - & - & $0.00 E+00$ & $0.00 E+00$ & $9.42 \mathrm{E}-07$ & $0.00 E+00$ & $0.00 E+00$ & 1.87E-06 \\
\hline 36 & CENWP_CL_16_WLK_3 & $0.00 \mathrm{E}+00$ & - & $0.00 \mathrm{E}+00$ & - & - & $0.00 E+00$ & $0.00 \mathrm{E}+00$ & $0.00 E+00$ & $0.00 E+00$ & $0.00 \mathrm{E}+00$ & $0.00 \mathrm{E}+00$ \\
\hline 37 & CENWP_CL_17_SLG_1 & $0.00 \mathrm{E}+00$ & - & $0.00 \mathrm{E}+00$ & - & - & $0.00 E+00$ & $0.00 E+00$ & 6.56E-06 & $0.00 \mathrm{E}+00$ & $0.00 \mathrm{E}+00$ & $6.48 \mathrm{E}-06$ \\
\hline 38 & CENWP_CL_17_SLG_2 & $0.00 \mathrm{E}+00$ & - & 9.34E-07 & - & - & $0.00 E+00$ & $0.00 \mathrm{E}+00$ & 7.55E-06 & $0.00 \mathrm{E}+00$ & $0.00 E+00$ & 8.38E-06 \\
\hline 39 & CENWP_CL_17_SLG_3 & $0.00 \mathrm{E}+00$ & - & $0.00 E+00$ & - & - & - & $0.00 \mathrm{E}+00$ & 2.94E-05 & - & - & 2.94E-05 \\
\hline 40 & CENWP_CL_18_LDB_1 & $0.00 \mathrm{E}+00$ & - & $0.00 E+00$ & - & - & $0.00 E+00$ & $0.00 E+00$ & 3.79E-06 & $0.00 E+00$ & $0.00 E+00$ & $3.74 \mathrm{E}-06$ \\
\hline 41 & CENWP_CL_18_LDB_2 & $0.00 \mathrm{E}+00$ & - & $0.00 E+00$ & - & - & $0.00 E+00$ & $0.00 E+00$ & $1.89 \mathrm{E}-06$ & $0.00 E+00$ & $0.00 \mathrm{E}+00$ & $1.88 \mathrm{E}-06$ \\
\hline 42 & CENWP_CL_19_UDB_1 & $0.00 \mathrm{E}+00$ & - & $0.00 E+00$ & - & - & $0.00 E+00$ & $0.00 E+00$ & 6.63E-06 & $0.00 \mathrm{E}+00$ & $0.00 E+00$ & $6.53 E-06$ \\
\hline 43 & CENWP_CL_19_UDB_2 & $0.00 \mathrm{E}+00$ & - & $9.47 \mathrm{E}-07$ & - & - & $0.00 E+00$ & $0.00 \mathrm{E}+00$ & 1.89E-06 & $0.00 \mathrm{E}+00$ & $0.00 E+00$ & $2.82 \mathrm{E}-06$ \\
\hline
\end{tabular}




\begin{tabular}{|c|c|c|c|c|c|c|c|c|c|c|c|c|}
\hline \multirow[b]{2}{*}{$\#$} & \multirow[b]{2}{*}{ Reach Code } & \multicolumn{10}{|c|}{ AIS Ship and Cargo Type } & \multirow[b]{2}{*}{$\begin{array}{c}\text { All Vessel } \\
\text { Types }\end{array}$} \\
\hline & & $\begin{array}{l}\text { Unknown } \\
(00)\end{array}$ & $\begin{array}{c}\text { WIG } \\
(20-29)\end{array}$ & $\begin{array}{c}\text { Class } 3 \\
(30,33-39)\end{array}$ & $\begin{array}{l}\text { High-Speed } \\
\text { (40-49) }\end{array}$ & $\begin{array}{l}\text { Harbor } \\
\text { Boats } \\
(50-57)\end{array}$ & $\begin{array}{c}\text { Medical } \\
\text { Transports } \\
\text { (58) }\end{array}$ & $\begin{array}{l}\text { Passenger } \\
(60-69)\end{array}$ & $\begin{array}{l}\text { Cargo } \\
\text { (70-79) }\end{array}$ & $\begin{array}{l}\text { Tanker } \\
\text { (80-89) }\end{array}$ & $\begin{array}{l}\text { Other } \\
\text { (90-99) }\end{array}$ & \\
\hline 44 & CENWP_CL_20_KLM_1 & $0.00 \mathrm{E}+00$ & - & $0.00 E+00$ & - & - & $0.00 E+00$ & $0.00 E+00$ & 1.90E-06 & $0.00 \mathrm{E}+00$ & $0.00 \mathrm{E}+00$ & 1.90E-06 \\
\hline 45 & CENWP_CL_20_KLM_2 & $0.00 \mathrm{E}+00$ & - & $0.00 E+00$ & - & - & $0.00 E+00$ & $0.00 E+00$ & 1.03E-04 & $0.00 \mathrm{E}+00$ & $0.00 E+00$ & $1.03 E-04$ \\
\hline 46 & CENWP_CL_20_KLM_3 & $9.51 \mathrm{E}-07$ & - & 1.77E-05 & - & - & $0.00 E+00$ & 7.61E-06 & 2.83E-06 & $0.00 E+00$ & $0.00 E+00$ & $2.89 \mathrm{E}-05$ \\
\hline 47 & CENWP_CL_21_LMT_1 & $0.00 \mathrm{E}+00$ & - & 3.93E-06 & - & - & $0.00 E+00$ & $0.00 \mathrm{E}+00$ & $0.00 \mathrm{E}+00$ & $0.00 \mathrm{E}+00$ & $0.00 \mathrm{E}+00$ & 4.17E-06 \\
\hline 48 & CENWP_CL_21_LMT_2 & $0.00 \mathrm{E}+00$ & - & $0.00 \mathrm{E}+00$ & - & - & $0.00 E+00$ & $0.00 \mathrm{E}+00$ & 7.54E-06 & $0.00 \mathrm{E}+00$ & $0.00 E+00$ & 7.47E-06 \\
\hline 49 & CENWP_CL_21_LMT_3 & $0.00 \mathrm{E}+00$ & - & $0.00 E+00$ & - & - & $0.00 E+00$ & $0.00 \mathrm{E}+00$ & $0.00 E+00$ & $0.00 \mathrm{E}+00$ & $0.00 E+00$ & $0.00 \mathrm{E}+00$ \\
\hline 50 & CENWP_CL_22_UMT_1 & 9.51E-07 & - & $0.00 \mathrm{E}+00$ & - & - & $0.00 E+00$ & $0.00 E+00$ & 9.50E-07 & $0.00 \mathrm{E}+00$ & $0.00 \mathrm{E}+00$ & 1.89E-06 \\
\hline 51 & CENWP_CL_22_UMT_2 & $0.00 E+00$ & - & $0.00 E+00$ & - & - & $0.00 E+00$ & $0.00 E+00$ & $0.00 \mathrm{E}+00$ & $0.00 E+00$ & $0.00 E+00$ & $0.00 E+00$ \\
\hline 52 & CENWP_CL_22_UMT_3 & $0.00 \mathrm{E}+00$ & - & $0.00 E+00$ & - & - & $0.00 E+00$ & $0.00 E+00$ & $0.00 E+00$ & $9.51 \mathrm{E}-07$ & $0.00 E+00$ & 9.38E-07 \\
\hline 53 & CENWP_CL_23_STH_1 & $0.00 \mathrm{E}+00$ & - & $1.04 \mathrm{E}-05$ & - & - & $0.00 E+00$ & $9.49 \mathrm{E}-07$ & $7.58 \mathrm{E}-06$ & $9.51 \mathrm{E}-07$ & $0.00 E+00$ & $1.89 \mathrm{E}-05$ \\
\hline 54 & CENWP_CL_23_STH_2 & $0.00 \mathrm{E}+00$ & - & 2.07E-05 & - & - & $0.00 E+00$ & $0.00 E+00$ & $1.23 E-05$ & $9.51 \mathrm{E}-07$ & $0.00 E+00$ & $3.25 \mathrm{E}-05$ \\
\hline 55 & CENWP_CL_24_WAR_1 & $0.00 \mathrm{E}+00$ & - & $0.00 E+00$ & - & - & $0.00 E+00$ & $9.48 \mathrm{E}-07$ & $0.00 E+00$ & $0.00 E+00$ & $0.00 E+00$ & $9.47 \mathrm{E}-07$ \\
\hline 56 & CENWP_CL_24_WAR_2 & $0.00 \mathrm{E}+00$ & - & $0.00 \mathrm{E}+00$ & - & - & $0.00 E+00$ & $0.00 \mathrm{E}+00$ & 2.84E-06 & $0.00 \mathrm{E}+00$ & $0.00 \mathrm{E}+00$ & 2.83E-06 \\
\hline 57 & CENWP_CL_24_WAR_3 & $0.00 \mathrm{E}+00$ & - & $0.00 E+00$ & - & - & $0.00 E+00$ & $0.00 E+00$ & $0.00 E+00$ & $0.00 E+00$ & $0.00 E+00$ & $0.00 E+00$ \\
\hline 58 & CENWP_CL_25_HEN_1 & $0.00 \mathrm{E}+00$ & - & $0.00 E+00$ & - & - & $0.00 E+00$ & $0.00 \mathrm{E}+00$ & $4.72 \mathrm{E}-06$ & 9.51E-07 & $0.00 \mathrm{E}+00$ & 5.61E-06 \\
\hline 59 & CENWP_CL_25_HEN_2 & $0.00 \mathrm{E}+00$ & - & $0.00 \mathrm{E}+00$ & - & - & $0.00 E+00$ & $0.00 E+00$ & $0.00 E+00$ & $0.00 E+00$ & $0.00 \mathrm{E}+00$ & $0.00 \mathrm{E}+00$ \\
\hline 60 & CENWP_CL_26_WLW_1 & $0.00 \mathrm{E}+00$ & - & $0.00 \mathrm{E}+00$ & - & - & $0.00 E+00$ & $0.00 \mathrm{E}+00$ & $0.00 E+00$ & $0.00 \mathrm{E}+00$ & $0.00 E+00$ & $0.00 \mathrm{E}+00$ \\
\hline 61 & CENWP_CL_26_WLW_2 & $0.00 \mathrm{E}+00$ & - & $0.00 E+00$ & - & - & $0.00 E+00$ & $0.00 \mathrm{E}+00$ & 5.67E-06 & $0.00 E+00$ & $0.00 E+00$ & 5.61E-06 \\
\hline 62 & CENWP_CL_27_MGN_1 & $0.00 \mathrm{E}+00$ & - & $0.00 E+00$ & - & - & $0.00 E+00$ & $0.00 E+00$ & $0.00 E+00$ & $0.00 \mathrm{E}+00$ & $0.00 E+00$ & $0.00 E+00$ \\
\hline 63 & CENWP_CL_27_MGN_2 & $0.00 \mathrm{E}+00$ & - & $0.00 E+00$ & - & - & $0.00 E+00$ & $0.00 E+00$ & $2.84 \mathrm{E}-06$ & $9.51 \mathrm{E}-07$ & $0.00 \mathrm{E}+00$ & 3.77E-06 \\
\hline 64 & CENWP_CL_27_MGN_3 & $0.00 \mathrm{E}+00$ & - & $0.00 E+00$ & - & - & $0.00 E+00$ & $0.00 E+00$ & $1.88 \mathrm{E}-06$ & $0.00 E+00$ & $0.00 E+00$ & $1.88 \mathrm{E}-06$ \\
\hline 65 & CENWP_CL_28_VBR_1 & $0.00 \mathrm{E}+00$ & - & $9.43 \mathrm{E}-07$ & - & - & - & $0.00 \mathrm{E}+00$ & 1.98E-05 & $0.00 \mathrm{E}+00$ & $0.00 E+00$ & 2.07E-05 \\
\hline
\end{tabular}




\begin{tabular}{|c|c|c|c|c|c|c|c|c|c|c|c|c|}
\hline \multirow[b]{2}{*}{ \# } & \multirow[b]{2}{*}{ Reach Code } & \multicolumn{10}{|c|}{ AIS Ship and Cargo Type } & \multirow[b]{2}{*}{$\begin{array}{c}\text { All Vessel } \\
\text { Types }\end{array}$} \\
\hline & & $\begin{array}{l}\text { Unknown } \\
\text { (00) }\end{array}$ & $\begin{array}{c}\text { WIG } \\
(20-29)\end{array}$ & $\begin{array}{c}\text { Class } 3 \\
(30,33-39)\end{array}$ & $\begin{array}{c}\text { High-Speed } \\
\text { (40-49) }\end{array}$ & $\begin{array}{l}\text { Harbor } \\
\text { Boats } \\
(50-57)\end{array}$ & $\begin{array}{c}\text { Medical } \\
\text { Transports } \\
\text { (58) }\end{array}$ & $\begin{array}{c}\text { Passenger } \\
(60-69)\end{array}$ & $\begin{array}{l}\text { Cargo } \\
\text { (70-79) }\end{array}$ & $\begin{array}{l}\text { Tanker } \\
\text { (80-89) }\end{array}$ & $\begin{array}{c}\text { Other } \\
\text { (90-99) }\end{array}$ & \\
\hline 66 & CENWP_CL_28_VBR_2 & $0.00 E+00$ & - & $0.00 E+00$ & - & - & - & $0.00 E+00$ & $9.47 \mathrm{E}-07$ & $0.00 E+00$ & - & $9.41 \mathrm{E}-07$ \\
\hline 67 & CENWP_CL_28_VBR_3 & $0.00 E+00$ & - & $0.00 E+00$ & - & - & - & $0.00 E+00$ & $0.00 E+00$ & $9.37 \mathrm{E}-07$ & - & $9.46 \mathrm{E}-07$ \\
\hline 68 & CENWP_CL_28_VBR_4 & $0.00 E+00$ & - & $0.00 E+00$ & - & - & - & $0.00 \mathrm{E}+00$ & $1.33 \mathrm{E}-05$ & $0.00 \mathrm{E}+00$ & - & 1.33E-05 \\
\hline 69 & CENWP_CL_28_VBR_5 & - & - & $0.00 E+00$ & - & - & - & $0.00 E+00$ & $1.05 \mathrm{E}-05$ & $0.00 E+00$ & - & $1.04 \mathrm{E}-05$ \\
\hline 70 & CENWP_CL_29_VTB_1 & $0.00 E+00$ & - & $9.41 \mathrm{E}-07$ & - & - & - & $0.00 E+00$ & $1.80 \mathrm{E}-05$ & $0.00 E+00$ & - & $1.88 \mathrm{E}-05$ \\
\hline 71 & CENWP_CL_29_VTB_2 & $0.00 E+00$ & - & $0.00 E+00$ & - & - & - & $0.00 \mathrm{E}+00$ & - & - & - & $0.00 E+00$ \\
\hline 72 & CENWP_CM_01_BB1_1 & $0.00 E+00$ & - & $0.00 E+00$ & - & - & - & - & - & - & $0.00 \mathrm{E}+00$ & $0.00 E+00$ \\
\hline 73 & CENWP_CM_01_BB1_2 & $0.00 E+00$ & - & $2.81 \mathrm{E}-06$ & - & - & - & - & - & - & $0.00 E+00$ & $2.81 \mathrm{E}-06$ \\
\hline 74 & CENWP_CM_02_BB2_1 & $0.00 E+00$ & - & $0.00 E+00$ & - & - & - & - & - & - & - & $0.00 \mathrm{E}+00$ \\
\hline 75 & CENWP_CM_05_CHK_1 & $0.00 E+00$ & - & $0.00 E+00$ & - & - & - & - & - & - & - & $0.00 \mathrm{E}+00$ \\
\hline 76 & CENWP_CM_05_CHK_2 & $0.00 E+00$ & - & $0.00 \mathrm{E}+00$ & - & - & - & - & - & - & - & $0.00 \mathrm{E}+00$ \\
\hline 77 & CENWP_CM_07_YGB_1 & - & - & $0.00 E+00$ & - & - & - & - & - & - & - & $0.00 E+00$ \\
\hline 78 & CENWP_CM_08_HMB_1 & - & - & $0.00 E+00$ & - & - & - & $0.00 E+00$ & - & - & $0.00 E+00$ & $0.00 E+00$ \\
\hline 79 & CENWP_CM_09_SKP_1 & $0.00 E+00$ & - & $1.65 \mathrm{E}-05$ & - & - & - & $0.00 E+00$ & $0.00 E+00$ & $0.00 E+00$ & $0.00 E+00$ & $1.65 \mathrm{E}-05$ \\
\hline 80 & CENWP_CM_09_SKP_2 & $0.00 E+00$ & - & $0.00 E+00$ & - & - & - & $0.00 \mathrm{E}+00$ & - & - & - & $0.00 \mathrm{E}+00$ \\
\hline 81 & CENWP_CM_11_CBY_1 & $1.90 \mathrm{E}-06$ & - & 2.83E-06 & - & - & - & $0.00 E+00$ & $0.00 E+00$ & $0.00 E+00$ & $0.00 E+00$ & 4.71E-06 \\
\hline 82 & CENWP_CM_11_CBY_2 & $2.85 \mathrm{E}-06$ & - & $2.85 \mathrm{E}-06$ & - & - & - & $0.00 E+00$ & - & - & $0.00 E+00$ & $5.68 \mathrm{E}-06$ \\
\hline 83 & CENWP_CM_13_ELO_1 & $0.00 E+00$ & - & $0.00 E+00$ & - & - & - & $0.00 E+00$ & - & - & - & $0.00 E+00$ \\
\hline 84 & CENWP_CM_14_CC1_1 & $0.00 E+00$ & - & $0.00 \mathrm{E}+00$ & - & - & - & $0.00 E+00$ & $0.00 E+00$ & - & $0.00 \mathrm{E}+00$ & $0.00 \mathrm{E}+00$ \\
\hline 85 & CENWP_CM_15_SKC_1 & - & - & - & - & - & - & $0.00 \mathrm{E}+00$ & - & - & $0.00 E+00$ & $0.00 E+00$ \\
\hline 86 & CENWP_CM_16_WFC_1 & - & - & $0.00 \mathrm{E}+00$ & - & - & - & $0.00 E+00$ & $0.00 E+00$ & - & $0.00 E+00$ & $0.00 \mathrm{E}+00$ \\
\hline 87 & CENWP_CM_17_WSL_1 & - & - & $0.00 E+00$ & - & - & - & $0.00 E+00$ & $0.00 E+00$ & - & $0.00 E+00$ & $0.00 E+00$ \\
\hline
\end{tabular}




\begin{tabular}{|c|c|c|c|c|c|c|c|c|c|c|c|c|}
\hline \multirow[b]{2}{*}{$\#$} & \multirow[b]{2}{*}{ Reach Code } & \multicolumn{10}{|c|}{ AIS Ship and Cargo Type } & \multirow[b]{2}{*}{$\begin{array}{c}\text { All Vessel } \\
\text { Types }\end{array}$} \\
\hline & & $\begin{array}{l}\text { Unknown } \\
\text { (00) }\end{array}$ & $\begin{array}{c}\text { WIG } \\
(20-29)\end{array}$ & $\begin{array}{c}\text { Class } 3 \\
(30,33-39)\end{array}$ & $\begin{array}{c}\text { High-Speed } \\
\text { (40-49) }\end{array}$ & $\begin{array}{c}\text { Harbor } \\
\text { Boats } \\
(50-57)\end{array}$ & $\begin{array}{c}\text { Medical } \\
\text { Transports } \\
(58)\end{array}$ & $\begin{array}{c}\text { Passenger } \\
(60-69)\end{array}$ & $\begin{array}{l}\text { Cargo } \\
\text { (70-79) }\end{array}$ & $\begin{array}{l}\text { Tanker } \\
\text { (80-89) }\end{array}$ & $\begin{array}{c}\text { Other } \\
\text { (90-99) }\end{array}$ & \\
\hline 88 & CENWP_CM_19_OSL_1 & - & - & $0.00 \mathrm{E}+00$ & - & - & - & $0.00 E+00$ & $0.00 \mathrm{E}+00$ & - & $0.00 \mathrm{E}+00$ & $0.00 E+00$ \\
\hline 89 & CENWP_CM_19_OSL_2 & - & - & $0.00 E+00$ & - & - & - & $0.00 \mathrm{E}+00$ & - & - & $0.00 \mathrm{E}+00$ & $0.00 E+00$ \\
\hline 90 & CENWP_CM_21_RAl_1 & - & - & $0.00 \mathrm{E}+00$ & - & - & - & $0.00 E+00$ & $0.00 \mathrm{E}+00$ & $0.00 E+00$ & $0.00 \mathrm{E}+00$ & $0.00 E+00$ \\
\hline 91 & CENWP_CM_24_MUC_1 & $0.00 \mathrm{E}+00$ & - & $1.88 \mathrm{E}-06$ & - & - & - & $0.00 \mathrm{E}+00$ & $0.00 \mathrm{E}+00$ & $0.00 \mathrm{E}+00$ & $0.00 \mathrm{E}+00$ & $1.87 \mathrm{E}-06$ \\
\hline 92 & CENWP_CM_24_MUC_2 & $0.00 \mathrm{E}+00$ & - & $0.00 \mathrm{E}+00$ & - & - & - & $0.00 \mathrm{E}+00$ & - & - & $0.00 \mathrm{E}+00$ & $0.00 \mathrm{E}+00$ \\
\hline 93 & CENWP_CM_24_MUC_A & $0.00 \mathrm{E}+00$ & - & $0.00 E+00$ & - & - & - & $0.00 \mathrm{E}+00$ & - & - & - & $0.00 E+00$ \\
\hline 94 & CENWP_CZ_00_CWM_1 & - & - & $0.00 \mathrm{E}+00$ & - & - & - & $0.00 E+00$ & $0.00 \mathrm{E}+00$ & - & - & $0.00 E+00$ \\
\hline 95 & CENWP_LK_01_LK1_1 & - & - & $0.00 E+00$ & - & - & - & - & - & - & - & $0.00 E+00$ \\
\hline 96 & CENWP_LK_02_LK2_1 & - & - & $0.00 E+00$ & - & - & - & - & - & - & - & $0.00 E+00$ \\
\hline 97 & CENWP_LK_03_LK3_1 & - & - & $0.00 \mathrm{E}+00$ & - & - & - & - & - & - & - & $0.00 \mathrm{E}+00$ \\
\hline 98 & CENWP_WR_01_WR1_1 & $0.00 \mathrm{E}+00$ & - & $0.00 E+00$ & - & - & $0.00 E+00$ & $0.00 E+00$ & 1.47E-05 & $0.00 E+00$ & $0.00 \mathrm{E}+00$ & $1.46 \mathrm{E}-05$ \\
\hline 99 & CENWP_WR_02_WR2_1 & $0.00 \mathrm{E}+00$ & - & $2.76 \mathrm{E}-06$ & - & - & $0.00 \mathrm{E}+00$ & $0.00 E+00$ & $1.88 \mathrm{E}-06$ & $0.00 \mathrm{E}+00$ & $0.00 E+00$ & 4.57E-06 \\
\hline 100 & CENWP_WR_03_WR3_1 & $0.00 \mathrm{E}+00$ & - & $0.00 \mathrm{E}+00$ & - & - & $0.00 \mathrm{E}+00$ & $0.00 \mathrm{E}+00$ & 4.64E-06 & 2.85E-06 & $0.00 \mathrm{E}+00$ & 7.24E-06 \\
\hline & All Federal Channels & 3.97E-05 & - & 2.31E-04 & - & - & $0.00 E+00$ & 2.56E-05 & 1.79E-04 & 1.70E-05 & $1.58 \mathrm{E}-06$ & $2.45 E-04$ \\
\hline
\end{tabular}


Figure 6-10. Unconditional frequency of SDVs in CRC, Entrance Range to Eureka Bar.

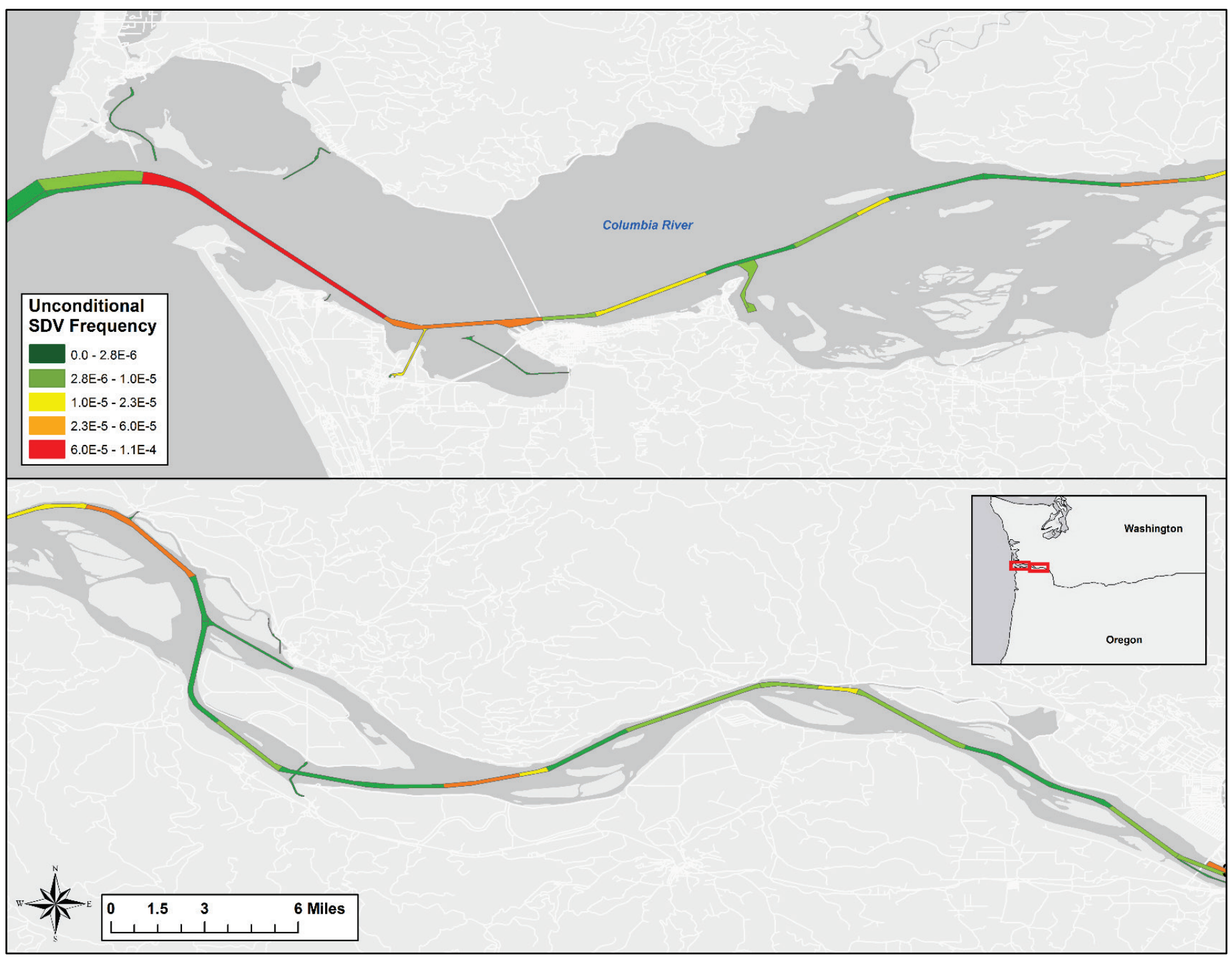


Figure 6-11. Unconditional frequency of SDVs in CRC, Eureka Bar to Interstate 5 bridge.

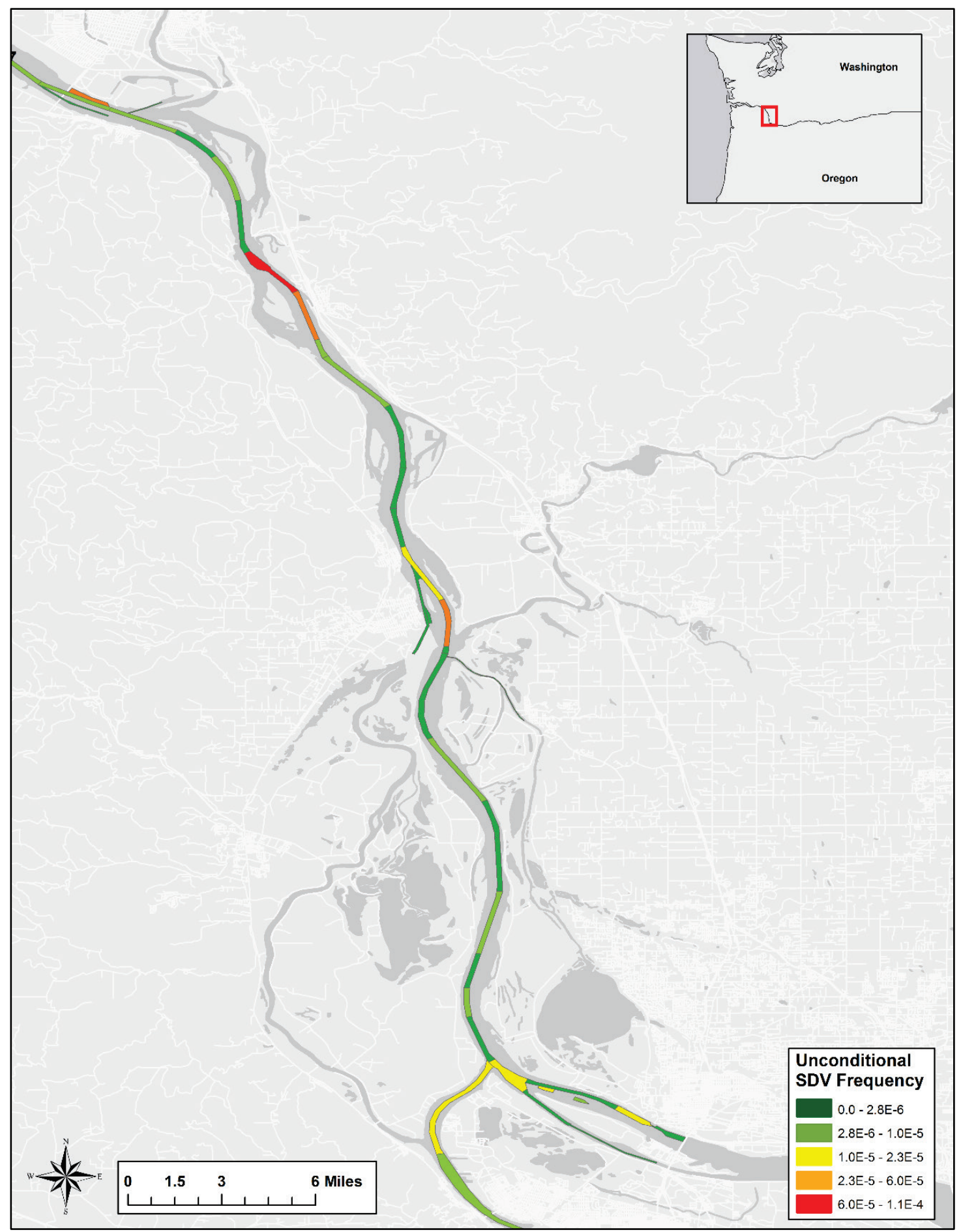


The third metric of collision risk is the relative frequency of SDVs by navigation channel reach. This metric indicates the probability that an SDV will occur in a particular reach given that an SDV has occurred in the navigation project. It is similar to the unconditional frequency of an SDV because it indicates where SDVs are most likely to occur in a navigation project. The relative frequency of SDVs is shown in Figures 6-12 and 6-13. During the 2015 calendar year, $12 \%$ of SDVs occurred in Westport Channel (\#26), approximately 10\% of SDVs occurred in St. Helen's Range and Turn (\#53-54), and 8\% of SDVs occurred in the Kalama Lower Range (\#45). Almost one-third of the SDVs that occurred in CRC in 2015 occurred in these four reaches.

Correlations among the metrics of collision risk are shown in Table 6-7. The correlations between the conditional probability of an SDV and the three other metrics are relatively low. The probability that at least one vessel is present in a reach is moderately correlated with the unconditional probability of an SDV (0.4915) and the relative frequency of SDVs (0.4331). These correlations are consistent with the idea that these two risk metrics will tend to be greater in those reaches that have more traffic. The correlation between the unconditional probability of an SDV and the relative frequency of an SDV is 0.6608 . This lower-than-expected correlation can be attributed to observations in Upper and Lower Desdemona Shoal (\#5-6) and Kalama Lower Range (\#45). The relative frequencies in these reaches seem to be much lower than would otherwise be expected given the unconditional probability of an SDV. Removing these three data points increases the correlation coefficient to 0.9280 , which affirms that these two risk metrics provide similar information.

Table 6-7. Pearson correlation coefficients for collision risk metrics in CRC.

\begin{tabular}{|c|c|c|c|c|}
\hline Metric of collision risk & $p\left(\right.$ SDV $\left.\mid n_{k t} \geq 1\right)$ & $p\left(n_{k t} \geq 1\right)$ & $p($ SDV $)$ & $f_{k}$ \\
\hline$p\left(\right.$ SDV $\left.\mid n_{k t} \geq 1\right)$ & 1.0000 & -0.0842 & 0.3487 & 0.2777 \\
\hline$p\left(n_{k t} \geq 1\right)$ & - & 1.0000 & 0.4915 & 0.4331 \\
\hline$p($ SDV $)$ & - & - & 1.0000 & 0.6608 \\
\hline$f_{k}$ & - & - & - & 1.0000 \\
\hline
\end{tabular}


Figure 6-12. Relative frequency of SDVs in CRC, Entrance Range to Eureka Bar.

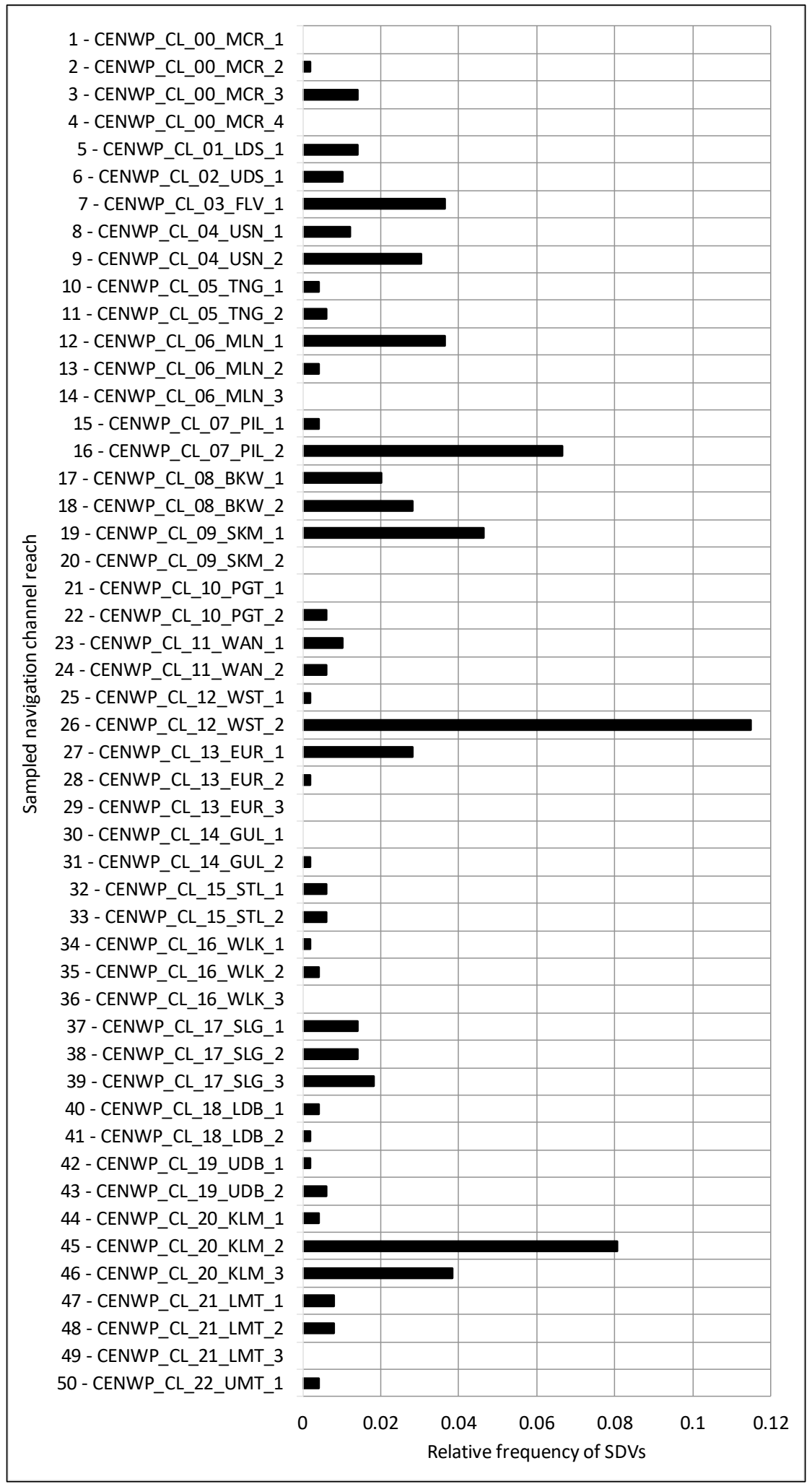


Figure 6-13. Relative frequency of SDVs in CRC, Eureka Bar to Interstate 5 bridge.

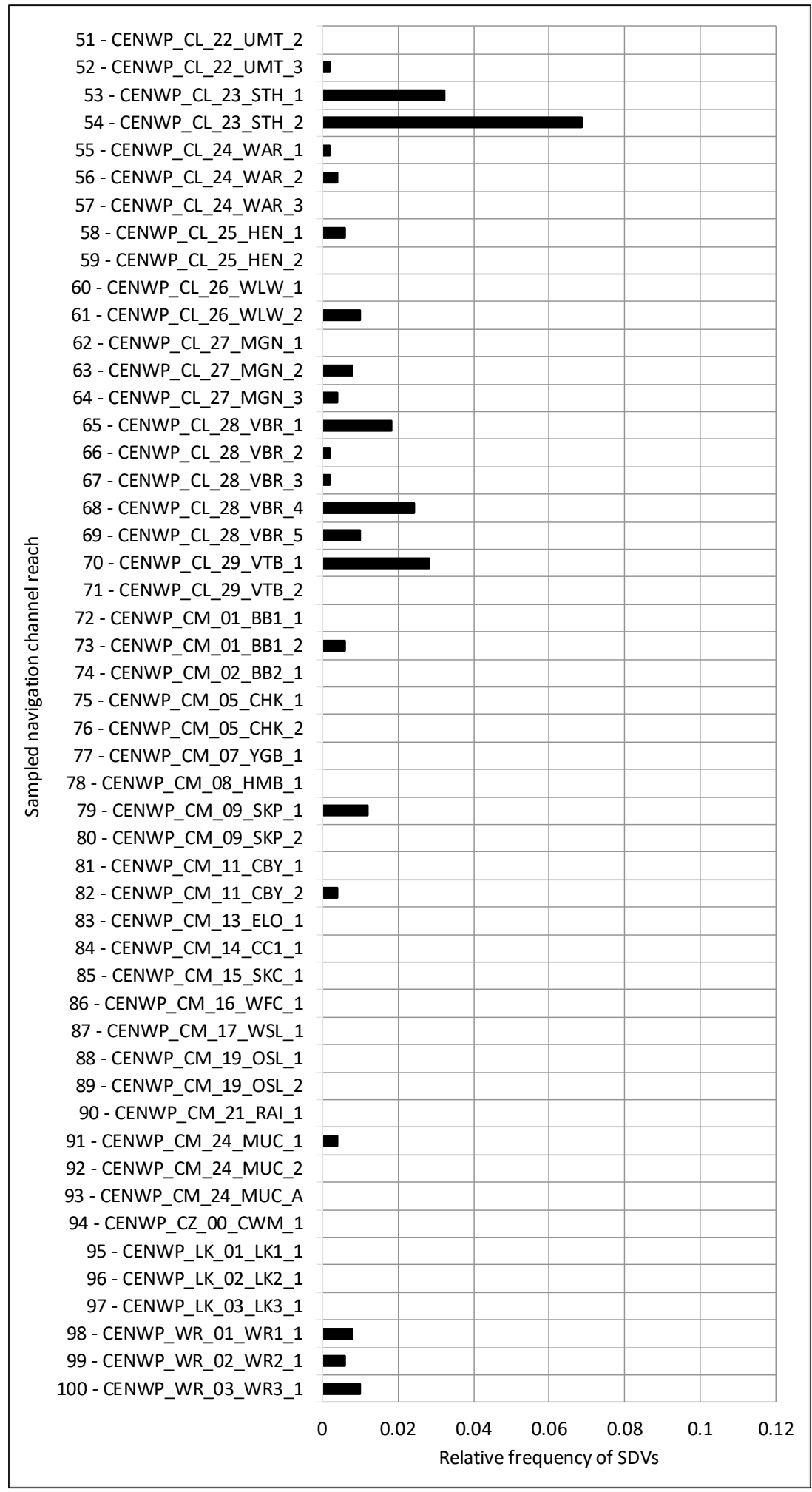




\subsection{Grounding analysis}

Two types of grounding events may be influenced by channel design and maintenance decisions. These include powered grounding on the side of a channel and powered grounding on a shoal in the channel. This analysis of grounding potential in CRC considers each type.

\subsubsection{Powered grounding on the side of the channel}

The distribution of channel side events in CRC is illustrated in Figures 6-14 and 6-15 for vessels with maximum drafts that are greater than $7.5 \mathrm{~m}$ and in transit at speeds greater than 7.5 knots. There are a large number of channel side events throughout the navigation project, suggesting that the natural depth in the Columbia River is sufficient to support deep draft navigation on the outside edge of the navigation channel. At the scale shown, little else can be seen in these figures. Because channel side events are the rule rather than the exception, it is more useful to identify those locations where channel side events do not occur. The absence of channel side events may indicate that pilots are intentionally avoiding certain areas, perhaps because of obstructions, shoaling, or hard edges and bottoms. 
Figure 6-14. Channel side events in Columbia River, Entrance Range to Longview, Washington.

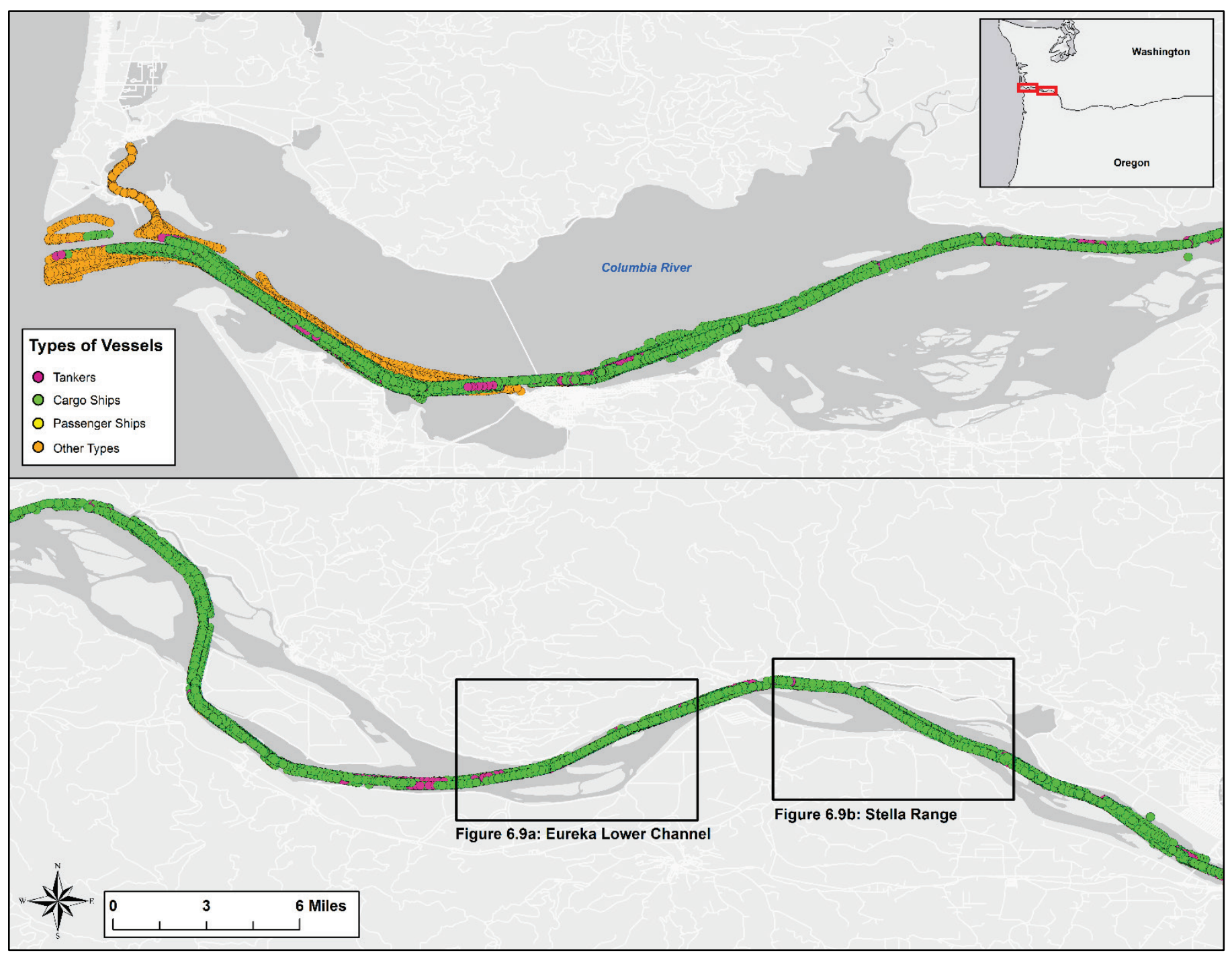


Figure 6-15. Channel side events in Columbia River, Longview, Washington to Interstate 5 bridge.

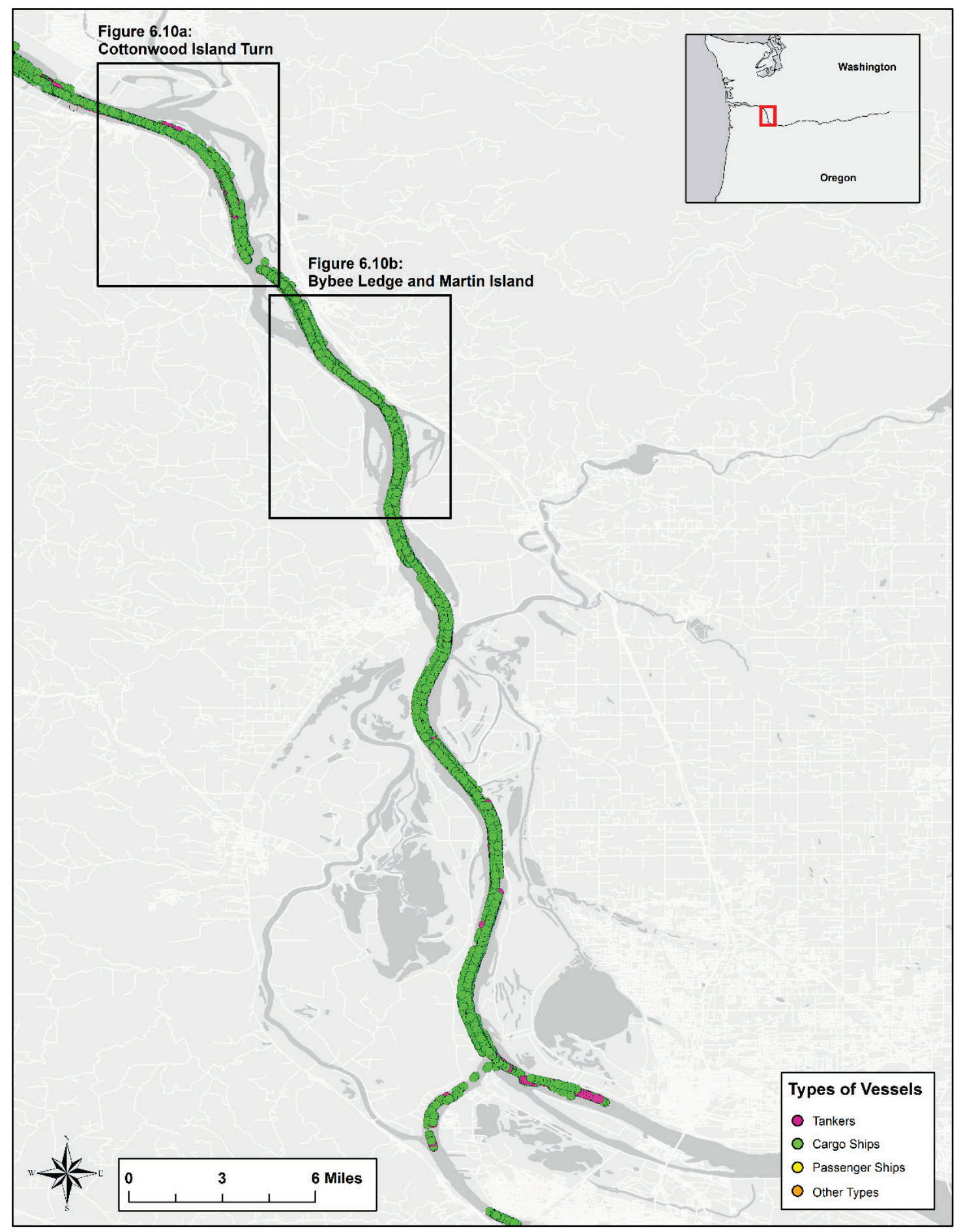


The absence of channel side events from sections of the federal channel is apparent in Figures 6-16 and 6-17. Channel side events are absent from the north side of the Eureka Lower Channel (\# 28) near Copper Island and Eureka Bar, as shown in Figure 6-16(a). In this example, there are five isolated events. Three of these events are attributed to an un-named $181 \mathrm{~m}$ tanker on June 28, and two of these events are attributed to an un-named $176 \mathrm{~m}$ cargo vessel on June 19. It is not possible to determine why these vessels are staying away from the northern boundary of the channel, but the absence of channel side events clearly suggests that a reason exists. Another example can be seen in Stella Range (\#33), which is shown in Figure 6-16(b). There are clearly fewer channel side events on the northern boundary of the channel than on the southern boundary. Although the pattern in this example is not as conspicuous as in Eureka Lower Channel, vessels appear to show a preference for avoiding the northern boundary of the channel.

Two other examples demonstrate that an analysis of channel side events can suggest where additional information about the condition of the channel may be needed. Channel side events are largely absent on the north side of the Cottonwood Island Turn (\#19-20), as shown in Figure 6-17(a). There are also far fewer channel side events on the east side of Willow Range (\#26-27) than the west side, suggesting vessels are avoiding the east side of that channel. However, no particular conclusions can be drawn from the absence of channel side events at these locations. Further investigation is needed to determine whether or not hazards to navigation may be causing this behavior. This can be accomplished, for example, by interviewing pilots or others who are familiar with the system. 
Figure 6-16. Detail map of channel side events showing (a) vessels avoiding the northern edge of Eureka Lower Channel (\#28) and (b) vessels avoiding the northern edge of Stella Range (\#33), between Crims Island and Hump Island.
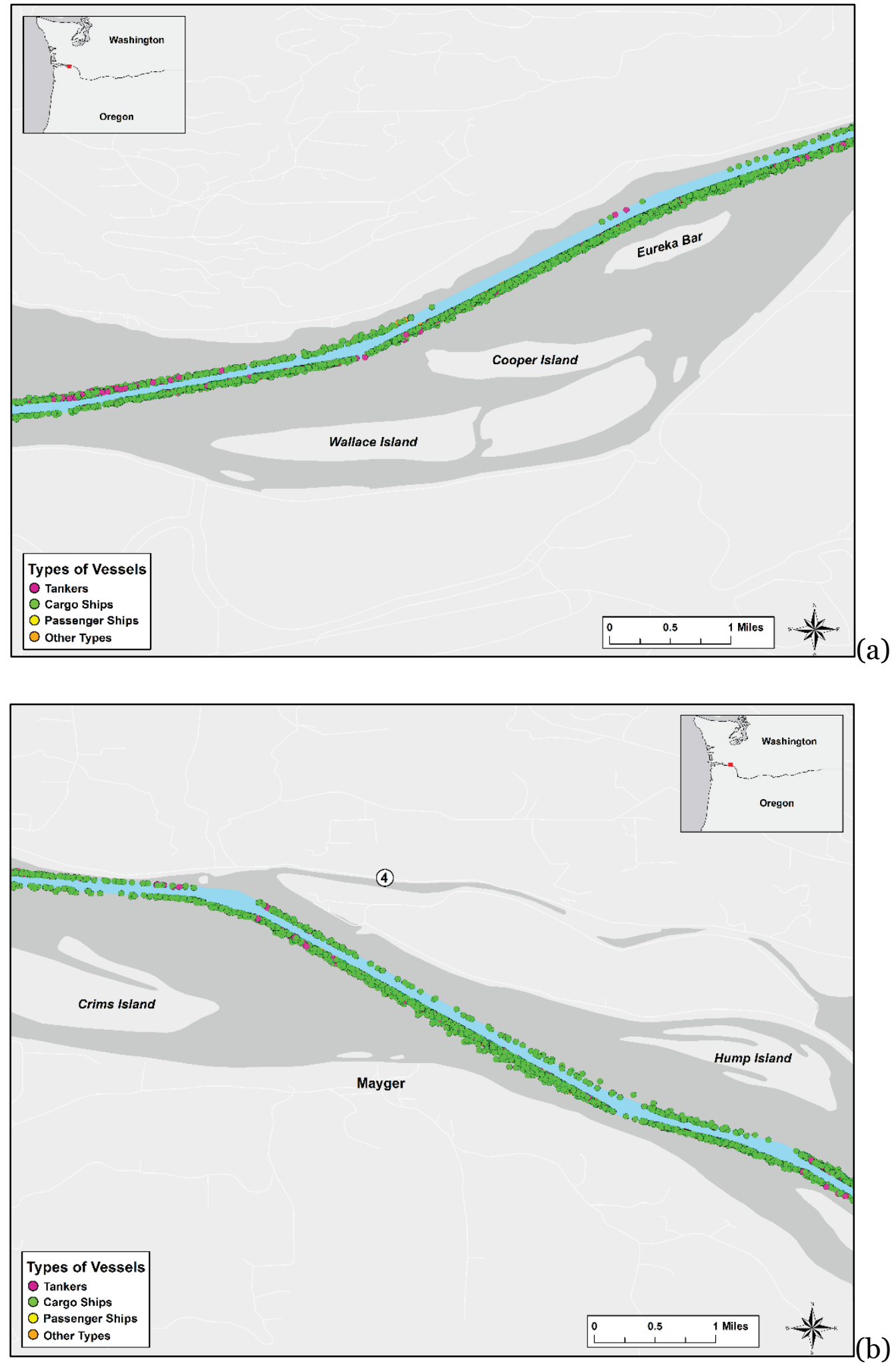
Figure 6-17. Detail map of channel side events showing the lower prevalence of channel side events (a) on the northeast side of Cottonwood Island Turn (\#41-42), and (b) on the east side of Bybee Ledge Channel (\#48) and Martin Island Channel (\#49).

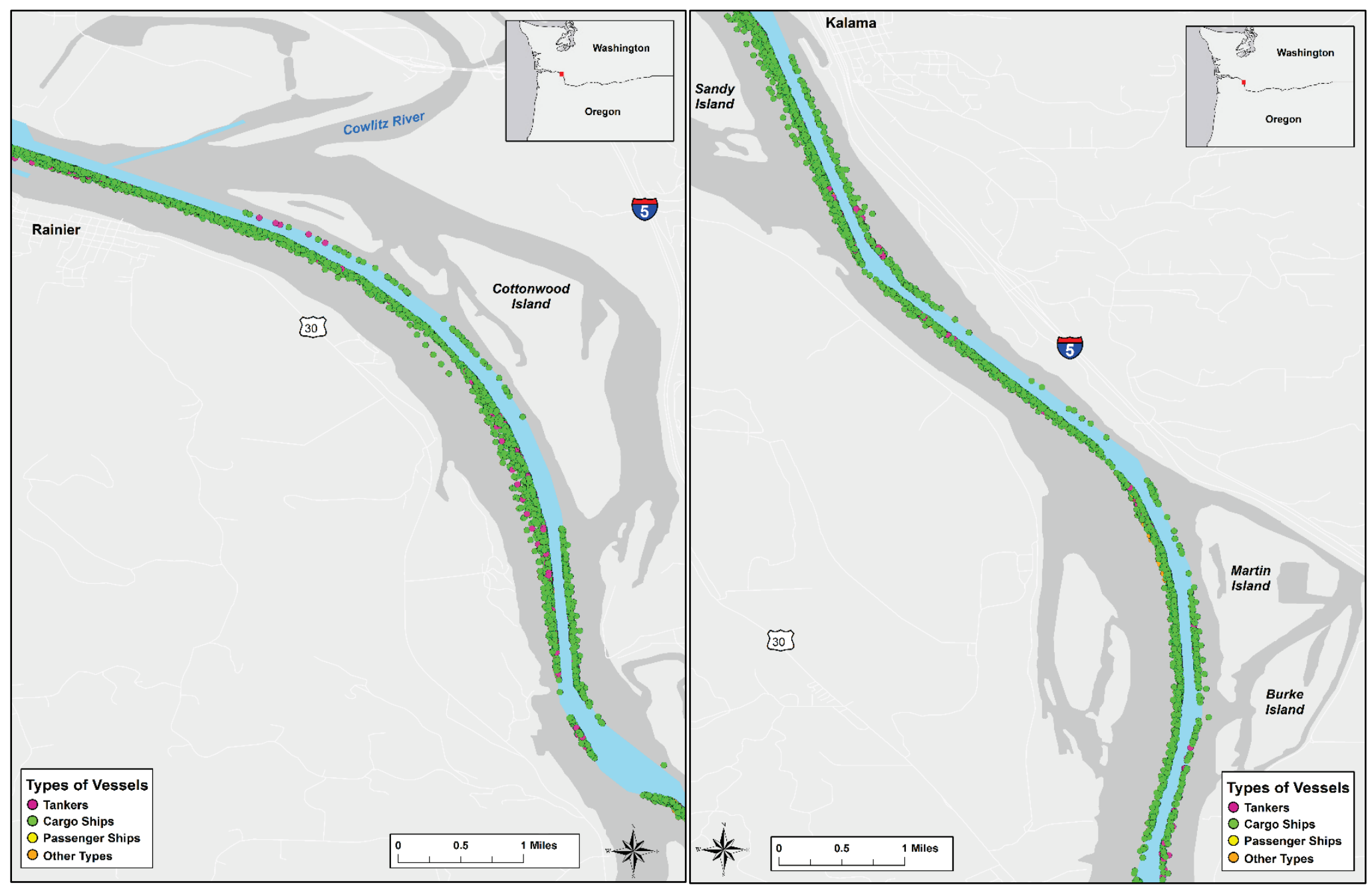

(a)

(b) 


\subsubsection{Powered grounding on a shoal in the channel}

Vessels that are depth limited have maximum drafts that are greater than available depth. The number of depth-limited cargo vessels and tankers is determined by comparing the maximum design draft of each cargo vessel and tanker using a reach to the available depth of the navigation channel. Only cargo vessels and tankers are considered because they represent the majority of vessels that might be depth limited. The number and fraction of cargo vessels (70-79) that are depth limited in CRC reaches that have cargo vessel traffic is reported in Table 6-8. The table shows that, in most navigation reaches, fewer than $2 \%$ of cargo vessels are depth limited at maintenance depth. As available depth is reduced to simulate shoaling between dredging events, the fraction of depth-limited cargo vessels increases to at most $12 \%$. The number and fraction of tankers (80-89) that are depth limited in CRC is summarized in Table 6-9. In $43 \mathrm{ft}$ channels, no tankers are depth limited at maintenance depth. As available depth is reduced to simulate shoaling, approximately $10 \%$ of tankers become depth limited.

\subsection{MISLE database reports}

The USCG MISLE database reports the location of safety and law enforcement incidents in the Columbia River. During the 4-year period 2011 and 2015, there were 7 collisions and 38 grounding events reported in the study area. The location of these events is reported in Figure 6-18. Public information about these events can be found on the USCG Maritime Information Exchange Incident Investigation Reports website (http://cgmix.uscg.mil/IIR/IIRSearch.aspx) using the activity identification numbers provided in the figure. 
Table 6-8. Number and fraction of cargo vessels (70-79) that are depth limited in CRC.

\begin{tabular}{|c|c|c|c|c|c|c|c|c|c|c|}
\hline \multirow{2}{*}{$\#$} & \multirow{2}{*}{ Reach Code } & \multirow{2}{*}{$\begin{array}{c}\text { Main- } \\
\text { tenance } \\
\text { Depth (ft) }\end{array}$} & \multirow{2}{*}{$\begin{array}{l}\text { Number of } \\
\text { Unique } \\
\text { Vessels }\end{array}$} & \multicolumn{7}{|c|}{ Reduction in Maintenance Depth (ft) } \\
\hline & & & & 0 & 1 & 2 & 3 & 4 & 5 & 6 \\
\hline 1 & CENWP_CL_00_MCR_1 & 55 & 827 & $1 / 0.001$ & $1 / 0.001$ & $1 / 0.001$ & $1 / 0.001$ & $1 / 0.001$ & $1 / 0.001$ & $1 / 0.001$ \\
\hline 2 & CENWP_CL_OO_MCR_2 & 48 & 443 & $0 / 0$ & $0 / 0$ & $1 / 0.002$ & $2 / 0.005$ & $3 / 0.007$ & $6 / 0.014$ & $7 / 0.016$ \\
\hline 3 & CENWP_CL_OO_MCR_3 & 55 & 824 & $1 / 0.001$ & $1 / 0.001$ & $1 / 0.001$ & 1/0.001 & $1 / 0.001$ & $1 / 0.001$ & $1 / 0.001$ \\
\hline 4 & CENWP_CL_OO_MCR_4 & 48 & 681 & $0 / 0$ & $0 / 0$ & $1 / 0.001$ & $3 / 0.004$ & $5 / 0.007$ & $8 / 0.012$ & $15 / 0.022$ \\
\hline 5 & CENWP_CL_01_LDS_1 & 43 & 827 & $15 / 0.018$ & $27 / 0.033$ & $42 / 0.051$ & $49 / 0.059$ & $67 / 0.081$ & $81 / 0.098$ & $89 / 0.108$ \\
\hline 6 & CENWP_CL_02_UDS_1 & 43 & 827 & $15 / 0.018$ & $27 / 0.033$ & $42 / 0.051$ & $49 / 0.059$ & $67 / 0.081$ & $81 / 0.098$ & $89 / 0.108$ \\
\hline 7 & CENWP_CL_03_FLV_1 & 43 & 827 & $15 / 0.018$ & $27 / 0.033$ & $42 / 0.051$ & $49 / 0.059$ & $67 / 0.081$ & $81 / 0.098$ & $89 / 0.108$ \\
\hline 8 & CENWP_CL_04_USN_1 & 43 & 820 & $15 / 0.018$ & $27 / 0.033$ & $42 / 0.051$ & 49/0.06 & $67 / 0.082$ & $81 / 0.099$ & $89 / 0.109$ \\
\hline 9 & CENWP_CL_04_USN_2 & 43 & 819 & $15 / 0.018$ & $27 / 0.033$ & $42 / 0.051$ & 49/0.06 & $67 / 0.082$ & $82 / 0.1$ & $90 / 0.11$ \\
\hline 10 & CENWP_CL_05_TNG_1 & 43 & 820 & $15 / 0.018$ & $27 / 0.033$ & $42 / 0.051$ & $49 / 0.06$ & $67 / 0.082$ & $82 / 0.1$ & $90 / 0.11$ \\
\hline 11 & CENWP_CL_05_TNG_2 & 43 & 820 & $15 / 0.018$ & $27 / 0.033$ & $42 / 0.051$ & $49 / 0.06$ & $67 / 0.082$ & $82 / 0.1$ & $90 / 0.11$ \\
\hline 12 & CENWP_CL_06_MLN_1 & 43 & 820 & $15 / 0.018$ & $27 / 0.033$ & $42 / 0.051$ & $49 / 0.06$ & $67 / 0.082$ & $82 / 0.1$ & $90 / 0.11$ \\
\hline 13 & CENWP_CL_06_MLN_2 & 43 & 820 & $15 / 0.018$ & $27 / 0.033$ & $42 / 0.051$ & 49/0.06 & $67 / 0.082$ & $82 / 0.1$ & $90 / 0.11$ \\
\hline 14 & CENWP_CL_06_MLN_3 & 43 & 820 & $15 / 0.018$ & $27 / 0.033$ & $42 / 0.051$ & $49 / 0.06$ & $67 / 0.082$ & $82 / 0.1$ & $90 / 0.11$ \\
\hline 15 & CENWP_CL_07_PIL_1 & 43 & 820 & $15 / 0.018$ & $27 / 0.033$ & $42 / 0.051$ & 49/0.06 & $67 / 0.082$ & $82 / 0.1$ & $90 / 0.11$ \\
\hline 16 & CENWP_CL_07_PIL_2 & 43 & 820 & $15 / 0.018$ & $27 / 0.033$ & $42 / 0.051$ & $49 / 0.06$ & $67 / 0.082$ & $82 / 0.1$ & $90 / 0.11$ \\
\hline 17 & CENWP_CL_08_BKW_1 & 43 & 820 & $15 / 0.018$ & $27 / 0.033$ & $42 / 0.051$ & 49/0.06 & $67 / 0.082$ & $82 / 0.1$ & $90 / 0.11$ \\
\hline 18 & CENWP_CL_08_BKW_2 & 43 & 820 & $15 / 0.018$ & $27 / 0.033$ & $42 / 0.051$ & $49 / 0.06$ & $67 / 0.082$ & $82 / 0.1$ & $90 / 0.11$ \\
\hline 19 & CENWP_CL_09_SKM_1 & 43 & 820 & $15 / 0.018$ & $27 / 0.033$ & $42 / 0.051$ & $49 / 0.06$ & $67 / 0.082$ & $82 / 0.1$ & $90 / 0.11$ \\
\hline 20 & CENWP_CL_09_SKM_2 & 43 & 820 & $15 / 0.018$ & $27 / 0.033$ & $42 / 0.051$ & $49 / 0.06$ & $67 / 0.082$ & $82 / 0.1$ & $90 / 0.11$ \\
\hline 21 & CENWP_CL_10_PGT_1 & 43 & 820 & $15 / 0.018$ & $27 / 0.033$ & $42 / 0.051$ & 49/0.06 & $67 / 0.082$ & $82 / 0.1$ & $90 / 0.11$ \\
\hline 22 & CENWP_CL_10_PGT_2 & 43 & 820 & $15 / 0.018$ & $27 / 0.033$ & $42 / 0.051$ & $49 / 0.06$ & $67 / 0.082$ & $82 / 0.1$ & $90 / 0.11$ \\
\hline 23 & CENWP_CL_11_WAN_1 & 43 & 820 & $15 / 0.018$ & $27 / 0.033$ & $42 / 0.051$ & 49/0.06 & $67 / 0.082$ & $82 / 0.1$ & $90 / 0.11$ \\
\hline
\end{tabular}




\begin{tabular}{|c|c|c|c|c|c|c|c|c|c|c|}
\hline \multirow{2}{*}{$\#$} & \multirow{2}{*}{ Reach Code } & \multirow{2}{*}{$\begin{array}{c}\text { Main- } \\
\text { tenance } \\
\text { Depth (ft) }\end{array}$} & \multirow{2}{*}{$\begin{array}{c}\text { Number of } \\
\text { Unique } \\
\text { Vessels }\end{array}$} & \multicolumn{7}{|c|}{ Reduction in Maintenance Depth (ft) } \\
\hline & & & & 0 & 1 & 2 & 3 & 4 & 5 & 6 \\
\hline 24 & CENWP_CL_11_WAN_2 & 43 & 819 & $15 / 0.018$ & 27/0.033 & $42 / 0.051$ & 49/0.06 & $67 / 0.082$ & $82 / 0.1$ & $90 / 0.11$ \\
\hline 25 & CENWP_CL_12_WST_1 & 43 & 820 & $15 / 0.018$ & $27 / 0.033$ & $42 / 0.051$ & 49/0.06 & $67 / 0.082$ & $82 / 0.1$ & $90 / 0.11$ \\
\hline 26 & CENWP_CL_12_WST_2 & 43 & 820 & $15 / 0.018$ & $27 / 0.033$ & $42 / 0.051$ & $49 / 0.06$ & $67 / 0.082$ & $82 / 0.1$ & $90 / 0.11$ \\
\hline 27 & CENWP_CL_13_EUR_1 & 43 & 820 & $15 / 0.018$ & $27 / 0.033$ & $42 / 0.051$ & $49 / 0.06$ & $67 / 0.082$ & $82 / 0.1$ & $90 / 0.11$ \\
\hline 28 & CENWP_CL_13_EUR_2 & 43 & 820 & $15 / 0.018$ & $27 / 0.033$ & $42 / 0.051$ & 49/0.06 & $67 / 0.082$ & $82 / 0.1$ & $90 / 0.11$ \\
\hline 29 & CENWP_CL_13_EUR_3 & 43 & 819 & $15 / 0.018$ & $27 / 0.033$ & $42 / 0.051$ & 49/0.06 & 67/0.082 & $82 / 0.1$ & $90 / 0.11$ \\
\hline 30 & CENWP_CL_14_GUL_1 & 43 & 820 & $15 / 0.018$ & $27 / 0.033$ & $42 / 0.051$ & $49 / 0.06$ & $67 / 0.082$ & $82 / 0.1$ & $90 / 0.11$ \\
\hline 31 & CENWP_CL_14_GUL_2 & 43 & 820 & $15 / 0.018$ & $27 / 0.033$ & $42 / 0.051$ & $49 / 0.06$ & $67 / 0.082$ & $82 / 0.1$ & $90 / 0.11$ \\
\hline 32 & CENWP_CL_15_STL_1 & 43 & 820 & $15 / 0.018$ & $27 / 0.033$ & $42 / 0.051$ & $49 / 0.06$ & $67 / 0.082$ & $82 / 0.1$ & $90 / 0.11$ \\
\hline 33 & CENWP_CL_15_STL_2 & 43 & 820 & $15 / 0.018$ & $27 / 0.033$ & $42 / 0.051$ & 49/0.06 & $67 / 0.082$ & $82 / 0.1$ & $90 / 0.11$ \\
\hline 34 & CENWP_CL_16_WLK_1 & 43 & 820 & $15 / 0.018$ & $27 / 0.033$ & $42 / 0.051$ & $49 / 0.06$ & $67 / 0.082$ & $82 / 0.1$ & $90 / 0.11$ \\
\hline 35 & CENWP_CL_16_WLK_2 & 43 & 820 & $15 / 0.018$ & $27 / 0.033$ & $42 / 0.051$ & $49 / 0.06$ & $67 / 0.082$ & $82 / 0.1$ & $90 / 0.11$ \\
\hline 36 & CENWP_CL_16_WLK_3 & 43 & 820 & $15 / 0.018$ & $27 / 0.033$ & $42 / 0.051$ & $49 / 0.06$ & $67 / 0.082$ & $82 / 0.1$ & $90 / 0.11$ \\
\hline 37 & CENWP_CL_17_SLG_1 & 43 & 819 & $15 / 0.018$ & $27 / 0.033$ & $42 / 0.051$ & 49/0.06 & 67/0.082 & $82 / 0.1$ & $90 / 0.11$ \\
\hline 38 & CENWP_CL_17_SLG_2 & 43 & 817 & $15 / 0.018$ & $27 / 0.033$ & $42 / 0.051$ & $49 / 0.06$ & $67 / 0.082$ & $82 / 0.1$ & $90 / 0.11$ \\
\hline 39 & CENWP_CL_17_SLG_3 & 40 & 176 & 6/0.034 & $10 / 0.057$ & $14 / 0.08$ & $15 / 0.085$ & 18/0.102 & $20 / 0.114$ & $27 / 0.153$ \\
\hline 40 & CENWP_CL_18_LDB_1 & 43 & 731 & $14 / 0.019$ & $25 / 0.034$ & $40 / 0.055$ & $47 / 0.064$ & $64 / 0.088$ & $76 / 0.104$ & $84 / 0.115$ \\
\hline 41 & CENWP_CL_18_LDB_2 & 43 & 715 & $14 / 0.02$ & 25/0.035 & $40 / 0.056$ & $47 / 0.066$ & $64 / 0.09$ & $76 / 0.106$ & $84 / 0.117$ \\
\hline 42 & CENWP_CL_19_UDB_1 & 43 & 715 & $14 / 0.02$ & $25 / 0.035$ & $40 / 0.056$ & $47 / 0.066$ & 64/0.09 & $76 / 0.106$ & $84 / 0.117$ \\
\hline 43 & CENWP_CL_19_UDB_2 & 43 & 713 & $14 / 0.02$ & $25 / 0.035$ & $40 / 0.056$ & $47 / 0.066$ & $64 / 0.09$ & $75 / 0.105$ & $83 / 0.116$ \\
\hline 44 & CENWP_CL_20_KLM_1 & 43 & 700 & $13 / 0.019$ & 23/0.033 & $38 / 0.054$ & $45 / 0.064$ & 62/0.089 & $72 / 0.103$ & $80 / 0.114$ \\
\hline 45 & CENWP_CL_2O_KLM_2 & 43 & 700 & $13 / 0.019$ & $23 / 0.033$ & $38 / 0.054$ & $45 / 0.064$ & $62 / 0.089$ & $72 / 0.103$ & $80 / 0.114$ \\
\hline 46 & CENWP_CL_20_KLM_3 & 43 & 629 & $9 / 0.014$ & $15 / 0.024$ & $29 / 0.046$ & $35 / 0.056$ & $48 / 0.076$ & $56 / 0.089$ & $64 / 0.102$ \\
\hline 47 & CENWP_CL_21_LMT_1 & 43 & 629 & $9 / 0.014$ & $15 / 0.024$ & 29/0.046 & $35 / 0.056$ & $48 / 0.076$ & $56 / 0.089$ & $64 / 0.102$ \\
\hline
\end{tabular}




\begin{tabular}{|c|c|c|c|c|c|c|c|c|c|c|}
\hline \multirow{2}{*}{$\#$} & \multirow{2}{*}{ Reach Code } & \multirow{2}{*}{$\begin{array}{c}\text { Main- } \\
\text { tenance } \\
\text { Depth (ft) }\end{array}$} & \multirow{2}{*}{$\begin{array}{c}\text { Number of } \\
\text { Unique } \\
\text { Vessels }\end{array}$} & \multicolumn{7}{|c|}{ Reduction in Maintenance Depth (ft) } \\
\hline & & & & 0 & 1 & 2 & 3 & 4 & 5 & 6 \\
\hline 48 & CENWP_CL_21_LMT_2 & 43 & 615 & $9 / 0.015$ & $15 / 0.024$ & $29 / 0.047$ & $35 / 0.057$ & 48/0.078 & $56 / 0.091$ & $64 / 0.104$ \\
\hline 49 & CENWP_CL_21_LMT_3 & 43 & 581 & $7 / 0.012$ & $12 / 0.021$ & $25 / 0.043$ & $31 / 0.053$ & $44 / 0.076$ & $52 / 0.09$ & $59 / 0.102$ \\
\hline 50 & CENWP_CL_22_UMT_1 & 43 & 581 & $7 / 0.012$ & $12 / 0.021$ & $25 / 0.043$ & $31 / 0.053$ & $44 / 0.076$ & $52 / 0.09$ & $59 / 0.102$ \\
\hline 51 & CENWP_CL_22_UMT_2 & 43 & 580 & $7 / 0.012$ & $12 / 0.021$ & $25 / 0.043$ & $31 / 0.053$ & $44 / 0.076$ & $52 / 0.09$ & $59 / 0.102$ \\
\hline 52 & CENWP_CL_22_UMT_3 & 43 & 580 & $7 / 0.012$ & $12 / 0.021$ & $25 / 0.043$ & $31 / 0.053$ & $44 / 0.076$ & $52 / 0.09$ & $59 / 0.102$ \\
\hline 53 & CENWP_CL_23_STH_1 & 43 & 580 & $7 / 0.012$ & $12 / 0.021$ & $25 / 0.043$ & $31 / 0.053$ & 44/0.076 & $52 / 0.09$ & $59 / 0.102$ \\
\hline 54 & CENWP_CL_23_STH_2 & 43 & 580 & 7/0.012 & $12 / 0.021$ & $25 / 0.043$ & $31 / 0.053$ & 44/0.076 & $52 / 0.09$ & $59 / 0.102$ \\
\hline 55 & CENWP_CL_24_WAR_1 & 43 & 580 & $7 / 0.012$ & $12 / 0.021$ & $25 / 0.043$ & $31 / 0.053$ & $44 / 0.076$ & $52 / 0.09$ & $59 / 0.102$ \\
\hline 56 & CENWP_CL_24_WAR_2 & 43 & 580 & $7 / 0.012$ & $12 / 0.021$ & $25 / 0.043$ & $31 / 0.053$ & 44/0.076 & $52 / 0.09$ & $59 / 0.102$ \\
\hline 57 & CENWP_CL_24_WAR_3 & 43 & 580 & $7 / 0.012$ & $12 / 0.021$ & $25 / 0.043$ & $31 / 0.053$ & $44 / 0.076$ & $52 / 0.09$ & $59 / 0.102$ \\
\hline 58 & CENWP_CL_25_HEN_1 & 43 & 580 & $7 / 0.012$ & $12 / 0.021$ & $25 / 0.043$ & $31 / 0.053$ & $44 / 0.076$ & $52 / 0.09$ & $59 / 0.102$ \\
\hline 59 & CENWP_CL_25_HEN_2 & 43 & 580 & $7 / 0.012$ & $12 / 0.021$ & $25 / 0.043$ & $31 / 0.053$ & 44/0.076 & $52 / 0.09$ & $59 / 0.102$ \\
\hline 60 & CENWP_CL_26_WLW_1 & 43 & 580 & $7 / 0.012$ & $12 / 0.021$ & $25 / 0.043$ & $31 / 0.053$ & $44 / 0.076$ & $52 / 0.09$ & $59 / 0.102$ \\
\hline 61 & CENWP_CL_26_WLW_2 & 43 & 580 & $7 / 0.012$ & $12 / 0.021$ & $25 / 0.043$ & $31 / 0.053$ & 44/0.076 & $52 / 0.09$ & $59 / 0.102$ \\
\hline 62 & CENWP_CL_27_MGN_1 & 43 & 580 & $7 / 0.012$ & $12 / 0.021$ & $25 / 0.043$ & $31 / 0.053$ & $44 / 0.076$ & $52 / 0.09$ & $59 / 0.102$ \\
\hline 63 & CENWP_CL_27_MGN_2 & 43 & 578 & $7 / 0.012$ & $12 / 0.021$ & $25 / 0.043$ & $31 / 0.054$ & $44 / 0.076$ & $52 / 0.09$ & $59 / 0.102$ \\
\hline 64 & CENWP_CL_27_MGN_3 & 43 & 578 & $7 / 0.012$ & $12 / 0.021$ & $25 / 0.043$ & $31 / 0.054$ & $44 / 0.076$ & $52 / 0.09$ & $59 / 0.102$ \\
\hline 65 & CENWP_CL_28_VBR_1 & 43 & 555 & 6/0.011 & $11 / 0.02$ & $21 / 0.038$ & $27 / 0.049$ & $40 / 0.072$ & $48 / 0.086$ & $55 / 0.099$ \\
\hline 66 & CENWP_CL_28_VBR_2 & 43 & 314 & $2 / 0.006$ & 6/0.019 & $12 / 0.038$ & $17 / 0.054$ & $26 / 0.083$ & $30 / 0.096$ & $35 / 0.111$ \\
\hline 67 & CENWP_CL_28_VBR_3 & 43 & 248 & $1 / 0.004$ & $4 / 0.016$ & $9 / 0.036$ & $13 / 0.052$ & $18 / 0.073$ & $21 / 0.085$ & 26/0.105 \\
\hline 68 & CENWP_CL_28_VBR_4 & 43 & 100 & $2 / 0.02$ & $5 / 0.05$ & $8 / 0.08$ & $10 / 0.1$ & $14 / 0.14$ & $15 / 0.15$ & $15 / 0.15$ \\
\hline 69 & CENWP_CL_28_VBR_5 & 25 & 39 & $19 / 0.487$ & $22 / 0.564$ & $26 / 0.667$ & $31 / 0.795$ & $39 / 1$ & $39 / 1$ & $39 / 1$ \\
\hline 70 & CENWP_CL_29_VTB_1 & 43 & 152 & $1 / 0.007$ & $4 / 0.026$ & $8 / 0.053$ & $12 / 0.079$ & $17 / 0.112$ & $19 / 0.125$ & $22 / 0.145$ \\
\hline 79 & CENWP_CM_09_SKP_1 & 16 & 80 & $80 / 1$ & $80 / 1$ & $80 / 1$ & $80 / 1$ & $80 / 1$ & $80 / 1$ & $80 / 1$ \\
\hline
\end{tabular}




\begin{tabular}{|c|c|c|c|c|c|c|c|c|c|c|}
\hline \multirow{2}{*}{$\#$} & \multirow{2}{*}{ Reach Code } & \multirow{2}{*}{$\begin{array}{c}\text { Main- } \\
\text { tenance } \\
\text { Depth (ft) }\end{array}$} & \multirow{2}{*}{$\begin{array}{c}\text { Number of } \\
\text { Unique } \\
\text { Vessels }\end{array}$} & \multicolumn{7}{|c|}{ Reduction in Maintenance Depth (ft) } \\
\hline & & & & 0 & 1 & 2 & 3 & 4 & 5 & 6 \\
\hline 81 & CENWP_CM_11_CBY_1 & 34 & 130 & $18 / 0.138$ & $20 / 0.154$ & $24 / 0.185$ & $27 / 0.208$ & $39 / 0.3$ & $46 / 0.354$ & $47 / 0.362$ \\
\hline 84 & CENWP_CM_14_CC1_1 & 10 & 2 & $2 / 1$ & $2 / 1$ & $2 / 1$ & $2 / 1$ & $2 / 1$ & $2 / 1$ & $2 / 1$ \\
\hline 86 & CENWP_CM_16_WFC_1 & 9 & 2 & $2 / 1$ & $2 / 1$ & $2 / 1$ & $2 / 1$ & $2 / 1$ & $2 / 1$ & $2 / 1$ \\
\hline 87 & CENWP_CM_17_WSL_1 & 28 & 1 & 0/0 & $0 / 0$ & $0 / 0$ & 0/0 & $0 / 0$ & $0 / 0$ & $1 / 1$ \\
\hline 88 & CENWP_CM_19_OSL_1 & 43 & 47 & $1 / 0.021$ & $2 / 0.043$ & $3 / 0.064$ & $4 / 0.085$ & $4 / 0.085$ & $4 / 0.085$ & $5 / 0.106$ \\
\hline 90 & CENWP_CM_21_RAI_1 & 24 & 7 & $6 / 0.857$ & $6 / 0.857$ & $7 / 1$ & $7 / 1$ & $7 / 1$ & $7 / 1$ & $7 / 1$ \\
\hline 91 & CENWP_CM_24_MUC_1 & 25 & 1 & $0 / 0$ & $1 / 1$ & $1 / 1$ & $1 / 1$ & $1 / 1$ & $1 / 1$ & $1 / 1$ \\
\hline 94 & CENWP_CZ_00_CWM_1 & 8 & 1 & $1 / 1$ & $1 / 1$ & $1 / 1$ & $1 / 1$ & $1 / 1$ & $1 / 1$ & $1 / 1$ \\
\hline 98 & CENWP_WR_01_WR1_1 & 40 & 268 & $8 / 0.03$ & $15 / 0.056$ & $19 / 0.071$ & $20 / 0.075$ & $22 / 0.082$ & $26 / 0.097$ & $33 / 0.123$ \\
\hline 99 & CENWP_WR_02_WR2_1 & 40 & 169 & $5 / 0.03$ & $9 / 0.053$ & $9 / 0.053$ & $10 / 0.059$ & $11 / 0.065$ & $14 / 0.083$ & $20 / 0.118$ \\
\hline 100 & CENWP_WR_03_WR3_1 & 40 & 93 & $1 / 0.011$ & 3/0.032 & 3/0.032 & $4 / 0.043$ & 4/0.043 & $6 / 0.065$ & $10 / 0.108$ \\
\hline
\end{tabular}


Table 6-9. Number and fraction of tankers (80-89) that are depth limited in CRC.

\begin{tabular}{|c|c|c|c|c|c|c|c|c|c|c|}
\hline \multirow{2}{*}{$\#$} & \multirow{2}{*}{ Reach Code } & \multirow{2}{*}{$\begin{array}{c}\text { Main- } \\
\text { tenance } \\
\text { Depth (ft) }\end{array}$} & \multirow{2}{*}{$\begin{array}{l}\text { Number of } \\
\text { Unique } \\
\text { Vessels }\end{array}$} & \multicolumn{7}{|c|}{ Reduction in Maintenance Depth (ft) } \\
\hline & & & & 0 & 1 & 2 & 3 & 4 & 5 & 6 \\
\hline 1 & CENWP_CL_00_MCR_1 & 55 & 54 & $0 / 0$ & $0 / 0$ & $0 / 0$ & $0 / 0$ & $0 / 0$ & $0 / 0$ & $0 / 0$ \\
\hline 2 & CENWP_CL_00_MCR_2 & 48 & 32 & $0 / 0$ & $0 / 0$ & $0 / 0$ & $0 / 0$ & $0 / 0$ & $0 / 0$ & $0 / 0$ \\
\hline 3 & CENWP_CL_00_MCR_3 & 55 & 54 & $0 / 0$ & $0 / 0$ & $0 / 0$ & $0 / 0$ & $0 / 0$ & $0 / 0$ & $0 / 0$ \\
\hline 4 & CENWP_CL_00_MCR_4 & 48 & 42 & $0 / 0$ & $0 / 0$ & $0 / 0$ & $0 / 0$ & $0 / 0$ & $0 / 0$ & $0 / 0$ \\
\hline 5 & CENWP_CL_01_LDS_1 & 43 & 54 & 0/0 & $0 / 0$ & $2 / 0.037$ & $2 / 0.037$ & $2 / 0.037$ & $4 / 0.074$ & $5 / 0.093$ \\
\hline 6 & CENWP_CL_02_UDS_1 & 43 & 54 & 0/0 & $0 / 0$ & $2 / 0.037$ & $2 / 0.037$ & $2 / 0.037$ & $4 / 0.074$ & $5 / 0.093$ \\
\hline 7 & CENWP_CL_03_FLV_1 & 43 & 54 & 0/0 & $0 / 0$ & $2 / 0.037$ & $2 / 0.037$ & $2 / 0.037$ & $4 / 0.074$ & $5 / 0.093$ \\
\hline 8 & CENWP_CL_04_USN_1 & 43 & 54 & 0/0 & 0/0 & $2 / 0.037$ & $2 / 0.037$ & $2 / 0.037$ & $4 / 0.074$ & $5 / 0.093$ \\
\hline 9 & CENWP_CL_04_USN_2 & 43 & 54 & $0 / 0$ & $0 / 0$ & $2 / 0.037$ & $2 / 0.037$ & $2 / 0.037$ & $4 / 0.074$ & $5 / 0.093$ \\
\hline 10 & CENWP_CL_05_TNG_1 & 43 & 54 & $0 / 0$ & $0 / 0$ & $2 / 0.037$ & $2 / 0.037$ & $2 / 0.037$ & $4 / 0.074$ & $5 / 0.093$ \\
\hline 11 & CENWP_CL_05_TNG_2 & 43 & 54 & 0/0 & $0 / 0$ & $2 / 0.037$ & $2 / 0.037$ & $2 / 0.037$ & $4 / 0.074$ & $5 / 0.093$ \\
\hline 12 & CENWP_CL_06_MLN_1 & 43 & 54 & 0/0 & 0/0 & $2 / 0.037$ & $2 / 0.037$ & $2 / 0.037$ & $4 / 0.074$ & $5 / 0.093$ \\
\hline 13 & CENWP_CL_06_MLN_2 & 43 & 54 & 0/0 & 0/0 & $2 / 0.037$ & $2 / 0.037$ & $2 / 0.037$ & $4 / 0.074$ & $5 / 0.093$ \\
\hline 14 & CENWP_CL_06_MLN_3 & 43 & 54 & $0 / 0$ & $0 / 0$ & $2 / 0.037$ & $2 / 0.037$ & $2 / 0.037$ & $4 / 0.074$ & $5 / 0.093$ \\
\hline 15 & CENWP_CL_07_PIL_1 & 43 & 54 & 0/0 & $0 / 0$ & $2 / 0.037$ & $2 / 0.037$ & $2 / 0.037$ & $4 / 0.074$ & $5 / 0.093$ \\
\hline 16 & CENWP_CL_07_PIL_2 & 43 & 54 & 0/0 & $0 / 0$ & $2 / 0.037$ & $2 / 0.037$ & $2 / 0.037$ & $4 / 0.074$ & $5 / 0.093$ \\
\hline 17 & CENWP_CL_08_BKW_1 & 43 & 54 & 0/0 & $0 / 0$ & $2 / 0.037$ & $2 / 0.037$ & $2 / 0.037$ & $4 / 0.074$ & $5 / 0.093$ \\
\hline 18 & CENWP_CL_08_BKW_2 & 43 & 54 & $0 / 0$ & $0 / 0$ & $2 / 0.037$ & $2 / 0.037$ & $2 / 0.037$ & $4 / 0.074$ & $5 / 0.093$ \\
\hline 19 & CENWP_CL_09_SKM_1 & 43 & 54 & $0 / 0$ & $0 / 0$ & $2 / 0.037$ & $2 / 0.037$ & $2 / 0.037$ & $4 / 0.074$ & $5 / 0.093$ \\
\hline 20 & CENWP_CL_09_SKM_2 & 43 & 54 & 0/0 & $0 / 0$ & $2 / 0.037$ & $2 / 0.037$ & $2 / 0.037$ & $4 / 0.074$ & $5 / 0.093$ \\
\hline 21 & CENWP_CL_10_PGT_1 & 43 & 54 & $0 / 0$ & $0 / 0$ & $2 / 0.037$ & $2 / 0.037$ & $2 / 0.037$ & $4 / 0.074$ & $5 / 0.093$ \\
\hline 22 & CENWP_CL_10_PGT_2 & 43 & 54 & $0 / 0$ & $0 / 0$ & $2 / 0.037$ & $2 / 0.037$ & $2 / 0.037$ & $4 / 0.074$ & $5 / 0.093$ \\
\hline 23 & CENWP_CL_11_WAN_1 & 43 & 54 & $0 / 0$ & $0 / 0$ & $2 / 0.037$ & $2 / 0.037$ & 2/0.037 & 4/0.074 & $5 / 0.093$ \\
\hline
\end{tabular}




\begin{tabular}{|c|c|c|c|c|c|c|c|c|c|c|}
\hline \multirow{2}{*}{$\#$} & \multirow{2}{*}{ Reach Code } & \multirow{2}{*}{$\begin{array}{c}\text { Main- } \\
\text { tenance } \\
\text { Depth (ft) }\end{array}$} & \multirow{2}{*}{$\begin{array}{c}\text { Number of } \\
\text { Unique } \\
\text { Vessels }\end{array}$} & \multicolumn{7}{|c|}{ Reduction in Maintenance Depth (ft) } \\
\hline & & & & 0 & 1 & 2 & 3 & 4 & 5 & 6 \\
\hline 24 & CENWP_CL_11_WAN_2 & 43 & 54 & $0 / 0$ & $0 / 0$ & $2 / 0.037$ & $2 / 0.037$ & $2 / 0.037$ & 4/0.074 & $5 / 0.093$ \\
\hline 25 & CENWP_CL_12_WST_1 & 43 & 54 & $0 / 0$ & $0 / 0$ & $2 / 0.037$ & $2 / 0.037$ & $2 / 0.037$ & $4 / 0.074$ & $5 / 0.093$ \\
\hline 26 & CENWP_CL_12_WST_2 & 43 & 54 & 0/0 & $0 / 0$ & $2 / 0.037$ & $2 / 0.037$ & $2 / 0.037$ & $4 / 0.074$ & $5 / 0.093$ \\
\hline 27 & CENWP_CL_13_EUR_1 & 43 & 54 & $0 / 0$ & $0 / 0$ & $2 / 0.037$ & $2 / 0.037$ & $2 / 0.037$ & $4 / 0.074$ & $5 / 0.093$ \\
\hline 28 & CENWP_CL_13_EUR_2 & 43 & 54 & 0/0 & 0/0 & $2 / 0.037$ & $2 / 0.037$ & $2 / 0.037$ & $4 / 0.074$ & $5 / 0.093$ \\
\hline 29 & CENWP_CL_13_EUR_3 & 43 & 54 & $0 / 0$ & $0 / 0$ & $2 / 0.037$ & $2 / 0.037$ & $2 / 0.037$ & $4 / 0.074$ & $5 / 0.093$ \\
\hline 30 & CENWP_CL_14_GUL_1 & 43 & 54 & $0 / 0$ & $0 / 0$ & $2 / 0.037$ & $2 / 0.037$ & $2 / 0.037$ & 4/0.074 & $5 / 0.093$ \\
\hline 31 & CENWP_CL_14_GUL_2 & 43 & 54 & 0/0 & $0 / 0$ & $2 / 0.037$ & $2 / 0.037$ & $2 / 0.037$ & $4 / 0.074$ & $5 / 0.093$ \\
\hline 32 & CENWP_CL_15_STL_1 & 43 & 54 & 0/0 & 0/0 & $2 / 0.037$ & $2 / 0.037$ & $2 / 0.037$ & $4 / 0.074$ & $5 / 0.093$ \\
\hline 33 & CENWP_CL_15_STL_2 & 43 & 54 & 0/0 & $0 / 0$ & $2 / 0.037$ & $2 / 0.037$ & $2 / 0.037$ & $4 / 0.074$ & $5 / 0.093$ \\
\hline 34 & CENWP_CL_16_WLK_1 & 43 & 54 & $0 / 0$ & $0 / 0$ & $2 / 0.037$ & $2 / 0.037$ & $2 / 0.037$ & $4 / 0.074$ & $5 / 0.093$ \\
\hline 35 & CENWP_CL_16_WLK_2 & 43 & 54 & $0 / 0$ & 0/0 & $2 / 0.037$ & $2 / 0.037$ & $2 / 0.037$ & $4 / 0.074$ & $5 / 0.093$ \\
\hline 36 & CENWP_CL_16_WLK_3 & 43 & 54 & 0/0 & $0 / 0$ & $2 / 0.037$ & $2 / 0.037$ & $2 / 0.037$ & $4 / 0.074$ & $5 / 0.093$ \\
\hline 37 & CENWP_CL_17_SLG_1 & 43 & 54 & 0/0 & 0/0 & $2 / 0.037$ & $2 / 0.037$ & $2 / 0.037$ & $4 / 0.074$ & $5 / 0.093$ \\
\hline 38 & CENWP_CL_17_SLG_2 & 43 & 53 & 0/0 & $0 / 0$ & $2 / 0.038$ & $2 / 0.038$ & $2 / 0.038$ & 4/0.075 & $5 / 0.094$ \\
\hline 40 & CENWP_CL_18_LDB_1 & 43 & 53 & 0/0 & $0 / 0$ & $2 / 0.038$ & $2 / 0.038$ & $2 / 0.038$ & $4 / 0.075$ & $5 / 0.094$ \\
\hline 41 & CENWP_CL_18_LDB_2 & 43 & 53 & $0 / 0$ & 0/0 & $2 / 0.038$ & $2 / 0.038$ & $2 / 0.038$ & $4 / 0.075$ & $5 / 0.094$ \\
\hline 42 & CENWP_CL_19_UDB_1 & 43 & 53 & 0/0 & $0 / 0$ & $2 / 0.038$ & $2 / 0.038$ & $2 / 0.038$ & $4 / 0.075$ & $5 / 0.094$ \\
\hline 43 & CENWP_CL_19_UDB_2 & 43 & 53 & 0/0 & $0 / 0$ & $2 / 0.038$ & $2 / 0.038$ & $2 / 0.038$ & $4 / 0.075$ & $5 / 0.094$ \\
\hline 44 & CENWP_CL_20_KLM_1 & 43 & 53 & $0 / 0$ & $0 / 0$ & $2 / 0.038$ & $2 / 0.038$ & $2 / 0.038$ & $4 / 0.075$ & $5 / 0.094$ \\
\hline 45 & CENWP_CL_2O_KLM_2 & 43 & 53 & 0/0 & $0 / 0$ & $2 / 0.038$ & $2 / 0.038$ & $2 / 0.038$ & 4/0.075 & $5 / 0.094$ \\
\hline 46 & CENWP_CL_20_KLM_3 & 43 & 49 & 0/0 & $0 / 0$ & $2 / 0.041$ & $2 / 0.041$ & $2 / 0.041$ & $4 / 0.082$ & $5 / 0.102$ \\
\hline 47 & CENWP_CL_21_LMT_1 & 43 & 49 & 0/0 & $0 / 0$ & 2/0.041 & $2 / 0.041$ & $2 / 0.041$ & $4 / 0.082$ & $5 / 0.102$ \\
\hline 48 & CENWP_CL_21_LMT_2 & 43 & 49 & $0 / 0$ & $0 / 0$ & 2/0.041 & $2 / 0.041$ & 2/0.041 & 4/0.082 & $5 / 0.102$ \\
\hline
\end{tabular}




\begin{tabular}{|c|c|c|c|c|c|c|c|c|c|c|}
\hline \multirow{2}{*}{$\#$} & \multirow{2}{*}{ Reach Code } & \multirow{2}{*}{$\begin{array}{c}\text { Main- } \\
\text { tenance } \\
\text { Depth (ft) }\end{array}$} & \multirow{2}{*}{$\begin{array}{c}\text { Number of } \\
\text { Unique } \\
\text { Vessels }\end{array}$} & \multicolumn{7}{|c|}{ Reduction in Maintenance Depth (ft) } \\
\hline & & & & 0 & 1 & 2 & 3 & 4 & 5 & 6 \\
\hline 49 & CENWP_CL_21_LMT_3 & 43 & 49 & $0 / 0$ & $0 / 0$ & $2 / 0.041$ & $2 / 0.041$ & $2 / 0.041$ & 4/0.082 & $5 / 0.102$ \\
\hline 50 & CENWP_CL_22_UMT_1 & 43 & 49 & $0 / 0$ & $0 / 0$ & $2 / 0.041$ & $2 / 0.041$ & $2 / 0.041$ & $4 / 0.082$ & $5 / 0.102$ \\
\hline 51 & CENWP_CL_22_UMT_2 & 43 & 49 & 0/0 & $0 / 0$ & $2 / 0.041$ & $2 / 0.041$ & $2 / 0.041$ & 4/0.082 & $5 / 0.102$ \\
\hline 52 & CENWP_CL_22_UMT_3 & 43 & 49 & 0/0 & $0 / 0$ & $2 / 0.041$ & $2 / 0.041$ & $2 / 0.041$ & 4/0.082 & $5 / 0.102$ \\
\hline 53 & CENWP_CL_23_STH_1 & 43 & 49 & 0/0 & 0/0 & $2 / 0.041$ & $2 / 0.041$ & $2 / 0.041$ & $4 / 0.082$ & $5 / 0.102$ \\
\hline 54 & CENWP_CL_23_STH_2 & 43 & 49 & 0/0 & $0 / 0$ & $2 / 0.041$ & $2 / 0.041$ & $2 / 0.041$ & 4/0.082 & $5 / 0.102$ \\
\hline 55 & CENWP_CL_24_WAR_1 & 43 & 49 & 0/0 & $0 / 0$ & $2 / 0.041$ & $2 / 0.041$ & $2 / 0.041$ & 4/0.082 & $5 / 0.102$ \\
\hline 56 & CENWP_CL_24_WAR_2 & 43 & 49 & 0/0 & $0 / 0$ & 2/0.041 & $2 / 0.041$ & $2 / 0.041$ & 4/0.082 & $5 / 0.102$ \\
\hline 57 & CENWP_CL_24_WAR_3 & 43 & 49 & 0/0 & $0 / 0$ & $2 / 0.041$ & $2 / 0.041$ & $2 / 0.041$ & 4/0.082 & $5 / 0.102$ \\
\hline 58 & CENWP_CL_25_HEN_1 & 43 & 49 & 0/0 & $0 / 0$ & $2 / 0.041$ & $2 / 0.041$ & $2 / 0.041$ & $4 / 0.082$ & $5 / 0.102$ \\
\hline 59 & CENWP_CL_25_HEN_2 & 43 & 49 & 0/0 & $0 / 0$ & $2 / 0.041$ & $2 / 0.041$ & $2 / 0.041$ & $4 / 0.082$ & $5 / 0.102$ \\
\hline 60 & CENWP_CL_26_WLW_1 & 43 & 49 & 0/0 & 0/0 & $2 / 0.041$ & $2 / 0.041$ & $2 / 0.041$ & 4/0.082 & $5 / 0.102$ \\
\hline 61 & CENWP_CL_26_WLW_2 & 43 & 49 & 0/0 & $0 / 0$ & $2 / 0.041$ & $2 / 0.041$ & $2 / 0.041$ & 4/0.082 & $5 / 0.102$ \\
\hline 62 & CENWP_CL_27_MGN_1 & 43 & 49 & 0/0 & 0/0 & $2 / 0.041$ & $2 / 0.041$ & $2 / 0.041$ & $4 / 0.082$ & $5 / 0.102$ \\
\hline 63 & CENWP_CL_27_MGN_2 & 43 & 49 & 0/0 & $0 / 0$ & $2 / 0.041$ & $2 / 0.041$ & $2 / 0.041$ & 4/0.082 & $5 / 0.102$ \\
\hline 64 & CENWP_CL_27_MGN_3 & 43 & 49 & 0/0 & $0 / 0$ & $2 / 0.041$ & $2 / 0.041$ & $2 / 0.041$ & $4 / 0.082$ & $5 / 0.102$ \\
\hline 65 & CENWP_CL_28_VBR_1 & 43 & 48 & 0/0 & 0/0 & $2 / 0.042$ & $2 / 0.042$ & $2 / 0.042$ & $3 / 0.063$ & $4 / 0.083$ \\
\hline 66 & CENWP_CL_28_VBR_2 & 43 & 27 & 0/0 & $0 / 0$ & $2 / 0.074$ & $2 / 0.074$ & $2 / 0.074$ & $2 / 0.074$ & $3 / 0.111$ \\
\hline 67 & CENWP_CL_28_VBR_3 & 43 & 23 & 0/0 & $0 / 0$ & $1 / 0.043$ & $1 / 0.043$ & $1 / 0.043$ & $1 / 0.043$ & $2 / 0.087$ \\
\hline 68 & CENWP_CL_28_VBR_4 & 43 & 5 & 0/0 & $0 / 0$ & $0 / 0$ & 0/0 & 0/0 & $0 / 0$ & 0/0 \\
\hline 69 & CENWP_CL_28_VBR_5 & 25 & 2 & $1 / 0.5$ & $1 / 0.5$ & $1 / 0.5$ & $1 / 0.5$ & $1 / 0.5$ & $1 / 0.5$ & $1 / 0.5$ \\
\hline 70 & CENWP_CL_29_VTB_1 & 43 & 23 & 0/0 & $0 / 0$ & $1 / 0.043$ & $1 / 0.043$ & $1 / 0.043$ & $1 / 0.043$ & $2 / 0.087$ \\
\hline 79 & CENWP_CM_09_SKP_1 & 16 & 6 & $6 / 1$ & $6 / 1$ & $6 / 1$ & $6 / 1$ & $6 / 1$ & $6 / 1$ & $6 / 1$ \\
\hline 81 & CENWP_CM_11_CBY_1 & 34 & 11 & $2 / 0.182$ & $2 / 0.182$ & $2 / 0.182$ & $3 / 0.273$ & $4 / 0.364$ & $4 / 0.364$ & $4 / 0.364$ \\
\hline
\end{tabular}




\begin{tabular}{|c|c|c|c|c|c|c|c|c|c|c|}
\hline \multirow{2}{*}{ \# } & \multirow{2}{*}{ Reach Code } & \multirow{2}{*}{$\begin{array}{c}\text { Main- } \\
\text { tenance } \\
\text { Depth (ft) }\end{array}$} & \multirow{2}{*}{$\begin{array}{l}\text { Number of } \\
\text { Unique } \\
\text { Vessels }\end{array}$} & \multicolumn{7}{|c|}{ Reduction in Maintenance Depth (ft) } \\
\hline & & & & 0 & 1 & 2 & 3 & 4 & 5 & 6 \\
\hline 90 & CENWP_CM_21_RAl_1 & 24 & 1 & $0 / 0$ & $0 / 0$ & $0 / 0$ & $0 / 0$ & $0 / 0$ & $0 / 0$ & $1 / 1$ \\
\hline 91 & CENWP_CM_24_MUC_1 & 25 & 2 & $0 / 0$ & $0 / 0$ & $0 / 0$ & $0 / 0$ & $0 / 0$ & $1 / 0.5$ & $1 / 0.5$ \\
\hline 98 & CENWP_WR_01_WR1_1 & 40 & 26 & $1 / 0.038$ & $1 / 0.038$ & $3 / 0.115$ & $3 / 0.115$ & $3 / 0.115$ & $3 / 0.115$ & $3 / 0.115$ \\
\hline 99 & CENWP_WR_02_WR2_1 & 40 & 23 & $1 / 0.043$ & $1 / 0.043$ & $3 / 0.13$ & $3 / 0.13$ & $3 / 0.13$ & $3 / 0.13$ & $3 / 0.13$ \\
\hline 100 & CENWP_WR_03_WR3_1 & 40 & 16 & $1 / 0.063$ & $1 / 0.063$ & $2 / 0.125$ & $2 / 0.125$ & $2 / 0.125$ & $2 / 0.125$ & $2 / 0.125$ \\
\hline
\end{tabular}


Figure 6-18. Collision and grounding events in Columbia River, 2011-2015, as reported in the USCG MISLE database.

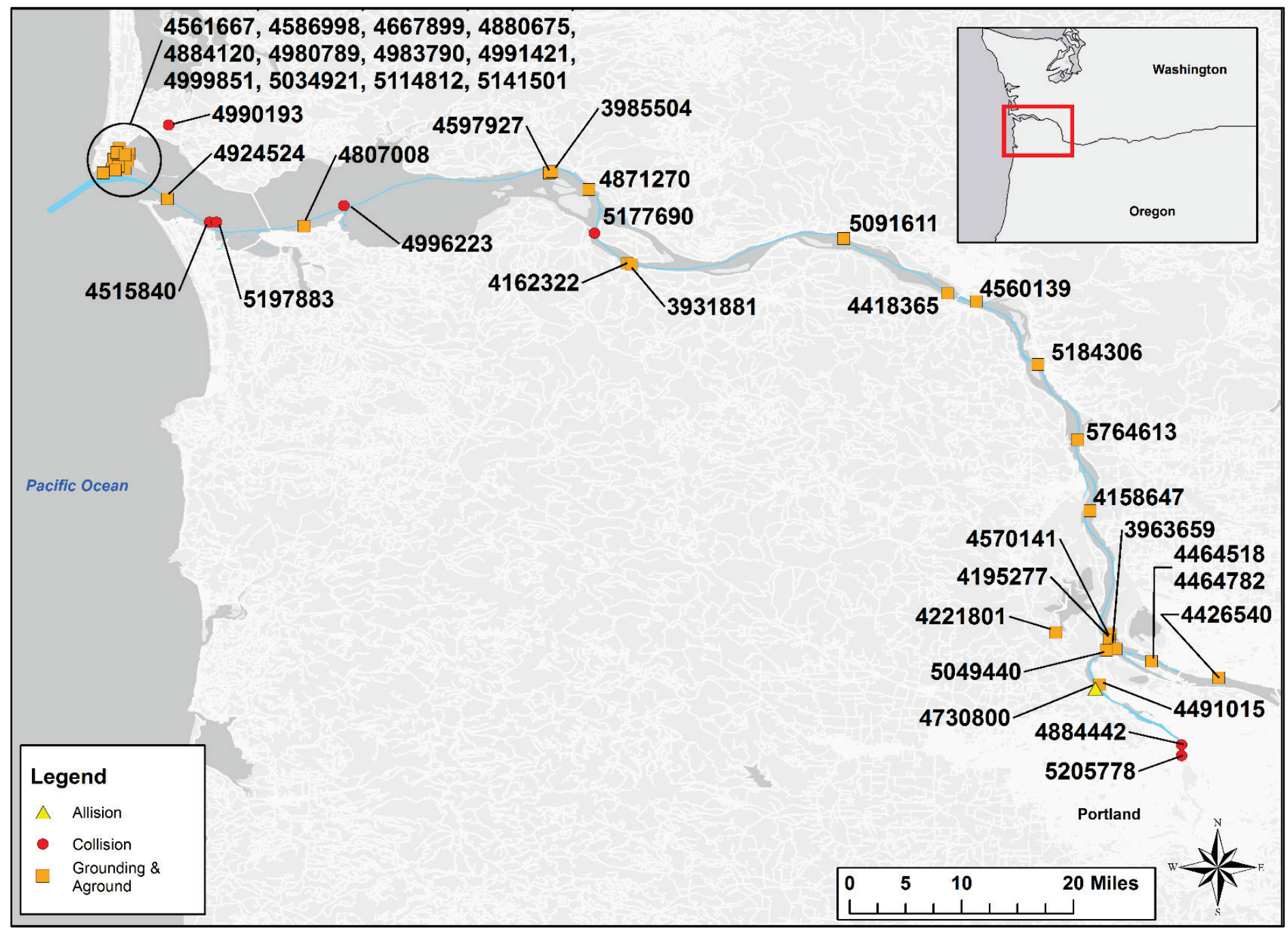




\section{Jacksonville Harbor Channel (JHC)}

JHC consists of 25 miles of channel that support deep draft navigation between the Atlantic Ocean and the Talleyrand Terminal in downtown Jacksonville, FL. A map of Jacksonville Harbor is provided in Figure 7-1. JHC navigation reaches are listed in Table 7-1, and their locations are shown in Figure 7-2. The entrance range, Barcut-3 (\#1), extends approximately 5 miles, from the Atlantic Ocean to the landside of the jetty. The maintenance depth is $42 \mathrm{ft}$ in the Atlantic Ocean and decreases to $40 \mathrm{ft}$ in the jetty. Each $40 \mathrm{ft}$ reach along the main stem of the channel, from the jetty west to Cut-50 (\#28), is flanked by two narrow side channels. Each side channel is $20 \mathrm{ft}$ wide and has a maintenance depth of $38 \mathrm{ft}$. The channel widths indicated in Table 7-1 include these flanking channels. NAIS data were requested for the entire navigation project for calendar year 2014 .

USACE completed a harbor deepening study in 2017 and has awarded contracts to begin deepening the existing navigation channel along the St. John's River to $47 \mathrm{ft}$. In anticipation of harbor deepening, USACE and Jacksonville Port Authority modified the navigation channel in the area known as Mile Point, where the Intracoastal Waterway intersects the St. Johns River. During ebb-tide, cross-currents make navigation difficult, which has led to a restriction on all vessels drafting more than $33 \mathrm{ft}$ inbound and $36 \mathrm{ft}$ outbound. The improvements were completed in 2017. 
Figure 7-1. Map of Jacksonville Harbor.

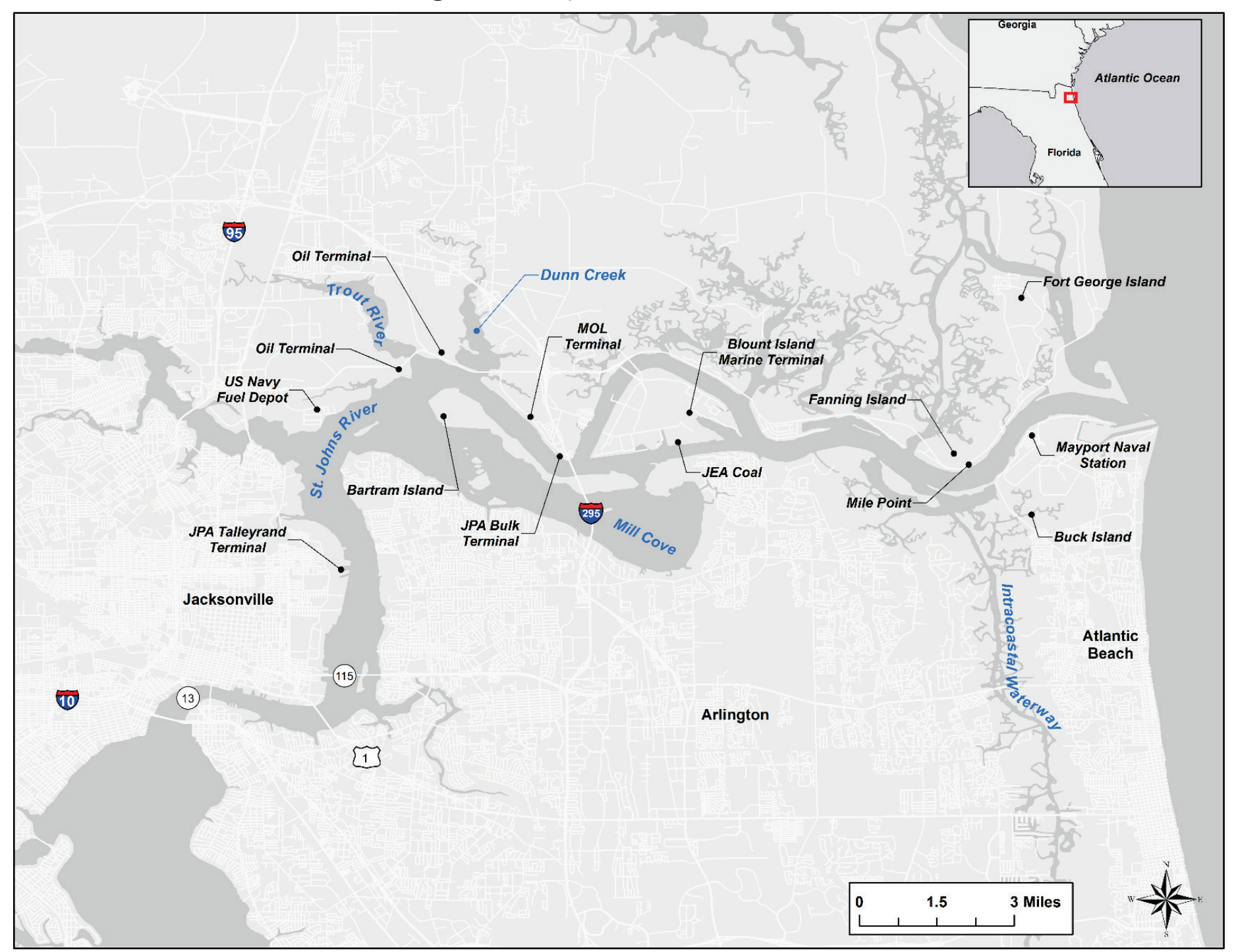


Figure 7-2. Jacksonville Harbor Navigation Channel.

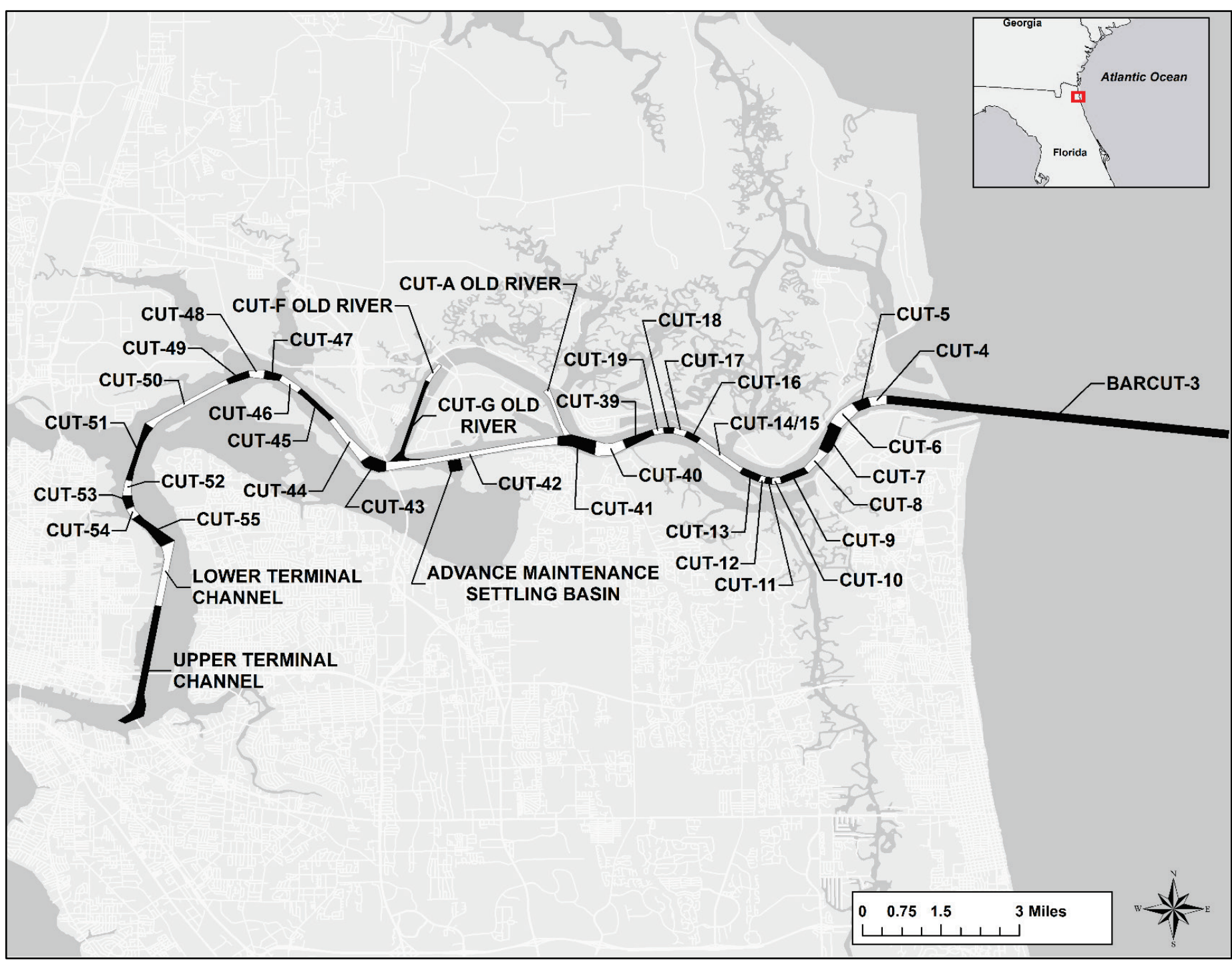


Table 7-1. Jacksonville Harbor Navigation Channel Reaches.

\begin{tabular}{|c|c|c|c|c|c|}
\hline \# & Reach Code & $\begin{array}{c}\text { Authorized } \\
\text { Depth (ft) }\end{array}$ & $\begin{array}{l}\text { Maintenance } \\
\text { Depth (ft) }\end{array}$ & $\begin{array}{l}\text { Length } \\
\text { (miles) }\end{array}$ & $\begin{array}{l}\text { Width } \\
\text { (ft) }\end{array}$ \\
\hline 1 & Barcut-3 & 42 & 42 & 5.0 & $800-800$ \\
\hline 2 & Cut-4 & 40 & 40 & 0.3 & $665-665$ \\
\hline 3 & Cut-5 & 40 & 40 & 0.3 & $40-373$ \\
\hline 4 & Cut-6 & 40 & 40 & 0.5 & $1140-1140$ \\
\hline 5 & Cut-7 & 40 & 40 & 0.5 & $665-665$ \\
\hline 6 & Cut-8 & 40 & 40 & 0.5 & $593-665$ \\
\hline 7 & Cut-9 & 40 & 40 & 0.5 & $567-593$ \\
\hline 8 & Cut-10 & 40 & 40 & 0.1 & $567-615$ \\
\hline 9 & Cut-11 & 40 & 40 & 0.1 & $615-615$ \\
\hline 10 & Cut-12 & 40 & 40 & 0.1 & $615-615$ \\
\hline 11 & Cut-13 & 40 & 40 & 0.3 & $589-615$ \\
\hline 12 & Cut-14/15 & 40 & 40 & 0.9 & $589-914$ \\
\hline 13 & Cut-16 & 40 & 40 & 0.3 & 791 - 914 \\
\hline 14 & Cut-17 & 40 & 40 & 0.2 & 708 - 791 \\
\hline 15 & Cut-18 & 40 & 40 & 0.2 & $708-925$ \\
\hline 16 & Cut-19 & 40 & 40 & 0.2 & $925-995$ \\
\hline 17 & Cut-39 & 40 & 40 & 0.5 & $517-995$ \\
\hline 18 & Cut-40 & 40 & 40 & 0.5 & $517-554$ \\
\hline 19 & Cut-41 & 40 & 40 & 0.6 & $554-640$ \\
\hline 20 & Cut-42 & 40 & 40 & 2.9 & $640-869$ \\
\hline 21 & Cut-43 & 40 & 40 & 0.4 & $640-869$ \\
\hline 22 & Cut-44 & 40 & 40 & 0.9 & $529-640$ \\
\hline 23 & Cut-45 & 40 & 40 & 0.8 & $900-900$ \\
\hline 24 & Cut-46 & 40 & 40 & 0.4 & $440-906$ \\
\hline 25 & Cut-47 & 40 & 40 & 0.3 & $557-866$ \\
\hline 26 & Cut-48 & 40 & 40 & 0.3 & $557-826$ \\
\hline 27 & Cut-49 & 40 & 40 & 0.4 & $749-826$ \\
\hline 28 & Cut-50 & 40 & 40 & 1.4 & $749-804$ \\
\hline 29 & Cut-51 & 40 & 40 & 1.1 & $804-1341$ \\
\hline 30 & Cut-52 & 40 & 40 & 0.3 & $575-1341$ \\
\hline 31 & Cut-53 & 40 & 40 & 0.2 & $575-630$ \\
\hline 32 & Cut-54 & 40 & 40 & 0.2 & 910 - 910 \\
\hline 33 & Cut-55 & 40 & 40 & 0.8 & $910-910$ \\
\hline
\end{tabular}




\begin{tabular}{|c|l|c|c|c|c|}
\hline$\#$ & Reach Code & $\begin{array}{c}\text { Authorized } \\
\text { Depth (ft) }\end{array}$ & $\begin{array}{c}\text { Maintenance } \\
\text { Depth (ft) }\end{array}$ & $\begin{array}{c}\text { Length } \\
\text { (miles) }\end{array}$ & $\begin{array}{c}\text { Width } \\
\text { (ft) }\end{array}$ \\
\hline 34 & $\begin{array}{l}\text { Lower Terminal } \\
\text { Channel }\end{array}$ & 40 & 40 & 1.2 & $837-1025$ \\
\hline 35 & $\begin{array}{l}\text { Upper Terminal } \\
\text { Channel }\end{array}$ & 34 & 34 & 2.4 & $625-837$ \\
\hline 36 & Cut-A Old River & 30 & 30 & 0.2 & $625-625$ \\
\hline 37 & Cut-F Old River & 38 & 38 & 0.4 & $625-625$ \\
\hline 38 & Cut-G Old River & 40 & 40 & 0.03 & $300-426$ \\
\hline 39 & $\begin{array}{l}\text { Advance Maintenance } \\
\text { Settling Basin }\end{array}$ & 40 & 40 & 0.2 & $0-1251$ \\
\hline
\end{tabular}

\subsection{Static vessel data}

During calendar year 2014, NAIS receivers intercepted AIS messages from 2,189 unique vessels in the federal channels of JHC. Static vessel data were screened to assess their completeness and to identify and correct potential problems before analyzing collision and grounding risks. At least six vessels (0.3\%) reported malformed MMSI codes, 156 records (7.1\%) were missing information about the vessel's name, and 182 records (8.3\%) contained unknown or missing ship and cargo type codes. Many records were also missing data on vessel dimensions: 300 records were missing data on length (13.7\%), 302 records were missing data on beam (13.8\%), and 1,212 records were missing data on draught (55.3\%).

Vessels operating under selected ship and cargo type codes were screened to confirm their classification or to re-classify them based on photographs available in Marine Traffic.com. These included vessels operating under ship and cargo type codes that were missing or unknown (0, 38-39, 56-57), reserved for WIG craft (20-29), or classified in the omnibus category (90-99). A summary of the vessels operating in JHC during 2014 is provided in Table 7-2. This table shows the number of vessels operating under each ship and cargo type code before and after the review of each vessels' ship and cargo type classification in the NAIS database. The number of vessels with unknown ship and cargo type codes was reduced from 134 to 70 . These vessels were re-classified as pleasure craft, sailing vessels, tug boats, cargo vessels, tankers, and vessels engaged in military operations. Vessels operating under other ship and cargo type codes were not validated unless specific information about that vessel suggested that it might be misclassified. 
Table 7-2. Descriptive summary of vessels using JHC in 2014. Classification based on ITU-R M.1371-5 (February 2014).

\begin{tabular}{|c|c|c|c|}
\hline \multirow[b]{2}{*}{ AIS Ship and Cargo Type } & \multirow{2}{*}{$\begin{array}{c}\text { AIS Ship and } \\
\text { Cargo } \\
\text { Type Code }\end{array}$} & \multicolumn{2}{|c|}{ Number of Unique Vessels } \\
\hline & & $\begin{array}{l}\text { Before Review of } \\
\text { Static Vessel Data }\end{array}$ & $\begin{array}{c}\text { After Review of } \\
\text { Static Vessel Data }\end{array}$ \\
\hline Unknown & 00 & 134 & 70 \\
\hline WIG & $20-29$ & 10 & 0 \\
\hline Fishing vessels & 30 & 26 & 9 \\
\hline Towing vessels & $31-32$ & 65 & 67 \\
\hline $\begin{array}{l}\text { Engaged in dredging or underwater } \\
\text { operations }\end{array}$ & 33 & 13 & 14 \\
\hline Engaged in diving operations & 34 & 0 & 0 \\
\hline Engaged in military operations & 35 & 29 & 45 \\
\hline Sailing vessels & 36 & 448 & 460 \\
\hline Pleasure craft & 37 & 689 & 727 \\
\hline Reserved for future use & $38-39$ & 3 & 0 \\
\hline $\begin{array}{l}\text { High-speed craft (HSC) or } \\
\text { passenger ferries }\end{array}$ & $40-49$ & 4 & 4 \\
\hline Pilot vessels & 50 & 6 & 6 \\
\hline Search and rescue vessels & 51 & 13 & 14 \\
\hline Tugs & 52 & 73 & 97 \\
\hline Port tenders & 53 & 1 & 1 \\
\hline Vessels with anti-pollution facilities & 54 & 1 & 1 \\
\hline Law enforcement vessels & 55 & 3 & 4 \\
\hline $\begin{array}{l}\text { Spare for assignment to local } \\
\text { vessels }\end{array}$ & $56-57$ & 0 & 0 \\
\hline Medical transports & 58 & 0 & 0 \\
\hline $\begin{array}{l}\text { Ships according to RR Resolution } \\
\text { (Mob-83) }\end{array}$ & 59 & 0 & 0 \\
\hline Passenger ships & $60-69$ & 14 & 14 \\
\hline Cargo ships & $70-79$ & 504 & 520 \\
\hline Tankers & $80-89$ & 110 & 112 \\
\hline Other vessels & $90-99$ & 43 & 24 \\
\hline Total & & 2,189 & 2,189 \\
\hline
\end{tabular}

There were 727 pleasure craft (37) recorded in JHC during 2014, making it the largest single category of vessels utilizing JHC. The next largest categories were cargo ships, with 520 unique vessels, followed by sailing vessels, with 460 unique vessels, and tankers, with 112 unique vessels. 
During 2014, there were 45 vessels identified as being engaged in military operations (35) in JHC. Much of this activity is focused at Naval Station Mayport, which is located just inside the jetty at the mouth of the St. Johns River.

The NAIS data used in this study were requested without information about the location of the AIS transponder on board the vessel. The location of the AIS transponder on board each vessel was taken from the AISAP vessel inventory when the length and beam reported in the NAIS data matched that reported in AISAP. This method worked for 1,548 vessels (69.4\%). If a matching MMSI was found, but the length and beam did not match, the vessel's name as reported in static vessel data was compared to that reported in AISAP, and if similar, the AIS transponder was placed in relative proportion to the position reported in AISAP. If no matching MMSI was found in the AISAP inventory or if the length, beam, or transponder location were not reported, then the AIS transponder was positioned at the center of the vessel.

\subsection{Collision risk assessment}

During calendar year 2014, there were 268 encounters in JHC. This inventory of encounters excludes interactions involving vessels classified as towboats and harbor work boats (i.e., vessels operating under ship and cargo type codes 31-32, and 50-57, interactions between two vessels classified as "engaged in dredging operations" (33), and interactions between yachts and their own yacht tenders. The inventory of SDVs is based on AIS position reports from within the federal channel. Events occurring outside the federal channel have not been analyzed.

\subsubsection{Location and severity of encounters}

The location and severity of encounters in JHC during the 2014 calendar year is shown in Figure 7-3. Each point represents the geometric center of the encroached vessel at the time of maximum SDV severity during its encounter with the other vessel. Clusters of points indicate locations where encounters are most common. There is a large cluster of encounters in the channel between Mayport and Fort George Island. Most of these involved a ferry that transports passengers and automobiles across the St. Johns River. The ferry was classified as the encroaching vessel in 190 of the 268 
encounters in JHC (71\%) and as the encroached vessel in eight encounters (3\%). The remaining encounters are scattered throughout JHC.

The color of each point in Figure 7-3 indicates the maximum SDV severity score during each encounter. There does not appear to be any clustering of encounters with the highest maximum SDV severity score. SDVs with scores greater than 0.8 are distributed throughout JHC. Figure 7-3 also shows a cluster of fifteen points at Mile Point, near the intersection of the Intracoastal Waterway and St. Johns River. Nine of these events involved pleasure craft, sailing vessels, or unknown vessel types interacting with cargo vessels, tankers, or cruise ships. As these data are from calendar year 2014, this cluster of events pre-date the improvements to the channel at Mile Point. The cluster of encounters at this location may reflect the presence of the Intracoastal Waterway crossing and may also reflect the difficulty vessels have maneuvering in this location. 
Figure 7-3. Location and severity of SDVs in JHC.

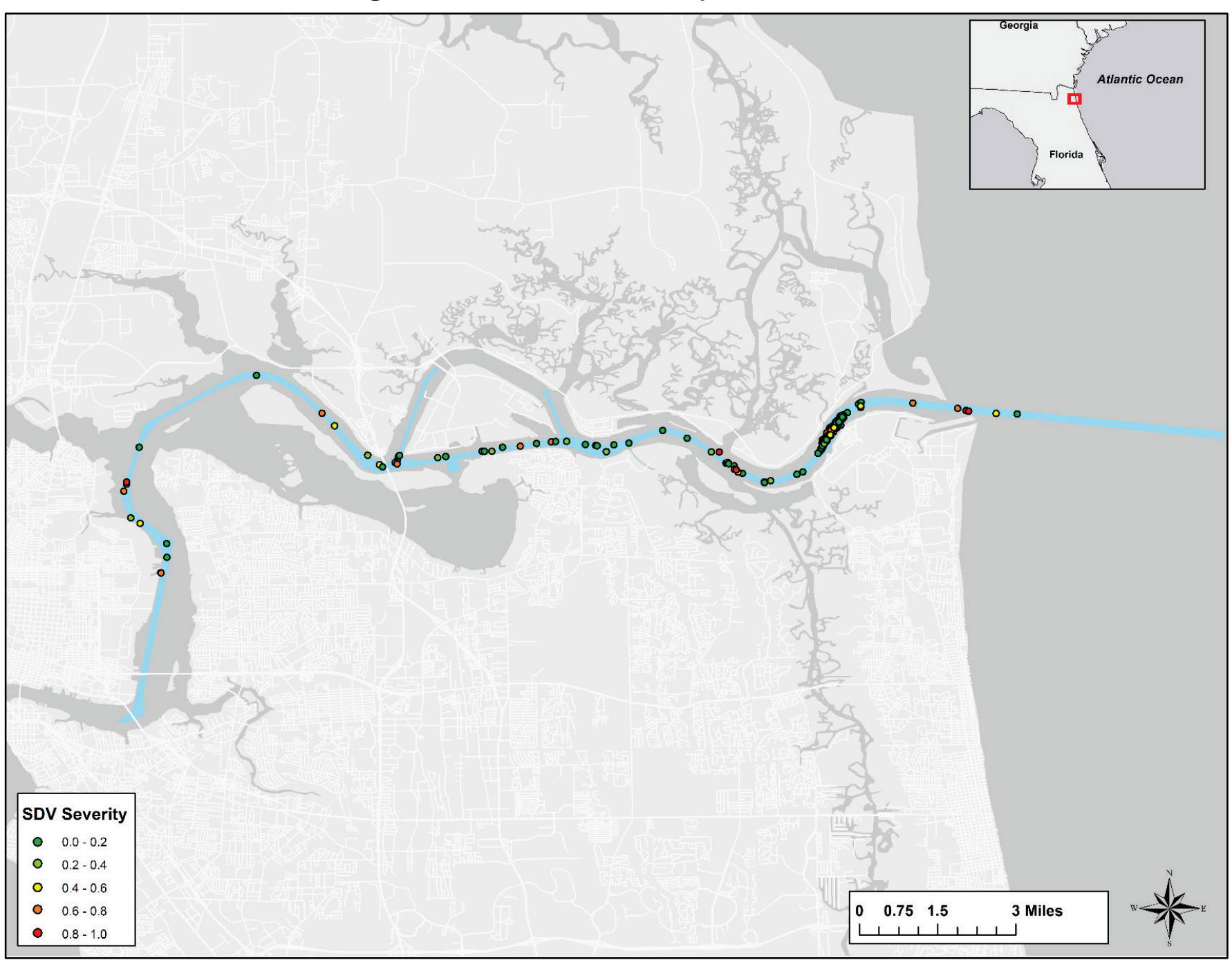


At least three characteristics of SDVs can help navigation managers evaluate the analysis of collision risks. These are the maximum SDV severity score during an encounter, the minimum distance between vessels during an encounter, and the duration of each encounter. These characteristics are summarized using empirical distribution functions in Figure 7-4. Overall, the severity scores in JHC are low, as shown in Figure 7-4(a). Almost 35\% of encounters have severity scores less than 0.1, and $50 \%$ of encounters have severity scores less than 0.25 . Less than $10 \%$ of encounters have severity scores greater than 0.7. This suggests that vessels have a strong tendency to stay away from each other, which is consistent with expected behavior.

An absolute measure of the distance between vessels also helps put the SDV severity score in perspective. The point of minimum distance between vessel perimeters during each encounter is shown in Figure 7-4(b). This distance can range from o to almost $450 \mathrm{~m}$. Approximately $75 \%$ of encounters are characterized by a minimum distance greater than $100 \mathrm{~m}$. This empirical distribution function on the actual distance between vessel perimeters also illustrates the tendency for vessels to maintain a safe distance from one another. Ultimately, the distance between vessels may be influenced by channel width. The channels in JHC are fairly wide, and this may help pilots maintain safe distances that reduce the frequency and severity of encounters.

If vessels are avoiding one another, the duration of encounters between vessels should be brief. The empirical distribution function for duration of encounters in Figure 7.4(c) reveals that $75 \%$ of encounters in JHC last for less than 1 minute and 97\% of encounters last for less than 4 minutes. Two extreme points are not shown in the figure. These two SDVs occurred when an $18 \mathrm{~m}$ yacht followed an $168 \mathrm{~m}$ cargo vessel from Talleyrand Terminal all the way out to sea on 27 July 2014. According to position reports, each vessels ship domain was encroached for the duration of transit, which lasted 134 minutes. 
Figure 7-4. Characteristics of SDVs in Jacksonville Harbor. The figure shows empirical distribution functions for (a) the maximum SDV severity score; (b) the minimum distance between vessels (meters); and (c) the duration of encounters between vessels.

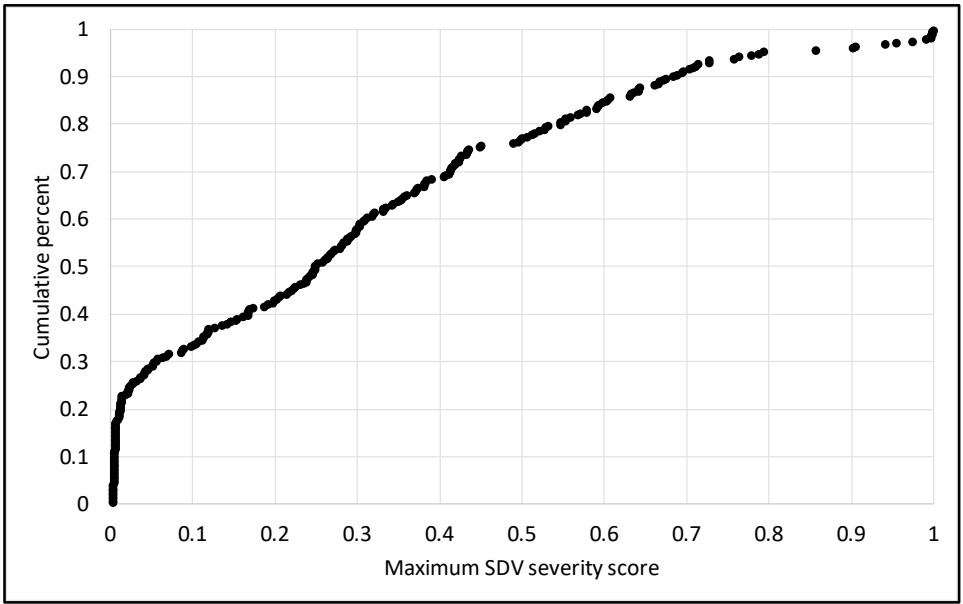

(a)

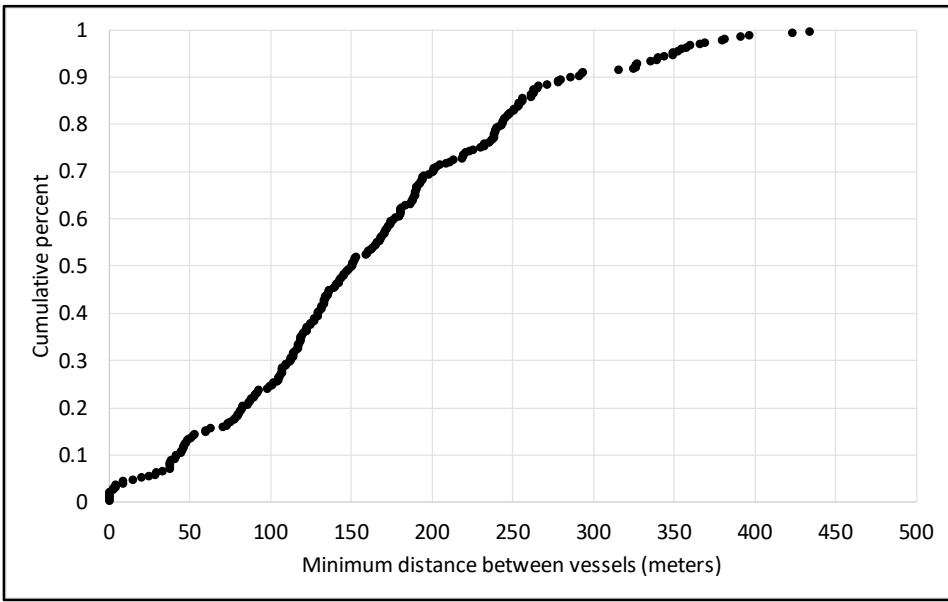

(b)

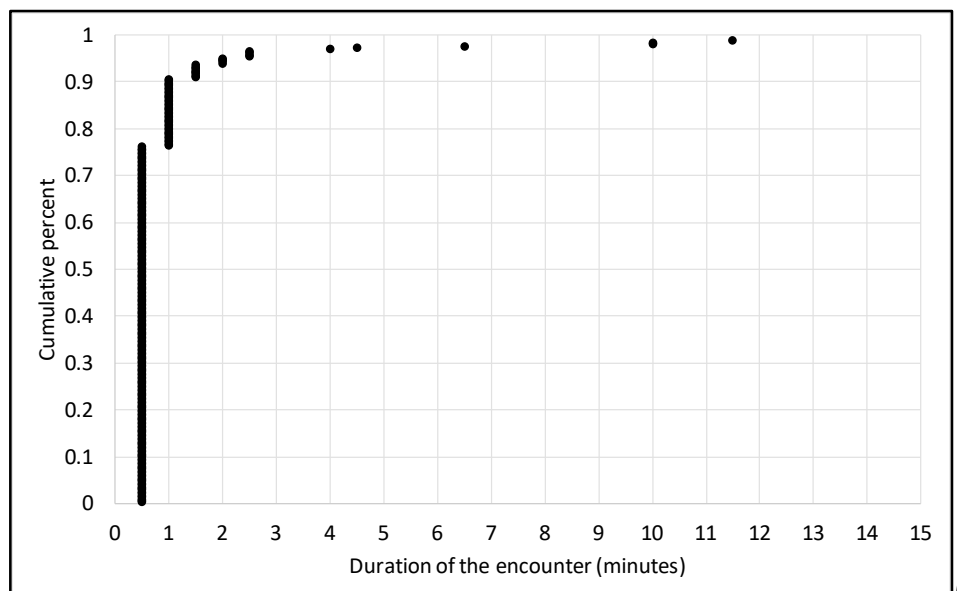




\subsubsection{Types of vessels involved in encounters}

The types of vessels involved in encounters is summarized in Table 7-3. During the 2014 calendar year, there were 268 encounters. Passenger vessels (60-69) were classified as the encroaching vessel 192 times. Of these encounters, passenger vessels encroached on the domains of cargo vessels 155 times, on the domains of tankers 20 times, and on the domains of other passenger vessels 13 times. All but two encroachments by passenger vessels were attributed to the Jean Ribault, which is a ferry that transports passengers across the St. Johns River between Mayport and St. George Island every 15 minutes. Overall, cargo vessels were classified as the encroaching vessel 37 times and as the encroached vessel 207 times. Of those encounters, 25 involved two cargo vessels. Therefore, there were 219 encounters that involved at least one cargo vessel, which is $82 \%$ of all encounters. Pleasure craft were classified as the encroaching vessel in 24 encounters and as the encroached vessel in four encounters. Only 1 encounter involved two pleasure craft, so a total of 27 encounters involved at least one pleasure craft. Vessels classified under other AIS ship and cargo type codes were involved in relatively few encounters.

\subsubsection{Frequency of SDVs}

During calendar year 2014, 978,326 AIS position reports were sampled from vessels operating in the federal channel in JHC, and 816 of these position reports were classified as SDVs. The conditional frequencies of an SDV are reported by reach and AIS ship and cargo type in Table 7-4. This metric is an estimate of the probability that a vessel operating in a given reach will be involved in an SDV. The rows of the table correspond to each of the $\mathrm{JHC}$ reaches, and the columns correspond to each of the nine major categories of AIS-equipped vessels. The last column gives the conditional probability of an SDV in each reach over all vessel categories, and the last row gives the conditional probability of an SDV for each vessel category over all reaches of the navigation project. Frequencies greater than $1.0 \times 10^{-3}$ are printed in red boldface type. Over all vessel types and reaches, the conditional probability of an SDV in $\mathrm{JHC}$ is $8.34 \times 10^{-4}$. 
Table 7-3. Number of encounters in JHC by encroached and encroaching vessel type.

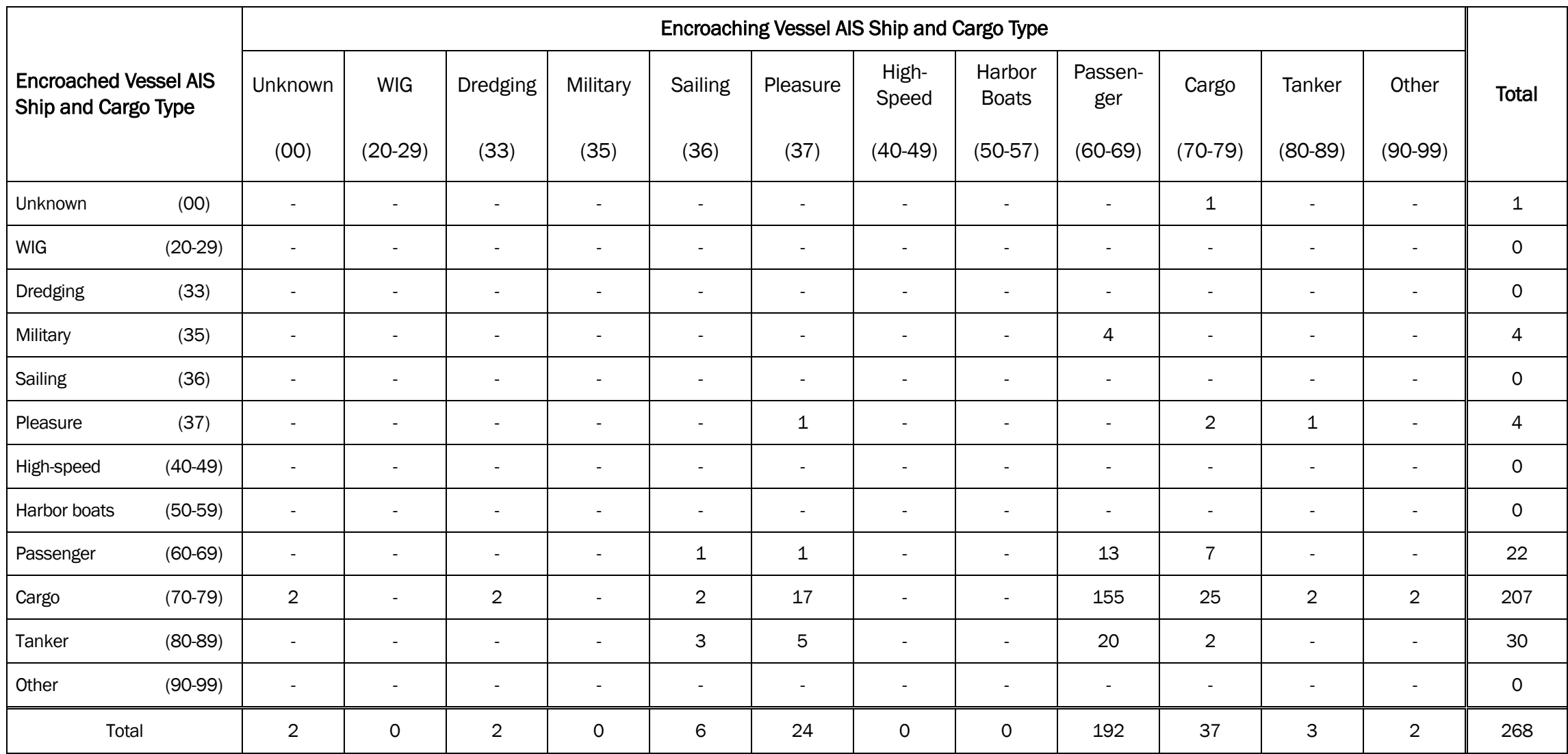


Table 7-4. The conditional frequency of SDVs in JHC by reach and vessel type. Frequencies greater than $1 \times 10^{-3}$ are in bold red typeface.

\begin{tabular}{|c|c|c|c|c|c|c|c|c|c|c|c|}
\hline \multirow[b]{2}{*}{$\#$} & \multirow[b]{2}{*}{ Reach Code } & \multicolumn{9}{|c|}{ AIS Ship and Cargo Type } & \multirow[b]{2}{*}{ All } \\
\hline & & $\begin{array}{l}\text { Unknown } \\
\qquad(00)\end{array}$ & $\begin{array}{c}\text { WIG } \\
(20-29)\end{array}$ & $\begin{array}{c}\text { Class } 3 \\
(30,33-39)\end{array}$ & $\begin{array}{l}\text { High-Speed } \\
\text { (40-49) }\end{array}$ & $\begin{array}{l}\text { Harbor } \\
\text { Boats } \\
(50-59)\end{array}$ & $\begin{array}{l}\text { Passenger } \\
(60-69)\end{array}$ & $\begin{array}{l}\text { Cargo } \\
\text { (70-79) }\end{array}$ & $\begin{array}{l}\text { Tankers } \\
\text { (80-89) }\end{array}$ & $\begin{array}{l}\text { Other } \\
(90-99)\end{array}$ & \\
\hline 1 & BarCut-3 & $0.00 \mathrm{E}+00$ & - & 1.16E-03 & - & - & $0.00 \mathrm{E}+00$ & $4.25 \mathrm{E}-04$ & 2.33E-04 & $0.00 \mathrm{E}+00$ & 4.71E-04 \\
\hline 2 & Cut-4 & $0.00 E+00$ & - & $5.75 \mathrm{E}-04$ & - & - & $0.00 E+00$ & $2.90 \mathrm{E}-04$ & $0.00 E+00$ & $0.00 E+00$ & 2.76E-04 \\
\hline 3 & Cut-5 & $0.00 E+00$ & - & $1.22 \mathrm{E}-03$ & - & - & $0.00 E+00$ & $1.22 \mathrm{E}-03$ & $0.00 E+00$ & $0.00 E+00$ & 1.03E-03 \\
\hline 4 & Cut-6 & $0.00 E+00$ & - & $8.02 \mathrm{E}-04$ & - & - & 4.47E-04 & 4.67E-03 & $6.13 E-03$ & $0.00 E+00$ & $1.98 \mathrm{E}-03$ \\
\hline 5 & Cut-7 & $0.00 E+00$ & - & $2.42 \mathrm{E}-03$ & - & - & $1.53 \mathrm{E}-04$ & $5.60 \mathrm{E}-03$ & 4.41E-03 & $0.00 E+00$ & $1.83 E-03$ \\
\hline 6 & Cut-8 & $0.00 E+00$ & - & $2.48 \mathrm{E}-03$ & - & - & $0.00 E+00$ & $4.56 \mathrm{E}-04$ & $0.00 E+00$ & $0.00 E+00$ & 5.64E-04 \\
\hline 7 & Cut-9 & $0.00 E+00$ & - & $5.65 \mathrm{E}-04$ & - & - & $0.00 E+00$ & 4.48E-04 & $0.00 E+00$ & $0.00 E+00$ & 3.89E-04 \\
\hline 8 & Cut-10 & $0.00 \mathrm{E}+00$ & - & $0.00 \mathrm{E}+00$ & - & - & $0.00 \mathrm{E}+00$ & $6.16 \mathrm{E}-04$ & $1.62 \mathrm{E}-03$ & $0.00 E+00$ & $6.21 \mathrm{E}-04$ \\
\hline 9 & Cut-11 & $0.00 E+00$ & - & $2.53 \mathrm{E}-03$ & - & - & $0.00 E+00$ & 5.33E-04 & 4.51E-03 & $0.00 E+00$ & $1.03 E-03$ \\
\hline 10 & Cut-12 & $0.00 E+00$ & - & $2.60 \mathrm{E}-03$ & - & - & $0.00 E+00$ & $6.52 \mathrm{E}-04$ & 2.61E-03 & $0.00 E+00$ & 9.82E-04 \\
\hline 11 & Cut-13 & $0.00 E+00$ & - & $2.09 \mathrm{E}-03$ & - & - & $0.00 E+00$ & 5.19E-04 & $0.00 E+00$ & $0.00 E+00$ & $6.27 \mathrm{E}-04$ \\
\hline 12 & Cut-14/15 & 4.83E-03 & - & $1.22 \mathrm{E}-03$ & - & - & $5.04 \mathrm{E}-04$ & $6.70 \mathrm{E}-04$ & 2.76E-04 & $0.00 E+00$ & 7.09E-04 \\
\hline 13 & Cut-16 & $0.00 E+00$ & - & $1.75 \mathrm{E}-03$ & - & - & $0.00 E+00$ & 4.69E-04 & $0.00 E+00$ & $0.00 E+00$ & $5.24 \mathrm{E}-04$ \\
\hline 14 & Cut-17 & $0.00 E+00$ & - & $2.39 \mathrm{E}-03$ & - & - & $0.00 E+00$ & $4.21 \mathrm{E}-04$ & $0.00 E+00$ & $0.00 E+00$ & 5.35E-04 \\
\hline 15 & Cut-18 & $0.00 E+00$ & - & $0.00 E+00$ & - & - & $0.00 E+00$ & 3.50E-04 & $0.00 E+00$ & $0.00 E+00$ & 2.71E-04 \\
\hline 16 & Cut-19 & $0.00 E+00$ & - & $1.56 \mathrm{E}-03$ & - & - & $0.00 E+00$ & 3.36E-04 & $0.00 E+00$ & $0.00 E+00$ & 3.86E-04 \\
\hline 17 & Cut-39 & $0.00 E+00$ & - & $1.68 \mathrm{E}-03$ & - & - & $0.00 E+00$ & 3.39E-04 & $0.00 E+00$ & $0.00 E+00$ & 4.23E-04 \\
\hline 18 & Cut-40 & $0.00 E+00$ & - & $2.10 \mathrm{E}-03$ & - & - & $0.00 E+00$ & 5.94E-04 & $0.00 E+00$ & $0.00 E+00$ & 6.40E-04 \\
\hline 19 & Cut-41 & $0.00 E+00$ & - & $1.58 \mathrm{E}-03$ & - & - & $0.00 E+00$ & $3.27 \mathrm{E}-04$ & 3.66E-04 & $0.00 E+00$ & $4.58 \mathrm{E}-04$ \\
\hline 20 & Cut-42 & $0.00 E+00$ & - & $1.69 \mathrm{E}-03$ & - & - & $0.00 E+00$ & $4.23 \mathrm{E}-04$ & 7.62E-04 & $0.00 E+00$ & 5.41E-04 \\
\hline 21 & Cut-43 & $0.00 E+00$ & - & $2.34 \mathrm{E}-03$ & - & - & $0.00 E+00$ & $1.59 \mathrm{E}-03$ & $6.00 \mathrm{E}-04$ & $0.00 E+00$ & $1.39 \mathrm{E}-03$ \\
\hline 22 & Cut-44 & $0.00 E+00$ & - & $1.71 E-03$ & - & - & $0.00 E+00$ & $5.84 \mathrm{E}-04$ & $9.51 \mathrm{E}-04$ & $0.00 E+00$ & 7.71E-04 \\
\hline
\end{tabular}




\begin{tabular}{|c|c|c|c|c|c|c|c|c|c|c|c|}
\hline \multirow[b]{2}{*}{$\#$} & \multirow[b]{2}{*}{ Reach Code } & \multicolumn{9}{|c|}{ AIS Ship and Cargo Type } & \multirow[b]{2}{*}{ All } \\
\hline & & $\begin{array}{l}\text { Unknown } \\
\text { (00) }\end{array}$ & $\begin{array}{c}\text { WIG } \\
(20-29)\end{array}$ & $\begin{array}{c}\text { Class } 3 \\
(30,33-39)\end{array}$ & $\begin{array}{l}\text { High-Speed } \\
\text { (40-49) }\end{array}$ & $\begin{array}{c}\text { Harbor } \\
\text { Boats } \\
(50-59)\end{array}$ & $\begin{array}{l}\text { Passenger } \\
\text { (60-69) }\end{array}$ & $\begin{array}{l}\text { Cargo } \\
(70-79)\end{array}$ & $\begin{array}{l}\text { Tankers } \\
\text { (80-89) }\end{array}$ & $\begin{array}{l}\text { Other } \\
(90-99)\end{array}$ & \\
\hline 23 & Cut-45 & $0.00 \mathrm{E}+00$ & - & 1.37E-03 & - & - & $0.00 \mathrm{E}+00$ & $1.11 \mathrm{E}-03$ & $5.53 \mathrm{E}-04$ & $0.00 \mathrm{E}+00$ & 8.61E-04 \\
\hline 24 & Cut-46 & $0.00 E+00$ & - & 5.96E-04 & - & - & $0.00 E+00$ & $1.21 \mathrm{E}-03$ & $0.00 E+00$ & $0.00 E+00$ & $6.23 \mathrm{E}-04$ \\
\hline 25 & Cut-47 & $0.00 E+00$ & - & $1.53 \mathrm{E}-03$ & - & - & $0.00 E+00$ & $1.19 \mathrm{E}-03$ & $0.00 E+00$ & $0.00 E+00$ & $7.82 \mathrm{E}-04$ \\
\hline 26 & Cut-48 & $0.00 E+00$ & - & $2.75 \mathrm{E}-03$ & - & - & $0.00 \mathrm{E}+00$ & 8.77E-04 & $1.06 \mathrm{E}-03$ & $0.00 E+00$ & $1.29 \mathrm{E}-03$ \\
\hline 27 & Cut-49 & $0.00 E+00$ & - & $1.39 \mathrm{E}-03$ & - & - & $0.00 E+00$ & $1.41 \mathrm{E}-03$ & $0.00 \mathrm{E}+00$ & $0.00 E+00$ & 7.94E-04 \\
\hline 28 & Cut-50 & $0.00 E+00$ & - & $1.67 \mathrm{E}-03$ & - & - & $0.00 E+00$ & $1.30 \mathrm{E}-03$ & $0.00 E+00$ & $0.00 E+00$ & $1.08 \mathrm{E}-03$ \\
\hline 29 & Cut-51 & $0.00 \mathrm{E}+00$ & - & $2.18 \mathrm{E}-03$ & - & - & $0.00 \mathrm{E}+00$ & $1.22 \mathrm{E}-03$ & $0.00 \mathrm{E}+00$ & $0.00 E+00$ & 1.14E-03 \\
\hline 30 & Cut-52 & $0.00 E+00$ & - & $1.75 \mathrm{E}-03$ & - & - & $0.00 E+00$ & 9.56E-04 & $2.61 \mathrm{E}-03$ & $0.00 E+00$ & $1.49 \mathrm{E}-03$ \\
\hline 31 & Cut-53 & $0.00 E+00$ & - & $2.36 \mathrm{E}-03$ & - & - & $0.00 E+00$ & 7.27E-04 & $0.00 E+00$ & $0.00 E+00$ & 8.60E-04 \\
\hline 32 & Cut-54 & $0.00 \mathrm{E}+00$ & - & 1.47E-03 & - & - & $0.00 \mathrm{E}+00$ & $1.68 \mathrm{E}-03$ & $0.00 \mathrm{E}+00$ & $0.00 E+00$ & $1.28 \mathrm{E}-03$ \\
\hline 33 & Cut-55 & $0.00 E+00$ & - & 1.71E-03 & - & - & $0.00 E+00$ & $1.28 \mathrm{E}-03$ & $0.00 E+00$ & $0.00 E+00$ & 1.07E-03 \\
\hline 34 & Lower Terminal Reach & $0.00 E+00$ & - & 3.37E-03 & - & - & $0.00 E+00$ & $2.15 \mathrm{E}-03$ & 2.61E-04 & $0.00 E+00$ & $2.06 \mathrm{E}-03$ \\
\hline 35 & Upper Terminal Reach & $0.00 E+00$ & - & $0.00 \mathrm{E}+00$ & - & - & $0.00 \mathrm{E}+00$ & $0.00 \mathrm{E}+00$ & $0.00 \mathrm{E}+00$ & $0.00 E+00$ & $0.00 \mathrm{E}+00$ \\
\hline 36 & Cut-A Old River & $0.00 E+00$ & - & $0.00 E+00$ & - & - & - & - & - & - & $0.00 \mathrm{E}+00$ \\
\hline 37 & Cut-F Old River & $0.00 E+00$ & - & $0.00 E+00$ & - & - & - & $0.00 E+00$ & - & - & $0.00 E+00$ \\
\hline 38 & Cut-G Old River & $0.00 E+00$ & - & $0.00 \mathrm{E}+00$ & - & - & $0.00 \mathrm{E}+00$ & $1.88 \mathrm{E}-04$ & $0.00 E+00$ & - & $1.84 \mathrm{E}-04$ \\
\hline 39 & $\begin{array}{l}\text { Advance Maintenance } \\
\text { Settling Basin }\end{array}$ & $0.00 \mathrm{E}+00$ & - & $0.00 E+00$ & - & - & - & - & - & - & $0.00 E+00$ \\
\hline & All & 2.33E-04 & - & $1.46 \mathrm{E}-03$ & - & - & 2.01E-04 & 8.98E-04 & 6.15E-04 & $0.00 E+00$ & 8.34E-04 \\
\hline
\end{tabular}


The highest conditional frequency of an SDV, $2.06 \times 10^{-3}$, occurs in the Lower Terminal Channel (\#34) near the Jacksonville Port Authority Talleyrand Terminal. In this reach, 67 out of 32,455 position reports were classified as SDVs during calendar year 2014. The second and third highest conditional frequencies were in Cut-6 (\#4) and Cut-7 (\#5). In Cut6,123 out of 62,041 position reports were classified as SDVs, and in Cut-7, 148 out of 80,785 position reports were classified as SDVs. Most of these SDVs involve the Mayport-St. George ferry as it crosses the St. Johns River and encroaches on the ship domains of cargo vessels and tankers. The map showing location and severity of encounters in Figure 7-3 suggests that this is where the overwhelming majority of SDVs occur. However, the conditional frequency of SDVs in Cut- 6 and Cut-7 is not much more than twice that in other reaches.

The conditional probability of an SDV by reach and vessel type is summarized in Table 7-4. Over all reaches, vessels classified under ship and cargo type codes 30 and 33-39, have the highest conditional probability of an SDV, which is $1.46 \times 10^{-3}$. Most of the events in this column are attributed to vessels classified as pleasure craft (37) and sailing vessels (36). This result stands in contrast to those in Table 7-3, which indicates that there are relatively few unique SDVs involving vessels classified under ship and cargo type codes 30 and 33-39. Although position reports from vessels in this ship and cargo type category are more likely to be classified as SDVs, vessels in this ship and cargo type category account for a small number of unique SDVs.

Passenger vessels have a very low conditional probability of being involved in an SDV. The conditional probability of a passenger vessel being involved in an SDV is non-zero only at the Mayport ferry crossing (Cut-6 and Cut-7) and at Milepoint (Cut 14/15). This result also seems inconsistent with the inventory of unique SDVs, which indicates most SDVs in JHC involve the Mayport Ferry. Although the passenger ferry at Mayport accounts for a large number of unique SDVs, the fraction of position reports from passenger vessels that are classified as SDVs is relatively low. Position reports from vessels classified under other ship and cargo types have a higher probability of being classified as SDVs than do those from vessels classified as passenger vessels. 
The conditional probability of an SDV indicates where a vessel's ship domain is most likely to be encroached (Figure 7-5). Depending on the pattern of usage in a reach, this metric may indicate that SDVs are more common in reaches that are less frequently used. An alternative measure of SDV frequency is provided by the unconditional probability of an SDV, which is the probability of an SDV occurring in a reach without regard to whether or not a vessel is present in that reach. This metric indicates where SDVs are most likely to occur in the navigation project and is calculated by multiplying the conditional probability of an SDV by the frequency that at least one vessel is present in the reach.

The probability that at least one vessel is present in a reach is summarized by reach and AIS ship and cargo type code in Table 7-5. This is calculated as the number of half-minute intervals represented by at least one position report in the sample of NAIS data divided by the total number of halfminute intervals during the sampling period. This metric provides some indication of channel utilization. For example, the table shows that there is at least one vessel in BarCut-3, the entrance to $\mathrm{JCH}$, approximately $16 \%$ of the time and that in Cut-42, in front of the Blount Island Marine Terminal, at least one vessel is present approximately $13.5 \%$ of the time. However, the primary purpose of this statistic is to calculate the unconditional probability of an SDV.

The unconditional probability of an SDV is the overall probability of observing an SDV in a reach. This metric of risk may provide navigation managers with information about which reaches in the navigation project are more likely to have SDVs. The unconditional probability of an SDV is calculated in Table 7-6. Figure 7-6 shows where the unconditional probability of an SDV is highest within the navigation project. These results show that overall, the highest probability of SDVs is at the Mayport ferry crossing (Cut-6, \#4 and Cut-7, \#5). There are also relatively high probabilities of SDVs in the entrance channel (BarCut-3, \#1), in front of the Blount Island Marine Terminal (Cut-42, \#20), and in the Lower Terminal Reach (\#34). Substantively, these results are similar to those for the conditional probability of an SDV. 
Figure 7-5. Conditional frequency of SDVs in JHC.

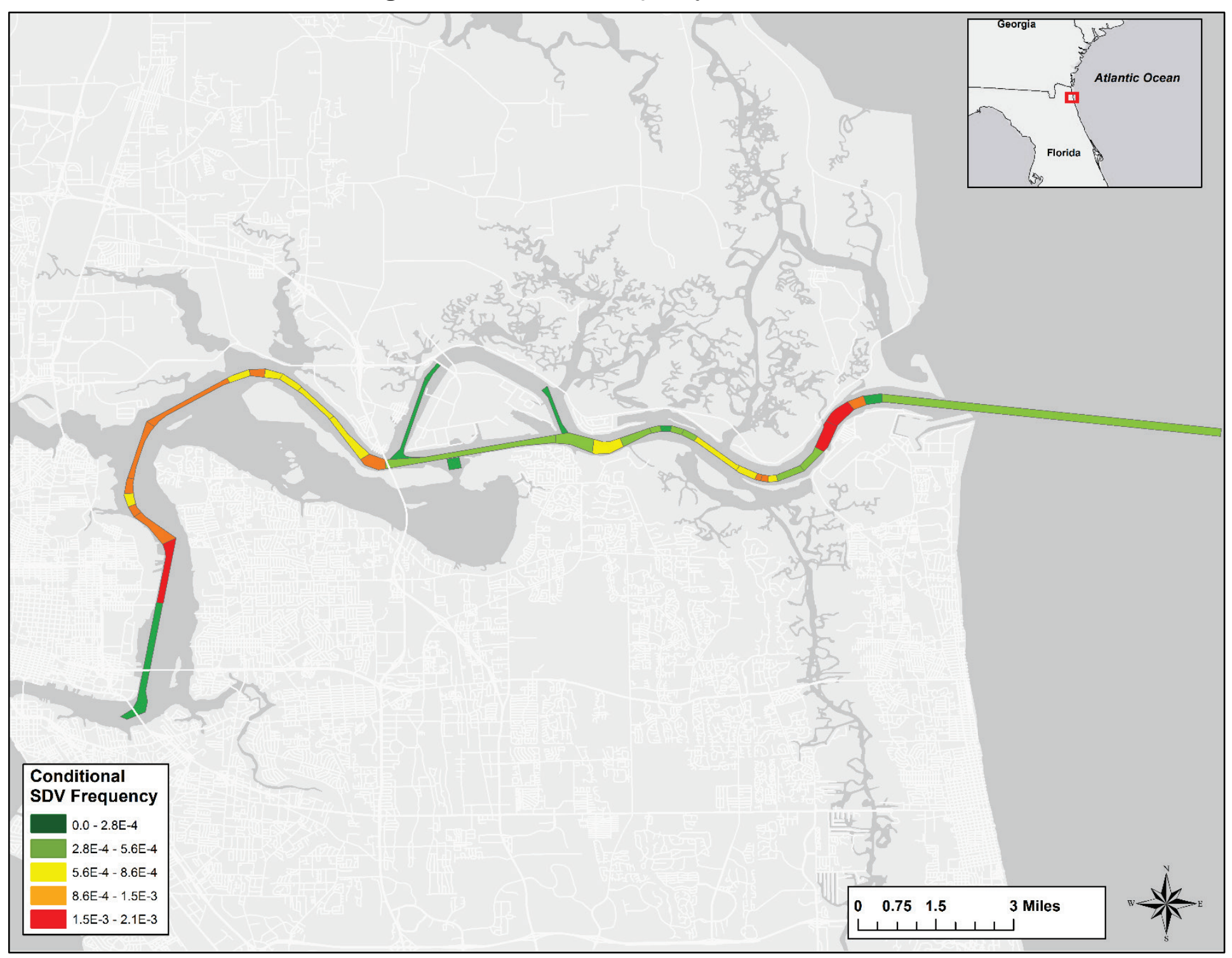

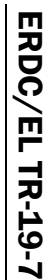


Table 7-5. Fraction of half-minute intervals during which at least one vessel is present in each JHC reach.

\begin{tabular}{|c|c|c|c|c|c|c|c|c|c|c|c|}
\hline \multirow[b]{2}{*}{$\#$} & \multirow[b]{2}{*}{ Reach Code } & \multicolumn{9}{|c|}{ AIS Ship and Cargo Type } & \multirow[b]{2}{*}{$\begin{array}{c}\text { Overall } \\
\text { Ship and } \\
\text { Cargo Types }\end{array}$} \\
\hline & & $\begin{array}{l}\text { Unknown } \\
\text { (00) }\end{array}$ & $\begin{array}{c}\text { WIG } \\
(20-29)\end{array}$ & $\begin{array}{c}\text { Class } 3 \\
(30,33-39)\end{array}$ & $\begin{array}{l}\text { High-Speed } \\
\text { (40-49) }\end{array}$ & $\begin{array}{l}\text { Harbor } \\
\text { Boats } \\
(50-59)\end{array}$ & $\begin{array}{l}\text { Passenger } \\
\text { (60-69) }\end{array}$ & $\begin{array}{l}\text { Cargo } \\
(70-79)\end{array}$ & $\begin{array}{l}\text { Tankers } \\
(80-89)\end{array}$ & $\begin{array}{c}\text { Other } \\
\text { (90-99) }\end{array}$ & \\
\hline 1 & BarCut-3 & 0.00085 & 0 & 0.021962 & 0 & - & 0.007157 & 0.118774 & 0.016239 & 0.004984 & 0.164438 \\
\hline 2 & Cut-4 & $6.28 \mathrm{E}-05$ & 0 & 0.00165 & 0 & - & 0.000602 & 0.009808 & 0.001201 & 0.000446 & 0.013749 \\
\hline 3 & Cut-5 & 4.38E-05 & 0 & 0.001549 & 0 & - & 0.000568 & 0.009293 & 0.001109 & 0.000341 & 0.012883 \\
\hline 4 & Cut-6 & 0.000136 & 0 & 0.003539 & 0 & - & 0.033983 & 0.018244 & 0.00217 & 0.000774 & 0.058126 \\
\hline 5 & Cut-7 & 0.000121 & 0 & 0.00313 & 0 & - & 0.049765 & 0.02029 & 0.002368 & 0.000859 & 0.07519 \\
\hline 6 & Cut-8 & $9.8 \mathrm{E}-05$ & 0 & 0.001898 & 0 & - & 0.000994 & 0.016651 & 0.002001 & 0.000244 & 0.021851 \\
\hline 7 & Cut-9 & 7.99E-05 & 0 & 0.001672 & 0 & - & 0.0009 & 0.014833 & 0.001805 & 0.000234 & 0.019503 \\
\hline 8 & Cut-10 & 2.19E-05 & 0 & 0.000486 & 0 & - & 0.000285 & 0.004636 & 0.000589 & 0.000108 & 0.006124 \\
\hline 9 & Cut-11 & 1.81E-05 & 0 & 0.000374 & 0 & - & 0.000202 & 0.003568 & 0.000421 & 4.76E-05 & 0.004629 \\
\hline 10 & Cut-12 & $1.52 \mathrm{E}-05$ & 0 & 0.000363 & 0 & - & 0.000174 & 0.002916 & 0.000364 & 3.81E-05 & 0.00387 \\
\hline 11 & Cut-13 & 6.94E-05 & 0 & 0.001809 & 0 & - & 0.000682 & 0.01098 & 0.001353 & 0.000245 & 0.015125 \\
\hline 12 & Cut-14/15 & 0.000197 & 0 & 0.004595 & 0 & - & 0.001888 & 0.02798 & 0.003449 & 0.000303 & 0.03818 \\
\hline 13 & Cut-16 & 5.61E-05 & 0 & 0.001078 & 0 & - & 0.000525 & 8.10E-03 & 0.000981 & 0.000122 & 0.010859 \\
\hline 14 & Cut-17 & 3.14E-05 & 0 & 0.000791 & $0.00 E+00$ & - & 0.000422 & 0.006771 & 0.000812 & 5.42E-05 & 0.008881 \\
\hline 15 & Cut-18 & 2.95E-05 & 0 & 0.000518 & 0 & - & 0.000331 & 0.005426 & 0.000664 & 4.09E-05 & 0.007008 \\
\hline 16 & Cut-19 & 4.47E-05 & 0 & 0.000609 & 0 & - & 0.000342 & 0.005652 & 0.000689 & 5.33E-05 & 0.007386 \\
\hline 17 & Cut-39 & 0.000226 & 0 & 0.00224 & 0 & - & 1.01E-03 & 0.016637 & 0.002004 & 0.000147 & 0.022206 \\
\hline 18 & Cut-40 & 7.99E-05 & 0 & 0.001792 & 0 & - & 0.000937 & 0.015907 & 0.001871 & 0.00012 & 0.020648 \\
\hline 19 & Cut-41 & 0.000149 & 0 & 0.003557 & 0 & - & 0.001351 & 0.023026 & 0.002597 & 0.00022 & 0.03075 \\
\hline 20 & Cut-42 & 0.000531 & 0 & 0.012623 & 0 & - & 0.006556 & 0.106003 & 0.012349 & 0.000819 & 0.135577 \\
\hline 21 & Cut-43 & 7.9E-05 & 0 & 0.001614 & 0 & - & 0.000891 & 0.005979 & 0.001586 & 8.47E-05 & 0.01021 \\
\hline 22 & Cut-44 & 1.63E-04 & 0 & 0.003833 & 0 & - & 0.002134 & 0.013003 & 0.003983 & 0.000231 & 0.023258 \\
\hline
\end{tabular}




\begin{tabular}{|c|c|c|c|c|c|c|c|c|c|c|c|}
\hline \multirow[b]{2}{*}{$\#$} & \multirow[b]{2}{*}{ Reach Code } & \multicolumn{9}{|c|}{ AIS Ship and Cargo Type } & \multirow[b]{2}{*}{$\begin{array}{c}\text { Overall } \\
\text { Ship and } \\
\text { Cargo Types }\end{array}$} \\
\hline & & $\begin{array}{l}\text { Unknown } \\
(00)\end{array}$ & $\begin{array}{c}\text { WIG } \\
(20-29)\end{array}$ & $\begin{array}{c}\text { Class } 3 \\
(30,33-39)\end{array}$ & $\begin{array}{l}\text { High-Speed } \\
\text { (40-49) }\end{array}$ & $\begin{array}{l}\text { Harbor } \\
\text { Boats } \\
(50-59)\end{array}$ & $\begin{array}{l}\text { Passenger } \\
\text { (60-69) }\end{array}$ & $\begin{array}{l}\text { Cargo } \\
(70-79)\end{array}$ & $\begin{array}{l}\text { Tankers } \\
\text { (80-89) }\end{array}$ & $\begin{array}{l}\text { Other } \\
\text { (90-99) }\end{array}$ & \\
\hline 23 & Cut-45 & $1.08 \mathrm{E}-04$ & 0 & 0.002754 & 0 & - & 1.86E-03 & 0.005998 & 0.00344 & 0.00016 & 0.014296 \\
\hline 24 & Cut-46 & $1.50 \mathrm{E}-04$ & 0 & 0.001582 & 0 & - & 6.35E-04 & 0.003144 & 0.002016 & 8.37E-05 & 0.007595 \\
\hline 25 & Cut-47 & 2.09E-05 & 0 & 0.001232 & 0 & - & $7.59 \mathrm{E}-04$ & 0.002388 & 0.001603 & $6.47 \mathrm{E}-05$ & 0.006055 \\
\hline 26 & Cut-48 & $1.52 \mathrm{E}-05$ & 0 & 0.001028 & 0 & - & 9.23E-05 & 0.002167 & 0.001796 & 5.33E-05 & 0.005141 \\
\hline 27 & Cut-49 & $2.76 \mathrm{E}-05$ & 0 & 0.001352 & 0 & - & 0.000144 & 0.003378 & 0.003389 & 8.18E-05 & 0.008361 \\
\hline 28 & Cut-50 & $1.08 \mathrm{E}-04$ & 0 & 0.005554 & 0 & - & $5.57 \mathrm{E}-04$ & 0.012363 & 0.004727 & 0.000329 & 0.023538 \\
\hline 29 & Cut-51 & 7.13E-05 & 0 & 0.00386 & 0 & - & 0.000399 & 0.009384 & 0.003558 & 0.000264 & 0.017494 \\
\hline 30 & Cut-52 & $1.14 \mathrm{E}-05$ & 0 & 0.001084 & 0 & - & 0.000107 & 0.002984 & 0.001455 & 9.32E-05 & 0.005726 \\
\hline 31 & Cut-53 & $1.24 \mathrm{E}-05$ & 0 & 0.0008 & 0 & - & 8.47E-05 & 0.002616 & 0.000854 & 5.14E-05 & 0.004416 \\
\hline 32 & Cut-54 & 1.05E-05 & 0 & 0.00064 & 0 & - & $7.9 \mathrm{E}-05$ & 0.002265 & 0.00066 & 4.28E-05 & 0.003693 \\
\hline 33 & Cut-55 & 3.14E-05 & 0 & 0.002746 & 0 & - & $2.75 \mathrm{E}-04$ & 0.008846 & 0.002894 & 0.000148 & 0.014883 \\
\hline 34 & Lower Terminal Reach & 6.37E-05 & 0 & 0.004988 & 0 & - & 0.000435 & 0.021172 & 0.003645 & 0.000414 & 0.030608 \\
\hline 35 & Upper Terminal Reach & 0.000207 & 0 & 0.009583 & $0.00 E+00$ & - & 0.001017 & 0.002275 & 0.000344 & 0.000463 & 0.013858 \\
\hline 36 & Cut-A Old River & $1.24 \mathrm{E}-05$ & 0 & 0.000298 & 0 & - & 0 & 0 & 0 & 0 & 0.00031 \\
\hline 37 & Cut-F Old River & 2.57E-05 & 0 & 2.19E-05 & 0 & - & 0 & 0.00112 & 0 & 0 & 0.001167 \\
\hline 38 & Cut-G Old River & 0.000107 & 0 & 0.000563 & $0.00 E+00$ & - & 4.76E-06 & 0.030065 & 5.71E-06 & 0 & 0.030733 \\
\hline 39 & $\begin{array}{l}\text { Advance Maintenance } \\
\text { Settling Basin }\end{array}$ & $3.81 \mathrm{E}-06$ & 0 & 0.000263 & 0 & - & 0 & 0 & 0 & 0 & 0.000266 \\
\hline \multicolumn{2}{|r|}{ Overall navigation channels } & 0.004091 & 0 & 0.099096 & 0 & - & 0.114466 & 0.411281 & 0.086357 & 0.012643 & 0.576542 \\
\hline
\end{tabular}


Table 7-6. Unconditional frequency of SDVs in JHC by reach and vessel type. Frequencies greater than $1 \times 10^{-5}$ are in bold red typeface.

\begin{tabular}{|c|c|c|c|c|c|c|c|c|c|c|c|}
\hline \multirow[b]{2}{*}{$\#$} & \multirow[b]{2}{*}{ Reach Code } & \multicolumn{9}{|c|}{ AIS Ship and Cargo Type } & \multirow[b]{2}{*}{$\begin{array}{c}\text { Overall } \\
\text { Ship and } \\
\text { Cargo Types }\end{array}$} \\
\hline & & $\begin{array}{l}\text { Unknown } \\
\text { (00) }\end{array}$ & $\begin{array}{c}\text { WIG } \\
(20-29)\end{array}$ & $\begin{array}{c}\text { Class } 3 \\
(30,33-39)\end{array}$ & $\begin{array}{l}\text { High-Speed } \\
\text { (40-49) }\end{array}$ & $\begin{array}{l}\text { Harbor } \\
\text { Boats } \\
(50-59)\end{array}$ & $\begin{array}{l}\text { Passenger } \\
\text { (60-69) }\end{array}$ & $\begin{array}{l}\text { Cargo } \\
(70-79)\end{array}$ & $\begin{array}{l}\text { Tankers } \\
(80-89)\end{array}$ & $\begin{array}{l}\text { Other } \\
(90-99)\end{array}$ & \\
\hline 1 & Barcut-3 & $0.00 E+00$ & - & $2.56 \mathrm{E}-05$ & - & - & $0.00 E+00$ & $5.04 \mathrm{E}-05$ & $3.79 \mathrm{E}-06$ & $0.00 E+00$ & $7.74 \mathrm{E}-05$ \\
\hline 2 & Cut-4 & $0.00 E+00$ & - & $9.49 \mathrm{E}-07$ & - & - & $0.00 E+00$ & $2.85 \mathrm{E}-06$ & $0.00 E+00$ & $0.00 \mathrm{E}+00$ & 3.79E-06 \\
\hline 3 & Cut-5 & $0.00 \mathrm{E}+00$ & - & $1.89 \mathrm{E}-06$ & - & - & $0.00 E+00$ & $1.14 \mathrm{E}-05$ & $0.00 E+00$ & $0.00 \mathrm{E}+00$ & 1.33E-05 \\
\hline 4 & Cut-6 & $0.00 E+00$ & - & 2.84E-06 & - & - & $1.52 \mathrm{E}-05$ & $8.51 \mathrm{E}-05$ & 1.33E-05 & $0.00 E+00$ & $1.15 E-04$ \\
\hline 5 & Cut-7 & $0.00 E+00$ & - & 7.56E-06 & - & - & $7.60 \mathrm{E}-06$ & $1.14 \mathrm{E}-04$ & $1.04 \mathrm{E}-05$ & $0.00 E+00$ & $1.38 \mathrm{E}-04$ \\
\hline 6 & Cut-8 & $0.00 \mathrm{E}+00$ & - & 4.70E-06 & - & - & $0.00 \mathrm{E}+00$ & 7.60E-06 & $0.00 \mathrm{E}+00$ & $0.00 \mathrm{E}+00$ & $1.23 E-05$ \\
\hline 7 & Cut-9 & $0.00 \mathrm{E}+00$ & - & $9.44 \mathrm{E}-07$ & - & - & $0.00 E+00$ & $6.65 \mathrm{E}-06$ & $0.00 E+00$ & $0.00 \mathrm{E}+00$ & 7.59E-06 \\
\hline 8 & Cut-10 & $0.00 \mathrm{E}+00$ & - & $0.00 \mathrm{E}+00$ & - & - & $0.00 \mathrm{E}+00$ & $2.85 \mathrm{E}-06$ & 9.51E-07 & $0.00 \mathrm{E}+00$ & 3.80E-06 \\
\hline 9 & Cut-11 & $0.00 \mathrm{E}+00$ & - & $9.46 \mathrm{E}-07$ & - & - & $0.00 E+00$ & $1.90 \mathrm{E}-06$ & $1.90 \mathrm{E}-06$ & $0.00 \mathrm{E}+00$ & $4.75 \mathrm{E}-06$ \\
\hline 10 & Cut-12 & $0.00 \mathrm{E}+00$ & - & $9.46 \mathrm{E}-07$ & - & - & $0.00 \mathrm{E}+00$ & 1.90E-06 & 9.51E-07 & $0.00 \mathrm{E}+00$ & 3.80E-06 \\
\hline 11 & Cut-13 & $0.00 E+00$ & - & $3.78 \mathrm{E}-06$ & - & - & $0.00 E+00$ & 5.70E-06 & $0.00 E+00$ & $0.00 E+00$ & 9.49E-06 \\
\hline 12 & Cut-14/15 & 9.51E-07 & - & 5.60E-06 & - & - & $9.51 \mathrm{E}-07$ & $1.88 \mathrm{E}-05$ & 9.51E-07 & $0.00 E+00$ & 2.71E-05 \\
\hline 13 & Cut-16 & $0.00 \mathrm{E}+00$ & - & $1.89 \mathrm{E}-06$ & - & - & $0.00 E+00$ & 3.80E-06 & $0.00 \mathrm{E}+00$ & $0.00 \mathrm{E}+00$ & 5.70E-06 \\
\hline 14 & Cut-17 & $0.00 E+00$ & - & $1.89 \mathrm{E}-06$ & - & - & $0.00 E+00$ & $2.85 \mathrm{E}-06$ & $0.00 E+00$ & $0.00 E+00$ & $4.75 \mathrm{E}-06$ \\
\hline 15 & Cut-18 & $0.00 E+00$ & - & $0.00 E+00$ & - & - & $0.00 E+00$ & 1.90E-06 & $0.00 E+00$ & $0.00 E+00$ & $1.90 \mathrm{E}-06$ \\
\hline 16 & Cut-19 & $0.00 \mathrm{E}+00$ & - & $9.47 \mathrm{E}-07$ & - & - & $0.00 E+00$ & 1.90E-06 & $0.00 E+00$ & $0.00 E+00$ & $2.85 \mathrm{E}-06$ \\
\hline 17 & Cut-39 & $0.00 \mathrm{E}+00$ & - & 3.76E-06 & - & - & $0.00 \mathrm{E}+00$ & 5.64E-06 & $0.00 E+00$ & $0.00 \mathrm{E}+00$ & 9.39E-06 \\
\hline 18 & Cut-40 & $0.00 \mathrm{E}+00$ & - & $3.77 \mathrm{E}-06$ & - & - & $0.00 E+00$ & $9.45 \mathrm{E}-06$ & $0.00 \mathrm{E}+00$ & $0.00 \mathrm{E}+00$ & $1.32 \mathrm{E}-05$ \\
\hline 19 & Cut-41 & $0.00 E+00$ & - & 5.63E-06 & - & - & $0.00 E+00$ & 7.54E-06 & 9.50E-07 & $0.00 \mathrm{E}+00$ & $1.41 E-05$ \\
\hline 20 & Cut-42 & $0.00 \mathrm{E}+00$ & - & $2.13 \mathrm{E}-05$ & - & - & $0.00 E+00$ & 4.48E-05 & $9.41 \mathrm{E}-06$ & $0.00 E+00$ & 7.34E-05 \\
\hline 21 & Cut-43 & $0.00 \mathrm{E}+00$ & - & $3.78 \mathrm{E}-06$ & - & - & $0.00 E+00$ & 9.51E-06 & 9.51E-07 & $0.00 \mathrm{E}+00$ & $1.42 \mathrm{E}-05$ \\
\hline 22 & Cut-44 & $0.00 E+00$ & - & 6.56E-06 & - & - & $0.00 E+00$ & $7.60 \mathrm{E}-06$ & 3.79E-06 & $0.00 \mathrm{E}+00$ & 1.79E-05 \\
\hline
\end{tabular}




\begin{tabular}{|c|c|c|c|c|c|c|c|c|c|c|c|}
\hline \multirow[b]{2}{*}{$\#$} & \multirow[b]{2}{*}{ Reach Code } & \multicolumn{9}{|c|}{ AIS Ship and Cargo Type } & \multirow[b]{2}{*}{$\begin{array}{c}\text { Overall } \\
\text { Ship and } \\
\text { Cargo Types }\end{array}$} \\
\hline & & $\begin{array}{l}\text { Unknown } \\
\text { (00) }\end{array}$ & $\begin{array}{c}\text { WIG } \\
(20-29)\end{array}$ & $\begin{array}{c}\text { Class } 3 \\
(30,33-39)\end{array}$ & $\begin{array}{l}\text { High-Speed } \\
\text { (40-49) }\end{array}$ & $\begin{array}{l}\text { Harbor } \\
\text { Boats } \\
(50-59)\end{array}$ & $\begin{array}{l}\text { Passenger } \\
\text { (60-69) }\end{array}$ & $\begin{array}{l}\text { Cargo } \\
\text { (70-79) }\end{array}$ & $\begin{array}{l}\text { Tankers } \\
\text { (80-89) }\end{array}$ & $\begin{array}{l}\text { Other } \\
(90-99)\end{array}$ & \\
\hline 23 & Cut-45 & $0.00 E+00$ & - & $3.76 \mathrm{E}-06$ & - & - & $0.00 E+00$ & 6.65E-06 & $1.90 \mathrm{E}-06$ & $0.00 E+00$ & 1.23E-05 \\
\hline 24 & Cut-46 & $0.00 \mathrm{E}+00$ & - & $9.42 \mathrm{E}-07$ & - & - & $0.00 \mathrm{E}+00$ & 3.79E-06 & $0.00 \mathrm{E}+00$ & $0.00 \mathrm{E}+00$ & 4.73E-06 \\
\hline 25 & Cut-47 & $0.00 E+00$ & - & $1.88 \mathrm{E}-06$ & - & - & $0.00 \mathrm{E}+00$ & $2.85 E-06$ & $0.00 \mathrm{E}+00$ & $0.00 E+00$ & 4.74E-06 \\
\hline 26 & Cut-48 & $0.00 E+00$ & - & 2.83E-06 & - & - & $0.00 \mathrm{E}+00$ & 1.90E-06 & 1.90E-06 & $0.00 E+00$ & 6.63E-06 \\
\hline 27 & Cut-49 & $0.00 E+00$ & - & $1.88 \mathrm{E}-06$ & - & - & $0.00 \mathrm{E}+00$ & 4.75E-06 & $0.00 \mathrm{E}+00$ & $0.00 E+00$ & 6.64E-06 \\
\hline 28 & Cut-50 & $0.00 E+00$ & - & 9.30E-06 & - & - & $0.00 E+00$ & $1.61 \mathrm{E}-05$ & $0.00 E+00$ & $0.00 E+00$ & 2.53E-05 \\
\hline 29 & Cut-51 & $0.00 E+00$ & - & 8.43E-06 & - & - & $0.00 \mathrm{E}+00$ & $1.14 \mathrm{E}-05$ & $0.00 E+00$ & $0.00 E+00$ & 1.99E-05 \\
\hline 30 & Cut-52 & $0.00 E+00$ & - & $1.89 \mathrm{E}-06$ & - & - & $0.00 \mathrm{E}+00$ & $2.85 E-06$ & 3.81E-06 & $0.00 \mathrm{E}+00$ & 8.54E-06 \\
\hline 31 & Cut-53 & $0.00 E+00$ & - & $1.88 \mathrm{E}-06$ & - & - & $0.00 \mathrm{E}+00$ & 1.90E-06 & $0.00 \mathrm{E}+00$ & $0.00 E+00$ & 3.80E-06 \\
\hline 32 & Cut-54 & $0.00 E+00$ & - & $9.44 \mathrm{E}-07$ & - & - & $0.00 \mathrm{E}+00$ & $3.80 \mathrm{E}-06$ & $0.00 \mathrm{E}+00$ & $0.00 E+00$ & 4.74E-06 \\
\hline 33 & Cut-55 & $0.00 E+00$ & - & 4.71E-06 & - & - & $0.00 E+00$ & $1.13 E-05$ & $0.00 \mathrm{E}+00$ & $0.00 \mathrm{E}+00$ & 1.60E-05 \\
\hline 34 & Lower Terminal Reach & $0.00 E+00$ & - & $1.68 \mathrm{E}-05$ & - & - & $0.00 E+00$ & 4.55E-05 & $9.51 \mathrm{E}-07$ & $0.00 E+00$ & $6.32 \mathrm{E}-05$ \\
\hline 35 & Upper Terminal Reach & $0.00 \mathrm{E}+00$ & - & $0.00 \mathrm{E}+00$ & - & - & $0.00 E+00$ & $0.00 E+00$ & $0.00 E+00$ & $0.00 E+00$ & $0.00 E+00$ \\
\hline 36 & Cut-A Old River & $0.00 \mathrm{E}+00$ & - & $0.00 E+00$ & - & - & - & - & - & - & $0.00 E+00$ \\
\hline 37 & Cut-F Old River & $0.00 E+00$ & - & $0.00 E+00$ & - & - & - & $0.00 E+00$ & - & - & $0.00 E+00$ \\
\hline 38 & Cut-G Old River & $0.00 E+00$ & - & $0.00 E+00$ & - & - & $0.00 E+00$ & 5.67E-06 & $0.00 E+00$ & - & 5.66E-06 \\
\hline 39 & $\begin{array}{l}\text { Advance Maintenance } \\
\text { Settling Basin }\end{array}$ & $0.00 E+00$ & - & $0.00 E+00$ & - & - & - & - & - & - & $0.00 E+00$ \\
\hline \multicolumn{2}{|r|}{ Overall navigation channels } & 9.51E-07 & - & 1.44E-04 & - & - & 2.30E-05 & $3.69 \mathrm{E}-04$ & 5.31E-05 & $0.00 E+00$ & 4.81E-04 \\
\hline
\end{tabular}


Figure 7-6. Unconditional frequency of an SDV in JHC navigation reaches.

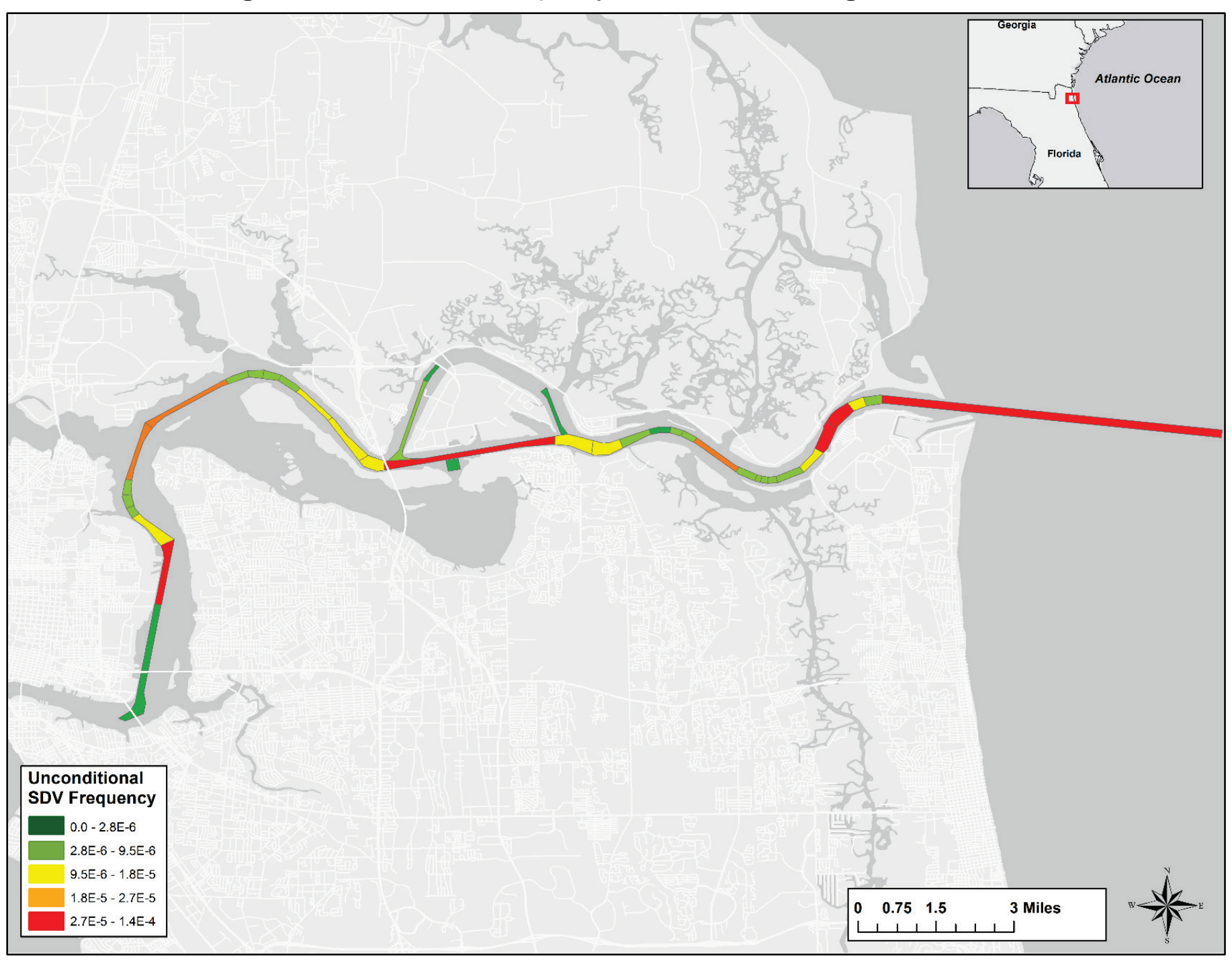

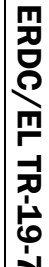


The third metric of collision risk is the relative frequency of SDVs by navigation channel reach. This metric indicates the probability that an SDV will occur in a particular reach given that one has occurred in the navigation project. It is similar to the unconditional probability of an SDV because it can be used to show where SDVs are most likely to occur in a navigation project. The relative frequency of SDVs is shown in Figure 7-7. During the 2014 calendar year, $77 \%$ of SDVs occurred at the Mayport ferry crossing (Cut-6, \#4 and Cut-7, \#5).

Figure 7-7. Relative frequency of SDVs in JHC by navigation channel reach.

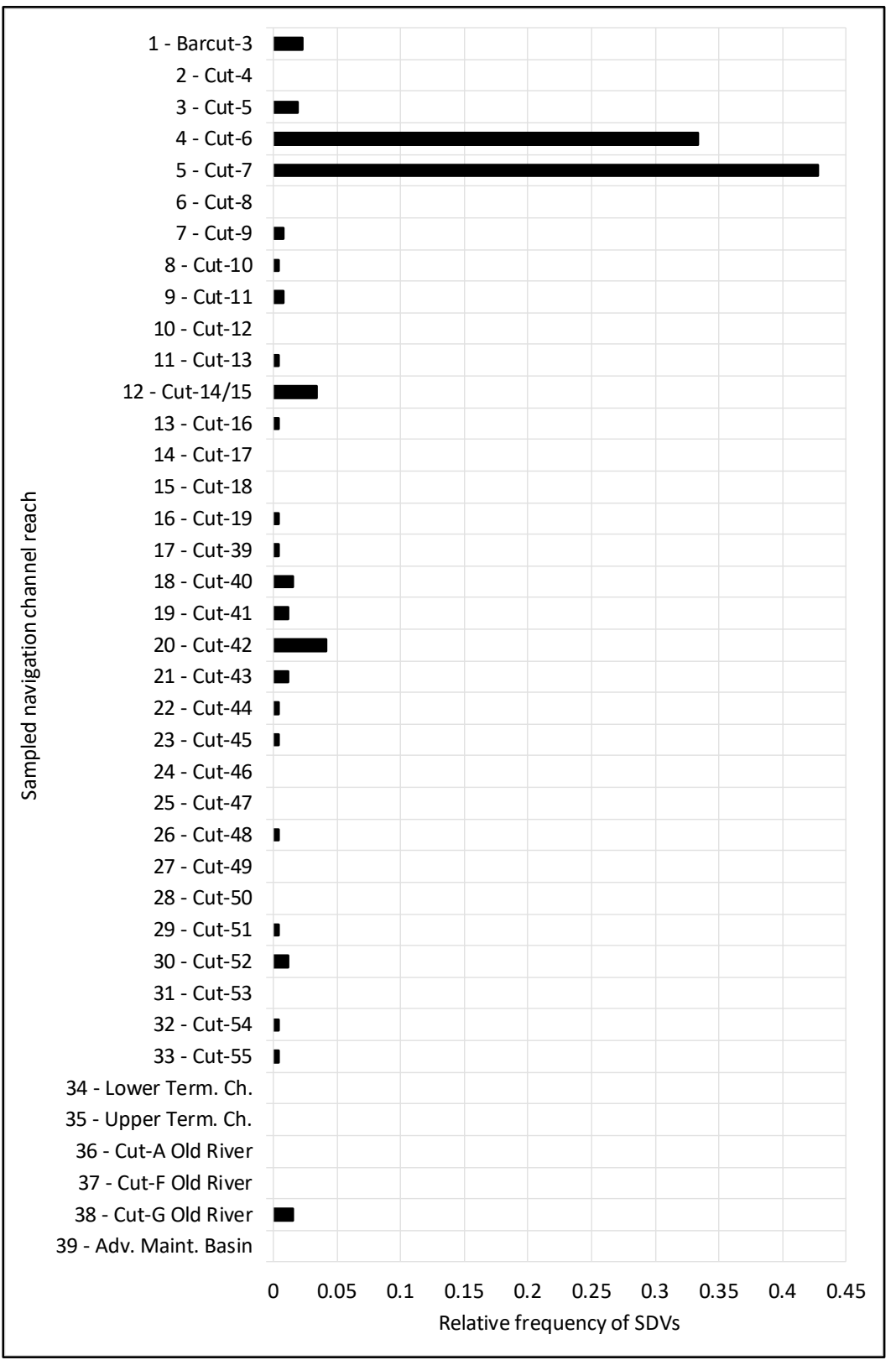


Three distinct metrics of collision risk have been calculated using the NAIS data. Some metrics are easier to calculate than others, so it is useful to consider the correlation between these metrics to assess the extent to which the information each conveys may be redundant. If each metric conveys the same information, the collision analysis might be simplified by focusing on that metric that is easiest to calculate. Table 7-7 shows the Pearson product moment correlations between four metrics that have been calculated for each reach, including the three risk metrics of collision risk and the probability that at least one vessel is present in the reach. The correlation between the conditional probability of an SDV, $p$ SDV $\mid n_{j k t} \geq 1$ ), and the probability of at least one vessel being present in the reach, $p\left(n_{j k t} \geq 1\right)$, is 0.0978 . The correlation between the unconditional probability of an SDV, $p(\mathrm{SDV})$, and the relative frequency of SDVs, $f_{k}$, is 0.5629 and 0.5170 , respectively. The correlation between the overall probability of an SDV and the relative frequency of SDVs is 0.8540 , indicating that these two metrics provide similar information.

Table 7-7 Pearson correlation matrix for collision risk metrics in JHC.

\begin{tabular}{|c|c|c|c|c|}
\hline Metric of Collision Risk & $p\left(\mathrm{SDV} \mid n_{k t} \geq 1\right)$ & $p\left(n_{k t} \geq 1\right)$ & $p(\mathrm{SDV})$ & $f_{k}$ \\
\hline$p\left(\mathrm{SDV} \mid n_{k t} \geq 1\right)$ & 1.0000 & 0.0978 & 0.5629 & 0.5170 \\
\hline$p\left(n_{k t} \geq 1\right)$ & - & 1.0000 & 0.7384 & 0.3832 \\
\hline$p(\mathrm{SDV})$ & - & - & 1.0000 & 0.8540 \\
\hline$f_{k}$ & - & - & - & 1.0000 \\
\hline
\end{tabular}

\subsection{Grounding analysis}

\subsubsection{Powered groundings on the side of the channel}

Deep draft vessels operating at the edge of the channel risk grounding on the channel side. Channel side events occur when the keel line of a vessel comes within $55 \%$ of one beam's width from the edge of the channel. Figure 7-8 shows the location of channel side events in JHC. These have been screened to include only those vessels drafting more than $7.5 \mathrm{~m}$ and traveling at a speed of 7.5 knots or greater. This effectively excludes smaller vessels that may not be confined to the channel because they have shallow draft, vessels that are moored at the edge of the channel, and 
vessels that are being pushed around by a tug. As in Columbia River, channel side events occur throughout the navigation project.

More information can be gleaned from detailed maps of channel side events. Figure 7-9 shows a detailed map of channel side events in the vicinity of Mile Point (Figure 7-9a) and in the vicinity of Bartram Island (Figure 7-9b). There is a high concentration of channel side events on the north side of the channel in Cut-4 (\#2) and Cut-5 (\#3), at the entrance to JHC. There is also a heavy concentration of channel side events on the southern edge of the navigation channel at Mile Point. This may reflect difficulty operating within the channel at this location. However, there are also channel side events on the northern edge of the channel. For example, the track of one vessel, a $115 \mathrm{~m}$ container vessel named Orient Spirit (MMSI 376482000), can be seen cutting the inside corner of the turn while headed into port.

A detail view of channel side events in the vicinity of Bartram Island can be seen in Figure 7-9(b). Vessels can be seen accessing the private container Terminal at Blount Island, where most of the channel side events are on the north side of the channel. There is a distinct absence of channel side events on the inside turn at Bartram Island and on the northern edge of the Cut-50. However, there is a concentration of channel side events on the northern edge of Cut-50 near the U.S. Navy Fuel Depot. Some of these are tankers that may be accessing the fuel depot, but a large fraction of these appear to be container vessels. A detail view of channel side events near Talleyrand Terminal and downtown Jacksonville is shown in Figure 7-10. This figure shows cargo vessels and tankers utilizing the eastern edge of the navigation channel in the turn approaching Talleyrand Terminal and in front of the terminal. 
Figure 7-8. Channel side events in Jacksonville Harbor.

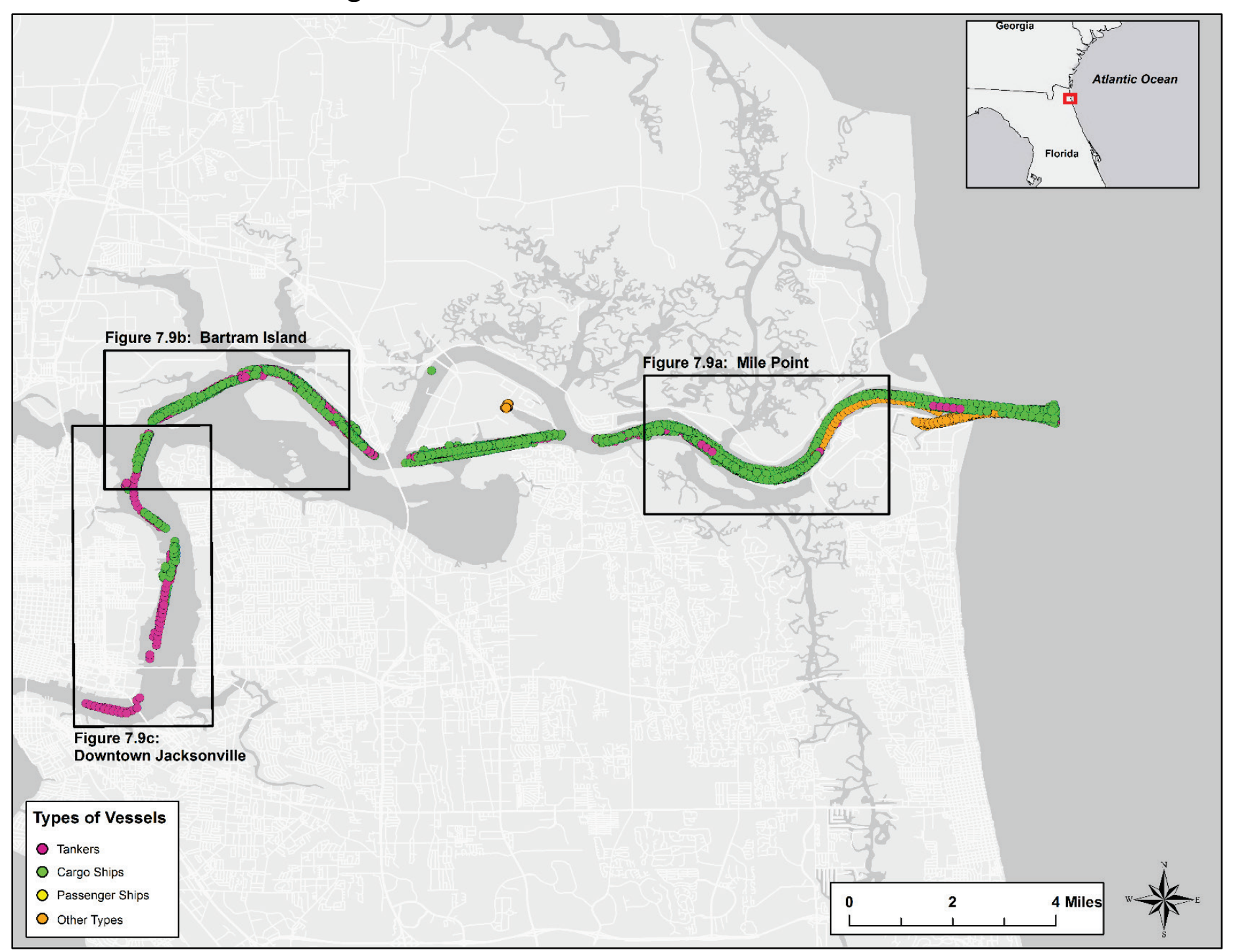


Figure 7-9. Detail map of channel side events near (a) Mile Point and

(b) Bartram Island.
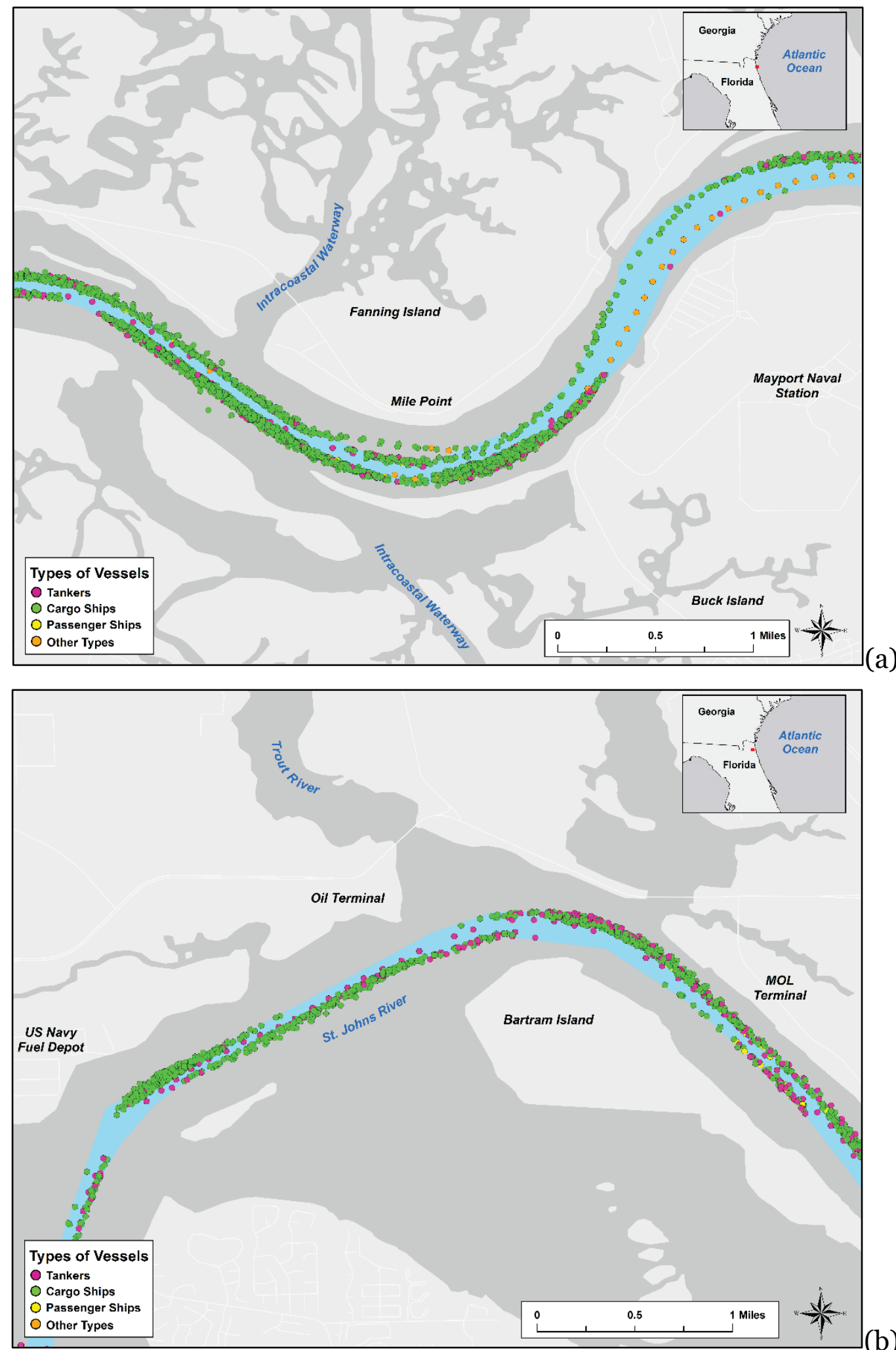
Figure 7-10. Detail map of channel side events near Talleyrand Terminal and downtown Jacksonville.

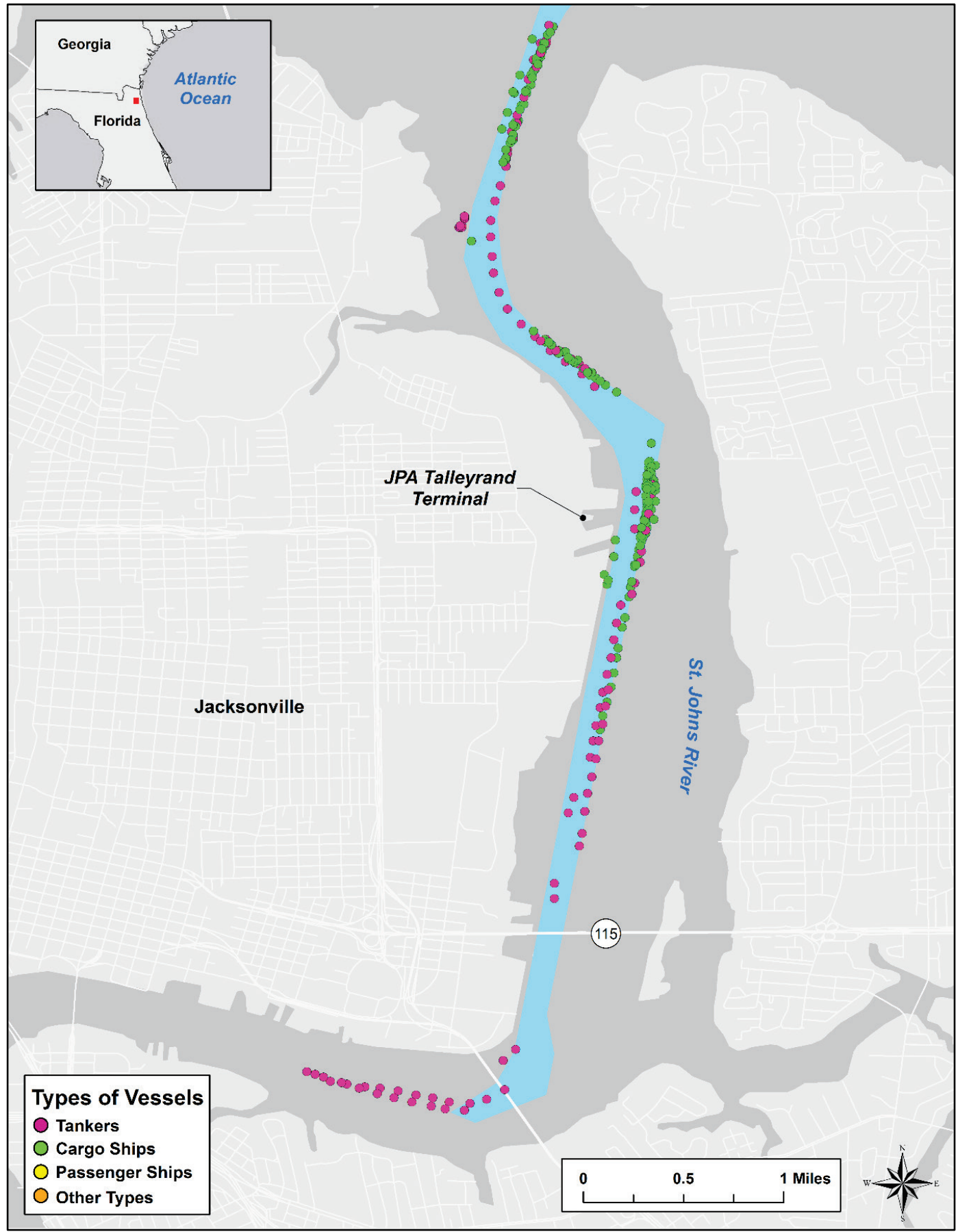

In contrast to maps of channel side events in other ports, those shown in Figures 7-9 and 7-10 indicate there are numerous channel side events closer toward the middle of the channel. For example, in Figure 7-9(a), there is a string of position reports that have been classified as channel 
side events and that extend from Mile Point to the entrance range (Barcut3). These position reports, which are most clearly visible in the turn at Mayport and are from a $289 \mathrm{~m}$ United States Navy supply ship. The vessel reports a heading that indicates its keel is perpendicular to the channel and a course and speed that indicate it is moving down the channel at approximately 9 knots. One possibility is that this vessel is moving perpendicular to the channel center line with the assistance of a tug assist, but it seems unusual for a vessel of this size to be moving this distance while situated perpendicular to the channel center line. Another possibility is that the vessel heading has not been reported correctly.

Although not as clearly visible in Figure 7-10, there is a similar string of points in the turn north of Talleyrand Terminal. These position reports are from the $144 \mathrm{~m}$ tanker, which can be seen moving down river perpendicular to the channel at a speed of 9.7 knots. The tanker can also be seen in Figure 7-9(b), in front of the fuel depot west of Bartram Island. It is moving down river at 9 knots and is perpendicular to the channel center line. In Figure 7-9(a), the tanker can be seen at the intersection of St. Johns River with the Intracoastal Waterway, moving perpendicular to the channel center line at a speed of approximately 11 knots. Again, it seems unusual to see a vessel of this size moving perpendicular to the channel, and it may be that the heading of this vessel has not been reported correctly.

\subsubsection{Powered groundings on a shoal in the channel}

Vessels that are depth limited have maximum design drafts that are greater than available depth. The number and fraction of cargo vessels (70-79) that are depth limited in JHC channels are reported in Table 7-8. Only those reaches that have cargo traffic have been listed in the table. The table shows that, at maintenance depth, fewer than $10 \%$ of cargo vessels are depth limited. The table also shows that, as available depth is reduced to simulate shoaling, the fraction of vessels that are depth limited increases. A $6 \mathrm{ft}$ reduction in available depth increases the fraction of depth-limited cargo vessels to as much as $25 \%$. The same analysis has been completed for tankers (80-89) in JHC, and the results, which are summarized in Table 7-9, are similar to those for cargo vessels. 
Table 7-8. Depth-limited fraction of cargo vessels in JHC.

\begin{tabular}{|c|c|c|c|c|c|c|c|c|c|c|}
\hline \multirow{2}{*}{ \# } & \multirow{2}{*}{ Reach Code } & \multirow{2}{*}{$\begin{array}{c}\text { Main- } \\
\text { tenance Depth } \\
(\mathrm{ft})\end{array}$} & \multirow{2}{*}{$\begin{array}{c}\text { Number of } \\
\text { Unique Vessels }\end{array}$} & \multicolumn{7}{|c|}{ Reduction in Maintenance Depth (ft) } \\
\hline & & & & 0 & 1 & 2 & 3 & 4 & 5 & 6 \\
\hline 1 & Barcut-3 & 42 & 493 & 8/0.016 & $17 / 0.034$ & 25/0.051 & 44/0.089 & $64 / 0.13$ & $82 / 0.166$ & $96 / 0.195$ \\
\hline 2 & Cut-4 & 40 & 492 & 25/0.051 & 44/0.089 & $64 / 0.13$ & $82 / 0.167$ & 96/0.195 & $110 / 0.224$ & $122 / 0.248$ \\
\hline 3 & Cut-5 & 40 & 492 & 25/0.051 & 44/0.089 & $64 / 0.13$ & $82 / 0.167$ & 96/0.195 & $110 / 0.224$ & $122 / 0.248$ \\
\hline 4 & Cut-6 & 40 & 492 & 25/0.051 & 44/0.089 & $64 / 0.13$ & $82 / 0.167$ & 96/0.195 & $110 / 0.224$ & $122 / 0.248$ \\
\hline 5 & Cut-7 & 40 & 492 & 25/0.051 & 44/0.089 & $64 / 0.13$ & $82 / 0.167$ & 96/0.195 & $110 / 0.224$ & $122 / 0.248$ \\
\hline 6 & Cut-8 & 40 & 492 & 25/0.051 & 44/0.089 & $64 / 0.13$ & $82 / 0.167$ & 96/0.195 & $110 / 0.224$ & $122 / 0.248$ \\
\hline 7 & Cut-9 & 40 & 492 & 25/0.051 & 44/0.089 & $64 / 0.13$ & $82 / 0.167$ & 96/0.195 & $110 / 0.224$ & $122 / 0.248$ \\
\hline 8 & Cut-10 & 40 & 492 & 25/0.051 & 44/0.089 & $64 / 0.13$ & $82 / 0.167$ & 96/0.195 & $110 / 0.224$ & $122 / 0.248$ \\
\hline 9 & Cut-11 & 40 & 492 & 25/0.051 & 44/0.089 & $64 / 0.13$ & $82 / 0.167$ & 96/0.195 & $110 / 0.224$ & $122 / 0.248$ \\
\hline 10 & Cut-12 & 40 & 489 & 25/0.051 & 44/0.09 & 64/0.131 & $82 / 0.168$ & 96/0.196 & $110 / 0.225$ & $122 / 0.249$ \\
\hline 11 & Cut-13 & 40 & 492 & 25/0.051 & 44/0.089 & $64 / 0.13$ & $82 / 0.167$ & 96/0.195 & $110 / 0.224$ & $122 / 0.248$ \\
\hline 12 & Cut-14/15 & 40 & 492 & 25/0.051 & 44/0.089 & $64 / 0.13$ & $82 / 0.167$ & 96/0.195 & $110 / 0.224$ & $122 / 0.248$ \\
\hline 13 & Cut-16 & 40 & 490 & 25/0.051 & 44/0.09 & $64 / 0.131$ & $82 / 0.167$ & $96 / 0.196$ & $110 / 0.224$ & $121 / 0.247$ \\
\hline 14 & Cut-17 & 40 & 491 & 25/0.051 & $44 / 0.09$ & $64 / 0.13$ & $82 / 0.167$ & 96/0.196 & $110 / 0.224$ & $122 / 0.248$ \\
\hline 15 & Cut-18 & 40 & 491 & $25 / 0.051$ & 44/0.09 & $64 / 0.13$ & $82 / 0.167$ & 96/0.196 & $110 / 0.224$ & $122 / 0.248$ \\
\hline 16 & Cut-19 & 40 & 491 & 25/0.051 & 44/0.09 & $64 / 0.13$ & $82 / 0.167$ & 96/0.196 & $110 / 0.224$ & $122 / 0.248$ \\
\hline 17 & Cut-39 & 40 & 491 & 25/0.051 & $44 / 0.09$ & $64 / 0.13$ & $82 / 0.167$ & 96/0.196 & $110 / 0.224$ & $122 / 0.248$ \\
\hline 18 & Cut-40 & 40 & 491 & 25/0.051 & $44 / 0.09$ & $64 / 0.13$ & $82 / 0.167$ & 96/0.196 & $110 / 0.224$ & $122 / 0.248$ \\
\hline 19 & Cut-41 & 40 & 491 & 25/0.051 & 44/0.09 & $64 / 0.13$ & $82 / 0.167$ & 96/0.196 & $110 / 0.224$ & $122 / 0.248$ \\
\hline 20 & Cut-42 & 40 & 490 & 25/0.051 & $44 / 0.09$ & $64 / 0.131$ & $82 / 0.167$ & $96 / 0.196$ & $110 / 0.224$ & $122 / 0.249$ \\
\hline 21 & Cut-43 & 40 & 193 & $19 / 0.098$ & 33/0.171 & $50 / 0.259$ & $62 / 0.321$ & 73/0.378 & $82 / 0.425$ & $90 / 0.466$ \\
\hline 22 & Cut-44 & 40 & 193 & $19 / 0.098$ & 33/0.171 & $50 / 0.259$ & $62 / 0.321$ & 73/0.378 & $82 / 0.425$ & $90 / 0.466$ \\
\hline 23 & Cut-45 & 40 & 115 & 4/0.035 & $5 / 0.043$ & $9 / 0.078$ & $13 / 0.113$ & $15 / 0.13$ & $20 / 0.174$ & $24 / 0.209$ \\
\hline
\end{tabular}




\begin{tabular}{|c|c|c|c|c|c|c|c|c|c|c|}
\hline \multirow{2}{*}{ \# } & \multirow{2}{*}{ Reach Code } & \multirow{2}{*}{$\begin{array}{c}\text { Main- } \\
\text { tenance Depth } \\
(\mathrm{ft})\end{array}$} & \multirow{2}{*}{$\begin{array}{c}\text { Number of } \\
\text { Unique Vessels }\end{array}$} & \multicolumn{7}{|c|}{ Reduction in Maintenance Depth (ft) } \\
\hline & & & & 0 & 1 & 2 & 3 & 4 & 5 & 6 \\
\hline 24 & Cut-46 & 40 & 115 & 4/0.035 & $5 / 0.043$ & $9 / 0.078$ & $13 / 0.113$ & $15 / 0.13$ & $20 / 0.174$ & 24/0.209 \\
\hline 25 & Cut-47 & 40 & 114 & 4/0.035 & $5 / 0.044$ & $9 / 0.079$ & $13 / 0.114$ & $15 / 0.132$ & $20 / 0.175$ & $24 / 0.211$ \\
\hline 26 & Cut-48 & 40 & 114 & 4/0.035 & $5 / 0.044$ & $9 / 0.079$ & $13 / 0.114$ & $15 / 0.132$ & 20/0.175 & $24 / 0.211$ \\
\hline 27 & Cut-49 & 40 & 114 & 4/0.035 & $5 / 0.044$ & $9 / 0.079$ & $13 / 0.114$ & $15 / 0.132$ & $20 / 0.175$ & $24 / 0.211$ \\
\hline 28 & Cut-50 & 40 & 114 & 4/0.035 & $5 / 0.044$ & $9 / 0.079$ & $13 / 0.114$ & $15 / 0.132$ & $20 / 0.175$ & $24 / 0.211$ \\
\hline 29 & Cut-51 & 40 & 114 & 4/0.035 & $5 / 0.044$ & 9/0.079 & $13 / 0.114$ & $15 / 0.132$ & $20 / 0.175$ & $24 / 0.211$ \\
\hline 30 & Cut-52 & 40 & 114 & 4/0.035 & $5 / 0.044$ & $9 / 0.079$ & $13 / 0.114$ & $15 / 0.132$ & $20 / 0.175$ & $24 / 0.211$ \\
\hline 31 & Cut-53 & 40 & 114 & 4/0.035 & $5 / 0.044$ & 9/0.079 & $13 / 0.114$ & $15 / 0.132$ & $20 / 0.175$ & $24 / 0.211$ \\
\hline 32 & Cut-54 & 40 & 114 & 4/0.035 & $5 / 0.044$ & 9/0.079 & $13 / 0.114$ & $15 / 0.132$ & $20 / 0.175$ & $24 / 0.211$ \\
\hline 33 & Cut-55 & 40 & 114 & 4/0.035 & $5 / 0.044$ & $9 / 0.079$ & $13 / 0.114$ & $15 / 0.132$ & $20 / 0.175$ & $24 / 0.211$ \\
\hline 34 & $\begin{array}{l}\text { Lower Terminal } \\
\text { Channel }\end{array}$ & 40 & 110 & $4 / 0.036$ & $5 / 0.045$ & $9 / 0.082$ & $13 / 0.118$ & $15 / 0.136$ & 20/0.182 & $24 / 0.218$ \\
\hline 35 & $\begin{array}{l}\text { Upper Terminal } \\
\text { Channel }\end{array}$ & 34 & 34 & $1 / 0.029$ & $2 / 0.059$ & $2 / 0.059$ & $2 / 0.059$ & $5 / 0.147$ & $9 / 0.265$ & $11 / 0.324$ \\
\hline 37 & Cut-F Old River & 38 & 21 & $4 / 0.19$ & $4 / 0.19$ & $5 / 0.238$ & $5 / 0.238$ & $6 / 0.286$ & $6 / 0.286$ & 8/0.381 \\
\hline 38 & Cut-G Old River & 40 & 238 & $2 / 0.008$ & $3 / 0.013$ & $6 / 0.025$ & $7 / 0.029$ & 8/0.034 & 9/0.038 & $11 / 0.046$ \\
\hline
\end{tabular}


Table 7-9. Depth-limited fraction of tankers in JHC.

\begin{tabular}{|c|c|c|c|c|c|c|c|c|c|c|}
\hline \multirow{2}{*}{$\#$} & \multirow{2}{*}{ Reach Code } & \multirow{2}{*}{$\begin{array}{l}\text { Main- } \\
\text { tenance Depth } \\
\text { (ft) }\end{array}$} & \multirow{2}{*}{$\begin{array}{c}\text { Number of } \\
\text { Unique Vessels }\end{array}$} & \multicolumn{7}{|c|}{ Reduction in Maintenance Depth (ft) } \\
\hline & & & & 0 & 1 & 2 & 3 & 4 & 5 & 6 \\
\hline 1 & Barcut-3 & 42 & 111 & $0 / 0$ & $1 / 0.009$ & $2 / 0.018$ & $7 / 0.063$ & $13 / 0.117$ & $17 / 0.153$ & $24 / 0.216$ \\
\hline 2 & Cut-4 & 40 & 111 & $2 / 0.018$ & $7 / 0.063$ & $13 / 0.117$ & $17 / 0.153$ & $24 / 0.216$ & $26 / 0.234$ & $29 / 0.261$ \\
\hline 3 & Cut-5 & 40 & 111 & 2/0.018 & $7 / 0.063$ & $13 / 0.117$ & $17 / 0.153$ & $24 / 0.216$ & $26 / 0.234$ & $29 / 0.261$ \\
\hline 4 & Cut-6 & 40 & 111 & $2 / 0.018$ & $7 / 0.063$ & $13 / 0.117$ & $17 / 0.153$ & $24 / 0.216$ & $26 / 0.234$ & $29 / 0.261$ \\
\hline 5 & Cut-7 & 40 & 111 & $2 / 0.018$ & $7 / 0.063$ & $13 / 0.117$ & $17 / 0.153$ & $24 / 0.216$ & $26 / 0.234$ & 29/0.261 \\
\hline 6 & Cut-8 & 40 & 111 & $2 / 0.018$ & $7 / 0.063$ & $13 / 0.117$ & $17 / 0.153$ & $24 / 0.216$ & $26 / 0.234$ & $29 / 0.261$ \\
\hline 7 & Cut-9 & 40 & 111 & 2/0.018 & $7 / 0.063$ & $13 / 0.117$ & $17 / 0.153$ & $24 / 0.216$ & $26 / 0.234$ & $29 / 0.261$ \\
\hline 8 & Cut-10 & 40 & 111 & $2 / 0.018$ & $7 / 0.063$ & $13 / 0.117$ & $17 / 0.153$ & $24 / 0.216$ & $26 / 0.234$ & $29 / 0.261$ \\
\hline 9 & Cut-11 & 40 & 111 & $2 / 0.018$ & $7 / 0.063$ & $13 / 0.117$ & $17 / 0.153$ & $24 / 0.216$ & $26 / 0.234$ & $29 / 0.261$ \\
\hline 10 & Cut-12 & 40 & 111 & $2 / 0.018$ & $7 / 0.063$ & $13 / 0.117$ & $17 / 0.153$ & $24 / 0.216$ & $26 / 0.234$ & $29 / 0.261$ \\
\hline 11 & Cut-13 & 40 & 111 & $2 / 0.018$ & $7 / 0.063$ & $13 / 0.117$ & $17 / 0.153$ & $24 / 0.216$ & $26 / 0.234$ & $29 / 0.261$ \\
\hline 12 & Cut-14/15 & 40 & 111 & $2 / 0.018$ & $7 / 0.063$ & $13 / 0.117$ & $17 / 0.153$ & $24 / 0.216$ & $26 / 0.234$ & $29 / 0.261$ \\
\hline 13 & Cut-16 & 40 & 111 & $2 / 0.018$ & $7 / 0.063$ & $13 / 0.117$ & $17 / 0.153$ & $24 / 0.216$ & $26 / 0.234$ & $29 / 0.261$ \\
\hline 14 & Cut-17 & 40 & 111 & $2 / 0.018$ & $7 / 0.063$ & $13 / 0.117$ & $17 / 0.153$ & $24 / 0.216$ & $26 / 0.234$ & $29 / 0.261$ \\
\hline 15 & Cut-18 & 40 & 111 & $2 / 0.018$ & $7 / 0.063$ & $13 / 0.117$ & $17 / 0.153$ & $24 / 0.216$ & $26 / 0.234$ & $29 / 0.261$ \\
\hline 16 & Cut-19 & 40 & 111 & $2 / 0.018$ & $7 / 0.063$ & $13 / 0.117$ & $17 / 0.153$ & $24 / 0.216$ & $26 / 0.234$ & $29 / 0.261$ \\
\hline 17 & Cut-39 & 40 & 111 & $2 / 0.018$ & $7 / 0.063$ & $13 / 0.117$ & $17 / 0.153$ & $24 / 0.216$ & $26 / 0.234$ & $29 / 0.261$ \\
\hline 18 & Cut-40 & 40 & 111 & $2 / 0.018$ & $7 / 0.063$ & $13 / 0.117$ & $17 / 0.153$ & $24 / 0.216$ & $26 / 0.234$ & $29 / 0.261$ \\
\hline 19 & Cut-41 & 40 & 111 & $2 / 0.018$ & $7 / 0.063$ & $13 / 0.117$ & $17 / 0.153$ & $24 / 0.216$ & $26 / 0.234$ & $29 / 0.261$ \\
\hline 20 & Cut-42 & 40 & 111 & $2 / 0.018$ & $7 / 0.063$ & $13 / 0.117$ & $17 / 0.153$ & $24 / 0.216$ & $26 / 0.234$ & $29 / 0.261$ \\
\hline 21 & Cut-43 & 40 & 111 & $2 / 0.018$ & $7 / 0.063$ & $13 / 0.117$ & $17 / 0.153$ & $24 / 0.216$ & $26 / 0.234$ & $29 / 0.261$ \\
\hline 22 & Cut-44 & 40 & 111 & $2 / 0.018$ & $7 / 0.063$ & $13 / 0.117$ & $17 / 0.153$ & $24 / 0.216$ & $26 / 0.234$ & $29 / 0.261$ \\
\hline 23 & Cut-45 & 40 & 111 & $2 / 0.018$ & $7 / 0.063$ & $13 / 0.117$ & $17 / 0.153$ & $24 / 0.216$ & $26 / 0.234$ & 29/0.261 \\
\hline
\end{tabular}




\begin{tabular}{|c|c|c|c|c|c|c|c|c|c|c|}
\hline \multirow{2}{*}{ \# } & \multirow{2}{*}{ Reach Code } & \multirow{2}{*}{$\begin{array}{c}\text { Main- } \\
\text { tenance Depth } \\
\text { (ft) }\end{array}$} & \multirow{2}{*}{$\begin{array}{c}\text { Number of } \\
\text { Unique Vessels }\end{array}$} & \multicolumn{7}{|c|}{ Reduction in Maintenance Depth (ft) } \\
\hline & & & & 0 & 1 & 2 & 3 & 4 & 5 & 6 \\
\hline 24 & Cut-46 & 40 & 111 & 2/0.018 & $7 / 0.063$ & $13 / 0.117$ & $17 / 0.153$ & $24 / 0.216$ & $26 / 0.234$ & $29 / 0.261$ \\
\hline 25 & Cut-47 & 40 & 111 & $2 / 0.018$ & $7 / 0.063$ & $13 / 0.117$ & $17 / 0.153$ & $24 / 0.216$ & $26 / 0.234$ & $29 / 0.261$ \\
\hline 26 & Cut-48 & 40 & 111 & $2 / 0.018$ & $7 / 0.063$ & $13 / 0.117$ & $17 / 0.153$ & $24 / 0.216$ & $26 / 0.234$ & $29 / 0.261$ \\
\hline 27 & Cut-49 & 40 & 111 & $2 / 0.018$ & $7 / 0.063$ & $13 / 0.117$ & $17 / 0.153$ & $24 / 0.216$ & $26 / 0.234$ & $29 / 0.261$ \\
\hline 28 & Cut-50 & 40 & 91 & $1 / 0.011$ & $5 / 0.055$ & $9 / 0.099$ & $12 / 0.132$ & $16 / 0.176$ & $18 / 0.198$ & $21 / 0.231$ \\
\hline 29 & Cut-51 & 40 & 89 & $1 / 0.011$ & $5 / 0.056$ & 9/0.101 & $12 / 0.135$ & $16 / 0.18$ & $18 / 0.202$ & $21 / 0.236$ \\
\hline 30 & Cut-52 & 40 & 89 & $1 / 0.011$ & $5 / 0.056$ & 9/0.101 & $12 / 0.135$ & $16 / 0.18$ & $18 / 0.202$ & $21 / 0.236$ \\
\hline 31 & Cut-53 & 40 & 87 & $0 / 0$ & 4/0.046 & 8/0.092 & $11 / 0.126$ & $15 / 0.172$ & $17 / 0.195$ & $20 / 0.23$ \\
\hline 32 & Cut-54 & 40 & 84 & $0 / 0$ & $4 / 0.048$ & $8 / 0.095$ & $11 / 0.131$ & $15 / 0.179$ & $16 / 0.19$ & $19 / 0.226$ \\
\hline 33 & Cut-55 & 40 & 83 & $0 / 0$ & $4 / 0.048$ & $8 / 0.096$ & $10 / 0.12$ & $14 / 0.169$ & 15/0.181 & $18 / 0.217$ \\
\hline 34 & $\begin{array}{l}\text { Lower Terminal } \\
\text { Channel }\end{array}$ & 40 & 79 & $0 / 0$ & $4 / 0.051$ & $7 / 0.089$ & $9 / 0.114$ & $13 / 0.165$ & $14 / 0.177$ & $17 / 0.215$ \\
\hline 35 & $\begin{array}{l}\text { Upper Terminal } \\
\text { Channel }\end{array}$ & 34 & 6 & $0 / 0$ & $1 / 0.167$ & $2 / 0.333$ & $3 / 0.5$ & $3 / 0.5$ & $3 / 0.5$ & $3 / 0.5$ \\
\hline 38 & Cut-G Old River & 40 & 4 & $0 / 0$ & $0 / 0$ & $0 / 0$ & $0 / 0$ & $0 / 0$ & $0 / 0$ & $0 / 0$ \\
\hline
\end{tabular}




\subsection{MISLE database reports}

The location of collision and grounding events that occurred in JHC during the 4-year period 2011-2015 are shown in Figure 7-11. These incidents were recorded in the USCG MISLE database. During the 4-year period, there are two grounding events and four collisions. Public information about these events can be found on the USCG Maritime Information Exchange Incident Investigation Reports website (http://cgmix.uscg.mil/IIR/IIRSearch.aspx) using the activity identification numbers provided in the figure. 
Figure 7-11. MISLE incidents in JHC. Each incident is identified by an activity identification number.

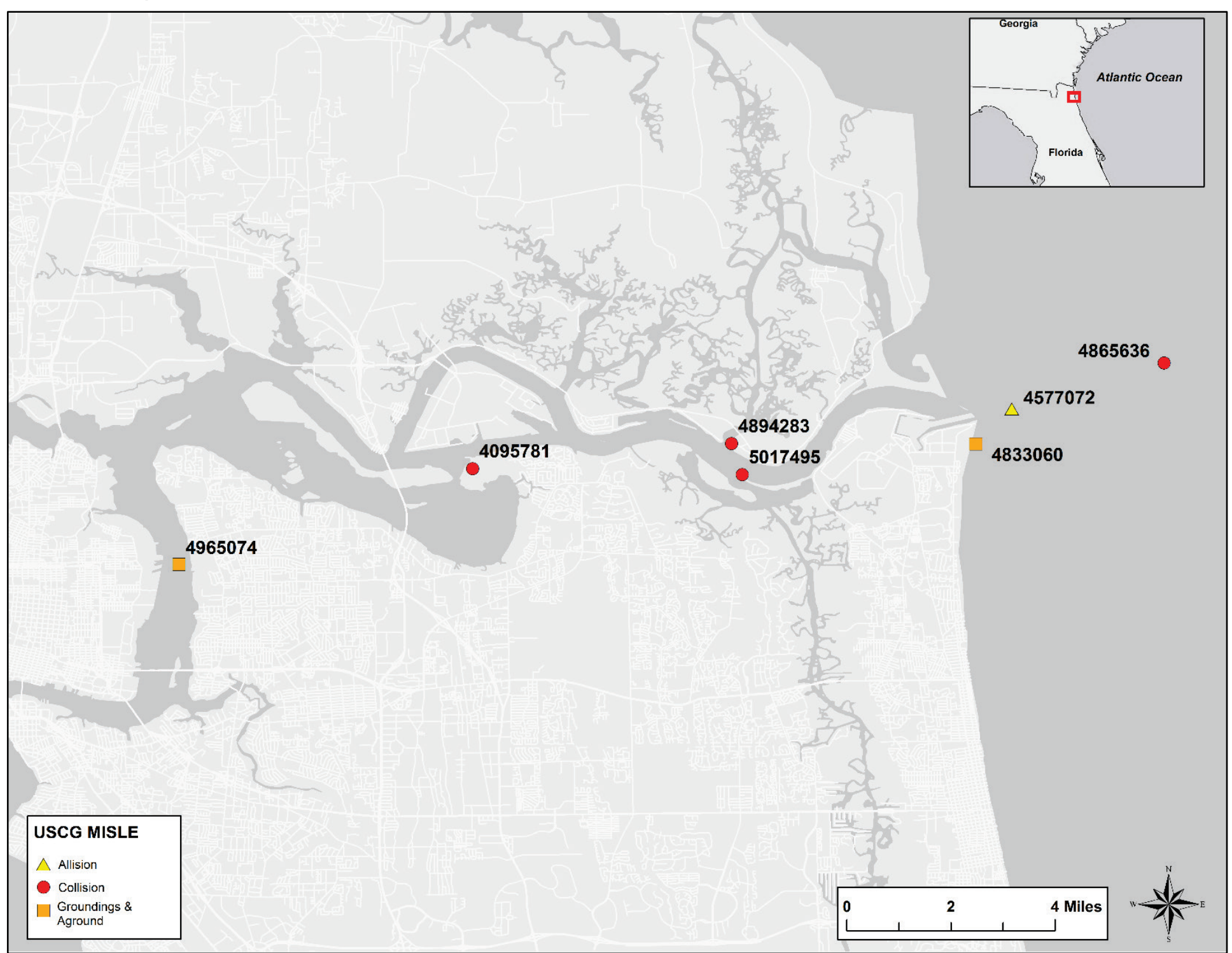




\section{Conclusion}

The approach to assessing collision and grounding risks in coastal ports developed in this report will assist navigation managers to (1) monitor and report on safety in federal navigation channels; (2) identify navigation projects and channels where risks of collision and grounding are relatively high; and (3) determine where improvements in design, construction, or maintenance might reduce the potential for accidents and associated losses. Quantitative comparisons of collision risks can also be used to justify navigation safety measures such as Vessel Traffic Service, aids to navigation, data systems to facilitate navigation (e.g., NOAA Physical Oceanographic Real-Time System), and additional regulations. This chapter outlines some of the advantages, challenges, and limitations of the methods and identifies opportunities for development.

\subsection{Collision analyses}

Three distinct metrics have been proposed to assess collision risks. These are the conditional frequency of an SDV, the unconditional frequency of an SDV, and the relative frequency of an SDV. There are subtle differences in how each metric is interpreted. The conditional frequency of an SDV is an estimate of the probability that a vessel operating in a navigation reach will be involved in an SDV. The unconditional frequency of an SDV is an estimate of the probability that an SDV will occur in a reach during a given half-minute interval. The relative frequency of an SDV is an estimate of the probability that an SDV occurred in a navigation reach given that an SDV has occurred in the navigation project.

The major advantage of the conditional frequency of an SDV is that it can be used to compare collision risk in navigation channels. Because SDVs are a proxy for collision events, the conditional frequency of an SDV can also be paired with a causation probability and used to compute expected damages from collision events in navigation channels. The unconditional frequency of an SDV and the relative frequency of an SDV cannot be used to compute expected damages or to compare collision risks because they are not normalized to control for differences in the reach size and vessel dwell time. Larger reaches and reaches with more traffic will tend to have more SDVs than smaller reaches and reaches with less traffic because 
there are a larger number of opportunities to be involved in an SDV. This can be seen in the results for Jacksonville Harbor. The Mayport ferry crosses the St. Johns River in Cut- 6 and Cut-7, and approximately $75 \%$ of all SDVs in JHC occur in these two reaches. However, the conditional frequency of an SDV is not noticeably higher than elsewhere in the navigation project.

The conditional frequency of an SDV is used in Table 8-1 to compare collision risks in the five navigation projects selected for demonstration. Table 8-1 lists the conditional frequency by project and AIS ship and cargo type code. The navigation projects are ranked based on the overall conditional frequency of an SDV. Calcasieu has the highest conditional frequency of an SDV, $1.10 \times 10^{-3}$. That is $19 \%$ higher than in Boston Harbor and 32\% higher than in Jacksonville Harbor. In contrast, Charleston Harbor and Columbia River have lower conditional frequency of an SDV levels of collision risk than Calcasieu. The conditional frequency of an SDV in Charleston Harbor is $2.84 \times 10^{-3}$ and in Columbia River is $2.58 \times 10^{-3}$. These probabilities are about one-fourth of those calculated for Calcasieu River. In other words, a vessel operating in the CSC is 4.26 times more likely to be involved in an SDV than a vessel operating in Columbia River.

Larger vessels such as cargo vessels and tankers are more dependent on navigation channels, so a focus on these types of vessels may be more useful for navigation managers. Therefore, Table 8-1 also lists the conditional frequency of an SDV for each AIS ship and cargo type. When the conditional frequency is calculated for cargo vessels and tankers, collision risks are the highest in Boston. The conditional frequency of an SDV is 70\% higher for cargo vessels in Boston than for cargo vessels in Calcasieu. Likewise, the conditional frequency of an SDV for tankers is 20\% higher in Boston than in Calcasieu. However, the comparison for cargo vessels deserves a caveat. Many of the cargo vessels operating in Calcasieu are actually offshore supply vessels, which are smaller, require less draft, and are easier to maneuver than container vessels, bulk carriers, and other types of cargo vessels.

In most cases, the conditional frequency of an SDV for cargo vessels and tankers is higher than for other AIS ship and cargo types. This can be explained by the fact that these vessels tend to be larger and therefore have larger ship domains. In narrow navigation channels, this makes it more difficult for other vessels to maneuver around them without violating their 
ship domains. In general, tankers exhibit a lower conditional probability of an SDV than cargo vessels. This may suggest that pilots are using extra caution when piloting tankers than cargo vessels. However, this result does not hold in Boston or in Charleston, where the conditional probability of an SDV for tankers is $28 \%$ and $19 \%$ higher than it is for cargo vessels, respectively.

All three metrics of collision risk are predicated on the concept of a ship domain. While many other authors have used this concept, a certain amount of ambiguity surrounds it. As mentioned in the introduction, the definition, size, and shape of ship domains vary across studies. While some authors have described the size and shape of ship domains as being determined by the actions of the encroached vessel, others have described it as being determined by the actions of the encroaching vessel. Various sizes and shapes have been proposed for ship domains, but at least one empirical study has documented that, in practice, ship domains are approximately elliptical. While there are good reasons for keeping the dimensions of the ship domains used in this study small, the actual dimensions used in this report are somewhat arbitrary, and there is room to experiment with different dimensions. This study has introduced elliptical ship domains that vary in size with the swept path of a vessel. Other factors may also affect the size of ship domains, including vessel speed, cargo type, weather visibility, and maneuverability. 
Table 8-1. Demonstration ports ranked by the overall conditional probability of an SDV.

\begin{tabular}{|c|c|c|c|c|c|c|c|c|c|c|c|}
\hline \multirow[b]{2}{*}{ Reach Code } & \multicolumn{10}{|c|}{ AIS Ship and Cargo Type } & \multirow[b]{2}{*}{ Overall } \\
\hline & $\begin{array}{l}\text { Unknown } \\
\text { Vessel type } \\
\text { (00) }\end{array}$ & $\begin{array}{l}\text { WIG Craft } \\
(20-29)\end{array}$ & $\begin{array}{l}\text { Class } 3 \\
\text { Vessels } \\
(30,33-39)\end{array}$ & $\begin{array}{l}\text { High-Speed } \\
\text { Craft or } \\
\text { Ferries } \\
(40-49)\end{array}$ & $\begin{array}{c}\text { Harbor Boats } \\
\qquad(50-57)\end{array}$ & $\begin{array}{l}\text { Medical } \\
\text { Transports } \\
\text { (58) }\end{array}$ & $\begin{array}{c}\text { Passenger } \\
\text { Vessels } \\
(60-69)\end{array}$ & $\begin{array}{c}\text { Cargo } \\
\text { Vessels } \\
(70-79)\end{array}$ & $\begin{array}{l}\text { Tankers } \\
\text { (80-89) }\end{array}$ & $\begin{array}{c}\text { Other } \\
\text { Vessels } \\
\text { (90-99) }\end{array}$ & \\
\hline Calcasieu & 3.89E-03 & - & $1.74 \mathrm{E}-04$ & $0.00 E+00$ & - & - & 4.15E-04 & 1.41E-03 & $1.80 \mathrm{E}-03$ & 2.80E-03 & $1.10 \mathrm{E}-03$ \\
\hline Boston & 9.43E-05 & - & 2.03E-04 & $6.49 \mathrm{E}-04$ & - & - & 6.06E-04 & $4.52 \mathrm{E}-03$ & $2.25 \mathrm{E}-03$ & 1.17E-04 & $9.32 \mathrm{E}-04$ \\
\hline Jacksonville & 2.33E-04 & - & $1.46 \mathrm{E}-03$ & - & - & - & $2.01 \mathrm{E}-04$ & $8.98 \mathrm{E}-04$ & $6.15 \mathrm{E}-04$ & $0.00 E+00$ & 8.34E-04 \\
\hline Charleston & $0.00 E+00$ & - & $1.24 \mathrm{E}-04$ & $0.00 E+00$ & - & - & $1.02 \mathrm{E}-04$ & 4.38E-04 & $5.22 \mathrm{E}-04$ & $0.00 E+00$ & $2.84 \mathrm{E}-04$ \\
\hline Columbia River & 7.91E-04 & - & $3.82 \mathrm{E}-04$ & - & - & $0.00 \mathrm{E}+00$ & 1.07E-04 & 2.17E-04 & $9.11 \mathrm{E}-05$ & $1.48 \mathrm{E}-05$ & $2.58 \mathrm{E}-04$ \\
\hline
\end{tabular}


An SDV is an imperfect proxy for situations that require evasive action because some SDVs might be resolved without either vessel taking any evasive action (Goerlandt and Kujala 2011). This undermines the ability to treat the conditional probability of an SDV as a geometric probability for the purpose of estimating collision probabilities. Multiplying the conditional probability of an SDV by a causation probability will tend to overestimate the probability of collision because not all SDVs require evasive action to avoid a collision. This study has side-stepped the issue by focusing on the probability of an SDV as a stand-alone metric of collision risk. This study has made no effort to pair these probabilities with causation probabilities or to compute the probability of collision. However, this could be an issue if these methods are used in the future.

When calculating metrics of collision risk, harbor work boats and towboats have not been considered. Harbor work boats, such as tugboats and police boats, routinely operate in close proximity to other vessels, so including these would inflate the risk metrics. The problem with including towboats is that the NAIS does not include data that describe the dimensions of the tow. These dimensions are critical for establishing ship domain boundaries and locating the perimeter of a barge tow. This exclusion of towboats may be more important in those ports with a significant amount of towboat traffic than in others. For example, in Calcasieu, where 821 towboats were recorded, the exclusion of towboats may be more important than in Boston, where only 43 towboats were recorded.

\subsection{Grounding analyses}

In this report, locations in the navigation channel where vessels have an elevated risk of grounding on the side or bottom of a navigation channel have been identified. This was accomplished by classifying position reports as channel side events if the distance between side of the channel and a point on the keel line of that vessel was less than or equal to $55 \%$ of that vessel's beam. Locations where vessels risk grounding on the bottom of the channel have been identified by calculating the depth-limited fraction of vessels utilizing each navigation channel reach. In contrast to the collision risk assessment, it was not possible to estimate frequencies or probabilities of grounding. Channel side events are displayed in a map to show where vessels may be coming too close to the edge of a channel and where modifications to channel width or configuration may be indicated. The depth-limited number and fraction of vessels are tabulated to show where and to what extent traffic may be depth limited. 
There are several caveats and limitations to consider when interpreting maps of channel side events. It can be difficult to distinguish events of interest from intentional departures from the channel. Pilots may depart from the channel intentionally, to access a pier or a private channel, accidentally because of poor piloting skill, or out of necessity because of difficulty maneuvering a vessel. Emphasis should be on placed on identifying those channel side events that are caused by difficulty maneuvering a vessel within a navigation channel. The frequency of these types of channel side events can potentially be reduced by modifying channel configuration. Emphasis should also be on understanding the causes of clusters of channel side events rather than isolated incidents because clusters suggest there is a problem that affects a large number of vessels whereas an isolated event is more likely to reflect an accidental departure from the channel. There are many potential causes of channel side events and inferences about the presence of problems with navigation should always be validated before taking action to address those issues.

Large vessels operating in narrow channels may generate a large number of channel side events throughout the channel. For example, this was observed in Boston's Chelsea River, where tanker traffic routinely generates channel side events. In this case, the waterway is so constrained it may not be possible to resolve this problem. In other cases, large numbers of channel side events may indicate that vessel traffic is not constrained to the channel by draft. For example, this was observed in the Columbia River. In this case, the presence of a hazard to navigation might be inferred from the absence of channel side events, as in the several examples shown in Columbia River and Jacksonville. Where an analysis of channel side events indicates that vessels are not constrained to a channel, a review of maintenance practices, schedules, and costs may be useful to confirm that money is not being spent to dredge channels unnecessarily.

When analyzing channel side events, it is useful to limit the analysis to deep draft vessels that are in transit by filtering out position reports that do not meet minimum speed and draft criteria. Different speed and draft criteria may needed in different ports. For example, no speed or draft filters were applied in Boston. Filters were applied in Columbia River and Jacksonville to weed out vessels with drafts of less than $7.5 \mathrm{~m}$ and traveling at less than 7.5 knots. The best way to determine what speed and draft criteria are useful is to experiment by gradually increasing the speed and draft criteria in an iterative fashion. 
Risks of grounding on a shoal in a navigation channel are assessed by calculating the number and fraction of cargo vessels and tankers that are depth limited in each reach. This provides a crude metric of risk by indicating where a large number or fraction of vessels have the potential to ground on the bottom of a channel. However, it would be unreasonable to equate this metric with a probability of grounding in the channel because that depends on vessel-specific factors that are not reported in AIS, such as the actual draft of the vessel and the condition of the channel at the time of transit. Efforts were made to integrate data about channel condition into this analysis. However, attempts to integrate available data greatly increased the level of effort required to process data for the risk assessment, and data on channel condition were not consistently available over time and space in the demonstration ports.

An assessment of the probability of grounding on a shoal in the channel would require a much more detailed study than was possible here. However, a great deal of insight can be gained by evaluating the depthlimited fraction of vessels. This metric provides an indication of the extent to which navigation traffic is utilizing available channel depth. If the number of vessels utilizing a channel is low, this may raise questions about whether or not a channel is sufficiently well utilized to justify maintenance costs. Similarly, if the fraction of depth-limited vessels is low, and it rises slowly in response to reductions in maintenance depth, this may indicate that existing maintenance is sufficient. If the fraction of depth-limited vessels is high or the depth-limited fraction of vessels increases rapidly in response to dredging, this may indicate a need for increases in maintenance depth.

\subsection{Limitations of AIS data}

There are obvious advantages to using AIS data for collision and risk assessment in coastal ports. In the United States, these data are collected via an existing process that is standardized, and these data are centrally managed. Therefore, methods of collision and grounding risk assessment can be applied consistently across the country. The quality of AIS data has improved greatly since archival NAIS data first became available, and it is continuing to improve. Therefore, it is expected that these issues will be resolved in the future. However, data quality was a factor limiting the ability to use AIS data from 2014 and 2015. To the extent practicable, the risk assessment methods described in this report have been developed with an eye for making them robust against known problems with AIS 
data. This requires knowing what kinds of issues might arise before developing the methods.

Issues pertinent to collision and grounding analysis include errors and missing information in static vessel data and errors in reported geographic positions. Vessel dimensions and ship and cargo type code classification are often missing or misreported in static vessel reports. Vessel dimensions are used to locate ship domain boundaries, calculate SDV severity scores, and locate vessel keel lines in relation to channel boundaries. Ship and cargo type codes are used to classify vessels for collision and grounding analysis. It is a good idea to validate the information about vessel type and dimensions in static vessel data before beginning an analysis. This can be accomplished by comparing it to an authoritative source of information. For example, commercial databases such as Lloyd's Register contain verified data compiled for insurance and business purposes.

Errors in the classification of vessels by AIS ship and cargo type code are particularly troublesome. Some of the errors in the classification of vessel can be attributed to ambiguity in the AIS ship and cargo type codes that were introduced in the ITU Recommendations. For example, there are codes for vessels engaged in military operations (35) and law enforcement vessels (55). In the United States, the USCG performs both functions, and it is not necessarily clear which code should be used. USCG vessels typically operate under either 35 or 55 , but others have been found operating under the ship and cargo type code for unknown vessel type (oo) or for other vessel type (90-99). Further clarification is needed to resolve this ambiguity.

There also appears to be some confusion over what AIS ship and cargo type code should be used for towboats. Tugboats and towboats are poorly distinguished in static vessel data. The ITU Recommendation defines AIS ship and cargo type codes for vessels towing astern (31), vessels towing astern while the length of the tow exceeds $200 \mathrm{~m}$ (32), and for tugboats or workboats (52). The review of NAIS data for this report suggests that most towboats in the United States are using AIS ship and cargo type codes 3132 or 20-29, which the ITU Recommendation assigns to WIG craft. In this study, a single category, 31-32, was created for towboats, and if a towboat was found to be using an AIS ship and cargo type code other than 31 or 32, it was assigned to this category. At least some of the ambiguity over what 
ship and cargo type codes towboats should use might be attributed to periodic revisions of the USCG AIS encoding guide.

In general, the vast majority of geographic positions reported in AIS position reports are accurate. However, some position reports are obviously inaccurate. For example, position reports are occasionally found on land, and a sequence of position reports marking a vessel's transit will sometimes indicate abrupt departures from the line of transit. Such errors are easy to recognize when the errors are large and the data are displayed on a map but are harder to recognize when the errors are small and when large amounts of data are processed without displaying each vessel's transit. Although inaccurate position reports represent only a small fraction of the data, their presence makes the analysis of collision and grounding risks more difficult because geographic positions are used in identifying SDVs and channel side events and in calculating SDV severity scores. While the NAIS database includes a field to indicate whether or not the instrument used to report positions aboard the vessel is accurate to within $10 \mathrm{~m}$, this code does not characterize the accuracy of each position report.

\subsection{Directions for future work}

Research and development efforts to advance collision and grounding risk assessment using AIS data should be aimed in three possible directions. These are improving the accessibility and quality of AIS data, improving the practical implementation of the risk assessment methods, and improving the risk assessment methods themselves. Potential improvements in AIS data quality have already been discussed above. With regard to practical implementation, it will be necessary to develop a platforms for storing data and conducting risk assessments. The demonstration studies described in this report were carried out on a desktop computer using SAS ${ }^{\circledR}$ and ArcGIS ${ }^{\circledR}$ software packages. The data storage and processing capability of this computer were adequate for the purpose of developing and demonstrating the method. High-performance computing platforms with more data storage and processing power should be considered if these methods will be applied to a larger number of ports.

This project was initiated with the hope that collision and grounding risks could be analyzed in a large number of ports efficiently by using standardized data inputs and automating data processing tasks. However, experience analyzing collision and grounding risks in the five 
demonstration ports covered in this report has shown that, even when data are standardized, there are bound to be exceptions and idiosyncrasies among ports that require modification of algorithms and data processing code or localized knowledge about the port to interpret results. For example, in Jacksonville, many of the navigation reaches that have maintenance depths of $40 \mathrm{ft}$ are flanked by $20 \mathrm{ft}$ wide channels that are $38 \mathrm{ft}$ deep. Modifications to the collision and grounding risk assessment algorithms were needed to accommodate these features. In Charleston, work-arounds were required to accommodate several navigation channel reaches that overlapped each other at the intersection of the deep draft navigation channel and the Intracoastal Waterway. This led to deep draft vessels being detected in the Ashley River reach and inflation of the depthlimited fraction of cargo vessels and tankers.

There are several opportunities for improving methods of collision and grounding risk assessments through applied research. Interactions with navigation mangers would provide useful feedback on the suitability of methods developed in this report. With respect to assessments of collision risk, additional research is needed to develop algorithms that distinguish between ship domain violations that require evasive action and those that do not. It may also be useful to develop methods of inferring the nautical situation during an encounter. Efforts were made to classify the situation using the bearing between vessels based on the first position report of an encounter that was classified as an SDV. However, when the tracks were viewed to validate the classification, it was found that many nautical situations were misclassified. This was attributed to the small size of ship domains. Methods are also needed to assess the accuracy of reported positions. While most positions are accurate, even a few inaccurate position reports can wreak havoc with analysis. This problem can be alleviated by excluding position reports that are regarded as inaccurate. Finally, methods are needed to validate and verify risk assessments. In general, there were an insufficient number of observations in the USCG MISLE data to use in rigorous validation of risk assessment results. 


\section{References}

Coldwell, T. G. 1983. Marine traffic behaviour in restricted waters. Journal of Navigation 36(3): 430-444. https://doi.org/10.1017/S0373463300039783

Fowler, T. G., and E. Sørgard. 2000. Modeling ship transportation risk. Risk Analysis 20(2): 225-244.

Friis-Hansen, P. 2008. Basic Modelling Principles for Prediction of Collision and Grounding Frequencies. IWRAP MK II Working Document. Technical University of Denmark.

Friis-Hansen, P., and P. T. Pedersen. 1998. Risk Analysis of Conventional and Solo Watch Keeping. Submitted to the 69th Session of the International Maritime Organization (IMO) Maritime Safety Committee.

Friis-Hansen, P., and B. C. Simonsen. 2002. GRACAT: Software for grounding and collision risk analysis. Marine Structures 15(4-5): 383-401.

Fuji, Y., and K. Tanaka. 1971. Traffic capacity. The Journal of Navigation 24(4): 543-552.

Fuji, Y., R. Oshima, H. Yamanouchi, and N. Mizuki. 1974. Some factors affecting the frequency of accidents in marine traffic: I- The diameter of evasion for crossing encounters, II- The probability of stranding, III- The effect of darkness on the probability of collision and stranding. The Journal of Navigation 27(2): 239247.

Goerlandt, F., and P. Kujala. 2011. Traffic simulation based ship collision probability modeling. Reliability Engineering and System Safety 96(1): 91-107.

Goerlandt, F., and P. Kujala. 2014. On the reliability and validity of ship-ship collision risk analysis in light of different perspectives on risk. Safety Science, No. 62: $348-365$.

Goerlandt, F., and J. Montewka. 2015. Maritime transportation risk analysis: Review and analysis in light of some foundational issues. Reliability Engineering and System Safety, No. 138: 115-134. Doi: http://dx.doi.org/10.1016/j.ress.2015.01.025

Goodwin, E. M. 1975. A statistical study of ship domains. The Journal of Navigation 28(3): $328-344$.

Hansen, M. G., T. K. Jensen, T. Lehn-Schiøler, K. Melchild, F. M. Rasmussen, and F. Ennemark. 2013. Empirical ship domain based on AIS data. The Journal of Navigation 66(2013): 931-940.

International Maritime Organization (IMO). 1972. Convention on the International Regulations for Preventing Collisions at Sea (COLREGS). United Nations Treaty Series. https://treaties.un.org/doc/Publication/UNTS/Volume\%201050/volume-1050-I15824-English.pdf 
International Telecommunications Union (ITU). 2014. Technical characteristics for a universal shipborne automatic identification system using time division multiple access in the VHF maritime mobile band. Recommendation ITU-R M.1371-5.

Jingsong, Z., W. Zhaolin, and W. Fengchen. 1993. Comments on ship domains. The Journal of Navigation 46(3): 422-436.

Li, S., Q. Meng, and X. Qu. 2012. An overview of maritime waterway quantitative risk assessment models. Risk Analysis: 32(3): 496-512.

Macduff, T. 1974. Probability of vessel collisions. Ocean Industry 9(9): 144-148.

Merrick J. R. W., and J. R. van Dorp. 2006. Speaking the truth in maritime risk assessment. Risk Analysis 26(1): 223-237.

Otto S., P. T. Pedersen, M. Samuelides, and P. C. Sames. 2002. Elements of risk analysis for collision and grounding of a RoRo passenger ferry. Marine Structures 15(45): 461-474.

Pedersen, P. T. 1995. Collision and grounding mechanics. In Proceedings of WEMT '95', Danish Society of Naval Architects and Marine Engineers. West European Confederation of Maritime Technology Societies (WEMT) Conference, 17-19 May 1995. Volume 1, session 5.

Pietrzykowski, Z. 2008. Ship's fuzzy domain - a criterion for navigational safety in narrow fairways. The Journal of Navigation 61(3): 499-514.

Rawson, A., E. Rogers, D. Foster, and D. Phillips. 2014. Practical application of domain analysis: Port of London case study. The Journal of Navigation 67(2): 193-209.

Robards, M. D., G. K. Silber, J. D. Adams, J. Arroyo, D. Lorenzini, K. Schwehr, and J. Amos. 2016. Conservation science and policy applications of the marine vessel Automatic Identification System (AIS)-a review. Bulletin of Marine Science 92(1): 75-103.

Scully, B., and K. N. Mitchell. 2015. Archival Automatic Identification System (AIS) Data for Navigation Project Performance Evaluation. ERDC/CHL CHETN-IX-40. Vicksburg, MS: U.S. Army Engineer Research and Development Center. https://erdc-library.erdc.dren.mil/xmlui/handle/11681/2066

Scully, B. M., and K. N. Mitchell. 2017. Underkeel clearance reliability model for dredged navigation channels, Transportation Research Record: Journal of the Transportation Research Board, No. 2611: 41-49.

Szlapczynski, R. 2006. A unified measure of collision risk derived from the concept of a ship domain. The Journal of Navigation 59(3): 477-490.

Szwed P., J. R. van Dorp, J. R. W. Merrick, T. A. Mazzuchi, and A. Singh. 2006. A Bayesian paired comparison approach for relative accident probability assessment with covariate information. European Journal of Operational Research 169(1): 157-177.

U.S. Army Corps of Engineers (USACE). 2006. Hydraulic Design of Deep-Draft Navigation Projects. EM 1110-2-1613. Washington, DC. 
U.S. Coast Guard (USCG). n.d. U.S. Coast Guard AIS Encoding Guide, v. 25. Accessed 29 June 2017. https://www.navcen.uscg.gov/pdf/AIS/AISGuide.pdf

Vincenty, T. 1975. Direct and inverse solutions of geodesics on the ellipsoid with application of nested equations. Survey Review 23(176): 88-93. https://www.ngs.noaa.gov/PUBS_LlB/inverse.pdf

Wang, N., X. Meng, X. Qingyan, and Z. Wang. 2009. A unified analytical framework for ship domains. The Journal of Navigation 62(4): 643-655.

Weng, J., Q. Meng, and X. Qu. 2012. Vessel collision frequency estimation in the Singapore Strait. Journal of Navigation 65(2): 207-221. 


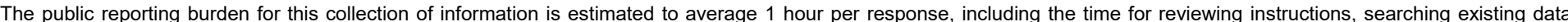

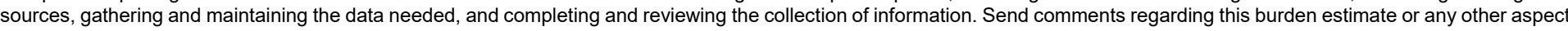

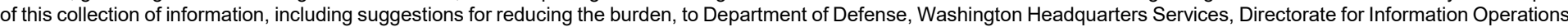

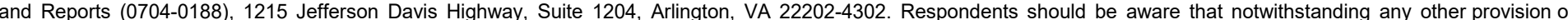
law, no person shall be subject to any penalty for failing to comply with a collection of information if it does not display a currently valid OMB control number. PLEASE DO NOT RETURN YOUR FORM TO THE ABOVE ADDRESS.

\begin{tabular}{l|l|l}
$\begin{array}{l}\text { 1. REPORT DATE } \\
\text { June } 2019\end{array}$ & $\begin{array}{l}\text { 2. REPORT TYPE } \\
\text { Final Report }\end{array}$ & 3. DATES COVERED (FrOm - To)
\end{tabular}

\section{TITLE AND SUBTITLE}

Final Report

Using Automatic Identification System (AIS) Data to Assess Collision and Grounding Risk in

U.S. Coastal Ports

5a. CONTRACT NUMBER

5b. GRANT NUMBER

5c. PROGRAM ELEMENT NUMBER

6. AUTHOR(S)

Martin T. Schultz and Scott G. Bourne

5d. PROJECT NUMBER

5e. TASK NUMBER

5f. WORK UNIT NUMBER

468419

8. PERFORMING ORGANIZATION REPORT NUMBER

ERDC/EL TR-19-7

3909 Halls Ferry Road

Vicksburg, Mississippi 39180-6199

9. SPONSORING/MONITORING AGENCY NAME(S) AND ADDRESS(ES)

Coastal and Hydraulics Laboratory

U.S. Army Engineer Research and Development Center

3909 Halls Ferry Road

Vicksburg, MS 39180-6199

\section{DISTRIBUTION/AVAILABILITY STATEMENT}

Approved for public release; distribution is unlimited.

\section{SUPPLEMENTARY NOTES}

\section{ABSTRACT}

The conventional approach to navigation risk assessment is qualitative and relies on the subjective input of waterway users. Quantitative and objective approaches are needed to monitor and report on safety, identify navigation projects and channels where risks are high, and determine where improvements in design, construction, or maintenance might reduce the potential for accidents and associated losses. This study develops, demonstrates, and evaluates a method of using archival automatic identification system data to quantify collision and grounding risk to support the U.S. Army Corps of Engineers mission with respect to design, construction, and maintenance of navigation channels. The methods are demonstrated in five coastal ports, including Boston, Massachusetts; Charleston, South Carolina; Jacksonville, Florida; Calcasieu River, Louisiana; and Columbia River, Oregon.

\section{SUBJECT TERMS}

Collisiona at sea_Risk assessment, Harbors, Navigation, Port cities, Ships_-Automatic identification systems, Stranding of ships_-Risk assessment

\section{SECURITY CLASSIFICATION OF:}

\begin{tabular}{|l|c|c|c|} 
a. REPORT & b. ABSTRACT & c. THIS PAGE & ABSTRACT \\
Unclassified & Unclassified & Unclassified & SAR
\end{tabular}

18. NUMBER OF PAGES

251 19a. NAME OF RESPONSIBLE PERSON

19b. TELEPHONE NUMBER (Include area code) 601-634-4313 